UNIVERSIDADE DE SÃO PAULO

FACULDADE DE ECONOMIA, ADMINISTRAÇÃO E CONTABILIDADE DEPARTAMENTO DE ADMINISTRAÇÃO PROGRAMA DE PÓS-GRADUAÇÃO EM ADMINISTRAÇÃO

O USO DE JOGOS DIGITAIS PARA O DESENVOLVIMENTO DE GESTORES PÚBLICOS: UM ESTUDO EMPÍRICO COM UM SERIOUS GAME

Fernando Nascimento da Silva

Orientadora: Prof ${ }^{\mathrm{a}}$. Dra. Bernadete de Lourdes Marinho Grandolpho

SÃO PAULO 
Prof. Dr. Marco Antonio Zago Reitor da Universidade de São Paulo

Prof. Dr. Adalberto Américo Fischmann

Diretor da Faculdade de Economia, Administração e Contabilidade

Prof. Dr. Roberto Sbragia

Chefe do Departamento de Administração

Prof. Dr. Moacir de Miranda Oliveira Junior

Coordenador do Programa de Pós-Graduação em Administração 


\title{
O USO DE JOGOS DIGITAIS PARA O DESENVOLVIMENTO DE GESTORES PÚBLICOS: UM ESTUDO EMPÍRICO COM UM SERIOUS GAME
}

Tese apresentada ao Departamento de Administração da Faculdade de Economia, Administração e Contabilidade da Universidade de São Paulo, para obtenção do título de Doutor em Ciências

Orientadora: Prof ${ }^{a}$. Dra. Bernadete de Lourdes Marinho Grandolpho

\author{
Versão Corrigida \\ (Versão original disponível na biblioteca da Faculdade Economia, Administração, Contabilidade e Economia)
}

\section{SÃO PAULO}


Autorizo a reprodução e divulgação total ou parcial deste trabalho, por qualquer meio convencional ou eletrônico, para fins de estudo e pesquisa, desde que citada a fonte.

FICHA CATALOGRÁFICA

Elaborada pela Seção de Processamento Técnico do SBD/FEA/USP

Silva, Fernando Nascimento da

O uso de jogos digitais para o desenvolvimento de gestores públicos: um estudo empírico com um serious game / Fernando Nascimento da Silva. - São Paulo, 2017.

294 p.

Tese (Doutorado) - Universidade de São Paulo, 2017.

Orientadora: Bernadete de Lourdes Marinho Grandolpho

1. Jogos eletrônicos 2. Serious game 3. Aprendizado baseado em jogos 4. Desenvolvimento de recursos humanos 5 . Gestão pública 6. Experimentos I. Universidade de São Paulo. Faculdade de Economia, Administração e Contabilidade. II. Título.

CDD -658.514 
à minha amada esposa Daniela, com quem, na vastidão do espaço e na imensidão do tempo, tenho o privilégio de dividir um planeta e uma época;

e ao meu filho Gustavo, que, com seu brilho, faz a jornada cósmica nesse pálido ponto azul ter algum sentido. 


\section{AGRADECIMENTOS}

A realização deste trabalho só foi possível com o importante apoio de muitas pessoas. Espero não ser injusto e agradecer a todos aqueles que direta ou indiretamente contribuíram para que esta pesquisa fosse concluída. A primeira delas, é claro, foi a minha orientadora, Bernadete. Duas frases ditas por ela logo na primeira reunião que tivemos me marcaram muito. A primeira foi "a pesquisa é sua, estou aqui, como seria de se esperar, para te orientar"; e a segunda foi "não existe tema de pesquisa bom ou ruim; existe pesquisa bem feita ou mal feita". Aprendi muito durante nosso convívio e devo boa parte de tudo que está escrito aqui ao incentivo que recebi ao longo de todo o processo. Agradeço pela confiança, pelo apoio e por ter me dado autonomia na realização da pesquisa, mas também agradeço por sua capacidade de me "puxar" de volta para a Terra quando necessário.

Outros professores da FEA-USP tiveram importância fundamental nesses quatro anos e meio. Agradeço ao prof. José Afonso Mazzon, que acompanhou praticamente todo o trabalho, dando sempre opiniões muito valiosas, atuando, em alguns momentos, praticamente como um co-orientador. Devo muito do formato final da pesquisa às nossas conversas. Agradeço também ao prof. Roy Martelanc, que em diversos momentos contribuiu com insights para a pesquisa em nossos papos informais, mas que, além disso, foi crucial à operacionalização do estudo cedendo o espaço para realização dos experimentos. Sem aquela magnífica estrutura e sem o apoio de sua equipe, teria sido impossível colocar em prática as ideias aqui desenvolvidas.

Não poderia deixar de citar o prof. Hélio Janny Teixeira, que apostou e confiou em meu trabalho no desenvolvimento do Liderança em Jogo, que acabou virando o núcleo da pesquisa. Outros professores da FEA e de fora dela também foram importantes, seja pelas conversas, seja por terem sido meus professores em disciplinas, seja ainda pelo incentivo: Adriana Backx, Edgard Cornacchione Jr., Maria Aparecida Gouvêa, Fernando Coelho, João Arantes, Lino Rodrigues Filho, Antonio Amaru, Joel Dutra e Alessandra Montini.

Agradeço à equipe de funcionários da FEA e, principalmente ao pessoal da biblioteca, que auxiliou na busca de artigos e referências "difíceis" para que a pesquisa pudesse ficar consistente. Não posso deixar de mencionar o Kitola do xerox no prédio da contabilidade: quebrou vários galhos e me ajudou na hora $\mathrm{H}$ da entrega da tese neste formato final. 
Agradeço aos colegas Eder, Danielle e Tatiani, parceiros de trabalhos e coautores de artigos e, principalmente, ao Filippe e à Vanessa, com quem iniciei minha trajetória na pós-graduação e que foram parceiros de pesquisa, em diversos sentidos; e Emerson, com quem aprendi que se não existissem os prazos, nada seria feito - inclusive esta tese!

Feito o agradecimento ao "lado acadêmico" da pesquisa, não posso deixar de fazer referência a outras pessoas fundamentais para o "ladro prático" do trabalho: Thiago Souza Santos, diretor da UCRH e principal incentivador do jogo como ferramenta para o desenvolvimento de gestores, e que teve participação crucial para que os experimentos da pesquisa fossem possíveis; Cida Novaes, que me abriu as portas na Secretaria da Saúde; Cristina Alonso, que organizou o curso Gestão Pública: Teoria e Prática e Fernanda Freitas e Juliana Feliciano pelo acompanhamento do curso.

Outras duas pessoas têm um lugar especial na consecução deste projeto: Adriano Duarte, amigo de longa data, que pôde emprestar sua genialidade à programação do jogo e que esteve disponível, mesmo do Canadá, para fazer todas as modificações necessárias nas horas mais críticas; e Otávio Dias, com quem já compartilhei muitos projetos e que cedeu suas ideias e sacadas perspicazes ao roteiro do jogo, sem falar no apoio fundamental nessa reta final da tese, "segurando as pontas" nos Planetários de São Paulo. E por falar nos planetários, não posso deixar de agradecer às pessoas que fizeram a instituição funcionar enquanto me ausentei para escrever a tese: Dorinha e Paula, principalmente, e a toda a equipe, sem falar no apoio da minha chefe Rose Inojosa.

No desenvolvimento do jogo, também foram importantes as participações do Sérgio Salomão, pela amizade e conselhos que foram além da realização do projeto, Fabio Marinho e Robson Leal, que criou as artes e deu cara aos personagens do jogo.

Outros amigos de longa data acabaram colaborando também para que a tese saísse: Bolinha, que testou o jogo e deu pitacos sobre ele; Léo, que em nossas conversas sobre educação e aprendizagem acabou trazendo luz em muitos momentos de incerteza no processo; Oxto, que com sua crítica conseguiu contribuir no desenho do experimento; e Gabriel, que trouxe seu olhar pedagógico em uma conversa sobre a pesquisa. 
Por fim, como não poderia deixar de ser, agradeço à minha família. Meu pai, Moacir, e minha mãe, Nilza, que sempre me apoiaram em tudo que fiz. Meus irmãos, Danilo e Gabriela. Minha avó Dora, que, desde muito pequeno, sempre instigou a minha curiosidade. E, finalmente, aos mais importantes: Dani, que está sempre ao meu lado em todas as loucuras que inventamos e Guguito, que, embora ainda não tenha idade para ter consciência, foi o mais privado da companhia do pai enquanto esse outro filho chamado tese precisava nascer. Espero que um dia ele possa se orgulhar desse "irmãozinho" de 300 páginas (nem no agradecimento consegui escrever pouco!).

A todos vocês, deixo minha eterna gratidão! 
Um curinga é um pequeno bobo da corte; uma figura diferente de todas as outras. Não é nem de paus, nem de ouros, nem de copas e nem de espadas. Não é oito, nem nove, nem rei e nem valete. É um caso à parte; uma carta sem relação com as outras. Ele está no mesmo monte das outras cartas, mas aquele não é o seu lugar. Por isso pode ser separado do monte sem que ninguém sinta falta dele.

(Jostein Gaarder, em O Dia do Curinga) 


\section{RESUMO}

Silva, F. N. (2017). O uso de jogos digitais para o desenvolvimento de gestores públicos: um estudo empírico com um serious game (Tese de Doutorado). Faculdade de Economia, Administração e Contabilidade, Universidade de São Paulo, São Paulo.

O presente estudo busca explicar de que forma o uso de jogos digitais contribui para o processo de desenvolvimento de gestores públicos, considerando-se que a capacitação gerencial é fundamental para o alcance de resultados e para a prestação de serviços públicos de qualidade. O primeiro passo da pesquisa foi compreender na literatura o que significa o uso de jogos digitais para fins educacionais e de desenvolvimento, o que foi feito por meio de um estudo bibliométrico. Na prática, o uso de jogos digitais relaciona-se a conceitos como jogos sérios (serious games), gamificação (gamification) e aprendizado por meio de jogos (gamebased learning). O estudo envolveu, então, o desenvolvimento do serious game Liderança em Jogo: Competências, Papéis e Responsabilidades, que leva em conta o contexto do setor público e foi pensado justamente como ferramenta para o desenvolvimento de gestores públicos. A aplicação do jogo foi feita por meio de um curso especialmente concebido para este trabalho e a avaliação de sua eficácia considerou o modelo de quatro níveis de Kirkpatrick (reação, aprendizado, comportamento e resultados). O impacto do uso desse jogo digital foi avaliado comparativamente por meio de um conjunto de dois experimentos completamente aleatorizados, com grupo de controle e no formato pré-teste/pós-teste (experimento 1) e pós-teste apenas (experimento 2). A pesquisa foi multimétodo, envolvendo triangulação metodológica, sendo complementada por análises qualitativas (entrevistas semiestruturadas e análise de conteúdo). Como principais resultados, foram verificados impactos nos quatro níveis avaliados. Os experimentos mostraram que, em comparação ao grupo de controle, quem joga (grupo experimental) gosta mais do processo de aprendizado (reação) e apresenta maiores níveis de atenção e relevância do modelo ARCS, desenvolvido por John M. Keller, utilizado para avaliar a motivação; demonstra maiores níveis de aquisição de conhecimento (aprendizado); desenvolve uma visão de gestão mais atrelada aos aspectos humanos (atitude como antecedente do comportamento); e vê mais impactos do treinamento sobre o resultado projetado de seu trabalho para o futuro (resultados). As entrevistas ainda indicaram que o jogo, além de ter seguido os preceitos de game design que o caracterizam como tal, provocou reflexões que resultaram em mudança de comportamento em situações do dia a dia. Assim, considerando-se o desenvolvimento gerencial do ponto de vista das competências como o conjunto de Conhecimentos, Habilidades e Atitudes (CHA) da pessoa, vê-se que o jogo digital utilizado é efetivo para o desenvolvimento gerencial, uma vez que os experimentos detectaram aquisição de conhecimentos e mudanças de atitudes. A contribuição do estudo é relevante pois, além de trazer evidências empíricas necessárias à literatura, integra em um framework conceitual as inter-relações de diversos referenciais teóricos como base para uma pesquisa operacionalizável. As principais limitações do estudo estão associadas à artificialidade dos experimentos e ao não controle de variáveis que possam ter impacto no aprendizado. Além da opção de avaliar apenas os níveis mais baixos de aprendizado da taxonomia de Bloom, com a utilização de questões diretas no instrumento de avaliação de conhecimento, o reduzido número de participantes também foi uma limitação, impactando as possibilidades estatísticas de identificar efeitos sobre os níveis de profundidade do conhecimento adquirido ou diferentes assuntos considerados no curso/treinamento.

Palavras-chave: Jogos Eletrônicos. Serious games. Gamificação. Aprendizado baseado em jogos. Desenvolvimento de Recursos Humanos. Gestão Pública. Experimentos. 


\begin{abstract}
Silva, F. N. (2017). The use of digital games for the development of public managers: an empirical study with a serious game (Tese de Doutorado). Faculdade de Economia, Administração e Contabilidade, Universidade de São Paulo, São Paulo.
\end{abstract}

This study aims to explain how the use of digital games can contribute to the process of development of public managers, considering that managerial capacity is key to the achievement of results and the provision of good quality public services. The first step of the research was to seek in the literature what the use of digital games means in terms of educational and development purposes. That was done through a bibliometric study. In practice, the use of digital games is related to concepts such as serious games, gamification and game-based learning. The following step involved the development of the serious game entitled Liderança em Jogo: Competências, Papéis e Responsabilidades, which takes into account the context of the Public Sector and was built specifically as a tool for the development of public managers. The application of the game was made through a course specially designed for this study and the assessment of its effectiveness considered Kirkpatrick's four-level model (reaction, learning, behavior and results). The impact of the use of this digital game was evaluated through a set of two randomized experiments, with a control group and in the pre-test /post-test format (experiment 1) and post-test only (experiment 2). The research was multi-method, involving methodological triangulation and was complemented by qualitative analyzes (semi-structured interviews and content analysis). The main results show impacts in the four evaluated levels. The experiments showed that, in comparison with the control group, the subjects who play (experimental group) enjoy more the learning process (reaction) and present higher levels of attention and relevance, according to the ARCS model developed by John M. Keller, used to evaluate motivation. In addition, they demonstrate higher levels of knowledge acquisition (learning); develop a management vision more linked to human aspects (attitude as antecedent of the behavior) and see more impact of the training on the outcomes of their job for the future (results). The interviews also indicated that the game, in addition to having followed the precepts of game design led to reflections that resulted in behavior change in day-to-day situations. Therefore, considering the managerial development from the point of view of the competences as the sum of knowledge, skills and attitudes (KSA) of a person, it is seen that the digital game used is effective, once the experiments detected acquisition of knowledge and changes in attitudes. The contribution of this study is relevant because, in addition to bringing empirical evidence to the literature, it integrates the inter-relationships of several theoretical references into a conceptual framework as the basis for an executable research. The main limitations of the study are associated with the artificiality of the experiments and the non-control of variables that may have an impact on learning. Besides evaluating only the lower learning levels according to the Bloom's taxonomy, using direct questions in the assessment instrument, the small number of participants was also a factor of limitation, which might have impacted on statistical inference of the effects on the levels of depth of knowledge acquired or on the different topics approached in the course/training.

Keywords: Digital games. Serious games. Gamification. Game-based learning. Human Resource Development. Public Management. Experiments. 


\section{LISTA DE FIGURAS}

Figura 1.1 - Esquema geral da pesquisa. 16

Figura 2.1 - Número de artigos (de periódicos e proceedings de conferências) sobre jogos (games) publicados desde 1981 Fonte: Elaboração do autor, a partir dos dados da base Scopus

Figura 2.2 - Número de artigos contendo as palavras-chave de cada categoria associadas à busca

"Game OR game" na base Scopus.

Figura 2.3 - Mapa perceptual construído com a técnica de escalonamento multidimensional a partir da matriz de coocorrência das palavras-chave na busca "use of games" na base Scopus.

Figura 2.4 - Sobreposição de palavras-chave com destaque nas duas buscas realizadas na base Scopus para os termos associados aos tipos de jogos. 28

Figura 2.5 - Sobreposição de palavras-chave com destaque nas duas buscas realizadas na base

Scopus para os termos associados à educação. 28

Figura 2.6 - Número de artigos contendo as palavras-chave de cada categoria associadas à terceira busca realizada na base Scopus. 30

Figura 2.7 - Mapa perceptual construído com a técnica de escalonamento multidimensional a partir da matriz de coocorrência das 257 principais palavras-chave da busca 3.

Figura 2.8 - Variação ao longo do tempo do número de registros para os termos e-Learning e

Distance Education na base Scopus no período de 2000 a 2014. 34

Figura 2.9 - Variação ao longo do tempo do número de registros para os termos gamification, serious games, serious gaming, game-based learning, learning game, educational game, business games e business simulation na base Scopus no período de 2000 a 2014. 34

Figura 2.10 - Relações entre as modalidades de aprendizado a distância e aprendizado por meio de jogos 38

Figura 2.11 - O modelo do canal de fluxo. 40

Figura 2.12 - Análise do Google Trends dos termos gamification e serious games, desde 2004. 48

Figura 2.13 - Gamification e serious games em um contexto mais amplo ...............................50

Figura 2.14 - Exemplos de playful design. 51

Figura 2.15 - O modelo de comportamento de Fogg (FBM), baseado em três fatores: motivação, habilidade e gatilhos

Figura 2.16 - Relação entre video games, serious games e serious gaming. 
Figura 2.17 - Diferentes métodos de ensino e diferentes processos de aprendizagem em função do objetivo do desenvolvimento gerencial.

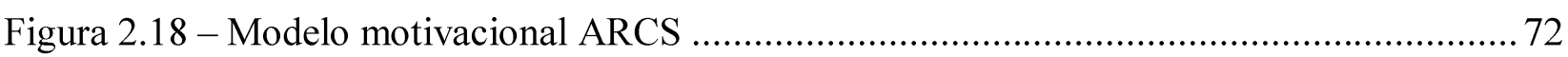

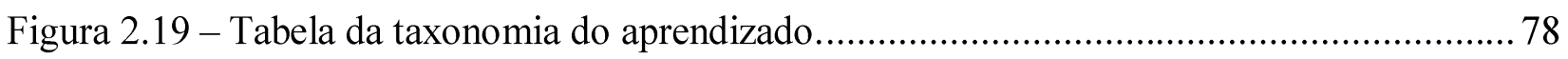

Figura 2.20 - O ciclo do aprendizado experiencial de Kolb.............................................. 86

Figura 2.21 - O modelo do processo de aprendizado de Jarvis. .............................................. 86

Figura 2.22 - Framework conceitual da pesquisa .............................................................. 93

Figura 3.1 - Visão geral do esquema da pesquisa............................................................. 96

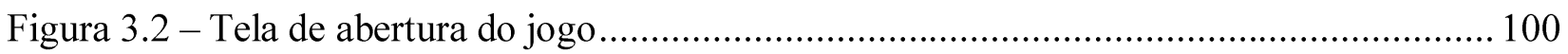

Figura 3.3 -Tela principal do jogo contendo barra de status: jogo mais "gamificado" ............. 103

Figura 3.4 - Esquema da construção do instrumento de avaliação e a relação do desempenho do

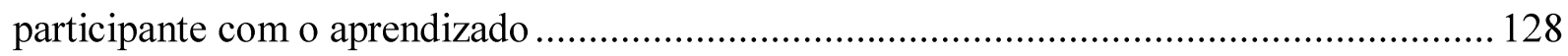

Figura 3.5 - Linha do tempo da realização dos experimentos............................................. 130

Figura 4.1 - Distribuição da avaliação de reação padrão para o desempenho do instrutor do primeiro experimento.

Figura 4.2 - Distribuição da avaliação de reação padrão para o processo de aprendizagem do primeiro experimento. 150

Figura 4.3 - Distribuição da avaliação de reação padrão para a infraestrutura do curso do primeiro experimento.

Figura 4.4 - Média dos construtos do modelo ARCS para os participantes do primeiro experimento.

Figura 4.5 - Distribuição da avaliação de reação padrão para o desempenho do instrutor do segundo experimento.

Figura 4.6 - Distribuição da avaliação de reação padrão para o processo de aprendizagem do segundo experimento. 154

Figura 4.7 - Distribuição da avaliação de reação padrão para a infraestrutura do curso do segundo experimento.

Figura 4.8 - Média dos construtos do modelo ARCS para os participantes do segundo experimento

Figura 4.9 - Diagrama de dispersão das notas no pré e pós-testes, por grupo.

Figura 4.10 - Médias das notas obtidas no pré-teste e pós-teste pelos participantes do experimento 1

Figura 4.11 - Gráfico de interação para o pré-teste e o pós-teste do experimento 1 
Figura 4.12 - Médias dos percentuais de acertos das questões classificadas em cada um dos verbos da taxonomia de Bloom para o experimento 1

Figura 4.13 - Nível descritivo (p-valor) das ANCOVAS utilizadas para comparar o percentual de acertos nas questões classificadas nos verbos da taxonomia de Bloom no experimento 1.... 165

Figura 4.14 - Gráfico de interação para as médias do percentual de acerto das questões nos pré e pós-teste, seguindo a classificação em níveis de profundidade (DoK) de Webb. 165

Figura 4.15 - Médias da nota final (pós-teste) para os grupos experimental e de controle no experimento 2 .

Figura 4.16 - Gráfico de pontos paralelos para o pós-teste do experimento 2

Figura 4.17 - Médias da quantidade de sentenças com visões hard e soft de gestão nos textos produzidos no experimento 1

Figura A1- Visão básica do processo do jogo. 205

Figura A2- Visão da lista de pedidos na caixa de entrada do jogador. 207

Figura A3 - Visão dos editais concluídos na caixa de saída do jogador.

Figura A4 - A mesa de trabalho do gestor/jogador e as caixas de entrada (direita) e saída (esquerda) 208

Figura A5 - Interação com funcionário e opções de priorização do trabalho 210

Figura A6 - O processo básico do jogo influenciado pelos atributos dos funcionários e dos pedidos 210

Figura A7 - Diretora da unidade do jogador dando orientações ao jogador

Figura A8 - Visão do formulário de avaliação de desempenho.

Figura A9 - Processo do jogo, fatores de influência no desempenho e os resultados da área .... 214

Figura A10 - Funcionário dá dica de que as condições do mobiliário não são as ideais

Figura A11 - Momento da decisão sobre a troca de computadores. 216

Figura A12 - Orçamento simplificado do jogo 219

Figura A13 - O sistema dinâmico do jogo "Liderança em jogo: competências papéis e responsabilidades" 220 
xviii 


\section{LISTA DE TABELAS}

Tabela 1.1 - Estruturação da pesquisa em função do desmembramento do problema de pesquisa 17

Tabela 2.1 - Palavras-chave excluídas da busca por "games OR game" na base Scopus. 23

Tabela 2.2 - Relação dos conceitos-chave nas categorias de Educação e Tipos de jogos selecionados para nortear a fundamentação teórica do trabalho.

Tabela 2.3 - Quantidade de registros encontrados na base Scopus para cada conceito-chave

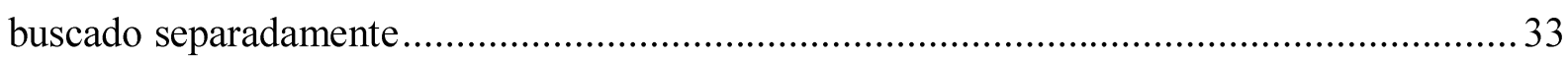

Tabela 2.4 - Taxonomia dos elementos dos jogos digitais.............................................. 44

Tabela 2.5 - Definições de GBL, serious games, simulações e gamification ............................ 46

Tabela 2.6 - Classificação dos jogos segundo Roger Caillois (1967)........................................ 49

Tabela 2.7 - Concepções da educação gerencial observadas nas publicações de três revistas proeminentes da área de educação e aprendizagem gerencial........................................6 60

Tabela 2.8 - Diretrizes e Dicas de Implementação de um SBT em Educação Gerencial .............67

Tabela 2.9 - Os principais tipos de conhecimento ............................................................. 76

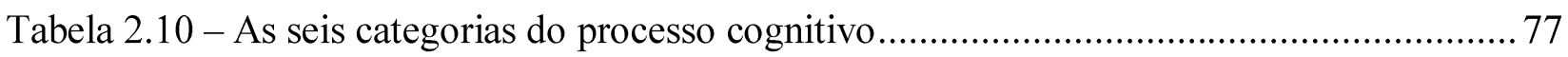

Tabela 2.11 - Níveis de profundidade de conhecimento (depth of knowledge) de Webb............ 79

Tabela 2.12 - Resumo da presença das teorias do aprendizado em alguns artigos dos últimos anos

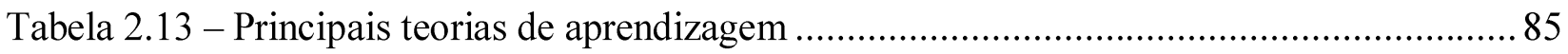

Tabela 2.14 - Impacto das perspectivas do aprendizado sobre o uso de jogos ......................... 90

Tabela 2.15 - Burocratas versus dirigentes públicos ........................................................... 92

Tabela 3.1 - Soluções de design do Liderança em Jogo dadas para incorporação dos elementos de

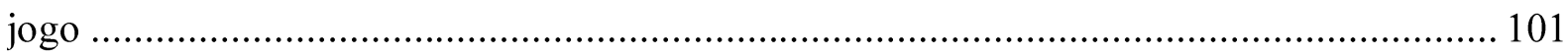

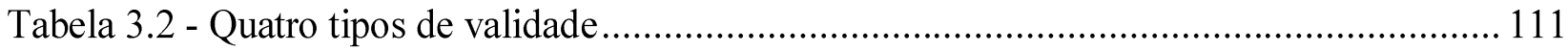

Tabela 3.3 - Ameaças à validade de conclusão estatística: razões pelas quais inferências sobre a correlação entre duas variáveis podem estar incorretas.

Tabela 3.4 - Ameaças à validade interna. Razões pelas quais a inferência sobre a relação causal

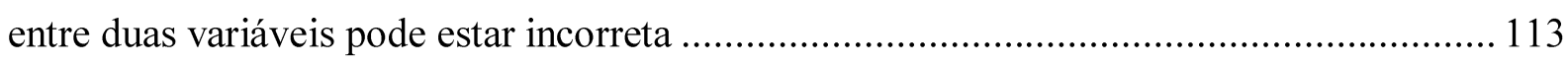

Tabela 3.5 - Ameaças à validade de construto. Razões pelas quais inferências sobre os construtos que caracterizam a operacionalização do estudo podem estar incorretas. 
Tabela 3.6 - Ameaças à validade externa. Razões pelas quais inferências podem estar incorretas sobre como as conclusões do estudo se sustentariam variando-se as pessoas, configurações, tratamentos e resultados.

Tabela 3.7 - Principais riscos ao experimento (ameaças à validade) e medidas para lidar com eles.

Tabela 3.8 - Resumo das melhores práticas para uma avaliação efetiva do DGBL

Tabela 3.9 - Representação das medidas tomadas (pré-teste e pós-teste) com os dois grupos do experimento.

Tabela 3.10 - Resumo dos instrumentos de coleta utilizados nos experimentos.

Tabela 4.1 - Trechos exemplificadores dos trabalhos do piloto 138

Tabela 4.2 - Evidências da adequação dos elementos do game design ao jogo desenvolvido com base nas entrevistas realizadas.

Tabela 4.3 - Termos mais frequentes nos trabalhos do piloto e sua relação com a ementa do curso 148

Tabela 4.4 - Comparativo da avaliação de reação, por item, no quesito "processo de aprendizagem" do primeiro experimento.

Tabela 4.5 - Comparativo da avaliação de reação, por item, no quesito "processo de aprendizagem" do segundo experimento

Tabela 4.6 - Comparação da avaliação de reação dos itens de processo de aprendizagem do grupo experimental com relação ao de controle para os dois experimentos. 158

Tabela 4.7 - Médias por critério para os grupos experimental e de controle para o experimento 2

Tabela 4.8 - comparação das médias para os itens de resultado projetado para os grupos experimental (tratamento) e de controle do experimento 2 


\section{LISTA DE ABREVIATURAS E SIGLAS}

ANOVA - Analysis of Variance (análise de variância)

ANCOVA - Analysis of Covariance (análise de covariância)

ARCS - Atenção, Relevância, Confiança e Satisfação

ATI - Attitude-treatment interaction

Cefor - Centro de formação (de servidores da Secretaria da Saúde)

CHA - Conhecimentos, Habilidades e Atitudes

CLP - Centro de Liderança Pública

CT\&D - Centro de Treinamento e Desenvolvimento

DGBL - Digital Game-based Learning (Aprendizado por meio de jogos digitais)

DoK - Depth of Knowledge

EAD - Educação a Distância

FBM - Fogg Behavior Model

FEA - Faculdade de Economia, Administração e Contabilidade da Universidade de São Paulo

FIA - Fundação Instituto de Administração

GBL - Game-based Learning (Aprendizado por meio de jogos)

G/P/S - Gameplay/ Purpose / Scope

HRD - Human Resource Development (Desenvolvimento de Recursos Humanos)

HRM - Human Resource Management (Gerenciamento de Recursos Humanos)

IBM - International Business Machines (empresa)

IMMS - Instructional Materials Motivation Survey

KSA - Knowledge, Skills and Attitudes (Conhecimentos, Habilidades e Atitudes)

MBA - Master in Business Administration

MDS - Multidimensional Scalling 
xxii

MIT - Massachussetts Institute of Techonology

MLG - Master em Liderança e Gestão Pública

MOOCs - Massive Open Online Courses

Moodle - Modular Object-Oriented Dynamic Learning Environment

NPM - New Public Management (A Nova Gestão Pública)

OE - Objetivo Específico (da pesquisa)

PEC - Planejamento, Execução e Controle

PG - Papeis Gerenciais

RIMMS - Reduced Instructional Materials Motivation Survey

SBT - Simulation-based Training (Treinamento baseado em simulações)

SES - Secretaria do Estado da Saúde do Governo de São Paulo

SFI - Secretaria de Formação e Informação (entidade fictícia no jogo)

$\mathrm{SG}$ - Serious Games

SGP - Secretaria de Gestão Pública

SPG - Secretaria de Planejamento e Gestão

T\&D - Treinamento e Desenvolvimento

TRI - Teoria de Resposta ao Item

UCRH - Unidade Central de Recursos Humanos

USP - Universidade de São Paulo

VS - Visão Sistêmica 


\section{SUMÁRIO}

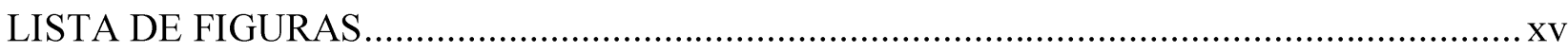

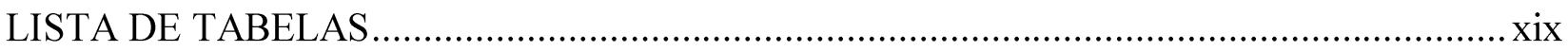

LISTA DE ABREVIATURAS E SIGLAS ..................................................................... xxi

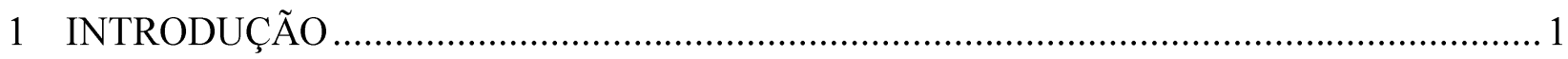

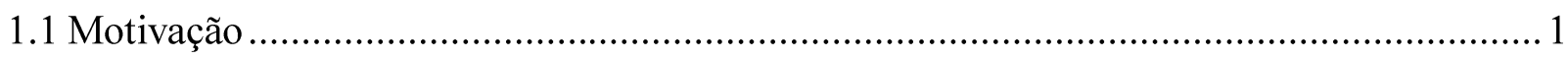

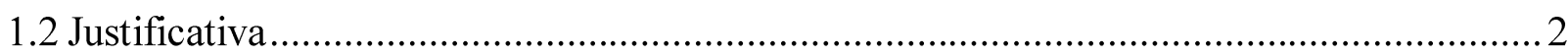

1.2.1 Desenvolvimento de gestores conectado ao Século 21........................................ 6

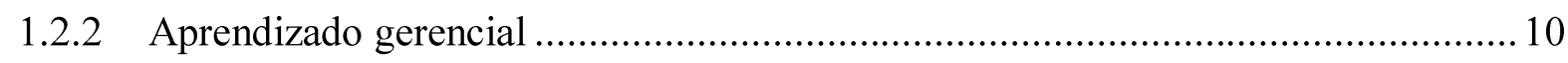

1.3 Foco, Problema de pesquisa e delimitação do estudo..................................................... 12

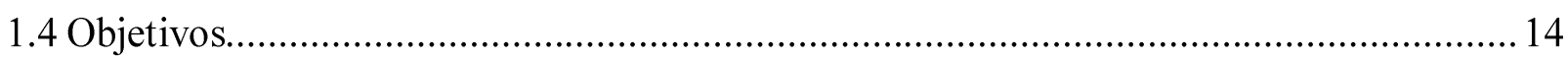

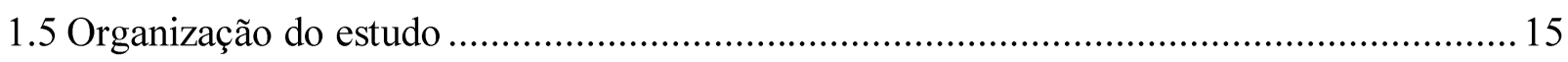

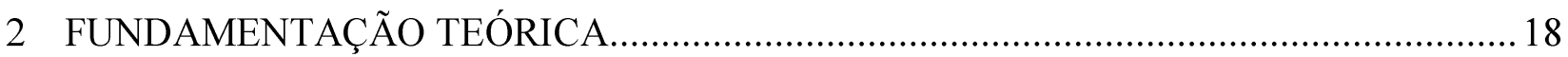

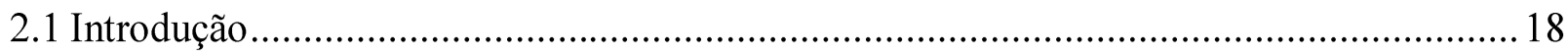

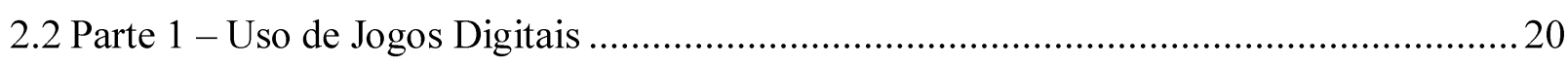

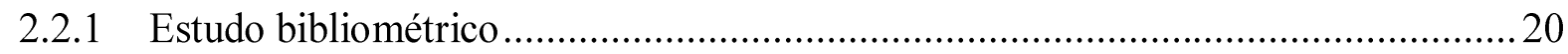

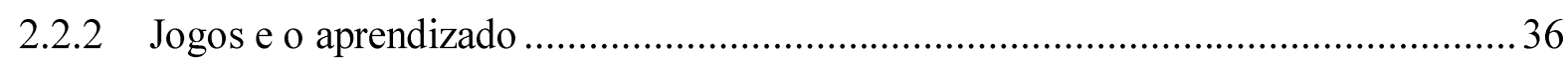

2.2.3 Aprendizado por meio de jogos (game-based learning)....................................... 37

2.2.4 Os pilares constitutivos do DGBL .................................................................. 45

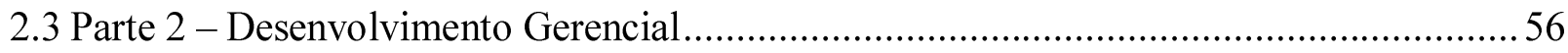

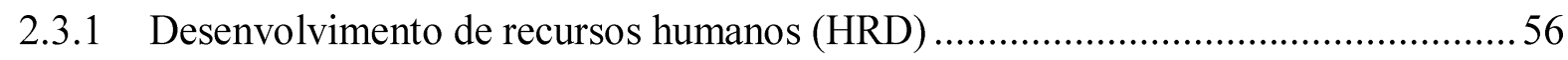

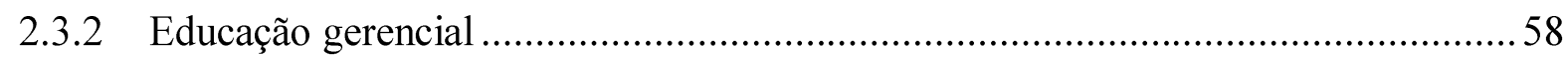

2.3.3 Treinamento e Desenvolvimento com jogos e simulações ....................................65

2.3.4 Avaliação de programas de treinamento e desenvolvimento ..................................68

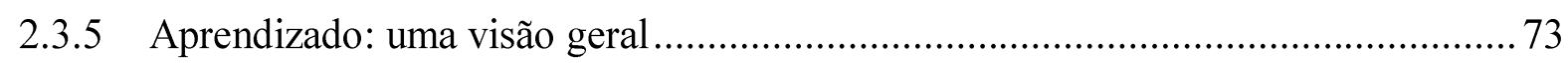

2.4 O Gestor Público: breve contextualização ................................................................. 90

2.5 Colocando tudo junto: Framework conceitual da pesquisa......................................... 93

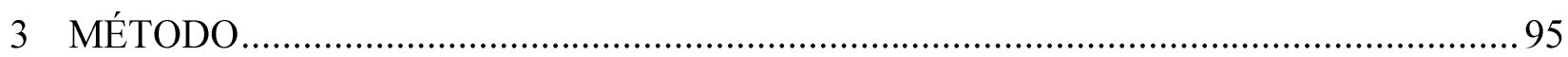

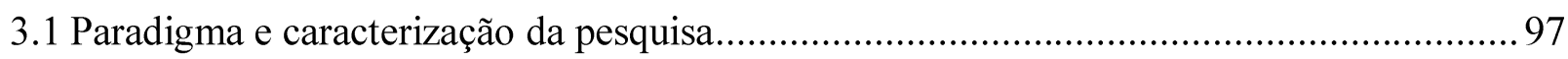

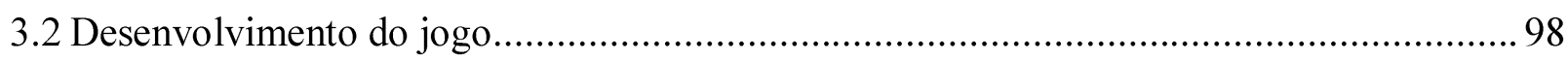

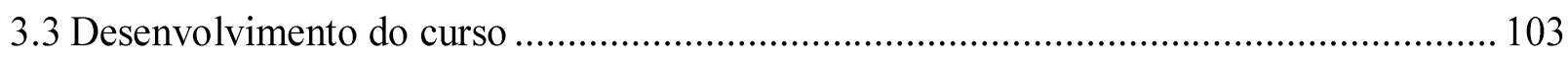

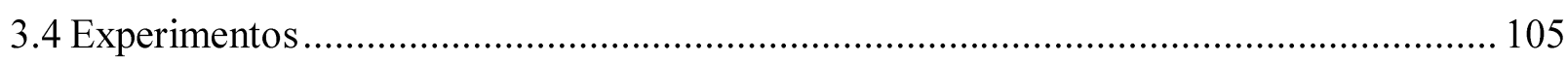


xxiv

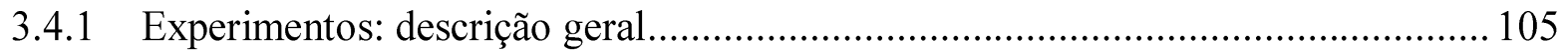

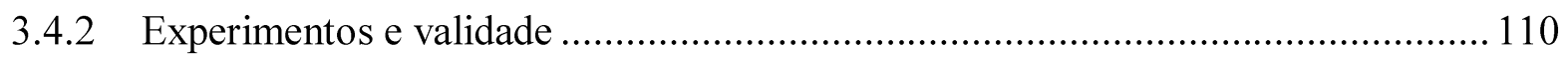

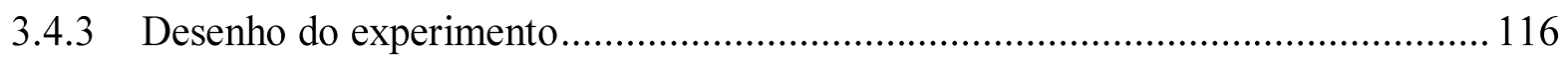

3.4.4 Riscos à validade e medidas de mitigação ........................................................... 117

3.4.5 Poder e tamanho da amostra........................................................................ 122

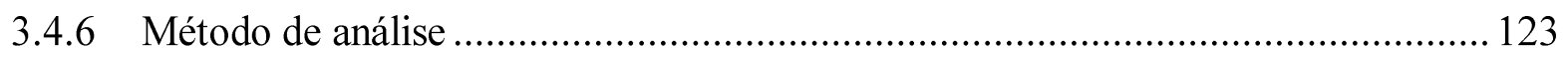

3.4.7 Instrumentos para avaliação do desenvolvimento dos gestores ........................... 127

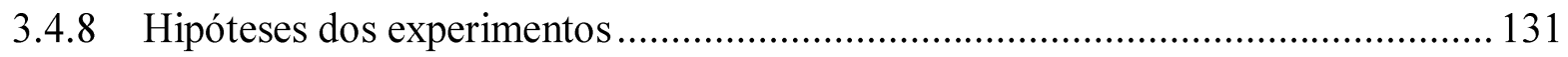

3.5 Descritivo dos experimentos realizados .................................................................... 133

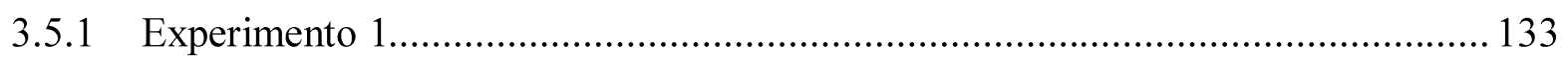

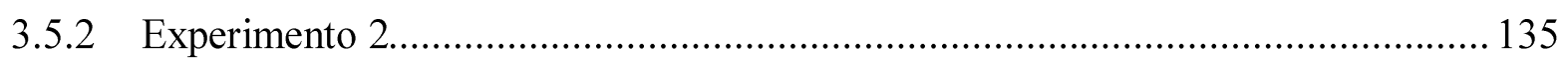

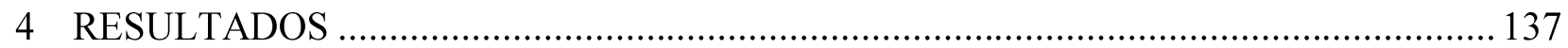

4.1 Considerações sobre o uso do jogo: piloto e desenvolvimento do curso .......................... 137

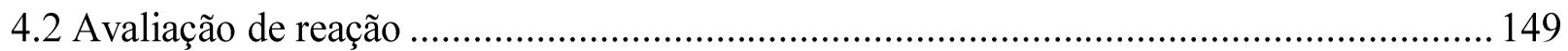

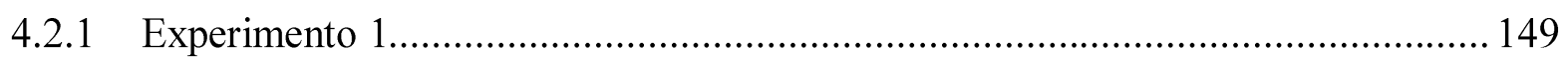

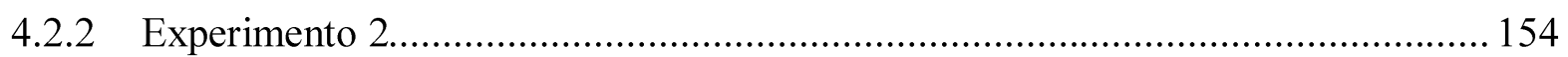

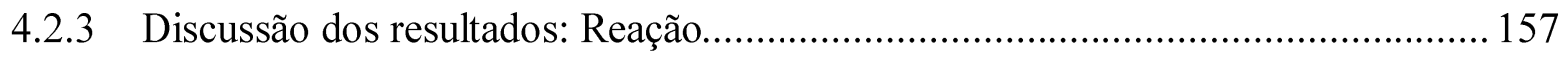

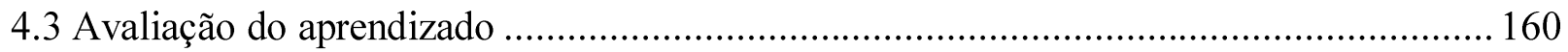

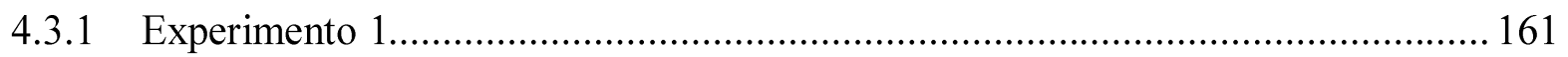

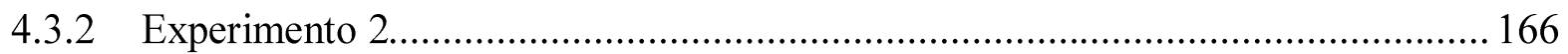

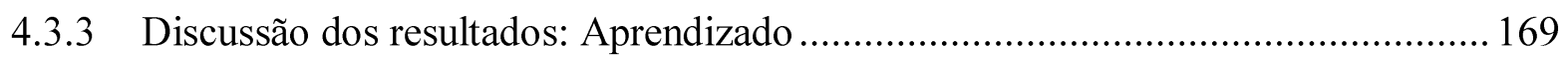

4.4 Percepção sobre a mudança de comportamento ..................................................... 170

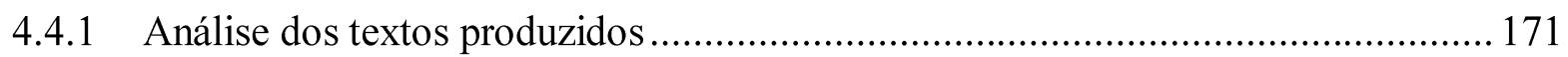

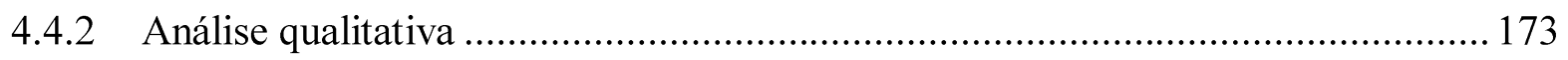

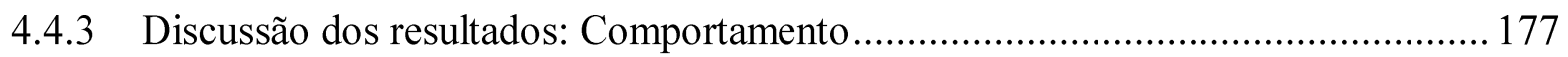

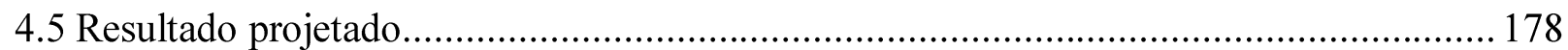

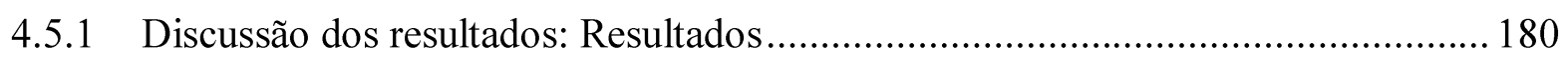

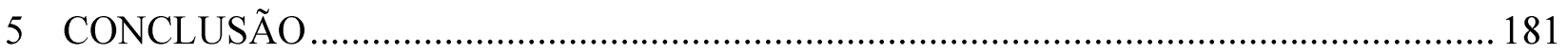

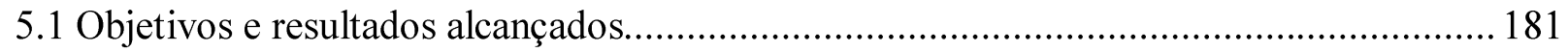

5.2 Limitações e sugestões de estudos futuros. ................................................................ 184

5.3 Contribuições e implicações para a prática ............................................................... 186

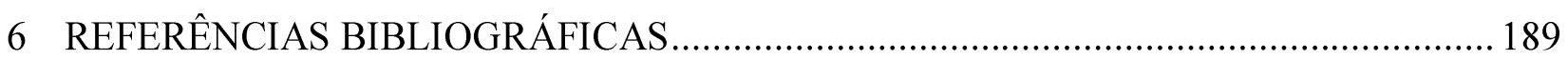

Apêndice A Desenvolvimento do Liderança em Jogo.......................................................... 205

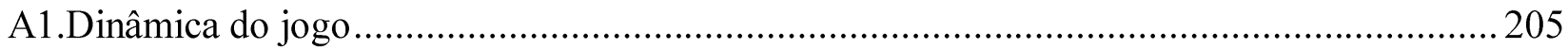

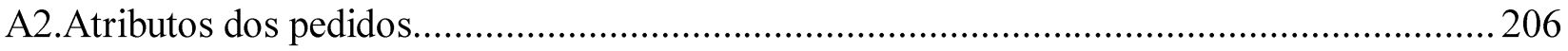

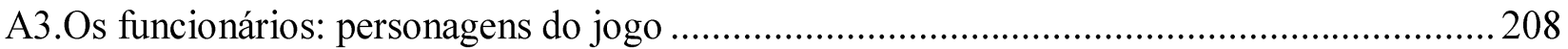


A4.Linha do tempo

A5.Metas da unidade

A6.Avaliação de desempenho

A7.Fatores ambientais

A8.Desafios

A9.Planejamento orçamentário

A10.Ilustração do sistema dinâmico do jogo.

Apêndice B Termo de consentimento para participação no estudo

Apêndice C Questionários IMMS

C1.Questionário RIMMS Original.

C2.IMMS - versão do Experimento 1 225

C3.IMMS - versão do Experimento 2 226

Apêndice D Saídas do SPSS para o nível de reação 229

D1.Experimento 1 - modelo ARCS. 229

D2.Experimento 2 - modelo ARCS

Apêndice E Questões utilizadas nos experimentos......................................................... 235

Apêndice F Saídas do SPSS para Experimento 1 ......................................................... 255

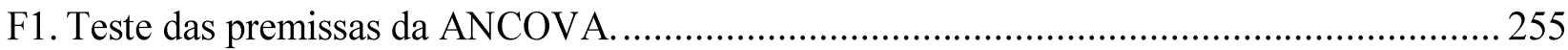

F2. ANCOVA para o pós-teste, com o pré-teste como covariável.......................................... 258

F3. ANCOVA para os níveis de profundidade (verbos) da taxonomia de Bloom modificada e para o DoK de Webb.

F4. ANCOVA para os diferentes assuntos considerados.................................................. 265

Apêndice G Saídas do SPSS para Experimento 2 ......................................................... 269

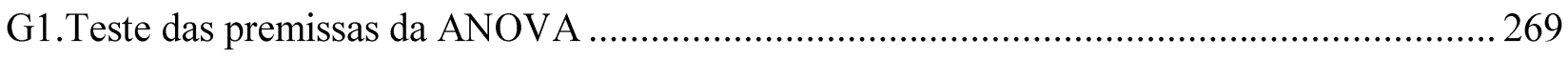

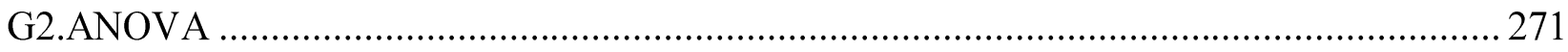

G3.ANOVA para o pós-teste do experimento 1 - comparativo ......................................... 271 
xxvi

G4.ANOVA para os níveis de profundidade (verbos) da taxonomia de Bloom modificada e para o DoK de Webb 273

G5.ANOVA para os diferentes assuntos considerados .279

Apêndice H Análise de Conteúdo dos textos 283

H1.Textos analisados e categorização 283

H2.Comparação de médias - Teste-U de Mann-Whitney 287

Apêndice I Roteiro das entrevistas e questões da consulta online 289

I1. Questões para guiar as entrevistas: 289

I2. Questões da consulta online: 289

Apêndice J Questionário sobre resultado projetado 291

J1. Versão online no questionário 291

J2. Saída do teste U de Mann-Whitney 291

Anexo 1 Questionário de avaliação de reação - CT\&D/Cefor - SES-SP 293 


\section{INTRODUÇÃO}

\subsection{Motivação}

A motivação para esta tese se origina na própria trajetória do autor da pesquisa. Como um físico atuando na direção dos Planetários de São Paulo, com apenas 25 anos, há mais de 10 anos, embora tendo o conhecimento técnico necessário para a função, vi a necessidade de me capacitar na gestão, que era, no fim das contas, o núcleo do trabalho. Fui percebendo, pela minha própria experiência e por observação dos outros gestores de diversas áreas e níveis, que a capacidade de gerir era fundamental para o alcance dos resultados. Ficava claro que melhorar a gestão (pública) dependia fortemente do desenvolvimento dos gestores.

Após essa vivência como gestor público, tive outras experiências tanto na iniciativa privada quanto na área pública. Nos últimos anos, tendo atuado em diversos projetos de consultoria na área pública, ficou ainda mais evidente para mim que a capacitação dos gestores públicos é de fundamental relevância para a melhoria dos serviços prestados. Essa vontade de contribuir, mesmo que em pequeno grau, para a melhoria da gestão - e em particular a gestão pública culminou com este trabalho. O contexto em que o país se insere desde o meu início na pósgraduação, em 2013, conforme descrito na próxima seção, também colaborou para essa vontade.

No meio do caminho, em um dos projetos em que atuei, tive ainda a oportunidade de participar ativamente na concepção e construção de um jogo digital focado no desenvolvimento de gestores públicos, abordando aspectos de gestão e liderança (com embasamento teórico). Ficava claro, também, que a capacitação dos gestores públicos precisava estar antenada às novas tecnologias, que deveria se conectar às gerações que, cada vez mais, estarão aptas a assumir funções de gestão.

Em um dado momento, em 2015, dei-me conta de que a minha preocupação acadêmica, de buscar um problema de pesquisa focado na melhoria da gestão pública, em particular no desenvolvimento de gestores, era a mesma que movia naquele que era apenas um projeto de trabalho até então, o desenvolvimento do jogo chamado "Liderança em Jogo: Competências, 
Papéis e Responsabilidades". Estavam na mesa todos os ingredientes que poderiam se transformar no objeto desta pesquisa. Será que o uso de novas formas de capacitação poderia contribuir de alguma maneira para o desenvolvimento dos gestores públicos? Com algumas adaptações, aquele jogo inicialmente pensado para compor um curso EAD poderia estar no núcleo do processo de capacitação de gestores públicos para fazer parte de uma pesquisa acadêmica. Explicar de que maneira o uso desse tipo de jogo digital poderia contribuir para o desenvolvimento de gestores públicos passou a fazer parte da minha busca como pesquisador.

O problema de pesquisa que emergiu foi: qual o impacto do uso de jogos digitais para o desenvolvimento de gestores públicos? Restava o árduo trabalho de operacionalizá-lo em uma pesquisa científica, o que esperamos ter conseguido fazer ao longo dessa trajetória, que em parte termina com a defesa da tese, mas que, ao mesmo tempo, marca o início de uma nova etapa e de novas perspectivas, inclusive com desdobramentos decorrentes deste trabalho.

As seções seguintes tratam da justificativa, do foco da pesquisa e de suas delimitações. A partir deste ponto, como seria mesmo esperado, deixo de lado a narrativa pessoal e, a partir da próxima seção, adoto o tom acadêmico, impessoal, linguagem que é requisito para este tipo de trabalho, mas com a expectativa de ter dado ao leitor, com esta breve introdução, um entendimento sobre o pano de fundo que motivou a pesquisa.

\subsection{Justificativa}

As manifestações populares de 2013 deixaram evidente a insatisfação da população com os serviços prestados pelo poder público. Quatro anos depois, persiste a sensação de que pouco mudou, em especial no que diz respeito à qualidade dos serviços públicos prestados à população. Em 2016, uma pesquisa da Confederação Nacional da Indústria revelou que 90\% dos brasileiros esperam uma qualidade maior dos serviços públicos, levando-se em conta o valor pago pelos impostos (CNI, 2016). Deixadas de lado a turbulência política que o país vive hoje e a polarização ideológica que tomou conta dos debates em anos recentes, não é difícil associar grande parte da má qualidade dos serviços públicos à baixa capacidade de 
gestão nas diferentes esferas do setor público ${ }^{1}$. Embora não exista um consenso na literatura sobre o que seria a capacidade de gestão (Melton \& Meier, 2017), há evidências de que essa capacidade é um determinante crítico dos resultados obtidos no setor público (Andrews \& Boyne, 2010; Andrews e Brewer, 2013; Ingraham, Joyce \& Donahue, 2003).

A capacidade de gestão passa pelas ideias de disponibilidade de recursos (tempo, pessoas e dinheiro) e também por comportamentos dos gestores, como coleta de informações, planejamento e integração de sistemas (Melton \& Meier, 2017; Lynn, Heinrich \& Hill, 2001). Já se sabe, também, que a liderança é capaz de ampliar os efeitos da capacidade de gestão sobre o desempenho de organizações do setor público (Andrews \& Boyne, 2010). Além disso, a gestão de recursos humanos (HRM - Human Resource Management), entendida como a habilidade para obter, reter e desenvolver recursos humanos críticos e talentos (Donahue, Selden e Ingraham, 2000) é outro aspecto importante que influencia o desempenho de organizações públicas (Andrews \& Boyne, 2010).

Pesquisas já demonstraram evidência de efeitos fortes positivos da qualidade da equipe, da estabilidade do pessoal e do planejamento sobre o desempenho (Walker \& Andrews, 2013). Porém, há também evidência de que o contexto em suas diferentes facetas (político, ambiental e interno) pode afetar a gestão e sua relação com o desempenho (O’Toole Jr \& Meier, 2014).

A noção de que os resultados obtidos advêm das práticas do gestor ganhou força com o movimento da chamada Nova Gestão Pública, ou o New Public Management (NPM), que buscou transformar a forma com que os serviços são prestados e a forma com que as organizações públicas são administradas (Denhardt \& Denhardt, 2000; Fattore, Dubois, \& Lapenta, 2012; Sanderson, 2001). O foco do NPM sobre os resultados organizacionais e sobre a efetividade gera expectativas para que os gestores públicos desempenhem papel ativo e empreendedor, transformando suas práticas e melhorando suas habilidades gerenciais (Moynihan \& Pandey, 2005). Ou seja, fortalece-se a ligação entre os resultados organizacionais e o esforço gerencial. Nesse sentido, Sun, Gregg e Ryzin (2014) trazem evidências empíricas que corroboram essa percepção. Em seu estudo, os autores

\footnotetext{
1 A percepção de que bons serviços públicos, resultado de uma boa gestão, são essenciais para o desenvolvimento de uma sociedade mais justa é vista em diversos setores e meios. Por exemplo, a entrevista do ator Pedro Cardoso comparando sua vida em Portugal com a do Brasil ilustra essa ideia e pode ser vista no seguinte link: http://youtu.be/B5I4ud3FTGA .
} 
identificaram, no âmbito da educação, relação positiva entre escolas que efetivamente praticam a gestão do desempenho e os resultados obtidos por elas em testes padronizados.

Dessa forma, pode-se argumentar que melhorar a capacidade de gestão, no que diz respeito ao desenvolvimento dos gestores públicos, pode ser um importante fator para a melhoria da gestão pública. Dagnino (2013) argumenta que para que seja possível migrar de uma visão de gestão de "Estado Herdado" para uma de um "Estado Necessário" deve-se desenvolver um novo estilo de capacitação de gestores, que vai muito além do compromisso com a democracia e com o futuro mais justo, do ativismo e da militância. Segundo o autor, "é imprescindível que um novo tipo de conhecimento teórico e prático acerca de como governar (para a população e em conjunto com ela) seja, urgentemente, disponibilizado" (p. 105).

A importância do enfoque na gestão pública se dá, ainda, pelo cenário desolador existente no Brasil. De acordo com Loureiro, Abrucio e Pacheco (2010), havia no país, na época da publicação de seu trabalho, cerca de 700.000 estudantes matriculados nos mais de 3.000 cursos de administração de empresas. São formados, anualmente, 100.000 novos profissionais, representando o maior contingente de formandos do ensino superior em nível nacional. Porém, especificamente na administração pública, existiam somente 71 cursos, nos quais estavam matriculados 4.000 alunos. Desses, apenas 1.500 estavam nos onze cursos mantidos por universidades públicas, formando apenas 170 profissionais por ano.

Somado a isso, existem alguns obstáculos para a atração de alunos, para a formação e para a inserção profissional dos egressos em cursos de administração pública. Coelho (2008) aponta que a atração de alunos para os cursos de administração pública é dificultada pelo desgaste da imagem do estado, associado a escândalos de corrupção e precariedade de alguns serviços públicos, por exemplo, e pelas perspectivas de trabalho nebulosas. A formação acadêmica, ainda segundo Coelho (2008), é prejudicada por seis fatores: falta de identidade do ensino, mimetismo da administração de empresas, dicotomia política-administração, escassez de material didático, carência de corpo docente e falhas na interface teoria-prática. Por fim, o autor atribui como obstáculo à inserção profissional o deslocamento para o setor privado, isto é, a tendência dos egressos em administração pública serem absorvidos pelo setor privado, em função da acirrada concorrência em concursos públicos e também da possibilidade de salários mais competitivos nas empresas privadas. Assim, como não é possível contar com 
profissionais formados especificamente para atuar como gestores públicos, é necessário contar com outras formas de desenvolver gestores públicos (Dagnino, 2013).

Iniciativas relativamente recentes como o Master em Liderança e Gestão Pública (MLG) do Centro de Liderança Pública (CLP) lançam um pouco de luz nesse cenário e são importantes para formar líderes para atuarem no setor público e estimular trabalhos de pesquisa na área (Coelho \& Dantas, 2017). Porém, há ainda uma grande lacuna de produção de estudos que tratem do desenvolvimento de gestores no setor público. É parte desse espaço vazio que esta tese busca ocupar.

Num contexto em que a efetividade dos programas de treinamento formal vem sendo questionada, repensar o desenvolvimento de gestores públicos torna-se crítico. Em 2015, foram gastos mais de 350 bilhões de dólares em programas de treinamento e educação em âmbito global e, mesmo assim, já se sabe que esse investimento não se traduz em melhor desempenho organizacional (Beer, Finsström \& Schrader, 2016).

Em sua crítica às praticas de treinamento das empresas, Beer et al. (2016) destacam que, embora sejam relatadas mudanças de atitude após a realização dos programas, algum tempo depois, as pessoas voltam a fazer o trabalho como costumeiramente faziam. A necessidade destacada pelos autores não é de mais investimento em capacitação das pessoas, mas de novas formas de se pensar a aprendizagem e o desenvolvimento, corroborando as visões de Becker e Bish (2017) e a necessidade apontada por Dagnino (2013).

A chave para a mudança, segundo Beer et al. (2016), está em abandonar o paradigma em que os problemas de desempenho e comportamento organizacional são vistos como decorrência de deficiências das pessoas e, por esse motivo, são tratados na lógica de se aprimorar as habilidades e atitudes dos funcionários, com a expectativa que a mudança individual leve à mudança organizacional. A lógica mais eficiente seria a de compreender que os problemas decorrem do sistema de gestão ineficiente e precariamente projetado. Assim, a mudança desse sistema no que diz respeito ao comportamento facilitaria o aprendizado e melhoraria o desempenho. Ou seja, nesse novo paradigma, o foco não é mais o indivíduo unicamente, mas primeiramente a organização para que depois possa ser feito o treinamento dos indivíduos. A 
mudança organizacional depende, no entanto, de pessoas - em geral aquelas que estão em posições de liderança e gestão.

Além disso, já se sabe há algum tempo que os empregados não se engajam com formas tradicionais de treinamento, incluindo o e-learning, classificando a experiência de aprendizado como desinteressante e tediosa. Por esse motivo, há um crescente interesse em novas formas de treinamento, como a gamificação (gamification) e o uso de jogos sérios (serious games) na capacitação de pessoas (Donovan, 2012).

O desenvolvimento de gestores (públicos ou privados), contudo, é complexo e advém de uma combinação de diferentes habilidades, associadas tanto ao trabalho em si quanto a questões emocionais e sociais (Lord \& Hall, 2005). Naturalmente, conseguir desenvolver esse tipo de combinação de habilidades vai muito além dos métodos utilizados em programas de treinamento tradicionais. Embora grande contingente dos gestores atribua a maior parte de sua capacidade de gestão ao aprendizado por meios informais, eles não desprezam os meios tradicionais, revelando até mesmo desejo por mais aprendizado formal. As pesquisas apontam que uma mescla de meios formais com informais é mais efetiva no desenvolvimento da capacidade gerencial (Becker \& Bish, 2017).

Assim, os aprendizados formal e informal não devem ser vistos como entidades separadas e devem existir em paralelo (Manuti, Pastore, Scardigno \& Morciano, 2015). Mais do que isso, os gestores, quando na posição de estudantes, percebem que o aprendizado formal é benéfico quando feito em conjunto com métodos para aprendizado informal, produzindo resultados mais efetivos (Becker \& Bish, 2017).

\subsubsection{Desenvolvimento de gestores conectado ao Século 21}

É inegável a constatação de o quanto a tecnologia digital vem dando forma ao mundo desde o início deste terceiro milênio. Não à toa, diz-se que vivemos a "Era Digital". Após mais de 20 anos de difusão da internet, com nossas vidas invadidas por uma enxurrada de dispositivos e engenhocas, como notebooks, tablets e smartphones, produtos dessa nova era, com relações mais líquidas (como diria o sociólogo polonês Zygmunt Bauman), facilitadas por redes sociais 
virtuais, depara-se com a necessidade de se repensar como muitas coisas são feitas, abrindo-se espaço para o novo. Gerir um mundo mais complexo e diferente daquele em que boa parte das gerações de idade mais avançada cresceram é o desafio que se apresenta nas primeiras décadas do século XXI.

O mundo digital é uma realidade e é nesse contexto que a administração deve ser encarada. Formar gestores e líderes capazes de conduzir as organizações em um novo paradigma é uma questão crítica. Como preparar as pessoas que já nasceram nesse paradigma digital para lidar com o mundo das organizações se continuarmos com abordagens que eram adequadas a outro contexto? As escolas e universidades precisam se reinventar. A própria relação ensinoaprendizagem precisa ser remodelada.

É por esse motivo que se observa o crescimento de alternativas e-learning, mais centrado no estudante. Um recente relatório de uma plataforma especializada em soluções e-learning para empresas projeta que esse mercado saltará, em cinco anos, de 165 bilhões em 2015 para mais de 240 bilhões de dólares em 2023, representando um crescimento anual médio da ordem de 5\%. Na América Latina, esse mercado deve atingir 2,1 bilhões de dólares, com uma taxa de crescimento de mais que o dobro da média mundial $(14,6 \%)$. Só no Brasil espera-se um crescimento médio anual de $25,7 \%$ no mercado de mobile learning, estimando-se a movimentação de um mercado de mais de 1 bilhão de dólares até 2019 (Docebo, 2017).

Da mesma maneira, desde sua criação, em 2008, os chamados MOOCs (Massive Open Online Courses) apresentam um crescimento acentuado, com a popularização de portais como Coursera, edX e Udacity (Clarke, 2013). O crescimento foi tamanho que, em 2012, o The New York Times bradou que aquele seria o ano dos MOOCs (White, 2014). Em meados de 2017, a plataforma Coursera reunia mais de 25 milhões de inscritos e mais de 2000 cursos diferentes (Coursera, 2017).

No entanto, apesar do crescimento dessas alternativas, as estatísticas mostram que a maior parte dos estudantes que começam cursos na modalidade e-learning não os terminam (Dutton \& Perry, 2002). A indicação é que, embora facilmente acessíveis e muitas vezes centrados no estudante, existem diversos fatores que podem afetar o engajamento em atividades e-learning, sendo que a motivação intrínseca tem papel central (Priego \& Peralta, 2013; Liaw, 2008). 
Os jogos são conhecidos por engajar as pessoas que os utilizam, pois são capazes de gerar um estado de fluxo - que, de acordo com Csikszentmihalyi (1991), é ficar completamente envolvido no que se está fazendo pelo propósito da atividade em si mesmo -, que pode gerar motivação e, consequentemente, aprendizado, desde que exista reflexão (Paras \& Bizzocchi, 2005). Assim, eles aparecem como uma alternativa natural na busca por soluções para o aprendizado. Mais do que isso, a integração entre jogos e simulações e cursos presenciais é vista como uma maneira efetiva de gerar aprendizado (Salas, Wildman \& Piccolo, 2009). Outra alternativa para buscar engajamento no aprendizado em diversas áreas tem sido o de utilizar elementos de jogos para os mais distintos fins. É a chamada gamificação, ou gamification, descrita mais adiante.

Desde seu surgimento, na década de 1970, os jogos digitais (games) ocuparam um espaço substancial nas atividades de lazer. Jogar é um tipo de atividade que engaja seus praticantes, embora os motivos para esse engajamento tenham origem complexa e natureza multifatorial (E. Boyle, Connoly, Hainey \& J. Boyle, 2012). No entanto, é com base nessa característica que seu uso tem sido ampliado para diversas finalidades.

O uso de games para diferentes áreas de formação e do conhecimento não é novo, talvez se originando com o próprio aparecimento dessa modalidade de entretenimento. Sua efetividade para fins educacionais é comprovada, seja pelo desenvolvimento específico de um jogo para o ensino ou para a aprendizagem de determinados tópicos, seja pelo uso de um jogo (game) existente, inicialmente concebido apenas para fins de entretenimento (Backlund \& Hendrix, 2013). Nesse cenário, foi aberto um espaço tanto para o desenvolvimento de jogos específicos para fins educacionais (serious games), quanto para o uso de elementos de jogos em situações que não necessariamente são de jogos (gamification). A justificativa para cada uma das abordagens se dá pelo aumento bem documentado da motivação daqueles que as utilizam (Connolly, E. Boyle, MacArthur, Hainey, \&J. Boyle, 2012; Lujan \& DiCarlo, 2006; Werbach, 2014).

Em administração e para a capacitação de gestores o uso dos chamados jogos de empresa (business games) é bem conhecido. Alguns autores consideram que seu uso começou com os chamados jogos de guerra (war games), ainda em tabuleiro, há milênios (Hodgetts, 1970; Wolfe, 1993). Contudo, a concepção moderna dos business games é feita a partir de suas 
versões informatizadas, desde a década de 1950 (Greco, Baldissin \& Nonino, 2013; Campion, 1995).

Os jogos de empresa (business games) são um tipo particular de jogos, mais especificamente dos jogos sérios (serious games), pois possuem uma proposta que não é apenas de entretenimento. Em geral, os business games envolvem basicamente um modelo de simulação de uma empresa ou negócio em que os jogadores devem tomar decisões gerenciais, muitas vezes afetando outros jogadores e podendo ser afetados pelas decisões deles (Greco et al., 2013). Para não ficar restrito aos modelos de simulação-decisão, o presente trabalho foca na categoria mais ampla, ou seja, os serious games.

Por simplicidade, quando este trabalho se referir a jogos está implicitamente assumindo que se trata de jogos digitais, jogos eletrônicos ou simplesmente jogos por computador, como sinônimo de games. Também, a partir deste ponto, adotam-se os termos serious games e gamification, em inglês, por serem mais usuais na literatura (mesmo em português), como referências ao longo de todo texto.

Com relação ao uso de jogos para formação de gestores (ou para o desenvolvimento de liderança), há ainda um vasto campo a ser explorado, pois são poucos os trabalhos acadêmicos relativos ao tema e, mais do que isso, há também poucos jogos específicos sobre essa temática (Lopes, Fialho, Cunha \& Niveiros, 2013). Há evidências, no entanto, de que o aprendizado por meio de jogos (GBL - game-based learning) é vantajoso para o sucesso organizacional dentro do contexto da educação, aprendizado, treinamento e desenvolvimento (Jorge \& Sutton, 2017). Dessa forma, como o desenvolvimento de gestores passa pelo aprendizado da administração e os jogos podem ser utilizados consistentemente para fins educacionais, essa modalidade apresenta-se como uma alternativa viável para o desenvolvimento de gestores, no contexto da necessidade atual e das tecnologias disponíveis.

No setor público, porém, a lacuna é mais evidente. Buscas em bases de dados que reúnem artigos de periódicos científicos resultam em pouquíssimos trabalhos associando business games ou apenas games ao setor público ("public management" ou "public sector"). Embora 
tenham sido encontrados 225 trabalhos na base Scopus e 144 na base ISI Web of Knowledge ${ }^{2}$, o termo "jogo" aparece quase sempre em sentido figurado ("as regras do jogo", "o jogo da gestão" etc.) ou associado à Teoria dos Jogos, da Economia. Os trabalhos que falam especificamente de jogos, tratam de simulações para controle social ou políticas públicas (ou seja, mais focados no cidadão). A produção acadêmica relativa à formação de gestores públicos com uso de jogos anda é incipiente. Embora existam estudos já desenvolvidos em relacionados à área pública - por exemplo, o trabalho de Pinto (2014) na área de contabilidade pública, o de Costa (2016) atrelando a gamification à gestão de pessoas no setor público e o de Rocha (2015) que trata exatamente da temática dos jogos digitais como estratégia de aprendizado para o ensino de gestão pública -, as bases de dados de publicações ainda não refletem um eventual interesse emergente de pesquisas nessa área.

\subsubsection{Aprendizado gerencial}

Já em 1990, Thorpe trazia uma metáfora para ilustrar como o aprendizado gerencial é tradicionalmente enxergado. Segundo o autor, as teorias da educação gerencial parecem considerar que o executivo carrega um balde no qual ele vai depositando conhecimento ao longo de sua trajetória. À medida que progride na carreira, o executivo colocaria cada vez mais conhecimento acadêmico no seu balde, que ficaria cada vez mais cheio e pesado. No entanto, "infelizmente, há pouca indicação de que a informação que transborda do balde tenha qualquer valor em particular e em alguns casos pode até impedir o progresso"33 (Thorpe, 1990, p. 3, tradução nossa). O autor ainda destaca que a educação gerencial falha ao desenvolver efetivamente as habilidades necessárias para uma gestão efetiva, como desenvolver equipes, assumir riscos e entender do negócio e das operações da empresa. A provocação de Thorpe (1990) continua no sentido de buscar evidências de que o aprendizado gerencial se dá por outras maneiras que não sejam programas de treinamentos e cursos. Para o autor, a principal forma para o desenvolvimento de gestores é o uso de atividades relacionadas ao trabalho (work-related activities), percepção que vai ao encontro das ideias defendidas por Mintzberg (2006), talvez o autor mais expressivo da atualidade na área de administração e um dos

\footnotetext{
${ }^{2}$ Última consulta em 06/07/2017

${ }^{3}$ Unfortunately there is little indication that the information slopped by the dollopful into the bucket is of any particular value, and in instances might even be impeding progress.
} 
principais defensores de que o desenvolvimento gerencial deve passar pelo respeito à experiência que os gestores já possuem e pela reflexão sobre a prática.

Negroponte (2012) compara o processo de aprendizagem ao processo iterativo de se programar um computador. Dificilmente um programa de computador funciona da primeira vez, e faz algo (em vez de nada), mas não o que o programador queria. É a partir do olhar sobre o comportamento inadequado do programa que o programador pode descobrir o que está errado e mudar o código. Entendido sob esse ponto de vista, o processo de aprendizado é semelhante ao que acontece quando se joga um jogo. Nesse sentido, não é necessário prover um currículo, mas, sim, as ferramentas para o aprendizado (Negroponte, 2009). Somado a isso, os jogos permitem que as pessoas possam praticar, avaliar, refletir e agir em um ambiente seguro e que seja semelhante à realidade que vivem, em que o custo de falhar é muito baixo (Gee, 2004). Dessa forma, podem acelerar o processo de aprendizagem que leva ao desenvolvimento da liderança (Lopes et al., 2013).

Portanto, colocando todos os fatores acima em consideração, o caminho escolhido para o presente estudo foi o de verificar se tecnologias conectadas ao século XXI são capazes de capacitar os gestores públicos. Especificamente, pensou-se em um jogo de gestão que leva em conta o contexto da área pública como representante dessas tecnologias. Para tal, além do jogo propriamente, o estudo necessitou da elaboração de um curso/treinamento em que o jogo pudesse ser utilizado em sua plenitude e, naturalmente, em que fosse possível proceder a uma avaliação do treinamento.

O desenvolvimento do jogo procurou seguir conceitos consolidados na área do game design, incorporando os princípios do chamado aprendizado por meio de jogos (game-based learning). O treinamento desenvolvido baseou-se em aspectos já conhecidos sobre desenvolvimento de recursos humanos e educação gerencial, especialmente no contexto do uso de simulação e jogos (Salas et al., 2009), tendo como pano de fundo o paradigma do desenvolvimento de recursos humanos (HRD - Human Resource Development) (Hamlin \& Stewart, 2011; Swanson \& Holton III, 2009).

Por fim, a avaliação da efetividade do uso do jogo para o aprendizado, foi construída considerando-se a principal base sobre avaliação de treinamentos utilizada pelas organizações 
em todo o planeta (Kirkpatrick, 1994), bem como se fundamentou na consolidação das teorias de aprendizado humano, como será detalhado no Capítulo 2.

\subsection{Foco, Problema de pesquisa e delimitação do estudo}

O presente estudo busca explicar de que forma o uso de jogos digitais contribui para o processo de desenvolvimento de gestores públicos, com o seguinte problema de pesquisa: “qual o impacto do uso de jogos digitais para o desenvolvimento de gestores públicos?". Como o desenvolvimento de gestores é um conceito muito amplo, que depende de uma série de fatores, neste trabalho foca-se o aspecto individual e associado às competências do indivíduo, o popular CHA (Conhecimentos, Habilidade e Atitudes). Assim, a ideia de impacto do uso de jogos digitais operacionaliza-se pela busca de mudanças de atitudes, desenvolvimento de habilidades ou aquisição de conhecimento.

Embora as mudanças de atitudes possam ser mensuradas - e neste trabalho foram objeto de forma marginal -, deu-se maior ênfase à aquisição de conhecimentos por parte dos gestores como medida do impacto do uso de jogos digitais. Assim, além de integrar o desenvolvimento do jogo em si à pesquisa, pois se considerou importante que o jogo levasse em conta o contexto e a realidade dos gestores públicos, buscou-se analisar o acréscimo de conhecimento proporcionado pelo uso do jogo em um treinamento especificamente desenhado para o público alvo. Entretanto, é importante ressaltar também que o foco do jogo e da pesquisa é a gestão, não incluindo elementos associados ao contexto político que circunda os gestores públicos e que, na prática, não pode ser desprezado. O objetivo dessa delimitação foi o de isolar variáveis para simplificar o entendimento sobre o objeto do estudo, ou seja, o jogo digital como potencial ferramenta para o desenvolvimento dos gestores.

Os gestores públicos são entendidos neste trabalho de forma similar à definida por de Bonis e Pacheco (2010), naquilo que os autores categorizam como dirigentes públicos: pessoas que atuam na gestão de órgãos públicos mas numa definição que foge à polarização entre políticos e burocratas. Esses atores têm um grau relevante de responsabilidade, pois é deles que depende a efetividade dos serviços públicos, mas, ao mesmo tempo, sua responsabilidade não se confunde com a dos políticos e é também distinta da responsabilidade dos funcionários 
públicos. Gestores públicos são, portanto, pessoas que ocupam cargos de gestão nos órgãos públicos, com responsabilidade significativa sobre as políticas públicas e pelo desempenho das organizações. Nesse sentido, esta pesquisa adota uma versão uma pouco mais ampla da proposta por de Bonis e Pacheco (2010), pois considera não apenas aqueles que respondem diretamente aos ministros ou secretários, podendo estar em diferentes níveis da organização. Esse assunto é retomado no Capítulo 2.

O problema de pesquisa colocado de maneira ampla acima apresenta duas facetas que precisam ser olhadas com atenção para sua operacionalização: (1) o uso de jogos digitais e (2) a avaliação do impacto sobre o desenvolvimento de gestores públicos.

Como já destacado, a estruturação da pesquisa não se limita à simples utilização de um "jogo de prateleira" e a aplicação de uma mera avaliação. A falta de convergência entre abordagens teóricas sobre aspectos da liderança (entendida como parte intrinsecamente ligada à gestão) e os jogos é um dos pontos críticos apontados por Lopes et al. (2013) em sua revisão sistemática da literatura sobre o uso de jogos de empresa para o desenvolvimento de liderança. Abre-se então uma oportunidade para que a pesquisa seja pautada no uso de um jogo que incorpore aspectos das teorias de administração e, mais do que isso, leve em conta o contexto e a realidade dos jogadores, nesse caso, gestores públicos. Esse é, assim, outro ponto que distancia o uso do jogo digital deste trabalho do uso dos business games tradicionais, predominantemente focados em decisões de estratégias de mercado e de alocações de recursos financeiros, com um viés fortemente do setor privado. Compreender o que caracteriza o uso de jogos digitais, à luz dos conceitos de game-based learning, serious games e gamification foi um dos aspectos que pautou a fundamentação teórica apresentada no Capítulo 2.

Com relação à segunda faceta do problema de pesquisa (avaliação do impacto sobre o desenvolvimento de gestores públicos), o presente trabalho pretendeu mensurar o impacto por meio de uma avaliação feita com aquelas pessoas que utilizaram o jogo (gestores e potenciais gestores). Essa mensuração pode ser encarada tanto do ponto de vista da aquisição de conhecimento, isto é, pela pontuação obtida em um teste de conhecimentos relacionados aos tópicos abordados pelo jogo, quanto das mudanças de comportamento. O referencial utilizado para avaliar a eficácia do treinamento com a utilização do jogo é o de Kirkpatrick (1994), que utiliza quatro níveis de avaliação - reação, aprendizado, comportamento e resultados - e é o 
mais amplamente difundido para a avaliação de programas de treinamento e capacitação em escala global.

Os dois primeiros níveis são de mais fácil mensuração. Porém, pretendeu-se inferir impactos sobre os demais níveis com o uso de entrevistas e outros instrumentos. Por se considerar que o aprendizado é central quando se fala no impacto do uso de um jogo digital para o desenvolvimento de gestores públicos, foi dada ênfase também a essa questão na fundamentação teórica (Capítulo 2).

Os detalhes de como se buscou mensurar esses aspectos são apresentados no Capítulo 3. Contudo, a avaliação do impacto só pode ser consistente, de fato, se for feita comparativamente a um grupo de controle que não tenha acesso ao jogo. Por esse motivo, a aplicação do jogo foi feita dentro de um experimento, cujo detalhamento também está no mesmo capítulo.

\subsection{Objetivos}

Como já dito na seção precedente, o presente estudo busca explicar de que forma o uso de jogos digitais contribui para o processo de desenvolvimento de gestores públicos. Para tal, ele se propõe a avaliar o impacto do uso de jogos digitais para o desenvolvimento de gestores públicos. Esse impacto é avaliado de forma comparativa, colocando-se frente a frente os resultados obtidos por aqueles que jogaram e os de quem não jogou, obtida por meio de conjunto de dois experimentos.

Abaixo, destacam-se os objetivos específicos do trabalho. Ao lado de cada item é colocada entre parênteses a parte do problema de pesquisa a que estão mais diretamente relacionados:

OE1. Identificar quais são os principais conceitos que associam a aplicação de jogos (games) para fins de desenvolvimento humano (uso de jogos digitais);

OE2. Desenvolver um serious game de gestão focado no setor público, que incorpore aspectos das teorias relacionadas à administração, e que possa ser utilizado para o desenvolvimento de gestores públicos (uso de jogos digitais); 
OE3. Aplicar o jogo em um contexto de desenvolvimento de gestores, por meio de um curso ou treinamento, em que seja possível avaliar o impacto de seu uso (impacto sobre o desenvolvimento de gestores públicos);

OE4. Mensurar a eficácia do uso de um jogo de gestão para o desenvolvimento dos gestores públicos (impacto sobre o desenvolvimento de gestores públicos).

\subsection{Organização do estudo}

O presente estudo está organizado em três etapas básicas: a fundamentação teórica, uma etapa de desenvolvimento e uma etapa conclusiva. $\mathrm{O}$ esquema geral, com os principais marcos em cada uma das etapas, é apresentado na Figura 1.1.

$\mathrm{Na}$ etapa da fundamentação teórica foi feita uma revisão da literatura concernente aos principais tópicos abordados pelo trabalho: jogos (games), contemplando seus usos para fins educacionais e/ou que não sejam apenas para entretenimento, bem como princípios gerais de desenvolvimento (game design); teorias do aprendizado, principalmente com a intenção de fundamentar a forma mais adequada para realizar avaliações do aprendizado na etapa conclusiva da pesquisa; e ensino e aprendizagem de administração, com o intuito de verificar peculiaridades que precisavam ser levadas em conta para a realização do estudo, especialmente com relação ao experimento. Isso foi possível por meio de um estudo bibliométrico dessa literatura. Porém, outros aspectos são importantes na fundamentação teórica, tais como uma visão sucinta sobre HRD e uma varredura sobre a literatura de desenvolvimento gerencial. 


\section{Fundamentação Teórica}

- Estudo bibliométrico

- Uso de jogos digitais

Serious games, gamification,

Game-based learning (GBL)

- Desenvolvimento de gestores HRD, aprendizado, avaliação

\section{Etapa de Desenvolvimento}

- Desenvolvimento do jogo

- Teste do jogo

- Aplicação do piloto

- Análise qualitativa do aprendizado

- Aprimoramento do jogo

\section{Etapa Conclusiva}

- Desenvolvimento de um curso utilizando o jogo para gestores públicos

- Realização do experimento

- Resultados e análises do experimento

- Entrevistas e consulta online

- Conclusões

Figura 1.1 - Esquema geral da pesquisa

A etapa de desenvolvimento compreende a construção do jogo em si e uma etapa de teste para garantir seu funcionamento de acordo com a dinâmica projetada. Além disso, essa etapa contemplou a aplicação de um piloto, isto é, submeter o jogo à utilização de um grupo de pessoas com o objetivo de ter feedback para seu aprimoramento antes da realização do experimento e, mais do que isso, ter uma fonte para relacionar os conceitos de administração envolvidos no jogo que são mais facilmente percebidos pelos jogadores para a estruturação do curso em que o experimento foi realizado. A percepção dos conceitos foi um direcionador para a escolha de quais assuntos precisavam ser priorizados na avaliação da etapa conclusiva.

Por fim, a etapa conclusiva e núcleo da presente pesquisa envolveu o desenho e a aplicação de um experimento para avaliar de forma rigorosa qual o aprendizado por meio do jogo e em que grau esse aprendizado difere do grupo de controle. Finalmente, por meio desse experimento, consegue-se responder à questão de pesquisa, avaliando-se o impacto do uso do jogo no desenvolvimento dos gestores públicos.

O desenrolar das etapas destacadas relaciona-se diretamente ao problema de pesquisa proposto. Assim, como uma espécie de guia do trabalho, foi elaborada a Tabela 1.1, que 
elenca os aspectos abordados na fundamentação teórica e no método da pesquisa com base no desmembramento do problema de pesquisa em duas partes.

Tabela 1.1 - Estruturação da pesquisa em função do desmembramento do problema de pesquisa

\begin{tabular}{|c|c|c|}
\hline $\begin{array}{c}\text { Aspecto do problema de } \\
\text { pesquisa }\end{array}$ & Fundamentação teórica & Método \\
\hline 1. Uso de jogos digitais & $\begin{array}{l}\text { - Estudo bibliométrico } \\
\text { - Jogos e aprendizado } \\
\text { - Game-based learning (GBL) } \\
\text { - Gamification } \\
\text { - Serious games } \\
\text { - Serious gaming }\end{array}$ & $\begin{array}{l}\text { - Análise semântica latente } \\
\text { - Desenvolvimento do jogo } \\
\text { - Teste e piloto do jogo } \\
\text { - Aprimoramento do jogo } \\
\text { - Desenvolvimento de curso } \\
\text { com o uso do jogo }\end{array}$ \\
\hline $\begin{array}{l}\text { 2. Impacto sobre o } \\
\text { desenvolvimento de } \\
\text { gestores públicos }\end{array}$ & $\begin{array}{l}\text { - Human Resource Development (HRD) } \\
\text { - Desenvolvimento gerencial } \\
\text { - T\&D com jogos e simulações } \\
\text { - Avaliação de treinamento (Kirkpatrick) } \\
\text { - Classificação do aprendizado (Bloom) } \\
\text { - Teorias do aprendizado }\end{array}$ & $\begin{array}{l}\text { - Análise qualitativa do } \\
\text { aprendizado } \\
\text { - Realização do experimento } \\
\text { - Resultados e análises do } \\
\text { experimento } \\
\text { - Entrevistas e consulta online }\end{array}$ \\
\hline
\end{tabular}




\section{FUNDAMENTAÇÃO TEÓRICA}

\subsection{Introdução}

A fundamentação teórica do presente estudo busca elencar, a partir do problema de pesquisa, “qual o impacto do uso de jogos digitais para o desenvolvimento de gestores públicos?”, os aspectos da literatura relevantes que precisam ser colocados em sintonia para respondê-lo. Ela foi orientada pelo desmembramento do problema de pesquisa em duas partes, como descrito na seção 1.3, ou seja, (1) uso de jogos digitais e (2) avaliação do impacto sobre o desenvolvimento de gestores públicos. Da mesma maneira, este capítulo está dividido em duas partes.

Como o primeiro assunto (uso de jogos digitais) é recente, sentiu-se a necessidade de esmiuçar essa literatura para entender melhor não só o que significa a utilização de jogos digitais, mas também qual a relação desse tema emergente com a área da administração. Para tal, empreendeu-se uma varredura na literatura por meio de um estudo bibliométrico inicial, que permitiu encontrar os principais conceitos que deveriam ser trabalhados na pesquisa. Esse estudo visou à consecução do primeiro dos objetivos específicos da pesquisa (OE1). Sem ele, seria difícil ter um ponto de partida para responder ao problema de pesquisa, pois só foi possível identificar os pontos relevantes da fundamentação teórica a partir de uma varredura preliminar na literatura. A intenção foi a de identificar os principais conceitos que associam a aplicação de jogos (games) para fins educacionais e na área de administração. Por essa razão, optou-se por apresentar o estudo bibliométrico no início da primeira parte do capítulo, na subseção 2.2.1.

O procedimento para esse estudo preliminar, realizado em meados de 2015, baseou-se na analise de palavras-chave de artigos disponíveis na base Scopus (a qual fornece essa informação para exportação, permitindo análise sistemática). A análise foi inspirada na análise semântica latente (latent semantic analysis) e complementada com a visualização por meio de mapas perceptuais originados por análise de escalonamento multidimensional MDS, do inglês, multidimensional scalling (Ziegler, 2009; Leydesdorff \& Vaughan, 2006). 
Em seguida, apresentam-se os conceitos teóricos importantes identificados (serious games, game-based learning e gamification), pois daí surgiram importantes aspectos que precisaram ser considerados na etapa de desenvolvimento do jogo. No entanto, o intuito não foi o de entrar em aspectos técnicos de design e de desenvolvimento de jogos, mas compreender quais conceitos que se destacam, em âmbito teórico, quando se relacionam ao aprendizado humano.

Já na segunda parte da fundamentação teórica (seção 2.3), até mesmo como uma forma de contrabalançar a novidade da primeira parte, optou-se por enfatizar referenciais clássicos e consolidados, também pelo fato de o trabalho ter um foco empírico e não teórico puramente, de forma que a consolidação da literatura com relação ao desenvolvimento humano foge ao escopo da pesquisa.

Ao final do capítulo são trazidas duas seções complementares. A seção 2.4 apresenta uma breve contextualização daquele que é o objeto da pesquisa: o gestor público. Esse contexto é importante para diferenciar a aplicação do jogo a esse público específico e não apenas como um desenvolvimento genérico de gestores, mesmo tendo possibilidades de contribuir para diferentes profissionais ou estudantes que venham a utilizá-lo. Por fim, por acreditar-se que a junção de diferentes temas da literatura é uma das contribuições desta tese, a seção 2.5 apresenta o framework conceitual da pesquisa.

Assim, inicia-se a parte 2 do capítulo com uma visão geral do desenvolvimento de recursos humanos (HRD - Human Resource Development) para, em seguida, aprofundar-se na questão da educação gerencial, olhando-se brevemente para avaliação de treinamentos e capacitações, centrando-se no modelo de quatro níveis proposto por Kirkpatrick (1994).

Como o principal foco com relação ao desenvolvimento de gestores foi dado à aquisição de conhecimentos, foi preciso também varrer parte da literatura sobre o aprendizado humano, trazendo as principais abordagens e enfoques, bem como formas para se classificar o aprendizado. A pesquisa centrou-se na aplicação da taxonomia mais utilizada, a de Bloom, em sua versão revisada (Anderson \& Krathwohl, 2001). 


\subsection{Parte 1 - Uso de Jogos Digitais}

\subsubsection{Estudo bibliométrico}

O estudo bibliométrico para dar uma visão geral sobre a literatura de jogos, com foco nos tipos de usos que são estudados por pesquisas, foi feito por meio de buscas nas duas principais bases de dados acadêmicos, os portais de periódicos Scopus e ISI Web of Knowledge. O objetivo geral desse estudo bibliométrico foi o de delimitar o foco da abordagem teórica do trabalho. Os seus objetivos específicos foram:

(i) Ter uma visão geral da produção da literatura sobre jogos;

(ii) Identificar os principais assuntos tratados na literatura sobre jogos;

(iii)Compreender a relevância do campo de administração para a pesquisa em jogos;

(iv)Relacionar os principais usos de jogos estudados na literatura;

(v) Identificar os principais termos e conceitos que relacionam jogos e aprendizado nos últimos anos.

Com relação às bases de dados utilizadas, Scopus e ISI Web of Knowledge, Vieira e Gomes (2009) encontraram uma correspondência típica de dois terços entre as duas bases, quando olhados os artigos ali contidos. Complementarmente, em um estudo comparando as revistas cobertas pelas duas bases, Gavel e Iselid (2008) encontraram que apenas 16,5\% da base do ISI Web of Knowledge (1.467 em 8.901 títulos) não são cobertos pelo Scopus. Em contrapartida, quando analisaram o contrário, o índice foi de $45,7 \%$, ou seja, quase metade dos periódicos da base Scopus não está na base ISI Web of Knowledge (6.256 em 13.690 títulos).

Somado a isso, outra diferença entre as bases é de cunho operacional. A base Scopus possibilita a exportação das palavras-chave dos autores enquanto a ISI Web of Knowledge, embora permita a consulta das palavras-chave item por item no resultado da busca, não as exporta para arquivos que permitam análise sistemática (sem levar em conta eventuais programações de rotinas via API - Application Programming Interface, cuja relação custobenefício para o objetivo das análises preliminares não seria compensadora). 
Como as palavras-chave eram um aspecto crucial para as análises realizadas na parte bibliométrica do estudo, optou-se por utilizá-las como fonte principal para as buscas na literatura a base Scopus.

A ideia básica das análises bibliométricas é a de identificar, inicialmente, as associações que são feitas de jogos (games) com diferentes áreas e com outras palavras-chave. $\mathrm{O}$ foco foram sempre artigos de periódicos científicos e de proceedings de conferências (fixando-se a fonte como "journals" e "conference proceedings", o que não exclui documentos publicados em outras modalidades como reviews e editoriais), deixando de lado outras fontes de produção bibliográfica tais como livros e capítulos de livros, que, em geral, não passam por revisões de pares. Todas as buscas foram realizadas ao longo do mês de agosto de 2015.

\subsubsection{Análise baseada em palavras-chave-Parte 1: busca por jogos (games)}

Com o intuito de obter uma visão geral da literatura sobre jogos, o ponto de partida foram os termos "games" e "game", mesmo sabendo-se que se tratava de uma busca bastante ampla. Justamente por isso, a busca direta desses termos na base Scopus ("games OR game") retornou mais de 145 mil registros (145.041). As referências mais antigas datam do século retrasado, sendo 1823 o primeiro ano registrado. Os trabalhos naquele século eram principalmente relativos a jogos específicos, como xadrez ("Origin of the game chess", 1823; Ashton, 1854) ou curling (Frost, 1852). No entanto, já havia registro da aplicação de jogos relacionada à medicina e à enfermagem ("Various games adapted", 1823; B.G.J., 1850). Nesses artigos, porém, os jogos são tratados apenas pelas suas finalidades de entretenimento para os pacientes.

O foco deste trabalho, entretanto, é nos jogos digitais ou por computador (video games ou computer games), com suas potenciais aplicações a diferentes contextos que não envolvam apenas o entretenimento e, mais especificamente, estejam associadas ao ensino/aprendizagem de administração. Contudo, a busca geral pelo termo "games" ajuda a dar uma percepção da

\footnotetext{
${ }^{4}$ A base Scopus, por padrão, já busca a palavra com o seu plural (Elsevier, 2014), de forma que a busca "Games OR game" não difere da busca apenas pelo termo "game".
} 
dimensão que o tema vem tomando. A Figura 2.1 indica o número de publicações (artigos de periódicos e proceedings) contendo os termos "games" ou "game" ao longo dos anos, desde 1981. Pode-se perceber um crescimento exponencial, visível a partir do início deste século, tendendo a se estabilizar nos últimos três anos.

Outro objetivo específico do estudo bibliométrico era o de encontrar os principais assuntos tratados na literatura relacionados ao uso de jogos. A busca simples de "games" ou "game" resultou em mais de 145 mil registros. Por outro lado, uma busca direta por "use of games" resultou em apenas 587 registros. Assim, para atingir esse objetivo, uma análise das palavraschave encontradas nas duas buscas foi realizada, contudo, com abordagens distintas para cada uma delas, em função da quantidade de registros envolvidos em cada caso.

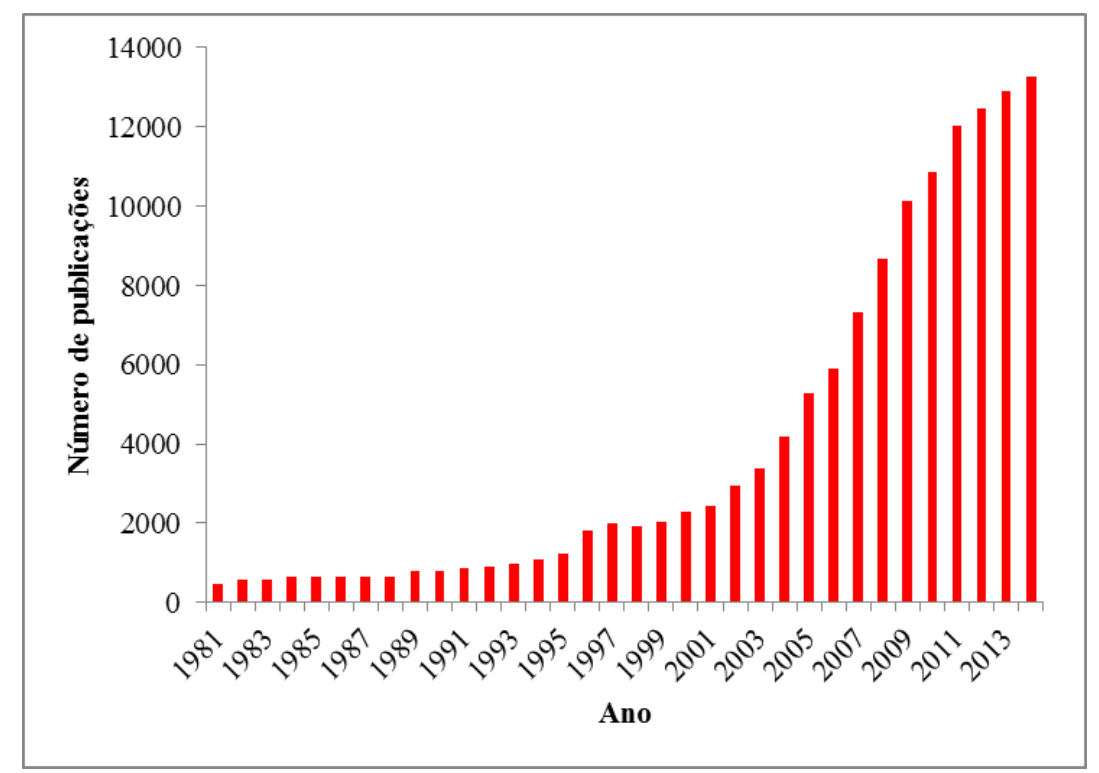

Figura 2.1 - Número de artigos (de periódicos e proceedings de conferências) sobre jogos (games) publicados desde 1981

Fonte: Elaboração do autor, a partir dos dados da base Scopus

A base Scopus permite avaliar de uma forma imediata as 160 palavras-chave com maior ocorrência nos artigos pesquisados, de forma que esse foi o primeiro critério de análise dos resultados. Na primeira busca (145 mil registros para "games OR game"), partiu-se das 160 palavras-chave mais frequentes na busca, verificando-se, uma a uma, se o tema associado a ela pode estar ou não diretamente associado ao uso de jogos. Dessa forma, foi possível criar uma lista de exclusões, ou seja, palavras-chave que provavelmente mostram que o artigo tem como objetivo central outro assunto que não sejam os jogos e suas aplicações propriamente, 
tais como "game theory", "Nash equilibrium", "gambling" e "Olympic Games". A Tabela 2.1 apresenta os 18 termos excluídos num primeiro momento, seguidos da razão pela qual foram excluídos.

Tabela 2.1 - Palavras-chave excluídas da busca por "games OR game" na base Scopus

\begin{tabular}{|c|c|c|c|}
\hline Termo excluído & Registros & $\%$ da base & Motivo da exclusão \\
\hline Game theory & 27295 & $18,8 \%$ & $\begin{array}{l}\text { Registros com esse termo provavelmente estão } \\
\text { tratando apenas da teoria dos jogos do ponto de vista } \\
\text { econômico }\end{array}$ \\
\hline Animals & 2330 & $1,6 \%$ & Provavelmente relacionado a artigos de Biologia \\
\hline Nash equilibrium & 2328 & $1,6 \%$ & $\begin{array}{l}\text { Registros com esse termo provavelmente estão } \\
\text { tratando apenas da teoria dos jogos do ponto de vista } \\
\text { econômico }\end{array}$ \\
\hline Nash equilibria & 1918 & $1,3 \%$ & $\begin{array}{l}\text { Registros com esse termo provavelmente estão } \\
\text { tratando apenas da teoria dos jogos do ponto de vista } \\
\text { da Economia }\end{array}$ \\
\hline Animal & 1628 & $1,1 \%$ & Provavelmente relacionado a artigos de Biologia \\
\hline Evolution & 1554 & $1,1 \%$ & Provavelmente relacionado a artigos de Biologia \\
\hline Major clinical study & 1528 & $1,1 \%$ & $\begin{array}{l}\text { Registros com esse termo são, em geral, artigos da } \\
\text { área médica com relatos de tratamentos nos pacientes }\end{array}$ \\
\hline Athlete & 1309 & $0,9 \%$ & $\begin{array}{l}\text { Provavelmente está tratando de games no contexto das } \\
\text { atividades esportivas }\end{array}$ \\
\hline Nash Equilibrium & 1220 & $0,8 \%$ & $\begin{array}{l}\text { Registros com esse termo provavelmente estão } \\
\text { tratando apenas da teoria dos jogos do ponto de vista } \\
\text { da Economia }\end{array}$ \\
\hline Animalia & 1200 & $0,8 \%$ & Provavelmente relacionado a artigos de Biologia \\
\hline Clinical article & 1192 & $0,8 \%$ & $\begin{array}{l}\text { Registros com esse termo são, em geral, artigos da } \\
\text { área médica com relatos de tratamentos nos pacientes }\end{array}$ \\
\hline Football & 1158 & $0,8 \%$ & $\begin{array}{l}\text { Provavelmente está tratando de games no contexto das } \\
\text { atividades esportivas }\end{array}$ \\
\hline Sport injury & 1134 & $0,8 \%$ & $\begin{array}{l}\text { Provavelmente está tratando de games no contexto das } \\
\text { atividades esportivas }\end{array}$ \\
\hline Soccer & 1022 & $0,7 \%$ & $\begin{array}{l}\text { Provavelmente está tratando de games no contexto das } \\
\text { atividades esportivas }\end{array}$ \\
\hline Evolutionary game theory & 956 & $0,7 \%$ & $\begin{array}{l}\text { Provavelmente relacionado a artigos de Biologia ou } \\
\text { Economia }\end{array}$ \\
\hline Evolutionary games & 826 & $0,6 \%$ & $\begin{array}{l}\text { Provavelmente relacionado a artigos de Biologia ou } \\
\text { Economia }\end{array}$ \\
\hline Olympic Games & 620 & $0,4 \%$ & Associado aos Jogos Olímpicos \\
\hline Gambling & 533 & $0,4 \%$ & Associado à prática de jogos de azar \\
\hline
\end{tabular}

Em seguida, a partir da busca sem esses termos, em que foram encontrados 105.610 registros, novamente com as 160 palavras-chave mais frequentes, foi feita uma classificação por área ou significado amplo da palavra, dando origem a 20 categorias de palavras-chave, com destaque à categoria "Game type", correspondendo a todos os termos que surgiram que demonstram um tipo de jogo, como "computer games", "videogames", "online games" etc. Ainda, houve 
casos em que não foi possível classificar a palavra-chave, dada a possibilidade de aplicação em mais de um campo, com sentidos muito distintos, casos, por exemplo, de "reinforcement learning" e "training", que poderiam tanto estar na psicologia ou educação quanto na área de computação, por sua terminologia em Machine Learning. O gráfico da Figura 2.2 apresenta a quantidade de artigos contendo as palavras-chave das 20 categorias criadas. Ressalta-se que um artigo pode conter mais de uma palavra. Por esse motivo, a soma das categorias não corresponde ao total de artigos.

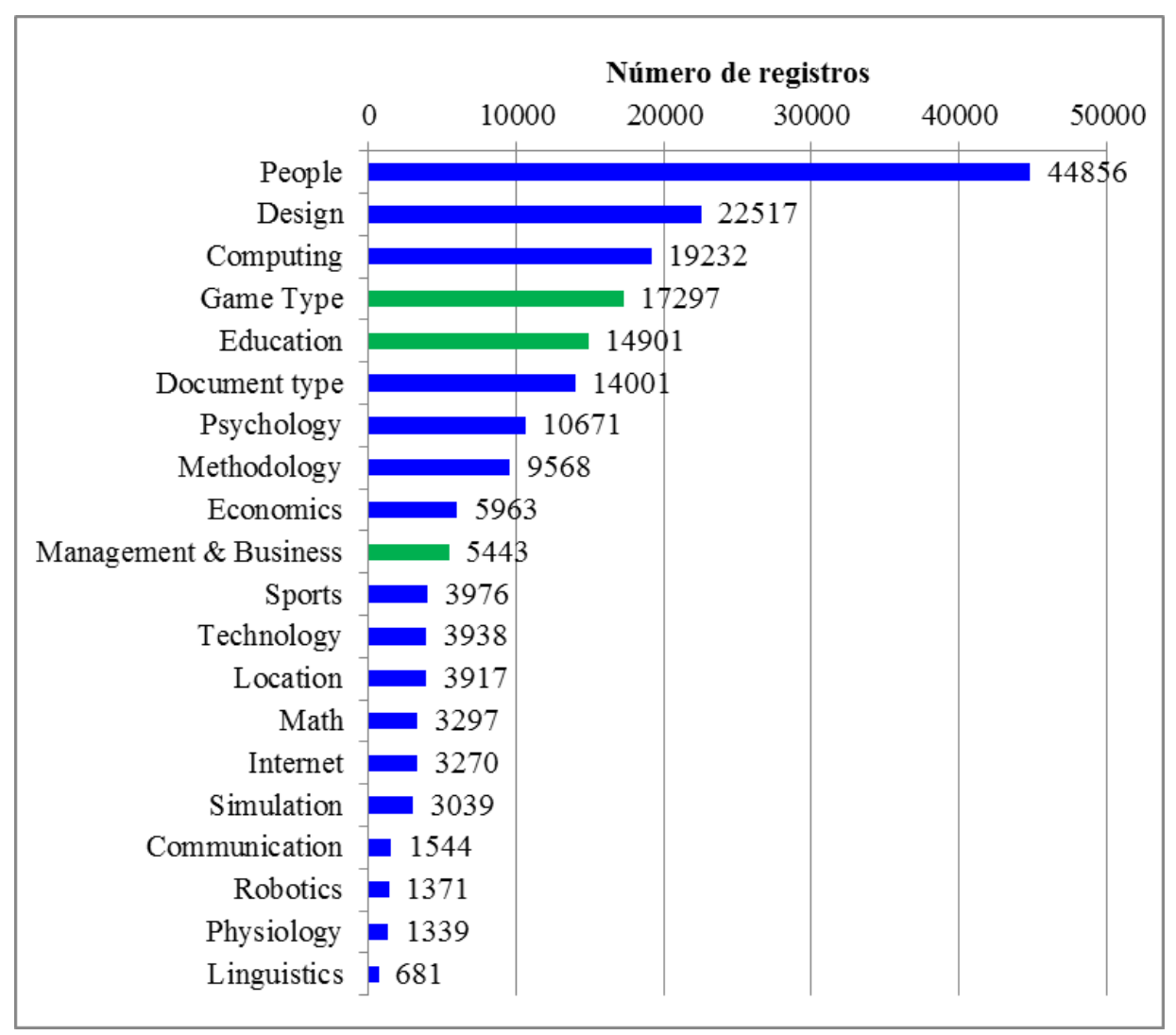

Figura 2.2 - Número de artigos contendo as palavras-chave de cada categoria associadas à busca "Game OR game" na base Scopus.

Nota. Foram excluídas as palavras-chave provavelmente não associadas ao uso de jogos em si. Em destaque (verde) as categorias diretamente relacionadas ao presente trabalho.

Os destaques ficam por conta das categorias "People", "Design" e "Computing", que contêm palavras que aparecem na maioria dos artigos. A categoria "People" contempla todas as palavras-chave que fazem menção a algum tipo de pessoa ou classificação das pessoas ("human", "male", "female", "adult", "children" etc., sendo que "teacher" e "student" foram colocados na categoria "Education"). A categoria "Design" contempla os elementos para a construção ou visualização de jogos ou softwares ("virtual reality", "animation", "game 
design", "user interface" etc.), enquanto a "Computing" contempla elementos específicos de programação ("algorithms", "artificial intelligence", "computer software" etc.).

Com relação às aplicações de jogos, as mais frequentes são educação (Education), psicologia (Psychology) e administração (Management \& Business). Embora esse resultado não traga pistas concretas sobre a pesquisa sobre jogos na literatura, já permite identificar que tanto o campo da educação quanto o da administração, áreas de interesse para este estudo, estão entre os mais relevantes, mesmo com a busca considerada de uma maneira ampla.

\subsubsection{Análise baseada em palavras-chave - Parte 2: busca pelo uso de jogos (use of games)}

Olhando-se para o outro extremo, com a busca específica de "use of games", foram obtidos pouco menos de 600 registros. Foi possível observar que das 160 palavras-chave mais frequentes, 96 delas também estavam nos destaques das outras duas buscas efetuadas (a "Games OR Game" e a mesma pesquisa feita com as exclusões da Tabela 2.1). A quantidade menor de artigos como resultado da busca permite uma análise mais detalhada.

Uma vez que é possível exportar da base Scopus todos os artigos dessa busca, procedeu-se com uma análise com a construção de matrizes de ocorrência e coocorrência das palavraschave, considerando-se as 160 mais frequentes. Foi necessário ignorar as diferenças entre maiúsculas e minúsculas (o que o Scopus não faz ao apresentar as principais palavras-chave) e também considerar singular e plural de forma semelhante. (Por exemplo, "games-based learning" e "game based learning", no plural e no singular, com e sem hífen, precisam ser consideradas como uma única palavra-chave).

Uma matriz de ocorrência é uma tabela em que há a indicação, por artigo analisado, se a palavra está presente ou não, assumindo valor 1 quando está presente e 0 quando não está (há ainda algumas variações da técnica que consideram a contagem de palavras em um texto, mas aqui, por se tratarem de palavras-chave apenas, a classificação binária é a recomendada). E uma matriz de coocorrência apresenta para todos os termos considerados, dois a dois, quantas vezes aparecem juntos (Leydesdorff \& Vaughan, 2006). 
A matriz de coocorrência permite a construção de mapas perceptuais com a técnica de Escalonamento Multidimensional (Leydesdorff \& Vaughan, 2006). O mapa perceptual da Figura 2.3 apresenta a relação das palavras-chave da busca de "use of games" na base Scopus. São apresentados os termos que apareceram no mínimo 8 vezes no total. No mapa perceptual, aquelas palavras que estão mais próximas tendem a aparecer juntas nos artigos publicados. Além disso, as palavras aparecem em tamanho proporcional ao número de ocorrências. A categorização em cores respeita os mesmos critérios estabelecidos para categorizar as palavras-chave da busca ampla ("games OR game"). O resultado da técnica desenvolvida é uma visualização que funde uma nuvem de tags e o mapa perceptual do escalonamento multidimensional.

$\mathrm{Na}$ figura, pode-se observar que tanto os termos associados aos tipos de jogos (vermelhos) quantos aos de educação (verdes) concentram-se majoritariamente nos quadrantes do lado direito, enquanto os elementos de computação e design estão, em sua maioria, do lado esquerdo. Isso permite inferir que a dimensão horizontal pode estar associada a alguma medida de complexidade técnica. Já a dimensão vertical apresenta aspectos mais parciais ("game elements", "simulation", "personal training") na parte inferior e mais completos na superior ("game", "methodology", "education").

Observando-se ainda as concentrações de palavras, pode-se obter uma resposta à questão do uso de jogos (termo da busca realizada na base Scopus), uma vez que os termos "game", "computer game" e "video game" aparecem concentrados com vários termos da categoria educação ("teaching", "education", "learning"), mostrando que quando se fala em uso de jogos, parece haver predomínio das aplicações com fins educacionais.

Outro aspecto a ser notado é que no meio dos termos educacionais também surgem conceitos como "gamification", "serious games", "educational game" e "game-based learning", que se tornaram norteadores para a fundamentação teórica desta pesquisa. Contudo, cabe notar que não houve entre os destaques nenhum termo associado à área de administração diretamente. Esses termos emergiram com o detalhamento da análise (mostrado nas próximas subseções). 


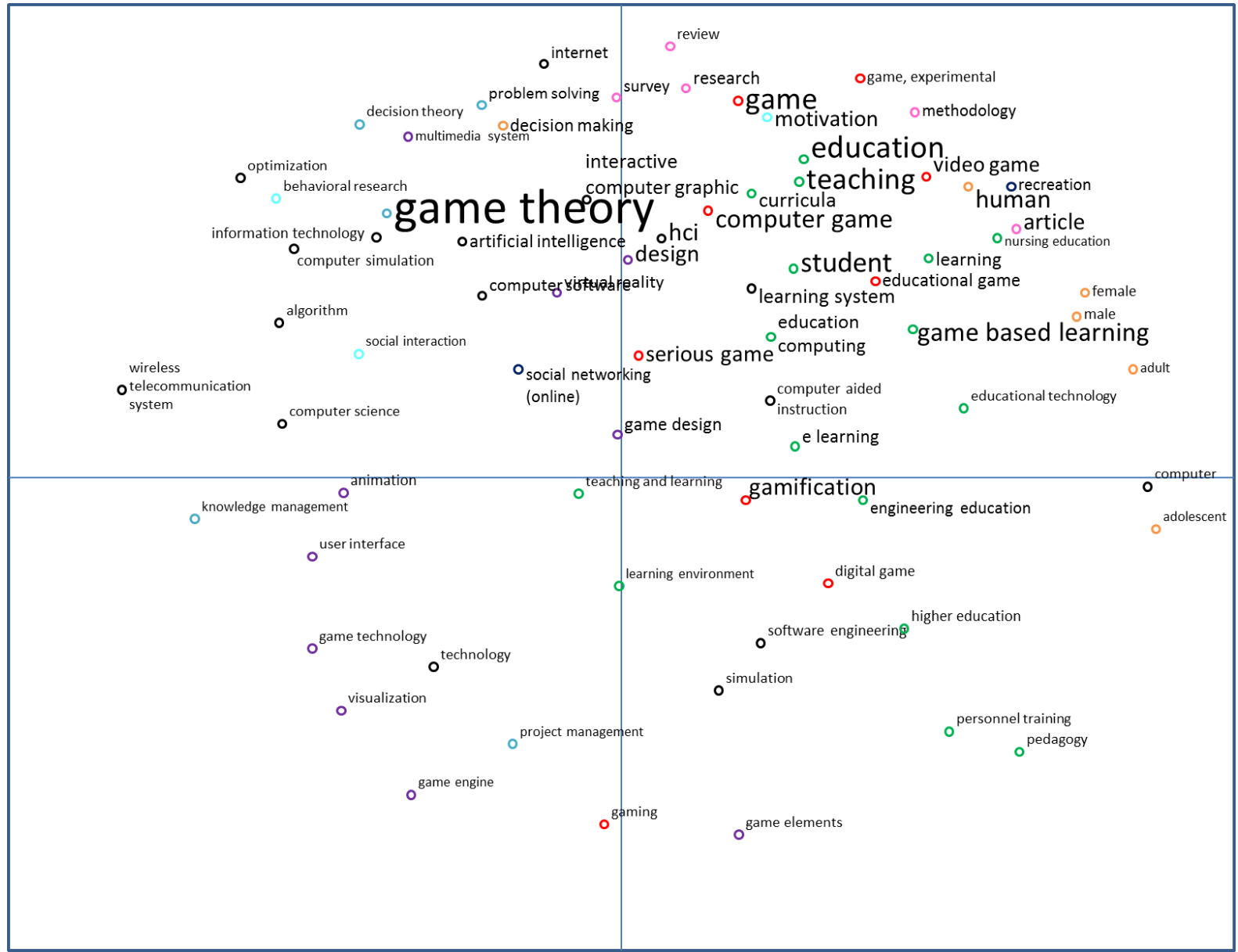

Figura 2.3 - Mapa perceptual construído com a técnica de escalonamento multidimensional a partir da matriz de coocorrência das palavras-chave na busca "use of games" na base Scopus.

Nota. O tamanho das palavras é proporcional ao número de ocorrências (máximo 162 e mínimo 8). As cores agrupam termos de mesma natureza (preto = computação/tecnologia, verde $=$ educação, vermelho $=$ categorias de jogos ou de uso de jogos/elementos de jogos, roxo = design).

\subsubsection{Análise baseada em palavras-chave - Parte 3: relação de jogos (games) com suas aplicações educacionais}

Colocando-se as duas buscas ("games OR game" e "use of games") lado a lado para uma comparação no que diz respeito às categorias de palavras-chave de tipos de jogos e de termos relacionados à educação, vê-se que há uma sobreposição da maior parte das palavras que tiveram destaque nas duas buscas. A Figura 2.4 mostra a intersecção entre as duas buscas para os termos associados aos tipos de jogos e a Figura 2.5 mostra a mesma relação para os termos associados à educação. 


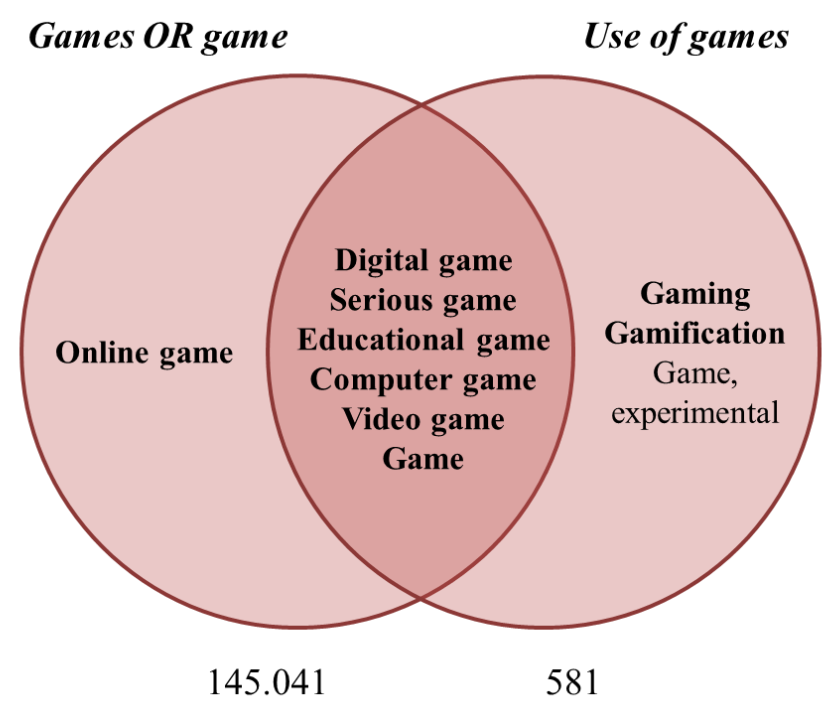

Figura 2.4 - Sobreposição de palavras-chave com destaque nas duas buscas realizadas na base Scopus para os termos associados aos tipos de jogos.

Nota. Abaixo de cada círculo está o número de registros encontrados em cada busca.

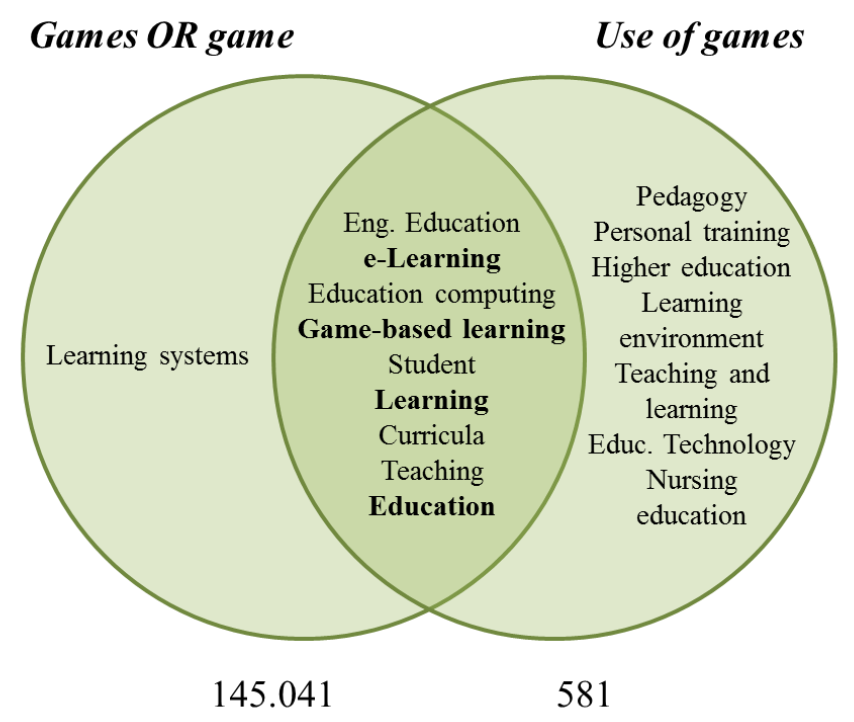

Figura 2.5 - Sobreposição de palavras-chave com destaque nas duas buscas realizadas na base Scopus para os termos associados à educação.

Nota. Abaixo de cada círculo está o número de registros encontrados em cada busca.

Nas figuras, foram marcados em negrito os termos que fizeram parte da busca específica associando os conceitos de interesse para o presente trabalho. A busca foi feita com todos os termos relacionados aos tipos de jogos, exceto o "game, experimental", que em 11 dos 12 artigos em que aparece está relacionado especificamente à área da saúde. Para os termos associados à educação, a seleção foi feita com base nos termos mais amplos, a saber: "elearning", "Game-based learning", "learning" e "education" e com foco no aprendizado (e não necessariamente no ensino, por isso "teaching" foi deixado de lado). 
O objetivo dessa etapa da análise bibliométrica era o de identificar quais os principais termos e conceitos recentes relacionando jogos e aprendizado, de forma que o período considerado para os artigos (de periódicos ou de proceedings de conferências) foi desde o início deste século (2001 em diante). A busca, que considerou apenas os termos no campo de palavraschave, retornou 10.360 registros e teve a seguinte sintaxe:

(KEY (game) OR KEY ("Digital game") OR KEY ("Serious game") OR KEY ("Educational game") OR KEY ("Computer game") OR KEY ("Video game") OR KEY ("Videogame") OR KEY ("online game") OR KEY ("on-line game") OR KEY ("gaming") OR KEY ("gamification")) AND (KEY ("e-learning") OR KEY ("game-based learning") OR KEY ("games based learning") OR KEY ("games-based learning") OR KEY ("game based learning") OR KEY ("learning") OR KEY ("Education")) AND (LIMIT-TO ( SRCTYPE, "j") OR LIMIT-TO (SRCTYPE, "p")) AND PUBYEAR > 2000

Com o aumento da profundidade da busca pelo tema, o maior detalhamento da análise se faz necessário. Assim, os mais de 10 mil resultados da busca foram exportados de maneira a permitir uma análise completa de suas palavras-chave. Havia mais de 150 mil palavras-chave considerando-se todos os registros, que uma vez tratadas com a unificação de singulares e plurais e variações de formas de escrever (por exemplo, "on line" e "online") e uso de hifens resultaram, ainda, em 34.946 registros exclusivos, sendo que destes, 22.719 palavras-chave apareciam uma única vez, por serem, em sua maioria, termos muito específicos.

O corte escolhido para análise foi o de palavras-chave que apareciam 50 vezes ou mais (presentes em cerca de pelo menos 0,5\% dos artigos), resultando em 329 palavras-chave. Como no caso da primeira busca, elas foram categorizadas uma a uma. No entanto, dentro das categorias consideradas relevantes para este trabalho, Educação (Education), Tipos de jogos (Game Type) e Administração (Management \& Business), foram buscados os conceitos-chave para nortear a fundamentação teórica do trabalho. A Figura 2.6 apresenta o número de artigos por categoria de palavra-chave e a Tabela 2.2 indica os conceitos-chave selecionados para nortear a revisão bibliográfica nas categorias de Educação e de Tipos de Jogos. 


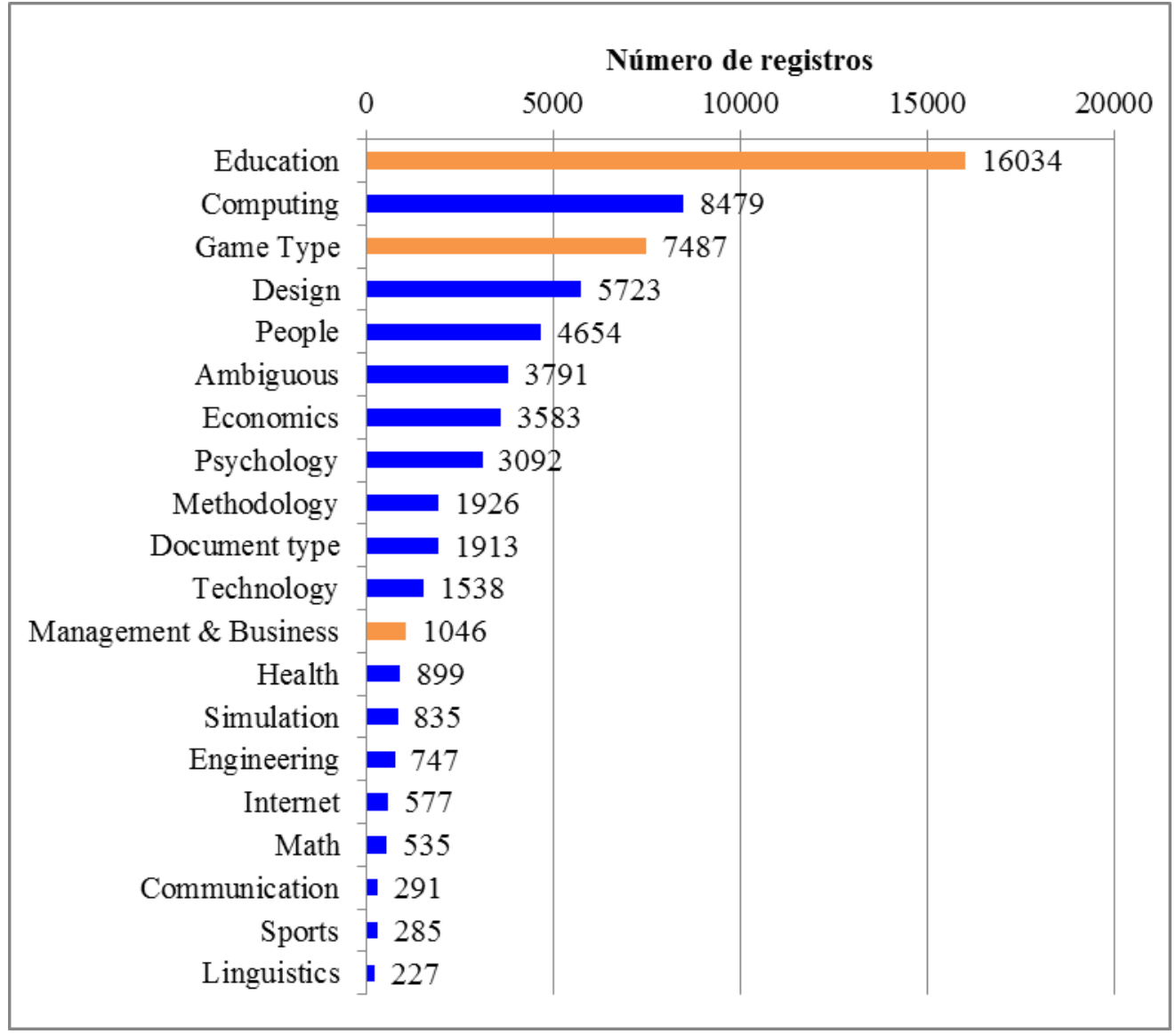

Figura 2.6 - Número de artigos contendo as palavras-chave de cada categoria associadas à terceira busca realizada na base Scopus.

Nota. Em destaque (laranja) as categorias diretamente relacionadas ao presente trabalho.

Tabela 2.2 - Relação dos conceitos-chave nas categorias de Educação e Tipos de jogos selecionados para nortear a fundamentação teórica do trabalho.

\begin{tabular}{llcc}
\hline \hline Conceito-chave & Categoria & \% artigos & \# artigos \\
\hline game based learning & Education & $10,5 \%$ & 1083 \\
serious game & Game Type & $8,7 \%$ & 900 \\
educational game & Game Type & $7,6 \%$ & 785 \\
e learning & Education & $7,5 \%$ & 780 \\
gamification & Game Type & $2,0 \%$ & 204 \\
learning game & Game Type & $1,5 \%$ & 159 \\
distance education & Education & $0,9 \%$ & 98 \\
educational computer game & Game Type & $0,9 \%$ & 90 \\
serious gaming & Game Type & $0,7 \%$ & 71 \\
business game & Game Type & $0,7 \%$ & 68 \\
learning in game & Education & $0,6 \%$ & 63 \\
\hline \hline
\end{tabular}

Uma vez selecionados os conceitos-chave norteadores para a construção da fundamentação teórica do presente trabalho, foi possível elaborar um mapa perceptual (Figura 2.7) semelhante ao que foi construído a partir da segunda busca na base Scopus. Foram incluídos 
os 11 conceitos-chave da Tabela 2.2 e todas as outras palavras-chave que apareceram em número maior ou igual ao conceito que apareceu menos vezes (learning in game: 63 ocorrências), num total de 257 palavras.

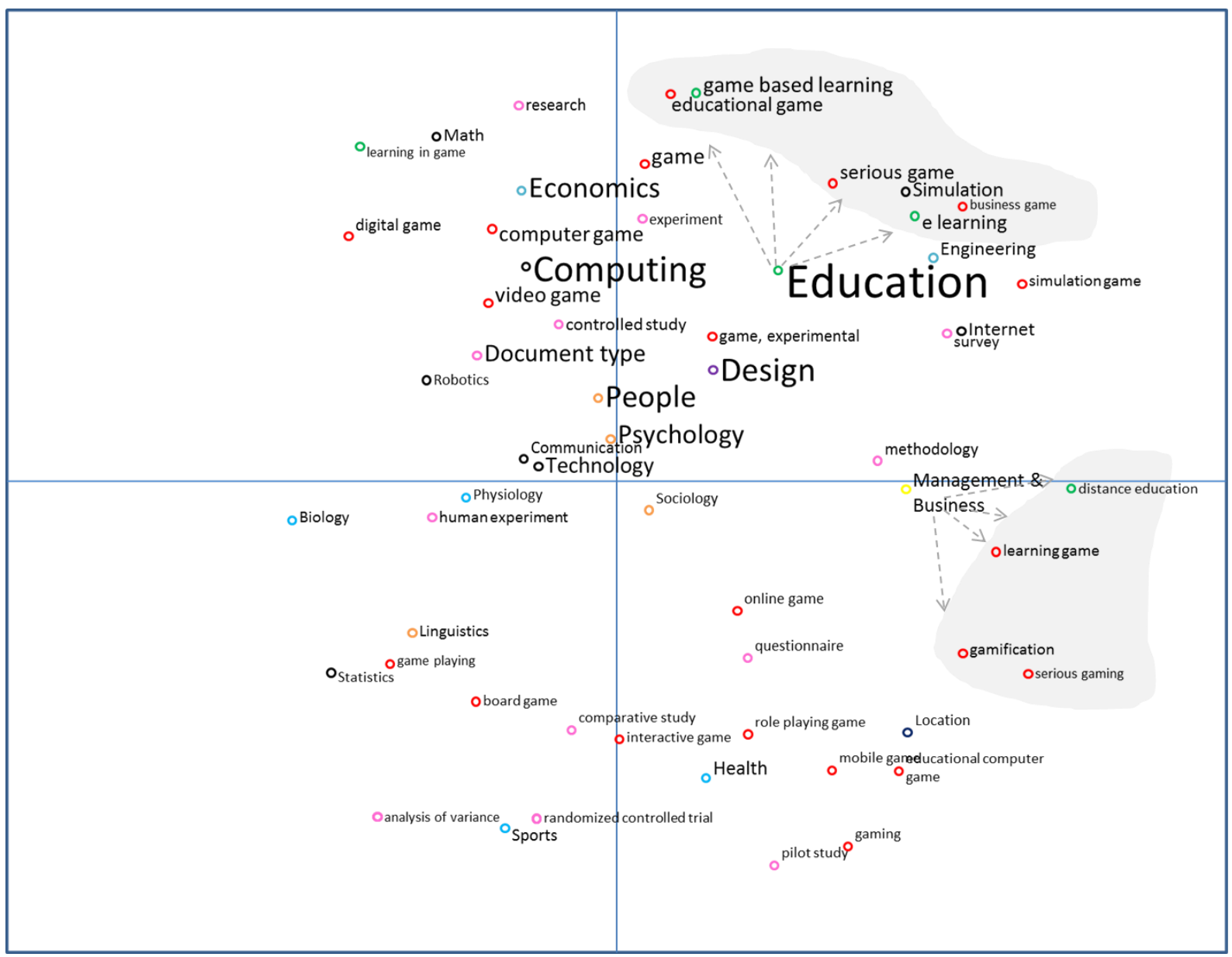

Figura 2.7 - Mapa perceptual construído com a técnica de escalonamento multidimensional a partir da matriz de coocorrência das 257 principais palavras-chave da busca 3 .

Nota. O tamanho das palavras é proporcional à raiz quadrada número de ocorrências (máximo 124 e mínimo 8). As cores agrupam termos de mesma natureza (preto = computação/tecnologia/ciências exatas, verde $=$ educação, vermelho = categorias de jogos ou de uso de jogos/elementos de jogos, roxo= design). As áreas na cor cinza destacam os conceitos-chave encontrados próximos à categoria Educação (Education) e à de Administração (Business \& Management)

A diferença na elaboração desse mapa com relação ao anterior é que, em vez de apresentar todas as 257 palavras ou uma parte delas, o que poluiria a visualização, a representação foi feita pela posição ponderada ("centro de gravidade") dos termos de cada categoria, representados pelo nome da categoria, além dos conceitos-chave da Tabela 2.2. O tamanho da fonte do termo é proporcional à raiz quadrada do número de aparições, consideradas pela soma para as categorias. Além dos conceitos-chave selecionados, a única categoria que foi 
"aberta" no mapa é a de metodologia, pois não faria sentido aparecer apenas um ponto no gráfico quando vários e diferentes métodos são utilizados para tratar o tema.

A análise do mapa perceptual permite inferir que conceitos como "serious gaming", "gamification", "learning game" e educação a distância ("distance education") aparecem, de alguma maneira, mais relacionados à área de Administração ("Management \& Business") no quadrante inferior direito. Também se pode observar a proximidade do termo "business game" com conceitos como "serious games" e "e-learning", além de simulações ("simulation") e a área de engenharia. Não muito longe desse agrupamento, ainda no quadrante superior direito, são vistos o conceitos de "game based learning" e "educational game". O centro desse quadrante é ocupado pela categoria Educação ("Education"), já com relativa proximidade das categorias "Game Type" e "Design". O lado esquerdo do mapa, com termos e categorias mais "distantes" dos conceitos-chave deste trabalho, estão outras áreas do conhecimento. A única exceção é feita ao termo "learning in game", na parte superior do lado esquerdo, mas que por não ser relacionado fortemente aos outros termos de interesse, foi deixado de lado nas buscas de artigos para a fundamentação teórica. O mesmo se aplica a "educational computer game", no canto inferior direito. As áreas na cor cinza destacam os conceitos-chave na figura. Parte deles está no quadrante superior direito, com relativa proximidade à categoria Educação (Education) e a outra parte, no quadrante inferior direito, próxima da categoria de Administração (Management \& Business).

Dessa forma, a sequência da análise bibliométrica, ainda antes da fundamentação teórica propriamente, foi realizada com esses dez conceitos: gamification, serious games, serious gaming, game-based learning, learning game, educational game, business games, simulation (que é, na verdade, uma categoria, mas incluída na área de interesse), e-learning e educação a distância (distance education). Os termos e-learning e educação a distância foram mantidos, pois no momento do estudo bibliométrico ainda se considerava a possibilidade da utilização do jogo apenas pela modalidade a distância, que foi a concepção inicial do jogo. 


\subsubsection{Análise ao longo do tempo}

Voltando para o primeiro objetivo específico do estudo bibliométrico, uma análise que ajuda a dar uma visão geral sobre a produção em uma determinada área é o quanto se tem falado sobre um conceito ao longo do tempo. Uma vez que foram definidos os principais conceitos da literatura de jogos no que tange ao seu uso para fins de aprendizado, é possível, agora, observar-se como vem sendo sua evolução no tempo.

Para analisar a presença de cada conceito-chave na literatura ao longo do tempo, foram realizadas buscas independentes na base de dados Scopus, sem aplicação de nenhum filtro (sem a restrição de journals e proceedings, para dar uma melhor noção do volume produzido, no geral). Os critérios foram apenas os termos que estão colocados na Tabela 2.3. Os termos foram separados em dois gráficos, por questão de ordem de grandeza da quantidade de artigos e, também, por ter ficado cada vez mais evidente que estão relacionados a aspectos diferentes da pesquisa: e-Learning e Distance Education (Figura 2.8) e gamification, serious games, serious gaming, game-based learning, learning game, educational game, business games e business simulation (Figura 2.9). O período considerado foi de 2000 a 2014.

Tabela 2.3 - Quantidade de registros encontrados na base Scopus para cada conceito-chave buscado separadamente

\begin{tabular}{|c|c|c|c|c|c|}
\hline Conceito-chave & $\begin{array}{l}\text { Total } \\
\text { Geral }\end{array}$ & $\begin{array}{c}\text { Total } \\
\text { considerado }\end{array}$ & Total+ & $\begin{array}{l}\text { Sobrepo- } \\
\text { sição (\%) }\end{array}$ & Restrição \\
\hline Business Game & 325 & 325 & 90 & $27,7 \%$ & \multirow{10}{*}{$\begin{array}{l}\text { AND (business OR management OR } \\
\text { administration) } \\
\text { AND (business OR management OR } \\
\text { administration) }\end{array}$} \\
\hline $\begin{array}{l}\text { Distance } \\
\text { education }\end{array}$ & 12.688 & 2.920 & 613 & $21,0 \%$ & \\
\hline $\begin{array}{l}\text { Educational } \\
\text { Game }\end{array}$ & 1.497 & 1.497 & 500 & $33,4 \%$ & \\
\hline e-Learning & 29.486 & 7.256 & 724 & $10,0 \%$ & \\
\hline $\begin{array}{l}\text { Game-based } \\
\text { learning }\end{array}$ & 1.668 & 1.668 & 807 & $54,4 \%$ & \\
\hline Gamification & 745 & 745 & 138 & $18,5 \%$ & \\
\hline Learning game & 1.021 & 1.021 & 489 & $47,9 \%$ & \\
\hline Serious games & 2.317 & 2.317 & 679 & $29,3 \%$ & \\
\hline Serious gaming & 255 & 255 & 143 & $56,1 \%$ & \\
\hline Simulation & 2.404 .117 & 2.223 & 105 & $4,7 \%$ & \\
\hline
\end{tabular}

Nota. A coluna Total Geral traz o número de registros obtidos na busca simples de cada termo. O Total Considerado leva em conta restrições à área de Administração para os casos em que houve excesso de registros. A coluna Total+ indica a quantidade de artigos relacionados a cada conceito-chave que apareceram em pelo menos mais uma das demais buscas de conceitos-chave. 


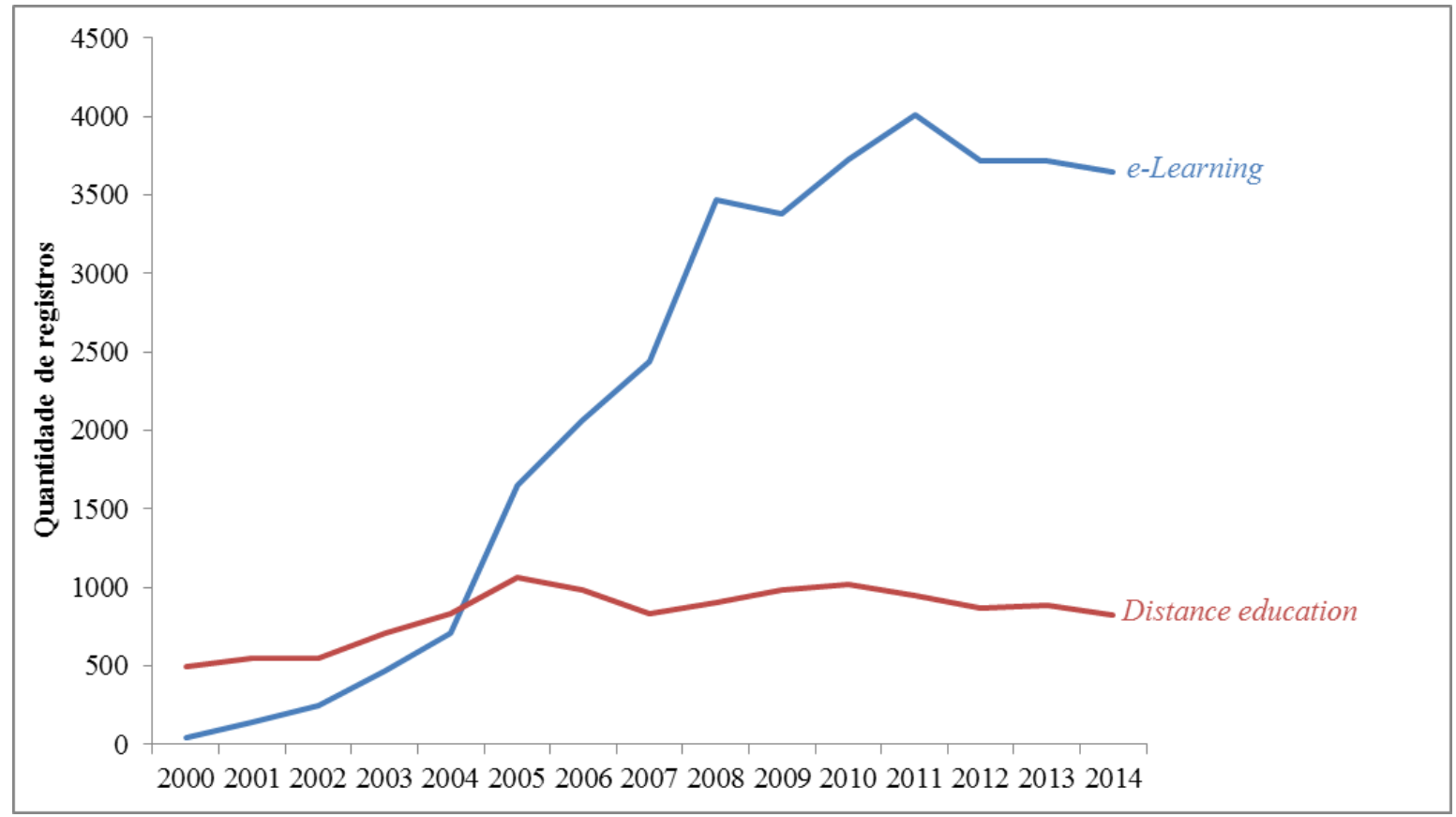

Figura 2.8 - Variação ao longo do tempo do número de registros para os termos e-Learning e Distance Education na base Scopus no período de 2000 a 2014.

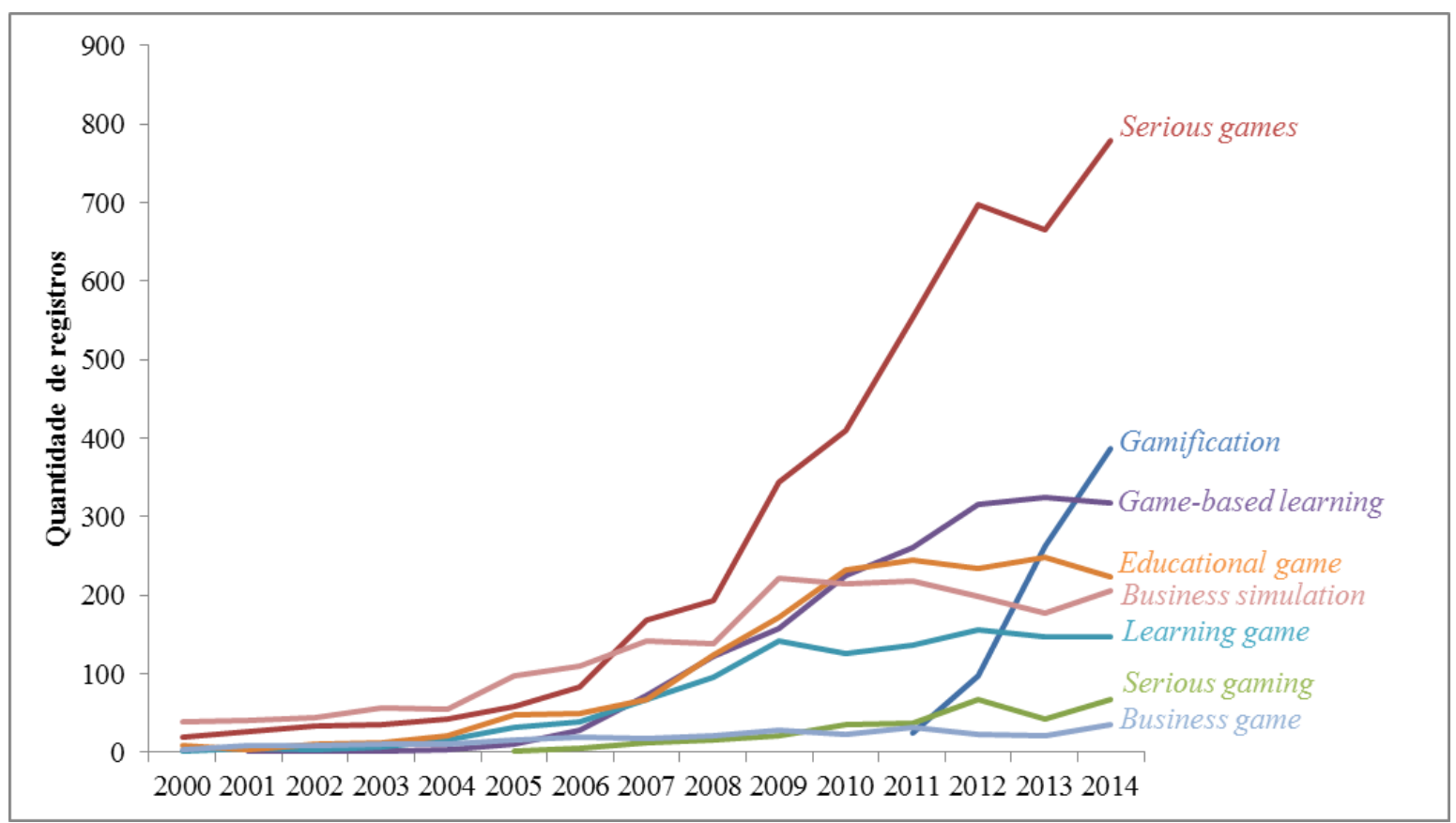

Figura 2.9 - Variação ao longo do tempo do número de registros para os termos gamification, serious games, serious gaming, game-based learning, learning game, educational game, business games e business simulation na base Scopus no período de 2000 a 2014.

Os gráficos dão uma ideia de importância relativa entre os conceitos-chave na literatura e, combinados aos achados das partes precedentes do estudo bibliométrico, auxiliam a estruturação da fundamentação teórica da pesquisa. A variação da presença dos conceitos na 
literatura evidencia o crescimento da modalidade e-Learning, especialmente entre 2003 e 2010 e também, mais recentemente dos serious games e da gamification, que, aparentemente, ganharam destaque na pesquisa nos últimos anos.

\subsubsection{Conclusão do estudo bibliométrico}

Para resumir, os achados do estudo bibliométrico, relacionados com cada um de seus objetivos específicos, foram:

(i) Ter uma visão geral da produção da literatura sobre jogos

- As técnicas bibliométricas utilizadas permitiram a construção de mapas perceptuais em que foi possível ver a relação entre as palavras-chave mais frequentes na literatura de jogos e de suas aplicações.

- A produção da literatura sobre jogos apresentou um crescimento exponencial a partir do início do século.

- Observou-se um crescimento acentuado de conceitos como serious games, gamification e e-learning desde o início do século.

(ii) Identificar os principais assuntos tratados na literatura sobre jogos

- De uma forma geral, as principais áreas tratadas nessa literatura são: computação, design (de jogos) e educação. Palavras-chaves associadas a pessoas (human, male, female, children) são as que aparecem com mais frequência, mas não dão pistas de áreas estudadas, assim como as da categoria de tipos de jogos (game, digital game, online game etc.).

(iii) Compreender a relevância do campo de administração para a pesquisa em jogos

- A área de administração (Management \& Business), embora não seja das mais expressivas, figura entre as demais, indicando que existe alguma produção relacionada a essa área, mas que também é um campo a ser mais explorado. 
(iv) Relacionar os principais usos de jogos estudados na literatura

- Pelos mapas perceptuais construídos ficou evidente que uma das principais finalidades de utilização de jogos (ao menos para estudos científicos) são as aplicações educacionais.

(v) Identificar os principais termos e conceitos que relacionam jogos e aprendizado nos últimos anos

- Os principais conceitos identificados foram: gamification, serious games, serious gaming, game-based learning, learning game, educational game, business games (também considerando simulações).

Com o fim do estudo bibliométrico, o primeiro objetivo específico da pesquisa, "identificar quais são os principais conceitos que associam a aplicação de jogos (games) para fins de desenvolvimento humano" (OE1), foi atingido.

\subsubsection{Jogos e o aprendizado}

A análise bibliométrica apresentada na subseção 2.2.1 permitiu encontrar os conceitos-chave associados ao uso de jogos em diferentes campos, com especial atenção ao aprendizado humano. O foco desta seção é conceituar, relacionar e diferenciar esses conceitos, a saber, gamification, serious games, serious gaming, game-based learning, learning game, educational game, business games (também considerando simulações), e-learning e educação a distância (distance education).

De acordo com a importância relativa percebida pela variação da presença dos termos na literatura (item 2.2.1.4) e pelas similaridades observadas nos mapas perceptuais apresentadas anteriormente (item 2.2.1.3), nota-se a existência de três grandes conjuntos de conceitos associados ao uso de jogos digitais, que nortearam a organização desta seção do capítulo.

O primeiro conjunto trata das modalidades para aprendizado não presencial mais recorrentes (embora não obrigatórias) para o uso de games para fins de aprendizagem (termos relacionados: e-learning e distance education). O segundo aborda o potencial dos jogos para o aprendizado (game-based learning). Por fim, o terceiro reúne os conceitos que são 
comumente considerados no contexto do uso de jogos ou de elementos de jogos para o aprendizado ou para gerar outros resultados que não sejam apenas associados ao entretenimento (termos considerados: gamification, serious games, serious gaming, learning game, educational game, business games e simulações).

Em função da decisão tomada de se construir um treinamento presencial que utilizasse o jogo, entendeu-se que o primeiro conjunto de conceitos, que trata das modalidades de aprendizado não presencial, fugia do escopo da pesquisa. Assim, esta seção do capítulo apresenta mais duas subseções: a primeira para tratar do aprendizado por meio de jogos (GBL - game-based learning) (subseção 2.2.3) e a segunda para trazer os conceitos relevantes para o uso de jogos com finalidades educacionais ou que não se restrinjam ao mero entretenimento (subseção 2.2.4).

\subsubsection{Aprendizado por meio de jogos (game-based learning)}

$\mathrm{O}$ aprendizado por meio de jogos - game-based learning, ou simplesmente $G B L$ - é uma subcategoria de todas as possibilidades de aprendizado com a presença do entretenimento (também conhecido com edutenimento ou, em inglês, edutainment). Se realizado no contexto online, poderia ser chamado de aprendizado por meio de jogos digitais - digital game-based learning ou DGBL (Breuer \& Bente, 2010). A Figura 2.10 apresenta uma visão esquemática dos subconjuntos.

De maneira geral, a entertainment education se refere a qualquer tentativa de tornar o aprendizado mais agradável, independentemente de utilizar recursos audiovisuais, online ou trabalhado dentro da sala de aula. O GBL inclui o uso de quaisquer tipos de jogos (tabuleiro, cartas, esportes ou digitais) para fins educacionais. Nessa categoria incluem-se, da mesma forma, os chamados jogos educacionais (ou educational games). O aprendizado por meio de jogos digitais (DGBL) é apenas uma parte do GBL. Como se pode ver na figura, o e-learning e seu subconjunto de aprendizado por meio de computador (computer-based learning) compõem outra categoria de classificações que não necessariamente está conectada ao entertainment education (Breuer \& Bente, 2010). 


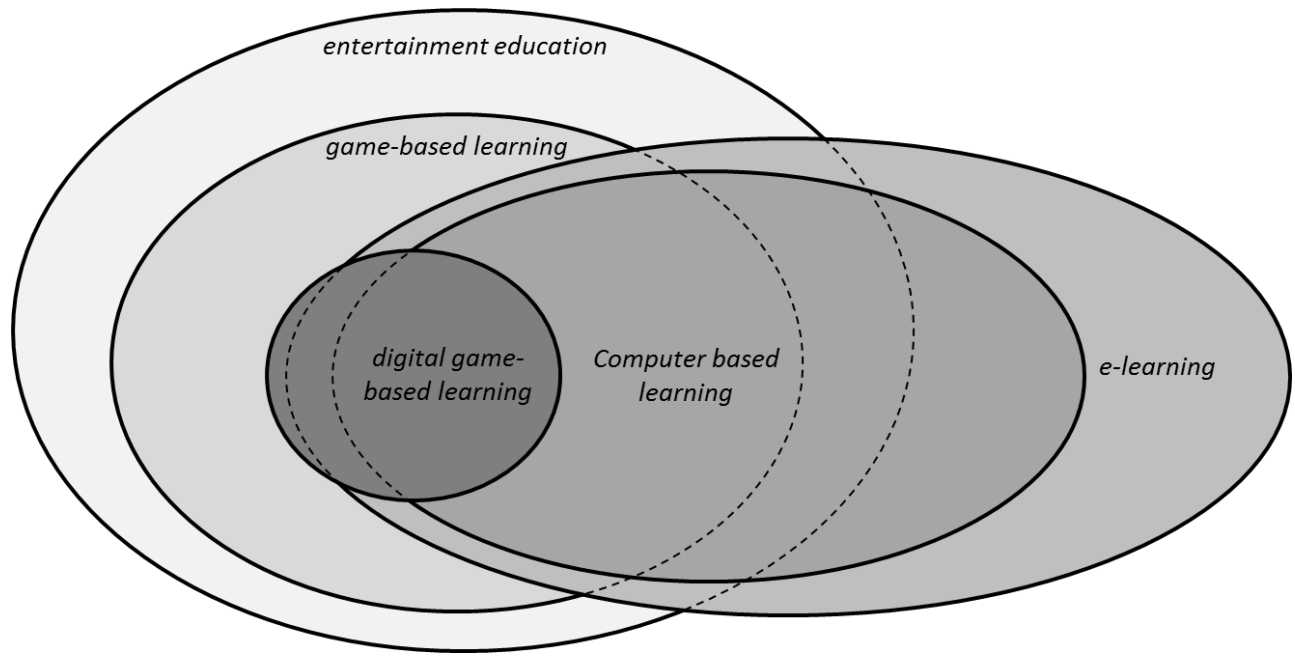

Figura 2.10 - Relações entre as modalidades de aprendizado a distância e aprendizado por meio de jogos Fonte: adaptado de Breuer e Bente (2010)

Os jogos eletrônicos podem ser considerados um novo meio de massa, com características comparáveis aos meios tradicionais como livros, televisão, filmes e música, salvo pelo fato de permitirem interação, com participação ativa do jogador e não simples recepção passiva de informação. Esse é um dos motivos que os coloca na frente para uso com fins educacionais (Minovic, Milosvanovic \& Starcevic, 2013).

Basicamente, a ideia contida no DGBL está em aproveitar a alta capacidade de entreter dos jogos digitais e utilizá-los com propósitos educacionais (Prensky, 2001). Como destacam Nussbaum e Beserra (2014), o DGBL é resultado de um equilíbrio entre os elementos de aprendizado e os de jogos. O propósito do game-based learning deve ser o de fornecer um ambiente que mescle divertimento ao mesmo tempo em que permite que os objetivos educacionais sejam atingidos. Já em 1981, Malone buscava entender como os jogos de computador estavam relacionados à motivação intrínseca e como essa motivação poderia ser aproveitada para o aprendizado. Seu intuito era o de responder a duas questões:

(1) por que os jogos de computador são tão cativantes e

(2) como as características que os fazem cativantes podem ser usadas para gerar aprendizado - especialmente com computadores - interessante e prazeroso? (Malone, 1981).

O autor concluiu que há três características de ambientes instrucionais intrinsecamente motivantes: desafio (challenge), fantasia (fantasy) e curiosidade (curiosity); adicionando mais tarde (Malone \& Lepper, 1987) uma quarta característica que é o controle (control). Com relação a cada uma das características, Minovic et al. (2013) resumem que o jogo não pode ser nem muito simples, nem muito complicado (desafio) e que o jogador deve sentir que o que 
faz afeta o resultado do jogo (controle). Além disso, oportunidades de explorar o universo do jogo podem levar a resultados inesperados (curiosidade), enquanto o jogador deve ter a percepção de participar do mundo imaginário do jogo (fantasia).

A literatura aponta que, em geral, os jogos são efetivos como instrumentos para elevar o nível de motivação dos estudantes, embora sua efetividade em termos de resultados de aprendizagem ainda seja pouco estudada (Bellotti, Kapralos, Lee, Moreno-Ger \& Berta, 2013). Outros estudos, entretanto, indicam que os jogos amplificam a retenção de conhecimento (Sitzmann, 2011; Wouters, Van Nimwegen, Van Oostendorp \& Van der Spek, 2013). Já se sabe, também, que os serious games são ferramentas efetivas para complementar os instrumentos educacionais já disponíveis para os professores, especialmente para estimular a motivação (Bellotti, Berta \& De Gloria, 2012) e para o atingimento de objetivos educacionais de níveis mais baixos da taxonomia de Bloom (Connolly et al., 2012). Os detalhes do significado dessa taxonomia são apresentados na segunda parte deste capítulo, na subseção 2.3.5.

Com relação especificamente à característica do desafio de um jogo, uma das quatro elencadas por Malone \& Lepper (1987), aparece um importante conceito da psicologia, o estado de fluxo, que emerge como um dos aspectos que impacta positivamente o aprendizado e a atitude dos jogadores (Kiili, 2005).

O conceito de estado de fluxo foi introduzido por Csikszentmihalyi (1991) e descreve um estado em que a pessoa fica completamente engajada em uma atividade ou absorvida por ela e se refere a uma experiência ótima. A experiência ótima é aquela em que a pessoa está tão envolvida com o objetivo da atividade que nada mais parece importar (Csikszentmihalyi, 1991). Webster, Trevino, e Ryan (1993) já demonstraram que o estado de fluxo tem impacto positivo sobre o aprendizado em ambientes de interação humana com o computador.

O estado de fluxo depende de um equilíbrio entre o nível de desafio e a habilidade que a pessoa tem para realizar a atividade (Csikszentmihalyi, 1991). Kiili (2005) propõe um acréscimo ao modelo de Csikszentmihalyi adicionando a zona de desenvolvimento proximal de Vygotsky (1978), que pode ser entendida como o conjunto de tarefas que a pessoa consegue resolver sem a ajuda de um professor (ou a criança sem a ajuda de um adulto). A 
Figura 2.11 apresenta a adaptação de Kiili (2005) ao modelo de Csikszentmihalyi. Cabe destacar, também, que a zona de desenvolvimento proximal se relaciona com outro conceito importante para o desenvolvimento de jogos, o scaffolding (colocação de andaimes). Para Wood, Bruner e Ross (1976) a definição de scaffolding é dada por "aqueles elementos da tarefa que são inicialmente além da capacidade do estudante, assim permitindo a ele que se concentre apenas naqueles elementos que estão dentro da sua faixa de competência e os complete" ${ }^{, 5}$. A ideia é que seja dado um suporte para que a pessoa alcance progressivamente níveis mais altos (como um andaime). $\mathrm{O}$ uso desse recurso para o desenvolvimento de jogos já é documentado na literatura (Melero, Hernandez-Leo \& Blat, 2012, 2011).

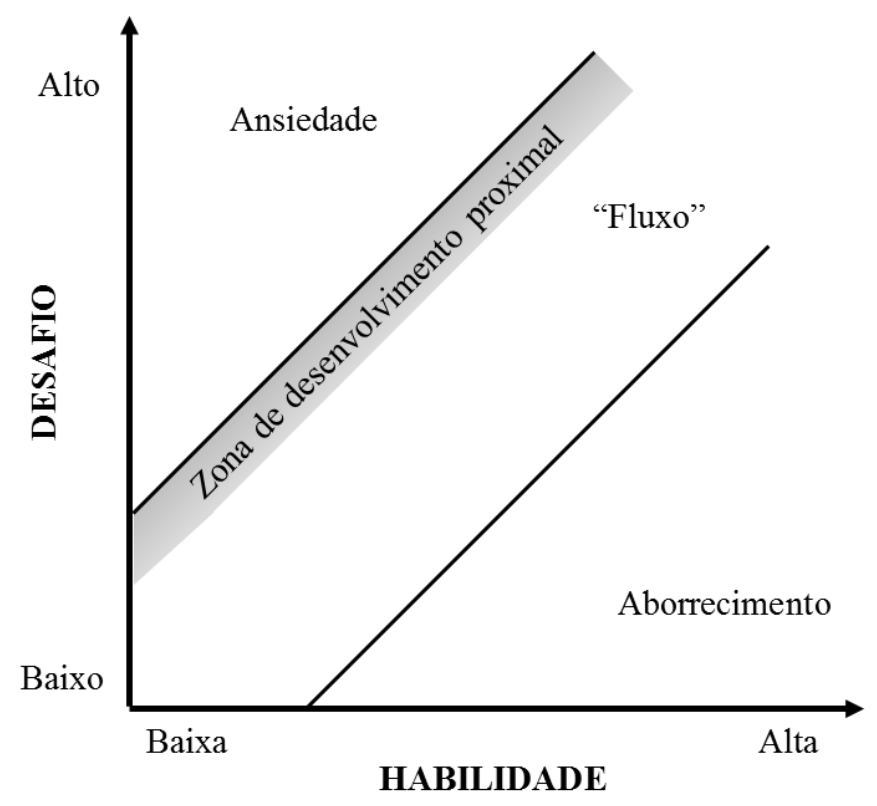

Figura 2.11 - O modelo do canal de fluxo Fonte: Traduzido de Kiili (2005).

Dessa forma, é importante que o desafio encarado pelo jogador corresponda à habilidade que ele tem. Se o desafio for muito elevado para o nível de habilidade do jogador, ele pode sentir ansiedade. Por outro lado, se o desafio foi muito fácil, o jogador pode se entediar ou se aborrecer. Prover um determinado nível de orientação ao jogador pode facilitar o atingimento do estado de fluxo (Kiili, 2005). O estado de fluxo pode ser atingido mesmo em jogos não digitais (como um jogo de tabuleiro para o aprendizado de gerenciamento de marcas e produtos) e também leva a maior motivação, mais divertimento e melhor absorção do conteúdo apresentado (Khan \& Pearce, 2015).

\footnotetext{
${ }^{5}$ Those elements of the task that are initially beyond the learner's capacity, thus permitting him to concentrate upon and complete only those elements that are within his range of competence
} 
A efetividade do DGBL é normalmente avaliada de duas maneiras, com foco no processo da intervenção em si, que normalmente descreve o processo da utilização do jogo; e avaliações conclusivas, cujo objetivo é verificar se a intervenção (uso do jogo) produz ou não os resultados educacionais imaginados. Enquanto o primeiro tipo é feito com base em estudos observacionais, o segundo é realizado por meio de experimentos (All, Castellar \& Looy, 2016). A avaliação do DGBL com experimentos é retomada no Capítulo 3, sobre o método desta pesquisa.

Lujan e DiCarlo (2006) apresentam evidências da literatura de que os jogos aumentam o envolvimento, a motivação e o interesse no material sendo trabalhado e permitem que o instrutor possa apresentar os tópicos de forma mais original e criativa, bem como permitem que os estudantes sejam desafiados a avaliar suas habilidades de pensamento crítico. Os jogos também proporcionam a criação de uma atmosfera de competição construtiva que facilita a interação entre os estudantes em um ambiente amigável e divertido.

Em sua revisão sistemática da literatura relacionando o uso de jogos por adolescentes e adultos (14 anos ou mais) e seus impactos (comportamentais, de aprendizado, de motivação etc.), Connolly et al. (2012) encontraram 129 artigos, no período de 2004 a 2009, que reportaram evidências empíricas do impacto e dos resultados de sua utilização. Seu objetivo principal na revisão era o de desenvolver uma classificação dos resultados e impactos do uso de jogos com relação ao engajamento e ao aprendizado. Os tipos de resultados mais presentes foram, em ordem de frequência, com o número de estudos relacionados entre parênteses: afetivos e motivacionais (33), aquisição de conhecimento/entendimento de conteúdo (32), habilidades perceptuais e cognitivas (20), mudança de comportamento (13), efeitos fisiológicos (11) e efeitos sociais e de soft-skills (11).

Com relação às disciplinas sobre as quais os estudos sobre os jogos foram realizados, os autores apontaram que as mais presentes foram saúde (21), jogos sobre questões sociais (14), ciência (11) e business (8). E, no que diz respeito à proposta principal dos jogos dos estudos, os autores classificaram os artigos em entretenimento (68), jogos para aprendizado (49) e serious games (12). Esses resultados reforçam a ideia de que o GBL é utilizado em diferentes áreas curriculares e os jogadores parecem considerar essa abordagem motivadora e divertida. Contudo, o baixo número de artigos classificados como serious games e a percepção de que a 
maioria ainda deveria ter sido categorizada como jogos para aprendizado sugere que existe uma confusão sobre a caracterização de um serious game. Nesta categoria, as simulações são, de longe, o gênero mais presente, indicando que seu uso para educação já é bem estabelecido (Connolly et al., 2012).

Jorge e Sutton (2017) desenvolveram um modelo para refletir o GBL para empresas, entes governamentais e no contexto da educação superior. $O$ estudo de como a diversão e a brincadeira (fun and play) se relacionam ao GBL deu origem ao que os autores chamam de funification. Embora o conceito de diversão (fun) possa ser associado a uma miríade de significados, já há algumas décadas o termo aparece como um importante elemento do design de jogos (Malone, 1984), mesmo que já se apontasse a necessidade de entender esse conceito mais profundamente (Carroll\& Thomas, 1988).

Tentativas recentes de relacionar a diversão ao aprendizado por meio de jogos (GBL), como a de Jorge e Sutton (2017), incorporam uma série de elementos, que vão desde diferentes tipos de prazer (físico, social, psicológico), elementos de game design (aparência, estética, utilidade), condições para o estado de fluxo (tarefas, feedback, foco, concentração) até o tipo de diversão que se obtém (curiosidade, domínio de uma habilidade, engajamento emocional e social), uso da gamification e aprendizagem experiencial (experiential learning).

Obviamente, colocar todos esses elementos juntos e ainda por cima avaliar sua efetividade para o aprendizado é uma difícil tarefa que deve ser encarada pelas pessoas que estão encarregadas de desenvolver os serious games. A lógica subjacente ao processo que conecta os jogos ao aprendizado foi sintetizada por Paras e Bizzocchi (2005), como mostra o encadeamento abaixo, mantido em inglês para evitar ambiguidades:

\section{Games $\rightarrow$ Play $\rightarrow$ Flow $\rightarrow$ Motivation $\rightarrow$ Learning}

Assim, "jogos fomentam a brincadeira, que produz um estado de fluxo, que, por sua vez, aumenta a motivação, que sustenta o processo de aprendizagem"6 (Paras \& Bizzocchi, 2005, p.4, tradução nossa). Os autores adicionam ainda que "uma mecânica de jogo bem projetada pode resultar em experiências de aprendizado que são intrinsecamente motivantes"7.

\footnotetext{
${ }^{6}$ Games foster play, which produces a state of flow, which increasesmotivation, which supports the learning process

${ }^{7}$ well-designed game mechanics can result in learning experienceswhich are intrinsically motivating,
} 
Já há exemplos na literatura de jogos e simulações que têm a capacidade de desenvolver os seus usuários tanto nas chamadas soft-skills quanto no conhecimento conceitual, favorecendo o aprendizado por meio da experiência (Geithner \& Menzel, 2016). Os serious games também são efetivos ao oferecer oportunidades para o entendimento de questões práticas que seriam muito custosas, difíceis ou perigosas de se reproduzir na realidade.

De acordo com Madani, Pierce e Mirchi (2017) uma série de conclusões pode ser tirada a partir da literatura do GBL:

1. A efetividade dos jogos não é universal para propósitos educacionais: ela depende do design e dos componentes de cada jogo;

2. Muitos estudos de jogos educacionais contêm problemas metodológicos e carecem de resultados quantitativos, tornando difícil avaliar a precisão dos resultados;

3. Há a necessidade de estudos longitudinais de forma a determinar a influência (se existir) da efetividade dos jogos;

4. O debriefing ${ }^{8}$ é um importante elemento do GBL, permitindo que os participantes tenham tempo para refletir sobre suas experiências e entendam as conexões entre os aspectos do jogo que vão além de seus gráficos e sons (gameplay ou jogabilidade) e os objetivos instrucionais;

5. O GBL pode aumentar a motivação e engajamento, que, por sua vez, têm efeitos benéficos nos resultados do aprendizado.

Dessa forma, existem características que são importantes de serem incorporadas no processo do design de jogos digitais e que complementam o referencial de Malone (1984). Nesse sentido, apresenta-se na Tabela 2.4 a síntese desenvolvida por Bober (2010), que se alinha com o que preconiza Gee (2004), ao afirmar que bons videogames incorporam bons princípios de aprendizagem, apoiados pelas pesquisas recentes em ciência cognitiva. Esse referencial guiou o desenvolvimento do Liderança em Jogo: Competências, Papéis e Responsabilidades e as características foram incorporadas ao jogo na medida do possível, conforme descrito no Capítulo 3. Além disso, esse referencial serve como base para a avaliação da percepção se a

\footnotetext{
${ }^{8} \mathrm{O}$ debriefing é entendido como o momento em que se reporta a execução de uma tarefa e não tem uma palavra correspondente em português que capte esse sentido.
} 
experiência de aprendizado com um jogo incorporando esses elementos é efetiva no contexto deste trabalho.

Tabela 2.4 - Taxonomia dos elementos dos jogos digitais

\begin{tabular}{|c|c|c|}
\hline № & Elem & Descrição \\
\hline 1 & Desafio & Um teste das habilidades do aprendiz, ajustado de forma a ampliá-las \\
\hline 2 & Fantasia & $\begin{array}{l}\text { Ambiente imaginário, personagens e história que podem ser uma metáfora para } \\
\text { o mundo real }\end{array}$ \\
\hline 3 & Feedback & Resposta às ações do aprendiz ou progresso ao longo do jogo \\
\hline 4 & Objetivos & $\begin{array}{l}\text { Objetivos claros que são significativos e atingíveis mas que ampliam as } \\
\text { habilidades do aprendiz }\end{array}$ \\
\hline 5 & Estímulos sensoriais & Efeitos visuais e sonoros atraentes \\
\hline 6 & $\begin{array}{l}\text { Aspectos sociais / } \\
\text { comunidade }\end{array}$ & Ou contra outras necsogs e interac̃̃ \\
\hline 7 & Aprendizagem ativa & Aprender fazendo, isto é, envolver-se ativamente na \\
\hline 8 & $\begin{array}{r}\text { Adaptabilid } \\
\text { individ }\end{array}$ & $\begin{array}{l}\text { Idade do jogo ou tarefas se ajusta para acomodar o nível de habilidade } \\
\text { or }\end{array}$ \\
\hline 9 & Avaliação & $\begin{array}{l}\text { Os aprendizes podem avaliar o quão bem estão indo no jogo e comparar seu } \\
\text { desempenho com os outros jogadores }\end{array}$ \\
\hline 10 & $\begin{array}{c}\text { Autenticidade / } \\
\text { realismo / } \\
\text { fidelidade }\end{array}$ & $\begin{array}{l}\text { Os efeitos visuais, sonoros e táteis e comportamento dos personagens que } \\
\text { contribuem para deixar o jogo mais convincente e fidedigno }\end{array}$ \\
\hline 11 & Competição & om outros ou consigo mesmo, com o objetivo de superar os outros ou \\
\hline 12 & Controle & O aprendiz é apto a conduzir e direcionar suas próprias ações no jogo \\
\hline 13 & Criatividade & $\begin{array}{l}\text { Usar a imaginação para resolver problemas ou produzir (e compartilhar) } \\
\text { artefatos no jogo }\end{array}$ \\
\hline 14 & tério / & Elemento de novidade, surpresa e complexidade informacional dentro do jogo \\
\hline 15 & $\begin{array}{l}\text { Solução de } \\
\qquad \text { (puzzl }\end{array}$ & $\begin{array}{l}\text { Desafios mentais, enigmas ou problemas que precisam ser resolvidos para o } \\
\text { progresso no jogo }\end{array}$ \\
\hline 16 & $\begin{array}{l}\text { Tomada rápida de } \\
\text { decisões }\end{array}$ & $\begin{array}{l}\text { Ter que tomar uma série de decisões rápida e continuamente para seguir adiante } \\
\text { no jogo }\end{array}$ \\
\hline 17 & $\begin{array}{l}\text { Relevância / interesse } \\
\text { para o aprendiz }\end{array}$ & az de se relacionar com o jogo de uma forma significativa \\
\hline 18 & Recompensa & $\begin{array}{l}\text { Prêmio ou incentivo dado em troca do que o aprendiz alcançou, compatível com } \\
\text { seu nível crescente de habilidade }\end{array}$ \\
\hline 19 & Papel & $\begin{array}{l}\text { O aprendiz assume uma parte específica no jogo e, assim, adquire habilidades e } \\
\text { conhecimentos relevantes no mundo real }\end{array}$ \\
\hline 20 & Regras & $\begin{array}{l}\text { Condições e restrições que direcionam as ações que o aprendiz pode realizar } \\
\text { dentro do jogo }\end{array}$ \\
\hline 21 & urança & As consequências da tomada de riscos no jogo não têm impacto no mundo real \\
\hline 22 & $\begin{array}{l}\text { Scaffolding e senso de } \\
\quad \text { progresso }\end{array}$ & $\begin{array}{l}\text { Aumento progressivo do nível de dificuldade do jogo e senso de progresso no } \\
\text { jogo }\end{array}$ \\
\hline 23 & Transferência & $\begin{array}{l}\text { O aprendizado proveniente do jogo pode ser aplicado em outros jogos ou no } \\
\text { contexto do mundo real }\end{array}$ \\
\hline
\end{tabular}




\subsubsection{Os pilares constitutivos do DGBL}

Por mais que se possa pensar, em função da atualidade do assunto, que o uso de jogos para fins educacionais é um fenômeno recente, em 1936, o historiador holandês Johan Huizinga, em sua notável obra Homo Ludens, apresentava a importância do jogar (play) como um importante elemento da cultura e da sociedade humana ao longo de toda a história. Diz o autor no prefácio de seu livro que "é no jogo e pelo jogo que a civilização surge e se desenvolve". Para ele, jogar tem uma conotação que vai além do entretenimento puro e simples, ultrapassando os limites da atividade puramente física ou biológica, caracterizando-se como um elemento inerente da própria cultura com uma função social. Diz o autor, "No jogo existe alguma coisa 'em jogo' que transcende as necessidades imediatas da vida e confere um sentido à ação. Todo jogo significa alguma coisa" (Huizinga, 2008, p. 3). Ele ainda destaca que o jogo

[...] é uma atividade ou ocupação voluntária, exercida dentro de certos e determinados limites de tempo e de espaço, segundo regras livremente consentidas, mas absolutamente obrigatórias, dotado de um fim em si mesmo, acompanhado de um sentimento de tensão e de alegria e de uma consciência de ser diferente da vida cotidiana (Huizinga, 2008, p.33).

Entretanto, o jogo é normalmente pensado como diametralmente oposto à seriedade. Porém, essa é uma visão fácil de refutar, pois como um fenômeno cultural, o jogo deve ser levado a sério e, mais do que isso, "a seriedade procura excluir o jogo, ao passo que o jogo pode muito bem incluir a seriedade" (Huizinga, 2008, p. 49). Daí surge a base para a construção do conceito de serious games, como uma forma de deliberadamente construir e utilizar jogos para fins que não sejam meramente o de entretenimento (Abt, 1970).

Embora o conceito dos serious games seja mais antigo, cunhado por Abt (1970), nos últimos anos tem-se observado o crescimento da gamification de uma maneira mais difundida na mídia, com uma estimativa de movimentação da ordem de 2 bilhões de dólares em 2015 (Sanders, 2015; Zichermann, 2013). O uso do termo tem tomado diferentes acepções na literatura, de forma que muitas vezes tem sido confundido com tudo o que envolve jogos e entretenimento, o que não é verdade. Esse escopo não tão bem definido tem levado à crença errônea de que os dois termos, serious games e gamification são sinônimos (Oliveira \& Petersen, 2014). 
Há muita confusão na literatura, especialmente aquela que não é focada em desenvolvimento de jogos (game design) sobre esses diferentes conceitos, por exemplo, a distinção entre simulações e jogos. Ahmed e Sutton (2017) lançam uma luz sobre a questão, apresentando um quadro sintético sobre os principais conceitos que se inter-relacionam na literatura e que são de vital interesse para este trabalho (Tabela 2.5).

Tabela 2.5 - Definições de GBL, serious games, simulações e gamification

\begin{tabular}{|c|c|}
\hline Conceito & Descrição \\
\hline $\begin{array}{l}\text { Aprendizado por meio de jogos } \\
\text { (GBL - game-based learning) }\end{array}$ & $\begin{array}{l}\text { O Game-based learning (GBL) emergiu no cenário acadêmico e } \\
\text { empresarial no fim dos anos 1990. O GBL engloba diversão (fun), } \\
\text { brincadeira (play), engajamento, aprendizado sério (serious learning) e } \\
\text { entretenimento interativo. GBL é uma abordagem pedagógica (até } 12 \\
\text { anos de idade) ou andragógica (adultos) ao aprendizado que pode ser } \\
\text { definida como: } \\
\text { um tipo de jogabilidade (gameplay) que tem resultados de } \\
\text { aprendizagem definidos. Geralmente, o GBL é projetado de forma } \\
\text { a equilibrar o assunto com a jogabilidade e a capacidade de o } \\
\text { jogador reter e aplicar o referido assunto no mundo real. O GBL } \\
\text { descreve uma abordagem para o ensino, na qual os alunos } \\
\text { exploram aspectos relevantes dos jogos em um contexto de } \\
\text { aprendizagem projetado pelos professores. Professores e alunos } \\
\text { colaboram para adicionar profundidade e perspectiva à experiência } \\
\text { de jogar o jogo. }\end{array}$ \\
\hline Jogos sérios (serious games) & $\begin{array}{l}\text { Os serious games podem ser definidos como: } \\
\text {... um jogo em que a educação (em suas diversas formas) é o } \\
\text { principal objetivo, e não o entretenimento (Michael \& Chen, 2006, } \\
\text { p. 17) } \\
\text {... mais do que apenas história, arte e software, no entanto [...] } \\
\text { envolvem pedagogia: atividades que educam ou instruem, } \\
\text { transmitindo conhecimentos ou habilidade. Esta adição torna os } \\
\text { jogos sérios (Zyda, 2005, p.26) } \\
\text {... [sendo jogados] de forma séria ou casualmente. Estamos } \\
\text { preocupados com jogos sérios no sentido de que esses jogos têm } \\
\text { um propósito educacional explícito e cuidadosamente pensado e } \\
\text { não se destinam a ser jogados principalmente para diversão. Isso } \\
\text { não significa que jogos sérios não sejam ou não devam ser } \\
\text { divertidos (Abt, 1970, p.9) }\end{array}$ \\
\hline Simulações & $\begin{array}{l}\text { As simulações restringem o foco de jogos sérios. A simulação é a } \\
\text { imitação da realidade, recriando uma realidade alternativa dentro de um } \\
\text { ambiente controlado. As simulações foram usadas há milênios para } \\
\text { treinamento, entretenimento e explicação. Os jogos de go, xadrez ou risk } \\
\text { são simulações representativas e bem conhecidas, enquanto simulações } \\
\text { GBL menos visíveis incluem SimCity; estudos de caso de Harvard: } \\
\text { Missão final de Columbia; Ou o desenvolvimento de lideranças do Planet } \\
\text { Jockey. As simulações combinam e abrangem uma gama de experiências } \\
\text { multissensoriais: vídeo, áudio, movimento, háptica e olfato. As } \\
\text { simulações são muitas vezes categorizadas em três gêneros: ao vivo, } \\
\text { virtuais e construtivas. Claro, qualquer simulação poderia combinar duas } \\
\text { ou mesmo três das categorias. Durante grande parte do aprendizado } \\
\text { dentro do GBL, a simulação envolve interações humanas, ao contrário de } \\
\text { simulações científicas que exigem que o indivíduo observe ou meça algo } \\
\text { (ou seja, uma simulação de física, química ou matemática) }\end{array}$ \\
\hline
\end{tabular}




\begin{tabular}{cc}
\hline \hline Conceito & \multicolumn{1}{c}{ Descrição } \\
\hline Gamification & A gamification pode ser definida como o processo de integração da teoria \\
e design, elementos, estética e mecânica do jogo em uma experiência de \\
aprendizagem. A gamification de processos, produtos e serviços aumenta \\
o envolvimento em funcionários, gerentes e clientes. Os resultados podem \\
ser demonstrados em termos de: \\
Atividades eficazes e eficientes no local de trabalho e no serviço \\
ao cliente \\
Maior participação e lealdade \\
Maior aquisição de conhecimento e aplicação em atividades \\
educativas e de aprendizado \\
Melhor gerenciamento de desempenho \\
Práticas comerciais inovadoras \\
Transformação organizacional e cultural \\
\hline \hline
\end{tabular}

Fonte: Traduzido de Ahmed \& Sutton (2017)

Tanto os serious games quanto a gamification são reconhecidos por engajar os seus usuários. No entanto, diferentemente da gamification, que, como destacam Oliveira e Petersen (2014), engaja os usuários para comportamentos específicos e não precisa necessariamente estar incorporada em um jogo (i.e. pode existir mesmo que não exista um jogo propriamente), os serious games, projetados com base em um conjunto de regras e ações que os usuários podem tomar, engajam os usuários de uma forma implícita com seu design mais holístico, no qual a pontuação total é baseada no comportamento ou no desempenho geral do jogador. Contudo, um dos riscos inerentes dos serious games advém da priorização dos objetivos sérios, quando esses objetivos são colocados acima da experiência do jogador (Ferrara, 2013).

O termo gamification teria sido cunhado por Nick Pelling em 2002 (Pelling, 2011), mas teve seu uso difundido do ponto de vista da literatura a partir de 2011, como se pode observar no gráfico da Figura 2.9 (item 2.2.1.4). Da mesma maneira, vê-se o crescimento do interesse pelo conceito fora do mundo acadêmico. Uma busca simples na ferramenta Google Trends mostra que o termo gamification vem sendo, nos últimos anos, muito mais procurado do que os serious games, que apresenta um desempenho praticamente constante contra o crescimento acentuado da gamification, muito embora as médias das buscas pelos termos sejam parecidas, considerando-se todo o período disponível para consulta, de 2004 até o presente ${ }^{9}$ (Figura 2.12).

\footnotetext{
${ }^{9}$ Consulta realizada em julho de 2017.
} 
Contudo, mesmo com o seu crescimento, a gamification tem sido criticada por ter aplicações muito amplas, podendo incluir desde o Farmville até a barra de preenchimento do perfil do LinkedIn ${ }^{10}$. Muitas vezes, o uso de elementos de jogos restringe-se à criação de formas de recompensas como pontos ou distintivos/insígnias (badges), deixando de lado características que tornam um jogo de fato um jogo (Ferrara, 2013). Nesse sentido, até mesmo um programa de milhagem de companhias aéreas ou de pontos de operadoras de cartão de crédito poderia ser categorizado como gamification.

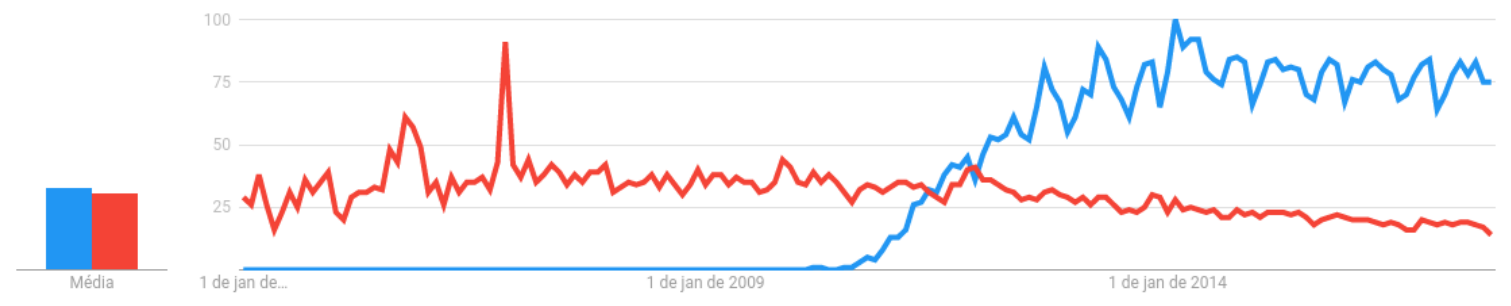

Figura 2.12 - Análise do Google Trends dos termos gamification e serious games, desde 2004 Fonte: Google (2017)

Por esse motivo, a definição do que é gamification torna-se importante. As definições usuais do termo envolvem, basicamente, a ideia do uso de elementos e técnicas de design de jogos em contextos que não são de jogos (non-game contexts) (Deterding, Dixon, Khaled \& Nacke, 2011; Werbach, 2012).

Na literatura, já houve tentativas de se definir uma separação clara entre as diferentes modalidades de usos de jogos para diferentes finalidades. Um referencial que já se tornou clássico nesse campo é o de Deterding et al. (2011), que procura contextualizar o conceito de gamification e posicioná-lo com relação a outras ideias correlatas, tais como os pervasive games, o playful design, os jogos de realidade alternativa e os próprios serious games. $\mathrm{O}$ objetivo dos autores foi o de determinar se o conceito, nascido de uma interação rica de tendências e tradições no campo dos jogos eletrônicos, difere significativamente de fenômenos e áreas de pesquisa anteriores. Os próprios mapas perceptuais da análise bibliométrica na subseção 2.2.1 indicam a distinção entre os conceitos.

\footnotetext{
${ }^{10}$ Farmville é um jogo social para a rede social Facebook que simula uma fazenda; LinkedIn é uma rede social de negócios, comparável às redes de relacionamentos, mas para fins profissionais.
} 
O ponto de partida dessa proposta está na separação entre jogar (games) e brincar (play), que tem origem na obra de 1958 do sociólogo francês Roger Caillois (1967), Les Jeux et Les Hommes, na qual o autor parte dos conceitos de paidia, termo grego associado a crianças e ludus, palavra do latim relacionada a jogos, para criar uma tipologia precisa para englobar os jogos combinada a uma visão que os relaciona ao dinamismo da sociedade.

A proposta é que na paidia é dominante uma forma mais livre, expressiva, improvisada, associada à diversão pura e simplesmente, sendo, no extremo, até mesmo tumultuada, típicos comportamentos das brincadeiras infantis. Por outro lado, o ludus associa-se a um jogar de forma mais estruturada, baseada em regras. Ambos teriam suas facetas associadas à competição (agôn), sorte (alea), simulação (mimicry) ou vertigem (ilinx). Exemplos de cada um poderiam ser: futebol, xadrez ou bilhar (agôn), roleta ou loteria (alea), uma peça como Hamlet (mimicry) e alpinismo (ilinx). A Tabela 2.6 sintetiza a classificação proposta pelo sociólogo.

Tabela 2.6 - Classificação dos jogos segundo Roger Caillois (1967)

\begin{tabular}{|c|c|c|c|c|}
\hline & $\begin{array}{c}\text { AGÔN } \\
\text { (competição) }\end{array}$ & $\begin{array}{l}\text { ALEA } \\
\text { (sorte) }\end{array}$ & $\begin{array}{l}\text { MIMICRY } \\
\text { (simulação) }\end{array}$ & $\begin{array}{c}\text { ILINX } \\
\text { (vertigem) }\end{array}$ \\
\hline \begin{tabular}{|l} 
PAIDIA \\
Tumulto \\
Agitação \\
Risadas excessivas
\end{tabular} & $\left.\begin{array}{l}\text { Corrida } \\
\text { Lutas } \\
\begin{array}{l}\text { Etc. } \\
\text { Atletismo }\end{array}\end{array}\right\} \begin{array}{l}\text { não } \\
\text { regulados }\end{array}$ & $\begin{array}{c}\text { Cantigas rimadas } \\
\text { Cara ou Coroa }\end{array}$ & $\begin{array}{l}\text { Imitações infantis } \\
\text { Jogos de ilusão } \\
\text { Bonecas } \\
\text { Máscaras, fantasias }\end{array}$ & $\begin{array}{c}\text { Brincadeira de roda } \\
\text { Hipismo } \\
\text { Balanço } \\
\text { Valsa }\end{array}$ \\
\hline $\begin{array}{l}\text { Empinar pipa } \\
\text { Jogo de paciência } \\
\text { Palavras cruzadas }\end{array}$ & $\begin{array}{cc}\text { Boxe } & \text { Bilhar } \\
\text { Esgrima } & \text { Damas } \\
\text { Futebol } & \text { Xadrez } \\
& \\
\text { Competições } \\
\text { esportivas em geral }\end{array}$ & $\begin{array}{c}\text { Apostas } \\
\text { Roleta } \\
\text { Loterias simples, } \\
\text { complexas, rifas }\end{array}$ & $\begin{array}{c}\text { Teatro } \\
\text { Espetáculos em } \\
\text { geral }\end{array}$ & $\begin{array}{l}\text { Volador } \\
\text { Parques de } \\
\text { diversões } \\
\text { Esqui } \\
\text { Alpinismo } \\
\text { Acrobacias }\end{array}$ \\
\hline LUDUS & & & & \\
\hline
\end{tabular}

Fonte: traduzido de Caillois (1967)

Inspirados por essa distinção feita por Caillois, de que brincar (no inglês playing, associado ao grego paidia) e jogar (no inglês gaming, associado ao termo em latim ludus) são coisas diferentes, embora relacionadas, e, ainda, considerando que essa duas atividades podem levar em conta artefatos como um todo (whole) ou apenas parcialmente (parts), Deterding et al. (2011) propõem um enquadramento matricial $2 \times 2$ que inclui a gamification em um dos quadrantes, separada dos serious games, dos brinquedos (toys) e do chamado playful design (que poderia ser traduzido como design ou projeto brincalhão ou divertido). 


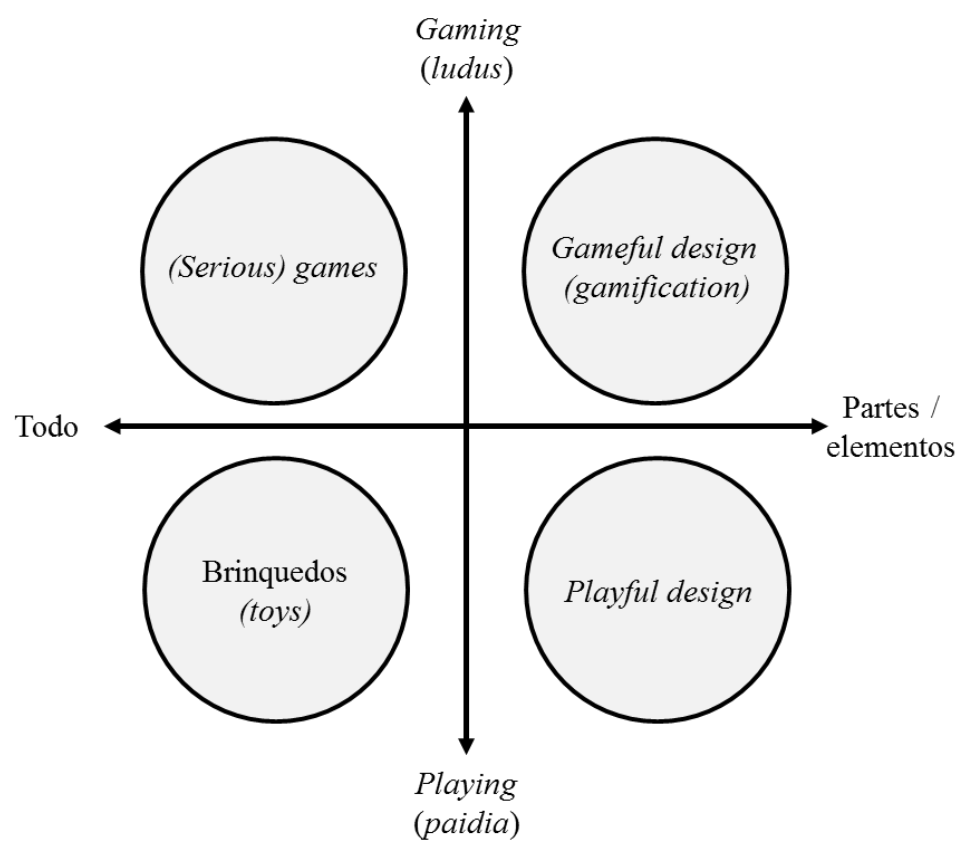

Figura 2.13-Gamification e serious games em um contexto mais amplo Fonte: Traduzido e adaptado de Deterding et al. (2011)

Nessa classificação fica evidente que gamification é diferente de serious games, assim como já se podia inferir pelos mapas perceptuais do estudo bibliométrico (seção 2.2.1). Pela sua própria definição, a gamification se utiliza de partes ou elementos do design de jogos, mas não necessariamente cria um jogo. Já os serious games envolvem, de fato, jogos em sua acepção completa, contudo, para fins que não sejam apenas de diversão, que tenham um propósito sério por trás, mas que incluam, como elemento fundamental, a diversão. A parte inferior da figura é de baixo interesse para este trabalho. Entretanto, cabe ressaltar que utilizar artefatos inteiros apenas para diversão enquadra-se na categoria de brinquedos, enquanto o playful design significa tornar as coisas um pouco mais divertidas, mas sem a preocupação de sistematicamente estruturá-las com regras e objetivos (Werbach, 2015). Um exemplo do playful design seria a criação de ícones animados enquanto se espera algum comando em um site da internet ou simplesmente formas de design que lembrem desenhos animados ou pareçam mais divertidas. Outros exemplos poderiam estar relacionados à forma de usar de aparelhos celular (smartphones) ou até mesmo dispositivos no mundo 'real', como uma prateleira ou um ambiente. A Figura 2.14 apresenta outros exemplos. 


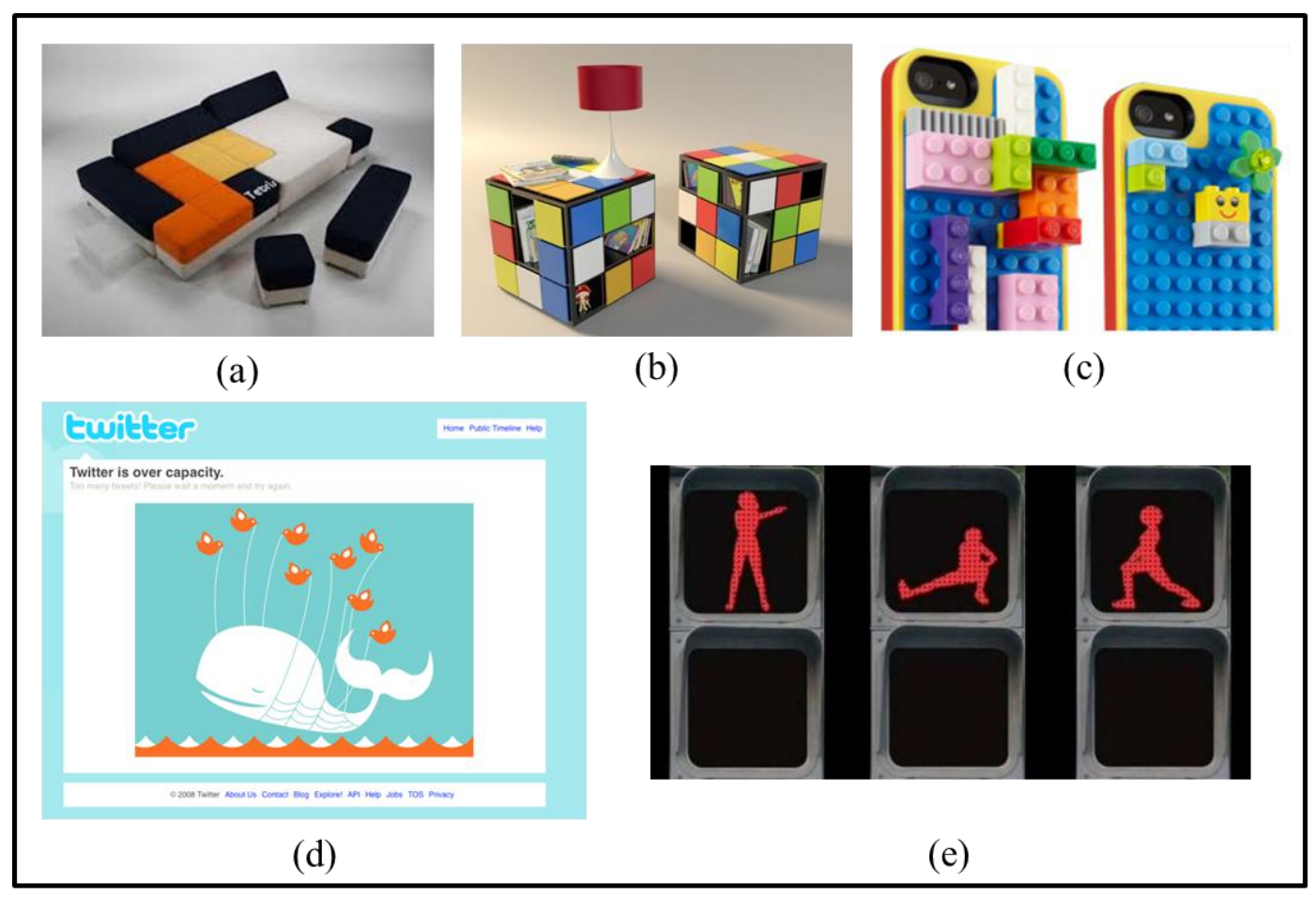

Figura 2.14 - Exemplos de playful design.

Nota. (a) Um sofá que faz alusão ao jogo Tetris, (b) uma mesinha que se parece com um cubo mágico, (c) capas de proteção de telefone celular que remetem a peças de Lego, (d) página de erro da rede social Twitter, (e) espera de semáforo para pedestres no trânsito em que a personagem faz yoga ${ }^{11}$.

Em 2014, o próprio Werbach revisitou sua definição, destacando que a anterior, por enfatizar os elementos de design de jogos, caracterizava-se apenas como uma definição elementar. Além disso, o autor salienta que conceitos como "elementos de design de jogo" e "contextos que não são de jogos" são contestáveis, de forma que uma definição mais apropriada para gamification seria "o processo de tornar as atividades mais parecidas com jogos" (Werbach, 2014).

A vantagem de se definir a gamification como um processo, como continua Werbach (2014), é que as atividades podem ser vistas apenas como mais ou menos parecidas com jogos, sem a necessidade de se definir um ponto a partir do qual o sistema que está sendo desenvolvido passe a ser classificado como gamification. Essa visão facilitaria os designers a aprofundarem

\footnotetext{
${ }^{11}$ Os exemplos foram extraídos de:

(a) http://bhousedesain.com/furniture-design/playful-tetris-games-couch-set-design.html

(b) http://freshome.com/2011/04/13/a-playful-design-kub-coffee-table-by-fabio-teixeira/

(c) http://divasanddorks.com/style-your-iphone-5-any-way-you-want-with-the-lego-builder-case/

(d) https://www.sitepen.com/blog/2008/06/11/playfulness-in-interaction-design/

(e) http://www.trendhunter.com/trends/smart-crosswalks
} 
os aspectos de jogo nos seus projetos em vez de acreditar que seu trabalho acaba uma vez que sejam criadas pontuações, listas de classificação dos jogadores ou distintivos (os chamados PBLs, points, badges and leaderboards). As implicações dessa visão contrariam a proposta de Deterding et al. (2012) de separar o desenvolvimento de serious games da gamification. "Uma atividade busca criar jogos; a outra busca tornar jogos ou não-jogos mais parecidos com jogos"12 (Werbach, 2014, tradução nossa, p. 268).

A definição de gamification como o processo de tornar as atividades mais parecidas com jogos, mas com o objetivo de influenciar o comportamento, a aproxima da chamada tecnologia persuasiva (persuasive technology). Esse é um tipo de tecnologia que é projetada com o propósito de influenciar as atitudes e os comportamentos dos seus usuários por meio de persuasão e influência social, mas não pelo uso da coerção (Fogg, 2003). Experiências que se assemelham a jogos podem promover tanto motivação quanto habilidade (Werbach, 2014).

O modelo para entendimento do comportamento humano proposto por Fogg (2009), o FBM (Fogg Behavior Model) leva em conta três fatores para que uma pessoa desenvolva um comportamento pretendido: (1) ela deve estar suficientemente motivada, (2) ela deve ter habilidade para se comportar da maneira pretendida e (3) ela deve ser provocada a ter o comportamento (Figura 2.15). Esse modelo se assemelha, em certo grau, a do estado de fluxo de Csikszentmihalyi (1991), se a motivação puder ser considerada como advinda dos desafios. $\mathrm{O}$ processo de gamification pode, portanto, funcionar como uma ferramenta especializada para promover as mudanças de comportamento a que Fogg se refere (Werbach, 2014).

\footnotetext{
${ }^{12}$ One activity seeks to create games; the other seeks to make games or non-games more game-like.
} 


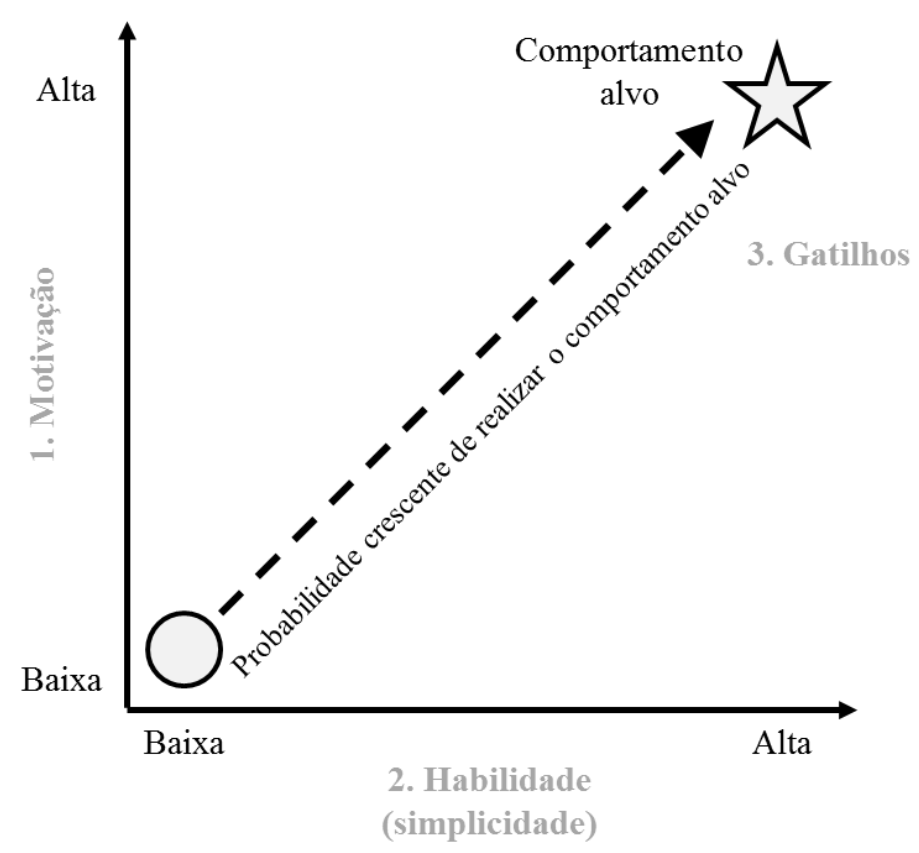

Figura 2.15 - O modelo de comportamento de Fogg (FBM), baseado em três fatores: motivação, habilidade e gatilhos

Fonte: Fogg (2009)

Então, quando se volta para o tema da presente pesquisa, percebe-se que o desenvolvimento dos gestores para criar um comportamento pretendido (melhor gestão) depende da motivação do indivíduo e também da habilidade para se comportar da maneira pretendida. Entende-se que o serious game desenvolvido, o Liderança em Jogo: Competências, Papéis e Responsabilidades, funciona no sentido de fornecer as habilidades necessárias para o comportamento. Neste estudo, olhou-se não para a habilidade em sentido estrito, mas para a competência em sentido amplo, envolvendo o sempre referenciado CHA (Conhecimentos, Habilidades e Atitudes). Essa visão sobre competências foi difundida por Parry (1996), que define:

Uma competência é um agrupamento de conhecimentos relacionados, habilidades e atitudes que afetam parte substancial da atividade de alguém (um papel ou uma responsabilidade). Esse agrupamento se relaciona com o desempenho no trabalho, que pode ser medido segundo padrões amplamente aceitos e melhorado por meio de treinamento e desenvolvimento ${ }^{13}$. (Parry, 1996, p. 50, tradução nossa)

Por outro lado, Ferrara (2013) destaca que a gamification deve incorporar determinados princípios (definir uma mensagem central; amarrar a mensagem à estratégia de jogo; permitir

\footnotetext{
${ }^{13}$ A competency is a cluster of related knowledge, skills, and attitudes that affect a major part of one's job (a role or responsibility), that correlates with performance on the job, that can be measured against well accepted standards, and can be improved via training and development
} 
descobertas autodirigidas; oferecer escolhas significativas; e tornar a coisa real), mas que, em fazendo isso, não se diferenciaria da criação de jogos em si. O autor procura enfatizar a importância dos jogos, ressaltando que eles podem ajudar a resolver problemas reais e que podem ser criados para persuadir as pessoas a adotar um determinado ponto de vista ou tomar ações específicas no mundo real. Essa visão se assemelha a de Negroponte (2012) ao comparar o processo de aprendizado ao processo iterativo de se programar um computador

De acordo com Michael e Chen (2006), um serious game é "um jogo em que a educação (em suas várias formas) é o objetivo principal, ao invés do entretenimento"14 (p. 17). Embora a estruturação como um campo de estudo e de desenvolvimento particular seja recente, o uso de jogos com objetivos que não apenas o entretenimento remonta tempos longínquos da história (e nesse caso são considerados todos os tipos de jogos, em papel, tabuleiro etc. e não apenas os digitais). Possivelmente, a primeira definição formal de serious games veio de Abt (1970):

Jogos podem ser jogados seriamente ou casualmente. Estamos preocupados com os serious games no sentido de que esses jogos têm uma proposta educacional explícita e cuidadosamente pensada e não são pensados primariamente para divertimento. Isso não significa que os serious games não sejam, ou não devam ser, interessantes ${ }^{15}$.

Mais do que fazer uma varredura nas definições e um levantamento pormenorizado delas, o sentido aqui proposto é o de contextualizar os serious games em relação aos jogos convencionais (video games) e explorar diferentes perspectivas de enquadramento nessa categoria.

Nesse sentido, Djaouti, Alvarez e Jessel (2011) fazem uma síntese adequada ao propor uma taxonomia para os serious games que envolve três dimensões para classificação: Gameplay (a maneira como o jogo é jogado), Proposta (a proposta planejada, além do entretenimento) e Escopo (a aplicação alvo, ou seja, quem usa o jogo), dando origem ao modelo G/P/S (Gameplay/Purpose/Scope). Mais rico do que a proposta em si é o panorama que os autores apresentam para caracterizar os serious games ou, uma categoria um pouco mais ampla, a de serious gaming. Como destacam Deterding et al. (2011), "enquanto o termo 'serious games' denota jogos projetados para conduzir material de aprendizado ao serem jogados, 'serious

\footnotetext{
${ }^{14} \mathrm{~A}$ serious game is a game in which education (in its various forms) is the primary goal, rather than entertainment.

${ }^{15}$ No original: "Games may be played seriously or casually. We are concerned with serious games in the sense that these games have an explicit and carefully thought-out educational purpose and are not intended to be played primarily for amusement. This does not mean that serious games are not, or should not be, entertaining".
} 
gaming' abarca qualquer utilização (educacional) de uma gama mais ampla de jogos"16 (p. 10, tradução nossa).

A ideia por trás dessa percepção é simples. O serious gaming envolve não só aqueles jogos que foram deliberadamente projetados com propostas que não tem o entretenimento como alvo principal (serious games) como também considera jogos (video games) convencionais, que foram projetados para o entretenimento, mas que acabam sendo utilizados com propósitos educacionais por determinados professores (desvio de propósito, ou purpose-shift). Além dessa categoria, o serious gaming também engloba jogos inicialmente concebidos para o entretenimento, mas que têm o design alterado para a utilização sem fins principais de entretenimento (i.e. sérias), os chamados "Mods" (em alusão a modificações). Assim, o jogo pode ser pensado a partir do seu projeto (design) e de sua utilização. A Figura 2.16 apresenta a concepção de Djaouti et al. (2011).

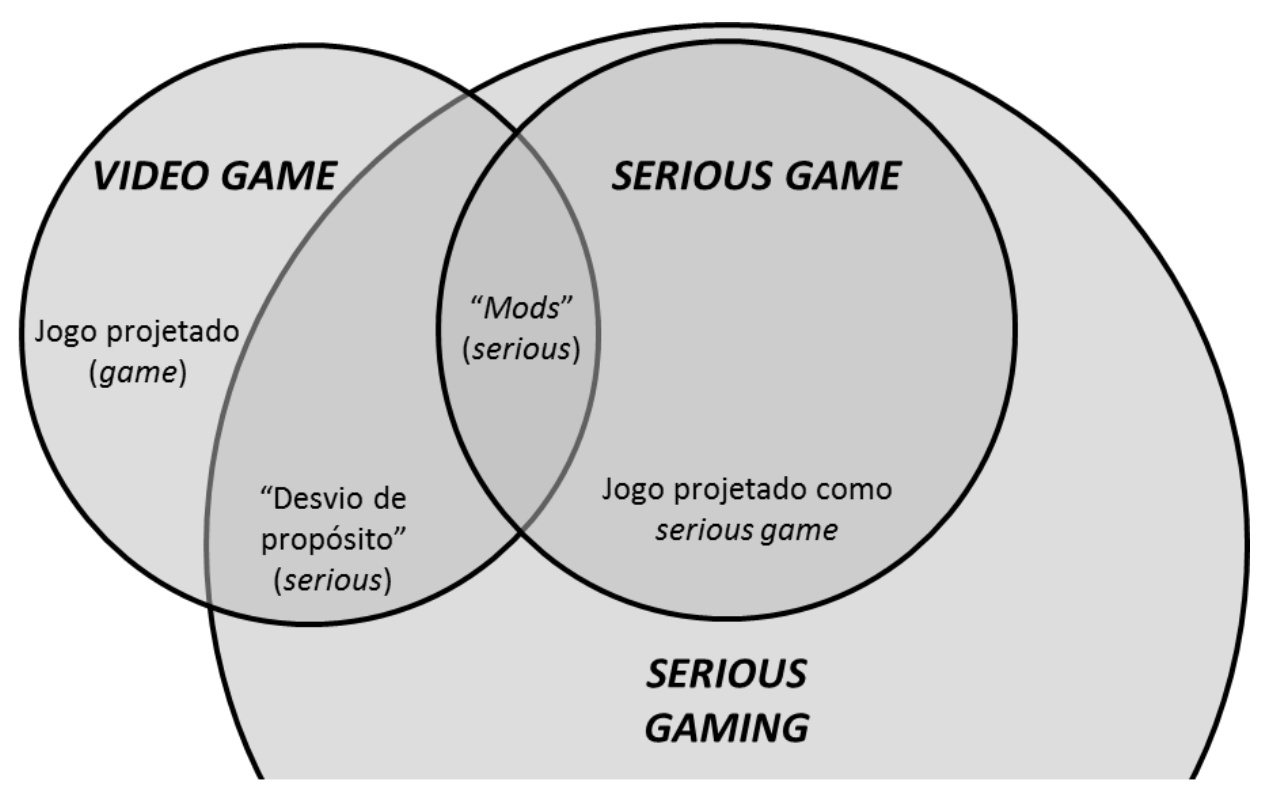

Figura 2.16 - Relação entre video games, serious games e serious gaming. Fonte: Djaouti et al. (2011)

O modelo G/P/S é útil, pois facilita a percepção de que os business games são uma subcategoria dos serious games. Afinal, a diferenciação se dá pela proposta ou pelo escopo, que pode ser a de melhorar a tomada de decisões de gestores ou apresentar um sistema que simule um mercado para estudantes de administração. É possível afirmar, então, que os

\footnotetext{
${ }^{16}$ Whereas the term 'serious games' denotes games designed to convey learning material in being played through, 'serious gaming' encompasses any (educational) utilization of the broader ecology of games.
} 
business games são apenas serious games focados para o ambiente de negócios (Petridis et al., 2014).

Dentre as poucas pesquisas encontradas buscando relacionar o uso de jogos digitais à área pública, o trabalho de Pinto (2014), em que se utilizou o consagrado jogo SimCity ${ }^{\circledR}$ para o aprendizado de contabilidade governamental, seria enquadrado como serious gaming, na categoria "mudança de propósito", em que houve a utilização de um jogo existente para outra finalidade que não fosse apenas o entretenimento.

\subsection{Parte 2 - Desenvolvimento Gerencial}

\subsubsection{Desenvolvimento de recursos humanos (HRD)}

O problema de pesquisa deste trabalho refere-se explicitamente a "desenvolvimento de gestores". A perspectiva teórica que trata do desenvolvimento das pessoas nas organizações é, em geral, a do desenvolvimento de recursos humanos (HRD - Human Resource Development). Essa perspectiva trata do funcionamento de seres humanos adultos em sistemas produtivos. A proposta do HRD é focar tanto no sucesso pessoal quanto organizacional trazido pelos seres humanos (Swanson \& Holton III, 2009).

Existem diferentes entendimentos sobre o que é, de fato, HRD, associados inclusive aos usos dos termos "desenvolvimento" e "recursos humanos" (Hamlin \& Stewart, 2011). Em seus estudos, Lee $(1997 ; 2001)$ destaca que há, normalmente, quatro perspectivas adotadas para o conceito de desenvolvimento. Quando os indivíduos se referem ao próprio desenvolvimento, normalmente apresentam uma perspectiva do desenvolvimento como uma viagem, em que as pessoas o percebem como uma jornada pessoal ao longo da vida em caminhos internos não explorados, sendo cada pessoa a principal responsável por esse processo. Já os gestores sêniores tendem a ver o desenvolvimento como um processo de moldagem, ou seja, as pessoas são vistas como ferramentas que podem ser moldadas para se adequarem à organização. Porém, quando o olhar é dado pelos acadêmicos, normalmente surgem duas outras perspectivas, a do desenvolvimento como um processo de amadurecimento 
(indivíduos, grupos e organizações são percebidos como capazes de serem completamente compreendidos e desenvolvidos por meio de uma progressão predeterminada, baseada em etapas e inevitável da aprendizagem) ou como um processo emergente (o desenvolvimento do grupo como organização não difere do desenvolvimento de qualquer sistema social em que o processo tende a ser desordenado e descontínuo, sem nenhum subsistema ou ator consistente desencadeando e conduzindo consistentemente o processo). Assim, a autora sugere que nem o conceito de desenvolvimento, nem o de recursos humanos sejam vistos como conceitos "unitários".

Apesar disso, a literatura sempre foi atrás de definições para o conceito de HRD. Desde a década de 1960, mais de 20 definições foram sugeridas (Swanson \& Holton III, 2009; Hamlin, Ellinger \& Beattie, 2008; Weinberger, 1998). Hamlin e Stewart (2011) analisaram diversas dessas definições e chegaram à conclusão de que o desenvolvimento de recursos humanos apresenta quatro propósitos principais:

(i) melhorar a efetividade e o desempenho de indivíduos ou grupos;

(ii) melhorar a efetividade e o desempenho organizacional;

(iii) desenvolver conhecimentos, habilidades e competências;

(iv) aumentar o potencial humano e o crescimento pessoal.

Em uma tentativa de colocar essas ideias juntas, os autores seguem uma declaração sobre o HRD:

O HRD engloba atividades, processos e/ou intervenções planejadas para impactar e
aprimorar a aprendizagem organizacional e individual, para desenvolver o potencial
humano, de forma a melhorar ou maximizar a efetividade e o desempenho tanto no
nível individual ou do grupo/time quanto no nível organizacional; e/ou para
provocar mudanças efetivas no comportamento organizacional ou pessoal e
melhorias dentro e além das fronteiras das empresas, órgãos públicos, organizações
do terceiro setor e qualquer outro tipo de entidade [... $]^{17}$ (Hamlin \& Stewart, 2011, p.
213 , tradução nossa). Já há estudos da literatura que trazem evidência de que intervenções planejadas de HRD podem ter impacto na construção de competências dos funcionários, o que se torna um

\footnotetext{
${ }^{17} \mathrm{HRD}$ encompasses planned activities, processes and/or interventions designed to have impact upon and enhance organisational and individual learning, to develop human potential, to improve or maximise effectiveness and performance at either the individual, group/team and/or organisational level, and/or to bring about effective, beneficial personal or organisational behaviour change and improvement within, across and/or beyond the boundaries (or borders) of private sector (for profit), public sector/governmental, or third/voluntary sector (not-for-profit) organisations, entities or any other type of personal-based, work-based, community-based, society-based, culture-based, political-based or nation-based host system
} 
instrumento fundamental para a melhoria da efetividade organizacional (Potnuru \& Sahoo, 2016).

Este trabalho adota a perspectiva do desenvolvimento individual, normalmente referido na literatura como Treinamento e Desenvolvimento (T\&D), que foca os indivíduos e se conecta com a organização, em complemento à perspectiva do desenvolvimento organizacional que considera o sentido inverso dessa relação. T\&D pode ser entendido com "o processo de desenvolver sistematicamente conhecimento e expertise relacionados ao trabalho com o intuito de melhorar o desempenho"18 (Swanson \& Holton III, 2009, p. 226, tradução nossa). As pessoas que vivenciam o T\&D devem terminar o processo com novos conhecimentos e estarem aptas a fazer melhor as coisas após o programa de treinamento (Zemke, 1990).

O coração do HRD é o aprendizado, não importa qual o paradigma em que se considere tanto para o HRD quanto para o aprendizado (Swanson \& Holton III, 2009). Por essa razão, além de entender o processo de desenvolvimento gerencial sob a perspectiva do treinamento e desenvolvimento (T\&D), é necessária também uma varredura na literatura sobre o aprendizado humano. Ou seja, entender o impacto do uso de jogos digitais para o desenvolvimento de gestores públicos passa por esses dois tópicos, o desenvolvimento gerencial em si, objeto da subseção 2.3.2 e o aprendizado humano, descrito na subseção 2.3.5. Entre essas seções é apresentada uma breve contextualização sobre o uso de jogos e simulações em programas de treinamento (subseção 2.3.3) e o referencial mais utilizado para avaliação de programas de treinamento (subseção 2.3.4), o de Kirkpatrick, que foi a base para a execução dos experimentos desta pesquisa.

\subsubsection{Educação gerencial}

Em geral, quando se fala em educação gerencial, pensa-se em um processo formal, atrelado a cursos oferecidos por universidades, escolas de negócios ou outras instituições. Essa associação decorre, dentre outros fatores, de o desenvolvimento gerencial ter seu início oficial

\footnotetext{
${ }^{18}$ Training and developments (T\&D) is defined as a process of systematically developing work-related knowledge and expertise for the purpose of improving performance.
} 
com o surgimento das primeiras escolas de comércio e de negócios, em meados do século XIX. Constituíam-se nessa época os primeiros lugares em que as pessoas encarregadas de funções de gestão poderiam formalmente aprender como gerenciar.

As primeiras escolas preocupadas com o ensino acadêmico de negócios surgiram nos Estados Unidos (University of Louisiania e University of Winsconsin, respectivamente em 1851 e 1852) e na Europa (Institut Supérieur de Commerce de l'Etat, em Antuérpia, na Bélgica, em 1852 e École Supérieure de Commerce, em Paris, França, em 1854). Atualmente, as escolas de negócio americanas, tais como Harvard, Wharton, Stanford, Columbia, Chicago, Nova Iorque, Darthmouth e MIT, ocupam a liderança no cenário mundial, com destaque em diversos rankings mundiais de MBAs. Há também escolas de destaque, principalmente na Europa, em países como Inglaterra, França, Alemanha e Holanda, que adotam filosofias parecidas com as primeiras, tornando o modelo americano dominante no ensino formal de administração (Engwall, 2007).

Korpiaho, Päiviö e Räsänen (2007), em uma revisão da literatura em três das mais destacadas revistas que tratam do tema de educação e aprendizagem gerencial (The Academy of Management Learning \& Education, The Journal of Management Education, e Management Learning) levantaram cinco concepções alternativas de educação gerencial, além da visão tradicional e do MBA. Não faria sentido, portanto, falar em um modelo americano, uma vez que existem diversas concepções de educação gerencial e muito menos considerar apenas a perspectiva do "balde" de conhecimento, muitas vezes presente quando se fala em um processo de cursos formais para educação gerencial.

As diferentes concepções identificadas pelos autores variam na forma como respondem a quatro questões: (a) quem está sendo educado e por quem?; (b) como se espera realizar a educação?; (c) O que deve ser alcançado e atingido com a educação?; e (d) Por que se justifica concentrar esforços para certos objetivos e para empregar determinados meios na educação? A Tabela 2.7 resume os principais aspectos de interesse para o presente trabalho associados a essas concepções. Por fugir do escopo do tema deste trabalho, a resposta à quarta questão não é apresentada. 
Tabela 2.7 - Concepções da educação gerencial observadas nas publicações de três revistas proeminentes da área de educação e aprendizagem gerencial

\begin{tabular}{|c|c|c|c|c|c|c|c|}
\hline & Tradicional & $\bar{~} \overline{\text { MBA }}$ & $\begin{array}{l}\text { Educação baseada } \\
\text { em ciência }\end{array}$ & $\begin{array}{l}\text { Educação baseada } \\
\text { em competências }\end{array}$ & $\begin{array}{ll}\begin{array}{l}\text { Aprendizado } \\
\text { serviços }\end{array} & \text { de } \\
\end{array}$ & $\begin{array}{l}\text { Educação baseada } \\
\text { em ação }\end{array}$ & $\begin{array}{l}\text { Educação gerencial } \\
\text { crítica }\end{array}$ \\
\hline $\begin{array}{l}\text { Alunos } \\
\text { (quem) }\end{array}$ & $\begin{array}{l}\text { 'carreiristas' } \\
\text { orientados } \\
\text { instrumentalmente }\end{array}$ & $\begin{array}{l}\text { Clientes pagantes, } \\
\text { com poucos anos de } \\
\text { experiência no } \\
\text { trabalho, em busca } \\
\text { de posições } \\
\text { executivas }\end{array}$ & $\begin{array}{l}\text { Submetidos à } \\
\text { qualidade das } \\
\text { teorias (bom/ruim) }\end{array}$ & $\begin{array}{l}\text { Indivíduos com } \\
\text { habilidades pessoais } \\
\text { para aperfeiçoar, } \\
\text { desenvolvendo-se } \\
\text { para tarefas } \\
\text { profissionais }\end{array}$ & $\begin{array}{l}\text { Profissionais e } \\
\text { cidadãos } \\
\text { privilegiados que } \\
\text { aprendem a partir de } \\
\text { encontros com os } \\
\text { menos privilegiados }\end{array}$ & $\begin{array}{l}\text { Profissionais } \\
\text { experientes com } \\
\text { capacidades } \\
\text { reflexivas }\end{array}$ & $\begin{array}{l}\text { Vítimas da } \\
\text { educação, ou } \\
\text { profissionais } \\
\text { potencialmente } \\
\text { responsáveis, } \\
\text { autorreflexivos e } \\
\text { aprendizes de mente } \\
\text { aberta }\end{array}$ \\
\hline $\begin{array}{l}\text { Professores } \\
\text { (por quem) }\end{array}$ & $\begin{array}{l}\text { Especialistas em } \\
\text { subdisciplinas }\end{array}$ & $\begin{array}{l}\text { Prestadores de } \\
\text { serviço }\end{array}$ & $\begin{array}{l}\text { Acadêmicos e } \\
\text { pesquisadores }\end{array}$ & $\begin{array}{l}\text { Pesquisadores, } \\
\text { formadores e } \\
\text { assessores } \\
\text { habilidosos }\end{array}$ & $\begin{array}{l}\text { Cidadãos } \\
\text { interessados e } \\
\text { especialistas em seu } \\
\text { próprio campo, } \\
\text { comprometidos com } \\
\text { o ensino }\end{array}$ & $\begin{array}{l}\text { Motivados a mudar } \\
\text { e construir uma } \\
\text { ponte entre a } \\
\text { academia e a vida } \\
\text { prática do trabalho, } \\
\text { desenvolvedores, } \\
\text { facilitadores e } \\
\text { copesquisadores }\end{array}$ & $\begin{array}{l}\text { Acadêmicos ativistas } \\
\text { e facilitadores }\end{array}$ \\
\hline $\begin{array}{l}\text { Método } \\
\text { (como) }\end{array}$ & $\begin{array}{l}\text { Aulas, casos e } \\
\text { exercícios em } \\
\text { ferramentas, } \\
\text { técnicas e modelos } \\
\text { específicos das } \\
\text { disciplinas }\end{array}$ & $\begin{array}{l}\text { Programa de cursos } \\
\text { modulares em uma } \\
\text { ampla gama de } \\
\text { ferramentas } \\
\text { gerenciais, com } \\
\text { métodos de ensino } \\
\text { tradicionais }\end{array}$ & $\begin{array}{l}\text { Introdução a teorias } \\
\text { robustas e baseadas } \\
\text { em evidências, com } \\
\text { prova de habilidades } \\
\text { de raciocínio, } \\
\text { escrita e leitura. }\end{array}$ & $\begin{array}{l}\text { Exercitar e } \\
\text { demonstrar } \\
\text { habilidades de } \\
\text { trabalho, definidos e } \\
\text { avaliados pelos } \\
\text { professores. }\end{array}$ & $\begin{array}{l}\text { Aplicação de } \\
\text { conhecimento } \\
\text { acadêmico em } \\
\text { projetos sem fins } \\
\text { lucrativos do setor, } \\
\text { em colaboração com } \\
\text { os outros }\end{array}$ & $\begin{array}{l}\text { Aprendizagem pela } \\
\text { ação ou projetos de } \\
\text { pesquisa sobre as } \\
\text { práticas } \\
\text { profissionais, com } \\
\text { suporte de espaços } \\
\text { para reflexão }\end{array}$ & $\begin{array}{l}\text { Fornecendo recursos } \\
\text { intelectuais e } \\
\text { espaços de reflexão } \\
\text { crítica sobre } \\
\text { práticas/ideologias } \\
\text { gerenciais e } \\
\text { experiências de } \\
\text { injustiça }\end{array}$ \\
\hline $\begin{array}{l}\text { Objetivos } \\
\text { (o quê é } \\
\text { alcançado) }\end{array}$ & $\begin{array}{l}\text { Formar } \\
\text { especialistas bem } \\
\text { sucedidos e futuros } \\
\text { gerentes }\end{array}$ & $\begin{array}{l}\text { Atestar o acesso a } \\
\text { cargos executivos e } \\
\text { à profissão, de uma } \\
\text { forma rentável }\end{array}$ & $\begin{array}{l}\text { Formação de } \\
\text { gestores } \\
\text { profissionais, } \\
\text { academicamente } \\
\text { educados e } \\
\text { responsáveis }\end{array}$ & $\begin{array}{l}\text { Formar } \\
\text { profissionais } \\
\text { competentes, } \\
\text { capazes de difundir } \\
\text { e desenvolver as } \\
\text { melhores práticas }\end{array}$ & $\begin{array}{l}\text { Formar cidadãos } \\
\text { educados e } \\
\text { responsáveis, para } \\
\text { uma sociedade } \\
\text { democrática }\end{array}$ & $\begin{array}{l}\text { Formar praticantes } \\
\text { reflexivos ou } \\
\text { autônomos }\end{array}$ & $\begin{array}{l}\text { Formar profissionais } \\
\text { (e intelectuais) } \\
\text { politicamente } \\
\text { conscientes e ativos }\end{array}$ \\
\hline
\end{tabular}

Fonte: Traduzido e adaptado de Korpiaho et al. (2007). 
Se por um lado os autores conseguem lançar luz sobre uma visão limitadora que associa o MBA tradicional como sinônimo de educação gerencial, por outro lado, limitam sua visão ao processo formal de educação gerencial, não ampliando a análise para uma perspectiva mais ampla, a da aprendizagem gerencial. Como destacava Fox (1997) uma década antes, a educação formal é apenas a ponta do iceberg. Esse autor destaca a importância do aprendizado dos gestores na prática. Mesmo assim, a contribuição de Korpiaho et al. (2007) é válida para a compreensão de quais elementos são cruciais no processo de educação de gestores e executivos.

Há mais de uma década já se critica o rumo tomado pelas escolas de negócios, não apenas pela questão da priorização a um ensino formal com forte viés teórico, que deixa a experiência prática de fora da sala de aula, mas também pela excessiva ênfase ao caráter científico da produção dos docentes nessas escolas, que privilegia muito mais a publicação de artigos em revistas academicamente bem conceituadas do que a experiência prática de que tanto os executivos precisam (Bennis \& O’Toole, 2005; Mintzberg, 2006).

De acordo com Bennis e O'Toole (2005), o problema das escolas de negócio decorre da, muitas vezes referida de maneira jocosa, "inveja da física" que parece ter acometido os professores na área de administração. Em áreas como física e economia, continuam os autores, os pesquisadores não precisam se preocupar em treinar praticantes, como o fazem em áreas como direito e medicina. Por isso, a área de administração não deve ser tratada como uma disciplina científica, mas como uma profissão, que, como as outras áreas de ênfase prática, deve basear-se em conhecimento científico, mas não o ter como um fim em si mesmo. Por esse motivo, as intervenções, assim como em outras áreas de ciências aplicadas, por exemplo, a medicina, são tão importantes.

Corroborando essa ideia, Mintzberg (2006) argumenta que um elemento essencial para o desenvolvimento de gestores é a consideração sobre sua experiência na função. As práticas de treinamento e desenvolvimento devem alavancar a experiência dos gestores em sua educação. A reflexão ponderada sobre a experiência, considerando-se ideias conceituais relevantes, segundo o autor, é a chave para que ocorra a aprendizagem gerencial. Essa percepção se alinha com a visão de aprendizagem experiencial de Kolb (1984), que será descrita adiante, na seção sobre aprendizado humano (subseção 2.3.5). 
Somado a isso, Bennis e O’Toole (2005) destacam que a integração de um conhecimento baseado em disciplinas não pode ser deixada a cargo dos estudantes. Por esse motivo, reforçam a importância de infundir nos currículos dos MBAs questões multidisciplinares, práticas e éticas. Em suas próprias palavras, "se a proposta da educação em administração em nível de pós-graduação é desenvolver executivos - líderes - então a faculdade precisa ter expertise em mais do que coleção de fatos"19 (tradução nossa).

Na mesma linha, Barker (2010) argumenta que é a habilidade de integração que diferencia gestores de outros profissionais e é o principal motivo de a educação gerencial não poder ser tratada da mesma maneira que a educação em outras profissões. O autor diz que "a chave aqui é reconhecer que integração não é ensinada, mas aprendida. Ela acontece na mente dos estudantes e não no conteúdo dos módulos do programa [de educação gerencial]"20 (tradução nossa). Assim, as escolas de negócios deveriam ver-se como ambientes de aprendizagem e não como ambientes de ensino nos quais são apresentados conteúdos técnicos e funcionais aos alunos.

Contudo, o que se pode observar, tanto nas críticas de Bennis e O’Toole (2005) e de Barker (2010), quanto na tipologia de Korpiaho et al. (2007), é uma vinculação da aprendizagem gerencial ao processo que ocorre nas escolas de negócios, ou seja, dependente de um local físico (mesmo que essas instituições ofereçam modalidades de cursos a distância) e com a presença de professores (mesmo que desempenhando variados papéis). Esse é um paradigma excessivamente centrado no conceito de ensino e não no aprendizado de administração.

Como destaca Thorpe (1990, p.3, tradução nossa), "um dos objetivos da aprendizagem gerencial é modificar as crenças e as 'teorias em uso' dos gestores"21. O autor enfatiza, porém, que, independentemente de acontecer dentro ou fora de cursos, o desenvolvimento gerencial tem, em última instância, o objetivo de melhorar a efetividade do negócio em que os gerentes estão inseridos.

\footnotetext{
19 "If the purpose of graduate business education is to develop executives-leaders - then the faculty must have expertise in more than just fact collection".

${ }^{20}$ The key here is to recognize that integration is not taught but learned. It takes place in the minds of the students rather than in the content of program modules.

${ }^{21}$ One aim of management learning is to modify a manager's beliefs and "theories in use".
} 
Dessa forma, fica claro nesse ponto que o desenvolvimento gerencial engloba todo tipo de atividade que faça o gerente aprender e, consequentemente, melhorar seu desempenho no trabalho. Na literatura, um aspecto fundamental evocado para a eficácia do processo de aprendizagem gerencial e que não necessariamente está atrelado à presença do executivo em uma sala de aula, é a experiência, assim como a reflexão crítica sobre o dia a dia de trabalho (Gray, 2007; Mintzberg, 2006; Kayes, 2002; Cunliffe, 2002; Reynolds, 1998).

Prozesky (2000) destaca seis características da aprendizagem: (1) ela pode ser formal ou informal; (2) além de conhecimento e fatos, habilidades e atitudes também podem ser aprendidas; (3) as pessoas aprendem de diferentes maneiras; (4) o aprendizado pode ser superficial ou profundo (apenas memorização versus colocar em prática o que foi aprendido); (5) a motivação é importante para o aprendizado; e (6) o aprendizado continua por toda a vida da pessoa (no mínimo de maneira informal).

Desses pontos, um aspecto de interesse no tocante à presente pesquisa é o segundo, que traz a já consagrada visão de que o aprendizado não se restringe ao conhecimento propriamente, mas também envolve habilidades e atitudes. Essa visão aparece em Thorpe (1990), que destaca que o processo de aprendizagem e os métodos de ensino podem variar de acordo com o que se quer aprender.

Segundo esse autor, a aprendizagem de fatos e técnicas (conhecimento), regida por um processo cognitivo e intelectual (e apenas uma parte do desenvolvimento gerencial), pode ser feita por meio de métodos que utilizem o tradicional audiovisual (presencial ou a distância). Já a mudança de atitudes passaria por um processo afetivo e emocional com uso de treinamentos que considerem a psicodinâmica, como o aprendizado pela ação (action learning). No caso do desenvolvimento de habilidades, a prática é o método recomendado para o aprendizado. Isso pode ser feito por meio de estudos de caso, business games, projetos de consultoria e também o aprendizado pela ação (Figura 2.17). Essas categorias e processos de aprendizado apresentados por Thorpe (1990) são variações dos chamados domínios do aprendizado, trazidos por Bloom, Engelhart, Furst, Hill e Krathwohl (1974) há mais de meio século, em sua taxonomia de objetivos educacionais, datada de 1956. 


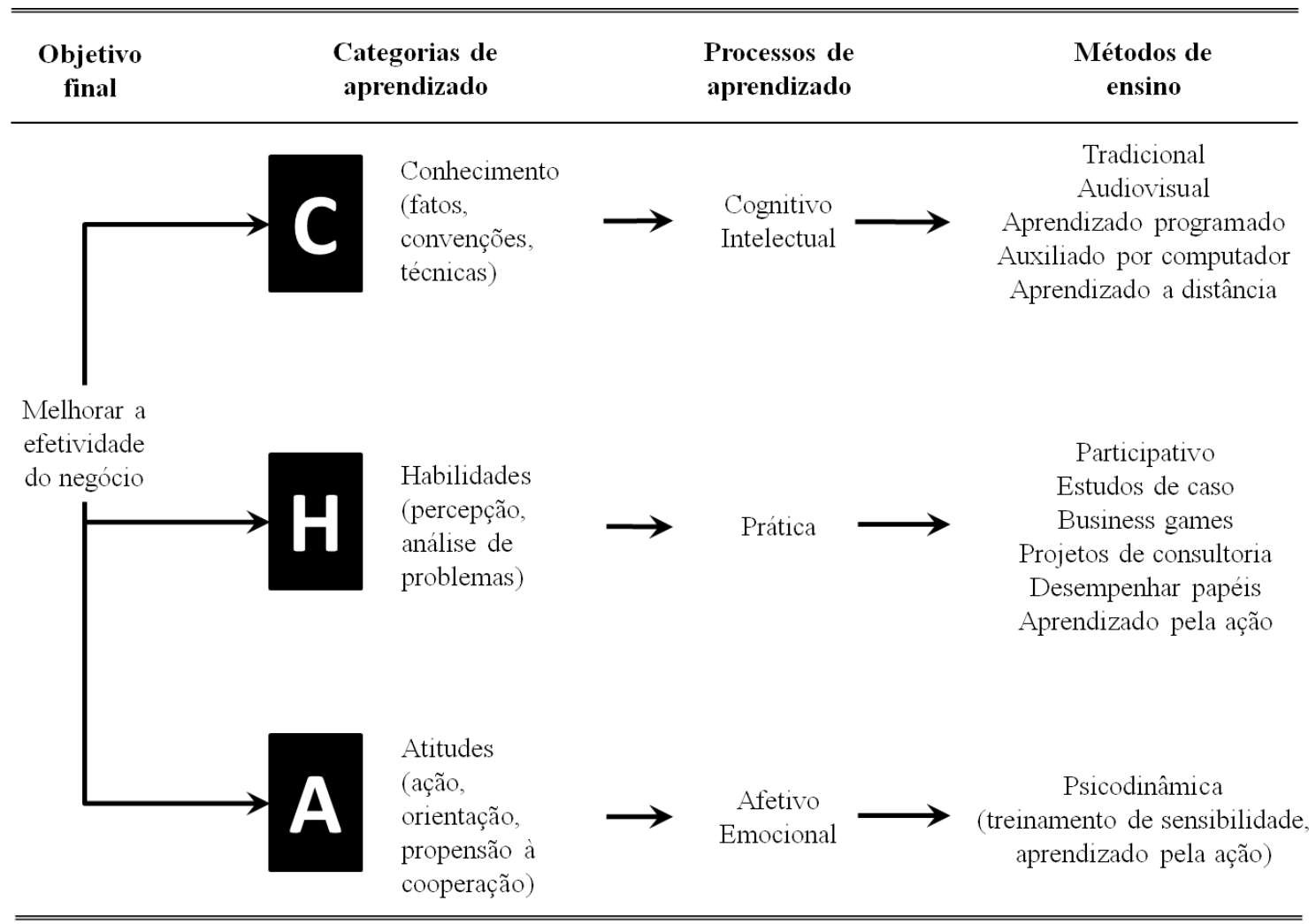

Figura 2.17 - Diferentes métodos de ensino e diferentes processos de aprendizagem em função do objetivo do desenvolvimento gerencial.

Fonte: traduzido e adaptado de Thorpe (1990)

Mais recentemente, em um estudo para compreender como os gestores desenvolvem sua capacidade e habilidades de gestão, Becker e Bish (2017) apresentam cinco importantes achados para a pesquisa e a prática do desenvolvimento gerencial: (1) embora os gestores reconheçam que grande parte de seu desenvolvimento decorre de práticas informais e valorizem o aprendizado formal, eles revelam que os meios formais e informais devem existir em paralelo. Assim, (2) o seu desenvolvimento pode ser mais efetivo quando o aprendizado por métodos formais e informais não são vistos como entidades separadas, mas são combinados estrategicamente para ampliar a possibilidade de aprendizado. Além disso, (3) os gestores relatam que o aprendizado em situações sociais, isto é, quando têm oportunidade de estar e interagir com outros gestores, é preferido. Ainda, (4) a consciência dos gestores de que muito de seu aprendizado se dá por "tentativa e erro" e pela prática reforça a essência da aprendizagem experiencial desenvolvida por Kolb (1984). Assim, oportunidades que permitam a reflexão sobre a experiência são fundamentais. Por fim, as autoras reforçam que (5) os fatores de contexto dos gestores precisam ser levados em conta na elaboração de programas de desenvolvimento gerencial. 
Nesse sentido, McGurk (2009) traz evidências de que intervenções para o desenvolvimento de gestores (no caso de seu estudo, gestores de nível intermediário na hierarquia) só podem ser efetivas se forem capazes de refletir de forma precisa as realidades do gestor e seu contexto. Em um artigo posterior (McGurk, 2010), o autor também destaca que programas de desenvolvimento tradicionais levam a um maior compromisso com objetivos prescritos, mas contribuem pouco para a mudança estratégica. Os programas individualizados de liderança, no entanto, tendem a trazer benefícios individuais, mas pouco ou nenhum impacto no negócio. Por fim, McGurk (2010) mostra que abordagens coletivas emergentes ao desenvolvimento de liderança podem contribuir de forma significativa (nem sempre deliberadamente) para a mudança estratégica.

Porém, para maximizar o impacto sobre a organização, entretanto, os programas de desenvolvimento gerencial precisam ser sustentados de forma contínua nas organizações, levando em conta tanto o papel dos gestores quanto a estratégia da organização, por meio de práticas que permitam refletir sobre a definição de objetivos e sua revisão (McGurk, 2010).

Esses aspectos são relevantes para o presente trabalho, pois indicam que mesmo as novas tecnologias devem ser consideradas em um conjunto de práticas formais e informais em um programa de treinamento. Por essa razão, a avaliação o impacto de um jogo digital sobre o desenvolvimento de gestores públicos deve ser feita em um contexto de treinamento que mescle esses fatores. O jogo, como elemento de aprendizado informal, pode compor um conjunto com o aprendizado formal. Desenha-se aqui o formato de um curso que utilize um jogo para a resposta do problema de pesquisa proposto. Na seção seguinte é trazido um referencial para a construção desse conjunto: um treinamento baseado em simulações.

\subsubsection{Treinamento e Desenvolvimento com jogos e simulações}

Os treinamentos baseados em simulações (SBT - Simulation Based Training) são ideais para programas de formação de gestores, pois permitem o desenvolvimento de habilidades de gerenciamento de uma forma mais rápida do que os treinamentos tradicionais (Salas et al., 2009). 
Salas et al. (2009) enfatizam que "ainda há uma relativa falta de estudos empíricos examinando o contexto sobre os quais os treinamentos baseados em simulações (SBT) são mais efetivos comparados a outras abordagens de treinamento"22. Para Bell, Kanar e Koslowski (2008), simulações são, em geral, qualquer ambiente artificial ou sintético criado para lidar com a experiência de um indivíduo (ou equipe) com a realidade. Nesse sentido, elas podem ser pensadas de forma mais ampla, numa categoria que inclui os jogos.

Em consonância com a discussão da seção precedente, o treinamento é visto como a aquisição de atitudes, conceitos, conhecimentos, regras ou habilidades que devem resultar na melhoria do desempenho (Goldstein, 1991). Assim, o treinamento baseado em simulações (SBT), de acordo com Salas et al. (2008), funde essas ideias, ou seja, é qualquer tipo de ambiente prático sintético criado de forma a transmitir essas competências que irão melhorar o desempenho da pessoa treinada. As simulações não precisam necessariamente ser eletrônicas (em computador), podendo também ser físicas ou teatrais. No entanto, sob essa perspectiva, podese perceber pelas descrições da Tabela 2.5 que o SBT e game-based learning são intimamente ligados.

Contudo, como destacam Salas et al. (2009, p. 564), "se o treinamento for mal projetado ou não considerar as competências necessárias, nem o jogo mais divertido do mundo será efetivo como uma intervenção de treinamento" ${ }^{, 23}$. Por isso, seguem os autores, todos os aspectos da concepção do treinamento devem ser levados em conta quando se estiver desenvolvendo (ou selecionando) uma intervenção com simulação.

Salas et al. (2009) relatam ainda que a literatura associada ao uso de simulações para a educação gerencial em geral se concentra em descrever os tipos de simulações utilizadas, mas não traz nenhum tipo de orientação sobre como utilizá-las de modo eficaz. Tentando preencher essa lacuna, os autores propõem uma estrutura orientativa para a construção de treinamentos baseados em simulações (SBT) definida em estágios que devem incluir (1) a análise das necessidades de treinamento, (2) o desenvolvimento de competências para tarefas, (3) a especificação dos objetivos de treinamento, (4) o desenvolvimento dos eventos de

\footnotetext{
${ }^{22}$ there is still a relative lack of empirical studies examining the context under which SBT is most effective compared to other training approaches

${ }^{23}$ if the training is badly designed or does not address the necessary competencies, the most entertaining game in the world will not be effective as a training intervention.
} 
treinamento, (5) o desenvolvimento de medidas, (6) o diagnóstico do desempenho e (7)

feedback e entrevistas. Seguindo essa linha, os autores elaboraram orientações com dicas de implementação de um SBT (Tabela 2.8).

Tabela 2.8 - Diretrizes e Dicas de Implementação de um SBT em Educação Gerencial

\section{Orientação}

1. Conheça suas competências: reúna as necessidades de aprendizagem dos alunos de gestão.

2. SBT não é uma panaceia: equilibre necessidades de aprendizado e custos.

3. Leve em conta as características dos estudantes quando escolher uma simulação.

4. Fidelidade no SBT gerencial: mais nem sempre é melhor.

5. Ofereça feedback detalhado focado no aprendizado com frequência.

6. Avalie o SBT: Meça diretamente os resultados (outcomes) do aprendizado.

7. Medidas de desempenho: incorpore e automatize dentro da simulação.

8. Antes, durante e depois: adote uma abordagem sistêmica ao SBT gerencial.
Dicas de implementação

- Aproveite as descrições do curso para informar as necessidades de aprendizagem.

- Avalie os níveis atuais de habilidade nos estudantes para informar as necessidades de aprendizagem.

- Pergunte aos estudantes diretamente quais competências eles precisam desenvolver.

- Use o SBT quando as competências desejadas são complexas, comportamentais ou baseadas em habilidades.

- Considere métodos baseados em aulas expositivas para treinamento de conhecimentos declarativos simples.

- Implemente o SBT o mais cedo possível na educação gerencial; estudantes com menos habilidades vão ganhar mais com a simulação.

- Use as informações de necessidades de aprendizagem para assegurar que o SBT foca em competências que são subdesenvolvidas naquele conjunto particular de estudantes.

- Use o menor nível de fidelidade necessário para cada necessidade de treinamento em particular.

- Foque no aumento da fidelidade cognitiva em vez do realismo mundano.

- Vincule o feedback diretamente aos objetivos de aprendizagem.

- Ofereça feedback diagnóstico que descreva as causas do desempenho efetivo e inefetivo (ex: explicação de por que uma escolha é errada, como desempenhar uma tarefa apropriadamente).

- Ofereça feedback em múltiplas instâncias ao longo do treinamento.

- Meça os resultados (outcomes) do aprendizado, além dos resultados de reação de forma a avaliar a efetividade da simulação.

- Considere todas as três categorias de resultados do aprendizado (resultados baseados no cognitivo, nas habilidades e no afetivo) quando desenvolver medidas da efetividade da simulação.

- Crie medidas de desempenho para avaliar os objetivos de aprendizagem e as competências educacionais.

- Incorpore medidas de desempenho na simulação da maneira mais discreta possível.

- Use medidas de desempenho automáticas (ex: número de erros registrado pelo programa de computador) sempre que possível.

- Assegure que os estudantes estão preparados para a simulação.

- Ofereça um ambiente de apoio para a simulação.

- Incentive os estudantes a se entusiasmarem com a simulação.

- Ofereça oportunidades para a prática após a simulação estar completa. 
Ainda, três condições são importantes para o uso bem sucedido de jogos e simulações para o aprendizado: (1) a especificidade do jogo, (2) a integração no curso e (3) o papel do instrutor/facilitador (de Smale, Overmans, Jeuring \& van de Grint, 2015). Por esse motivo, as considerações sobre a construção de um SBT se tornam relevantes no âmbito desta pesquisa. É preciso garantir que a intervenção que se destina à avaliação do impacto do uso de jogos digitais (simulação em sentido amplo) seja consistente no sentido de cobrir os aspectos já sabidos na literatura.

Outro aspecto importante a ser considerado quando se pensa em uma intervenção para responder ao problema de pesquisa deste trabalho é a avaliação do treinamento estruturado em si. A próxima subseção apresenta o referencial mais utilizado para a avaliação de programas de treinamento, o modelo de quatro níveis proposto por Kirkpatrick (1994). Ainda, são apresentadas as formas escolhidas para avaliar o treinamento nos níveis sugeridos por esse autor, deixando a questão específica do aprendizado para ser discutida em uma subseção à parte (2.3.5).

\subsubsection{Avaliação de programas de treinamento e desenvolvimento}

Avaliar o resultado de programas de treinamento e desenvolvimento envolve coletar informações sobre os resultados obtidos, de forma a analisá-los e avaliá-los, com vistas a aprimorar os treinamentos futuros e, mais do que isso, buscar saber qual a contribuição do programa para o desempenho organizacional e qual o retorno sobre o investimento realizado, à luz das necessidades da organização. A avaliação de treinamento é, portanto, a análise sobre o valor de um sistema de treinamento tanto em termos sociais quanto financeiros (Pineda, 2010).

Quando se fala em avaliação de treinamento, o modelo de Kirkpatrick, que foi publicado pela primeira vez em 1959 (Kirkpatrick \& Kirkpatrick, 2009), tem sido o mais amplamente adotado por organizações (Kennedy, Chyung, Winiecki \& Brinkerhoff, 2014). O modelo se baseia em quatro níveis de resultado dos programas de treinamento: 
1. Reação: O quão favoráveis os participantes reagiram à instrução; $O$ quanto eles gostaram de um programa em particular. Também conhecido como avaliação de "carinhas" (felizes ou tristes).

2. Aprendizado: O quão bem os participantes aprenderam os conhecimentos, habilidades ou atitudes durante a instrução; inclui os indicadores quantificáveis do aprendizado utilizados durante o curso ou treinamento.

3. Comportamento: Em que grau os novos conhecimentos e habilidades adquiridos no treinamento são aplicados no trabalho ou resultam em melhora do desempenho no trabalho. Algumas vezes referenciado como 'transferência'.

4. Resultados: Até que ponto a instrução atinge o impacto pretendido no resultado do trabalho; qual o impacto do treinamento sobre os objetivos e metas organizacionais. Mais do que ser relacionado ao retorno sobre investimento (ROI), pode ser considerado como o Retorno sobre Expectativas (ROE).

(Kirkpatrick, 1994; Bates, 2004; Keneddy et al., 2014; Paull, Whitsed e Girardi, 2016)

Os dois primeiros níveis do modelo são os mais amplamente mensurados pelas organizações, muitas vezes, focando-se apenas, ainda, no nível da reação (Éboli, 2015; 2012; Hourneaux Jr, Freitas-Dias \& Éboli, 2013; Kirkpatrick \& Kirkpatrick, 2009). No Brasil, enquanto 73\% das empresas que possuem programas de educação corporativa avaliam sempre seus treinamentos em relação ao primeiro nível, 18\% sempre avaliam o segundo nível e apenas $6 \%$ e 4\% sempre avaliam os níveis 3 e 4, respectivamente (Éboli, 2015).

Os níveis mais altos do modelo são, em geral, mais difíceis de avaliar e, por esse motivo, são deixados de lado. Pulichino (2007, como citado em Muhammad, 2016, p.12) destaca como principais razões para a não avaliação dos níveis comportamental e de resultados a dificuldade de obtenção dos dados necessários para avaliação desses níveis, a falta de suporte da gestão e o tempo e alto custo necessários para sua avaliação. Esse resultado é corroborado pela pesquisa de Kennedy et al. (2014), que ainda adicionam como fator explicativo para a ausência de avaliações dos níveis mais altos a falta de conhecimento e de expertise dos profissionais de treinamento sobre como avaliá-los.

Os motivos da popularidade do modelo de Kirkpatrick são discutidos há um bom tempo na literatura. Bates (2004), por exemplo, destaca três motivos para a ampla adoção do modelo 
pelas organizações. Primeiramente, o modelo supre a necessidade dos profissionais de treinamento de poder avaliar seus programas de uma forma sistemática. O modelo trouxe um sistema direto e uma linguagem para se falar de resultados de programas de treinamento e, ainda, que tipo de informações devem ser obtidas para avaliar o grau de atingimento de seus objetivos.

Em segundo lugar, o destaque dado por Kirkpatrick ao quarto nível, insistindo que esse é o aspecto mais importante dos programas de treinamento, trouxe meios para que as organizações os passassem a olhar em termos do negócio. O treinamento só funciona se puder contribuir para o sucesso organizacional.

Como terceiro ponto de sucesso do modelo, o autor ainda aponta, criticamente, as simplificações que ele faz do processo complexo de treinamento: (1) o modelo representa um guia de questões que devem ser feitas e os critérios que devem ser apropriados para avaliar o treinamento; (2) o modelo reduz a demanda por medidas de avaliação dos programas; (3) os dados podem ser coletados após o treinamento (ou no máximo antes para efeitos comparativos); (4) como as conclusões sobre o treinamento são baseadas apenas em medidas de desempenho, ele reduz consideravelmente o número de variáveis com que os avaliadores devem se preocupar. Ou seja, segundo Bates (2004), "o modelo elimina a necessidade de medir ou de levar em conta a complexa rede de fatores que cercam o processo de treinamento e que interagem com ele",24 (p.342).

Embora existam críticas ao modelo de Kirkpatrick, ele deve ser considerado como tal: um modelo. E como qualquer modelo apresenta imperfeições. Bates (2004) afirma que três grandes limitações do modelo são (1) sua incompletude, (2) a premissa de causalidade e (3) a premissa de que as informações são mais relevantes à medida que se sobe nos níveis avaliados.

Porém, os benefícios advindos de sua aplicação devem superar as desvantagens. É o que apontam Paull et al. (2016). Em seu recente estudo sobre a efetividade desse modelo para a avaliação dos resultados de um modelo de aprendizado focado em prover oportunidade de

\footnotetext{
${ }^{24}$ the model eliminates the need to measure or account for the complex network of factors that surround and interact with the training process
} 
interação entre pares, aos autores concluíram que o modelo de quatro níveis de Kirkpatrick é adequado para avaliação de intervenções educacionais, contudo, deve ser sempre adaptado às circunstâncias e às configurações utilizadas.

Existem modelos alternativos ao de Kirkpatrick, que na verdade o complementam, como o modelo de seis níveis de Pineda (2010). Os seis níveis propostos pela autora são (1) satisfação dos participantes, (2) aprendizado, (3) coerência pedagógica, (4) transferência do treinamento para o ambiente de trabalho, (5) impacto sobre os objetivos organizacionais e (6) lucratividade do treinamento para a organização. Ainda, Pineda (2010) sugere a avaliação durante quatro períodos: antes, durante, imediatamente no término e algum tempo depois do treinamento. Outros modelos complementares bastante conhecidos são os de Hamblin (1978), que adiciona um quinto nível, o de "valor final" e denomina o quarto nível como "mudança organizacional", e o de Phillips (1996), que introduz como quinto nível a medida de retorno sobre o investimento (ROI).

Embora sejam acréscimos válidos, a aplicação de um modelo mais complexo como o de Pineda (2010), além de não ser amplamente validada pela literatura, poderia tornar a execução inviável considerando-se o tempo disponível para a realização da pesquisa e, principalmente, a carga sobre os participantes do treinamento. Além disso, os níveis adicionais propostos por Hamblin (1978) e Phillips (1996) apresentam uma métrica mais fortemente aplicada a empresas do setor privado. Assim, o trabalho foca em incorporar, na medida do possível, o modelo consagrado de quatro níveis de Kirkpatrick, com medidas antes, imediatamente depois e passado algum tempo depois do treinamento.

Para este trabalho, o nível que apresenta maior relevância e é explorado em mais detalhes é o do aprendizado, que será detalhado na próxima subseção. A reação pode ser obtida por meio de questionários usuais de avaliação de treinamentos, mas também pode ser complementada por instrumentos mais elaborados, como o modelo ARCS, desenvolvido por Keller (1987a; 1987b; 1987c; 1999).

Esse modelo foi originalmente pensado para avaliar a motivação dos estudantes com métodos tradicionais de ensino e aprendizagem, mas tem tido seu escopo de aplicação ampliado, especialmente com o crescimento de formas de instrução com o uso de tecnologia, como as 
com softwares ou modalidades a distância (Loorbach, Peters, Karreman \& Steehouder, 2015; Astleitner \& Hufnagl, 2003; Bellon \& Oates, 2002; Chang \& Lehman, 2002).

De acordo com Keller (2010), o Modelo de Design Motivacional ARCS baseia-se em uma extensa revisão da literatura para agrupar a motivação em quatro construtos: Atenção, Relevância, Confiança e Satisfação, de cujas iniciais constrói-se o acrônimo que o nomeia. A ideia central do modelo é a de que há uma relação de antecedência entre os construtos. $\mathrm{O}$ primeiro passo é que a pessoa possa ter sua curiosidade e interesses estimulados (Atenção) para que, em seguida, antes de ficar motivada a aprender, acredite que a instrução oferecida se relaciona com seus objetivos e motivos pessoais (Relevância). Mesmo que a pessoa considere o conteúdo relevante e esteja curiosa para aprender, ainda assim ela precisa ter expectativa de que vai ser bem sucedida em seu aprendizado (Confiança). Atendidos esses antecedentes, a pessoa vai estar motivada para aprender e, como consequência, pode ter sentimentos de satisfação com o processo ou com os resultados das atividades de aprendizado (Satisfação). A Figura 2.18 traduz essa ideia.

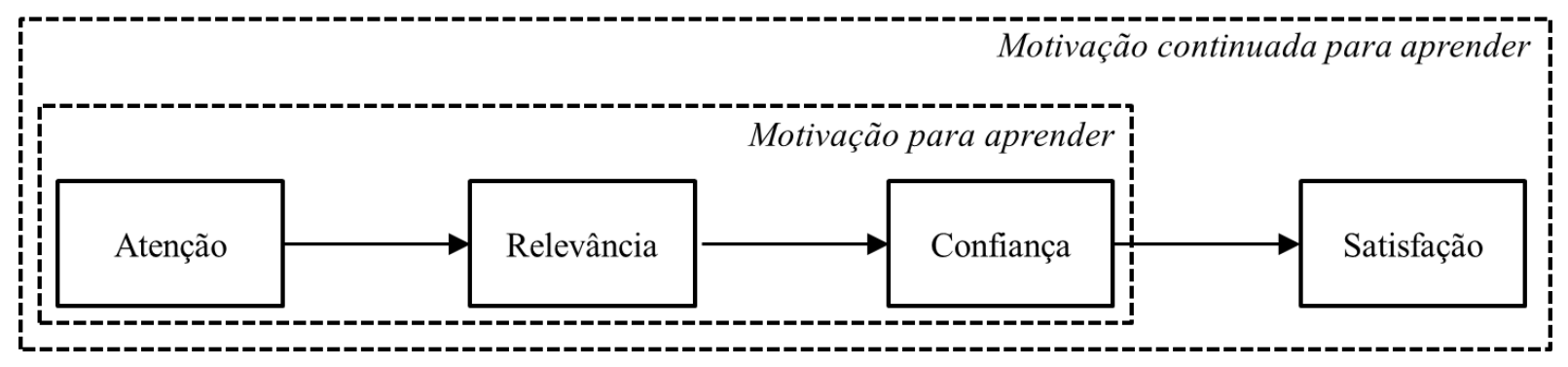

Figura 2.18 - Modelo motivacional ARCS

Fonte: traduzido de Loorbach et al. (2015).

O modelo baseia-se ainda em três pressupostos no que tange ao funcionamento de um método instrucional: (1) o nível de motivação do estudante pode ser influenciado por fatores externos (motivação extrínseca), (2) a motivação pode influenciar o desempenho e (3) o processo de produção do conhecimento estruturado e sistematizado pode afetar a motivação, que pode ser mensurada (Keller, 1999).

Um dos instrumentos desenvolvidos por Keller (2010) foi o Levantamento de Motivação sobre Materiais Instrucionais, o IMMS (do inglês, Instructional Materials Motivation Survey), que se propõe a medir a reação das pessoas a materiais instrucionais à luz do modelo ARCS. O instrumento desenvolvido originalmente conta com 36 assertivas cobrindo cada um dos 
quatro construtos do modelo. Uma versão reduzida foi testada e validada por Loorbach et al. (2015) no contexto de materiais tecnológicos. Essa versão é apresentada no Apêndice C e serviu de referência para elaboração de parte dos instrumentos de medida utilizados nos experimentos da presente pesquisa, conforme pode ser visto no capítulo sobre o método (Capítulo 3).

A mudança de comportamento requer um tempo significativo após o treinamento para ser observada e por esse motivo foi tratada neste trabalho investigando-se qualitativamente seus efeitos. Existem instrumentos que permitem a verificação de intenções e a predisposição para comportamentos, como a Teoria do Comportamento Planejado, de Ajzen (1991). Porém o desenvolvimento adequado de um instrumento capaz de fazer esse levantamento seria, em si, objeto de outra pesquisa do porte desta, envolvendo diversas etapas para sua construção e validação. Por essa razão optou-se por abordar esse nível apenas qualitativamente.

O mesmo raciocínio se aplica ao quarto nível de avaliação (resultado). Porém, como será visto no Capítulo 4, tentou-se verificar, após o treinamento, se os participantes percebem de forma diferente o impacto que ele terá sobre os resultados futuros.

\subsubsection{Aprendizado: uma visão geral}

Normalmente, quando se pensa em aprendizagem, associa-se o conceito à ideia de aquisição de conhecimento. É no contexto da psicologia educacional, no entanto, que aparecem as primeiras definições de aprendizagem (learning) sistematicamente associadas à ideia de mudança de comportamento (Stones, 1966). Em uma visão mais moderna, também afastada da clássica noção de aprendizado como aquisição de conhecimento, pode-se pensar no aprendizado como um processo que "leva a mudanças da capacidade relativamente duradouras, sejam elas de caráter motor, cognitivo, psicodinâmico (i.e. emocional, motivacional ou atitudinal) ou social e que não são devidas a maturação genético-biológica" ${ }^{25}$ (Illeris, 2003, p. 397). Essa visão é praticamente a mesma apresentada por Gagné (1976), que

25 lead to relatively lasting changes of capacity, whether they be of a motor, cognitive, psychodynamic (i.e. emotional, motivational or attitudinal) or social character, and which are not due to genetic-biological maturation. 
diz que "a aprendizagem é uma modificação na disposição ou na capacidade do homem, modificação essa que não pode ser retirada e que não pode ser simplesmente atribuída ao processo de crescimento" (p. 3).

Uma definição complementar para aprendizagem é a de Shuell (1986), que considera três aspectos: (1) uma mudança no comportamento ou na habilidade de fazer alguma coisa (2) como resultado de uma experiência e (3) que seja duradoura. Essas ideias são sintetizadas por Schunk (1991): “aprendizado é uma mudança permanente no comportamento ou na capacidade de se comportar de uma dada maneira que resulta da prática ou de outras formas de experiência"26 (p. 2, tradução nossa). No entanto, a noção de que o aprendizado se caracteriza por mudanças no comportamento não deve ser confundida com a perspectiva comportamentalista (ou behaviorista) sobre o aprendizado humano (Anderson \& Krathwohl, 2001).

Já o conceito de ensino (teaching) é definido por Cohen (2011) como uma atividade deliberada para aumentar a probabilidade de os estudantes desenvolverem habilidades e conhecimentos. $\mathrm{O}$ autor ressalta que ensino e aprendizagem são esforços distintos. Em suas palavras, "Muito do aprendizado depende de nenhum ensino cuidadoso, e muito ensino cuidadoso não produz aprendizado" ${ }^{27}$ (p. 25, tradução nossa).

É nesse sentido que Haramati (2000) destaca que "há uma diferença significativa entre ensino e aprendizagem, há muito ensino e não muita aprendizagem"28 (p. 119, tradução nossa). O autor, em um artigo em que se preocupa com o ensino de fisiologia, mas que traz insights igualmente importantes para qualquer área do conhecimento, salienta que o foco dos professores deve ser no aprendizado e para tal se deve lançar mão de formatos que engajem as pessoas para facilitar o aprendizado, tais como aulas, grupos de discussão e sessões de aprendizado baseado em problemas.

O autor ainda contrapõe duas visões metafóricas do aprendizado, dizendo que não se trata de encher baldes do conhecimento das pessoas, mas sim acender a chama dos estudantes com

\footnotetext{
${ }^{26}$ Learning is an enduring change in behavior, or in the capacity to behave in a given fashion, which results from practice or other forms of experience.

${ }_{27}^{27}$ Much learning depends on no attentive teaching, and much attentive teaching produces no learning.

${ }^{28}$ There is a great difference between teaching and learning, there is too much teaching and not enough learning.
} 
relação ao desenvolvimento profissional. Essa ideia recupera um pouco do que já falava o educador Paulo Freire (1983) sobre a educação bancária, que vê os estudantes como recipientes vazios nos quais os professores depositam seu conhecimento (Prozesky, Stevens \& Hubley, 2006) e recupera a metáfora trazida por Thorpe (1990) sobre o balde do conhecimento que os executivos carregam e que deve ser preenchido ao longo de sua carreira, discutida na subseção 2.3.2. Ao negar tal comparação, Haramati (2000) enfatiza que os gestores devem desenvolver-se pelo uso de atividades relacionadas ao trabalho (work-related activities).

É para desvincular os conceitos de ensino e aprendizagem dessa ideia limitada do processo que Lujan e DiCarlo (2006), também no contexto da educação para a área da saúde, ressaltam que "aprender não é depositar um conjunto de fatos na memória, mas a habilidade de usar recursos para encontrar, avaliar e aplicar informação"29 (p. 17, tradução nossa). A questão fundamental, segundo esses autores, é ajudar os estudantes a se tornarem ativos, independentes e solucionadores de problemas. Para tal, sugerem justamente que o uso de aulas expositivas de formato passivo tenha seu uso reduzido. Somado a isso, deve-se reduzir a quantidade de informações factuais que deveriam ser memorizadas. A solução para criar um amor pelo aprendizado, que inspire e engaje os estudantes, segundo os autores, passa, portanto, pela utilização formas alternativas que favoreçam o aprendizado. Essas formas alternativas incluiriam atividades colaborativas de aprendizado, modelos interativos, jogos educacionais e aprendizado baseado em experimentos.

\subsubsection{Referenciais para classificar o aprendizado}

Na década de 1950, o professor da Universidade de Chicago, Benjamin S. Bloom, coordenou um trabalho para criar uma taxonomia de objetivos educacionais. Esse trabalho, que tinha por objetivo auxiliar professores e especialistas em currículos a classificar objetivos de ensino, facilitando o planejamento de experiências de aprendizagem e o preparo de programas de

\footnotetext{
${ }^{29}$ Learning is not committing a set of facts to memory, but the ability to use resources to find, evaluate, and apply information.
} 
avaliação, tendo ainda como um dos principais norteadores a finalidade de facilitar a comunicação (Bloom et al., 1974).

O trabalho coordenado por Bloom, que foi ainda revisado no início do século (Anderson \& Krathwohl, 2001), trouxe importantes insights para qualquer trabalho que se relacione com a área educacional. Com a presente pesquisa não é diferente e, aqui, é dada preferência à versão revisada. Inicialmente, a taxonomia desenvolvida por Bloom apresenta três domínios do conhecimento, o cognitivo, o afetivo e o psicomotor. O domínio cognitivo trata da memória, do desenvolvimento das habilidades intelectuais. É associado ao conhecimento. Já o domínio afetivo refere-se às mudanças de interesse, às atitudes, aos valores. Por fim, o domínio psicomotor diz respeito essencialmente às habilidades da pessoa (Bloom et al., 1974).

É interessante notar que os três domínios relacionados por Bloom fazem referência ao conhecimento (domínio cognitivo), habilidades (domínio psicomotor) e atitudes (domínio afetivo), que são os três pilares que dão a ideia de competência na literatura de administração (Dutra, 2004). É chamado pelo acrônimo CHA (ou KSA - Knowledge, Skills and Attitudes, no inglês). E o destaque a esse conceito é trazido, pois faz referência imediata à abordagem de Thorpe (1990) na questão do aprendizado gerencial (Figura 2.17), que preferiu vincular cada um dos domínios a métodos de ensino, uma visão um tanto restrita do processo de aprendizado. Além disso, se encarada de maneira estanque, essa categorização pode mais atrapalhar do que ajudar a compreensão dos fenômenos ligados ao aprendizado.

A taxonomia original de Bloom falava em três níveis de conhecimento, factual, conceitual e procedural e, em sua revisão por Anderson e Krathwohl (2001), um quarto nível foi adicionado, o metacognitivo. A Tabela 2.9 apresenta uma breve descrição de cada um dos níveis.

Tabela 2.9 - Os principais tipos de conhecimento

\begin{tabular}{ll}
\hline \hline Conhecimento factual: & $\begin{array}{l}\text { Os elementos básicos que os estudantes devem saber para } \\
\text { estar inteirados com uma disciplina ou resolver problemas }\end{array}$ \\
Conhecimento conceitual: & $\begin{array}{l}\text { As inter-relações entre os elementos básicos dentro de uma } \\
\text { estrutura mais ampla que os permitem funcionar juntos } \\
\text { Como fazer alguma coisa, métodos de investigação e } \\
\text { critérios para usar habilidades, algoritmos, técnicas e } \\
\text { métodos }\end{array}$ \\
Conhecimento procedural: & $\begin{array}{l}\text { Conhecimento da cognição em geral assim como } \\
\text { consciência e conhecimento da própria cognição da pessoa. }\end{array}$ \\
\hline \hline
\end{tabular}

Fonte: traduzido e adaptado de Anderson \& Krathwohl (2001). 
A taxonomia de Bloom traz ainda seis categorias do processo cognitivo, que na versão revisada por Anderson \& Krathwohl (2001) são representadas por seis verbos, colocados geralmente em ordem crescente de grau de dificuldade: lembrar, entender, aplicar, analisar, avaliar e criar. A Tabela 2.10 apresenta uma descrição das categorias, bem como apresenta exemplos de declarações objetivos de aprendizado associados a cada categoria.

Tabela 2.10 - As seis categorias do processo cognitivo

\section{Lembrar: recuperar conhecimento relevante da memória de longo prazo}

\subsection{Identificar ex: identificar as datas de eventos históricos importantes}

1.2 Recordar ex: recordar as datas de eventos históricos importantes

2. Compreender: construir significado a partir de mensagens instrucionais, incluindo comunicação verbal, escrita e gráfica

\subsection{Interpretar}

2.2 Exemplificar

2.3 Classificar

2.4 Sumarizar

2.5 Inferir

2.6 Comparar

2.7 Explicar

ex: parafrasear falas e documentos importantes

ex: dar exemplos de vários estilos de pintura artística ex: classificar casos de desordem mental observados ou descritos ex: escrever um breve resumo dos eventos descrito em vídeos ex: ao aprender uma língua estrangeira, inferir princípios gramaticais a partir de exemplos ex: comparar eventos históricos a situações contemporâneas ex: explicar as causas de eventos importantes na França no século XVIII

3. Aplicar: implementar ou utilizar um procedimento em uma dada situação

\subsection{Executar} ex: dividir um número inteiro por outro número inteiro, ambos com múltiplos algarismos

3.2 Implementar ex: determinar em que situações a segunda lei de Newton pode ser aplicada

4. Analisar: decompor o material em suas partes constitutivas e determinar como as partes se relacionam umas com as outras e com uma estrutura ou proposta geral

\subsection{Diferenciar} ex: distinguir entre números relevantes e irrelevantes no enunciado de um problema matemático

4.2 Organizar ex: estruturar evidências em uma descrição histórica em evidência pró e contra uma explicação histórica em particular

4.3 Atribuir ex: determinar o ponto de vista do autor de um ensaio em termos de sua perspectiva política

5. Avaliar: Fazer julgamentos baseados em critérios ou padrões

\subsection{Verificar}

ex: determinar se uma conclusão de um cientista decorre dos dados observados

5.2 Criticar ex: julgar qual de dois métodos é a melhor forma para solucionar um dado problema

6. Criar: colocar os elementos juntos para formar um todo coerente ou funcional, reorganizar elementos em um novo padrão ou estrutura

6.1 Gerar

6.2 Planejar

6.3 Produzir ex: gerar hipóteses para dar conta de um fenômeno observado ex: planejar um artigo de pesquisa em um dado tópico da História ex: construir habitats para certas espécies para certos propósitos 
Um dos méritos da revisão de Anderson \& Krathwohl (2001) é apresentar uma estrutura bidimensional para a classificação dos objetivos educacionais, reunindo nas linhas os quatro tipos de conhecimento (dimensão do conhecimento) e, nas colunas, as seis categorias do processo cognitivo (dimensão do processo cognitivo), conforme ilustrado na Figura 2.19. A ideia é que cada objetivo de aprendizado possa ser colocado em uma das células da tabela.

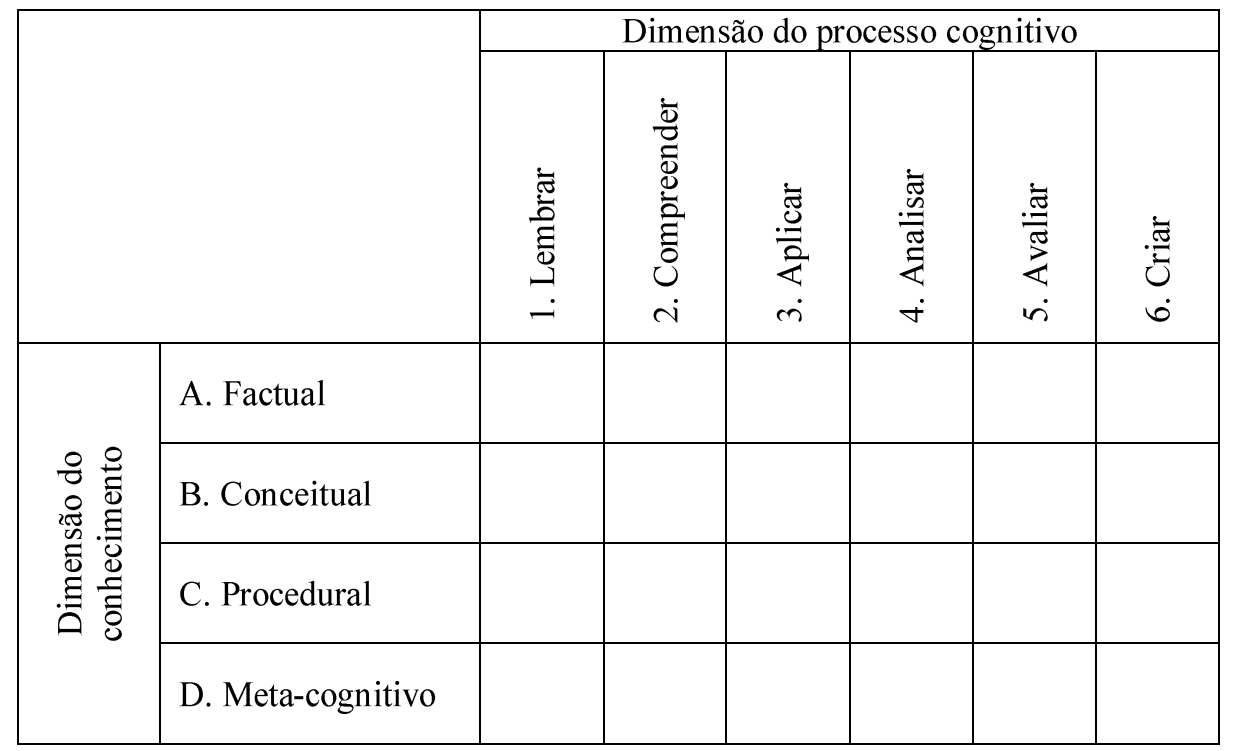

Figura 2.19 - Tabela da taxonomia do aprendizado.

Fonte: Traduzido de Anderson \& Krathwohl (2001)

Outro referencial útil para a classificação do aprendizado é o da profundidade do conhecimento (depth of knowledge), desenvolvido por Norman Webb (1997, 2007). Em geral, as ideias dos diferentes níveis de profundidade do conhecimento são associadas ao instrumento de avaliação do conhecimento (Wyse \& Viger, 2011). Embora a classificação de Webb muitas vezes seja considerada uma alternativa à taxonomia de Bloom, alguns autores sugerem o uso combinado das ideias de ambos autores para uma efetiva avaliação do aprendizado (Hess, Jones, Carlock \& Walkup, 2009). A descrição dos níveis de profundidade de conhecimento de Webb é apresentada na Tabela 2.11, já considerando o ponto de vista das avaliações construído por Wyse e Viger (2011).

De Smale et al. (2015) falam que, quando se trata de jogos, a taxonomia mais adequada seria a de Romiszowski, que foca na aquisição de habilidades. No entanto, essa é uma das chamadas taxonomias para o domínio psicomotor, focada quase que exclusivamente em habilidades desse domínio. Para o interesse deste trabalho, considera-se que a taxonomia de 
Bloom é adequada para classificar o aprendizado, podendo ser complementada pela ideia de profundidade do conhecimento de Webb.

Tabela 2.11 - Níveis de profundidade de conhecimento (depth of knowledge) de Webb.

\begin{tabular}{|c|c|}
\hline Nível 1 - Lembrança e reprodução & $\begin{array}{l}\text { Itens de avaliação neste nível requerem que o avaliado se } \\
\text { lembre de fatos, definições, termos ou procedimentos } \\
\text { simples, assim como que execute um algoritmo simples ou } \\
\text { aplique uma fórmula. }\end{array}$ \\
\hline Nível 2 - Habilidades e conceitos & $\begin{array}{l}\text { Itens de avaliação neste nível requerem que o avaliado } \\
\text { desenvolva conexões mentais e tome decisões sobre como } \\
\text { abordar um problema. }\end{array}$ \\
\hline Nível 3-Pensamento estratégico & $\begin{array}{l}\text { Itens de avaliação neste nível requerem que o avaliado } \\
\text { raciocine, construa argumentos, faça conjecturas e use } \\
\text { evidências com um nível de pensamento mais elevado que } \\
\text { nos outros dois níveis. }\end{array}$ \\
\hline Nível 4 - Pensamento estendido & $\begin{array}{l}\text { Itens de avaliação neste nível requerem que o avaliado se } \\
\text { engaje em planejamento, raciocínio, conjecturas e } \\
\text { desenvolvimento de linha de argumentação complexos; } \\
\text { exige múltiplas conexões entre muitos conceitos complexos } \\
\text { e diferentes. }\end{array}$ \\
\hline
\end{tabular}

Fonte: traduzido e adaptado de Webb (1997, 2002) e Wyse \& Viger (2011).

Outro referencial bastante difundido e útil como pano de fundo para esta pesquisa é o de Gagné. O foco nas condições de aprendizagem e sua influência no design instrucional, o modelo prevê nove eventos de instrução: (1) obter atenção, (2) informar o objetivo ao aluno, (3) estimular a recuperação do aprendizado prévio, (4) apresentar o estímulo, (5) prover orientação ao aluno, (6) provocar o desempenho, (7) dar feedback, (8) avaliar o desempenho e (9) melhorar a retenção e a transferência (Gagné, Briggs \& Wager, 1992).

Esse modelo é, em si, a própria descrição do que acontece dentro de um jogo, desde seu início quando o jogador é atraído e aprende as regras do jogo (eventos 1, 2, 3 e 4 e 5) até o momento em que ele começa a entender o que está acontecendo e passa a melhorar seu desempenho, com o jogo dando retorno (feedback) sobre suas ações (eventos 6, 7, 8). Após o processo, o jogador pode estar apto a adquirir informações verbais e visuais e habilidades intelectuais. Esse processo associado a jogos digitais é ilustrado por Sreelakshmi et al. (2015) em um experimento que mostra que o uso de um jogo é mais efetivo que um treinamento tradicional nos nove eventos do modelo de Gagné; e por Roodt e Joubert (2009) com o uso do jogo Innov8, da IBM. 


\subsubsection{Teorias do aprendizado}

O fenômeno do desenvolvimento gerencial pode ser mais bem compreendido se olhado sob a perspectiva do processo do aprendizado de forma geral. Ampliar o olhar sobre a educação gerencial sob a ótica das teorias do aprendizado pode ajudar a esclarecer um pouco mais o papel de outros meios que não os treinamentos tradicionais para o desenvolvimento de gestores e executivos. Afinal, do ponto de vista das organizações, quando se pensa na melhoria da eficácia gerencial, o elo mais importante nessa cadeia de ensino-aprendizagem é o próprio executivo ou gestor, isto é, aquele que aprende (ou deveria aprender) para gerir a organização de forma efetiva.

A compreensão de como se dá o aprendizado humano tem sido objeto de discussão ao longo de várias épocas, iniciando-se com os filósofos gregos, como Sócrates (469-399 a.C.), Platão (427-347 a.C.) e Aristóteles (384-322 a.C.), passando por pensadores como Descartes (15961650), Locke (1632-1704), Rousseau (1712-1778) e Kant (1724-1804), consolidando-se nas chamadas teoria do aprendizado praticamente nos últimos 100 anos (Hammond, Austin, Orcutt \& Rosso, 2001).

Basicamente, as visões de aprendizado contrastam o racionalismo proposto por Platão, revisitado por Descartes e Kant, com o empirismo de Aristóteles, revivido em Locke (Merriam \& Caffarella, 1999; Hammond et al. 2001). Nos séculos XIX e XX, com estudos mais científicos sobre o comportamento e a mente humanos, consolidaram-se algumas abordagens principais.

Embora exista uma série de outras abordagens, as ditas teorias contemporâneas do aprendizado (Illeris, 2009), mesmo em estudos mais recentes predominam categorizações que englobam as chamadas abordagens clássicas do aprendizado. Por exemplo, Nurulnadwan, Ariffin e Siti Mahfuzah (2014), em um estudo sobre um modelo de design conceitual para o aprendizado de pessoas com pouca visão, falam em três principais teorias do aprendizado: comportamentalismo (ou behaviorismo), cognitivismo e construtivismo. Já Lau (2014), ao abordar o ensino por computador, destaca as mesmas três teorias e cita uma quarta categoria, de teorias modernas. Na mesma linha, em artigo sobre o aprendizado por meio de jogos, W. 
Wu, Hsiao, P. Wu, Lin, \& Huang (2012) consideram o comportamentalismo, o cognitivismo, o construtivismo e a abordagem humanista.

As abordagens dadas ao aprendizado são relevantes também para a disposição física das salas de aula em uma escola, como destacado por Guney e Al (2012), que abordam os pontos de vista do comportamentalismo, cognitivismo, construtivismo, humanismo, aprendizagem experiencial e aprendizagem social-situacional. No outro extremo dos ambientes de aprendizagem, o mundo virtual do e-learning, também são consideradas abordagens semelhantes, como o comportamentalismo, cognitivismo, construtivismo e o aprendizado ativo (Pange \& Pange, 2011); comportamentalismo, cognitivismo, construtivismo e humanismo (Huandong, Shulei, Chunhui \& Mingrui, 2009); e comportamentalismo, cognitivismo, construtivismo, aprendizado baseado em atividades, aprendizado socialsituacional, aprendizado experiencial e teoria dos sistemas (Conole, Dyke, Oliver, \& Seale, 2004). No caso desses últimos autores, a teoria de sistemas é considerada no contexto do aprendizado organizacional, que não é o foco deste trabalho e, por esse motivo, não será objeto de descrição.

Especificamente quanto ao uso de jogos digitais (games) no contexto educacional, EgenfeldtNielsen (2006), comparando diversos estudos na área, aborda quatro teorias do aprendizado: behaviorismo, cognitivismo, construcionismo (baseado no construtivismo) e a abordagem sociocultural.

A Tabela 2.12 mostra um resumo envolvendo as teorias do aprendizado citadas por esses estudos recentes, além do clássico referencial de Merriam \& Caffarella (1999) sobre o aprendizado na idade adulta, que considera as seguintes teorias do aprendizado: o comportamentalismo, o cognitivismo, o humanismo, a abordagem social e o construtivismo.

A abordagem comportamentalista (ou behaviorista) assume, basicamente, duas premissas. A primeira é a de que o aprendizado se manifesta pelas mudanças observáveis de comportamento. A segunda é a de que o ambiente externo molda o comportamento. Assim, o que a pessoas aprendem é determinado pelos elementos no ambiente e não pelo indivíduo (Merriam \& Caffarella, 1999). Sob essa perspectiva, o aprendizado se dá na base estímuloresposta, isto é, os indivíduos são expostos a estímulos externos até que uma determinada 
resposta ocorra (Guney \& Al, 2012). As respostas desejadas podem ser estimuladas por reforços positivos (dar algo prazeroso para que o comportamento de quem aprende vá na direção desejada) ou negativos (eliminar algo desprazeroso para que o comportamento vá na direção desejada) ou desestimuladas com punições positivas (dar algo desprazeroso para que o comportamento não vá na direção errada) ou negativas (eliminar algo prazeroso para que o comportamento não vá na direção errada) (Nurulnadwan et al., 2014).

Tabela 2.12 - Resumo da presença das teorias do aprendizado em alguns artigos dos últimos anos

\begin{tabular}{|c|c|c|c|c|c|c|c|c|}
\hline Autores & 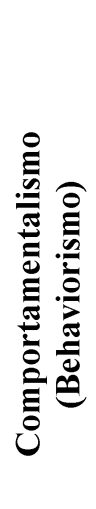 & ن & 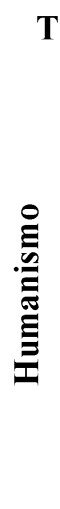 & 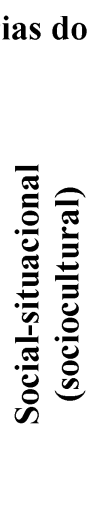 & 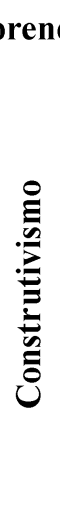 & 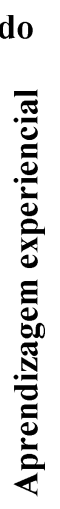 & 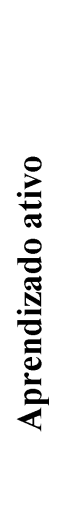 & 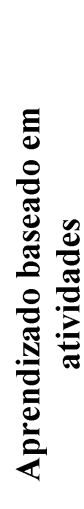 \\
\hline Merriam \& Caffarella (1999) & $\checkmark$ & $\checkmark$ & $\checkmark$ & $\checkmark$ & $\checkmark$ & & & \\
\hline $\begin{array}{l}\text { Nurulnadwan, Ariffin e Siti } \\
\text { Mahfuzah (2014) }\end{array}$ & $\checkmark$ & $\checkmark$ & & & $\checkmark$ & & & \\
\hline Lau (2014) & $\checkmark$ & $\checkmark$ & & & $\checkmark$ & & & \\
\hline Guney e Al (2012) & $\checkmark$ & $\checkmark$ & $\checkmark$ & $\checkmark$ & $\checkmark$ & $\checkmark$ & & \\
\hline Wu et al. (2012) & $\checkmark$ & $\checkmark$ & $\checkmark$ & & $\checkmark$ & & & \\
\hline Pange \& Pange (2011) & $\checkmark$ & $\checkmark$ & & & $\checkmark$ & & $\checkmark$ & \\
\hline Huandong et al. (2009) & $\checkmark$ & $\checkmark$ & $\checkmark$ & $\checkmark$ & & & & \\
\hline Egenfeldt-Nielsen (2006) & $\checkmark$ & $\checkmark$ & & $\checkmark$ & $\checkmark$ & & & \\
\hline Conole et al. (2004) & $\checkmark$ & $\checkmark$ & & $\checkmark$ & $\checkmark$ & $\checkmark$ & & $\checkmark$ \\
\hline
\end{tabular}

A abordagem behaviorista desconsidera os desejos internos do indivíduo e o papel da linguagem e da comunicação. Somado a isso, o ambiente externo não pode ser tomado como único fator que contribui para o aprendizado (Hassan, 2011). A abordagem cognitivista apareceu como uma resposta ao behaviorismo (Guney \& Al, 2012). O cognitivismo baseia-se em duas premissas principais, a de que o sistema de memória é um processador de informações ativo e organizado e que o conhecimento prévio desempenha um papel importante no aprendizado. Dessa forma, o processo de aprendizado é interno e mental, 
envolvendo percepção, processamento de informações e insights (Merriam \& Caffarella, 1999).

Outra visão sobre o aprendizado é a abordagem humanista. Segundo Huitt (2009), a premissa central dessa perspectiva é que a intencionalidade e os valores estão por trás do comportamento humano. Essa abordagem preconiza que o aprendizado deve ser centrado no estudante e personalizado, sendo o educador um facilitador do processo de aprendizagem. As necessidades afetivas e cognitivas seriam, portanto, aspectos fundamentais para o aprendizado (Wu et al., 2012). O aprendizado seria um ato pessoal para realizar o potencial (Merriam \& Caffarella, 1999).

A abordagem sociocultural, que combina tanto elementos do behaviorismo quanto do cognitivismo, considera que as pessoas aprendem ao observar os outros. Essas observações estão inseridas em um contexto social (Merriam \& Caffarella, 1999). O ponto de partida é o conhecimento acumulado pela comunidade em que o indivíduo está inserido e o aprendizado se dá pela interação do indivíduo com a sociedade, ocorrendo principalmente pela participação nas atividades e não pelo ensino (Hassan, 2011).

O construtivismo engloba outras perspectivas relacionadas. Sua ideia básica é a de que o aprendizado é um processo de construção de significado. Trata-se de como a pessoa dá sentido às suas experiências (Merriam \& Caffarella, 1999). Essa perspectiva tende a valorizar atividades práticas ("mão na massa") e atividades autodirigidas (Conole et al., 2004). Dentre as diversas perspectivas enquadradas no construtivismo, duas delas se sobressaem: a abordagem pessoal versus a social. Na abordagem pessoal, o aprendizado é visto como uma atividade cognitiva interna, sendo que as experiências induzem essa atividade. Do pondo de vista pedagógico, atividades práticas e discussões em grupo são consideradas essenciais nessa abordagem. Por outro lado, o construtivismo sob o ponto de vista social atesta que o conhecimento tem origem no engajamento social dos indivíduos em tarefas ou na solução de problemas compartilhados (Driver, Asoko, Leach, Mortimer \& Scott, 1994).

Os outros três termos elencados na Tabela 2.12 (aprendizagem experiencial, aprendizado ativo e aprendizado baseado em atividades) não necessariamente são considerados no conjunto das abordagens clássicas, sendo, às vezes, descritos dentro de alguma das outras 
abordagens já descritas (especialmente do construtivismo e da abordagem sociocultural). Tanto que Merriam e Caffarella (1999), em sua importante obra sobre o aprendizado de adultos, enfatizam apenas essas cinco abordagens descritas acima. A Tabela 2.13 traz um resumo dessas que são as abordagens mais frequentes para o aprendizado.

A ideia da aprendizagem experiencial (experiential learning) é atribuída à Kolb (1984). Mas como o próprio autor ressalta seu embasamento para essa abordagem veio das concepções de Dewey, Lewin e Piaget, o que a aproxima de uma perspectiva construtivista. É do primeiro a ideia de que "toda educação genuína acontece pela experiência" (Dewey, 1938). Outros autores, como Paulo Freire, reforçam a ideia do aprendizado pelo ciclo da "ação-reflexãoação" (Freire, 1983). Kolb tem um papel importante na área da administração, pois suas ideias fundamentam a formulação da teoria do aprendizado organizacional e são amplamente utilizadas em consultoria de gestão e treinamentos em liderança, mas também aparecem relacionadas aos estilos de processamento cognitivo (Miettnen, 2000).

Ainda na área de administração, como já enfatizado em outras partes deste trabalho, autores notáveis como Henry Mintzberg destacam o papel fundamental da reflexão sobre a ação como fundamental para o aprendizado gerencial (Mintzberg, 2006). Como salienta Barker (2010), “a educação gerencial é tipicamente pós-experiência, indicando que os participantes não são novatos" ${ }^{30}$ (p.57, tradução nossa), o que evidencia importância de Kolb para a área.

O modelo de aprendizado experiencial de Kolb (1984) foi estruturado em um ciclo de quatro fases, conforme pode ser visto na Figura 2.20. O ciclo de Kolb assemelha-se à já comentada ideia da ação-reflexão-ação de Paulo Freire. Contudo, a fim de torna-lo de mais fácil utilização na prática, Barnett (1989) adicionou uma quinta fase entre a conceituação abstrata e experimentação ativa, a fase de "planejamento para implementação". No entanto, pela própria descrição de Kolb (1984), pode-se inferir que esse planejamento faz parte da etapa de experimentação ativa. Interessante notar que a percepção de que existe um planejamento antes da ação torna esse modelo de aprendizado ainda mais próximo daquele que é considerado o ciclo de gestão (planejamento-execução-controle) também alinhado ao ciclo de aprendizado de Paulo Freire (Teixeira, Salomão \& Teixeira, 2010).

\footnotetext{
${ }^{30}$ But business education is typically post-experience, meaning that participants are not novices.
} 
Tabela 2.13 - Principais teorias de aprendizagem

\begin{tabular}{|c|c|c|c|c|c|}
\hline Aspecto & $\begin{array}{l}\text { Comportamentalismo } \\
\text { (Behaviorismo) }\end{array}$ & Cognitivismo & Humanismo & $\begin{array}{l}\text { Social-situacional } \\
\text { (sociocultural) }\end{array}$ & Construtivismo \\
\hline Autores & $\begin{array}{l}\text { Guthrie, Hull, Pavlov, Skinner, } \\
\text { Thorndike, Tolman, Watson }\end{array}$ & $\begin{array}{l}\text { Ausubel, Bruner, Gagné, Koffka, } \\
\text { Kohler, Lewin, Piaget }\end{array}$ & Maslow, Rogers & Bandura, Rotter & $\begin{array}{l}\text { Candy, Dewey, Lave, } \\
\text { Piaget, Rogoff, von } \\
\text { Glasersfeld, Vygotsky }\end{array}$ \\
\hline $\begin{array}{l}\text { Visão do processo } \\
\text { de aprendizado }\end{array}$ & Mudança no comportamento & $\begin{array}{l}\text { Processo mental interno } \\
\text { (incluindo insight, } \\
\text { processamento de informações, } \\
\text { memória, percepção) }\end{array}$ & $\begin{array}{l}\text { Um ato pessoal para } \\
\text { realizar o potencial }\end{array}$ & $\begin{array}{l}\text { Observação dos outros e } \\
\text { interação com eles em um } \\
\text { contexto social }\end{array}$ & $\begin{array}{l}\text { Construção de significado } \\
\text { pela experiência }\end{array}$ \\
\hline $\begin{array}{l}\text { Locus do } \\
\text { aprendizado }\end{array}$ & Estímulo do ambiente externo & Estruturação cognitiva interna & $\begin{array}{l}\text { Necessidades afetivas e } \\
\text { cognitivas }\end{array}$ & $\begin{array}{l}\text { Interação da pessoa, } \\
\text { comportamento e } \\
\text { ambiente }\end{array}$ & $\begin{array}{l}\text { Construção interna da } \\
\text { realidade pelo indivíduo }\end{array}$ \\
\hline $\begin{array}{l}\text { Proposta da } \\
\text { educação (formal) }\end{array}$ & $\begin{array}{l}\text { Produzir mudança de } \\
\text { comportamento em uma } \\
\text { direção desejada }\end{array}$ & $\begin{array}{l}\text { Desenvolver capacidade e } \\
\text { habilidades para aprender } \\
\text { melhor }\end{array}$ & $\begin{array}{l}\text { Tornar-se } \\
\text { autorrealizado e } \\
\text { autônomo }\end{array}$ & $\begin{array}{l}\text { Modelar novos papéis e } \\
\text { comportamentos }\end{array}$ & Construir conhecimento \\
\hline Papel do professor & $\begin{array}{l}\text { Organiza o ambiente para } \\
\text { extrair a resposta desejada }\end{array}$ & $\begin{array}{l}\text { Estrutura o conteúdo da } \\
\text { atividade de aprendizado }\end{array}$ & $\begin{array}{l}\text { Facilita o } \\
\text { desenvolvimento da } \\
\text { pessoa como um todo }\end{array}$ & $\begin{array}{l}\text { Modela e guia novos } \\
\text { papéis e comportamentos }\end{array}$ & $\begin{array}{l}\text { Facilita e negocia o } \\
\text { significado com o } \\
\text { aprendiz }\end{array}$ \\
\hline $\begin{array}{l}\text { Manifestação no } \\
\text { aprendizado de } \\
\text { adultos }\end{array}$ & $\begin{array}{l}\text { - Objetivos comportamentais } \\
\text { - Educação baseada em } \\
\text { competência } \\
\text { - Treinamento e } \\
\text { desenvolvimento de } \\
\text { habilidades }\end{array}$ & $\begin{array}{l}\text { - Desenvolvimento cognitivo } \\
\text { - Inteligência, aprendizado e } \\
\text { memória como função da idade } \\
\text { - Aprender como aprender }\end{array}$ & $\begin{array}{l}\text { - Andragogia } \\
\text { - Aprendizado } \\
\text { autodirigido }\end{array}$ & $\begin{array}{l}\text { - Socialização } \\
\text { - Papéis sociais } \\
\text { - Mentoria } \\
\text { - Locus de controle }\end{array}$ & $\begin{array}{l}\text { - Aprendizado } \\
\text { experiencial } \\
\text { - Aprendizado } \\
\text { autodirigido } \\
\text { - Transformação de } \\
\text { perspectiva } \\
\text { - Prática reflexiva }\end{array}$ \\
\hline
\end{tabular}

Fonte: Traduzido de Merriam \& Caffarella (1999, p.264). 


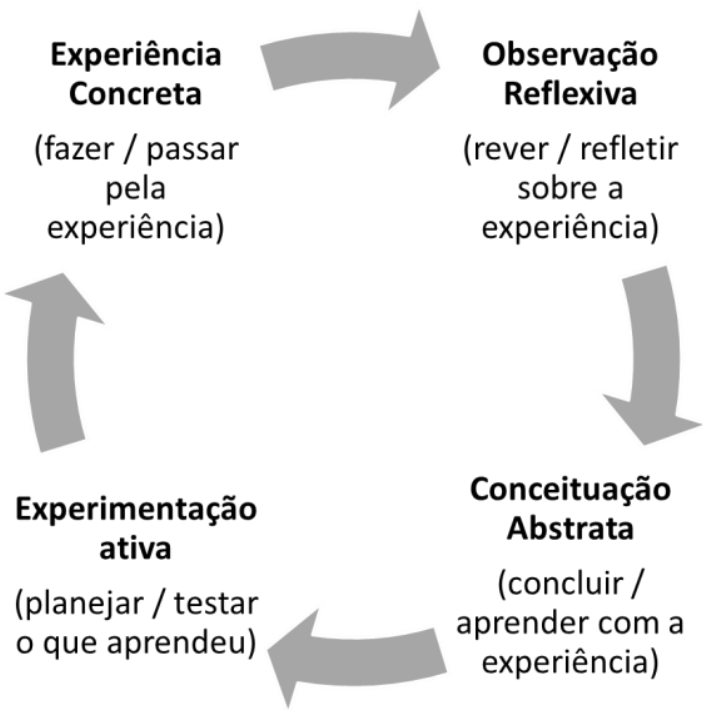

Figura 2.20 - O ciclo do aprendizado experiencial de Kolb Fonte: Kolb (1984)

A experiência também é central no modelo do processo de aprendizado de Jarvis (1987). Contudo, ao contrário de Kolb, o autor considerou a interação social e, embora assumidamente uma simplificação demasiada da realidade, é um modelo mais sofisticado do que qualquer outro existente à época (Jarvis, 2012). O modelo de Jarvis (Figura 2.21) se diferencia de outros modelos de aprendizagem de adultos (Andragogia, Teoria da Proficiência de Knox e Teoria da Margem de McClusky, dentre outros) por tratar do processo de aprendizagem em si (Merriam \& Caffarella, 1999).

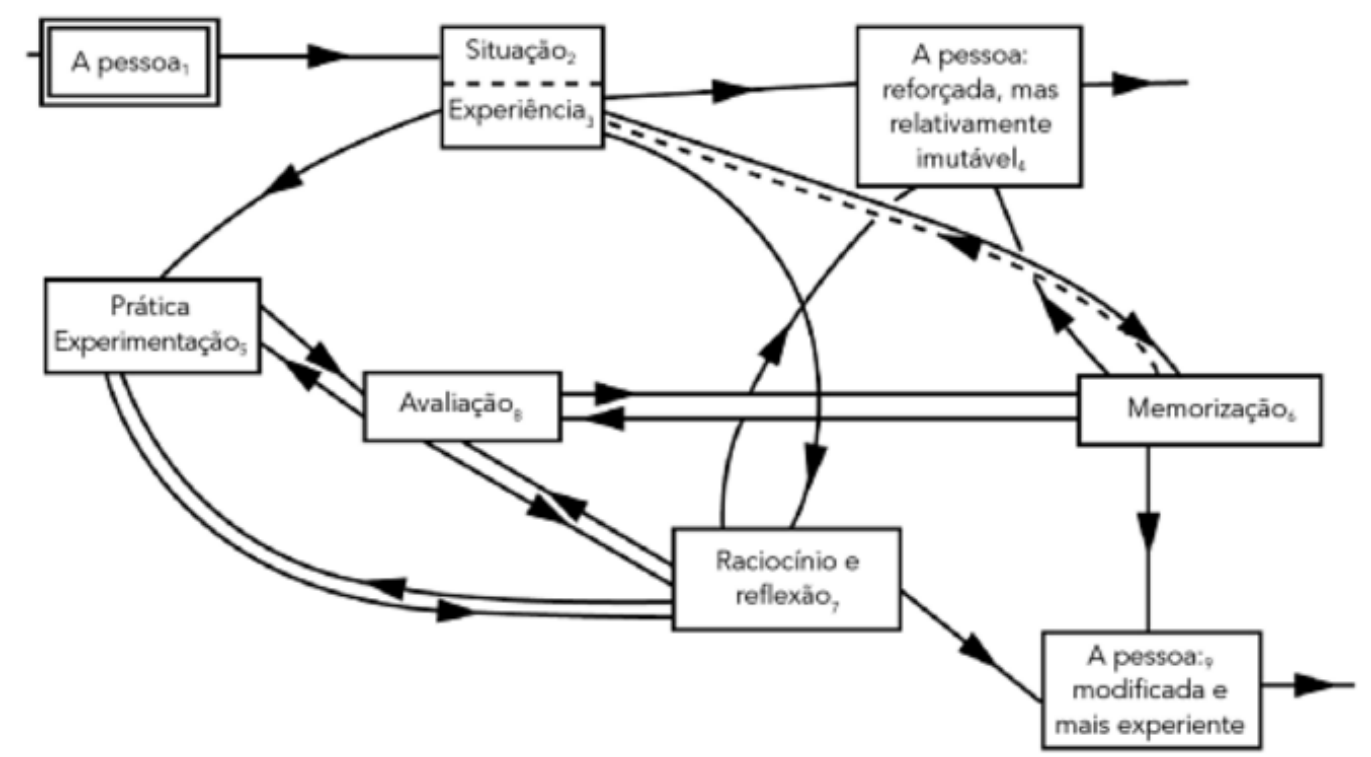

Figura 2.21 - O modelo do processo de aprendizado de Jarvis.

Fonte: Traduzido de Jarvis (1987) 
No modelo de Jarvis (1987), a pessoa (box 1) que passa por uma situação (box 2) ou experiência (box 3) pode tomar diferentes rotas, algumas levando ao aprendizado, outras não. As que não levam ao aprendizado são a presunção, a não consideração e a rejeição. Elas acontecem quando a pessoa simplesmente faz o caminho $1 \rightarrow 2 \rightarrow 3 \rightarrow 4$. O aprendizado não ocorre porque a pessoa pode responder de uma maneira mecânica (presumindo que o que funcionava antes vai funcionar outra vez), pode estar muito preocupada para considerar uma resposta ou pode simplesmente rejeitar a oportunidade de aprender (Merriam \& Caffarella, 1999). Já o aprendizado pode acontecer de duas formas: não reflexiva ou reflexiva. No primeiro grupo estão os processos pré-consciente - quando a pessoa internaliza algo inconscientemente $(1 \rightarrow 2 / 3 \rightarrow 6 \rightarrow 4$ ou 9$)$; a prática - que pode ser de uma nova habilidade até que seja aprendida $(1 \rightarrow 2 / 3 \rightarrow 5 \rightarrow 8 \rightarrow 6 \rightarrow 4$ ou 9); e a memorização - a reprodução posterior de algo que lhe foi apresentado $(1 \rightarrow 2 / 3 \rightarrow 6 \rightarrow 4$ ou 9$)$. No segundo grupo, dos processos reflexivos, estão a contemplação - pensar sobre o que está sendo aprendido e não requer um resultado comportamental $(1 \rightarrow 2 / 3 \rightarrow 7 \rightarrow 9)$; a prática reflexiva - semelhante à solução de problemas $(1 \rightarrow 2 / 3 \rightarrow 5 \rightarrow 7 \leftrightarrow 8 \leftrightarrow 6 \leftrightarrow 7 \rightarrow 9)$; e o aprendizado experimental - resultado da experimentação no ambiente (idem) (Jarvis, 1987; Merriam \& Caffarella, 1999; Jarvis, Holfold \& Griffin, 2003).

Em certo sentido, os modelos de Kolb e Jarvis se equivalem, pois ambos estão preocupados com a reflexão sobre a experiência e a possibilidade de se experimentar o mundo para gerar reflexão. Essa ideia coaduna com a visão de aprendizado como um processo experimentação, tentativa e erro trazida por Negroponte (2012). Esse é exatamente o processo pelo qual se passa quando se joga um jogo. Como destacado por Lopes et al. (2013), o processo de aprendizagem que leva ao desenvolvimento da liderança pode ser acelerado pensando-se que num jogo as pessoas podem praticar, avaliar, refletir e agir em um ambiente seguro, em que o preço pago por erros cometidos é muito baixo, incentivando a iniciativa e a reflexão.

Assim, o modelo de Kolb, por ser mais simples que o de Jarvis e outros modelos, é o pano de fundo para o processo de aprendizado deste trabalho. Ainda, opta-se deliberadamente por não escolher uma única abordagem de aprendizado (comportamentalismo, cognitivismo, construtivismo), pois o uso de um jogo pode caracterizar aprendizado independente da perspectiva (Egenfeldt-Nielsen 2006), como mostrado adiante. 
Outro termo que aparece frequentemente na literatura sobre o aprendizado é o chamado aprendizado ativo (active learning), embora não caracterize um modelo ou uma teoria do aprendizado em si. A definição de aprendizado ativo é a de "atividades instrucionais que envolvam os estudantes a fazer coisas e pensar a respeito do que estão fazendo"31 (Bonwell \& Eison, 1991). Essa definição deixa claro que o aprendizado ativo é uma faceta da aprendizagem experiencial, considerado em um contexto mais amplo como derivado do construtivismo e/ou da abordagem sociocultural. Da mesma ideia surgem termos assemelhados como aprendizado baseado na ação (action-based learning) e aprendizado baseado em atividades (activity based learning). Além dessas, o aprendizado baseado em jogos (GBL - game-based learning) também se aproxima do aprendizado experiencial (Kiili, 2005).

Sobre a questão do uso de games para fins educacionais, Egenfeldt-Nielsen (2006) comparou diversos estudos na área sob quatro diferentes perspectivas do aprendizado, behaviorismo, cognitivismo, construcionismo (baseado no construtivismo) e a abordagem sociocultural. Para o autor, o entendimento completo para o uso educacional de games precisa ser feito sob diferentes perspectivas do aprendizado. $\mathrm{O}$ autor concluiu que olhar a utilização de jogos como um campo homogêneo não é benéfico, pois existem diferentes formas de ensino e de gêneros de aplicação dos jogos que podem favorecer diferentes objetivos educacionais.

Do ponto de vista do behaviorismo, a diferença com relação às demais formas de aprendizado é que os jogos dificilmente são jogados de forma bem sucedida de uma única vez, permitindo e estimulando a repetição. A lógica de estímulo-resposta é coerente com a ideia de aprendizado por reforço, o que favorece os jogos nessa perspectiva.

Já com relação ao cognitivismo, a diferença reside no fato de os jogadores se engajarem e aprenderem pelo fato de o jogo ser interessante em si mesmo. O aprendizado adviria de fatores como desafio, curiosidade, experiência de controle e elementos de fantasia, que contribuiriam para a motivação intrínseca do jogador, fator relevante para essa perspectiva do aprendizado. Esses quatro fatores elencados por Egenfeldt-Nielsen (2006) são aspectos fundamentais a serem considerados no desenvolvimento de jogos (Malone \& Lepper, 1987; Minovic et al., 2013)

\footnotetext{
${ }^{31}$ Instructional activities involving students in doing things and thinking about what they are doing
} 
Os jogos que envolvem a perspectiva construcionista são frequentemente vistos como "micromundos", nos quais os jogadores podem interagir com diferentes artefatos e que representam uma parte do mundo que é simplificada e construída para facilitar o trabalho com objetos concretos. Nessa perspectiva, como prossegue Egenfeldt-Nielsen (2006), o aprendizado não vem por transferência a partir do jogo e não se trata de elaboração de conteúdo relevante. O objetivo é que o jogador se engaje com o material, discuta-o, reflita sobre ele e utilize o jogo para construir o conhecimento.

Por fim, a última perspectiva analisada por Egenfeldt-Nielsen (2006) foi a abordagem sociocultural, na qual o conhecimento é uma ferramenta para mediar as atividades e não informações memorizadas. Assim, conclui o autor que a questão está muito mais associada ao uso que se faz de um jogo específico do que o seu próprio desenvolvimento. Sob essa perspectiva, os jogos não se prestam ao aprendizado pela rotina, mas possuem o objetivo da exploração da relação entre variáveis, eventos e padrões complexos. Portanto, os jogos são ferramentas para a construção de uma experiência viável de aprendizado, mas não a experiência de aprendizado em si.

O uso de jogos (games) no contexto educacional vem sendo estudado com relativa frequência nos anos recentes. Egenfeldt-Nielsen (2006) ressalta, também, que, embora se argumente que se trata de um campo de pesquisa emergente no qual não existe muita pesquisa, esse não é o caso. Já de partida o autor mostra que os jogos podem facilitar o aprendizado. Contudo, destaca, também, que, na maioria dos estudos envolvendo jogos (video games), os pesquisadores examinam o efeito de um curso que inclui jogos, mas não fazem comparações com cursos similares que não incluam os jogos. Ou seja, a ausência de grupos de controle é crítica. A questão a ser avaliada é: o que os jogos podem oferecer que os colocaria à parte de outras praticas educacionais? Com base no exposto sobre teorias de aprendizagem, nos achados de Egenfeldt-Nielsen (2006) e no modelo de aprendizado experiencial para jogos de Kiili (2005) foi construído um resumo das ideias advindas das diferentes perspectivas do aprendizado aplicáveis aos jogos (Tabela 2.14). 
Tabela 2.14 - Impacto das perspectivas do aprendizado sobre o uso de jogos

\begin{tabular}{ll}
\hline \hline \multicolumn{1}{c}{ Perspectiva } & \multicolumn{1}{c}{ Ideias aplicáveis aos jogos } \\
\hline Behaviorismo & $\begin{array}{l}\text { Estímulo-resposta; repetição (jogo é, geralmente, jogado mais } \\
\text { de uma vez) } \\
\text { Motivação intrínseca; desafios; descobertas; forma de } \\
\text { apresentação que leva em conta as limitações e potenciais da } \\
\text { cognição humana }\end{array}$ \\
& $\begin{array}{l}\text { Objetos externos facilitando o aprendizado; abordagem ativa; } \\
\text { micromundos; interação com micromundo para produzir } \\
\text { significados; jogo como facilitador do aprendizado }\end{array}$ \\
& $\begin{array}{l}\text { Interação social pela zona de desenvolvimento proximal de } \\
\text { Construtivismo }\end{array}$ \\
& $\begin{array}{l}\text { Vygotsky; Diferentes ferramentas em diferentes contextos } \\
\text { facilitam uma variedade de experiências de aprendizado; Jogos } \\
\text { são as ferramentas para construir o aprendizado e não a } \\
\text { experiência de aprendizado em si. }\end{array}$ \\
& Estado de fluxo de Csikszentmihalyi; objetivos; controle; \\
feedback; Jogo provê experiência concreta
\end{tabular}

Fonte: elaborado pelo autor com base em Egenfeldt-Nielsen (2006) e Kiili (2005).

\subsection{O Gestor Público: breve contextualização}

Villoria e Iglesias (2011) destacam oito características que distinguem a gestão pública da gestão praticada na iniciativa privada. São elas: (1) maior influência política, (2) capacidade quasi-legislativa e quasi-legal, (3) maiores expectativas para tratamento equitativo e igual e por transparência, (4) maior ambiguidade e/ou contradição nos objetivos, (5) maiores restrições à tomada de decisões do gestor público tanto para dentro quanto para fora da organização, (6) maior dificuldade em ligar incentivos à performance, (7) sistema de valores relacionado ao trabalho ligeiramente diferente e (8) baixo nível de satisfação dos empregados.

Por causa dessas diferenças, a mera importação dos conceitos de liderança desenvolvidos para a atuação em entidades privadas não é suficiente quando se pensa em desenvolvimento de gestores públicos. As diferenças entre gestores públicos e privados não se restringem ao contexto, pois já foram reportadas diferenças significativas no seu comportamento de liderança (Andersen, 2010). Além disso, as práticas privadas trouxeram apenas ganhos moderados para a gestão pública (Motta, 2013). 
Somado a isso, Ysa e Salvador (2015) pontuam que os estudos envolvendo liderança no setor público são feitos normalmente sob uma perspectiva estática. Para os autores, é importante que o ciclo de vida durante o mandato do cargo diretivo seja levado em consideração, pois o gestor público é um ator importante para a elaboração e implementação de políticas públicas. As decisões e ações do gestor público influenciam os objetivos das organizações que dirigem (Cook, 1998). Assim, o balanço entre a gestão política, gestão estratégica e gestão operacional varia ao longo do mandato de um gestor.

O equilíbrio entre os apectos político, estratégico e operacional da gestão é aquilo que Moore (2002) define como a função primordial do gestor público (ou gerente público, nas palavras do próprio autor) para a geração de valor público. Essa seria, na visão do autor, a principal diferença da atuação de um gerente público em comparação com o privado, especialmente no que diz respeito à gestão do entorno político. Já o valor público adviria de ações e decisões dos agentes públicos que refletem as aspirações coletivas e convertem os recursos obtidos por meio do poder coercitivo do estado (impostos e taxas) em serviços e bens em que a sociedade enxerga valor (Moore, 2002). Por isso, ganha importância a necessidade de legitimação das organizações públicas, o que pode ser obtido por diferentes tipos de liderança a serem desempenhados pelos gestores públicos (Villoria \& Iglesias, 2011).

Os gestores públicos são, portanto, uma categoria de atores no governo (em suas diferentes esferas) que tem um grau relevante de responsabilidade nas organizações públicas, pois é por meio de sua ação e de suas decisões que a efetividade dos serviços públicos pode ser obtida. Por outro lado, sua responsabilidade não se confunde com a dos políticos e é também distinta da responsabilidade dos funcionários públicos. Por essa razão, de Bonis e Pacheco (2010) colocam os gestores ou dirigentes públicos numa categoria à parte, fugindo da dicotomia entre burocratas e políticos. Nesse sentido, os gestores públicos são entendido como aqueles que ocupam cargos de gestão nos órgãos públicos, com responsabilidade significativa sobre as políticas públicas e pelo desempenho das organizações. Nesta pesquisa, adota-se um sentido ainda mais amplo que o dos autores, considerando-se não apenas aqueles que respondem diretamente aos ministros ou secretários, mas também aqueles que atuam nos diferentes níveis da organização, desde que responsáveis pela elaboração e pela execução das políticas públicas e/ou pelo desempenho de diferentes unidades da organização, e que tenham subordinados. 
Dessa forma, a separação dos dirigentes públicos dos burocratas resulta num rol de competências diferentes para a atuação efetiva desses dirigentes e, consequentemente, das organizações que dirigem. São competências que "dizem respeito diretamente à sua capacidade de melhor utilizar recursos em busca de resultados; são, portanto, competências gerenciais que incluem a capacidade de dirigir e motivar equipes, analisar dados orçamentários e financeiros, coordenar compras, investimentos e contratações de serviços, negociar relações com pessoas e organizações etc., à luz dos resultados a serem alcançados" (de Bonis \& Pacheco, 2010, p. 337). As expectativas sobre a atuação do gestor efetivamente como um gestor (ou dirigente) público em contraposição a uma atuação como burocrata são sintetizadas na Tabela 2.15 .

Tabela 2.15 - Burocratas versus dirigentes públicos

\begin{tabular}{|c|c|c|}
\hline Variável & Burocratas & Dirigente Público \\
\hline Ethos & Aplicação impessoal da regra & $\begin{array}{l}\text { Uso eficiente dos recursos } \\
\text { visando à maximização dos } \\
\text { resultados }\end{array}$ \\
\hline Recurso de poder & Crescimento técnico & Competência gerencial \\
\hline Discricionariedade & Baixa & Média \\
\hline Acesso à posição & $\begin{array}{l}\text { Concurso público e progressão } \\
\text { na carreira }\end{array}$ & $\begin{array}{l}\text { Indicação ou seleção aberta } \\
\text { conforme laços pessoais e } \\
\text { competências }\end{array}$ \\
\hline Permanência no cargo & Longa & Curta \\
\hline Responsividade & Baixa & Média-alta \\
\hline
\end{tabular}

Fonte: de Bonis \& Pacheco (2010).

Num contexto em que se discute a profissionalização do gestor público, com a emergência de escolas de governo, a educação continuada se impõe no contexto da chamada sociedade da informação, na ideia de que os gestores públicos estão permanentemente num processo de formação. Assim, as alternativas utilizando novas tecnologias, como a Educação a Distância, mas não se restringindo a ela, constituem-se como instrumentos capazes de contribuir para a capacitação dos gestores públicos, sendo interfaces ou ambientes que promovem uma nova cultura de aprendizagem (Duran, 2017). 


\subsection{Colocando tudo junto: Framework conceitual da pesquisa}

Nas seções precedentes foram tratadas diversas abordagens teóricas, que vão desde como os jogos e a motivação para o aprendizado se relacionam e quais as ferramentas que existem para potencializar seu uso para fins educacionais, até quais os principais paradigmas quando se pensa o aprendizado humano, passando, naturalmente, pelo desenvolvimento de gestores.

Além de tentar preencher algumas das lacunas destacadas na literatura, por exemplo poucos estudos empíricos envolvendo simulações e jogos (Salas et al., 2009) ou baixa utilização de grupos de controle em experimentos educacionais com jogos (Egenfeldt-Nielsen 2006), uma contribuição importante deste trabalho é colocar esses diversos referenciais teóricos em um todo significativo para compor a base de uma pesquisa operacionalizável, como descreve o próximo capítulo. Para ajudar a visualização dessas inter-relações avindas da teoria, foi construída a Figura 2.22 que contém o quadro de referência (framework) conceitual do trabalho.

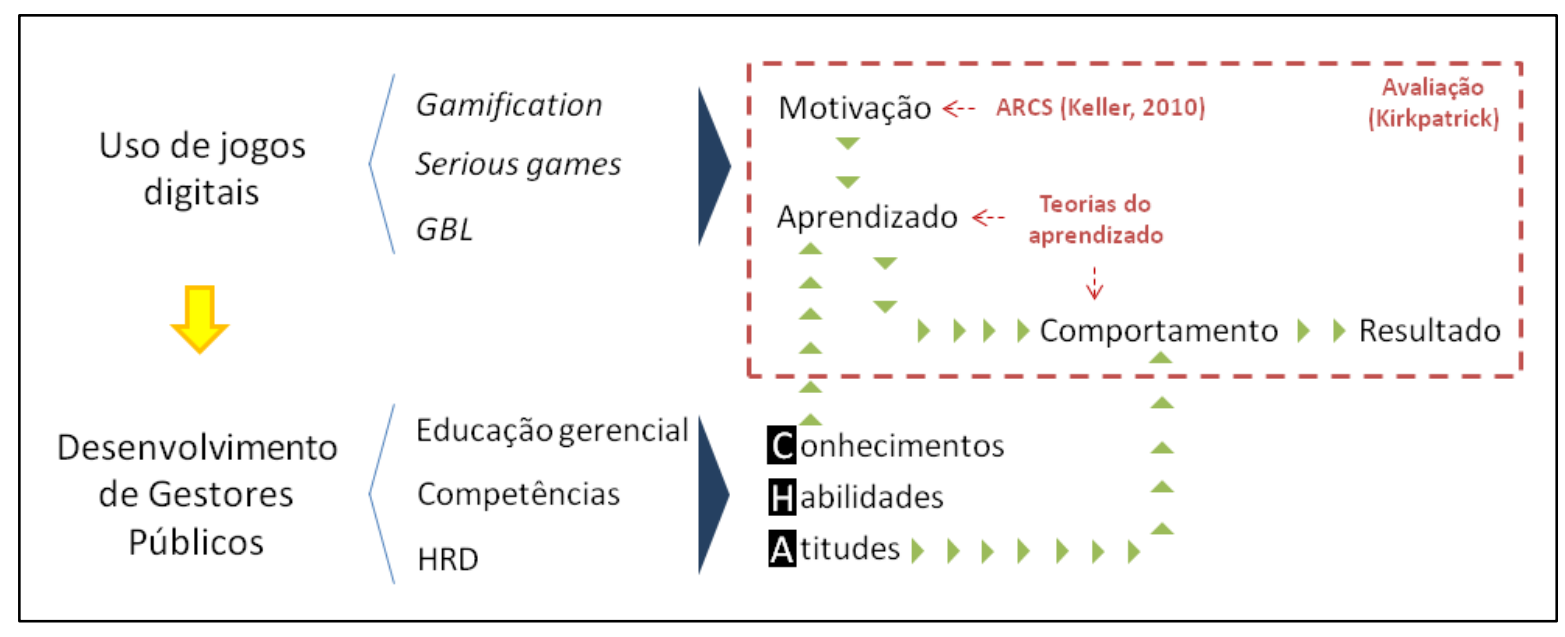

Figura 2.22 - Framework conceitual da pesquisa

Embora Rocha (2015) também tenha estudado a temática dos serious games e da gamification para o aprendizado de administração pública, seu estudo de caráter fenomenológico buscou dimensionar o valor estratégico desses conceitos como ferramentas pedagógicas. O presente trabalho, portanto, tem relevância, pois é o primeiro de que se teve notícia que busca explicar qual a efetividade do uso de um jogo especificamente projetado para o desenvolvimento de gestores públicos. 


\section{MÉTODO}

Este capítulo apresenta os procedimentos metodológicos utilizados para responder ao problema de pesquisa, "qual o impacto do uso de jogos digitais para o desenvolvimento de gestores públicos?". A abordagem da pesquisa é multimétodo. A parte central para responder ao problema de pesquisa é o conjunto de dois experimentos realizados na etapa conclusiva do trabalho, que recebe maior ênfase neste capítulo. No entanto, como o jogo utilizado e o curso desenvolvido foram partes importantes para a consecução dos objetivos da pesquisa, eles são

tratados como partes integrantes do método, alinhados com as perspectivas teóricas apresentadas no Capítulo 2.

São os objetivos da pesquisa que delineiam a abordagem que deve ser adotada para sua resposta (Cohen, Manion \& Morrisson, 2007). O "método é o conjunto das atividades sistemáticas e racionais que, com maior segurança e economia, permite alcançar o objetivo [...] traçando o caminho a ser seguido [...]" (Marconi \& Lakatos, 2010, p.65). Essa ideia se alinha com a percepção de que a metodologia diz respeito à lógica da investigação científica, delineando os caminhos pelos quais se produz conhecimento (Grix, 2004).

Dessa forma, os caminhos escolhidos para responder ao problema de pesquisa passaram por diversas abordagens, mas centraram esforços no experimento final. Porém, muito material produzido ao longo do estudo foi de natureza qualitativa (entrevistas, textos), o que exigiu técnicas apropriadas, que foram buscar inspiração na Análise de Conteúdo. Os dados quantitativos, por sua vez, foram analisados com técnicas estatísticas adequadas para os experimentos desenhados (ANOVA e ANCOVA).

A subdivisão do capítulo segue a orientação dos objetivos específicos da pesquisa, que são (OE1) identificar quais são os principais conceitos que associam a aplicação de jogos (games) para fins de desenvolvimento humano; (OE2) desenvolver um serious game de gestão focado no setor público, que incorpore aspectos das teorias relacionadas à administração, e que possa ser utilizado para o desenvolvimento de gestores públicos; (OE3) aplicar o jogo em um contexto de desenvolvimento de gestores, por meio de um curso ou treinamento, em que seja 
possível avaliar o impacto de seu uso; e (OE4) mensurar a eficácia do uso de um jogo de gestão para o desenvolvimento dos gestores públicos.

O primeiro objetivo está diretamente alinhado ao estudo bibliométrico apresentado na subseção 2.2.1 do capítulo precedente e não será abordado neste capítulo. Assim, a primeira seção trata do processo de desenvolvimento do Liderança em Jogo: Competências, Papéis e Responsabilidades, jogo que leva em conta o contexto do setor público e foi concebido para o desenvolvimento de gestores públicos. Em seguida, descreve-se o curso desenvolvido para a utilização do jogo. Por fim, trata-se da questão do experimento projetado para avaliar o impacto do uso de jogos digitais no desenvolvimento de gestores públicos, objetivo final do estudo, bem como são descritos os instrumentos de coleta utilizados. Antes dessas seções, no entanto, apresentam-se brevemente o paradigma em que a pesquisa está inserida e como ela é caracterizada. A Figura 3.1 apresenta o esquema geral da pesquisa.

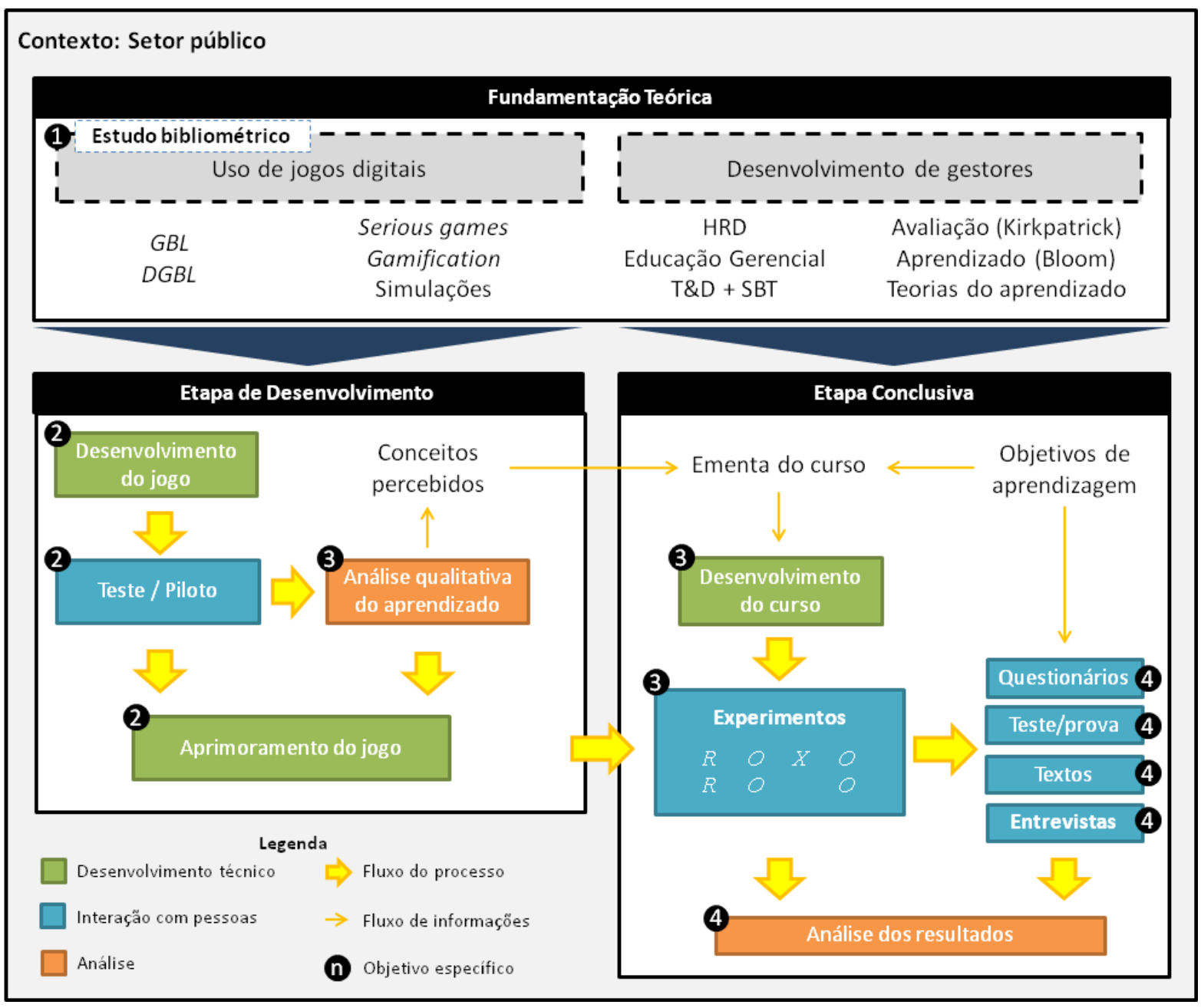

Figura 3.1 - Visão geral do esquema da pesquisa. 


\subsection{Paradigma e caracterização da pesquisa}

De acordo com Guba e Lincoln (1994), um paradigma é um conjunto de crenças que trata de princípios básicos e finais, representando uma visão de mundo que define o mundo propriamente e o lugar dos indivíduos nele. No que diz respeito à ciência, seguem os autores, eles variam na ontologia, isto é, qual a forma e a natureza da realidade e o que pode ser conhecido dela; na epistemologia, ou seja, qual a relação entre o que se quer saber e o que se pode saber sobre a realidade; e na metodologia, que trata das formas como o pesquisador pode descobrir o que quer que ele acredite que pode ser descoberto.

Os paradigmas dominantes nas ciências em geral são o positivismo e o pós-positivismo, que pressupõem que a realidade pode ser apreendida por leis naturais e pelo menos probabilisticamente. Embora neste estudo se tenha ciência da existência de outros paradigmas (teoria crítica e construtivismo) e, mais do que isso, que eles não precisam necessariamente excluir uns aos outros, nota-se que, em função da natureza do problema de pesquisa proposto, acabou-se por adotar uma perspectiva mais marcadamente pós-positivista. O método hipotético-dedutivo se manifesta com a proposta de experimentos, hipóteses e outras questões que são assumidas como mensuráveis neste trabalho.

O caráter multimétodo da pesquisa se evidencia pela análise tanto quantitativa quanto qualitativa. É a chamada triangulação metodológica, em que são utilizados métodos distintos, de forma complementar (Vergara, 2012). Houve certo grau de simultaneidade na utilização dos métodos, pois as coletas por meio de questionários, produção de textos e da avaliação de aprendizado foram concomitantes, mas também houve triangulação sequencial, quando, por exemplo, pontos importantes relatados nas entrevistas feitas após o primeiro experimento trouxeram elementos que foram levados em conta para o desenho do segundo experimento.

Dito isso, mesmo tendo-se ciência de que classificações podem empobrecer o olhar sobre qualquer tipo de trabalho, por facilitar ao leitor, a pesquisa é caracterizada dentro das classificações tradicionais. Em última instância, esta é uma pesquisa causal, pois trata de uma relação de causa e efeito (Sampieri, Collado \& Lucio, 2006), ou seja, busca explicar se o uso do jogo digital pode ser causa do desenvolvimento de gestores públicos. Contudo, em alguns 
momentos a pesquisa teve caráter exploratório e descritivo, principalmente em sua etapa de desenvolvimento.

Como já dito, os experimentos foram centrais na pesquisa. No entanto, em determinados momentos o trabalho foi "beber na fonte" dos métodos qualitativos de pesquisa, trazendo elementos da análise de conteúdo, uma técnica utilizada para o tratamento de dados que visa identificar o que está sendo dito a respeito de determinado tema (Vergara, 2012) e, em certo grau, apresentado uma faceta de pesquisa-ação.

Cabe salientar que a pesquisa-ação é distinta da consultoria, pois, segundo Roesch (2001), busca elaborar e desenvolver conhecimento teóricos, ao mesmo tempo em que tenciona resolver problemas práticos. De acordo com Vergara (2012, p.190), esse método de pesquisa "visa à resolução de problemas por meio de ações definidas por pesquisadores e sujeitos envolvidos com a situação sob investigação. Objetiva, simultaneamente, a intervenção, a elaboração e o desenvolvimento de teoria".

\subsection{Desenvolvimento do jogo}

O jogo desenvolvido neste trabalho intitula-se "Liderança em jogo: competências, papéis e responsabilidades" (Figura 3.2) e sua construção fez parte, inicialmente, de um projeto realizado na então Secretaria de Gestão Pública do Governo do Estado de São Paulo ${ }^{32}$, especificamente para a Unidade Central de Recursos Humanos (UCRH), pela Fundação Instituto de Administração (FIA).

A equipe núcleo que desenvolveu o jogo na prática contou com a participação de quatro pessoas: um desenvolvedor-programador, um desenvolvedor-artista gráfico, um roteirista, além do próprio pesquisador, que coordenou os trabalhos e participou da programação, da roteirização e do design instrucional. O time ainda teve a contribuição de um designer

\footnotetext{
${ }^{32}$ Um processo de reestruturação de secretarias levado a cabo pelo Governo do Estado de São Paulo em 2015, fundiu a Secretaria de Gestão Pública (SGP) com a Secretaria de Planejamento e Gestão (SPG), passando a chamar o conjunto pelo nome da segunda. A partir de 2017, a Unidade Central de Recursos Humanos incorporou a Escola de Governo e Adminsitração Pública (EGAP), de acordo com o Decreto 62.598/2017.
} 
instrucional e o apoio de cinco pessoas que testaram o jogo, antes de sua liberação para acesso ao público-alvo: gestores do estado de São Paulo. No entanto, o jogo foi pensado para ter acesso livre e irrestrito e seria hospedado pela UCRH. Hoje ele se encontra no endereço www.liderancaemjogo.com.br, mantido pelo autor da pesquisa, e requer um login para acesso $^{33}$.

A motivação para a construção do jogo veio da necessidade de prover métodos alternativos de treinamento que fossem capazes de auxiliar o gestor no aprendizado de aspectos importantes da gestão pública e da gestão em geral, em seu desenvolvimento. A intenção durante o desenvolvimento do jogo foi a de incorporar conceitos da Teoria da Administração, de forma que o jogo pudesse ser consistente do ponto de vista teórico.

O desenvolvimento do jogo procurou incorporar os quatro aspectos considerados importantes para gerar motivação intrínseca: desafio, controle, curiosidade e fantasia (Malone, 1981, Malone \& Lepper, 1987; Minovic et al., 2013) e foi dada atenção aos 23 elementos (dos quais esses quatro aspectos fazem parte) sintetizados por Bober (2010) para sua incorporação ao Liderança em Jogo. A Tabela 3.1 indica as medidas de game design tomadas para cada um desses elementos. Antes de sua utilização no experimento, o jogo foi objeto de um estudo piloto. Uma descrição geral sobre o funcionamento do jogo é apresentada no Apêndice A.

O piloto foi realizado com duas turmas de alunos do primeiro ano da FEA/USP, uma do curso de administração e outra do curso contabilidade. Os alunos foram solicitados a jogar pelo menos um dos dois ciclos que compõem o jogo e produzir, em duplas, um texto relacionando conceitos estudados na disciplina Fundamentos de Administração e o jogo. Antes do piloto, uma fase de testes foi necessária. Duas pessoas foram encarregadas de jogar o jogo de forma intensa para detectar eventuais bugs de programação. Apenas pequenos problemas foram reportados (erros ortográficos no texto de fala dos personagens, por exemplo) e as correções foram realizadas antes da realização do piloto.

\footnotetext{
${ }^{33}$ O leitor que tiver interesse pode entrar como convidado com o login: leitortese; e senha: tese2017
} 


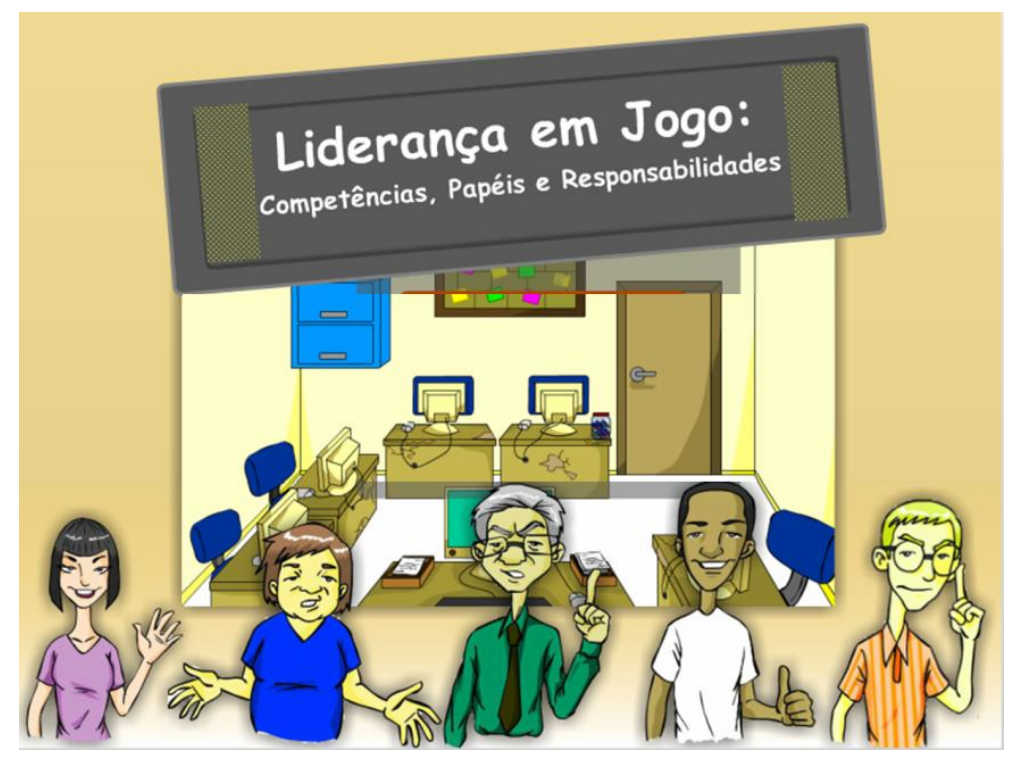

Figura 3.2 - Tela de abertura do jogo

Os alunos participantes do piloto produziram 63 trabalhos, cuja avaliação fez parte da composição da nota final dos alunos na disciplina. Essa medida visou garantir que todos os alunos (ou pelo menos metade deles) participassem da atividade, mesmo que com graus diferentes de interesse e de dedicação ao jogo.

Os trabalhos entregues, isto é, os textos produzidos, variaram em extensão e profundidade de abordagem. Porém, já fornecem indícios de que aspectos do jogo são mais notáveis pelos jogadores, embora os participantes do piloto estivessem orientados a buscar as relações entre os conceitos aprendidos ao longo do curso de Fundamentos de Administração e o jogo.

A análise dos trabalhos foi feita de maneira simples, envolvendo a leitura e a enumeração dos conceitos citados, com busca dos termos mais frequentes no conjunto de trabalhos. Essa análise permitiu a definição de uma ênfase sobre determinados conceitos para a construção do instrumento de avaliação do aprendizado para o experimento realizado, conforme descrição da próxima seção. 
Tabela 3.1 - Soluções de design do Liderança em Jogo dadas para incorporação dos elementos de jogo

\begin{tabular}{|c|c|c|}
\hline № & Elemento & Descrição \\
\hline 1 & Desafio & $\begin{array}{l}\text { Manter a área funcionando e melhorar a condição de trabalho são as situações } \\
\text { de desafio ligadas ao objetivo do jogo. Ao longo do jogo há ainda situações } \\
\text { específicas que devem ser resolvidas pelo jogador. }\end{array}$ \\
\hline 2 & Fantasia / narrativa & $\begin{array}{l}\text { O jogo se passa em uma secretaria fictícia (SFI) que possui características } \\
\text { comuns com os órgãos públicos do estado. Foram criados seis personagens } \\
\text { (Álvaro, Bruna, Carlos, Dirce, Eduardo e Fátima) que, em algum grau, } \\
\text { incorporam alguns estereótipos de trabalhadores e funcionários públicos. }\end{array}$ \\
\hline 3 & Feedback & $\begin{array}{l}\text { O jogador tem noção de como está gerindo a área a partir do acúmulo ou não de } \\
\text { processos de trabalho e das reclamações ou elogios vindos de outras áreas. Na } \\
\text { fase de aprimoramento foi incluída uma barra de pontuação para que o jogador } \\
\text { possa ter noção imediata de seu desempenho no jogo. }\end{array}$ \\
\hline 4 & Objetivos & $\begin{array}{l}\text { No tutorial, a chefe do jogador fala explicitamente nos dois objetivos do jogo: } \\
\text { manter a unidade funcionando (com entregas de qualidade dentro dos prazos) e } \\
\text { melhorar continuamente as condições de trabalho. Esses objetivos são } \\
\text { trabalhados implicitamente ao longo de todo o jogo. }\end{array}$ \\
\hline 5 & Estímulos sensoriais & $\begin{array}{l}\text { Embora não seja sonorizado, o jogo conta com um visual despojado, estilo } \\
\text { desenho animado. }\end{array}$ \\
\hline 6 & $\begin{array}{l}\text { Aspectos sociais / } \\
\text { comunidade }\end{array}$ & $\begin{array}{l}\text { O jogador pode comparar seu desempenho consigo próprio e sua evolução ao } \\
\text { longo das jogadas. Porém, na experiência de aprendizado proporcionada, os } \\
\text { jogadores interagiam na sala de aula para falar sobre aspectos do jogo. }\end{array}$ \\
\hline 7 & Aprendizagem ativa & $\begin{array}{l}\text { Muito do que os jogadores percebem no jogo se dá por tentativa e erro. Os } \\
\text { acontecimentos estimulavam os jogadores a buscarem entender o que se } \\
\text { passava e comparar as situações de jogo com a prática. }\end{array}$ \\
\hline 8 & $\begin{array}{l}\text { Adaptabilidade / } \\
\text { individualização }\end{array}$ & $\begin{array}{l}\text { O desenvolvimento do jogo não levou em conta que diferentes níveis de } \\
\text { familiaridade com jogos poderiam fazer diferença. No entanto, o jogo permite } \\
\text { que pessoas menos familiarizadas joguem num ritmo mais lento, enquanto os } \\
\text { mais habituados a jogos podem fazer as coisas de modo mais rápido. }\end{array}$ \\
\hline 9 & Avaliação & $\begin{array}{l}\text { Outros personagens do jogo dão dicas o tempo inteiro sobre as ações tomadas } \\
\text { pelo jogador. Os pontos e badges também são indicadores de desempenho na } \\
\text { gestão da unidade fictícia do jogo. }\end{array}$ \\
\hline 10 & $\begin{array}{l}\text { Autenticidade / } \\
\text { realismo / } \\
\text { fidelidade }\end{array}$ & $\begin{array}{l}\text { A vivência na área pública das pessoas que elaboraram o roteiro trouxe } \\
\text { elementos que se assemelham à realidade dos órgãos públicos. Um certo nível } \\
\text { de precariedade da infraestrutura foi introduzido no início do jogo, o que é, } \\
\text { infelizmente, um retrato de muitos órgãos públicos. }\end{array}$ \\
\hline 11 & Competição & $\begin{array}{l}\text { A pontuação permite que o jogador compita consigo mesmo a cada jogada. A } \\
\text { tabela de classificação (leaderboard) era mostrada como parte do curso em que } \\
\text { o jogo foi utilizado e permitia que os jogadores comparassem seus desempenhos } \\
\text { uns com os outros. }\end{array}$ \\
\hline 12 & Controle & $\begin{array}{l}\text { O jogador tem controle pleno sobre suas decisões. Há alguns elementos de } \\
\text { aleatoriedade na execução das tarefas pelos subordinados ao jogador/gestor que } \\
\text { foram intencionalmente adicionados com a intenção de mostrar que algumas } \\
\text { coisas não podem ser controladas pelo gestor. }\end{array}$ \\
\hline 13 & ativida & jogador é convidado a pensar de que maneiras pode planejar e controlar o \\
\hline
\end{tabular}




\begin{tabular}{|c|c|c|}
\hline $\mathbf{N}^{\mathbf{0}}$ & Elemento & Descrição \\
\hline 14 & Mistério / curiosidade & $\begin{array}{l}\text { serviço realizado em sua unidade. Abre-se espaço para diferentes soluções. } \\
\text { Algumas situações foram intencionalmente projetadas para surpreender o } \\
\text { jogador ou criar algum rompimento no fluxo "normal" do jogo. }\end{array}$ \\
\hline 15 & $\begin{array}{l}\text { Solução de desafios } \\
\text { (puzzle solving) }\end{array}$ & $\begin{array}{l}\text { Foram projetadas } 12 \text { situações-problema ao longo do jogo que precisam ser } \\
\text { solucionadas, mas que não impedem o avanço do jogo. }\end{array}$ \\
\hline 16 & $\begin{array}{l}\text { Tomada rápida de } \\
\text { decisões }\end{array}$ & $\begin{array}{l}\text { Em alguns momentos o jogador é pressionado a tomar decisões, mesmo que não } \\
\text { tenha todos os elementos necessários para resolver as questões. }\end{array}$ \\
\hline 17 & $\begin{array}{l}\text { Relevância / interesse } \\
\text { para o aprendiz }\end{array}$ & $\begin{array}{l}\text { A similaridade da unidade imaginária do jogo e dos personagens estereotipados } \\
\text { com a vida real é um aspecto projetado para que o jogo seja de interesse para os } \\
\text { jogadores. }\end{array}$ \\
\hline 18 & Recompensa & $\begin{array}{l}\text { Ao longo do jogo, à medida que o desempenho melhora, o jogador vê seu nível } \\
\text { aumentar. Quando o desempenho é satisfatório, o jogador recebe elogios da sua } \\
\text { chefe e das outras unidades da SFI, que correspondem aos badges da barra de } \\
\text { pontuação. }\end{array}$ \\
\hline 19 & Papel & O jogador é o gestor da unidade \\
\hline 20 & Regras & $\begin{array}{l}\text { O jogador é informado de como deve proceder para o adequado andamento dos } \\
\text { trabalhos na unidade do jogo }\end{array}$ \\
\hline 21 & Segurança & $\begin{array}{l}\text { O jogador pode errar à vontade e reiniciar o jogo quantas vezes quiser, sem } \\
\text { consequências ou impactos no mundo real. }\end{array}$ \\
\hline 22 & $\begin{array}{l}\text { Scaffolding e senso de } \\
\quad \text { progresso }\end{array}$ & $\begin{array}{l}\text { Esse aspecto é um pouco limitado no projeto do jogo, mas o jogador percebe } \\
\text { seu desenvolvimento como gestor no jogo à medida que as condições de } \\
\text { trabalho melhoram e à medida que não há mais acúmulo de processos. A chefe } \\
\text { do jogador e os funcionários dão dicas de como progredir no jogo. }\end{array}$ \\
\hline 23 & Transferência & $\begin{array}{l}\text { O jogo foi pensado para que o aprendizado dentro dele possa levar à reflexão } \\
\text { sobre as práticas do mundo real, com possível melhora de desempenho. Esse } \\
\text { elemento é o núcleo do objetivo do jogo: desenvolvimento dos gestores. }\end{array}$ \\
\hline
\end{tabular}

Após a realização do piloto, o jogo passou por uma fase de aprimoramento, a partir das percepções apresentadas pelos alunos que participaram dessa fase, bem como das colocações dos gestores públicos que tiveram contato com o jogo. O objetivo desse aprimoramento é contribuir para a geração de estado de fluxo e para tal tornará o jogo ainda mais game-like (Werbach, 2014). A ideia foi a de adicionar os elementos tradicionais de gamification, como o PBL (points, bagdes e leaderboard), criando-se uma barra de informações na interface com o jogador para que ele possa acompanhar seu desempenho. A tabela de classificação (leaderboard) é acessível apenas em nível administrador do jogo e pode ou não ser mostrada aos jogadores, dependendo do uso que se estiver fazendo do jogo. A Figura 3.3 apresenta a tela de jogo final, já com a barra de informações para deixar o jogo mais "gamificado". 


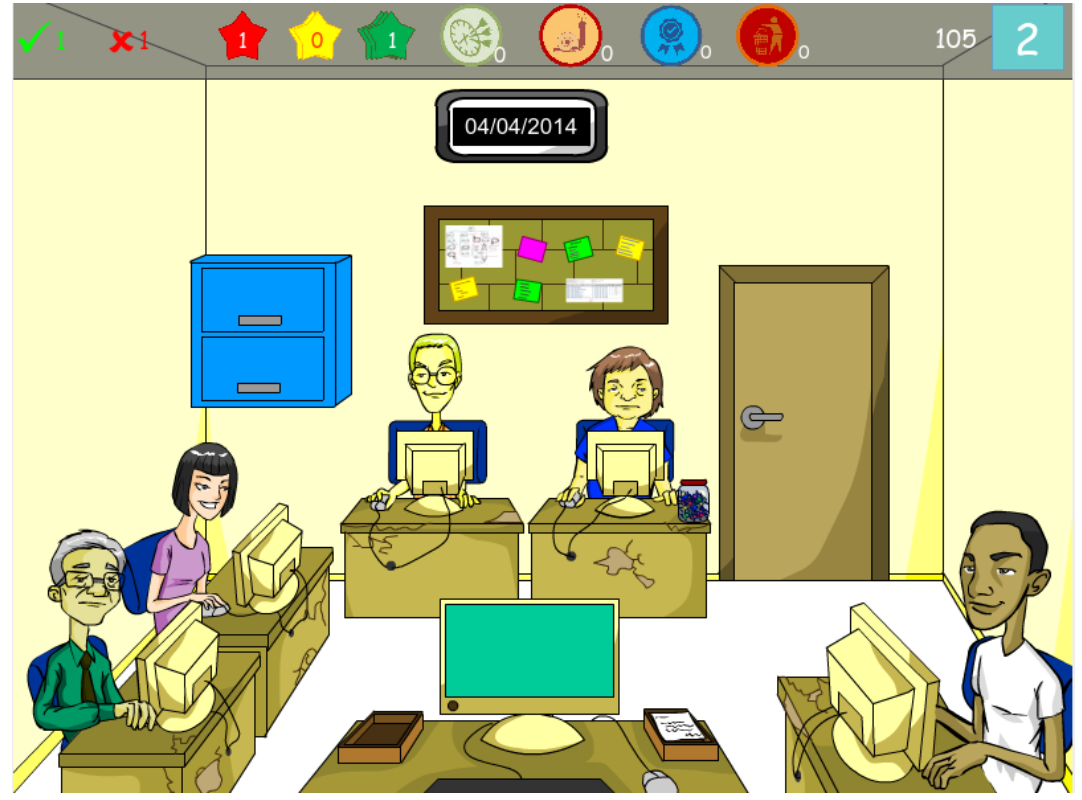

Figura 3.3 -Tela principal do jogo contendo barra de status: jogo mais "gamificado"

\subsection{Desenvolvimento do curso}

O curso em que o jogo foi aplicado foi intitulado "Gestão Pública: Teoria e Prática" e contou com a seguinte ementa:

I. Teorias basilares da gestão

II. Administração Pública versus Privada

III. Visão sistêmica

IV. O ciclo de planejamento-execução-controle

V. Papéis gerenciais

VI. Gestão do desempenho no setor público

O conjunto curso+jogo, o programa de treinamento desenvolvido para esta pesquisa, procurou seguir ao máximo as dicas de implantação de Salas et al. (2009) constantes na Tabela 2.8. Como para atingir o objetivo da pesquisa era necessário um grupo de controle, isto é, pessoas que assistissem ao mesmo curso e não tivessem acesso ao jogo, foram utilizadas atividades complementares com os mesmos objetivos do jogo (leituras de textos, discussões em grupo), mas sem o "princípio ativo", isto é, o ato de jogar em si. 
No total, foram realizadas três turmas. As duas primeiras, concomitantes, foram objeto do primeiro experimento da pesquisa. A terceira turma, realizada três meses depois, assistiu ao mesmo curso, mas com a introdução de alguns elementos, já considerando as lições aprendidas no primeiro experimento. A principal diferença é que, no primeiro experimento, uma das turmas (grupo experimental) utilizou o jogo durante diferentes momentos das aulas, enquanto a outra turma (grupo de controle) fez uso de atividades tradicionais (análise de casos e discussões), além das aulas expositivas, com o mesmo conteúdo para ambas as turmas. No segundo experimento, o jogo era uma atividade complementar, oferecido apenas à metade da turma como parte das atividades solicitadas a cada semana. A outra metade recebia atividades convencionais apenas (leituras e vídeos).

Os cursos, que tinham duração de 16 horas-aula, foram organizados pelo Centro de Treinamento e Desenvolvimento (CT\&D) do Centro de Formação (Cefor) da Secretaria do Estado da Saúde do Governo do Estado de São Paulo - SES-SP e foram realizados em salas de aula da unidade de pós-graduação em finanças da FIA, gentilmente cedidas para este estudo.

Cada aluno contava com um notebook à sua disposição durante todas as aulas do curso e podia acessar tanto o jogo (para o grupo experimental) quanto um portal customizado para o curso, por meio do Moodle (Modular Object-Oriented Dynamic Learning Environment), um software livre que constitui uma plataforma de acesso gratuito, utilizada por diversas instituições de ensino ao redor do mundo. Todo material de apoio ao curso foi disponibilizado online, bem como os questionários, que foram todos preenchidos online, durante o tempo de aula, na mesma plataforma, de maneira a eliminar eventuais etapas de transcrição e tabulação dos dados.

O uso do jogo ao longo do curso foi pensado sob a perspectiva do ciclo de aprendizagem experiencial de Kolb (Figura 2.20). A ideia é que o jogo fosse um componente vital do ciclo, sendo um espaço para experimentação ativa e, em certo grau, também o espaço para a experiência concreta. No restante do ciclo entra a importância de o jogo estar inserido num curso, ou, nos termos de Salas et al. (2009), um SBT. As aulas, discussões e outras atividades são o espaço dado para o aluno completar o ciclo, com a observação reflexiva e a conceituação abstrata. Dessa forma, ele pode voltar para a experimentação ativa no jogo e assim sucessivamente em seu processo de aprendizado. 


\subsection{Experimentos}

O cerne da etapa conclusiva da pesquisa foi a realização de um experimento ${ }^{34}$ que permitisse verificar o objetivo específico de número $4 \mathrm{e}$, por fim, respondesse ao problema de pesquisa, que é avaliar o impacto do uso de um jogo digital para o desenvolvimento de gestores públicos. Nas subseções a seguir, portanto, são descritos experimentos e características que precisam ser levadas em conta em estudos dessa natureza. Na sequência é exposto o desenho do experimento desta pesquisa, bem como são feitas considerações sobre as medidas tomadas para mitigar os riscos inerentes aos experimentos.

\subsubsection{Experimentos: descrição geral}

Ao contrário das ciências naturais, como astronomia, física e química, nas quais floresceu o interesse pela ciência tal qual a concebemos hoje, experimentos em áreas como saúde e educação se caracterizam pela dificuldade de controlar influências externas. Os controles feitos em laboratório para as ciências naturais funcionam de forma limitada nas ciências sociais. Dessa forma, foram desenvolvidos métodos para lidar com a influência externa, tais como atribuição aleatória ou a adição de um grupo de controle não aleatorizado (Shadish, Cook \& Campbell, 2002).

A força das conclusões que podem ser tiradas dos dados de um determinado estudo advém do fato de se tratar de um estudo experimental ou não experimental. Os experimentos são um dentre os diferentes métodos de pesquisa quantitativa e se diferenciam dos demais (não experimentais), pois são aqueles capazes de prover o teste mais rigoroso de hipóteses causais, ou seja, é o método que permite verificar se uma determinada relação observada entre variáveis é de causa e efeito (Tabachnicks \& Fidell, 2007; Gall, Gall \& Borg, 2007). Ainda, Shadish et al. (2002, p. 9, tradução nossa) reiteram que "a única força da experimentação está

\footnotetext{
${ }^{34} \mathrm{Na}$ prática, foram realizados dois experimentos similares. Mantém-se no singular no texto para preservar o espírito da pesquisa.
} 
em descrever as consequências atribuíveis à variação deliberada de um tratamento. Chamamos isso de descrição causal"35.

Uma das diferenças fundamentais da pesquisa experimental para a não experimental é que na primeira o pesquisador manipula as variáveis independentes. $\mathrm{O}$ pesquisador tem controle sobre pelo menos uma das variáveis independentes, definindo quando, como e a que nível da variável os sujeitos são expostos. Outras duas características especiais dos experimentos são a atribuição aleatória dos sujeitos aos diferentes níveis da variável independente (ou tratamento) e o controle de outros fatores que podem influenciar o fenômeno em questão (variáveis externas), mantendo-os constantes, contrabalanceando ou aleatorizando a sua influência (Tabachnicks \& Fidell, 2007; 2013).

Shadish et al. (2002, xvii) afirmam que os experimentos têm quatro requisitos para que uma relação causal seja obtida a partir deles: (1) variação no tratamento, (2) medidas dos resultados pós-tratamento, (3) que pelo menos uma unidade em que a observação seja feita e (4) um mecanismo para inferir qual seria o resultado se não tivesse havido tratamento (inferência contrafactual ou conterfactual inference, obtida geralmente pela utilização de grupos de controle).

Há diferentes termos sinônimos para tratar os conceitos da pesquisa experimental. Quando necessário, a terminologia adotada neste trabalho seguirá a utilizada por Tabachnicks e Fidell (2007). No entanto, é necessário definir alguns termos comumente utilizados associados a esse método e explicitar quais são os termos utilizados de maneira sinônima. Os termos que serão privilegiados, especialmente na análise dos dados e discussão dos resultados (Capítulo 4), estão em negrito. No entanto, podem ser utilizados seus sinônimos a fim de evitar repetições excessivas, por mera questão de estilo.

Os experimentos são estudos em que uma intervenção é deliberadamente introduzida para observar seus efeitos. Aqueles objetos submetidos à intervenção podem ser chamados genericamente de unidades (Shadish et al., 2002), que, no caso das ciências sociais, são

\footnotetext{
${ }^{35}$ The unique strenght of experimentation is in describing the consequences attributable to deliberately varying a treatment. We call this causal description
} 
pessoas, tratadas por indivíduos ou participantes (Gall et al., 2007) ou também por sujeitos ou casos (Tabachnicks \& Fidell, 2007).

Os experimentos podem ser de uma variável (one-variable experiments ou apenas one-way), isto é, quando apenas um fator é manipulado para observar a sua consequência sobre uma ou mais variáveis; ou pode ser fatorial, quando mais de uma variável ou condição é alterada para que seus efeitos sejam observados. O presente trabalho trata da situação one-way, ou seja, apenas uma condição foi alterada, que é o tipo de treinamento a que os participantes do experimento foram submetidos (treinamento com ou sem uso do jogo digital).

A variável manipulada (a causa) é usualmente chamada de tratamento experimental, mas também é chamada de variável independente, variável experimental, variável de tratamento ou intervenção (Gal et al., 2007). Alguns autores utilizam o termo variável independente (Tabachnicks \& Fidell, 2007). Analogamente, a variável observada (o efeito) será tratada por variável dependente, mas também é sinônimo de pós-teste ou variável critério (Gall et al., 2007) ou de resultado ou outcome (Tabachnicks \& Fidell, 2007). Além dessas, uma variável externa é qualquer variável que não o tratamento (variável independente) que pode afetar o resultado do experimento (Gall et al., 2007).

Outra ambiguidade que precisa ser desfeita é a da nomenclatura de pré-teste e pós-teste. Em geral, quando se fala de outros métodos de pesquisa quantitativa ou mesmo qualitativa, um pré-teste é uma simulação em escala menor da mesma pesquisa a ser feita, a fim de aprimorar o instrumento de coleta (ou roteiro de entrevista ou o que seja). Neste trabalho, esse conceito é tratado por piloto e já foi utilizado quando da descrição da aplicação do jogo a um grupo de pessoas em caráter de teste para seu aprimoramento. No que diz respeito aos métodos experimentais, a ideia é semelhante, mas o sentido é diferente, pois pré-teste é a medida da variável dependente feita antes da manipulação da variável independente (Gall et al., 2007). Por exemplo, em um experimento para testar um medicamento para baixar os níveis de pressão arterial dos pacientes, tirar uma medida da pressão arterial antes de aplicar o medicamento é um pré-teste. Por sua vez, o termo pós-teste representa a medida dessa mesma variável após a manipulação da variável independente (Gall et al., 2007). No exemplo, seria a medida da pressão arterial após submeter os pacientes ao tratamento com o medicamento (e 
eventualmente um placebo para parte das pessoas) para justamente avaliar os efeitos de sua aplicação.

Mais um termo comumente utilizado em pesquisas experimentais é o chamado grupo de controle. Esse termo usualmente se refere a um grupo de comparação (Gall et al., 2007), isto é, um grupo de pessoas que não recebe o tratamento ou recebe um tratamento alternativo (como o placebo do exemplo acima) para garantir que as mudanças na variável dependente observadas sejam causadas exclusivamente pela alteração no nível da variável independente.

Um exemplo trazido por Gall et al. (2007, tradução nossa) ajuda a deixar claros os conceitos descritos acima:

[...] considere um experimento para determinar o efeito de um novo programa de leitura sobre o desempenho dos estudantes em leitura [variável dependente]. $\mathrm{O}$ tratamento experimental [variável independente] seria a introdução do novo programa de leitura na rotina diária das atividades de aprendizado de um grupo de estudantes. O grupo de controle receberia o seu programa de leitura regular. O préteste seria uma medida do desempenho dos alunos em um teste de leitura feito antes de o novo programa ser introduzido no currículo. O pós-teste seria a medida do desempenho dos estudantes em um teste de leitura após terem passado pelo novo programa por um período de tempo ${ }^{36}$.

Com relação à afirmação sobre as mudanças observadas na variável dependente serem causadas exclusivamente pela alteração no nível da variável independente, é importante destacar que é justamente nesse fato que reside o poder dos experimentos. No entanto, isso só é possível devido às três características mencionadas acima (atribuição aleatória aos níveis da variável independente, manipulação dos níveis das variáveis independentes e controle das variáveis externas), que, dada sua importância no sucesso do experimento, são detalhadas na sequência. A ausência de cada uma dessas características dá origem a outros tipos de métodos, como os quasi-experimentos (sem atribuição aleatória), experimentos naturais (sem manipulação das variáveis independentes) e observações, surveys e outras pesquisas correlacionais (sem controle de variáveis externas) (Shadish et al., 2002).

\footnotetext{
${ }^{36}[\ldots .$.$] consider an experimente to determine the effect of a new Reading program on students' Reading$ achievement. The experimental treatment would be the introduction of the new reading program into the daily schedule of learning activities of a group of students. The control group would receive its regular reading program. The pretest would be the measure of students' reading achievement before the new reading program had been introduced into the curriculum. The posttest would be the measure of students' reading achievement after they had experienced the new program for a period.
} 
Os experimentos a que este trabalho se refere são também chamados de experimentos aleatórios ou aleatorizados (randomized experiments) ou experimentos verdadeiros (true experiments), em alusão à primeira característica desse método (a atribuição aleatória dos indivíduos), atribuída a Sir Ronald Fisher. Os experimentos aleatorizados teriam surgido na agricultura, mas rapidamente espalharam-se por diversas áreas, devido à possibilidade de controlar a variação originada por fatores externos em precisar do isolamento físico em um laboratório (Shadish et al., 2002). A atribuição aleatória deve ser utilizada por duas razões: (1) remover do estudo o viés do pesquisador (que poderia atribuir, mesmo que inconscientemente, as pessoas mais inteligentes para a condição que ele considera mais efetiva) e (2) para que as diferenças entre os casos sejam removidas, na média, pelo processo de aleatorização. A forma de garantir que isso seja feito é utilizar um processo aleatório para definir quais casos devem submeter a quais níveis da variável independente, como jogar uma moeda, utilizar uma tabela de números aleatórios ou mesmo fichas de pôquer (Tabachnicks \& Fidell, 2007). Neste trabalho, foram utilizados números aleatórios gerados em planilhas Excel.

Preocupados com que os pesquisadores possam atribuir seus resultados às causas estudadas, Mardsen \& Torgerson (2012) reforçam a importância do uso de experimentos aleatorizados com grupo de controle. Na maior parte dos estudos que não consideram grupos de controle, os chamados pré-experimentos, os resultados observados são normalmente advindos de efeitos de maturação, histórico ou regressão à média e não da intervenção propriamente. No entanto, estudos críticos da literatura demonstram que poucas pesquisas, em torno de $10 \%$, utilizam experimentos aleatorizados, design mais legítimo para testar relações causais, especialmente quando investigam relações de mediação de variáveis em HRD (Ghosh \& Jacobson, 2016). Isso reforça a necessidade do grupo de controle para se atingir o objetivo desta pesquisa.

A manipulação dos níveis do tratamento permite que o pesquisador controle tanto a natureza precisa de cada nível de tratamento quanto o momento em que ele deve ser realizado. $\mathrm{O}$ intuito dessa medida é mostrar que diferentes tratamentos levam a respostas médias diferentes e que as diferença na resposta média são produzidas pela manipulação de que grupo receberá qual tipo de tratamento (Tabachnicks \& Fidell, 2007).

Por fim, o controle de variáveis externas garante que apenas uma coisa muda durante o estudo, que é o nível de tratamento. Uma forma de controlar as variáveis externas e mantê-las 
constantes (por exemplo, colocando o mesmo instrutor para dar as aulas, na mesma hora do dia, com os mesmos exercícios solicitados aos alunos etc.). Espalhar as variáveis externas aleatoriamente pelos grupos do estudo é outra maneira de evitar sua influência, ou ao menos de esperar que seus efeitos se cancelem, em média. Outra forma de lidar com as variáveis externas é controlá-las e contrabalançar seus efeitos. Por exemplo, um estudo querendo avaliar o impacto do uso de um livro texto sobre os alunos poderia ser feito com quatro turmas, duas delas com aulas pela manhã e duas delas com aulas à tarde, sendo que em cada período uma turma utiliza o livro em questão e a outra utiliza um livro alternativo (Tabachnicks \& Fidell, 2007).

Essas características são importantes, pois falhas na garantia de que sejam respeitadas, ou ainda, problemas que possam decorrer delas ao longo do experimento podem afetar a validade do estudo. A próxima subseção descreve sucintamente os tipos de validade considerados em experimentos e possíveis ameaças que podem afetá-la.

\subsubsection{Experimentos e validade}

Uma das questões cruciais nos experimentos é a sua generalização. Em primeiro lugar, o pesquisador quer garantir que as mudanças observadas no pós-teste possam ser atribuídas às mudanças na variável independente. Do experimento que de fato cumpre essa exigência diz-se que é internamente válido (Gall et al., 2007). Entretanto, pelo menos num cenário ideal, o intuito de um experimento deve ser o de gerar teoria e para isso precisa ser válido em mais aspectos. Shadish et al. (2002) utilizam uma tipologia de quatro tipos de validade: validade de conclusão estatística, validade interna, validade de construto e validade externa. Segundo os autores, a validade se refere a uma verdade aproximada ou uma inferência. Hernandez, Basso e Brandão (2014) reforçam essa ideia afirmando que "validade é um termo utilizado para referir-se à aproximação entre a inferência e a verdade" (p. 109). 
Além disso, "quando dizemos que alguma coisa é válida, fazemos um julgamento sobre até que ponto evidência relevante suporta essa inferência como sendo verdadeira ou correta"37 (p. 34, tradução nossa). A Tabela 3.2 mostra a tipologia de validade apresentada pelos autores.

\section{Tabela 3.2 - Quatro tipos de validade}

Validade de conclusão estatística: A validade das inferências sobre a correlação (covariação) entre o tratamento e o resultado.

Validade interna: A validade das inferências sobre se uma covariação observada entre A (o tratamento presumido) e B (o resultado presumido) reflete uma relação causal de A para B uma vez que essas variáveis foram manipuladas ou medidas.

Validade de construto: A validade das inferências sobre os construtos de alta ordem que representam amostras particulares

Validade externa: A validade das inferências sobre se a relação de causa e efeito se mantém com variações nas pessoas, configurações, variáveis de tratamento e variáveis medidas.

Fonte: Shadish et al. (2002)

Basicamente, a validade interna diz respeito ao controle de variáveis externas pelo pesquisador, de maneira que qualquer efeito que seja observado possa ser atribuído apenas ao tratamento realizado, como já ressaltado acima (Gall et al., 2007). Ela responde à questão "de fato o estímulo experimental fez alguma diferença significativa nessa instância específica?"38 (Campbell, 1957, p. 297) e refere-se ao fato de a covariação resultar de uma relação causal (Shadish et al., 2002).

A validade de conclusão estatística refere-se ao uso apropriado da estatística para inferir se as variáveis dependente e independente são correlacionadas (Shadish et al., 2002). Essa questão se relaciona diretamente com o tamanho do efeito (effect size) e com o tamanho da amostra, discutida na subseção 3.4.5.

Tanto a validade externa quanto a validade de construto estão preocupadas com generalização. A primeira refere-se à extensão do resultado das amostras, configurações e momento do estudo para a população, outros momentos e outras configurações. Já a segunda diz respeito à generalização das operacionalizações para os construtos (Shadish et al., 2002). Isto é, se aquilo que o experimento se dispôs a medir representa de fato aquilo que deveria estar sendo medido.

\footnotetext{
${ }^{37}$ When we say something is valid, we make a judgement about the extent to which relevant evidence supports that inference as being true or correct.

${ }^{38}$ Did in fact the experimental stimulus make some significant difference in this specific instance?
} 
Shadish et al. (2002) elencam nove ameaças à validade de conclusão estatística (Tabela 3.3), que seriam as principais razões por que os pesquisadores podem errar ao fazer inferências sobre a existência de correlação entre duas variáveis e sobre o tamanho dessa correlação. Dentre essas ameaças, a principal questão é a do poder estatístico, tratada na subseção 3.4.5.

Tabela 3.3 - Ameaças à validade de conclusão estatística: razões pelas quais inferências sobre a correlação entre duas variáveis podem estar incorretas.

1. Baixo poder estatístico: Um experimento com poder insuficiente pode levar à conclusão incorreta de que a relação entre o tratamento e o resultado não é significativa.

2. Violação das premissas dos testes estatísticos: Violações das premissas do teste estatístico podem levar à superestimação ou subestimação do tamanho e significância do efeito.

3. Fishing e problema da taxa de erro: Testes repetidos para relações significativas, e não corrigidos para o número de testes, podem artificialmente inflar a significância estatística.

4. Medidas não confiáveis: Erros de medida enfraquecem a relação entre duas variáveis e reforçam ou enfraquecem as relações entre três ou mais variáveis.

5. Restrição da faixa: Uma faixa reduzida de uma variável usualmente enfraquece a relação entre ela e outra variável.

6. Implementação não confiável do tratamento: Se se pretende implantar o tratamento de uma maneira padronizada, mas implementa-se apenas parcialmente para alguns respondentes, os efeitos podem ser subestimados comparativamente à implementação completa.

7. Variância espúria na configuração experimental: Algumas características de uma configuração experimental podem inflar o erro, tornando a detecção de um efeito ainda mais difícil.

8. Heterogeneidade das unidades: Um aumento na variabilidade da variável de resultado dentro das condições aumenta a variância do erro, tornando a detecção de uma relação mais difícil.

9. Estimação do tamanho do efeito imprecisa: Algumas estatísticas superestimam ou subestimam sistematicamente o tamanho de um efeito.

Fonte: Shadish et al. (2002).

Ameaças à validade interna dizem respeito a problemas que podem ocorrer que invalidem a conclusão sobre a relação causal entre duas variáveis (Tabela 3.4). A maior parte delas pode ser evitada pelo próprio desenho do experimento e, também, pelo rigor ao seguir a atribuição aleatória dos sujeitos e pelo controle das variáveis externas. As ameaças à validade de construto, por sua vez, relacionam-se à correspondência entre os construtos utilizados e suas operacionalizações (Tabela 3.5). Já as ameaças à validade externa são problemas que impedem que os resultados encontrados no experimento sejam generalizados a outras situações, outras condições ou outras pessoas (Tabela 3.6). Por vezes, a validade externa pode ser dividida em validade populacional, ou seja, se os resultados podem ser generalizados para um grupo maior de pessoas, e validade ecológica, que trata da extensão dos resultados para 
outras condições ambientais, diferentes da do experimento (Gall et al., 2007). Os principais riscos no experimento deste estudo, bem como medidas para evitá-los, são tratados na subseção 3.4.4.

Tabela 3.4 - Ameaças à validade interna. Razões pelas quais a inferência sobre a relação causal entre duas variáveis pode estar incorreta

1. Precedência temporal ambígua: Falta de clareza sobre qual variável ocorreu primeiro pode levar a uma confusão sobre qual variável é a causa e qual é o efeito.

2. Seleção: Diferenças sistemáticas nas características dos respondentes de diferentes grupos analisados podem ser a causa para o efeito observado.

3. História: Eventos que ocorram simultaneamente ao tratamento podem ser a causa do efeito observado.

4. Maturação: Mudanças naturais que ocorram ao longo do tempo podem ser confundidas com o efeito do tratamento.

5. Regressão à média: Quando unidades (sujeitos) são selecionadas por suas pontuações extremas, elas frequentemente terão pontuações menos extremas em outras variáveis, o que pode ser confundido com o efeito do tratamento.

6. Desistência (mortalidade ou attrition): Perda de respondentes durante o experimento pode produzir efeitos artificiais se a perda estiver sistematicamente correlacionada com as condições do experimento.

7. Testes/provas: Exposição a um teste pode afetar a pontuação em exposições subsequentes a esse teste (ou outro similar), fato que pode ser confundido com o efeito do tratamento.

8. Instrumentação: A natureza da medida pode mudar ao longo do tempo ou sob determinadas condições de forma a ser confundida com o efeito do tratamento.

9. Interação seleção-maturação: Similar ao item 2 , exceto pelo fato de que a maturação é a variável de confusão. Diferenças de seleção ao longo do tempo (grupo de controle e experimental participam em momentos muito separados no tempo) podem gerar diferenças no efeito observado. 
Tabela 3.5 - Ameaças à validade de construto. Razões pelas quais inferências sobre os construtos que caracterizam a operacionalização do estudo podem estar incorretas.

1. Explicação inadequada dos construtos: Falha ao explicar adequadamente o construto pode levar a inferências incorretas sobre a relação entre a operacionalização e o construto.

2. Mistura de construtos: operacionalizações que envolvem mais de um construto e falhas ao descrever todos eles podem resultar em inferências incompletas dos construtos.

3. Viés mono-operacionalização: Qualquer operacionalização de um construto que sub-represente o construto de interesse e que meça construtos irrelevantes dificulta as inferências.

4. Viés mono-método: Quando todas as operacionalizações usam o mesmo método (por exemplo, autoavaliação), o método passa a fazer parte do construto em estudo.

5. Misturar construtos com os níveis dos construtos: Inferências sobre os construtos que melhor representem as operacionalizações do estudo podem falhar ao descrever os níveis do construto que foram na verdade estudados.

6. Estrutura fatorial sensível ao tratamento: A estrutura de uma medida pode mudar como resultado do tratamento, mudança que pode ficar escondida se a mesma pontuação (scoring) é sempre usada.

7. Mudanças autorreportadas reativas: Autoavaliações podem ser afetadas pela motivação do participante em estar na condição do tratamento, motivação que pode mudar após a atribuição dos indivíduos.

8. Reação à situação experimental: As respostas dos participantes refletem não apenas o tratamento e medidas mas também as percepções dos participantes da situação experimental e essas percepções são parte do construto do tratamento testado.

9. Expectativas do experimentador: O experimentador pode influenciar as respostas dos participantes ao transmitir expectativas sobre as respostas desejáveis e essas expectativas fazem parte do construto testado.

10. Novidade e efeitos disruptivos: Participantes podem, de uma forma não usual, responder bem a uma inovação ou mal àquilo que perturba sua rotina, uma resposta que deve ser incluída como parte da descrição do construto de tratamento.

11. Equalização compensatória de tratamentos: Se grupo experimental for submetido a uma condição que é desejável, os pesquisadores podem ser pressionados a oferecer uma compensação ao grupo de controle e essa ação deve ser incluída como parte da descrição do construto de tratamento.

12. Rivalidade compensatória pelo grupo de controle: Membros do grupo de controle se empenham para ter resultados melhores porque percebem que estão em competição com o grupo experimental e essa rivalidade compensatória deve ser incluída como parte da descrição do construto de tratamento.

13. Desmoralização ressentida do grupo de controle: Membros do grupo de controle se desmotivam se perceberem que o grupo experimental está recebendo uma condição desejável da qual estão sendo privados e essa desmoralização ressentida deve ser incluída como parte da descrição do construto de tratamento.

14. Difusão do tratamento experimental: Se a condição do tratamento é percebida como altamente vantajosa, os membros do grupo de controle podem tentar acessá-la. Se os participantes receberem tratamento de uma condição não atribuída a eles, as descrições dos construtos ficam mais difíceis.

Fonte: baseado em Shadish et al. (2002) e Gall et al. (2007). 
Tabela 3.6 - Ameaças à validade externa. Razões pelas quais inferências podem estar incorretas sobre como as conclusões do estudo se sustentariam variando-se as pessoas, configurações, tratamentos e resultados.

1. Interação da relação causal com as unidades (pessoas): Um efeito encontrado com certos tipos de unidades (pessoas) pode não se sustentar se outros tipos de unidades (pessoas) tivessem sido estudados

2. Interação da relação causal sobre as variações do tratamento: Um efeito encontrado com uma variação do tratamento pode não se sustentar com outras variações do tratamento ou quando o tratamento é combinado com outros, ou ainda quando apenas parte do tratamento for usada.

3. Interação da relação causal com os resultados: Um efeito encontrado em um tipo de observação de resultado pode não se sustentar se outras observações de resultado fossem usadas.

4. Interações da relação causal com as configurações: Um efeito encontrado em um tipo de configuração pode não se sustentar se outros tipos de configurações fossem usados.

5. Mediação dependente do contexto: Um mediador explicativo de uma relação causal em um contexto pode não mediá-la em outro contexto.

Fonte: Shadish et al. (2002).

Em experimentos de natureza semelhante ao deste trabalho, a questão da validade externa acaba ficando em segundo plano, sendo muito mais importante garantir a validade interna. Isso decorre do fato de, em geral, não ser possível utilizar amostragem aleatória que seja representativa da população de interesse. Por exemplo, de uma turma de alunos para o conjunto de alunos de uma cidade ou país (Gall et al., 2007). Ou, como no caso deste estudo, de um grupo de gestores do Governo do Estado de São Paulo disponível para a realização do experimento para gestores em geral, ou mesmo, para todos os gestores do Estado de São Paulo.

Bracht e Glass (1968) definem a população da qual a amostra foi colhida como a população experimentalmente acessível. Em geral, a população acessível é predominantemente local, isto é, definida pela proximidade com o pesquisador. O objetivo é o de generalizar os resultados da população experimentalmente acessível para uma população alvo (um grupo maior de indivíduos para o qual e pretende generalizar os resultados). Contudo, fazer essas generalizações pode ser arriscado. Seria necessário avaliar se as duas populações são similares em aspectos críticos (Gall et al., 2007). Essa generalização foge ao escopo e às pretensões deste trabalho.

Para Campbell e Stanley (1963) a validade interna é a condição sine qua non de um experimento. Isso por que, como complementam Cook e Campbell (1979), a principal razão 
para se realizar um experimento é a busca da relação causal, mais do que a sua generalização. Neste estudo, a preocupação é o fato de um jogo digital causar (ou não) o desenvolvimento dos gestores, seja por aquisição de novos conhecimentos, seja por mudanças de atitude com relação à gestão. Por esse motivo, a priorização é dada sobre a validade interna do experimento.

\subsubsection{Desenho do experimento}

Existe uma notação relativamente padronizada para simplificar a visualização dos desenhos de experimento (Campbell \& Stanley, 1963; Shadish et al., 2002; Gall et al., 2007). Uma letra $O$ seguida de um subscrito $\left(O_{1}, O_{2}\right.$ etc.) representa uma observação sobre algum dos grupos do experimento. Essa observação pode ser feita antes (pré-teste) ou depois (pós-teste) do tratamento, que é representado pela letra $X$. Quando há mais de um tratamento (design fatorial), outras letras são utilizadas $(Y, A$ ou $B)$. Um subscrito nas letras que designam os tratamentos indica o nível do tratamento, usualmente utilizado quando há mais de um nível para cada tratamento $\left(X_{1}, X_{2}, Y_{1}, Y_{2}\right.$, ou ainda, nos designs fatoriais, uma combinação de tratamentos $A_{1} B_{1}, A_{1} B_{2}$ etc.). Se houver atribuição aleatória dos casos aos tratamentos, a indicação é feita pela letra $R$ (a ausência da letra $R$ na representação do estudo representa um quasi-experimento).

Os experimentos do presente estudo estão estruturados com dois grupos (tratamento e controle). A representação conforme a notação apresentada é:

Experimento 1 (pré-teste/pós-teste):

$\begin{array}{cccc}R & O & X & O \\ R & O & & O\end{array}$

Experimento 2 (pós-teste apenas):

$\begin{array}{lll}R & X & O \\ R & & O\end{array}$

Os riscos à validade interna são anulados nesse tipo de experimento, por causa da aleatorização. Já os principais riscos à validade de construto nesses dois tipos de experimentos (com e sem pré-teste) são os mesmos: reação à situação experimental, equalização compensatória de tratamentos, rivalidade compensatória pelo grupo de controle, desmoralização ressentida do grupo de controle e difusão do tratamento experimental. A 
validade de conclusão estatística é obtida com o aumento do poder do experimento, que, no fundo, depende do tamanho da amostra e do tamanho do efeito observado, enquanto a validade externa é obtida pelas técnicas de amostragem e pela realização de experimentos semelhantes, a fim de generalização, exigência que não é foco do estudo.

\subsubsection{Riscos à validade e medidas de mitigação}

A população alvo para o experimento, como já descrito anteriormente, é um grupo de gestores e potenciais gestores do Governo do Estado de São Paulo. Os experimentos foram realizados com gestores da Secretaria do Estado da Saúde (SES). Os participantes foram convidados a participar de um curso sobre gestão pública, sem saber que se tratava de um experimento científico. No entanto, foram informados de que os dados coletados ao longo de sua participação seriam utilizados em um estudo acadêmico. Portanto, os grupos foram compostos por pessoas que se voluntariaram a participar do estudo.

A utilização do design de Solomon, usualmente feita com quatro grupos, para descartar problemas de validade com a possibilidade de o pré-teste influenciar o pós-teste (maturação e reação à situação experimental), demandaria grupos muito maiores e, por esse motivo, foi descartada. No entanto, optou-se por realizar o segundo experimento sem o pré-teste para que fosse possível, pelo menos em um dos casos, eliminar a ameaça de o pré-teste influenciar o pós-teste (maturação).

Como medida para mitigar os riscos associados às ameaças de equalização compensatória de tratamentos, rivalidade compensatória pelo grupo de controle e desmoralização ressentida do grupo de controle, depois do pós-teste, todos os participantes do grupo de controle tiveram acesso ao jogo e puderam utilizá-lo como parte integrante do curso e do processo de aprendizado. Porém, esse fato inviabilizou medidas comparativas posteriores ao curso, cerca de dois meses depois, com vistas a obter percepções sobre mudanças de comportamento e de atitude. Mesmo assim, foram documentadas as percepções colhidas nas entrevistas.

As entrevistas, ao lado da observação direta, são medidas sugeridas por Shadish et al. (2002) para lidar com esses riscos identificados. E para lidar com o risco de difusão, que nesse caso 
seria o de os participantes trocarem experiências sobre o que cada grupo está fazendo, o ideal é tentar isolar os grupos, o que não foi inteiramente possível, pois, por terem sido sorteados, participantes da primeira e segunda turmas do experimento 1 se conheciam e podem ter comentado sobre o tratamento (uso do jogo) uns com os outros. No decorrer do curso não foi registrado nenhum comentário nesse sentido. Já no experimento 2, por estarem na mesma turma tanto as pessoas submetidas ao tratamento quanto as do grupo de controle, houve o registro de dois participantes do grupo de controle que pediram acesso ao jogo durante o experimento. Apesar disso, os dados deles foram igualmente considerados na análise.

A blocagem é o processo de dividir as unidades nos grupos do experimento com distribuições semelhantes em uma variável, mantendo cada grupo com o mesmo número de unidades (pessoas) com determinadas características nos grupos. Por exemplo, garantir que o número de homens e o de mulheres sejam proporcionalmente iguais às características do grupo como um todo. O emparelhamento (matching) aparece muitas vezes como sinônimo da blocagem, mas noutras vezes é mais específico, significando que as unidades blocadas apareçam em número exatamente igual e não apenas similar nos grupos. Já a estratificação é o processo de criar grupos homogêneos em que os grupos experimentais tenham mais unidades que o grupo de controle (Shadish et al., 2002). O processo de aleatorização garante que os grupos sejam parecidos e, pelo fato de não haver outras variáveis que pudessem a priori influenciar o resultado, foi o sistema escolhido para ambos experimentos.

Levando em consideração tudo o que foi exposto nesta subseção, foi possível confeccionar a Tabela 3.7, que apresenta os principais riscos à validade identificados, uma avaliação qualitativa da sua probabilidade de ocorrência e seu impacto no experimento, bem como as medidas adotadas para evitá-los. 
Tabela 3.7 - Principais riscos ao experimento (ameaças à validade) e medidas para lidar com eles.

\begin{tabular}{|c|c|c|c|}
\hline Risco & Probabilidade & Impacto & Medida para lidar com o risco \\
\hline $\begin{array}{l}\text { Influência do pré-teste sobre } \\
\text { o pós-teste }\end{array}$ & Média & Moderado & O segundo experimento não teve pré-teste. \\
\hline Desistência (attrition) & Alta & Elevado & $\begin{array}{l}\text { Tentar garantir o compromisso das pessoas } \\
\text { que aderirem ao experimento (mitigação); } \\
\text { Fazer análises estatísticas que levem em conta } \\
\text { as perdas (aceitação). }\end{array}$ \\
\hline $\begin{array}{l}\text { Equalização e rivalidade } \\
\text { compensatórias, } \\
\text { desmoralização ressentida } \\
\text { pelo grupo de controle }\end{array}$ & Média & Moderado & $\begin{array}{l}\text { Compreender se há vantagem ou } \\
\text { desvantagem percebida. Oferecer } \\
\text { "tratamento" após experimento (eliminação); } \\
\text { entrevistas não estruturadas }\end{array}$ \\
\hline Difusão & Alta & Moderado & $\begin{array}{l}\text { O risco foi aceito. Apenas dois casos foram } \\
\text { registrados no segundo experimento e } \\
\text { considerou-se que não influenciaram o } \\
\text { resultado, pois os participantes não acessaram } \\
\text { o jogo durante o experimento }\end{array}$ \\
\hline
\end{tabular}

No contexto específico da avaliação do aprendizado por meio de jogos digitais (digital gamebased learning - DGBL), All et al.(2016) desenvolveram uma lista de boas práticas a serem adotadas pelos pesquisadores que vão realizar experimentos envolvendo jogos. A Tabela 3.8 reproduz as recomendações dos autores. Elas foram seguidas dentro do que foi possível na pesquisa. 
Tabela 3.8 - Resumo das melhores práticas para uma avaliação efetiva do DGBL

\begin{tabular}{|c|c|c|}
\hline Melhores práticas & Vantagens & Desvantagens \\
\hline \multicolumn{3}{|l|}{ Design da pesquisa (geral) } \\
\hline \multicolumn{3}{|l|}{ 1. Grupo de controle } \\
\hline 1.1 Grupo de controle 1: "business as usual" & $\begin{array}{l}\text { Controlar se os resultados não resultam apenas da passagem } \\
\text { do tempo }\end{array}$ & Requer amostra maior \\
\hline & Comparar aspectos motivacionais & \\
\hline 1.2 Grupo de controle 2: jogo sem conteúdo educacional & Comparar aspectos motivacionais & Requer amostra maior \\
\hline 2. Pré-teste & $\begin{array}{l}\text { - Controlar diferenças pré-existentes entre o grupo } \\
\text { - } \quad \text { Determerimental e o de controle } \\
\text { resultado da intervesçcão / ganhos de aprendizagem como } \\
\text { - Tornar possível controlar características dos desistentes } \\
\text { (i.e. desistência aleatória ou não aleatória) }\end{array}$ & Efeitos práticos \\
\hline $\begin{array}{l}\text { 3. Similaridade entre grupo experimental e de controle deve: } \\
\text { a) aleatorizar os sujeitos }\end{array}$ & $\begin{array}{l}\text { Grupos balanceados com respeito a variáveis observadas e } \\
\text { não observadas }\end{array}$ & Requer amostra maior \\
\hline b) aletorizar as classes/escolas & Frequentemente mais prático em pesquisa educacional & Influência da classe/professor/escola \\
\hline c) emparelhar (desenho aleatório em blocos) & Controlar similaridade entre as condições & $\begin{array}{l}\text { Variáveis latentes não emparelhadas } \mathrm{p} \\
\text { resultado }\end{array}$ \\
\hline $\begin{array}{l}\text { 4. Estudo de follow-up (Mínimo duas semanas após o fim da } \\
\text { intervenção). }\end{array}$ & $\begin{array}{l}\text { - Controlar efeitos de novidade } \\
\text { - Controlar resultados positivos como efeito de } \\
\text { treinamento intensivo }\end{array}$ & Desistência \\
\hline \multicolumn{3}{|l|}{ Intervenção } \\
\hline 5. Sessão de treinamento & $\begin{array}{l}\text { - Pode reduzir a necessidade de ajuda procedural durante } \\
\text { a intervenção } \\
\text { - É utilizada menos carga cognitiva para aprender a } \\
\text { trabalhar com o ambiente do jogo }\end{array}$ & Pode enviesar o resultado \\
\hline $\begin{array}{l}\text { 6. DGBL como única intervenção } \\
\text { 6.1 Não adicionar elementos que contenham informação substancial } \\
\text { 6.2 Papel do instrutor reduzido à ajuda procedural }\end{array}$ & Potenciais misturas são reduzidas & Validade ecológica pode ser reduzida \\
\hline \multicolumn{3}{|l|}{ 7. Tipo do instrutor } \\
\hline a) Pesquisador & Controle experimental maior & Validade ecológica é comprometida \\
\hline b) Pessoa familiar & Aumenta a validade ecológica & $\begin{array}{l}\text { - Menor controle experimental } \\
\text { - Influência dos professores }\end{array}$ \\
\hline 8. Similaridade entre intervenções deve ser assegurada por & Potenciais misturas são reduzidas & Validade ecológica pode ser reduzida \\
\hline
\end{tabular}




\begin{tabular}{|c|c|c|}
\hline Melhores práticas & Vantagens & Desvantagens \\
\hline $\begin{array}{l}\text { 8.1 exposição temporal } \\
\text { 8.2 Conteúdo } \\
\text { 8.3 Suporte recebido } \\
\text { 8.4 Ambiente } \\
\text { 8.5 Ciência do momento de teste } \\
\text { 8.6 recompensa pela participação }\end{array}$ & & \\
\hline $\begin{array}{l}\text { Participantes } \\
\text { 9. Mínimo } 20 \text { participantes por condição }\end{array}$ & $\begin{array}{l}\text { Determinar diferenças nas variáveis dependentes entre } \\
\text { grupos }\end{array}$ & $\begin{array}{l}\text { Análises mais sofisticadas não são possíveis (ex: } \\
\text { ajustamento de covariância) }\end{array}$ \\
\hline $\begin{array}{l}\text { Medidas } \\
\text { 10. Validade de instrumento }\end{array}$ & - Ter sido validado & \\
\hline 10.1 Testes padronizados & $\begin{array}{l}\text { - Prover sugestões com relação ao tempo requerido entre } \\
\text { pré e pós-teste para aplicar o mesmo teste }\end{array}$ & $\begin{array}{l}\text { - Pode não cobrir exatamente o que discutido pelo jogo/ } \\
\text { aula tradicional }\end{array}$ \\
\hline 10.2 Teste ad hoc desenvolvido pelo pesquisador & $\begin{array}{l}\text { - Alinhamento mais próximo ao conteúdo tratado pelo } \\
\text { jogo/ aula presencial }\end{array}$ & $\begin{array}{l}\text { - Estudo piloto é necessário } \\
\text { - Conteúdo pode ser demasiadamente alinhado ao } \\
\text { conteúdo tratado pelo jogo/ aula }\end{array}$ \\
\hline 11. Realização dos estudantes (ex: pontuação em exames) & - Medida de validade ecológica & $\begin{array}{l}\text { - Pode ser influenciada por outros fatores além do jogo/ } \\
\text { intervenção de controle } \\
\text { - Alunos podem vir da mesma escola (ou mesmo } \\
\text { classe) } \\
\text { - Relevante apenas para intervenções de longo prazo } \\
\text { (ex: semestre todo) }\end{array}$ \\
\hline $\begin{array}{l}\text { Análise de dados } \\
\text { 12. Medidas repetidas }\end{array}$ & - Analisar interação entre condição e tempo & $\begin{array}{l}\text { - Diferenças com respeito às variáveis dependentes } \\
\text { entre os grupo podem existir antes da intervenção }\end{array}$ \\
\hline $\begin{array}{l}\text { 13. Adicionar efeitos aleatórios, se observados } \\
\text { 14. Adicionar as características dos participantes como covariáveis } \\
\text { (ex: experiência com jogos, habilidades com computador, destreza). }\end{array}$ & $\begin{array}{l}\text { Estimativa mais precisa do efeito do tratamento } \\
\text { Levar em conta diferenças individuais de forma a } \\
\text { determinar para quem as intervenções DGBL são mais } \\
\text { benéficas }\end{array}$ & $\begin{array}{l}\text { Requer amostra maior } \\
\text { Requer amostra maior }\end{array}$ \\
\hline
\end{tabular}

Fonte: All et al. (2016) 


\subsubsection{Poder e tamanho da amostra}

Em um contexto experimental (na verdade, de qualquer teste estatístico), considerando-se que a hipótese nula $\left(H_{0}\right)$ do teste é a de que não existe efeito, enquanto a hipótese alternativa $\left(H_{a}\right)$ é aquela que corresponde à existência do efeito, de uma relação causal no experimento, quatro possibilidades podem ocorrer. (1) $H_{0}$ é verdadeira (não há efeito) e o pesquisador não a rejeita (decisão correta); (2) $H_{0}$ é verdadeira, mas o pesquisador a rejeita (decisão incorreta), dando origem ao erro tipo I, $\alpha$; (3) $H_{0}$ é falsa (existe o efeito) e o pesquisador a rejeita (decisão correta); e (4) $H_{0}$ é falsa, mas o pesquisador não a rejeita (decisão incorreta), dando origem ao erro tipo II, $\beta$ (Tabachnicks \& Fidell, 2007).

Assim, a situação mais desejável em um experimento é a de encontrar um efeito que realmente exista (situação 3). A probabilidade de rejeitar corretamente uma hipótese nula falsa, que é esse caso, é o chamado poder estatístico, dado por $1-\beta$ (Shadish et al., 2002). O poder, portanto, representa a probabilidade de que um efeito que realmente existe tenha uma chance de produzir significância estatística na análise de dados (Tabachnicks \& Fidell, 2013). $\mathrm{O}$ valor normalmente utilizado para $\alpha$ é de $0,05(=5 \%)$. Assim, em qualquer teste estatístico em que o nível de significância seja 5\% (intervalo de confiança de 95\%), se a estatística do teste resultar em uma probabilidade inferior a 5\% (nível descritivo), rejeita-se a hipótese nula e diz-se que há o efeito. Mas, em vez de se olhar cegamente para esse valor, é importante ter em mente o que esse conceito significa. A estatística do teste, em geral, sinaliza a probabilidade de aquele resultado ter acontecido por mero acaso. Dependendo do fenômeno que se quer estudar ou das condições em que foram realizados os estudos, é importante considerar níveis de significância superiores a 5\%. Uma probabilidade de 10 a $15 \%$ de um resultado ser fruto do acaso pode ser indício de um efeito real. Por isso, neste trabalho, procurou-se sempre estar atento ao resultado do nível descritivo dos testes com seu significado em mente, confrontando-se os resultados não apenas com os 5\% usualmente aceitos, mas, em muitos casos, também com os $10 \%$.

Contudo, o valor de $\alpha$ tem implicações sobre o poder do teste. Existe um trade-off entre os erros tipo I e tipo II e uma das maneiras de se aumentar o poder do teste é justamente aumentando-se $\alpha$, o que significa aumentar o erro do tipo I. Outras maneiras para se ter um maior poder no teste estatístico são: aplicar tratamentos mais fortes (que faria as médias 
ficaram mais distintas entre os grupos), reduzir a variabilidade entre os resultados de cada tratamento por meio de um controle experimental maior e aumentar o tamanho da amostra. Normalmente, como são interconectados, a partir de um nível de significância ( $5 \%$, por exemplo) e de um poder desejado ( $80 \%$ ou $85 \%$, em geral), calcula-se o tamanho da amostra (Tabachnicks \& Fidell, 2007).

O cálculo do tamanho da amostra é feito com base nos cálculos apresentados por Chow, Shao e Wang (2008), pela fórmula:

$$
n=2\left(\sigma \frac{z_{1-\alpha /(2 \tau)}+z_{1-\beta}}{\mu_{A}-\mu_{B}}\right)^{2}
$$

Na equação acima, $n$ é o tamanho da amostra, enquanto $\sigma$ é o desvio padrão (a variabilidade esperada); $\tau$ representa o número de combinações a serem feitas, que, para $k$ grupos, é dado por $k(k-1) / 2$, que é o número de combinações de $k$ grupos, dois a dois. $\mu_{A}-\mu_{B}$ representa a diferença entre as médias de dois grupos e $z$ é o valor na distribuição normal padrão correspondente a determinada área $(95 \%$ para $1-\alpha$ e $85 \%$ para $1-\beta$, com correções no caso da comparação de mais de dois grupos).

Na situação real, entretanto, o tamanho da amostra é dado, já em função das desistências observadas nos dois grupos. Assim, o cálculo é inverso. Estipulando-se um nível de significância, calcula-se o poder do teste. Esse passo é feito automaticamente pelos softwares estatísticos. Os resultados são apresentados no Capítulo 4.

\subsubsection{Método de análise}

Considerando que o experimento do presente trabalho consiste de duas medidas (pré-teste e pós-teste) com dois grupos (tratamentos e controle), uma das formas apropriadas para tratar esse tipo de coleta é por meio da análise de variância - ANOVA, do inglês analysis of variance (Tabachnicks \& Fidell, 2007). Trata-se de uma técnica estatística que compara a variância entre os grupos (between-groups) e a variância dos indivíduos dentro dos grupos (within-groups). Se a razão entre a variância entre grupos e a de dentro dos grupos for 
suficientemente alta, há indicações de que há mais diferença entre os grupos do que dentro dos grupos (Gall et al., 2007). A Tabela 3.9 apresenta uma visão simplificada dos dados coletados em um arranjo similar ao do experimento deste trabalho.

Tabela 3.9 - Representação das medidas tomadas (pré-teste e pós-teste) com os dois grupos do experimento.

\begin{tabular}{ccccccc}
\hline \hline & \multicolumn{2}{c}{ Tratamento } & & \multicolumn{2}{c}{ Controle } \\
\cline { 2 - 3 } \cline { 6 - 6 } caso & Pré-teste & Pós-teste & Caso & Pré-teste & Pós-teste \\
\hline$s_{1}$ & $O_{1,1}$ & $O_{2,1}$ & $s_{6}$ & $O_{1,6}$ & $O_{2,6}$ \\
$s_{2}$ & $O_{1,2}$ & $O_{2,2}$ & $s_{7}$ & $O_{1,7}$ & $O_{2,7}$ \\
$s_{3}$ & $O_{1,3}$ & $O_{2,3}$ & $s_{8}$ & $O_{1,8}$ & $O_{2,8}$ \\
$s_{4}$ & $O_{1,4}$ & $O_{2,4}$ & $s_{9}$ & $O_{1,9}$ & $O_{2,9}$ \\
$s_{5}$ & $O_{1,5}$ & $O_{2,5}$ & $s_{10}$ & $O_{1,10}$ & $O_{2,10}$ \\
\hline \hline
\end{tabular}

Nota: Por simplicidade, são apresentados apenas 10 sujeitos no experimento, 5 por grupo.

O intuito é verificar se, em média, há aumento da pontuação média entre o pós-teste e o préteste para os diferentes níveis da variável independente $\left(X_{1}\right.$ : jogo) com relação ao grupo de controle. Existem duas formas para abordar essa questão. A primeira é utilizar uma variável dependente que corresponde ao ganho na pontuação entre o pré-teste e o pós-teste $\left(O_{2}-O_{1}\right)$. A segunda possibilidade é tratar o esquema da pesquisa como uma ANOVA fatorial, com o tratamento como um fator e o pré-teste/pós-teste como um segundo fator.

Com relação à primeira possibilidade, com a utilização do ganho de pontuação ou da pontuação ganha (gain score), apesar de ser uma abordagem simplificadora, alguns problemas podem ocorrer. Gall et al. (2007) relatam 5 pontos de atenção para o uso de ganhos de pontuação:

(1) efeito de teto: se a faixa de pontuação é limitada, pontuações altas não podem melhorar mais do que um teto. Por exemplo, um estudante que tenha uma nota de 90 em um préteste de 100 questões não pode melhorar mais do que 10 pontos, diferentemente de quem faz 60 pontos no mesmo teste.

(2) regressão à média: é o fenômeno que descreve a tendência de participantes que têm pontuações muito altas (ou muito baixas) piorarem (ou melhorarem) no próximo teste pelo simples fato de obterem pontuações mais próximas à média.

(3) premissa de intervalos iguais: ganhos de pontuação assumem que os intervalos em todos os pontos do teste são iguais, o que nem sempre é verdadeiro. No exemplo do teste de 
100 pontos possíveis, um ganho de 90 para 95 não deveria ser tido como igual ao de 40 para 45.

(4) diferentes tipos de habilidades: o ganho de pontuação nos testes pode refletir diferentes tipos e níveis de habilidade dos participantes. Uma mesma pontuação total de duas pessoas pode representar uma distribuição completamente diferente dentro dos "subtestes" que compõem a avaliação.

(5) baixa confiabilidade: quanto maior a correlação entre o pré-teste e o pós-teste, menor é a confiabilidade da mudança na pontuação.

Assim, uma forma de lidar com as mudanças de pontuação é por meio da ANOVA de medidas repetidas (Gall et al., 2007; Tabachnicks \& Fidell, 2007). Há ainda uma terceira possibilidade que é utilizar uma análise de regressão múltipla (Tabachnicks \& Fidell, 2007; Gall et al., 2007).

Entretanto, a melhor alternativa para experimentos que consideram pré-testes e pós-testes é a utilização da Análise de Covariância (ANCOVA) (Dean \& Voss, 2000; Cobb, 1998). Essa análise envolve ajustar a variável de resposta observada ao efeito de uma variável concomitante ou covariável. Trata-se de um método para ajustar os efeitos de uma variável não controlada (Montgomery, 2013). O pré-teste representa, portanto, o conhecimento prévio dos participantes do experimento e seu controle aumenta a precisão da observação do efeito, se houver (Cobb, 1998).

Cabe salientar, ainda, que a $\mathrm{ANOVA}^{39}$ apresenta quatro premissas que devem ser cuidadosamente verificadas antes de sua aplicação: (1) Normalidade da distribuição das médias para cada nível; (2) Independência dos erros; (3) Homogeneidade da variância; e (4) Ausência de outliers. Existem testes estatísticos para verificar cada uma das premissas. E em caso de violação delas, existem medidas que podem ser adotadas para manter a robustez do teste (Tabachnicks \& Fidell, 2007).

\footnotetext{
39 Quando a comparação é entre dois grupos, a ANOVA é equivalente o conhecido teste-t, sendo que as estatísticas de relacionam da seuite forma: $F=t^{2}$ e o nível descritivo dos testes (p-valor) é igual.
} 
A ANCOVA traz, ainda, algumas premissas adicionais às da ANOVA. Ela assume uma relação linear entre a covariável e a variável de resposta, com a mesma inclinação para cada tratamento (Dean \& Voss, 2000). Além disso, não pode haver diferenças estatisticamente significativas para a covariável entre os grupos (Cobb, 1998). A violação da primeira dessas premissas adicionais indica que a técnica não é a mais indicada para os dados em questão; e a violação da segunda premissa pode indicar a presença de uma interação do tipo atitudetratamento (ATI - aptitude-treatment interaction). Isso significa que os indivíduos demonstram desempenho diferente em função dos tratamentos devido alguma variável atitudinal não controlada no experimento, por exemplo, uma característica do aluno, um atributo ou habilidade, ansiedade, estilo de aprendizagem ou motivação (Johnson, 2016).

Na prática, o teste de cada uma dessas premissas da ANOVA é dado por procedimentos simples com o auxílio de softwares estatísticos. A normalidade da distribuição das médias para cada nível da variável independente é feita com os testes de distribuição normal, em geral Komolgorov-Smirnov ou Shapiro-Wilk. A independência dos erros pode ser verificada com os mesmos testes, porém, efetuados para os resíduos, isto é, para a diferença entre as medidas experimentais e as médias obtidas para cada grupo. A homogeneidade da variância pode ser avaliada com o teste estatístico de Levene. Tanto nesse caso quanto nos testes de normalidade, deseja-se obter um nível descritivo (p-valor) superior ao nível de significância estabelecido (em geral, $\alpha=0,05$ ). Por fim, a ausência de outliers é facilmente verificada com o uso de box-plots (Cobb, 1998; Tabachnicks \& Fidell, 2007). A verificação das premissas adicionais da ANCOVA é feita por meio de ajustes lineares entre a covariável (pré-teste) e a variável de resultado medida (pós-teste) para cada grupo (Dean \& Voss, 2000; Johnson, 2016).

Quando as premissas da ANOVA não são satisfeitas, pode-se partir para dois caminhos com o intuito de verificar se há diferenças entre dois grupos: (1) efetuar uma transformação de variáveis, de modo que ela possa atender as premissas da técnica ou (2) utilizar um teste não paramétrico. Para os casos deste trabalho, optou-se pela utilização do teste $U$ de MannWhitney. Diferentemente do teste $t$ ou da ANOVA, que testam a igualdade de médias, o teste $U$ de Mann-Whitney verifica a igualdade de medianas. Os valores de $U$ calculados pelo teste avaliam o grau de entrelaçamento dos dados dos dois grupos após a ordenação. A maior separação dos dados em conjunto indica que as amostras são distintas, rejeitando-se a hipótese de igualdade das medianas. 


\subsubsection{Instrumentos para avaliação do desenvolvimento dos gestores}

Como já destacado, o desenvolvimento dos gestores é pensado sobre a perspectiva da aquisição do conhecimento e da mudança de comportamento, que são as formas como usualmente se pensa o aprendizado, ao mesmo tempo em que se faz a associação com o desenvolvimento de competências em termos de conhecimentos, habilidades e atitudes (CHA). A atitude é vista como um antecedente para a mudança de comportamento (Ajzen, 1991) e por esse motivo, uma das análises pretendeu avaliar se, após o curso, havia entre o grupo experimental e de controle, diferença na percepção sobre a gestão. Ainda, tentou-se colher, qualitativamente, impressões sobre mudanças de comportamento com entrevistas (experimento 1) e consulta online (experimento 2) passado um tempo da realização do curso, especificamente dois meses após o experimento 1 e três meses após o experimento 2.

Inicialmente, o instrumento para avaliar o aprendizado dos participantes no experimento foi pensado para trabalhar o conhecimento do ponto de vista do domínio cognitivo. Dessa forma, o cerne da avaliação do aprendizado está em focar aspectos tratados no curso e no jogo e perceber se houve ganho de aprendizado antes e depois do tratamento (aplicação dos níveis da variável independente do experimento aos grupos de participantes).

Com base nos resultados do piloto, foram elencados três temas considerados relevantes para serem tratados no curso e que tinham relação com o jogo para compor a avaliação de aprendizado. O primeiro deles trata do processo de planejamento, execução e controle (PEC) em administração e segundo assunto foi visão sistêmica (VS), enquanto o terceiro foram os papéis gerenciais (PG). Foram desenvolvidas questões diretas (múltipla escolha, preenchimento de lacunas, relação de colunas etc.) sobre cada um dos três temas. Cada questão foi categorizada com base em um dos verbos da taxonomia de Bloom (lembrar, entender, aplicar e analisar), cobrindo os quatro primeiros níveis de classificação em nível cognitivo. De maneira direta, as questões também foram enquadradas em níveis de profundidade do conhecimento (DoK) de Webb, sendo considerados apenas o nível um (DoK1, correspondendo aos verbos "lembrar" e "entender") e o nível 2 (DoK2, correspondendo aos verbos "aplicar" e "analisar"). A Figura 3.4 ilustra a lógica da classificação e seleção das questões para compor o instrumento de avaliação, que constitui uma métrica para o aprendizado. 


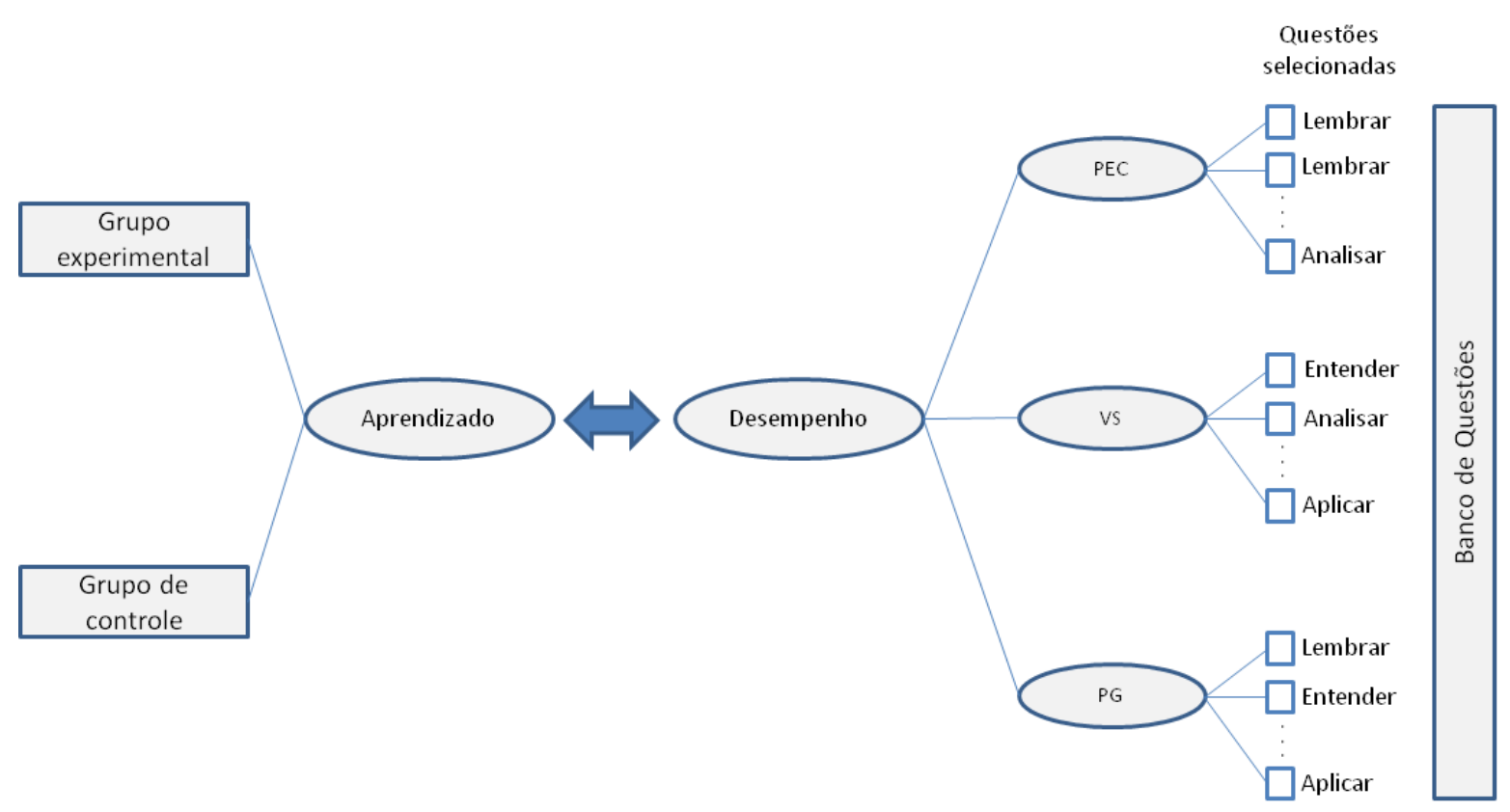

Figura 3.4 - Esquema da construção do instrumento de avaliação e a relação do desempenho do participante com o aprendizado

No primeiro experimento, as questões foram sorteadas tanto no pré-teste quanto no pós-teste, mantendo-se um número fixo de questões por tema para todos os participantes. Pode ser que um mesmo participante tenha respondido à mesma questão no pré-teste e no pós-teste, mas também havia probabilidade de determinadas questões só serem vistas em um dos dois testes. O conjunto de questões gerou uma pontuação que poderia variar de zero a dez. Já no segundo experimento, em que houve apenas o pós-teste, decidiu-se aplicar a mesma avaliação para todos, ou seja, todas as pessoas responderam às mesmas questões.

O que diferiu o primeiro experimento do segundo experimento, como já dito brevemente, foi o fato de, no primeiro, duas turmas diferentes, geradas por sorteio, fazerem o mesmo curso, mas apenas uma delas utilizar o jogo em aula (Turma 2). A outra turma (Turma 1) fez outras atividades complementares no período equivalente ao do jogo para a outra turma. Por outro lado, no segundo experimento havia uma única turma (Turma 3) e, como o jogo era uma atividade externa às aulas, os participantes de cada grupo recebiam uma lista de tarefas a cada semana. Para o grupo experimental as tarefas englobavam jogar o Liderança em Jogo enquanto para o grupo de controle uma outra tarefa (ler um texto, ver um vídeo) substituía o jogo. 
Outra questão considerada foi a avaliação do aprendizado sob a perspectiva da mudança de comportamento. Essa mudança de comportamento não deve ser confundida com o comportamentalismo ou behaviorismo (Anderson \& Krathwohl, 2001). Contudo, trata-se de um conceito de mais complexa operacionalização. De qualquer maneira, é preciso que um intervalo de tempo decorra entre o tratamento e a medida. Alguns participantes do primeiro experimento foram escolhidos e foi feita uma entrevista semiestruturada dois meses após o curso. Por limitações operacionais, foram feitas apenas seis entrevistas. Já com relação ao segundo experimento, foi enviado um e-mail (consulta online) perguntando sob a percepção dos participantes em relação ao impacto do jogo sobre seu trabalho três meses após o curso. Contudo, como o acesso ao jogo foi oferecido como medida compensatória logo após as medidas do pós-teste, não se pode considerar os dados obtidos como experimentais, servindo apenas para alguns insights qualitativos. Como é comum nesse tipo de pesquisa, apenas cinco pessoas retornaram.

Como destacado acima, uma medida de atitude com relação à gestão foi considerada como antecedente à mudança de comportamento. Ela foi obtida a partir dos textos produzidos no fim do curso pelos participantes do primeiro experimento. Por simplicidade, observou-se se o texto produzido apresentava visões de gestão de um ponto de vista mais tradicional (visão hard), focado em planejamento e controle, ou uma visão mais focada no lado humano, na interação, motivação e comunicação, ou seja, mais atenta às soft-skills (visão soft). Os detalhes são apresentados no Capítulo 4.

A Figura 3.5 apresenta uma visão esquemática da linha do tempo do experimento, facilitando a compreensão da sequência de ações utilizada na etapa conclusiva da pesquisa. Por sua vez, a Tabela 3.10 apresenta os instrumentos de coleta utilizados nos experimentos, considerando os quatro níveis de avaliação do modelo de Kirkpatrick, bem como quais as hipóteses do estudo que se relacionam com as medidas. As hipóteses são detalhadas na próxima subseção. 
Experimento 1

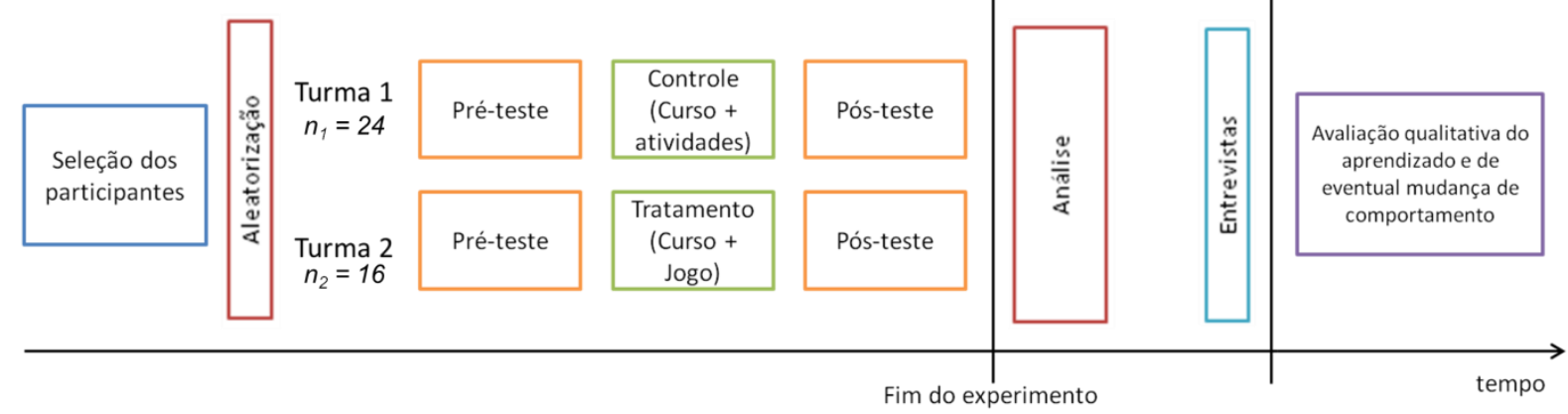

Experimento 2

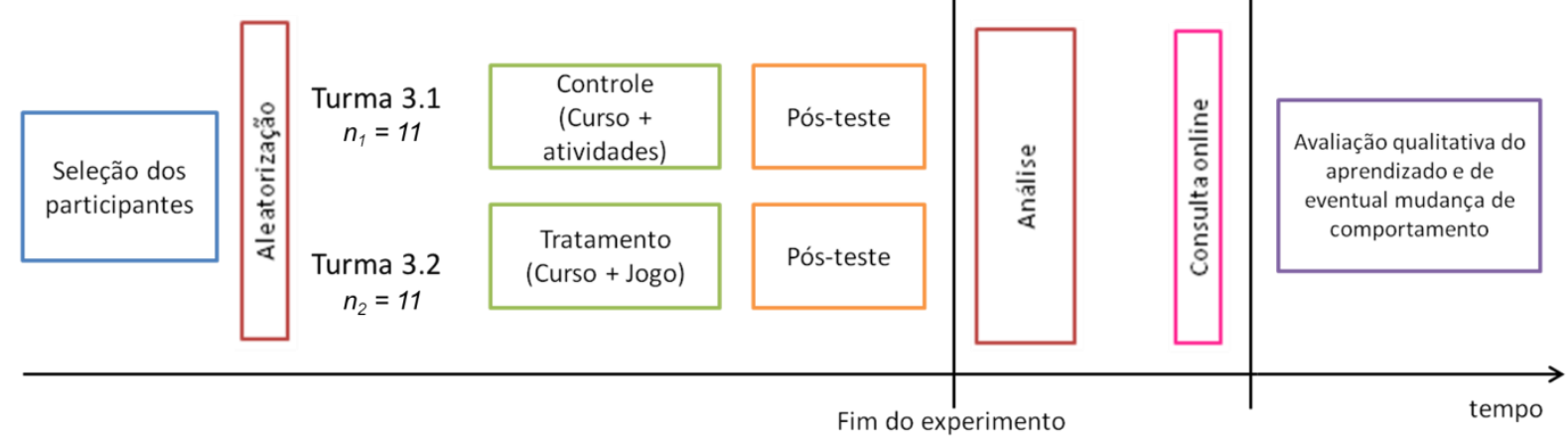

Figura 3.5 - Linha do tempo da realização dos experimentos.

Cabe ainda ressaltar que as entrevistas foram gravadas e posteriormente transcritas para, assim como os textos produzidos, serem analisadas pela técnica de análise de conteúdo. Segundo Martins e Theóphilo (2009) essa é uma técnica utilizada para se estudar e analisar a comunicação de maneira objetiva e sistemática. "Buscam-se inferências confiáveis de dados e informações com respeito a determinado contexto, a partir dos discursos escritos ou orais de seus atores e/ou autores" (p. 98). Bardin (2008) completa essa visão ao dizer que a análise deve ocorrer por meio de procedimentos objetivos e sistemáticos de forma que se possa fazer a inferência, isto é, conectar elementos do discurso à categoria conceitual inferida.

Tabela 3.10 - Resumo dos instrumentos de coleta utilizados nos experimentos

\begin{tabular}{llcll}
\hline \multicolumn{1}{c}{$\begin{array}{c}\text { Nível de } \\
\text { avaliação }\end{array}$} & Instrumentos utilizados & Exp 1 & Exp 2 & \multicolumn{1}{c}{ Hipóteses relacionadas } \\
\hline $\begin{array}{ll}\text { Nível 1: } \\
\text { Reação }\end{array}$ & $\begin{array}{l}\text { Questionário IMMS baseado } \\
\text { no modelo ARCS (Apêndice }\end{array}$ & $\checkmark$ & $\checkmark$ & $\bullet \mathrm{H}_{1 \mathrm{~A}}-$ ARCS \\
\hline
\end{tabular}




\begin{tabular}{|c|c|c|c|c|}
\hline $\begin{array}{c}\text { Nível de } \\
\text { avaliação }\end{array}$ & Instrumentos utilizados & Exp 1 & $\operatorname{Exp} 2$ & Hipóteses relacionadas \\
\hline & $\begin{array}{l}\text { - Questionário padronizado da } \\
\text { SES-SP (Anexo 1) }\end{array}$ & $\checkmark$ & $\checkmark$ & - $\mathrm{H}_{1 \mathrm{~B}}-$ Reação \\
\hline $\begin{array}{l}\text { Nível 2: } \\
\text { Aprendizado }\end{array}$ & $\begin{array}{l}\text { Avaliação com questões } \\
\text { diretas para compor } \\
\text { (Apêndice E): } \\
\circ \text { pré-teste } \\
\circ \text { pós-teste }\end{array}$ & $\begin{array}{l}\checkmark \\
\checkmark\end{array}$ & $\checkmark$ & - $\mathrm{H}_{2}$ - Conhecimentos \\
\hline $\begin{array}{l}\text { Nível 3: } \\
\text { Comportamento }\end{array}$ & $\begin{array}{ll}\text { - } & \text { Textos produzidos sobre a } \\
\text { percepção sobre gestão } \\
\text { (mudança de atitude- } \\
\text { experimento 1) (Apêndice H) } \\
\text { - } & \text { Entrevistas (Apêndice I) } \\
\text { - } & \text { consulta online (Apêndice I) }\end{array}$ & $\checkmark$ & $\checkmark$ & $\begin{array}{l}\text { - } \mathrm{H}_{3} \text { - Atitude sobre a gestão } \\
\text { - Dados não experimentais }\end{array}$ \\
\hline $\begin{array}{l}\text { Nível 4: } \\
\text { Resultados }\end{array}$ & $\begin{array}{l}\text { - Questionário sobre } \\
\text { expectativa de impacto do } \\
\text { curso sobre o resultado } \\
\text { organizacional (Apêndice J) }\end{array}$ & & $\checkmark$ & - $\mathrm{H}_{4}-$ Resultados projetados \\
\hline
\end{tabular}

\subsubsection{Hipóteses dos experimentos}

As hipóteses são guias de orientação para uma investigação. São definidas como tentativas testáveis que predizem o que se espera encontrar nos dados (Sekaran \& Bougie, 2009). Assim, de forma sucinta, são apresentadas a seguir as hipóteses consideradas para a etapa conclusiva da pesquisa, seguindo a lógica da avaliação do treinamento em quatro níveis. Na prática, elas se associam ao último objetivo específico do trabalho e são descritas como segue:

\footnotetext{
$H_{1}$ : Quem joga tem uma reação mais favorável ao curso/treinamento com relação a quem não joga.
}

$\mathrm{H}_{2}$ : Quem joga aprende mais os conceitos de administração com relação a quem não joga.

$H_{3}$ : Quem joga muda de atitude com relação à gestão, passando a vê-la como diferente do tradicional com relação a quem não joga. 


\section{H4: Quem joga percebe maior influência do curso/treinamento na projeção de} resultados de seu trabalho com relação a quem não joga

Na prática, a hipótese $H_{l}$ é testada pela comparação das pontuações médias obtidas pelos grupos de tratamento e controle nos construtos do modelo ARCS da motivação para o aprendizado (Keller, 2010) e também pela distribuição de "excelente", "bom”, "regular" ou "ruim" atribuída pelos dois grupos no questionário de reação aplicado ao término do curso.

A hipótese $\mathrm{H}_{2}$ é operacionalizada pela pontuação que o participante obtém em um teste (avaliação/prova). Ou seja, o objetivo é observar se a pontuação do grupo que joga (tratamento) é superior à pontuação do grupo que de controle.

Essa hipótese pode ser desmembrada em sub-hipóteses para mensurar os resultados por conceito avaliado (PEC, VS e PG). E o mesmo pode ser feito considerando-se os níveis da taxonomia de Bloom, operacionalizada pela classificação das questões por verbos, ou da profundidade de conhecimento (DoK) de Webb, pois cada uma dessas subdivisões permite um teste estatístico específico.

A hipótese $H_{3}$ traz a ideia subjacente de que a mudança de atitude antecede a mudança de comportamento (Ajzen, 1991). Assim, ela foi avaliada com base na visão sobre gestão que os participantes do experimento apresentaram ao término do curso. O intuito era o de comparar se os grupos veem a gestão de forma diferente, tanto mais atreladas à visão tradicional da gestão, apoiada no comando e controle (visão hard) ou mais preocupada com os processos interpessoais (visão soft).

Por fim, a hipótese $H_{4}$ se concretiza na comparação da pontuação atribuída em diferentes itens do questionário de resultado projetado. Esses itens apresentam diferentes aspectos do trabalho e são avaliados pelo respondente em que grau ele imagina que o curso pode contribuir (ou não) para a melhora em um componente do trabalho, que é tratado em maior ou menor grau, direta ou indiretamente, no jogo e no curso realizado. 


\subsection{Descritivo dos experimentos realizados}

\subsubsection{Experimento 1}

O primeiro experimento foi realizado com as duas primeiras turmas do curso especialmente desenvolvido para este trabalho (Gestão Pública: Teoria e Prática), compostas de gestores e aspirantes a gestores da Secretaria do Estado da Saúde do Governo do Estado de São Paulo (SES-SP). Foram oferecidas 90 vagas (a capacidade da sala era de 45 pessoas) e os inscritos foram sorteados, com uso de números aleatórios em uma planilha Excel, para compor a Turma 1 (controle, isto é, sem a utilização do jogo durante o curso) ou a Turma 2 (tratamento experimental, isto é, utilização do jogo durante o curso). Trata-se de um experimento completamente aleatorizado.

O curso do primeiro experimento foi realizado durante duas semanas no período de 28 de novembro a 08 de dezembro de 2016. O ideal seria ter sorteado inclusive os dias em que cada turma participaria dentre todas as datas disponíveis para realização do curso (Cobb, 1998), o que não foi possível, visando facilitar o processo para os participantes e para a organização das turmas. Assim, foi necessário fixar uma turma às segundas e quartas-feiras e outra às terças e quintas-feiras. Contudo, uma das quintas-feiras precisou ter sua aula transferida para uma sexta-feira, em função de um conflito de datas com um evento importante da SES-SP e esse fator pode explicar um menor número de alunos presentes nessa turma. A Turma 1 (controle), programada para segundas e quartas-feiras, foi concluída por 24 pessoas, enquanto a Turma 2 (tratamento), programada para terças e quintas-feiras, por 16 pessoas. As turmas 1 e 2 foram iniciadas por 28 e 22 pessoas, respectivamente.

A média de idade dos participantes do curso foi de 42,9 $\pm 9,1$ anos e o tempo médio de casa foi de $7,6 \pm 8,9$. Dos concluintes, $85 \%$ eram do sexo feminino e $15 \%$ do sexo masculino. Essa distribuição de idade, tempo de casa e gênero é representativa da SES-SP.

Nesse experimento, foram feitas diferentes coletas de dados. Para avaliar a reação foi desenvolvida uma variação do questionário IMMS focada em aspectos gerais do curso. Além 
dela, o questionário padrão utilizado pelo Cefor foi aplicado e também teve seus dados analisados.

O aprendizado foi avaliado na forma de pré-teste e pós-teste, ou seja, com uma avaliação feita no início do curso e outra no fim. Foi construído um banco com 37 questões, das quais 18 foram sorteadas para o pré-teste e o pós-teste, blocadas por assunto, garantindo que os participantes respondessem ao mesmo número de questões sobre cada tema. No pós-teste foram ainda adicionadas três questões, com conceitos que foram tratados nas aulas e que faziam parte da dinâmica do jogo. Cada um dos testes poderia resultar em uma nota de 0 a 10 . As questões, bem como o desempenho das turmas em cada uma delas, são apresentadas no Apêndice E.

Visando-se avaliar o comportamento (nível 3 do modelo de Kirkpatrick) foi construído um instrumento baseado na teoria do comportamento planejado (Ajzen, 1991). Porém, verificouse durante a etapa de entrevistas com alguns dos participantes que o questionário estava muito distante de atingir seus objetivos, indicando problemas em sua elaboração. Por essa razão, seus resultados não serão apresentados aqui.

Foi também solicitado aos alunos que produzissem, ao final do curso, pequenos textos em que eles dissessem quais os papéis e responsabilidades de um gestor, segundo sua opinião. Esses textos foram analisados à luz da análise de conteúdo para se buscar verificar diferenças de visão entre quem jogou e quem não jogou. No decorrer da análise, notou-se que esses textos continham percepções sobre a gestão que a caracterizavam sob uma perspectiva mais soft (preocupada com as interações e as soft-skills) ou hard (tradicional, focada em comando e controle). A frequência de percepções hard e soft foi considerada como uma métrica da atitude do participante sobre a gestão e, como já se sabe, a atitude é um antecedente da mudança de comportamento.

Por fim, após dois meses da realização do curso, foram realizadas seis entrevistas com os participantes com um duplo objetivo: (1) fazer eventuais correções de rota para o segundo experimento e (2) ter uma percepção daqueles que jogaram o jogo de quais poderiam ter sido os aprendizados que ele propiciou e quais impactos eles imaginavam que ter jogado poderia ter sobre a prática e os comportamentos deles. 


\subsubsection{Experimento 2}

O segundo experimento também contou com a participação de gestores da Secretaria do Estado da Saúde, com perfil semelhante ao do primeiro experimento ${ }^{40}$. O seu design foi um pouco diferente do primeiro, de forma que o jogo (tratamento) foi atribuído também aleatoriamente, mas como uma tarefa complementar ao curso e não uma atividade para ser realizada durante as aulas. Essa medida foi influenciada pela percepção de alguns entrevistados de que o jogo "tirava tempo de aula". Assim, com uma turma única, outras variáveis puderam ser controladas, como o dia e horário do curso e as aulas, garantindo-se rigorosamente que todos os alunos assistissem às mesmas aulas. A turma contou com 27 inscritos, inicialmente sorteados nos dois grupos, sendo 14 para o grupo experimental e 13 para o grupo de controle. Dos inscritos, 22 participantes terminaram o curso, sendo 11 de cada grupo.

Além da diferença na forma de aplicação do tratamento, o curso contou com outras atividades complementares (leituras e vídeos), fornecidos para os dois grupos, exceto um conjunto de leituras e vídeos destinado apenas ao grupo de controle, de forma a equilibrar a quantidade de horas de atividades com relação ao grupo experimental.

Nesse segundo experimento, para não haver sobrecarga aos participantes, optou-se pela não aplicação do pré-teste. Assim, pôde-se utilizar o mesmo instrumento para todos os participantes como pós-teste, sem aleatorização das questões, que foram selecionadas com base nos percentuais de aproveitamento do primeiro experimento, havendo um equilíbrio entre questões fáceis, médias e difíceis. Foram separadas um total de 23 questões, novamente em um teste que podia ter notas de 0 a 10.

O instrumento IMMS utilizado para mensuração da motivação para o aprendizado foi também reformulado para o segundo experimento, focando em questões mais específicas relacionadas

\footnotetext{
${ }^{40}$ Por algum motivo que foge ao controle do pesquisador, os dados descritivos das pessoas que participaram do segundo experimento foram perdidos. Essas informações são armazenadas pelo CT\&D da SES-SP e não estavam mais disponíveis após a realização do experimento. Contudo, o centro de treinamentos informou que o perfil do grupo era o mesmo das turmas anteriores.
} 
às atividades (dentre as quais se incluía o jogo). As versões utilizadas na pesquisa são apresentadas no Apêndice C.

Para o segundo experimento foi desenvolvido um instrumento adicional de coleta focado em aferir se os participantes veriam algum tipo de influência do curso nos resultados de seu trabalho - resultado projetado (nível 4 do modelo de Kirkpatrick). Esse questionário substituía a elaboração dos textos, o que, no momento do desenho experimental, ainda não se tinha percebido sua conexão com o nível 3 do modelo de Kirkpatrick. 


\section{RESULTADOS}

Este capítulo apresenta resultados da pesquisa. Cabe recuperar o problema de pesquisa proposto: "qual o impacto do uso de jogos digitais para o desenvolvimento de gestores públicos?", lembrando que, para estruturação da fundamentação teórica, ele foi dividido em duas partes (1) uso de jogos digitais e (2) avaliação do impacto sobre o desenvolvimento de gestores públicos.

Assim, o primeiro passo da investigação foi, uma vez caracterizado que o uso de jogo seria a sua aplicação em um curso/treinamento, verificar se o jogo, além de cumprir os requisitos preconizados pela teoria de game design, atenderia seu objetivo com relação ao desenvolvimento dos gestores. Esse passo foi importante, pois não se tratava de um "jogo de prateleira", de forma que o desenvolvimento do Liderança em Jogo foi considerado uma importante etapa do trabalho. Feita essa verificação, pôde-se partir para a execução dos experimentos que respondem ao problema de pesquisa.

Este capítulo se estrutura seguindo essa lógica. Na primeira seção são apresentadas as evidências de que o jogo se caracteriza como uma ferramenta adequada para o desenvolvimento de gestores, com base no piloto realizado e com informações qualitativas extraídas das entrevistas realizadas após o primeiro experimento. As demais seções focam o núcleo da pesquisa e dividem-se de acordo com os níveis de avaliação do modelo de Kirkpatrick, o que corresponde ao quarto objetivo específico da pesquisa (OE4).

\subsection{Considerações sobre o uso do jogo: piloto e desenvolvimento do curso}

Entre fevereiro e junho de 2015 foi realizado um piloto da aplicação do jogo com estudantes de graduação da Faculdade de Economia, Administração e Contabilidade da Universidade de São Paulo. Duas turmas do curso de Fundamentos de Administração, uma com alunos de contabilidade e outra com alunos de administração, foram convidadas a jogar o "Liderança em Jogo" ao longo do semestre e, no fim do período letivo, produzir um trabalho relacionando seu aprendizado na disciplina com o aprendizado que o jogo propiciou. 
Foram produzidos 63 trabalhos (28 da turma de contabilidade e 35 da turma de administração), por duplas de alunos.

Os trabalhos foram analisados qualitativamente e foram utilizados com dois objetivos: (1) validar a dinâmica do jogo, colhendo percepções dos alunos para avaliar que características do game design eles percebem mais facilmente e (2) subsidiar o desenvolvimento do curso em que se realizou o experimento desta pesquisa, procurando observar quais conceitos da teoria foram mais relacionados ao jogo, com vistas a se criar uma ementa consistente, mas também relacionada ao público-alvo de gestores públicos. A validação do game design, isto é, se o jogo desenvolvido realmente funciona como tal, foi complementada pelas entrevistas realizadas após o primeiro experimento, com vistas a obter evidências de que os elementos necessários do game design para seu uso como instrumento de aprendizado estão presentes no Liderança em Jogo.

Todos os trabalhos foram lidos e foi avaliada sua adequação com relação ao solicitado aos alunos (relacionar o jogo ao conteúdo visto ao longo da disciplina). Trechos de alguns desses trabalhos foram selecionados para ilustrar que (1) os alunos/jogadores entenderam a dinâmica do jogo, (2) eles relacionaram os acontecimentos do jogo à teoria vista na disciplina em que o jogo se inseriu, e (3) houve aprendizado sobre a prática de gestão. A Tabela 4.1 traz os trechos exemplificadores, por categoria. Naturalmente, é mostrada apenas uma ínfima fração dos comentários produzidos nos trabalhos, a título ilustrativo. Os trechos selecionados mostrados na tabela somam pouco menos de 1.000 palavras, enquanto a soma de todo o conteúdo dos 63 trabalhos é um documento com mais de 50.000 palavras. Só a análise pormenorizada dessa documentação poderia constituir uma pesquisa inteira específica, mas com objetivos distintos deste trabalho. Por isso, optou-se por apenas ilustrar as percepções dos participantes do piloto.

Tabela 4.1 - Trechos exemplificadores dos trabalhos do piloto

\begin{tabular}{cl}
\hline \hline Categoria & \multicolumn{1}{c}{ Comentário } \\
\hline & "Por meio da observação destes dados, o gestor pode perceber, claramente, que \\
& Eduardo é o funcionário mais motivado, visto que é o mais eficiente na \\
Aspectos sobre a & produção de processos, obtendo o terceiro maior aproveitamento em qualidade \\
dinâmica do jogo & ótima, a maior porcentagem de licitações entregues no prazo estipulado, o maior \\
& comprometimento (assiduidade) da equipe, ou seja, foi o funcionário que obteve \\
& a máximo desempenho geral." \\
\hline
\end{tabular}




\begin{tabular}{ll}
\hline \hline Categoria & Comentário \\
\hline
\end{tabular}

"Por exemplo, Carlos possui facilidade com TI, editais que envolvam TI a prioridade será dele, a prospecção de talentos normalmente resultou em nota máxima de qualidade e entregas no prazo"

"Conforme os funcionários são requisitados para cada tipo de processo, ele acaba se tornando mais eficaz nas subsequentes tarefas da mesma natureza."

"Carlos é ótimo em processos relacionados a informática enquanto Dirce é boa em processos de aquisição de materiais. Ao contrário de Dirce que não gosta de processos de contratação de serviços, Bruna é ótima em realizar esta tarefa. Já Álvaro é bom em processos de interesse pessoal e Eduardo é excelente em processos difíceis e urgentes."

"Muitas vezes teve que se enfrentar o trade off entre prazo e qualidade"

"Existe uma interligação entre prazo e qualidade. Quanto mais se acumula processos, maior é a cobrança e o stress do funcionário, o que diminui a sua produtividade e rendimento. Portanto, aumenta a chance de entregar um trabalho atrasado e mal feito, o que pode ser interpretado como falta de planejamento e competência pelo cliente."

"devemos decidir onde temos que aplicar os recursos disponíveis levando em conta as necessidades do setor e as opiniões dos cinco colaboradores. Essa decisão influencia no desempenho geral do seu setor."

"ao decorrer do jogo, diferentes funcionários (com comprometimento e modo de trabalhar distintos), ao trabalhar em processos de mesma natureza, obtiveram resultados semelhantes. [...] podemos concluir que, nem sempre existe 'a única maneira correta de realizar trabalhos', mas Taylor foi sensato ao propor que o gestor delegasse 'os papéis aos atores certos' ".

Relação do jogo com as teorias vistas na disciplina
"Como um bom gestor foi preciso em todo momento planejar a quem seria dado cada processo e organiza-los em ordem de importância e prazo e é claro nunca esquecer de monitorar o andamento e a qualidade de cada processo, sendo preciso muitas vezes prescrever aos funcionários que refazessem (sic) os processos até que estes atingissem boa ou ótima qualidade".

"Era necessário acompanhar de perto o andamento de cada processo e quando este era preciso ser refeito era fundamental rever a agenda e conferir se era realmente possível refazê-lo [...] A comparação entre metas e produtividade serve de parâmetro para saber que tem algo errado na organização, ou para ver como melhorar as condições de trabalho."

Aprendizados sobre a "Esta 'vivência' demonstra que o gestor deve ter sensibilidade para perceber as vivência em gestão características particulares dos membros de sua equipe, mas também deve 
"Aspectos da 'vida real', como a pressão de superiores para cumprir metas (individuais e globais), críticas e elogios, dentre outros, podem influenciar sua atuação e abordagem para com os funcionários".

"Uma opção, é a de não sobrecarregar os funcionários para não pressioná-los muito (eles acabam dando um feedback quando estão sendo sobrecarregados), não solicitar tarefas com prazos muito apertados, caso contrário, os funcionários irão entregar um edital de baixa qualidade"

"O retrabalho é bastante oneroso, toma praticamente o mesmo tempo que um trabalho começado do zero, no começo do jogo quando distribuímos sem parcimônia os trabalhos, verificamos que o retrabalho atrasa todos os demais prazo do planejamento."

"nota-se que pressionar demais os funcionários enchendo-os de processos não garante bons resultados, no contexto do jogo isso se mostrou "ineficiente". Observa-se que é necessário entender as pessoas com as quais se trabalha, pois nem todas entregam bons resultados quando estão sob pressão"

"Um bom gerente é aquele que consegue enxergar os pontos fracos e pontos fortes dos seus funcionários, e assim, planeja-los para que haja uma harmonia e máxima eficiência no trabalho."

"Percebe -se uma mudança na produtividade dos participantes ao trabalharem em um caso/processo que os agrada, fato que pode ser explicado pela psicologia e pelas teorias motivacionais já estudadas. Cabe ao gestor perceber tal fenômeno e designar seus funcionários para as tarefas em que eles mais se encaixam, visando o máximo de produtividade possível."

"Portanto, um bom levantamento de dados ajuda não só no dia a dia da organização como também ajuda a lidar com imprevistos que podem surgir no 


\begin{tabular}{l}
\hline Categoria \\
\hline meio do caminho". \\
"Inicialmente, o jogo pode parecer como uma simples distribuição de trabalhos, \\
porém logo percebemos que os cinco colaboradores possuem personalidades, \\
defeitos e aptidões diferentes. A parte mais difícil na liderança, e \\
principalmente no jogo, está na identificação das características dos \\
funcionários para que os trabalhos possam ser realizados dentro do prazo e com \\
alta qualidade". \\
"Se os funcionários não atingem uma determinada meta pode ser por vários \\
motivos. Pode ser um erro na atribuição de metas, por exemplo. Uma pessoa \\
que só resolva casos complicados, por exemplo, talvez produza muito menos \\
que alguém que só faça coisas fáceis".
\end{tabular}

No jogo, alguns elementos foram introduzidos implicitamente com a intenção de que o jogador, com o passar dos dias no jogo, percebesse sua influência na dinâmica do jogo. Os principais aspectos percebidos pela análise preliminar de todos os trabalhos foram (1) Características diferenciadoras dos personagens: individualidade, aptidões e motivação; (2) trade-off entre cumprimento de prazos e entrega com qualidade elevada e (3) ganhos de produtividade advindos de aprendizagem, capacitação e melhoria das condições de trabalho.

Além disso, foi importante, como uma medida para constatar a adequação do uso do jogo no experimento da pesquisa, verificar se o jogo funciona como tal, seguindo os preceitos do game-based learning, já destacados na subseção 2.2.3 e na seção 3.2. Aqui, apresenta-se de novo a Tabela 2.4 com os elementos do game design, porém, são ilustrados todos os aspectos encontrados com trechos das entrevistas realizadas após o primeiro experimento (Tabela 4.2),

Tabela 4.2 - Evidências da adequação dos elementos do game design ao jogo desenvolvido com base nas entrevistas realizadas

\begin{tabular}{|c|c|c|}
\hline $\mathrm{N}^{\mathrm{o}}$ & Elemento & Descrição \\
\hline 1 & Desafio & $\begin{array}{l}\text { “Às vezes a pessoa pensa lá 'ah, eu quero um dia ser um diretor', mas quando } \\
\text { ele vai atuar, porque o jogo faz com que você atue na realidade [entre aspas] é } \\
\text { como se fosse uma realidade entre aspas, mas é muito real né? Então, dá para } \\
\text { você perceber se você tem habilidade de ser líder mesmo”" (entrevista 3) }\end{array}$ \\
\hline
\end{tabular}




\begin{tabular}{l}
\hline № Descrição \\
\hline “as dicas que a diretora vem e fala. "ó, você pode melhorar nisso, fazendo \\
assim uma planilha”, lembra que ela falou de uma planilha? Se organizar, \\
colocar quantos processos você tem no setor, tal. Então, assim, algumas dicas \\
que não são pra mim, são pra todos” (entrevista 1) \\
"Eu acho que você tem que ter uma vivência no setor, independente de você ser \\
gestor ou não. Até por que você pode não ser, mas você tem toda habilidade \\
pra ser um gestor...” (entrevista 2) \\
"Eu acho que fui muito pelo jogo mesmo, para tentar entender o que o jogo \\
queria de mim” (entrevista 2)
\end{tabular}

$2 \quad$ Fantasia / narrativa

“Eu vi que existe... Até, na verdade, foi o contrário... Quando eu estava jogando eu percebi isso... Situações do meu dia a dia que estavam aparecendo ali" (entrevista 2)

"foi muito importante o jogo porque, assim, a gente passa por essa situação na realidade só que a gente não consegue ver da mesma forma como no jogo" (entrevista 1)

"achei engraçado a reação das pessoas, elas riram, é bem isso, esse aqui é fulano do setor, né, que eu fui ouvindo... e é bem isso..." (entrevista 6)

$3 \quad$ Feedback

$4 \quad$ Objetivos

"eu achei que foi muito importante a questão de estar jogando e você estar dando aqueles feedbacks do que... e a própria diretora lá do jogo acaba te dando alguns feedbacks, então isso foi muito importante” (entrevista 1)

"justamente comecei a tentar pegar o... vamos dizer... as dicas do jogo e tentar refazer a coisa da maneira certa". (entrevista 5)

"lá era realmente importante cumprir a meta, mas eu comecei a perceber que não era esse só o objetivo principal, era ver o que você realmente discutiu com a gente, que às vezes tem pessoas que são mais afeitas a determinado serviço e que não adianta eu querer que ela faça o X que ela odeia” (entrevista 5)

"acho que eu percebi um pouco no jogo, embora não sei se veio de mim ou se esse era realmente um dos objetivos do jogo, é... tentar reparar mais na sua equipe mesmo" (entrevista 5)

"Serve para ver como é sua atuação como gestora. Acho que esse é o objetivo." (entrevista 2)

$5 \quad$ Estímulos sensoriais

Não abordado

6 Aspectos sociais / "Acho que foi bacana, porque ali se tornou um grupo mesmo, uma equipe, comunidade como se fôssemos uma equipe de trabalho real. Então, apesar de cada um estar 


\begin{tabular}{ll}
\hline \hline № $\quad$ Elemento & Descrição \\
\hline & fazendo o seu próprio jogo, mas nós nos tornamos uma equipe" (entrevista 1) \\
& "embora eu até mostrei pra minha chefe e falei "ó, você quer tentar?" mostrei \\
pra ela o jogo, que eu achei super engraçado e até pra ver... Mas, não numa \\
questão de competitividade, tipo, joga pra ver sua pontuação, não. Eu até \\
brinquei com a [Nome da Colega] que foi que fez comigo, a gente foi super \\
mal, a gente não ia dar pra ser gestor, a gente até brincou" (entrevista 3) \\
"porque você acaba parando para ajudá-lo, entendeu? E a pessoa fica com \\
vergonha de perguntar para o instrutor e acaba perguntando para quem tá \\
mais próximo" (entrevista 1)
\end{tabular}

$7 \quad$ Aprendizagem ativa

“Após, não. Durante o jogo mesmo, entendeu? Isso... É.. Eu já passei por situações muito parecidas. Então durante o jogo eu acabei aprendendo isso: que não é eu chegar e já achar que eu vou delegando as coisas... é... que eu vou conseguir atingir minhas metas, meus objetivos" (entrevista 1)

"Só que também tem uma questão, claro, de observação, de também ter anotado... é... de anotar muita coisa do jogo. Por exemplo, os tipos de processos que você deu e pra quem você deu, pra você ver o desempenho de cada um. Então assim, eu não observei isso. Se eu tivesse anotado pra cada personagem que eu dei e o desempenho de cada um deles no processo, talvez eu teria percebido qual é a facilidade e a dificuldade de cada um deles em fazer aquilo, entendeu?" (entrevista 3 )

"Aí eu fui tentando. Tipo assim, como eu estava muito no começo, tinha alguém que estava lá atrás, ai, eu, então, por exemplo eu percebi que engenharia o Eduardo era bom. Ai eu falava: então vou começar a dar engenharia pra ver se ele faz bem". (entrevista 3)

"Acho que eu não tinha... talvez eu até tivesse essa coisa, mas não parei para pensar igual jogando, sabe?" (entrevista 5)

$8 \quad$ Adaptabilidade / individualização
"Não sei, acho que o tempo de cada um é diferente. Acho que tem algumas pessoas ali que poderiam ter aprendido mais jogando mais" (entrevista 2)

"porque como é que vou mudar os processos das pessoas se eu não sei em que pé que eles estão? E aí eu achei que demorou um pouco pra eu conseguir..." (entrevista 3)

"Eu fiquei muito devagar... teve gente que avançou, sim, conseguiu até dar um ano. Eu fiquei, assim, acho que três meses, sabe assim, quatro meses, entendeu?" (entrevista 3)

"Mas eu preciso entender se eu vou, conforme, com a medida que eu tomei 


\begin{tabular}{|c|c|c|}
\hline $\mathrm{N}^{\mathbf{0}}$ & Elemento & Descrição \\
\hline
\end{tabular}
uma hora que você começa a perder pontuação com algumas outras atitudes" (entrevista 1)

10 Autenticidade /

“eu acho que o jogo foi muito bem feito" (entrevista 2)

realismo /

fidelidade

"eu comecei a comparar assim com a prática mesmo, de que cada pessoa é diferente da outra e cada um você tem que tratar de uma forma, se não, não funciona" (entrevista 2)

11 Competição

“Então, assim, se eu tivesse anotado bonitinho pra quem eu dei, as notas de cada um, as facilidades e o tempo de demora pra fazer um estudo sobre o jogo, assim, ai meu desempenho teria sido bem melhor" (entrevista 3)

"Eu acho que eu consegui fazer aquela pontuação quando eu comecei a entender que era individual ali..." (entrevista 2)

"Porque você viu que muita gente estava triste porque estava só no negativo, só no negativo... Eu também estava só no negativo e aquilo começou a me incomodar bastante." (entrevista 5)

12 Controle

13 Criatividade

"Por exemplo, o cara que é muito técnico, que tinha um lá dos personagens, mas que não gostava de fazer mais nada, só aquilo ali, que estava ligado àquele assunto ali. Então, num gerenciamento, né?... numa gestão, o que você faz? Você fica dando murro em ponta de faca e fazendo ele fazer outras coisas ou aproveita melhor aquilo ali que ele sabe fazer?" (entrevista 2)

"Fazer essa diferenciação entre as pessoas. Para mim, o mais forte do jogo foi isso: foi diferenciar as pessoas que trabalhavam ali." (entrevista 2)

"Então isso para mim foi muito bacana... e mostrou também que a gente precisa de conhecer as pessoas primeiro antes de tomar qualquer atitude. Né? Porque tomar atitude sem conhecer as pessoas acaba nos trazendo pontos negativos também, né? $E$ aí acaba gerando às vezes conflitos, enfim, desnecessariamente. Então para mim foi muito útil aquele jogo." (entrevista 1)

"Não deixar cada um fazer o que quer, em si, mas estar sempre coordenando. Essa coordenação é muito bacana." (entrevista 1)

"E lá isso é uma coisa cobrada dentro do jogo, que você ouça o que eles querem. Em relação a... eu não tenho um sistema de gratificações ali no jogo, né? Que seria a avaliação... Isso eu não tenho... Acho que é mais essa questão, de ouvir as pessoas, de perceber o que elas querem, porque o jogo é isso..." (entrevista 2) 


\begin{tabular}{ll}
\hline \hline № $\quad$ Elemento & Descrição \\
\hline & "eu sei que a gente tá com um projeto novo e eu sei que é uma coisa que ela \\
& gosta, então hoje eu já coloquei ela à frente desse projeto, justamente pensando \\
& no jogo... vamos dar as coisas que a pessoa gosta, porque... aí eu percebi \\
& também que, eu tinha vivido isso antes e no jogo ficou tão claro pra mim..." \\
& (entrevista 5)
\end{tabular}

14 Mistério / curiosidade "porque eu sei que chega uma hora que você começa a perder pontuação com algumas outras atitudes durante, então isso eu fiquei super curiosa" (entrevista 1)

15 Solução de desafios

"Então o jogo eu achei legal no sentido de que, se você nunca se tocou ou (puzzle solving) nunca parou pra pensar que cada pessoa tem uma dificuldade e uma facilidade, o jogo te mostra isso, já que eu não estava muito atenta pra essas mensagens que o jogo passou" (entrevista 3)

16 Tomada rápida de decisões

"de você toda hora entra um processo novo e você tem aquele tempo e você pede pro... tem o retorno... o processo tá péssimo, o desenho... e daí já venceu o prazo... Então isso foi, pra mim, foi dificil, organizar, né"(entrevista 6)

"Na primeira vez eu estava indo super mal, porque eu achava que era só distribuir e não é tão objetivo assim, tem alguns aspectos mais subjetivos. Então foi legal essa questão de saber o que dar para quem fazer, qual o trabalho... a quantidade, que é uma coisa que a gente vê na prática" (entrevista 2)

17 Relevância / interesse

"Eu acho que foram apresentados vários conceitos, né?... que estavam no jogo para o aprendiz também, que foram muito bacanas. Para um gestor atento, sim, traz [insights]" (entrevista 2)

"Eu acho que seria interessante pra... pra todos os gestores, assim, até pros gestores que [...]. Seria interessante ampliar esse acesso. Eu acho que era isso que eu queria dizer, seria interessante para gestores mais experientes. Porque às vezes ele não percebe alguma coisa ali que tá acontecendo, até por ter muita experiência... Pode ser que tenha algum insight, eu acho... Eu, por exemplo, eu tive insights de coisas que acontecem ali com outras pessoas, que eu queria que elas jogassem para perceber" (entrevista 2)

"Acho que também... acho que eu percebi um pouco no jogo, embora não sei se veio de mim ou se esse era realmente um dos objetivos do jogo, é... tentar reparar mais na sua equipe mesmo". (entrevista 5).

"E até indiquei para os colegas, para quem quisesse fazer quando abrir novamente, para eles estarem... é... para eles estarem fazendo, porque achei extremamente importante, porque nós nos deparamos com essas situações diariamente, entendeu? Não só comigo, mas com os próprios colegas que são líderes também. E nós discutimos muitas vezes as aptidões, as situações, os 


\begin{tabular}{ll}
\hline \hline № Elemento & Descrição \\
\hline & conflitos... Então esse jogo acabou você tendo a condição de como lidar melhor \\
& com o conflito, uma coisa totalmente à parte do teu contexto lá, que seria a \\
& gestão, mas lidar com o conflito, eu percebi que no jogo, a gente consegue \\
& saber como lidar melhor com isso” (entrevista 1)
\end{tabular}

18 Recompensa

19 Papel

20 Regras

21 Segurança

22 Scaffolding e senso de progresso
"Eu acho que eu consegui fazer aquela pontuação quando eu comecei a entender que era individual ali... que você não podia tratar a equipe como um monte de robozinhos, é uma coisa individual. Isso foi muito legal, assim, incorporou bem." (entrevista 2)

"foi muito importante o jogo porque, assim, a gente passa por essa situação na realidade só que a gente não consegue ver da mesma forma como no jogo. Então no jogo você conseguiu enxergar o aspecto negativo nosso mesmo, né? O que você precisa como ferramenta para você entrar como uma pessoa nova, como um líder novo, né? Então isso para mim foi muito bacana..." (entrevista 1)

"Eu acho que a união dos dois fatos, de você ter algumas noções de como ser lider e como direcionar a liderança dentro do jogo" (entrevista 4)

"Não dá para guardar tudo. Mas existem algumas regras, digamos assim, que tinha no jogo, que pra você ser um melhor líder... a própria diretora dava." (entrevista 1)

"eu comecei de novo e você até comentou isso lá. Na primeira vez eu estava indo super mal” (entrevista 2)

"Mas eu acho que três vezes eu tenho certeza, mas eu acho que foi umas quatro vezes que eu reiniciei." (entrevista 5)

"Se eu tivesse anotado desde o princípio, talvez meu desempenho tivesse sido melhor. Por exemplo, eu podia ter anotado assim, num primeiro momento, você não consegue conversar com os caras, mas você consegue dar os processos". (entrevista 3)

"porque logo de cara você depara com as dificuldades próprias, né? E onde você acaba não tendo, não alcançando seu objetivo, não atingindo metas, enfim. E o reinício dá esse feedback” (entrevista 1)

"Eu, por exemplo, eu tive insights de coisas que acontecem ali com outras pessoas, que eu queria que elas jogassem para perceber" (entrevista 2)

"aí eu percebi também que, eu tinha vivido isso antes e no jogo ficou tão claro pra mim... eu falei assim: gente é exatamente o que eu fiz com a pessoa, entendeu? E aí ela se envolveu de uma outra forma que virou uma outra pessoa 


\begin{tabular}{lcc}
\hline \hline № & Elemento & Descrição \\
\hline & na equipe... Então isso dai foi muito legal, eu achei fantástico”. (entrevista 5) \\
& \\
\hline \hline
\end{tabular}

Com a análise preliminar dos trabalhos, começou-se a notar que havia três temas que apareciam de forma mais consistente nas análises dos alunos: (1) a teoria clássica de administração e sua relação com o ciclo de planejamento-execução-controle (PEC), (2) a importância da visão sistêmica (VS) e (3) os papéis gerenciais tanto do ponto de vista teórico quanto percebidos e desempenhados pelo jogador (PG).

Assim, depois do processo de leitura individual, os 63 trabalhos foram colocados num arquivo único de texto, mantendo-se apenas a parte de conteúdo (excluindo-se capa, identificações, títulos e subtítulos) a fim de se proceder a uma análise quantitativa de termos utilizados nos textos.

Com auxílio do software R, por meio do pacote $t m$ de mineração de dados (text mining) foi possível produzir um corpus comum a todos os trabalhos, eliminando-se a pontuação e as palavras ditas de ruído, os conectores "por", "de", "pelo", "a", "e" etc. Compuseram o corpus dos trabalhos 5443 palavras. Adotou-se um corte para análise: foram considerados apenas os termos que apareceram pelo menos 30 vezes ao longo dos trabalhos. Com isso, a base de palavras ficou em 180 termos. Destes, buscou-se observar quais deles estariam relacionados aos conceitos de administração discutidos ao longo da disciplina. Além das exclusões óbvias de verbos e outros termos muito usados ("ser", "deve", "exemplo", "além", "sobre", "pode"), que pouco teriam a acrescentar na análise, foram também desconsiderados os termos obviamente relacionados ao jogo tais como os nomes dos personagens, palavras que dão título ao jogo (liderança, jogo, competências, papéis, responsabilidades) e outros termos do vocabulário do jogo (jogador, prazos, qualidade, diretora, funcionários, processos etc.).

A Tabela 4.3 apresenta os termos mais frequentes, após a aplicação desses critérios, já com sua relação com os itens da ementa do curso preparado para a execução do experimento deste trabalho (exposta na seção 3.3). 
Tabela 4.3 - Termos mais frequentes nos trabalhos do piloto e sua relação com a ementa do curso

\begin{tabular}{|c|c|c|}
\hline Termo & Freq. & $\begin{array}{l}\text { Itens da } \\
\text { ementa }\end{array}$ \\
\hline desempenho & 116 & IV, VI \\
\hline planejamento & 97 & I, IV \\
\hline orçamento & 75 & II, IV \\
\hline resultados & 73 & III, IV, VI \\
\hline motivação & 66 & II, V \\
\hline papel & 66 & $\mathrm{~V}$ \\
\hline burocracia & 63 & I, II \\
\hline controle & 55 & $\mathrm{I}, \mathrm{IV}, \mathrm{V}$ \\
\hline decisões & 55 & II, IV, V \\
\hline avaliação & 49 & III, V, VI \\
\hline produtividade & 49 & III, VI \\
\hline eficiente & 42 & III, VI \\
\hline gestão & 39 & Todos \\
\hline eficiência & 38 & III, VI \\
\hline delegar & 37 & $\mathrm{~V}, \mathrm{VI}$ \\
\hline teoria & 37 & I, IV \\
\hline clássica & 35 & I, IV \\
\hline controlar & 33 & I, II, IV \\
\hline fayol & 32 & $\mathrm{I}, \mathrm{IV}$ \\
\hline
\end{tabular}

A análise do material qualitativo produzido no piloto e nas entrevistas após o primeiro experimento mostra que, de fato, o jogo desenvolvido, além de atender os requisitos para ser um serious game, isto é, um jogo que não tem apenas a finalidade de entretenimento (e, portanto, sério), caracteriza-se como um jogo de fato, cobrindo os elementos necessários para seu adequado game design. Com isso, pode-se considerar que o objetivo específico de número 2, “desenvolver um serious game de gestão focado no setor público, que incorpore aspectos das teorias relacionadas à administração, e que possa ser utilizado para o desenvolvimento de gestores públicos" (OE2), foi integralmente atingido.

Igualmente, com os subsídios obtidos pela análise qualitativa dos trabalhos do piloto somados aos conceitos vistos na revisão da literatura, tinham-se em mãos todos os subsídios necessários para a construção de um curso/treinamento que permitiram aplicar o jogo em um contexto de desenvolvimento de gestores, em que fosse possível avaliar o impacto de seu uso, que é o objetivo específico de número 3 (OE3) do presente trabalho, o qual também se considerou atingido nesse ponto. 


\subsection{Avaliação de reação}

Para avaliar a reação com relação ao curso oferecido e identificar se havia diferenças entre a turma que jogou (tratamento) e a que não jogou (controle), foram utilizados dois instrumentos. O primeiro é baseado no questionário IMMS - Instructional Materials Motivation Survey, em tradução livre, o levantamento de motivação sobre materiais instrucionais, desenvolvido por Keller (2010) com base em seu modelo ARCS (Atenção, Retenção, Confiança e Satisfação), em uma versão reduzida, adaptada de Loorbach et al. (2015). Além desse instrumento, específico desta pesquisa, foram também analisados os dados do questionário padrão de avaliação de reação utilizado pelo Centro de Treinamento e Desenvolvimento (CT\&D) do Centro de Formação de Servidores da Saúde (Cefor), uma vez que o curso foi organizado por esse centro. O questionário aplicado é objeto do Anexo 1 . $\mathrm{O}$ questionário IMMS é apresentado no Apêndice C.

\subsubsection{Experimento 1}

No questionário padrão aplicado são avaliados três grandes blocos: desempenho do instrutor, processo de aprendizagem e infraestrutura, mensurados, respectivamente, por 9, 6 e 5 itens, em quatro níveis (Excelente, Bom, Regular e Ruim). Por simplicidade, optou-se inicialmente por olhar o resultado agregado em cada um dos blocos, somando-se as quantidades de respostas em cada nível para cada bloco. O que se observou foram distribuições muito parecidas.

A diferença estatística pode ser mensurada por meio do teste $\chi^{2}$ para independência. Para atender as premissas desse teste estatístico (a contagem esperada por cruzamento entre nível e critério tem que ser maior ou igual a 5), foi necessário agrupar os dados referentes aos níveis Bom e Regular, já que o nível Ruim estava zerado em todas as respostas e pôde ser desprezado. Estatisticamente, as distribuições para desempenho do instrutor $\left(\chi^{2}=1,36\right) \mathrm{e}$ infraestrutura $\left(\chi^{2}=1,87\right)$ são iguais. Já para o processo de aprendizagem $\left(\chi^{2}=10,40\right)$, podese inferir que quem jogou teve maior incidência do nível Excelente do que quem não jogou 
(45\% versus $31 \%$ ), ocorrendo o contrário para o nível Bom+Regular ${ }^{41}$. As distribuições são apresentadas nos gráficos da Figura 4.1, da Figura 4.2 e da Figura 4.3.

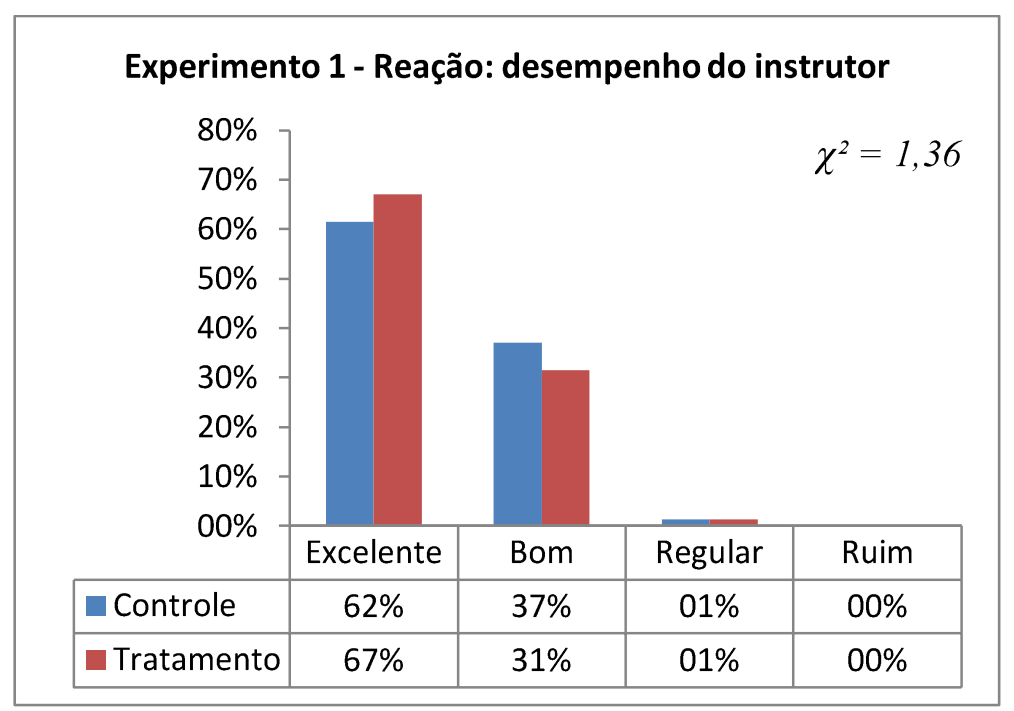

Figura 4.1 - Distribuição da avaliação de reação padrão para o desempenho do instrutor do primeiro experimento.

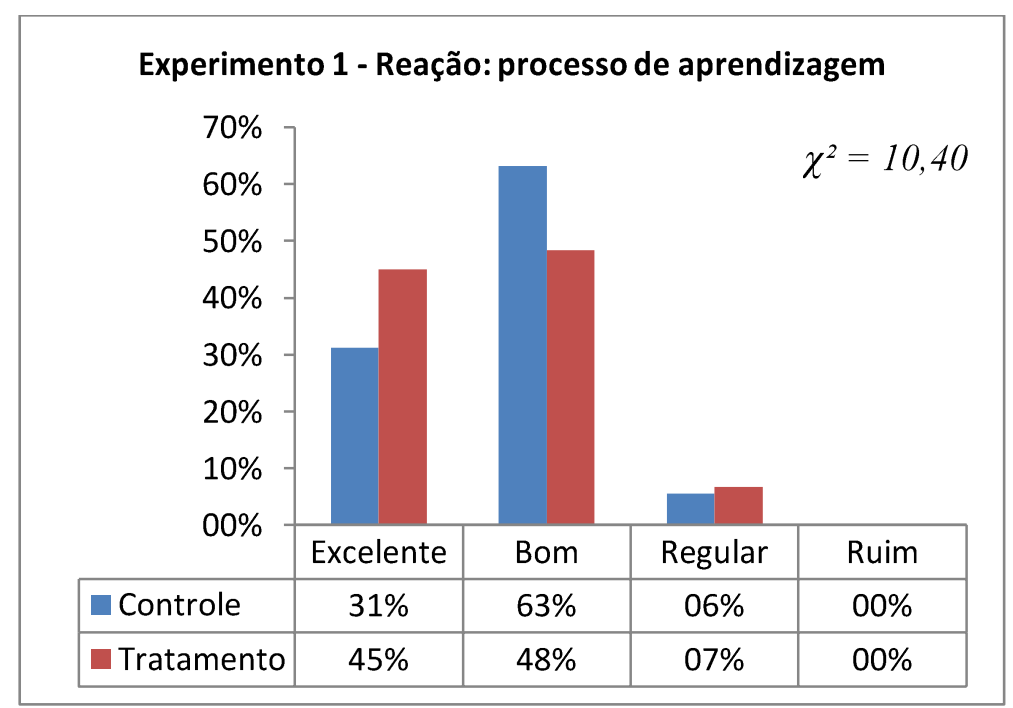

Figura 4.2 - Distribuição da avaliação de reação padrão para o processo de aprendizagem do primeiro experimento.

\footnotetext{
${ }^{41}$ Para efeitos de comparação, o valor crítico para a estatística $\chi^{2}$ é de 3,841 , considerando-se $5 \%$ de nível de significância e 1 grau de liberade (2 linhas x 2 colunas). Se o cálculo de $\chi^{2}$ for maior que o valor crítico, rejeita-se a hipótese nula, indicando que as distribuições são diferentes.
} 


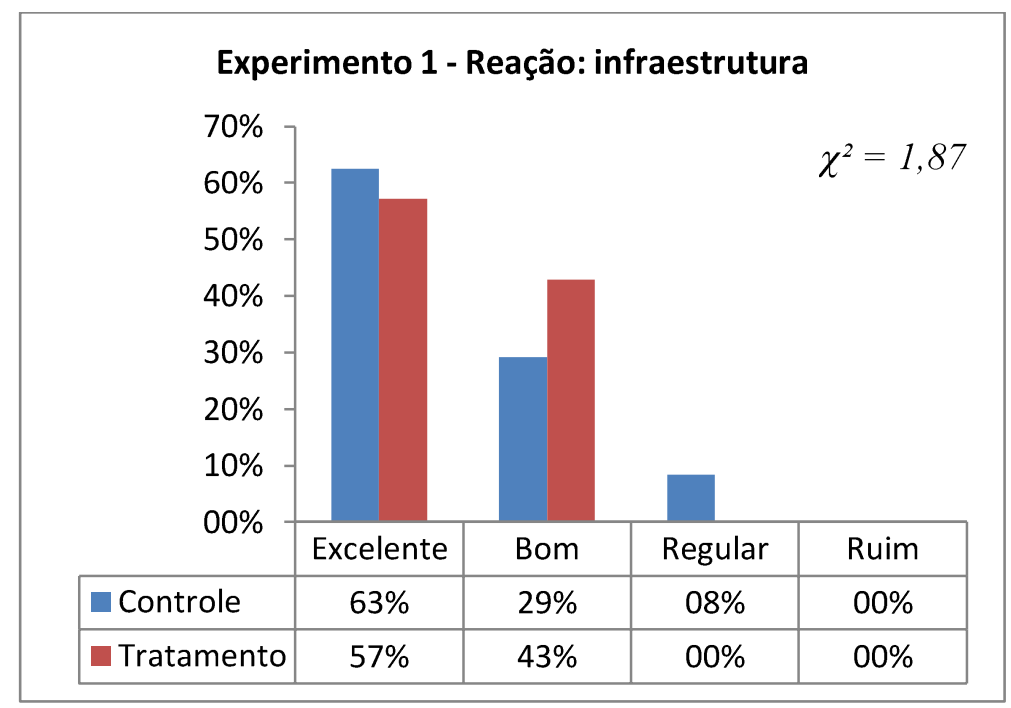

Figura 4.3 - Distribuição da avaliação de reação padrão para a infraestrutura do curso do primeiro experimento.

Para o contexto desta pesquisa, vale olhar mais detidamente para a avaliação do processo de aprendizagem, inclusive por ter sido nesse aspecto em que foi observada a diferença estatística entre os grupos de tratamento e controle. Os itens componentes do bloco são:

(a) Nível de integração entre os participantes e o instrutor

(b) Nível de relevância dos temas abordados

(c) Em que nível você classifica como adequadas as atividades e os recursos didáticos utilizados

(d) Em que nível você classifica o conteúdo apresentado e como ele contribuirá para aperfeiçoar o seu desempenho profissional

(e) Aplicabilidade do conteúdo do curso à sua realidade de trabalho

(f) Como você avalia sua participação durante o treinamento

A Tabela 4.4 apresenta o percentual de cada nível de avaliação para cada um desses itens, bem como o valor da estatística $\chi^{2}$ e se a diferença nas distribuições é estatisticamente significativa ou não. As diferenças são significativas para quatro dos seis itens. Os participantes do experimento não viram diferenças no nível de relevância dos temas abordados (item b) e em como o conteúdo contribuirá para aperfeiçoar seu desempenho (item d). Curiosamente, os membros do grupo experimental (jogo) acharam o nível de integração com o instrutor maior (item b) e avaliaram melhor sua participação durante o treinamento (item f), mesmo havendo uma sensação, detectada nas entrevistas, de que o jogo "tirava 
tempo de aula". Contudo, as diferenças mais relevantes foram relacionadas à adequação dos recursos didáticos (item c) e a aplicabilidade do conteúdo do curso ao trabalho (item e).

Tabela 4.4 - Comparativo da avaliação de reação, por item, no quesito "processo de aprendizagem" do primeiro experimento

\begin{tabular}{llcccccc}
\hline \hline & & (a) & (b) & (c) & (d) & (e) & (f) \\
\hline \multirow{4}{*}{ Grupo } & Excelente & $46,7 \%$ & $46,7 \%$ & $73,3 \%$ & $40,0 \%$ & $42,9 \%$ & $20,0 \%$ \\
Experimental & Bom & $46,7 \%$ & $46,7 \%$ & $26,7 \%$ & $53,3 \%$ & $42,9 \%$ & $73,3 \%$ \\
& Regular & $6,7 \%$ & $6,7 \%$ & $0,0 \%$ & $6,7 \%$ & $14,3 \%$ & $6,7 \%$ \\
& Ruim & $0,0 \%$ & $0,0 \%$ & $0,0 \%$ & $0,0 \%$ & $0,0 \%$ & $0,0 \%$ \\
\hline \multirow{4}{*}{ Grupo de } & Excelente & $12,5 \%$ & $54,2 \%$ & $50,0 \%$ & $41,7 \%$ & $20,8 \%$ & $8,3 \%$ \\
Controle & Bom & $70,8 \%$ & $45,8 \%$ & $50,0 \%$ & $54,2 \%$ & $66,7 \%$ & $91,7 \%$ \\
& Regular & $16,7 \%$ & $0,0 \%$ & $0,0 \%$ & $4,2 \%$ & $12,5 \%$ & $0,0 \%$ \\
& Ruim & $0,0 \%$ & $0,0 \%$ & $0,0 \%$ & $0,0 \%$ & $0,0 \%$ & $0,0 \%$ \\
\hline \multicolumn{2}{c}{ Diferença estatística } & 70,04 & 2,81 & 28,79 & 0,14 & 27,93 & 13,99 \\
\hline \hline
\end{tabular}

Nota: o teste $\chi^{2}$ foi efetuado considerando-se os níveis "excelente" e "bom+regular".

O questionário IMMS utilizado no primeiro experimento focou o curso de forma ampla e pode ser visto no (Apêndice C). Seguindo a metodologia de Keller (2010), os itens de avaliação, para os quais é atribuída uma pontuação de 1 a 7 , em função da concordância do respondente com a assertiva, são agrupados em cada um dos construtos do modelo ARCS, atenção, relevância, confiança e satisfação, gerando uma pontuação para cada um deles. No questionário, cada um desses construtos poderia, para cada respondente, ter uma pontuação também variando entre 1 e 7, pois cada construto é a média dos 3 itens que o compõem. $\mathrm{O}$ gráfico da Figura 4.4 apresenta as médias de pontuação para cada construto para os grupos experimental e de controle.

A comparação das médias pode ser feita com o uso de uma ANOVA. No entanto, esse tipo de distribuição (1 a 7, com nível de concordância) nem sempre resulta em uma pontuação agregada ou média com distribuição normal, o que viola uma das premissas da técnica. Podem-se fazer transformações de variáveis a fim de se atender as premissas da técnica ou pode-se lançar mão de um teste estatístico não paramétrico. Adotou-se a segunda opção para esse caso, com o uso do teste $U$ de Mann-Whitney. 


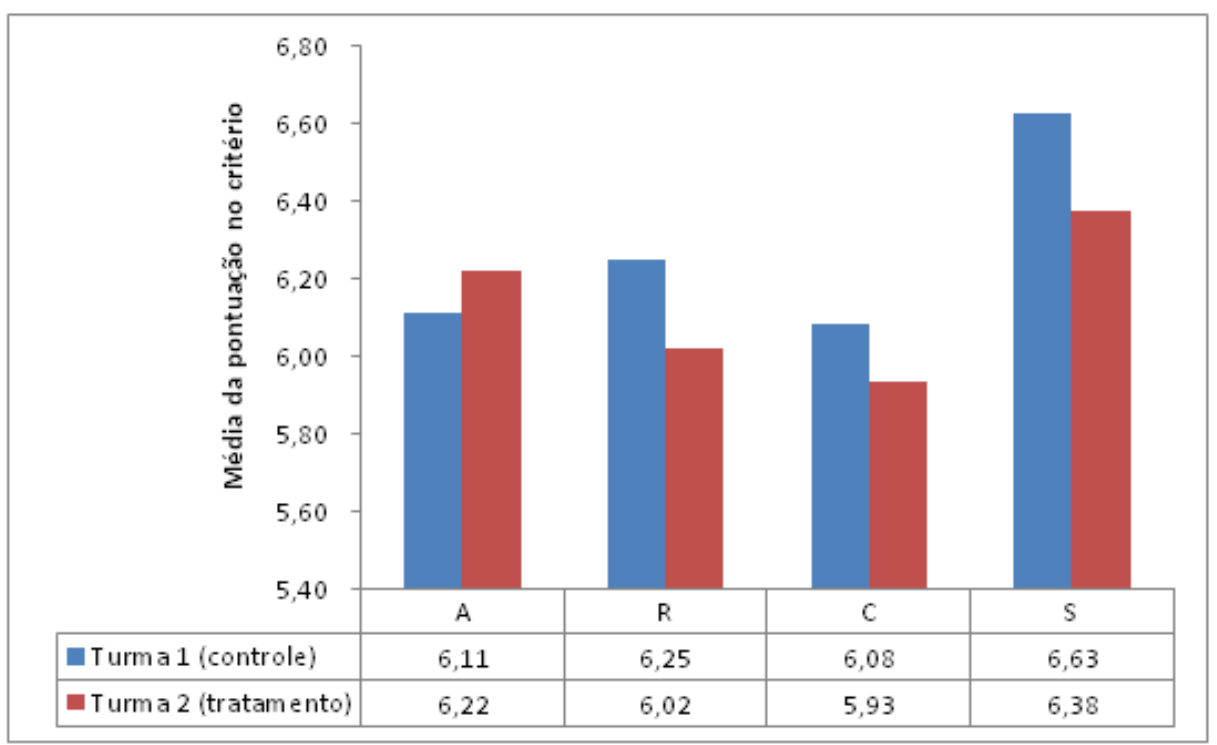

Figura 4.4 - Média dos construtos do modelo ARCS para os participantes do primeiro experimento.

Para os quatro construtos as médias foram consideradas estatisticamente iguais, ou seja, os participantes que jogaram e os que não jogaram tiveram, estatisticamente, o mesmo nível de atenção $(p=0,809)$, de relevância $(p=0,338)$, de confiança $(p=0,679)$ e de satisfação $(p=0,484)$.

Em princípio, seria esperado que os participantes tivessem percepções diferentes com relação a esses construtos, pois eles se relacionam à motivação para o aprendizado e a literatura traz evidências sólidas de que jogos são mais motivantes no processo de aprendizado (Paras \& Bizzocchi, 2005). Uma das explicações decorre de o instrumento elaborado focar o curso em sua totalidade e não as atividades feitas (jogo versus outras atividades em aula). Sendo assim, o resultado contribui para mostrar que o experimento foi consistente e ambos os grupos ficaram satisfeitos em participar dele. Porém, essa questão foi levada em conta no sentido de, no segundo experimento, aprimorar o instrumento para dar um foco maior às atividades em si. 


\subsubsection{Experimento 2}

Analogamente ao procedimento realizado para o primeiro experimento, utilizou-se o questionário padrão de avaliação de reação fornecido pela SES-SP para avaliar os três grandes grupos de avaliação: desempenho do instrutor, processo de aprendizagem e infraestrutura. Dessa vez, não houve diferenças estatísticas para nenhum dos três grandes grupos agregados. Porém, quando o segundo grupo é aberto nos itens que o compõem, há diferenças estatísticas para todos os seis itens. A Figura 4.5, a Figura 4.6 e Figura 4.7 mostram os resultados para os grupos agregados, enquanto a Tabela 4.5 traz os resultados para cada item separadamente.

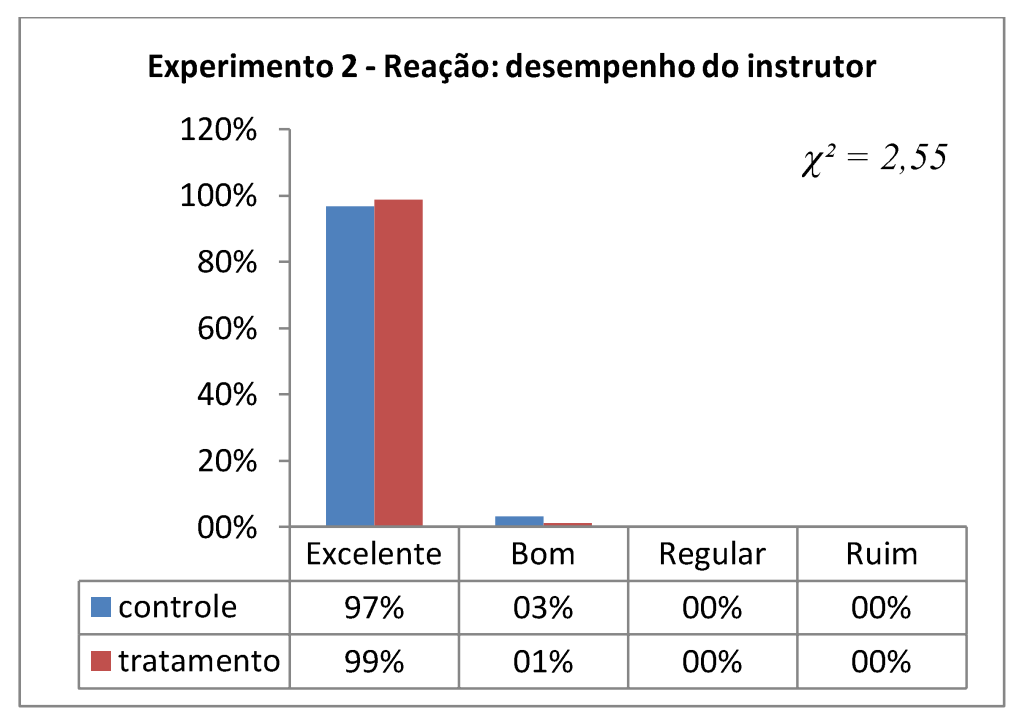

Figura 4.5 - Distribuição da avaliação de reação padrão para o desempenho do instrutor do segundo experimento.

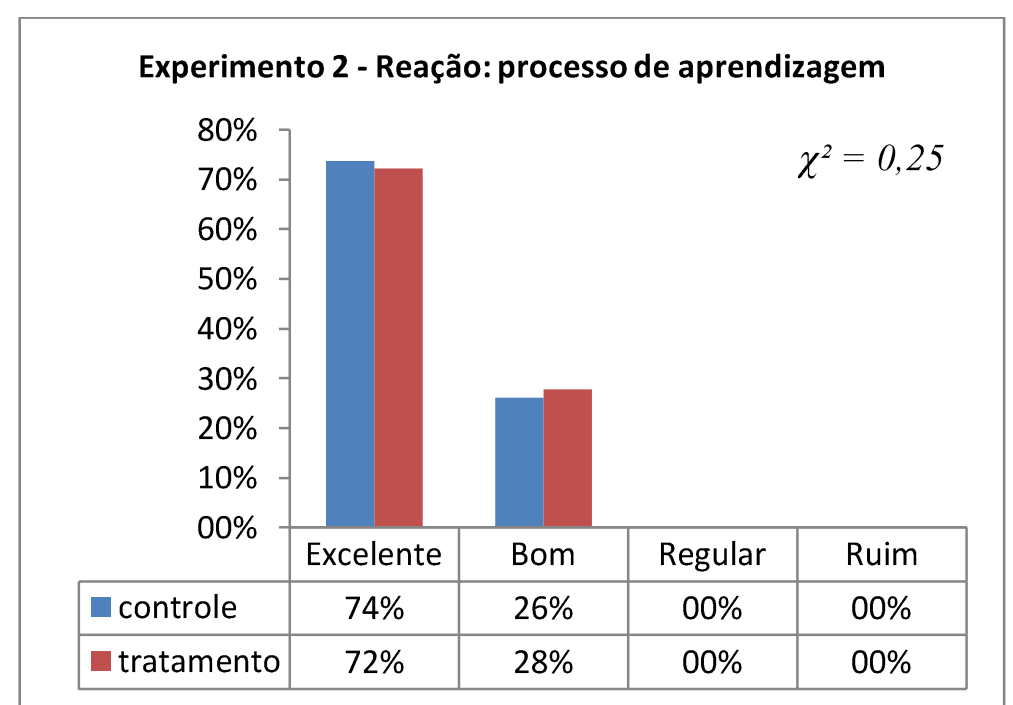

Figura 4.6 - Distribuição da avaliação de reação padrão para o processo de aprendizagem do segundo experimento. 


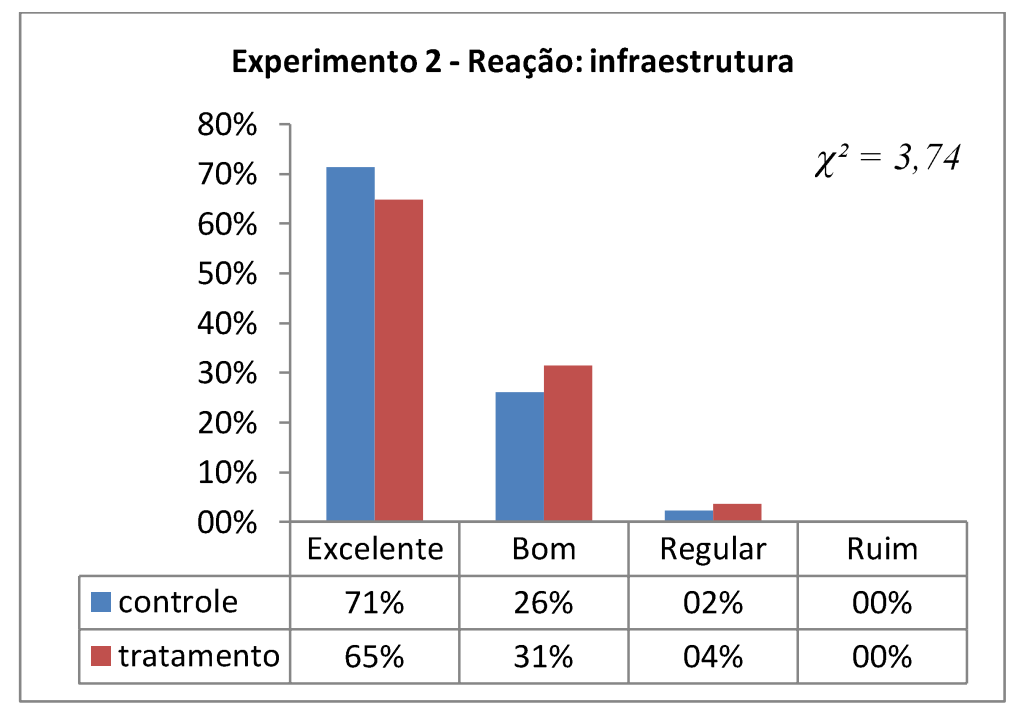

Figura 4.7 - Distribuição da avaliação de reação padrão para a infraestrutura do curso do segundo experimento.

Tabela 4.5 - Comparativo da avaliação de reação, por item, no quesito "processo de aprendizagem" do segundo experimento

\begin{tabular}{llcccccc}
\hline \hline & & (a) & (b) & (c) & (d) & (e) & (f) \\
\hline \multirow{4}{*}{ Grupo } & Excelente & $55,6 \%$ & $77,8 \%$ & $88,9 \%$ & $100,0 \%$ & $88,9 \%$ & $22,2 \%$ \\
Experimental & Bom & $44,4 \%$ & $22,2 \%$ & $11,1 \%$ & $0,0 \%$ & $11,1 \%$ & $77,8 \%$ \\
& Regular & $0,0 \%$ & $0,0 \%$ & $0,0 \%$ & $0,0 \%$ & $0,0 \%$ & $0,0 \%$ \\
& Ruim & $0,0 \%$ & $0,0 \%$ & $0,0 \%$ & $0,0 \%$ & $0,0 \%$ & $0,0 \%$ \\
\hline \multirow{3}{*}{ Grupo de } & Excelente & $100,0 \%$ & $85,7 \%$ & $71,4 \%$ & $85,7 \%$ & $42,9 \%$ & $57,1 \%$ \\
Controle & Bom & $0,0 \%$ & $14,3 \%$ & $28,6 \%$ & $14,3 \%$ & $57,1 \%$ & $42,9 \%$ \\
& Regular & $0,0 \%$ & $0,0 \%$ & $0,0 \%$ & $0,0 \%$ & $0,0 \%$ & $0,0 \%$ \\
& Ruim & $0,0 \%$ & $0,0 \%$ & $0,0 \%$ & $0,0 \%$ & $0,0 \%$ & $0,0 \%$ \\
\hline \multicolumn{2}{c}{ Diferença estatística } & 142,85 & 5,27 & 23,96 & 38,46 & 117,82 & 63,68 \\
\hline \hline
\end{tabular}

Nota: 0 teste $\chi^{2}$ foi efetuado considerando-se os níveis "excelente" e "bom", pois os demais estão zerados.

Nota: em negrito as diferenças estatísticas diferentes do primeiro experimento

O que se pode notar pela tabela é que os itens (b) e (d), respectivamente, o nível de relevância dos temas abordados e o nível do quanto o conteúdo contribuirá para o aperfeiçoamento profissional, apresentaram diferença estatisticamente significativa no segundo experimento, ao contrário do que se tinha observado no primeiro. Enquanto o grupo experimental considerou em maior proporção que o conteúdo contribuirá para o aperfeiçoamento profissional, no outro item, foi o grupo de controle que considerou o conteúdo do curso mais relevante, embora isso não se confirme no resultado de relevância do modelo ARCS, como será visto adiante. 
Também foi identificada uma percepção inversa comparativamente ao primeiro experimento no item (a), nível de integração entre os participantes e o instrutor, sendo que o controle atribui maior percentual de excelentes nesse quesito. O mesmo se observou no item (f) sobre a avaliação do participante no treinamento. Por fim, o resultado do experimento 1 nos itens de adequação dos recursos didáticos (item c) e da aplicabilidade do conteúdo do curso ao trabalho (item e) se repetiu.

Com relação ao modelo ARCS, cuja mensuração foi feita pelo questionário IMMS, os resultados são apresentados no gráfico da Figura 4.8. O questionário foi modificado em relação ao do primeiro experimento para cobrir aspectos relativos às atividades realizadas fora do espaço de interação com o instrutor, lembrando que o jogo, nesse segundo curso, era uma atividade complementar às aulas. A fim de melhorar a estatística, foram utilizados seis itens dentro de cada um dos construtos.

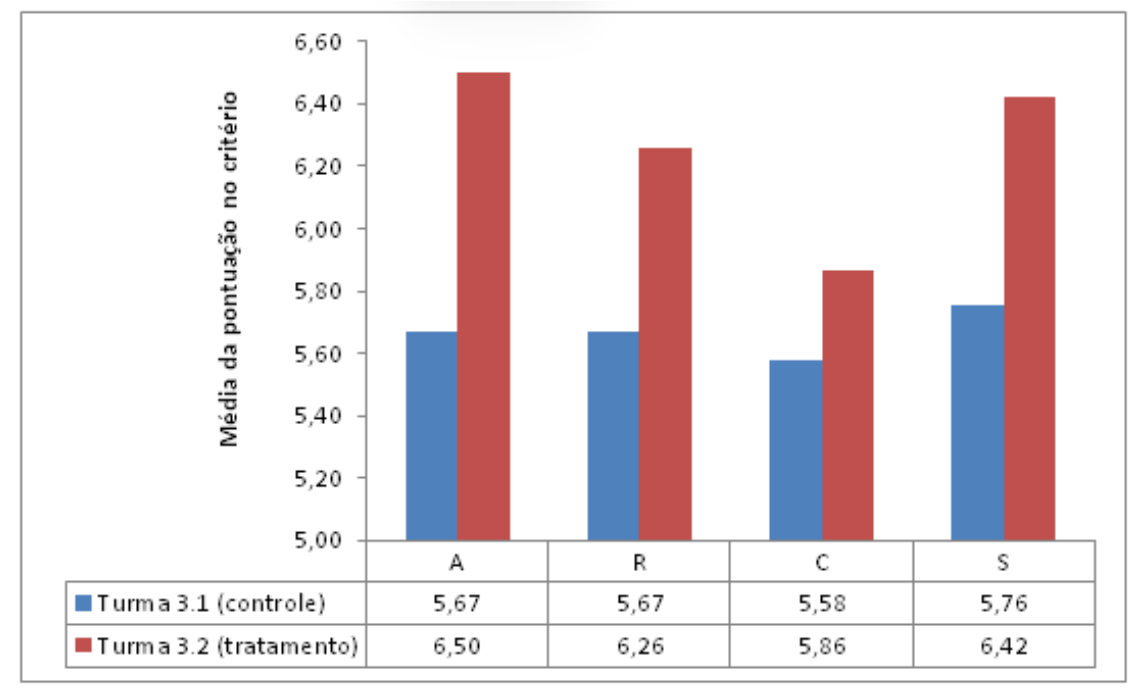

Figura 4.8 - Média dos construtos do modelo ARCS para os participantes do segundo experimento

Verifica-se que as médias para os quatro construtos são sempre maiores para o grupo experimental do que para o grupo de controle. A aplicação do teste U de Mann Whitney resulta no seguinte resultado, considerando-se o nível descritivo do teste: atenção $(p=0,076)$, relevância $(p=0,065)$, confiança $(p=0,652)$ e satisfação $(p=0,519)$. A um nível de significância de $\alpha=5 \%$, a hipótese nula associada a cada um dos construtos não seria rejeitada. Porém, as diferenças observadas são estatisticamente significativas para a atenção e a relevância a um nível de significância $\alpha=10 \%$, trazendo evidências de que o grupo que 
jogou teve sua atenção atraída pelo jogo e considerou as atividades mais relevantes do que aqueles que não jogaram. As saídas do teste estão contidas no Apêndice D.

\subsubsection{Discussão dos resultados: Reação}

No experimento 1, com o jogo na aula, os alunos da turma que jogou valorizaram mais o processo de aprendizagem. No segundo experimento, como o jogo estava fora da aula, no meio das outras atividades, a valorização foi igual. Nos dois casos, o instrutor e a infraestrutura foram avaliados de forma equivalente, o que indica que o curso, em suas características não centrais, foi "sentido" de forma igual tanto pelos participantes do grupo experimental quanto do grupo de controle. Esse resultado é importante, pois o primeiro experimento envolveu duas turmas diferentes, em momentos diferentes, mas com o mesmo instrutor. Avaliarem o instrutor e a infraestrutura de forma semelhante reforça a ideia de que a única diferença foi, de fato, o "princípio ativo" do experimento, isto é, o jogo. Dessa forma, as diferenças de resultados podem ser atribuídas ao fato de um grupo ter jogado.

Quando considerados os itens que compõem o quesito processo de aprendizagem separadamente, nota-se que, nos dois experimentos, os participantes que jogaram consideraram que as atividades didáticas foram mais adequadas e que o conteúdo do curso é aplicável à sua realidade com relação àqueles que não jogaram.

A Tabela 4.6 apresenta um comparativo dos resultados obtidos na consolidação dos formulários de reação para os itens do bloco de processo de aprendizagem. O grupo base de referência na comparação da tabela é o de controle. Assim, se a célula indicar "Maior", significa que o grupo experimental obteve um maior percentual de "Excelentes" naquele item. Se for "Menor", o percentual de "Excelentes" de quem jogou é menor do que o grupo de controle. Por fim, registra-se a igualdade com o termo "Empate".

O que se verifica com a consolidação da reação para os dois experimentos é que nos dois casos quem jogou considerou as atividades e recursos didáticos utilizados mais adequados (item c) e também o conteúdo do curso mais aplicável à realidade de trabalho (item e) do que quem não jogou. Esse é um indicativo da incorporação efetiva dos elementos de 
aprendizagem ativa e de transferência da taxonomia dos elementos de jogos digitais sintetizada por Bober (2010) (Tabela 2.4).

Tabela 4.6 - Comparação da avaliação de reação dos itens de processo de aprendizagem do grupo experimental com relação ao de controle para os dois experimentos

\begin{tabular}{llcc}
\hline \hline \multicolumn{1}{c}{ Item do processo de aprendizagem } & Exp. 1 & Exp. 2 \\
\hline a & Nível de integração entre os participantes e o instrutor & Maior & Menor \\
b & Nível de relevância dos temas abordados & Empate & Maior \\
c $\quad \begin{array}{l}\text { Em que nível você classifica como adequadas as atividades e os } \\
\text { recursos didáticos utilizados }\end{array}$ & Maior & Maior \\
d $\quad \begin{array}{l}\text { Em que nível você classifica o conteúdo apresentado e como ele } \\
\text { contribuirá para aperfeiçoar o seu desempenho profissional }\end{array}$ & Empate & Maior \\
e Aplicabilidade do conteúdo do curso à sua realidade de trabalho & Maior & Maior \\
f Como você avalia sua participação durante o treinamento & Maior & Menor \\
\hline \hline
\end{tabular}

Quanto aos itens em que há divergência, nível de integração com o instrutor (item a) e avaliação da própria participação durante o treinamento (item f), o próprio formato dos experimentos pode ajudar na explicação. No primeiro experimento, o jogo fazia parte das atividades realizadas em aula. A atividade equivalente para o grupo de controle era composta de discussões sobre casos. No segundo experimento, a aula era a mesma para os dois grupos, cuja divisão em controle e tratamento só importava na hora de fazer as atividades, que eram externas à parte presencial.

Assim, é possível que os alunos que jogaram na presença do instrutor (experimento 1) tenham sentido um maior nível de integração comparativamente aos que discutiam em grupos (controle), uma vez que podiam fazer perguntas ao próprio instrutor enquanto jogavam. Aqueles que jogaram fora do tempo de aula não tinham essa opção e, talvez por essa razão, tenham sentido um menor nível de integração (experimento 2).

Porém, o que diferiu nos dois experimentos com relação ao primeiro item, de fato, não foi a proporção de "excelentes" no grupo experimental (46,7\% no primeiro experimento e 55,6\% no segundo), mas sim essa proporção no grupo de controle (12\% no primeiro e $100 \%$ no segundo). Nesse caso, evidencia-se que o tipo de atividade utilizado no primeiro experimento ou o fato de as turmas assistirem às aulas em dias diferentes possa ter influenciado essa percepção. 
Se de Smale et al. (2015) destacam que um dos fatores de sucesso para treinamentos com uso de jogos é o papel do instrutor/facilitador, esse resultado não pode ser ignorado. O formato do primeiro experimento pode, então, ter introduzido uma variável de confusão. Isso acontece quando o desenho do experimento torna impossível isolar os efeitos (Cobb, 1998). Nesse sentido, o segundo experimento é mais robusto, pois conseguiu eliminar essa variável de confusão. Entretanto, o resultado de igualdade estatística no primeiro bloco (desempenho do instrutor) reduz as dúvidas da existência dessa variável de confusão. Se existisse um efeito substancial, o bloco relativo ao instrutor no primeiro experimento teria apresentado diferenças, o que não foi o caso.

Outro item que teve resultados opostos nos dois experimentos foi aquele relativo ao próprio desempenho do participante no treinamento (item f). No entanto, pode-se especular que o fato de o jogo ser uma atividade não delimitada no tempo (não há um número de páginas ou uma quantidade de minutos com que o aluno consiga mensurar o quanto atingiu do solicitado) pode ter trazido a sensação de que quem estava no grupo experimental fazia menos do que quem estava no controle especificamente no segundo experimento.

Os itens relativos ao conteúdo, relevância (item b) e contribuição para aperfeiçoar o desempenho (item d) andam juntos. No primeiro experimento o grupo que jogou não considerou esses aspectos mais relevantes que o grupo de controle. No entanto, isso foi observado no segundo experimento. Por questões de desenho experimental, o segundo experimento é mais confiável para a inferência de resultados, indicando que quem joga considera o conteúdo do curso mais relevante e com potencial para aperfeiçoar o desempenho. Mesmo assim, opta-se por não cravar uma conclusão. Se houver interesse em estudar algum desses pontos em particular, a melhor solução é estruturar um estudo específico para tal.

Quanto aos questionários IMMS, não houve diferença estatística para os construtos do modelo ARCS (Keller, 2010) no primeiro experimento. No segundo experimento, os níveis para atenção e relevância foram estatisticamente maiores para o grupo que jogou com relação a quem não jogou. Além disso, as médias para os quatro construtos foram numericamente superiores para o grupo experimental. 
Como já dito, a diferença provavelmente é fruto do enfoque dado ao primeiro questionário. Como se trata de um instrumento que visa avaliar a eficácia do material instrucional utilizado, talvez tenha sido um equívoco focar no curso em sua totalidade no primeiro experimento. Com a devida correção e a ampliação dos itens por construto, esse problema foi resolvido e os resultados indicam uma maior possibilidade de motivação para quem usa o jogo digital no treinamento, confirmando boa parte do que já se sabe nessa literatura (Bellotti et al., 2012; Connolly et al., 2012; Khan \& Pearce, 2015; Lujan \& DiCarlo; 2006; Madani et al., 2017; Werbach, 2014).

Assim, confirma-se a primeira hipótese do estudo:

$H_{1}$ : Quem joga tem uma reação mais favorável ao curso/treinamento com relação a quem não joga,

Ou seja, de maneira geral, os gestores públicos gostam mais do treinamento quanto utilizam um jogo digital. Até aqui, pelo menos um tipo de impacto dos jogos digitais no desenvolvimento dos gestores público foi verificado. Há impacto na parte afetiva do desenvolvimento (reação/motivação), o que responde parte do objetivo específico de número 4 do trabalho (OE4).

\subsection{Avaliação do aprendizado}

O aprendizado foi avaliado com um teste de conhecimento (prova) aplicado ao término do curso (pós-teste). No experimento 1 foi também aplicada uma avaliação desse tipo antes do início do curso (pré-teste). As provas foram aplicadas online, via plataforma Moodle, durante o tempo de aula (cada participante tinha um notebook à sua disposição). A descrição da elaboração do instrumento consta na subseção 3.4.7 do capítulo anterior.

Com as notas obtidas em cada prova foram feitos testes estatísticos para ver se as diferenças eram significativas e poderiam ser atribuídas ao tratamento a que o grupo experimental foi submetido, isto é, o uso do jogo. Como o experimento 1 foi estruturado na forma préteste/pós-teste, a análise foi realizada com uma ANCOVA. Já no segundo experimento, apenas com pós-teste, a técnica escolhida foi a ANOVA. A verificação das premissas das técnicas, bem como as saídas com os resultados detalhados obtidas por meio do software 
estatístico SPSS encontram-se no Apêndice F e no Apêndice G, para os experimentos 1 e 2, respectivamente.

As análises consideram a pontuação total obtida em cada um dos testes (variáveis notal para o pré-teste e nota2 para o pós-teste no primeiro experimento e variável grade para o pós-teste do segundo experimento), mas também os percentuais de acerto em relação às questões atendendo os diferentes níveis (verbos) da taxonomia de Bloom, revisada por Anderson e Krathwohl (2001) e também da profundidade de conhecimento (DoK - Depth of Knowledge) de Webb (1997; 2007). Também foram considerados os assuntos principais avaliados: ciclo de planejamento-execução-controle (PEC), visão sistêmica (VS) e papéis gerenciais (PG). Adicionalmente, houve tentativas de separar os assuntos por nível de profundidade do aprendizado, porém o número pequeno de questões e de respondentes impede que seja possível fazer qualquer inferência relevante, de forma que esses resultados não são apresentados.

\subsubsection{Experimento 1}

A variável nota2 não apresentou outliers em nenhum dos grupos e o teste de KolmogorovSmirnov é compatível com uma distribuição normal. Embora o valor do teste de normalidade Shapiro-Wilk tenha resultado em $p=0,038$ para o grupo experimental, a ANCOVA é robusta com relação a violação de normalidade (Montgomery, 2013). As saídas do software estatístico para a verificação da ausência de outliers e normalidade da distribuição para os grupos constam no Apêndice F.

Em seguida, é importante testar a linearidade da variável dependente (nota2, o pós-teste) com relação à covariável (notal, o pré-teste) para cada nível da variável independente (turma, o tratamento). Por inspeção visual, pelos gráficos de dispersão adicionados ao referido apêndice, vê-se uma relação aproximadamente linear. Contudo, uma análise de regressão linear para cada nível mostra que apenas no grupo de controle a relação é linear a um nível de significância de 5\%. Para o grupo experimental, o nível descritivo foi de $p=0,134$. 
Por fim, cabe testar os dados coletados para a premissa que diz que deve haver homogeneidade dos coeficientes lineares das regressões. Isso é verificado aplicando-se um modelo linear considerando-se a interação da covariável (notal) com a variável independente (turma). Os resultados indicaram que a interação é estatisticamente significativa, o que viola uma das premissas da técnica. Quando isso acontece, há um indicativo de um efeito de interação do tipo atitude-tratamento (ATI).

Uma ATI em geral leva o pesquisador à conclusão de que não há diferença entre os tratamentos quanto na verdade há. É necessário avaliar a região de significância simultânea, isto é, a porção do gráfico contendo as regressões lineares para os dois grupos em que as inclinações se cruzam para que seja aplicada uma correção (Johnson, 2016). Contudo, para o experimento em questão, a análise de covariância não mostra a equivalência dos tratamentos e a região onde as retas de regressão se cruzariam estaria fora da região de resultados obtidos (Figura 4.9). Dessa forma, as correções sugeridas por Johnson (2016) não são necessárias e pode-se seguir com a ANCOVA como se o efeito não tivesse aparecido. Como resultado, sai dessa escolha uma das limitações da pesquisa, para a qual se faz a recomendação de, em estudos futuros dessa natureza, quando possível, que sejam identificadas e controladas outras variáveis que possam influenciar o desempenho dos participantes.

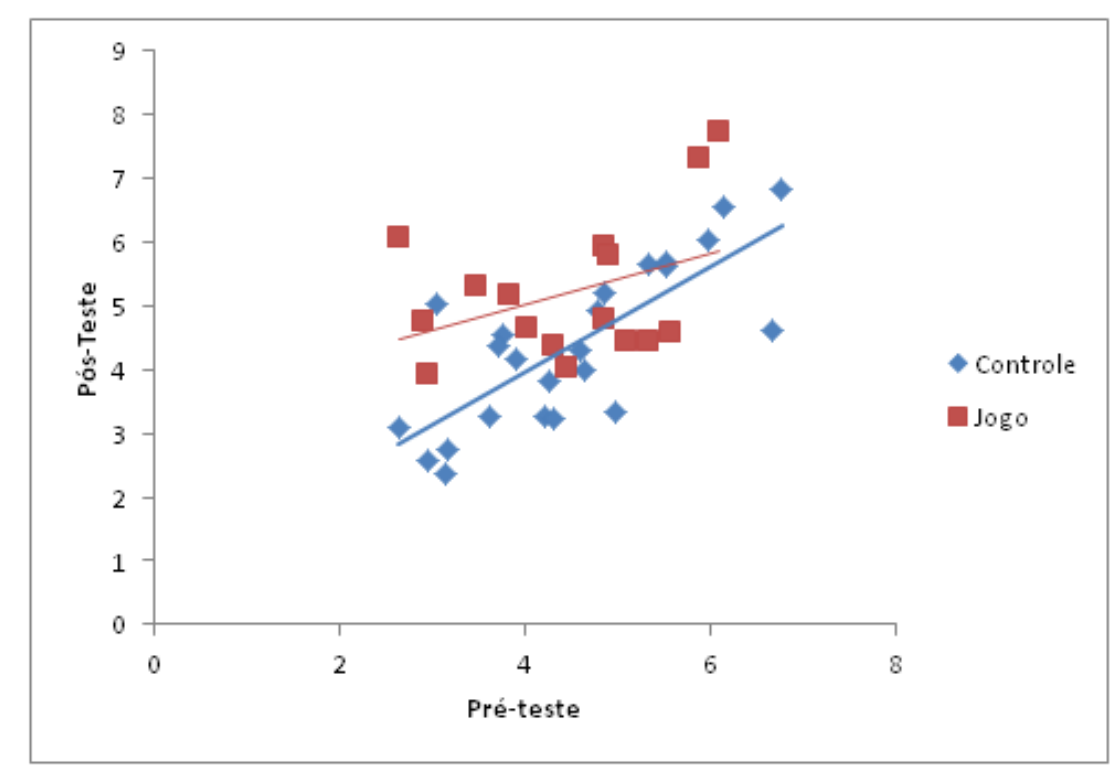

Figura 4.9 - Diagrama de dispersão das notas no pré e pós-testes, por grupo 
O gráfico da Figura 4.10 mostra as médias obtidas pelos participantes do experimento, tanto no pré-teste quanto no pós-teste. A ANCOVA resultou em uma diferença estatisticamente significativa para as diferenças de médias $(p=0,007<\alpha=0,05)$, indicando que os resultados superiores de aprendizado obtidos pelo grupo experimental podem ser atribuídos à diferença do tratamento. Isto é, aqueles participantes que utilizaram o jogo durante o curso obtiveram resultados melhores nas medidas de aprendizado. O poder estatístico observado no teste foi de 0,802. Todas as saídas do software estatístico estão contidas no Apêndice F. O gráfico de interação da Figura 4.11 auxilia igualmente a visualização.

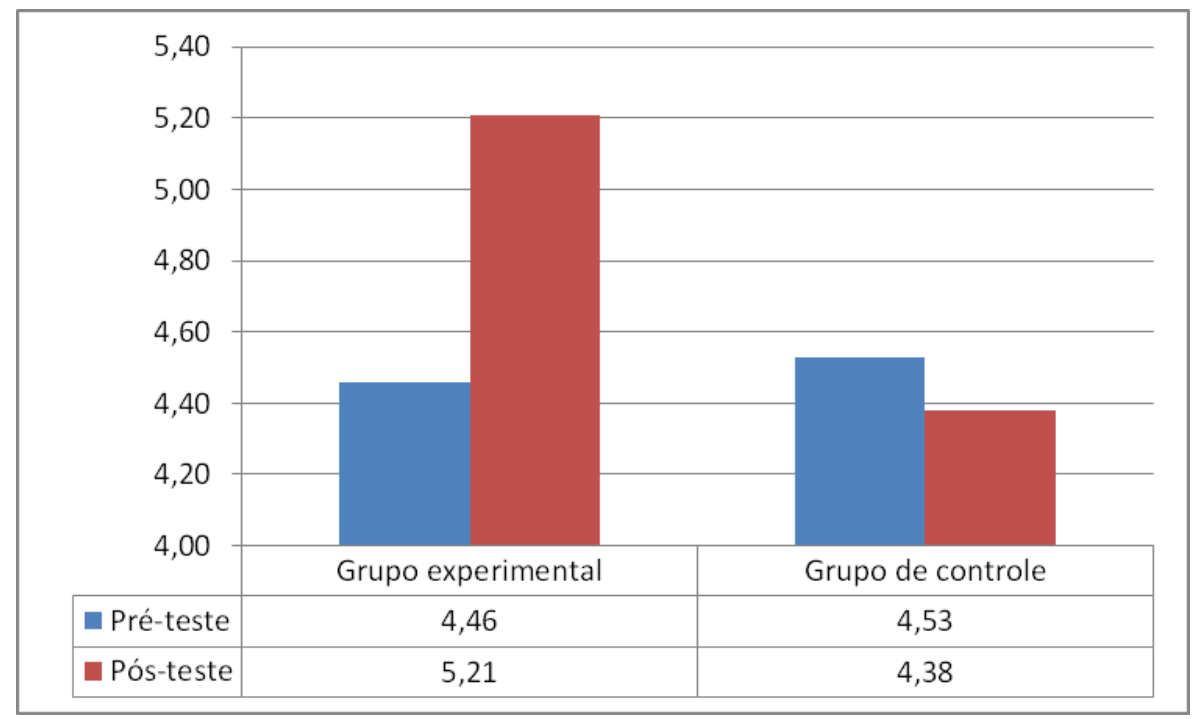

Figura 4.10 - Médias das notas obtidas no pré-teste e pós-teste pelos participantes do experimento 1

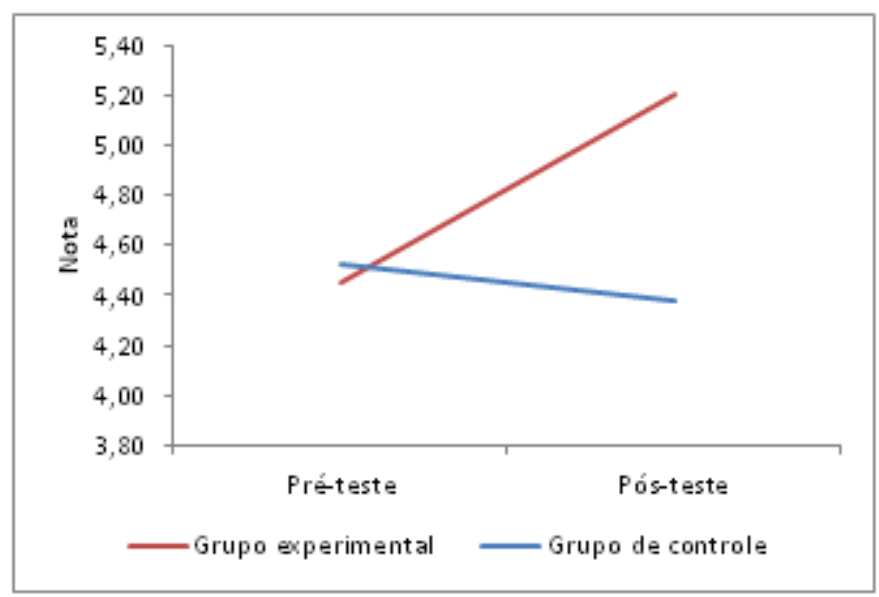

Figura 4.11 - Gráfico de interação para o pré-teste e o pós-teste do experimento 1 
Além da análise com o desempenho global dos participantes, outras tentativas de avaliar as diferenças de aprendizado foram feitas. A primeira ideia era a de separar as questões pelos temas abordados e a segunda pelo nível de profundidade de aprendizado avaliado, considerando-se os verbos da taxonomia modificada de Bloom e o nível DoK de Webb.

O que se percebeu é que para níveis mais altos da taxonomia de Bloom, o nível descritivo ( $p$ valor) da ANCOVA decresceu, sendo significativo para os níveis mais altos, dos verbos "aplicar" e "analisar". Os gráficos da Figura 4.12 mostram o percentual de acerto obtido no pré-teste e pós-teste pelos participantes do experimento em cada um dos grupos para cada conjunto de questões considerado; e a Figura 4.13 traz o nível descritivo dos testes em função do nível de profundidade da taxonomia de Bloom.

Esse resultado é confirmado quando as questões são avaliadas segundo o nível de profundidade de Webb. Embora o resultado não seja estatisticamente significativo para o primeiro nível (DoK1), com $p=0,517$ na comparação do tratamento com o controle, no segundo nível considerado (DoK2), o resultado é de $p=0,025$ com poder de 62,4\%. A Figura 4.14 traz o gráfico de interação com os percentuais de acerto das questões classificadas nessa lógica.
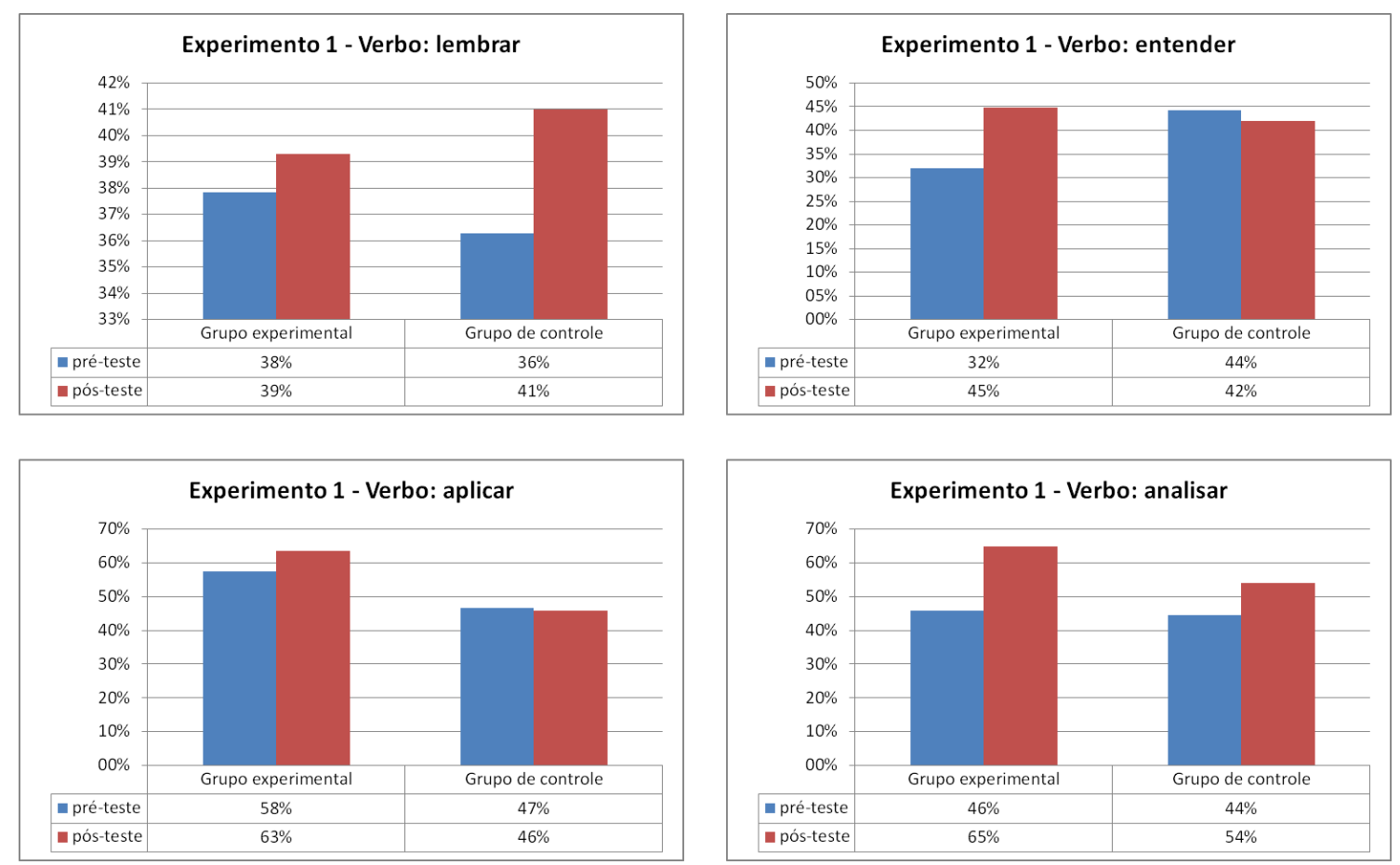

Figura 4.12 - Médias dos percentuais de acertos das questões classificadas em cada um dos verbos da taxonomia de Bloom para o experimento 1 


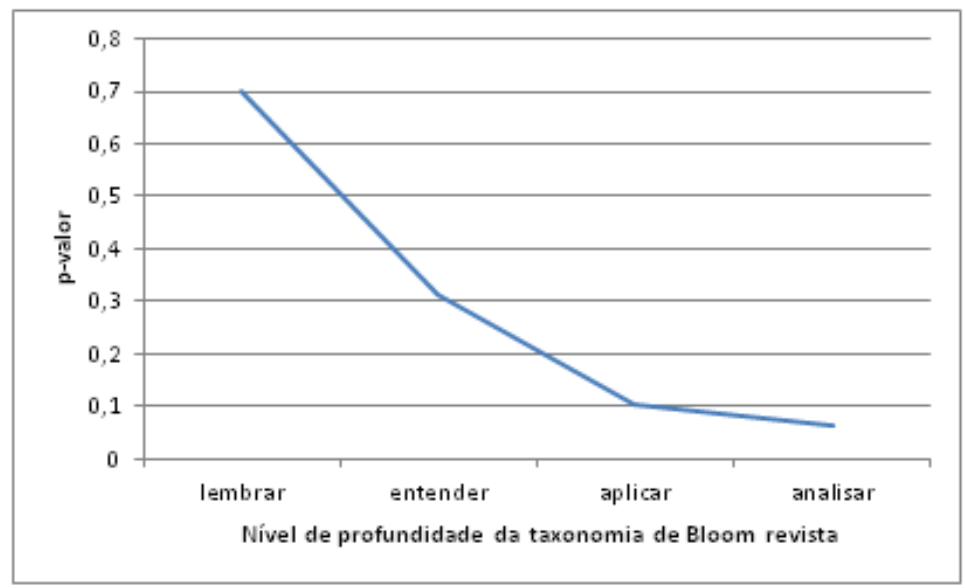

Figura 4.13 - Nível descritivo (p-valor) das ANCOVAS utilizadas para comparar o percentual de acertos nas questões classificadas nos verbos da taxonomia de Bloom no experimento 1

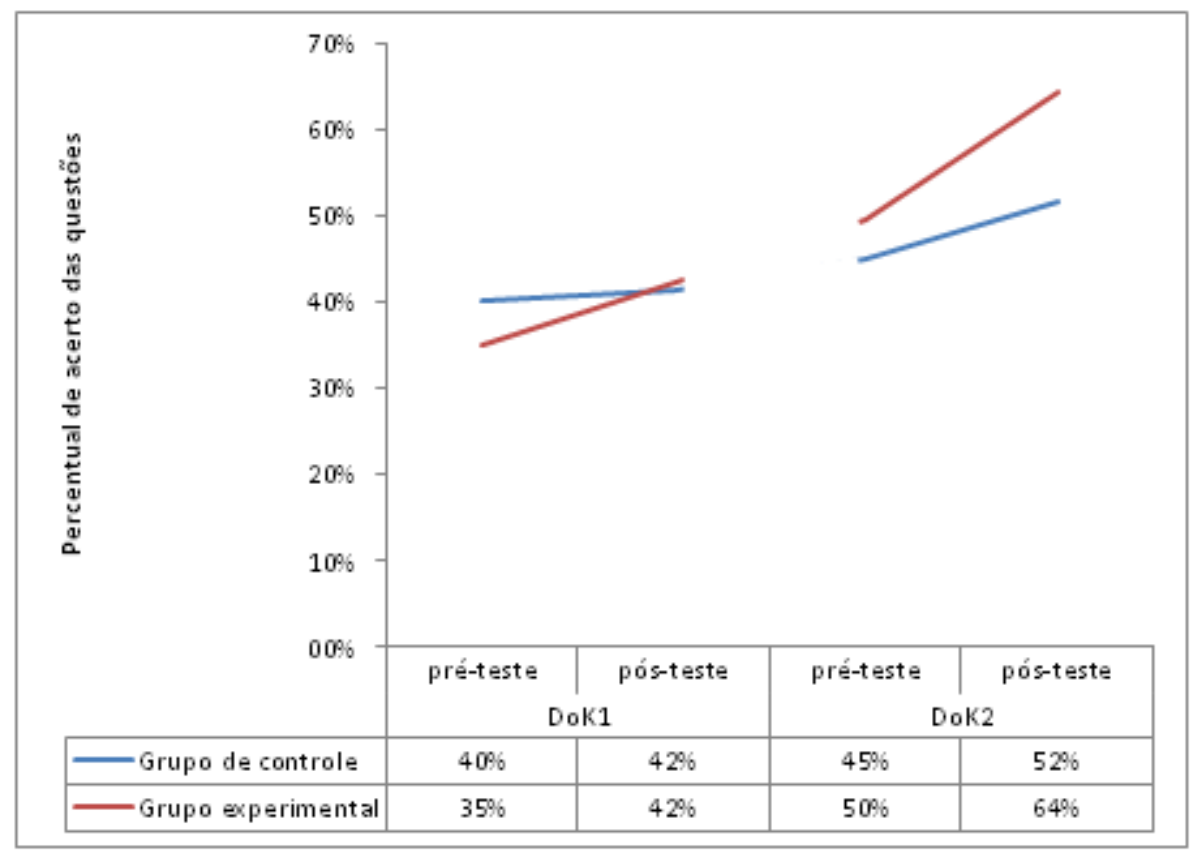

Figura 4.14 - Gráfico de interação para as médias do percentual de acerto das questões nos pré e pósteste, seguindo a classificação em níveis de profundidade (DoK) de Webb.

Cabe notar, portanto, que o resultado se afasta da condição em que seria gerado simplesmente pelo acaso, indicando que o jogo é efetivo para o aprendizado de níveis mais altos ou mais profundos de conhecimento. Os resultados vão no sentido oposto do que diz a literatura, em que os jogos normalmente são mais efetivos para o aprendizado dos níveis mais baixos da taxonomia de Bloom e não para os mais altos (Connolly et al., 2012). Estudos futuros podem ser desenhados para testar a hipótese de que para níveis mais profundos os jogos fazem mais 
diferença para o aprendizado enquanto podem não ser tão efetivos para os níveis mais baixos (o tratamento não faz diferença em níveis mais baixos e pode fazer em níveis mais altos). Ainda, podem-se testar os níveis ainda mais altos, como os DoK3 e DoK4 de Webb e os verbos de natureza mais abstrata, como "sintetizar" e "avaliar", cuja avaliação provavelmente requereria outro tipo de instrumento que não os utilizados nesta pesquisa contendo questões diretas, evidenciando outra das limitações do presente estudo.

No que tange aos diferentes assuntos abordados, ciclo de planejamento-execução-controle (PEC), visão sistêmica (VS) e papéis gerenciais (PG), não houve diferença estatisticamente significativa entre o grupo de controle e o grupo experimental no primeiro experimento.

\subsubsection{Experimento 2}

O experimento 2 teve sua medida de aprendizado realizada apenas no fim do curso (pósteste). A técnica utilizada para comparação de médias em experimentos com apenas uma medida é a Análise de Variância (ANOVA). Antes de sua aplicação, devem ser verificadas as premissas da técnica, como já destacado na subseção anterior. Os resultados da verificação das premissas constam no Apêndice G.

A variável grade (nota final no teste) não apresenta outliers e possui distribuição normal para os dois grupos, tanto pelo teste estatístico de Kolmogorov-Smirnov quanto pelo teste ShapiroWilks. O teste de Levene de homogeneidade de variâncias não foi estatisticamente significativo, com nível descritivo de $p=0,345$, indicando que a variância pode ser assumida como igual nos dois grupos. A independência dos erros pôde ser testada a partir dos resíduos da variável grade. Nesse caso, os testes de Kolmogorov-Smirnov e de Shapiro-Wilks indicaram que os resíduos possuem distribuição normal, o que é o indício de que são independentes. A Figura 4.15 mostra a média da nota final de cada um dos grupos. A Figura 4.16 apresenta o gráfico de pontos paralelos, que facilita a visualização de resultados experimentais. As saídas do software estatístico para a verificação das premissas e da aplicação da ANOVA são apresentadas no Apêndice G. 


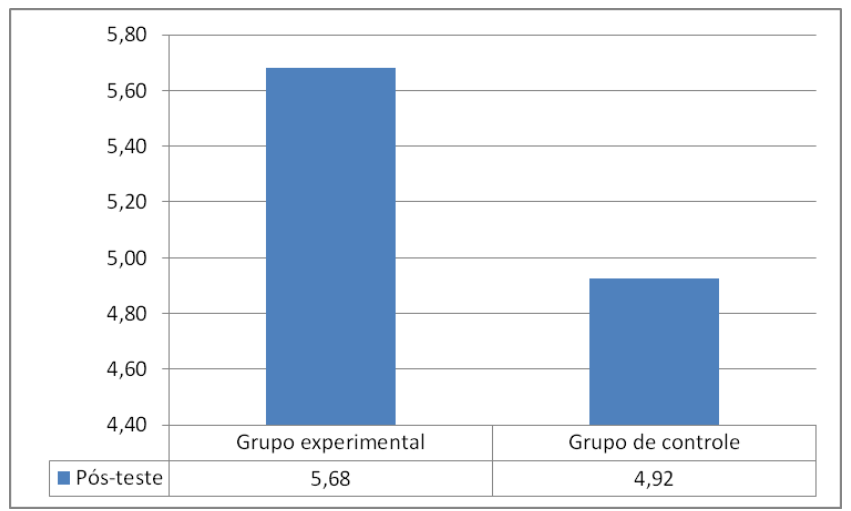

Figura 4.15 - Médias da nota final (pós-teste) para os grupos experimental e de controle no experimento 2.

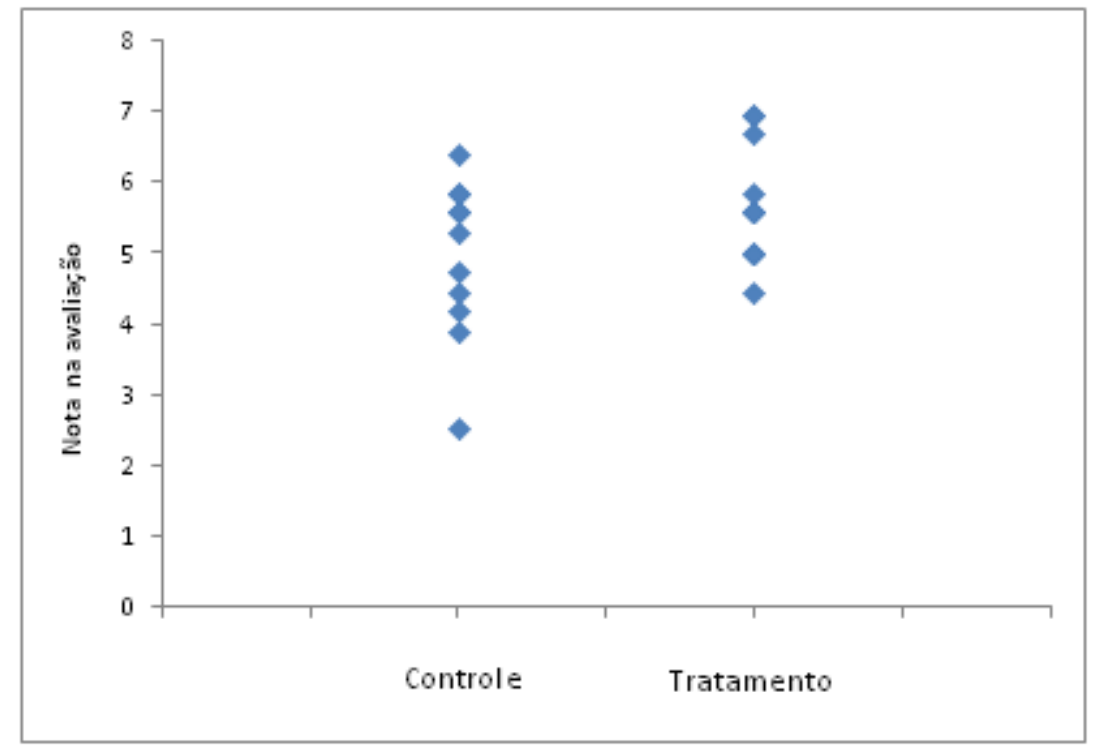

Figura 4.16 - Gráfico de pontos paralelos para o pós-teste do experimento 2

Na comparação das médias, o nível descritivo ficou acima de $\alpha=5 \%$, mas abaixo de $\alpha=$ $10 \%$, sendo $p=0,088$, valor que pode ser considerado baixo para um experimento como esse, indicando que a probabilidade de as diferenças terem ocorrido por mero acaso e não em função do tratamento como sendo inferiores a 10\%. Como uma comparação, se fosse considerado apenas o pós-teste do experimento 1 , o nível descritivo teria sido de $p=0,263$. A consideração do pré-teste fez o p-valor cair abaixo dos 5\%. Pode-se inferir que comportamento semelhante seria observado no segundo experimento caso o conhecimento prévio tivesse sido controlado, o que dá segurança para se afirmar de que as diferenças no nível de conhecimento adquirido no curso se devem ao tratamento, isto é, à utilização do jogo. 
Com relação aos níveis de profundidade de conhecimento (Bloom e Webb), ao contrário do resultado do primeiro experimento, foi encontrada diferença estatística apenas para o primeiro nível ( $p=0,083$ para o verbo "lembrar" e $p=0,109$ para o DoK1). Os demais níveis ficaram todos acima de 0,3, mas, novamente, decrescendo do nível 2 para o nível 4, como pode ser visto no Apêndice F. Para o DoK2, o nível descritivo foi $p=0,245$. A não realização do préteste, ou seja, não ter controle do conhecimento prévio, pode ter influenciado esse resultado.

Outro fato que pode ter atrapalhado a estatística é o reduzido número de questões consideradas em cada nível ou assunto. No primeiro experimento havia 60 questões, divididas aleatoriamente entre pré-teste e pós-teste para cada participante, enquanto no segundo experimento foram fixadas 23 questões no total. Isso resultaria em poucas questões por nível ou por assunto, necessitando de um efeito muito elevado para que as diferenças nas médias pudessem ser estatisticamente observadas.

Portanto, recomenda-se fortemente que em estudos futuros preocupados com a avaliação do aprendizado o conhecimento prévio seja controlado, como no experimento 1, e que sejam utilizadas mais questões por nível para garantir uma estatística mais efetiva para os testes.

Considerando-se os diferentes assuntos abordados na avaliação, observa-se diferença a 10\% de significância apenas para o grupo de questões sobre o ciclo Planejamento-ExecuçãoControle $(p=0,068)$, indicando que quem jogou absorveu melhor os conhecimento sobre esse tema do que quem não jogou. A taxa de acerto dessas questões foi de 59\% para o grupo experimental e de $50 \%$ para o grupo de controle.

Apesar do empate técnico do ponto de vista estatístico na maioria dos casos descritos acima, os valores médios do grupo experimental foram sistematicamente superiores aos do grupo de controle. A Tabela 4.7 resume esses dados, incluindo o nível descritivo das ANOVAS aplicadas. Um dado isolado seria insuficiente para permitir qualquer inferência, mas como o resultado é sistemático, ou seja, o resultado do grupo de tratamento é sempre maior que o de controle, seria uma questão de aumentar o número de questões em um dado conjunto ou a quantidade de respondentes para o experimento de forma que o efeito possa ser detectado de forma indubitável. Caso o resultado não existisse, isto é, houvesse empate de fato, seria esperado que em cerca de metade dos casos o controle superasse o tratamento, o que não se 
observa em nenhum caso. Provavelmente, não houve amostra em tamanho suficiente (respondentes e questões) para detectar o efeito em todos os grupos de questões.

Tabela 4.7 - Médias por critério para os grupos experimental e de controle para o experimento 2

\begin{tabular}{clccccc}
\hline \hline & & $\begin{array}{c}\mathbf{N}^{\mathbf{0}} \text { de } \\
\text { questões }\end{array}$ & $\begin{array}{c}\text { Pontos na } \\
\text { prova }\end{array}$ & Controle & Tratamento & $\begin{array}{c}\text { p-valor } \\
\text { (ANOVA) }\end{array}$ \\
\hline \multicolumn{2}{c}{ Geral } & 23 & 23 & 4,92 & 5,58 & 0,088 \\
\hline \multirow{2}{*}{$\begin{array}{c}\text { Verbos } \\
\text { (Bloom) }\end{array}$} & Entender & 5 & 2,5 & $47,6 \%$ & $51,7 \%$ & 0,539 \\
& Aplicar & 5 & 1,4 & $50,9 \%$ & $60,0 \%$ & 0,400 \\
& Analisar & 3 & 3,3 & $52,2 \%$ & $58,3 \%$ & 0,354 \\
\hline DoK & DoK1 & 15 & 5,3 & $46,9 \%$ & $55,1 \%$ & 0,109 \\
(Webb) & DoK2 & 8 & 4,7 & $51,8 \%$ & $58,8 \%$ & 0,245 \\
\hline \multirow{2}{*}{ Assunto } & PEC & 11 & 4,2 & $50,4 \%$ & $59,5 \%$ & 0,068 \\
& VS & 3 & 3,3 & $53,0 \%$ & $59,0 \%$ & 0,359 \\
\hline \hline
\end{tabular}

\subsubsection{Discussão dos resultados: Aprendizado}

Os resultados do primeiro e do segundo experimento, individualmente e em conjunto, mostram que, de maneira geral, os gestores públicos aprendem mais com o uso do jogo digital.

Esse resultado traz uma perspectiva complementar ao que já se sabe da literatura. Em geral, os estudos apontam que os níveis motivacionais são maiores naqueles que utilizam jogos ou elementos de jogos para seu aprendizado (Bellotti et al., 2012; Connolly et al., 2012; Khan \& Pearce, 2015; Lujan \& DiCarlo; 2006; Werbach, 2014), mas nem sempre o nível de aprendizado é maior (Connolly et al., 2012; Madani et al., 2017). Neste estudo, obteve-se um resultado consistente para uma métrica de aprendizado objetiva no mesmo sentido de Sitzmann (2011) e Wouters et al. (2013).

Sitzmann (2011) destaca que a aquisição de conhecimento é 11\% maior com o uso de jogos, enquanto a retenção é $9 \%$. No presente estudo, comparando-se as pontuações do grupo experimental com o grupo de controle, a diferença é da ordem de $15 \%$ a favor de quem jogou. $\mathrm{O}$ autor também salienta que os alunos aprendem mais quando podem acessar o jogo ou 
simulação quantas vezes quiserem. Essa é a situação do segundo experimento em que a nota no pós-teste superou em $9 \%$ a nota do pós-teste do primeiro experimento, comparando-se apenas o grupo de tratamento $(5,21$ versus 5,68$)$.

A evidência de aprendizado maior pelo grupo experimental responde também à segunda hipótese do estudo:

$\mathrm{H}_{2}$ : Quem joga aprende mais os conceitos de administração com relação a quem não joga,

ao mesmo tempo em que se soma mais um elemento para o atingimento do objetivo específico de número 4 da pesquisa (OE4). Assim, gestores públicos aprendem mais quando utilizam jogos digitais em seu processo de desenvolvimento. Há, portanto, impacto sobre o aprendizado considerado como aquisição de conhecimento.

Havendo aprendizado considerado como aquisição de conhecimento, há indícios de que houve desenvolvimento de competências, do ponto de vista do tradicional CHA (Conhecimentos, Habilidades e Atitudes).

Outra forma de se avaliar o aprendizado é pela perspectiva da mudança de comportamento (Gagné, 1976; Illeris, 2003; Schunk 1991; Stones, 1966). Como o comportamento, em geral, é antecedido pela mudança de atitude (Ajzen, 1991), faz sentido ampliar essa discussão na próxima seção, onde se aborda o terceiro nível de avaliação do modelo de Kirkpatrick.

\subsection{Percepção sobre a mudança de comportamento}

Como visto na seção 2.2.4, o modelo comportamental de Fogg (FBM) vincula um comportamento pretendido à motivação e à habilidade (Fogg, 2009). O jogo, nesse contexto, é pensado como o veículo para dar a habilidade que o jogador precisa para ter o comportamento pretendido, que neste trabalho, significa melhorar a gestão. Além disso, como destacado na seção 2.3.5, a mudança de comportamento é um indicador de que houve aprendizado (Schunk, 1991). Por fim, outro ingrediente importante nessa combinação é mudança de atitude, tanto como antecedente da mudança de comportamento, quanto como componente das competências a serem desenvolvidas pelos gestores (CHA) para a melhoria da gestão. 
Dessa forma, esta seção procura analisar essas questões de duas maneiras. Primeiro, a partir dos textos que os alunos produziram logo após o experimento 1, verificou-se de que maneira eles se posicionavam com relação à sua percepção de gestão. Ali, o texto poderia trazer assertivas com visões mais soft da gestão (focada em comportamentos, motivação, relacionamento e outros aspectos humanos) ou em visões mais tradicionais (focam mais na cadeia de comando e controle, no planejamento e no cumprimento de metas, por exemplo), ditas aqui hard, em contraposição à visão soft. Em segundo lugar, buscaram-se nas entrevistas, que foram realizadas dois meses após o primeiro experimento, e nas respostas da consulta online, realizada três meses depois do segundo experimento, elementos que pudessem indicar mudanças de comportamento. Nesse caso, no entanto, a medida não poderia mais ser comparativa, pois como medida compensatória do experimento, os participantes do grupo de controle passaram a ter acesso ao jogo assim que os experimentos acabaram. $\mathrm{O}$ material foi complementado por comentários encontrados especificamente sobre o jogo nos questionários de avaliação de reação.

\subsubsection{Análise dos textos produzidos}

Ao término do curso do experimento 1, antes de responder à avaliação de aprendizado, cada participante foi convidado a escrever um breve texto sobre suas impressões de quais seriam os papéis e responsabilidades de um gestor. 22 participantes da Turma 1 (grupo de controle) e 15 da Turma 2 (grupo experimental) enviaram suas respostas.

Como dito no capítulo sobre o método da pesquisa, a análise de conteúdo é uma técnica complementar e não central neste estudo. Assim, os textos foram analisados a partir de uma categorização simples, em que foram avaliadas as posições escritas em dois aspectos da gestão: o hard, que considera basicamente a visão da escola clássica de administração e a soft, que incorpora o pensamento da escola de relações humanas e suas influências. O objetivo dessa classificação foi o de verificar se haveria maior ou menor concentração de posições em uma ou outra categoria em função do grupo avaliado. 
Cada texto teve todas suas sentenças avaliadas e algumas delas foram enquadradas na categoria soft e outras na categoria hard. Cada respondente tinha, portanto, uma pontuação em cada categoria. O gráfico da Figura 4.17 apresenta as médias em cada categoria em função do grupo considerado. Com os dados por respondente procedeu-se com uma comparação de médias para ver se as diferenças eram estatisticamente significativas. O Apêndice $\mathrm{H}$ apresenta os resultados dessa análise, bem como a tabela de respostas com as categorizações.

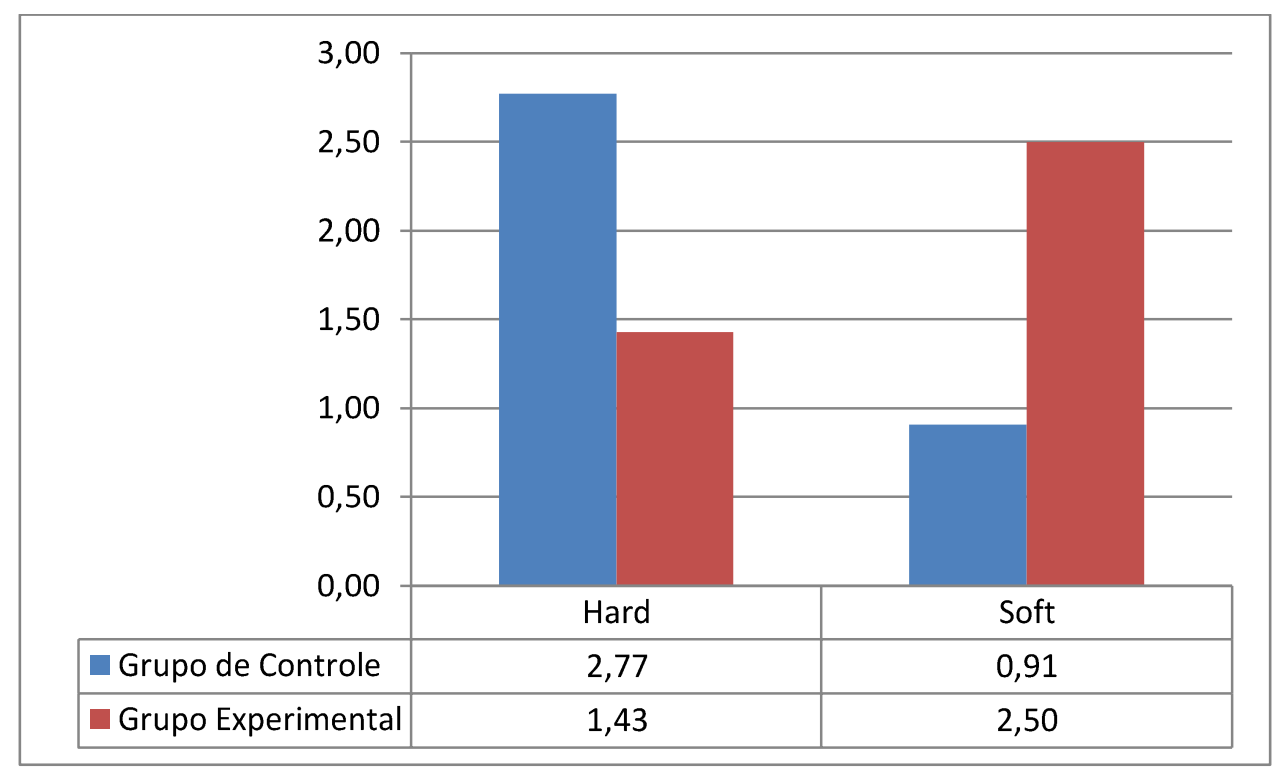

Figura 4.17 - Médias da quantidade de sentenças com visões hard e soft de gestão nos textos produzidos no experimento 1

Como os dados em questão são contagens, a distribuição dos dados dificilmente é normal (em geral é uma binomial negativa). Assim, optou-se novamente pelo uso do teste não paramétrico de Mann-Whitney, o teste $U$. O nível descritivo do teste foi $p=0,011$ para a contagem hard e $p=0,024$ para a contagem soft (ambos menores que o nível de significância $\alpha=0,05$ ), indicando que a proporção de opiniões que consideram visões hard e soft da administração é diferente nos grupos experimental e de controle, sendo que o grupo experimental apresentou uma maior proporção de visões soft. 


\subsubsection{Análise qualitativa}

As entrevistas realizadas dois meses após o primeiro experimento e a consulta online feita três meses depois do segundo experimento serviram de fonte para discussão nesta subseção. As transcrições das entrevistas e respostas recebidas por e-mail foram ainda complementadas pelos comentários encontrados nos questionários de avaliação de reação. O intuito desta subseção é apresentar, qualitativamente, evidências de que o jogo possa ter contribuído para mudanças no comportamento.

Por exemplo, a similaridade do jogo com a realidade facilitou a percepção de algumas pessoas sobre as práticas que normalmente tinham, como nos comentários abaixo:

[O jogo] mostra um cenário muito próximo da nossa realidade, desde pessoas, prazos, cobrança (comentário no questionário de reação)

O jogo é bem interessante, e nos mostra de uma formal "real" os conflitos que enfrentamos ou podemos enfrentar no dia-a-dia. Ótimo jogo! (comentário no questionário de reação)

Eu já passei por situações muito parecidas. Então durante o jogo eu acabei aprendendo isso: que não é eu chegar e já achar que eu vou delegando as coisas... é... que eu vou conseguir atingir minhas metas, meus objetivos. Não. Eu primeiro tenho que conhecer pessoas, saber a habilidade de cada um e respeitá-los para poder eu conseguir o trabalho objetivo mesmo, atingir minhas metas (entrevista 1)

Eu vi que existe... Até, na verdade, foi o contrário... Quando eu estava jogando eu percebi isso... Situações do meu dia a dia que estavam aparecendo ali. (entrevista 2)

O jogo, os vídeos, ampliaram minha visão no meu trabalho, agora observo pontos, coisas que eu fazia ou deixava de fazer, ou características de funcionários, que antes nem notava. (comentário no questionário de reação)

o curso de Gestão Pública contribuiu muito para melhorar minhas percepções no ambiente de trabalho, adquiri mesmo em pouco tempo uma sensibilidade no convívio com minha liderança e colegas de trabalho onde posso dar, se assim posso dizer, opinião balanceada em certas situações rotineiras. Opinar e avaliar pontos de vista. (e-mail 1)

Além disso, as pessoas também relataram explicitamente ter mudado determinadas práticas ou comportamentos:

Eu tinha um pouco de resistência em demandar os serviços, era centralizadora, não confiava muito que o serviço iria sair da forma que precisava. Depois do curso, percebi que consigo demandar, e ao mesmo tempo estar ciente de tudo o que está acontecendo e conseguir fazer o que é minha competência. (e-mail 3) 
Aprendi a ouvir, a considerar cada resposta (pensar, analisar, antes de responder) e a importância da responsabilidade de cada funcionário em fazer o que lhe é determinado, orientando sempre que necessário, elogiando, etc. (comentário no questionário de reação)

Converso mais com as Chefias, colocando-as ao par dos problemas, o que ajuda nas tomadas de decisões e no empenho de cada um. (e-mail 5)

Porém, um dos fatos mais notados sobre o jogo e transposto para a realidade foi a questão da individualidade das pessoas. Perceber que os funcionários têm diferentes habilidades e que isso deve ser aproveitado da melhor forma possível para atingir os objetivos da unidade foi um comentário recorrente:

O jogo mostrou a dificuldade de lidar com diferentes perfis e a necessidade de estar atento para a solução de conflitos oriundos destas diferenças, posto que cada ação interfere diretamente na qualidade do trabalho entregue (comentário no questionário de reação)

foi muito importante o jogo porque, assim, a gente passa por essa situação na realidade só que a gente não consegue ver da mesma forma como no jogo e mostrou também que a gente precisa de conhecer as pessoas primeiro antes de tomar qualquer atitude. Porque tomar atitude sem conhecer as pessoas acaba nos trazendo pontos negativos também, né? E aí acaba gerando às vezes conflitos, enfim, desnecessariamente. Então para mim foi muito útil aquele jogo. (entrevista 1)

aprendi que devemos aproveitar o que cada um tem de melhor, suas habilidades (comentário no questionário de reação)

Estimulando a me reorganizar com prazos e prioridades para conseguir desenvolver mais rapidamente e com mais qualidade os serviços designados. Identificando falhas e qualidades dos subordinados, na qual torna-se importante na hora de delegar atividades e funções (comentário no questionário de reação)

O jogo me ajudou a analisar as pessoas, suas preferências e como elas mais se destacam. É claro que não dá pra fazer só o que a gente gosta, mas priorizar quem se sente melhor com tal procedimento melhora o desenvolvimento da equipe (comentário no questionário de reação)

E, assim, eu comecei de novo e você até comentou isso lá. Na primeira vez eu estava indo super mal, porque eu achava que era só distribuir e não é tão objetivo assim, tem alguns aspectos mais subjetivos. Então foi legal essa questão de saber o que dar para quem fazer, qual o trabalho... a quantidade, que é uma coisa que a gente vê na prática. Não sei se seria novo, mas eu comecei a comparar assim com a prática mesmo, de que cada pessoa é diferente da outra e cada um você tem que tratar de uma forma, se não, não funciona. (entrevista 2)

Acho que tem que ter um jogo de cintura ali que o jogo cobra da gente. Fazer essa diferenciação entre as pessoas. Para mim, o mais forte do jogo foi isso: foi diferenciar as pessoas que trabalhavam ali. (entrevista 2)

A questão de... muito, muito parecida... foi a questão de colega reclamar e você não saber por que... você como líder às vezes não consegue identificar por que ele reclama tanto. E pelo jogo eu consegui observar que às vezes ele está fazendo repetidamente o que ele não gosta (entrevista 1) 
Acho que é mais essa questão, de ouvir as pessoas, de perceber o que elas querem, porque o jogo é isso... Eu acho que eu consegui fazer aquela pontuação quando eu comecei a entender que era individual ali... que você não podia tratar a equipe como um monte de robozinhos, é uma coisa individual. Isso foi muito legal, assim, incorporou bem. (entrevistado 2)

uma coisa que eu acho bacana é esse lance do jogo, assim, de você tentar perceber que uma pessoa tem uma facilidade e uma dificuldade com alguma coisa (entrevista 3)

Ah, essa visão de que... às vezes, é... lá era realmente importante cumprir a meta, mas eu comecei a perceber que não era esse só o objetivo principal, era ver o que você realmente discutiu com a gente, que às vezes tem pessoas que são mais afeitas a determinado serviço e que não adianta eu querer que ela faça o X que ela odeia. Às vezes ela vai ter que fazer o que ela odeia também, porque nem sempre o mundo é perfeito. Mas se eu conseguir realmente delegar aquilo que a pessoa gosta pra ela fazer, muito provavelmente a coisa vai fluir com mais... fluir com fluidez é redundância, mas é mais ou menos isso, né? A coisa vai ser mais redonda, vai ficar bom pra todo mundo, porque eu acho que quando você faz a coisa que você gosta, você faz com mais prazer, entendeu? (entrevista 5)

ter a sensibilidade de perceber o que as pessoas gostam de fazer e tentar, na medida do possivel, estar delegando essas funções pra determinadas pessoas. Acho que eu percebi um pouco no jogo, embora não sei se veio de mim ou se esse era realmente um dos objetivos do jogo, é... tentar reparar mais na sua equipe mesmo. Entendeu? Acho que eu não tinha... talvez eu até tivesse essa coisa, mas não parei para pensar igual jogando, sabe? De tentar justamente ver isso, o que a pessoa tem mais afinidade, tentar delegar, na medida do possível, a função... acho que isso foi o que mais me marcou no jogo. (entrevista 5)

\section{Mesmo quando a pessoa não percebeu no jogo, de fato, que isso ocorria:}

Então, assim, eu não captei muito o jogo, a facilidade de cada um, que eu acredito que eles deviam ter. Porque não é possível que aquela menininha fosse ruim em tudo, por que tudo que eu entreguei ela era péssima. Mas assim, não é possível, talvez, eu é que não consegui sacar no que que ela era boa. Então, assim, se eu tivesse anotado bonitinho pra quem eu dei, as notas de cada um, as facilidades e o tempo de demora pra fazer um estudo sobre o jogo, assim, aí meu desempenho teria sido bem melhor (entrevista 3)

\section{E, mais do que isso, essa percepção da individualidade produziu resultados práticos:}

Cheguei à conclusão de que você tem que aproveitar o que a pessoa sabe fazer... por que... se não, você não vai conseguir tirar nada dele. Principalmente no serviço público, porque no serviço privado ou ele faz ou ele é mandado embora. Aqui ou ele faz ou ele não faz e dá no mesmo, então é melhor que faça alguma coisa. Numa gestão, o que que você faz? Você fica dando murro em ponta de faca e fazendo ele fazer outras coisas ou aproveita melhor aquilo ali que ele sabe fazer? Aqui eu vejo muito isso... (entrevista 2)

mas antes de sair de férias eu já tinha tido uma conversa com ela e eu sei que a gente tá com um projeto novo e eu sei que é uma coisa que ela gosta, então hoje eu já coloquei ela à frente desse projeto, justamente pensando no jogo... vamos dar as coisas que a pessoa gosta, porque... aí eu percebi também que, eu tinha vivido isso antes e no jogo ficou tão claro pra mim... eu falei assim: gente é exatamente o que 
eu fiz com a pessoa, entendeu? E aí ela se envolveu de uma outra forma que virou uma outra pessoa na equipe... Então isso dai foi muito legal, eu achei fantástico. (entrevista 5)

O jogo contribui em ter maneiras diferentes de organizar a divisão de trabalho e de outras ações (comentário no questionário de reação)

pude verificar como melhorar a gestão do tempo, como compreender melhor as necessidades do setor, verificar que os problemas enfrentados são comuns a maioria dos gestores (comentário no questionário de reação)

Mas outros tipos de percepção com implicações práticas também foram relatados:

Ficou muito evidente que não estou realizando muitos afazeres juntamente, e nada tão focado... só superficial. Como gosto de fazer corretamente com prazos, o jogo me possibilitou ver que estou desorganizada. Pretendo jogá-lo novamente, não como um jogo e sim como um exercício... (comentário no questionário de reação)

Outra coisa seria eu saber liderar, que eu tenho que liderar de qualquer forma. Mesmo... não deixar jogado, eu tenho que estar ali presente [...] Não deixar cada um fazer o que quer, em si, mas estar sempre coordenando. Essa coordenação é muito bacana. (entrevista 1)

o jogo me mostrou que para ser boa gestora, tenho que conhecer bem os meus funcionários para designar as tarefas e aproveitar ao máximo o potencial de cada funcionário. isso tb ajuda a estimular o funcionário a querer realizar seu serviço com qualidade. (comentário no questionário de reação)

Então esse jogo acabou você tendo a condição de como lidar melhor com o conflito, uma coisa totalmente à parte do teu contexto lá, que seria a gestão, mas lidar com o conflito, eu percebi que no jogo, a gente consegue saber como lidar melhor com isso (entrevista 1)

Entendo que esse jogo nos faz refletir sobre o andamento e conduta em nosso trabalho. Gostei muito e através dele posso adquirir melhores habilidades em relação às atividades que desempenho na área de compras onde hoje trabalho. (comentário no questionário de reação)

Além disso, na consulta online, os participantes foram provocados a explorar justamente aspectos que haviam aprendido com o jogo:

Aprendi que um verdadeiro líder sempre tem que buscar atualizações e condições para manter a equipe focada e disposta para desenvolver o processo de trabalho. (e-mail 1)

Aprendi a ouvir, a considerar cada resposta (pensar, analisar, antes de responder) e a importância da responsabilidade de cada funcionário em fazer o que lhe é determinado, orientando sempre que necessário, elogiando, etc. (e-mail 3)

Aprendi que devemos planejar, ver as possibilidades, dar valor ao melhor empenho de cada um. (e-mail 5) 
Embora os trechos apresentados acima não sejam suficientes para afirmar que o jogo provoca a mudança de comportamento, eles trazem alguns indícios de que as reflexões que o jogo proporcionou aos jogadores possam estar relacionadas aos aprendizados relatados.

\subsubsection{Discussão dos resultados: Comportamento}

Somando-se as análises das duas subseções precedentes, pode-se discutir o impacto do uso do jogo digital sobre o comportamento. Primeiramente, nota-se que o grupo experimental apresentou, em média, uma visão de gestão mais atrelada às questões humanas, com foco no relacionamento interpessoal, na comunicação, atribuindo uma importância mais acentuada sobre as soft-skills quando comparado ao grupo de controle. Esse resultado não foi acidental, pois o jogo foi confeccionado com a intenção de cobrir esses aspectos. O resultado mostra que o jogo foi bem sucedido nessa tarefa, o que é comprovado pelo teste estatístico que o fundamenta.

A visão sobre a gestão, com essa ênfase mais soft em contraposição à visão hard, isto é, com foco na tradicional cadeia de comando e controle, enfatizando planejamento e cumprimento de metas, foi considerada, neste estudo, como um indicador da atitude do participante no experimento. Como já destacado, a atitude é considerada um antecedente da mudança do comportamento (Ajzen, 1991), sendo o primeiro passo necessário para que um comportamento desejado ocorra. O modelo comportamental de Fogg (2009), o FMB, preconiza que o comportamento desejado depende das habilidades necessárias e da motivação para, a partir de gatilhos, acontecer. A mudança de atitude pode ser vista, também, como relacionada a esses gatilhos e à motivação para o gestor passar a ter um novo comportamento.

É interessante notar que o jogo permitiu a construção de uma visão mais soft mesmo se tratando de um sistema que só permite a interação com a máquina, apresentando possibilidades reduzidas de se fazer o que se faz na vida real, como dar feedback, solicitar informações ou mesmo pedir ajuda a um colega ou ao superior imediato. Mesmo assim, o jogo foi bem sucedido na tarefa de sensibilizar os gestores para esse lado da gestão. 
Assim, havendo mudança da atitude, pode-se inferir que existe impacto do uso do jogo sobre o desenvolvimento de competências, do ponto de vista do CHA do indivíduo. Somando-se as evidências de mudança de comportamento evidenciadas pelas entrevistas, verifica-se um acréscimo duplo: o ganho de conhecimento e o aprendizado se manifestando como mudança de comportamento. Se o gestor desenvolver as habilidades necessárias, pode reforçar o comportamento desejado também do ponto de vista do FBM.

Dessa forma, estão postos os elementos necessários para a verificação da terceira hipótese do estudo:

H3: Quem joga muda de atitude com relação à gestão, passando a vê-la como diferente do tradicional com relação a quem não joga.

Ou seja, há desenvolvimento do gestor. Soma-se mais um impacto percebido com o uso do jogo digital desenvolvido neste trabalho. Com as evidências de que o jogo pode provocar mudanças de atitudes ou de comportamentos no processo de desenvolvimento dos gestores públicos, adiciona-se mais uma parcela à consecução do objetivo específico de número 4 da pesquisa (OE4).

\subsection{Resultado projetado}

Para execução do segundo experimento, decidiu-se incorporar um instrumento adicional de medida, com o intuito de inferir se os participantes percebiam diferenças do impacto do curso que tinham acabado de realizar sobre os resultados futuros de seu trabalho. O intuito era o de verificar diferenças entre os grupos experimental e de controle. Obviamente, avaliar o impacto de treinamento com relação aos resultados organizacionais é algo que toma tempo e deve ser feito criteriosamente. Mas aqui, o objetivo era ter uma indicação sobre o quarto nível do modelo de avaliação de Kirkpatrick, mesmo que de forma aproximada.

A Tabela 4.8 apresenta as médias da pontuação dos grupos e o nível descritivo do teste $U$ de Mann-Whitney. Há ainda a indicação de se o resultado é significativo a um nível de significância de $10 \%$ ou 5\%. Optou-se por mostrar as médias por ser um parâmetro mais intuitivo para comparação, mesmo sabendo-se que o teste de Mann-Whitney faz a 
comparação de medianas. O questionário e as saídas dos testes estatísticos encontram-se no Apêndice J.

Tabela 4.8 - comparação das médias para os itens de resultado projetado para os grupos experimental (tratamento) e de controle do experimento 2

\begin{tabular}{clcccc}
\hline \hline Item & \multicolumn{1}{c}{ Descrição } & $\begin{array}{c}\text { Con- } \\
\text { trole }\end{array}$ & $\begin{array}{c}\text { Trata- } \\
\text { mento }\end{array}$ & $\begin{array}{c}\text { p-valor } \\
\text { (Teste U) }\end{array}$ & \\
\hline 1 & Planejamento das atividades dos meus subordinados & 5,70 & 6,83 & 0,036 & $* *$ \\
2 & Levar em consideração o perfil de competências dos & 5,70 & 6,75 & 0,197 & \\
& funcionários na hora de distribuir as tarefas & & & & \\
3 & Melhoria geral do serviço prestado pela minha unidade & 4,70 & 5,83 & 0,173 & \\
4 & Eficiência nos processos realizados pela minha unidade & 4,40 & 5,92 & 0,061 & $*$ \\
5 & Planejamento orçamentário da minha unidade & 5,60 & 6,58 & 0,061 & $*$ \\
6 & Execução orçamentária da minha unidade & 4,70 & 6,58 & 0,013 & $* *$ \\
7 & Cumprimento dos prazos & 5,90 & 6,67 & 0,282 & \\
8 & Qualidade das entregas da unidade & 5,70 & 6,58 & 0,132 & \\
9 & Identificação das demandas de treinamento da equipe & 5,70 & 6,83 & 0,016 & $* *$ \\
10 & Relacionamento com os superiores & 5,10 & 6,33 & 0,349 & \\
11 & Relacionamento com os subordinados & 5,56 & 6,25 & 0,099 & $*$ \\
\hline \hline
\end{tabular}

Nota: os valores marcados com um asterisco $\left(^{*}\right)$ indicam significância estatística a um nível de $10 \%$, enquanto os marcados com dois asteriscos $(* *)$ indicam significância estatística a $5 \%$.

A 10\% de significância, vê-se que 6 dos 11 itens apresentam diferença estatisticamente significativa (Planejamento das atividades dos meus subordinados, Eficiência nos processos realizados pela minha unidade, Planejamento orçamentário da minha unidade, Execução orçamentária da minha unidade, Identificação das demandas de treinamento da equipe e Relacionamento com os subordinados). A 5\%, são três itens com diferenças significativas. Além disso, pode-se observar que as médias do grupo experimental superam sistematicamente as médias do grupo de controle, indicando uma baixa probabilidade de o resultado ter ocorrido por mera coincidência. Isso indica que o jogo tem impacto sobre o resultado projetado.

Naturalmente, a confirmação da efetividade do uso de jogos digitais sobre o resultado organizacional só é possível com outros tipos de estudos, envolvendo diferentes intervenções e medidas longitudinais. O difícil é atribuir qual a parcela do resultado organizacional foi causada pelo eventual uso de jogos digitais no processo de desenvolvimento de gestores. No caso da área pública, os resultados são muito difusos, sendo ainda mais difícil qualquer tipo de vinculação de treinamentos desse tipo com os resultados. 


\subsubsection{Discussão dos resultados: Resultados}

De maneira geral, percebe-se que os gestores públicos que jogaram viram, logo após o curso, maior impacto sobre o resultado de seu trabalho, pensando-se em uma projeção para o futuro. Esse fato está em consonância com a análise da seção 4.2, em que foi encontrada diferença significativa para os itens do questionário de reação associados à aplicabilidade do conteúdo visto no curso (item e) e o nível de contribuição do conteúdo para o desempenho profissional (item d).

Numericamente, a média de todos os 11 itens que avaliam o impacto do curso sobre o resultado é superior para o grupo experimental comparada à do grupo de controle. Mesmo que existisse diferença em apenas um item, já se teria evidência da percepção do impacto do uso do jogo digital sobre o resultado. Estatisticamente, no entanto, a diferença é verificada em seis desses itens. Dessa forma, já há elementos para confirmar a quarta e última hipótese do experimento do estudo:

$H_{4}$ : Quem joga percebe maior influência do curso/treinamento na projeção de resultados de seu trabalho com relação a quem não joga.

É possível, portanto, inferir que os gestores públicos veem maior possibilidade de impacto nos resultados de seu trabalho depois de utilizarem jogos digitais em seu processo de desenvolvimento. Atinge-se, assim, o objetivo específico de número 4 da pesquisa (OE4) em sua totalidade, dentro da operacionalização do estudo, considerando-se as discussões da presente subseção e também das subseções 4.2.3, 4.3.3 e 4.4.3. 


\section{CONCLUSÃO}

\subsection{Objetivos e resultados alcançados}

A presente pesquisa nasceu de uma conjunção de fatores. De um lado, a inquietação do autor sobre como melhorar a gestão pública e a percepção de que uma melhor prestação de serviços públicos à sociedade depende de gestores capacitados. De outro lado, o contexto em que o país se insere, evidenciando ainda mais a carência de mecanismos para o preparo desses gestores em pleno século XXI. Some-se a isso a oportunidade prática de produzir um jogo digital para o desenvolvimento de gestores públicos. Uma nova tecnologia, antenada às necessidades dos dias atuais e, principalmente, adequada ao contexto daqueles que precisam ser preparados para mudar essa realidade.

O Liderança em Jogo: Competências, papéis e responsabilidades surgiu praticamente junto com esta pesquisa e foi o núcleo da investigação para responder ao seguinte problema de pesquisa: "qual o impacto do uso de jogos digitais para o desenvolvimento de gestores públicos?".

O problema de pesquisa precisou ser desdobrado em duas importantes partes, de forma a guiar desde a fundamentação teórica até sua operacionalização. Incialmente, pretendeu-se entender o que seria, do ponto de vista teórico, o uso de jogos digitais para posteriormente proceder sua aplicação de forma a avaliar o impacto sobre o desenvolvimento dos gestores públicos.

O estudo foi multimétodo, adotando por vezes uma abordagem exploratória com uso de técnicas qualitativas, mas foi predominantemente de natureza quantitativa, causal, sob um paradigma pós-positivista com a intenção de seguir um processo hipotético-dedutivo, a fim de explicar de que forma o uso de jogos digitais contribui para o processo de desenvolvimento de gestores públicos.

O impacto foi avaliado de forma comparativa, por meio de um conjunto de dois experimentos, colocando-se frente a frente os resultados obtidos por aqueles que jogaram (grupo 
experimental) e os de quem não jogou (grupo de controle). Porém, para se chegar ao experimento, o trabalho se desenrolou em três etapas principais: a fundamentação teórica, uma etapa de desenvolvimento e uma etapa conclusiva.

Na primeira etapa, a fundamentação teórica, foi realizado um estudo bibliométrico que visava identificar quais os principais conceitos que associam a aplicação de jogos (games) para fins de desenvolvimento humano (OE1). Três conceitos se destacam quando se fala em jogos para usos com finalidade de aprendizado: game-based learning (GBL), serious games e gamification. O primeiro trata do equilíbrio do jogo com os objetivos educacionais, caracterizando-se como uma abordagem de ensino, em um contexto projetado (Ahmed \& Sutton, 2017). Os serious games tratam do desenvolvimento de jogos (ou uso de jogos existentes, em uma categoria mais ampla, o serious gaming) com as finalidades educacionais prevalecendo sobre as de entretenimento, mas não as excluindo (Michael \& Chen, 2006). A gamification se caracteriza como uso de elementos de jogos em contextos que não são de jogos ou como ou "o processo de tornar as atividades mais parecidas com jogos" (Werbach, 2014).

Com isso em mente, o estudo também pretendeu desenvolver um serious game de gestão focado no setor público, que incorporasse aspectos das teorias relacionadas à administração, e que pudesse ser utilizado para o desenvolvimento de gestores públicos (OE2). Esse objetivo foi alcançado, pois o jogo foi considerado adequado, atendendo os princípios de game design para o GBL, como mostraram as evidências qualitativas trazidas pelos trabalhos sobre ele no piloto realizado em 2015 e pelos relatos das entrevistas realizadas após o primeiro experimento da pesquisa.

As análises qualitativas também forneceram subsídios para o desenvolvimento de um curso/treinamento (contexto de desenvolvimento de gestores, isto é, T\&D) em que fosse possível aplicar o jogo que permitisse avaliar o impacto de seu uso (OE3). O curso, intitulado Gestão Pública: Teoria e Prática, contou com uma ementa com seis assuntos principais, incluindo aqueles que foram avaliados no teste de conhecimento do experimento - ciclo de planejamento-execução-controle (PEC), visão sistêmica (VS) e papéis gerenciais (PG).

A mensuração da eficácia do uso de um jogo de gestão para o desenvolvimento dos gestores públicos (OE4) foi feita com dois experimentos, ambos completamente aleatorizados, sendo o 
primeiro no formato pré-teste/pós-teste e o segundo com pós-teste apenas, no que diz respeito à avaliação de conhecimento.

A avaliação do impacto do uso do jogo baseou-se no modelo desenvolvido por Kirkpatrick para avaliação de treinamentos em quatro níveis: reação, aprendizagem, comportamento e resultados. A reação foi avaliada por questionário padrão utilizado pela unidade que ofereceu o curso (Centro de Treinamento e Desenvolvimento da Secretaria Estadual da Saúde do Governo de São Paulo - CT\&D / SES-SP) e foi complementada pelo levantamento de motivação sobre materiais instrucionais - questionário IMMS, baseado no modelo ARCS de Keller (2010), contemplando quatro construtos - atenção, relevância, confiança e satisfação que se associam à motivação para o aprendizado.

Os impactos sobre o desenvolvimento observado foram nos quatro níveis avaliados, sendo:

- Impacto sobre a satisfação: os participantes do grupo experimental valorizaram mais (comparativamente ao grupo de controle) o processo de aprendizagem no treinamento, principalmente na adequação das atividades e atividades e dos recursos didáticos utilizados e da aplicabilidade do conteúdo à realidade de trabalho;

- Impacto sobre a atenção e a relevância, como precursores da motivação para aprender: no segundo experimento, os participantes que jogaram pontuaram mais nos construtos de atenção e relevância com relação aos que não jogaram;

- Impacto sobre o aprendizado: de maneira geral, os participantes que jogaram adquiriram mais conhecimento sobre os conceitos de administração dos que os que não jogaram;

- Impacto sobre o aprendizado em níveis mais profundos: há indícios de que o jogo permitiu maior absorção de conhecimento nos níveis mais altos de profundidade considerados no estudo;

- Impacto sobre a atitude: no primeiro experimento, os participantes que jogaram apresentaram uma visão de gestão mais relacionada aos aspectos humanos (comunicação, relacionamento e soft-skills em geral), em contraposição ao grupo de controle que apresentou uma visão mais tradicional (planejamento, controle e atingimento de metas); 
- Impacto sobre o comportamento: as entrevistas trouxeram alguns exemplos de pessoas que passaram a se comportar de forma diferente do que faziam pela reflexão que o jogo as permitiu fazer;

- Impacto sobre o resultado: os participantes do segundo experimento perceberam de forma diferente o impacto do treinamento sobre seis dos onze aspectos de seu trabalho futuro avaliados (resultado projetado).

Com influência direta sobre diferentes aspectos, pode-se inferir que o jogo contribui para o desenvolvimento dos gestores públicos, do ponto de vista do desenvolvimento de competências considerado sob a ótica da visão tradicional do conjunto de conhecimentos, habilidades e atitudes (CHA) da pessoa. O jogo permitiu maior aquisição de conhecimentos em relação às práticas tradicionais, o mesmo se observando com relação à atitude. Além disso, a mudança de comportamento indica que houve aprendizado de fato, o qual é sustentado pela maior motivação no processo de aprendizagem. As quatro hipóteses do trabalho foram verificadas, de forma que esses resultados indicam que o estudo atingiu seu objetivo e respondeu ao problema de pesquisa.

\subsection{Limitações e sugestões de estudos futuros.}

São diversas e de diferentes naturezas as limitações deste estudo. Dentre as mais relevantes, destaca-se a limitação do próprio método do experimento, pois, embora seja a única técnica que permita inferências causais, a artificialidade que o caracteriza pode ter influência em como as pessoas se sentem e consequentemente no resultado. As pessoas envolvidas nesse trabalho sabiam que participavam de um estudo, mas não que se tratava de um experimento, desconhecimento que é importante para esse tipo de pesquisa. No entanto, houve difusão do tratamento, marcadamente no segundo experimento, quando tanto o grupo experimental quanto o grupo de controle participavam concomitantemente da parte expositiva do curso. Por outro lado, essa medida controlou outras variáveis com relação ao primeiro experimento, como o desempenho do instrutor e o dia da aula. Essa é outra das limitações do estudo, em particular no primeiro experimento. Embora os sujeitos tenham sido aleatorizados nos grupos, uma vez que passaram a fazer parte de turmas diferentes (uma de controle e outra de 
tratamento), a unidade de análise deixa de ser o indivíduo e passa a ser a turma. Assim, estudos futuros podem, mantendo a lógica da separação em turmas, realizar várias turmas, sorteando e controlando, inclusive, os dias e horários em que serão realizadas.

Outra limitação deste estudo está no não controle de variáveis que possam ter influenciado o desempenho nos testes, além do conhecimento prévio, controlado no primeiro experimento. Outras variáveis precisam ser identificadas e controladas, por exemplo, por meio de blocagem antes do sorteio dos grupos. Fora isso, nas turmas dos experimentos havia tanto gestores quanto pessoas que ainda não são gestores mas pretendem ser. Eventuais efeitos diferentes do jogo sobre esses dois perfis não puderam ser detectados. Dividir os participantes em dois grupos adicionais teria prejudicado a inferência estatística. Ainda, o aprendizado pode ser influenciado, por exemplo, pelo nível de experiência do participante, outra variável não controlada, que provavelmente teve seus efeitos minimizados pela aleatorização. Mas estudos experimentais futuros podem tentar levar isso em conta, com uma quantidade maior de participantes e técnicas de blocagem.

Com um reduzido número de participantes, não foi possível utilizar o design de quatro grupos de Solomon em um mesmo experimento. Esse desenho experimental evitaria quaisquer dúvidas sobre a influência da diferença de formato (pré-teste/pós-teste versus pós-teste apenas) nos resultados dos dois experimentos realizados. Sugere-se que em estudos futuros com esse tipo de método adote-se um número maior de participantes para que seja possível superar essa limitação.

Outro fator limitante do estudo foi o acúmulo de papéis desempenhados pelo pesquisador, que também atuou como instrutor no curso em que o jogo foi aplicado. Mesmo com todo o esforço para controlar variáveis relacionadas a essa influência, não se pode descartar o chamado efeito do experimentador. Estudos futuros que disponham de mais recursos podem resolver facilmente eventuais vieses associados a esse efeito, atribuindo papéis diferentes a pessoas diferentes, por exemplo.

$\mathrm{Na}$ avaliação do aprendizado, foram utilizadas apenas questões diretas, o que permitiu apenas avaliar os primeiros níveis da taxonomia de Bloom a da profundidade de conhecimento (DoK) de Webb. Para superar essa limitação, sugere-se a utilização de questões abertas ou outro tipo 
de construção que permita avaliar os níveis mais elevados de aquisição de conhecimento. Isso permitirá verificar se jogos como o deste estudo podem, de fato, ser mais úteis para o aprendizado em níveis mais altos da taxonomia.

Essa limitação também decorre do tempo disponível para as coletas dentro do curso. Como o estudo visou avaliar os quatro níveis do modelo de Kirkpatrick, foram necessárias várias medidas diferentes. Estudos futuros que investiguem pontos particulares do resultado de treinamento podem explorá-los mais detidamente, inclusive de forma qualitativa.

A reduzida quantidade de questões por nível de profundidade e por assunto também caracterizou outra limitação do estudo, em especial no segundo experimento. Se os efeitos não forem grandes o suficiente, é importante utilizar mais questões por nível e por assunto para que a inferência estatística não seja prejudicada. Sugere-se, a estudos que visem avaliar o aprendizado do ponto de vista cognitivo, utilizar uma quantidade maior de questões e, se possível, utilizar uma etapa preliminar para validá-las e utilizá-las sob outras perspectivas de avaliação, por exemplo, a Teoria de Resposta ao Item (TRI). No presente estudo isso não foi possível, pois requereria um tempo considerável e uma massa substancial de respondentes apenas com o intuito de gerar estatística para as questões.

Por fim, o presente experimento foi realizado apenas com servidores de uma única secretaria, em uma única esfera de governo. Por um lado, esse fato é importante para um experimento, pois elimina variáveis de confusão, tornando a amostra mais uniforme, de maneira a isolar o efeito do tratamento, mas, por outro lado, embora não seja a preocupação primeira de um estudo experimental, os resultados não podem ser generalizados. Sugere-se, então, que outros estudos sejam feitos com diferentes públicos, até mesmo estudantes na área de administração e administração pública, inclusive com a utilização de diferentes jogos, estudando-se, por exemplo, separadamente, cada impacto encontrado nesta pesquisa.

\subsection{Contribuições e implicações para a prática}

A presente pesquisa teve o mérito de utilizar diferentes referenciais teóricos $(\mathrm{HRD}$, teorias e taxonomias de aprendizado, educação gerencial, design de jogos, GBL) e colocá-los juntos 
em um todo coerente para atingir seus objetivos, com triangulação metodológica e também uma parte empírica que permitiu inferências causais sobre o objeto de estudo. Ou seja, por ter sido metodologicamente consistente, a pesquisa permitiu atribuir as diferenças observadas ao uso do jogo digital. Em ciências sociais aplicadas como a administração, as intervenções dessa natureza talvez sejam tão importantes quanto aquelas de outras áreas aplicadas como a medicina e a odontologia.

Outro aspecto importante da pesquisa foi o de partir do zero em uma literatura normalmente não explorada na área de administração (a do uso de jogos digitais para fins educacionais) e explorar os principais conceitos, tais como serious games, gamification e game-based learning, consolidando um referencial que pode servir de base para estudos futuros.

Além disso, a própria incorporação do desenvolvimento do jogo ao trabalho em si é outra contribuição do estudo. Um determinado grau de controle sobre o "princípio ativo" que está sendo experimentado é importante e, ao ser exposto neste trabalho, tem implicações práticas no sentido de mostrar que caminhos podem ser adotados pelos diferentes atores envolvidos com o desenvolvimento dos gestores públicos. A mensagem que fica é que esse ramo emergente é promissor em muitas vertentes, seja para a academia, seja para a aplicação prática.

O Governo passa a saber que deve fazer investimentos em novas tecnologias e novas formas de capacitação gerencial, que podem ter impacto não só no desenvolvimento das pessoas como também nos resultados organizacionais. As universidades e outros centros de formação podem entender que o uso de jogos digitais é o futuro da educação e investir mais fortemente nessa área. Empresas podem se estabelecer nesse mercado, seja no desenvolvimento dos jogos propriamente ou na estruturação de soluções educacionais que os considerem. Por fim, os próprios gestores públicos podem ter formas para se desenvolver que sejam mais agradáveis e efetivas, que, no final do dia, melhorem não só na sua prática cotidiana, mas que ajudem a levar ao objetivo maior que todos esperam: uma maior qualidade na prestação dos serviços públicos à população. 


\section{REFERÊNCIAS BIBLIOGRÁFICAS}

Abt, C. (1970). Serious Games. New York: The Viking Press

Ahmed, A.; \& Sutton, M.J.D. (2017). Gamification, serious games, simulations, and immersive learning environments in knowledge management initiatives. World Journal of Science, Technology and Sustainable Development, 14(2/3), 78-83

Ajzen, I. (1991). The theory of planned behavior. Organizational Behavior and Human Decision Processes, 50, 179-211

All, A., Castellar; \& E.P.N., Looy, J.V. (2016). Assessing the effectiveness of digital gamebased learning: Best practices. Computers \& Education, 92-93, 90-103.

Andersen, J.A. (2010). Public versus private managers: how public and private managers differ in leadership behavior. Public Administration Review, 70 (1), 131-141.

Anderson, L.W.; \& Krathwohl, D.R. (eds). (2001). A taxonomy for learning, teaching and assessing - A revision of Bloom's taxonomy of educational objectives. New York: Addison Wesley Longman.

Andrews, R.; \& Boyne, G.A.(2010). Capacity, Leadership, andOrganizational Performance: Testing the Black Box Model of Public Management. Public Administration Review, 70 (3), 443-54.

Andrews, R.; \& Brewer, G.A. (2013). Social Capital, Management Capacityand Public Service Performance: Evidence from the U.S. States . Public Management Review, 15 (1), $19-42$

Ashton, B. (1854). The game of chess. Notes and Queries, s1-IX(228), 224.

Astleitner, H.; \& Hufnagl, M. (2003). The effects of situation-outcome-expectancies and of ARCS-strategies on self-regulated learning with web-lectures. Journal of Educational Multimedia and Hypermedia, 12 (4) 361-376.

Backlund, P.; \& Hendrix, M. (2013). Educational Games - Are They Worth The Effort? A literature survey of the effectiveness of serious games. In: Games and Virtual Worlds for Serious Applications (VS-GAMES), 5th International Conference on, 2013, 1-8.

Bardin, L. (2008). Análise de Conteúdo. (5 ed.) São Paulo: Edições 70.

Barker, R. (2010). The big idea: No, management is not a profession. Harvard Business Review, 88 (7-8), 52-60.

Barnett, B.G. (1989). Reflection: The cornerstone of learning from experience. Paper apresentado na Convenção Anual do Conselho Universitário para Administradores Educacionais em outubro de 1989, Scottsdale, Arizona. 
Bates, R. (2004). A critical analysis of evaluation practice: the Kirkpatrick model and the principle of beneficence. Evaluation and Program Planning, 27, 341-347

Becker, K.; \& Bish, A. (2017). Management development experiences and expectations: informal versus formal learning.Education + Training, 59(6).

Beer, M.; Finnstrôm, M.; \& Schrader, D. (2016). Why leadership training fails - and what to do about it. Harvard Business Review, 94 (10), 50-57.

Bell, B.S.; Kanar, A.M.; \& Kozlowski, S.W. (2008). Current issuesand future directions in simulation-based training in North America. International Journal of Human Resource Management, 19, 1416-1434.

Bellon, T.; \& Oates, R. (2002). Best practices in cyberspace: motivating the online learner. In 23rd National Educational Computing Conference, San Antonio, Texas, June 17-19 2002.

Bellotti, F.; Kapralos, B.; Lee, K.; Moreno-Ger, P.; \& Berta, R. (2013). Assessment in and of Serious Games: An Overview, Advances in Human-Computer Interaction, 13, 1-11.

Bennis, W.G., \& O'Toole, J. (2005). How Business Schools Lost Their Way. Harvard Business Review, 83 (5), 96-104.

B.G.J. (1850). Nursery games and rhymes. Notes and Queries, s1-I (25), 401.

Caillois, R. (1967). Les jeux et les hommes: la masque et le vertige. Edition revue et augmentée, Paris: Gallimard.

Bloom, B.S., Engelhart, M.D., Furst, E.J., Hill, W.H,, \& Krathwohl, D.R. (1974). Taxionomia de objetivos educacionais - Compêndio primeiro: domínio cognitivo. Porto Alegre: Globo.

Bober, M. (2010), Games Based Experiences for Learning, Futurelab, Bristol. Disponível online em https://www.nfer.ac.uk/publications/FUTL11/FUTL11.pdf [acessado em 15/07/2017]

Bonwell, C.C.; \& Eison, J.A. (1991). Active learning: creating excitement in the classroom. Washington, DC: ERIC Clearinghouse on Higher Education. Disponível em http://files.eric.ed.gov/fulltext/ED340272.pdf [acessado em 20/11/2015]

Boyle, E. A.; Connolly, T. M.; Hainey, T.; \& Boyle, J. M. (2012) Engagement in digital entertainment games: A systematic review. Computers in Human Behavior, 28, 771780.

Bracht, G.H.; \& Glass, G.V. (1968). The external validity of experiments. American Educational Research Journal, 5, 437-474.

Breuer, J.; \& Bente, G. (2010). Why so serious? On the Relation of Serious Games and Learning. Eludamos. Journal for Computer Game Culture, 4 (1), 7-24.

Campbell, D.T. (1957). Factors relevant to the validity of experiments in social settings. Psychological Bulletin, 54, 297-312. 
Campbell, D.T.; \& Stanley, J.C. (1963). Experimental and quase-experimental designs for research. Chicago: RandMcNally.

Campion, M. C. (1995). A historian and his games. Simulation \& Gaming, 26, 168-178.

Carroll, J.M.; \& Thomas, J.C. (1988). Fun.Special Interest Group on Computer-Human Interaction - SIGCHI Bulletin,19(3), 21-24.

Chang, M.; \& Lehman, J. D. (2002). Learning foreign language through an interactive multimedia program:an experimental study on the effects of the relevance component of the ARCS model. CALICO Journal, 20 (1), 81-98.

Chow S; Shao J; \& Wang H. (2008). Sample Size Calculations in Clinical Research. 2a ed., New York: Chapman \& Hall/CRC

Clarke, T. (2013). The advance of the MOOCs (massive open online courses): The impending globalisation of business education? Education + Training, 55, (4/5), 403-413.

Cobb, G.W. (1998). Introduction to design and analysis of experiments. New York: Springer.

Coelho, F.S. (2008). A problemática atual do ensino de graduação em administração pública no Brasil. Cadernos EBAPE.BR (FGV), 6, 1-21

Coelho, F.S.; \& Dantas, H. (2017). Fazendo a diferença no setor público e também na academia. O Estado De São Paulo. Obtido dehttp://politica.estadao.com.br/blogs/blog-do$\mathrm{mlg}$ /fazendo-a-diferenca-no-setor-publico-e-tambem-na-academia/ [acessado em 19/07/2017]

Cohen, D.K. (2011). Teaching and its predicaments. Cambridge, MA: Harvard Business Press

Cohen, L.; Manion, L.; \& Morrison, K. (2007). Research Methods in Education. (6 ed.) New York: Routledge

Cook, B. J. (1998). Politics, political leadership, and public management. Public Administration Review, 58 (3), 225-230.

Cook, T.D.; \& Campbell, D.T. (1979). Quase-experimentation: Design and analysis issues for field settings. Chicago: RandMcNally.

Costa, L.F.C. (2016). Gamificação: Regras claras para um gestão pública orientada a resultados (Dissertação de Mestrado). Universidade de Brasília, Brasília.

CNI - Confederação Nacional das Indústrias (2016). 90\% dos brasileiros dizem que qualidade dos serviços públicos deveria ser melhor considerando o valor dos impostos. Obtido de http://www.portaldaindustria.com.br/agenciacni/noticias/2016/07/90-dos-brasileirosdizem-que-qualidade-dos-servicos-publicos-deveria-ser-melhor-considerando-o-valor-dosimpostos-2/ 
Conole, G.; Dyke, M.; Oliver, M.; \& Seale, J. (2004). Mapping pedagogy and tools for effective learning design. Computers \& Education,43, 17-33.

Connolly, T.M.; Boyle, E.A.; MacArthur, E.; Hainey, T; \& Boyle, J.M. (2012). A systematic literature review of empirical evidence on computer games and serious games. Computers \& Education 59 (2), 661-686.

Coursera (2017). Coursera [acessado em 06/07/2017] http://www.coursera.org/.

Csikszentmihalyi, M. (1991). Flow: the psychology of optimal experience. New York: Harper Perennial

Cunliffe, A.L. (2002). Reflexive dialogical practice in management learning. Management Learning, 33 (1), 35-61.

Dagnino, R. (2013). A capacitação de gestores públicos: uma aproximação ao problema sob a ótica da Administração Política. Revista Brasileira de de Administração Política, 6 (1), 97 118.

de Bonis, D.; \& Pacheco, R. S. (2010). Nem político nem burocrata: o debate sobre o dirigente público. In: F.L. Abrucio; M.R. Loureiro; R.S. Pacheco (Orgs.) Burocracia e política no Brasil: desafios para o Estado democrático no século XXI (pp. 329-363), São Paulo: FGV.

de Smale, S.; Overmans, T.; Jeuring, J.; \& van de Grint, L. (2015). The Effect of Simulations and Games on Learning Objectives in Tertiary Education: A Systematic Review. Technical Report UU-CS-2015-017, Department of Information and Computing Sciences Utrecht University, Utrecht, The Netherlands.

Dean, A.; \& Voss, D. (2000). Design and analysis of experiments. New York: Springer.

Denhardt, R. B.; \& Denhardt, J. V. (2000). The new public service: Serving rather than steering. Public Administration Review, 60, 549-559.

Deterding, S.; Dixon, D.; Khaled, R.; \& Nacke, L. (2011). From Game Design Elements to Gamefulness: Defining “Gamification”. In: MindTrek, pp. 9-15. New York: ACM Press

Djaouti, D.; Alvarez, J.; \& Jessel, J.P. (2011). Classifying Serious Games: the G/P/S model. In P. Felicia (Ed.), Handbook of research on improving learning and motivation through educational games: multidisciplinary approaches (pp. 118-136), Hershey-PA - USA: Information Science Reference.

Djaouti, D.; Alvarez, J.; Jessel, J.P.; \& Rampnoux, O. (2011). Origins of serious games. In M. $\mathrm{Ma}$, A. Oikonomou, L.C. Jain (Eds.), Serious games and Edutainment Applications (pp. 25-43), Berlin: Springer.

Docebo (2017). E-learning Market Trends \& Forecast 2017-2021 Report. Disponível para download em em https://www.docebo.com/resource/elearning-market-trends-and-forecast2017-2021/ [acessado em 06/07/2017] 
Donahue, A.K.; Selden, S.C.; \& Ingraham, P.W. (2000). Measuring Government Management Capacity: A Comparative Analysis of City Human Resources Management Systems . Journal of Public Administration Research and Theory, 10 (2): 381 - 411 .

Donovan, L. (2012). The use of serious games in the corporate sector: a state of art report. Learning Inovation, Dublin: Lenorvate Centre.

Driver, R.; Asoko, H.; Leach, J.; Mortimer, E.; \& Scott, P. (1994). Constructing scientific knowledge in the classroom. Educational Researcher, 23 (7), 5-12.

Duran, D. (2017). A educação a distância no processo de formação continuada da administração pública: as contribuições da Revista do Serviço Público. Revista do Serviço Público, 68 (3), 705-736.

Dutra, J.S. (2004). Competências: conceitos e instrumentos para gestão de pessoas na empresa moderna. São Paulo: Atlas

Dutton, J., \& Perry, J. (2002). How do online students differ from lecture students? Journal of Management Information Systems, 18 (4), 169-190.

Éboli, M. (Coord.) (2015). Pesquisa Nacional Práticas e Resultados da Educação Corporativa. Relatório.

Éboli, M. (Coord.) (2012). Pesquisa Nacional Práticas e Resultados da Educação Corporativa. Relatório.

Egenfeldt-Nielsen, S. (2006). Overview of research on the educational use of video games. Digital Kompetanse, 1 (3), 184-213.

Elsevier B.V. (2014). Scopus Help. [acessado em 31/08/2015]http://help.scopus.com/Content/

Engwall, L. (2007). The anatomy of management education. Scandinavian Journal of Management, 23, pp. 4-35.

Fattore, G.; Dubois, H. F. W.; \& Lapenta, A. (2012). Measuring new public management and governance inpolitical debate. Public Administration Review, 72, 218-227.

Fogg, B.J. (2003). Persuasive Techonology: Using computers to change what we think and what we do. San Francisco: Morgan Kaufmann Publishers

Fogg, B.J. (2009). A behavior model for persuasive design. In: S. Chatterjee \& P. Dev (Eds.), Persuasive 2009: 4th International Conference on Persuasive Technology (pp. 1-7), Claremont - California: ACM

Fox, S. (1997). Situated Learning Theory versus Traditional Cognitive Learning Theory: Why management education should not ignore management learning. Systems Practice, 10 (6), 727-747.

Freire, P. (1983).Pedagogia do Oprimido. 13.ed. Rio de Janeiro: Paz e Terra. 
Frost, J. (1852). The game of curling. Notes and Queries, 1-V(114), 13-14.

Gagné, R.M. (1976). Como se realiza a aprendizagem; Tradução: Maria Ramos Tovar. Rio de Janeiro: LTC

Gagné, R.M.; Briggs, L.J.; \& Wager, W.W. (1992). Principles of Instructional Design. (4 ed.) Orlando, FL: Harcourt Brace College Publishers.

Gall, M.D.; Gall, P.G.; \& Borg, W.R. (2007). Educational Research: an introduction, $8^{\mathrm{a}}$ ed. Boston: Pearson Education.

Gavel, Y.; \& Iselid, L. (2008). Web of Science and Scopus: a jornal title overlap study. Online Information Review, 32 (1), 8-21.

Gee, J.P. (2004). What video games have to teach us about learning and literacy. New York: Palgrave Macmillan.

Geithner, S.; \& Menzel, D. (2016). Effectiveness of Learning Through Experience and Reflection in a Project Management Simulation. Simulation \& Gaming, 47 (2), 228-256.

Ghosh, R.; \& Jacobson, S. (2016). Contending claims to causality:a critical review of mediationresearch in HRD. European Journal of Training and Development, 40 (8/9), 595614

Goldstein, L. L. 1991. Training in work organizations. In M. D.Dunnette \& L. M. Hough (Eds.), Handbook of industrial organizational psychology, 2, 507-620.

Google (2017). Google Trends [acessado em 17/07/2017]

https://www.google.com.br/trends/explore $\# \mathrm{q}=$ gamification $\% 2 \mathrm{C} \% 20$ serious $\% 20$ games\&cmpt $=\mathrm{q} \& \mathrm{tz}=\mathrm{Etc} \% 2 \mathrm{FGMT} \% 2 \mathrm{~B} 3$

Gray, D.E. (2007). Facilitating management learning - Developing critical reflection through reflective tools. Management Learning, 38 (5), 495-517.

Greco, M.; Baldissin, N.; \& Nonino, F. (2013). An exploratory taxonomy of business games. Simulation \& Gaming, 44 (5), 645-682.

Grix, J. (2004). The foundations of Research. New York: Palgrave MacMillarn.

Guba, E.; \& Lincoln, Y.S. (1994). Competing paradigms in qualitative research. In Denzin, N. K., Handbook of Qualitative Research, 105-117.

Guney, A.; \& Al, S. (2012). Effective learning environments in relation to different learning theories. Procedia - Social and Behavioral Sciences, 46, $2334-2338$.

Hamlin, B.; \& Stewart, J. (2011). What is HRD? A definitional review and synthesis of the HRD domain. Journal of European Industrial Training, 35 (3), 199-220. 
Hamlin, R.G.; Ellinger, A.D.; \& Beattie, R.S. (2008). The emergent 'coaching industry': a wake-up call for HRD professionals, Human Resource Development International, 11(3), 287-305

Hammond, L.D.; Austin, K.; Orcutt, S; \& Rosso J. (2001). How people learn: Introduction to learning theories. Obtido de http:/www.stanford.edu/class/ed269/hplintrochapter.pdf, acessado em 12/09/2015.

Haramati, A. (2000). Teaching physiology: filling a bucket or lighting a fire? The Physiologist, 43 (3), 117-121.

Hassan, O.A.B. (2011). Learning theories and assessment methodologies - an engineering educational perspective. European Journal of Engineering Education, 36 (4), 327-339.

Hernandez, J.M.; Basso, K.; \& Brandão, M.M. (2014). Pesquisa experimental em marketing. Revista Brasileira de Marketing, 13 (2), 98-117

Hess, K.; Jones, B.S.; Carlock, D.; \& Walkup, J.R. (2009). Cognitive Rigor: Blending the strengths of Bloom's Taxonomy and Webb's Depth-of-Knowledge to enhance classroomlevel processes. [Technical Report]. Obtido de http://files.eric.ed.gov/fulltext/ED517804.pdf [acessado em 20/11/2015]

Hodgetts, R. (1970). Management gaming for didactic purposes: A new look. Simulation \& Gaming, 1, 55-66.

Hourneaux Jr, F.; Freitas-Dias, C.A.; \& Éboli, M. (2013). Avaliação de Resultados em Educação Corporativa: Análise dos Níveis de Avaliação de Kirkpatrick-Phillips e sua Relação com o Balanced Scorecard. In XXXVII EnANPAD 2013, Rio de Janeiro

Huandong, C.; Shulei, W.; Chunhui, S.; \& Mingrui, C. (2009). Research on the Learning Theory of E-Learning. In Fifth International Joint Conference on INC, IMS and IDC 2009 (pp. 1185-1187), Seoul: Institute of Electrical and Electronics Engineers

Huitt, W. (2009). Humanism and open education. Educational Psychology Interactive. Valdosta, GA: Valdosta State University. Obtido de http://www.edpsycinteractive.org/topics/affect/humed.html, acessado em 03/10/2015.

Huizinga, J. (2008). Homo ludens: o jogo como elemento da cultura. (5 ed.) São Paulo:Perspectiva.

Illeris, K. (2003). Towards a contemporary and comprehensive theory of learning. International Journal of Lifelong Education, 22 (4), 396-406.

Illeris, K. (2009). Contemporary theories of learning: learning theorists ... in their own words. New York: Routledge.

Ingraham, P.W.; Joyce, P.G.; \& Donahue, A. K. (2003). Government Performance: Why Management Matters. Baltimore: Johns Hopkins University Press.

Jarvis, P. (1987) Adult Learning in the Social Context. London: Croom Helm. 
Jarvis, P.; Holford, J.; \& Griffin, C. (2003) Theory and Practice of Learning. ${ }^{\mathrm{a}}$ ed. London: Kogan Page.

Johnson, T. S. (2016) Violation of the homogeneity of regression slopes assumption in ANCOVA for two-group pre-post designs: Tutorial on a modified Johnson-Neyman procedure. The Quantitative Methods for Psychology, 12 (3), 253-263.

Jorge, C.F.B.; \& Sutton, M.J.D. (2017) "FUNIFICATION 2.0: Knowledge mobilization model for corporate and educational game-based learning. World Journal of Science, Technology and Sustainable Development, 14(2/3), 84-110

Kayes, D.C. (2002). Experiential Learning and Its Critics: Preserving the Role of Experience in Management Learning and Education. Academy of Management Learning \& Education, $1(2), 137-149$.

Keller, J. M. (1987a). Development and use of the ARCS Model of Instructional Design. Journal of Instructional Development, 10(3), 2-10.

Keller, J. M. (1987b). Strategies for stimulating the motivation to learn. Performance and Instruction. 28(8), 1-7.

Keller, J. M. (1987c). The systematic process of motivational design. Performance and Instruction, $26(9 / 10), 1-8$.

Keller, J. M. (1999). Using the ARCS motivational process in computer-based instruction and distance education. New Directions for Teaching and Learning, 78, 39-47

Keller, J. M. (2010). Motivational design for learning and performance: the ARCS model approach. New York, NY: Springer.

Kennedy, P. E.; Chyung, S. Y.; Winiecki, D. J;. \& Brinkerhoff, R. O. (2014). Training professionals' usage and understanding of Kirkpatrick's level 3 and level 4 evaluations. International Journal of Training and Development, 18, 1-21.

Khan, A.; \& Pearce, G. (2015). A study into the effects of a board game on flow in undergraduate business students. The International Journal of Management Education, 13, 193-201.

Kiili, K. (2005). Digital game-based learning: Towards an experiential gaming model. Internet and Higher Education, 8, 13-24.

Kirkpatrick, D.L. (1994). Evaluating training programs: the four levels. San Francisco: Berret-Koehler.

Kirkpatrick, J.; \& Kirkpatrick, W. (2009). The Kirkpatrick model: past, present and future. Chief Learning Ofiicer, disponível online em http://www.cedmaeurope.org/newsletter\%20articles/Clomedia/The\%20Kirkpatrick\%20Model\%20\%20Past,\%20Present\%20and\%20Future\%20(Nov\%2009).pdf [acessado em 14/07/2017] 
Kolb, D. (1984). Experiential learning. Experience as the source of learning and Development, Englewood Cliffs, NJ: Prentice Hall.

Lau, K.H.V. (2014). Computer-based teaching module design: principles derived from learning theories. Medical Education, 48, 247-254.

Lee, M. (2001). A refusal to define HRD.Human Resource Development International, 4 (3), $327-41$.

Lee, M. (1997). The developmental approach: a critical reconsideration, in Burgoyne, J. \& Reynolds, M. (Eds).Management Learning, Sage, London, 199-214.

Leydesdorff, L., \& Vaughan, L. (2006). Co-occurrence matrices and their applications in Information Science: Extending ACA to the web environment. Journal of the American Society for Information Science and Technology - JASIST, 57 (12), 1616-1628.

Liaw, S.S. (2008). Investigating students' perceived satisfaction, behavioral intention, and effectiveness of e-learning: A case study of the Blackboard system. Computers \& Education, 51, 864-873.

Loorbach, N.; Peter, O.; Karreman, J.; \& Steehouder, M. (2015). Validation of the Instructional Materials Motivation Survey (IMMS) in a self-directed instructional setting aimed at working with technology. British Journal of Educational Technology, 46 (1), 204-218.

Lord, R.G., \& Hall, R.J. (2005). Identity, deep structure and the development ofleadership skill. The Leadership Quarterly, 16(4), 591-615.

Lopes, M.C.; Fialho, F.A.P.; Cunha, C.J.C.A.; \& Niveiros, S.I. (2013). Business Games for Leadership Development: A Systematic Review. Simulation \& Gaming, 44 (4), 523-543.

Loureiro, M.R.; Abrucio, F.L.; Pacheco, R.S. (2010). Burocracia e política no Brasil: desafios para a ordem democrática no Século XXI. Rio de Janeiro: Editora FGV.

Lujan, H.L.; \& DiCarlo, S.E. (2006). Too much teaching, not enough learning: what is the solution? Advances in Physiology Education, 30, 17-22.

Lynn Jr, L.E.; Heinrich, C.J.; \&Hill, C.J. (2001). Improving Governance: A New Logic for Empirical Research. Washington, DC: GeorgetownUniversity Press.

Madani, K.; Pierce, T.W.; Mirchi, A. (2017). Serious games on environmental management. Sustainable Cities and Society, 29, 1-11.

Malone, T.W. (1981). Towards a theory of intrinsically motivating instruction. Cognitive Science, 4, 333-369.

Malone, T.W. (1984), Heuristics for designing enjoyable user interfaces: lessons from computer games. In Thomas, J.C. \& Schneider, M.L. (Eds).Human Factors in Computer Systems, Ablex, Norwood, NJ, 1-12. 
Malone, T.W.; \& Lepper, M.R. (1987). Learning Fun: A Taxonomy of Intrinsic Motivations for Learning. In: Snow, R., Farr, M.J., Urednici (eds.) Aptitute, Learning and Instruction: III. Conative and Affective Process Analyses, pp. 223-253.

Manuti, A.; Pastore, S.; Scardigno, A.F.; Giancaspro, M.L.; \&Morciano, D. (2015). Formal and informal learning in the workplace: a research review.International Journal of Training and Development, 19(1), 1-17.

Marconi, M.A; \& Lakatos, E.M. (2010). Fundamentos de metodologia científica. (7 ed.). São Paulo: Atlas

Martins, G.; \& Theóphilo, C.R. (2009). Metodologia da investigação científica para ciências socias aplicadas (2 ed.) São Paulo: Atlas

McGurk, P. (2009). Developing "middle leaders" in the public services?: The realities of managementand leadership development for public managers.International Journal of Public Sector Management,22(6), 464-477.

McGurk, P. (2010). Outcomes of management and leadership development.Journal of ManagementDevelopment, 29(5), 457-470

Melero, J.; Hernandez-Leo, D.; \& Blat, J. (2011). A review of scaffolding approaches in game-based learning environments. In: Proceedings of the European Conference on Games-based Learning, January, 717-724.

Melero, J.; Hernandez-Leo, D.; \& Blat, J. (2012). A Review of Constructivist Learning Methods with Supporting Tooling in ICT Higher Education: Defining Different Types of Scaffolding. Journal of Universal Computer Science, 18 (16), 2334-2360.

Melton, E.K.; Meier, K.J. (2017) For the Want of a Nail:The Interaction of Managerial Capacity and Human ResourceManagement on Organizational Performance.Public Administration Review, 77 (1), 118-130.

Merriam S.B.; \& Caffarella R.S. (1999). Learning in Adulthood: A Comprehensive Guide, $2^{\text {a }}$ ed, San Francisco, CA: Jossey-Bass Publishers

Michael, D.; \& Chen, S. (2006) Serious Games: games that educate, train and inform. Boston: Thomson Course Technology PTR.

Miettnen, R. (2000). The concept of experiential learning and John Dewey's theory of reflective thought and action. International Journal of Lifelong Education, 19 (1), 54-72.

Minovic, M.; Milosvanovic, M.; \& Starcevic, D. (2013). Literature review in game-based learning. Communications in Computer and Information Science, 278, 146-154.

Mintzberg, H. (2006). MBA? Não, obrigado: uma visão crítica sobre a gestão e o desenvolvimento de gerentes. Porto Alegre: Bookman

Moore, M. (2002). Criando valor público: gestão estratégica no governo. Rio de Janeiro: Uniletras 
Montgomery, D.C. (2013). Design and Analysis of Experiments.(8 ed.) Hoboken, NJ: John Wiley \& Sons, Inc.

Motta, P.R.M. (2013). O estado da arte da gestão pública. RAE, 53 (1), 82-90.

Moynihan, D. P.; \& Pandey, S. K. (2005). Testing how management matters in an era of government byperformance management. Journal of Public Administration Research and Theory, 15, 421-439.

Muhammad, S. (2016). A Case Study on Exploring the Relevance of Evaluation Characteristics in Designing an Evaluation Approach on Behaviour Level on Training Effectiveness. Masther Thesis, University of Twente, Enschede, Netherlands.

Negroponte, N. (2012). Another Way to Think about Learning. Technology Review, 115(6), $37-40$.

Negroponte, N. (2009). Telecommunications and education. ITU News, 5, 30 -31

Nurulnadwan, A., Ariffin, A.M., \& Siti Mahfuzah S. (2014). Reviews and Critiques on Learning Theories towards Proposing a Conceptual Design Model of Assistive Courseware for Low Vision (AC4LV) Learners. In: Knowledge Management International Conference (KMICe) (760-765), Malaysia.

Nussbaum, M.; \& Beserra, V. d. S. (2014). Educational videogame design. In Advanced learning technologies (ICALT), 2014 IEEE 14 $4^{\text {th }}$ international conference on IEEE, Atenas, Grécia.

Oliveira, M.; \& Petersen, S. (2014). The choice of serious games and gamification: a case study to illustrate key differences. In M. Ma, M. F. Oliveira, \& J. B. Hauge (Eds.), Serious games development and applications: 5th International Conference, SGDA 2014 (pp. 213223), Berlin: Springer.

Origin of the game of chess (1823). The Lancet, 1 (3), 105-107.

O’Toole Jr, L.J.; \& Meier, K.J. (2014) Public Management, Context, andPerformance: In Quest of a More General Theory.Journal of Public Administration Research and Theory, 25. 237-256

Pange, A.; \& Pange. J. (2011). Is E-learning Based On Learning Theories? A Literature Review. World Academy of Science, Engineering and Technology, 5 (8), 56-60.

Paras, B.; \& Bizzocchi, J. (2005). Game, Motivation, and Effective Learning: An Integrated Model for Educational Game Design. In: DiGRA '05 - Proceedings of the 2005 DiGRA International Conference: Changing Views: Worlds in Play, Vancouver, Canada.

Parry, S.B. (1996). The quest for competencies. Training, 33 (7), 48-54. 
Paull, M.; Whitsed, C.; Girardi, A. (2016). Applying the Kirkpatrick model: Evaluating an Interaction for Learning Framework curriculum intervention. Issues in Educational Research, 26(3), 490-507.

Pelling, N. (2011). The (short) pre-history of "gamification". Obtido de https://nanodome.wordpress.com/2011/08/09/the-short-prehistory-of-gamification/

Petridis, P.; Hadjicosta, K.; Guang, V.S.; Dunwell, I.; Baines, T. et al. (2014). State-of-the-art in Business Games. International Journal of Serious Games, 2 (1), 55-69.

Pineda, P. (2010). Evaluation of training in organisations: a proposal for an integrated model. Journal of European Industrial Training, 34 (7), 673-693.

Pinto, M.R. (2014). Educação com entretenimento: um experimento com Simcity ${ }^{\circledR}$ para curtir e aprender contabilidade governamental (Tese de Doutorado), Faculdade de Economia, Administração e Contabilidade, Universidade de São Paulo, São Paulo

Potnuru, R.K.G.; Sahoo, C.K. (2016). HRD interventions, employeecompetencies and organizational effectiveness: an empirical study. European Journal of Training and Development, 40(5),345-365

Prensky, M. (2001). Digital game-based learning. New York, NY: McGraw-Hill.

Priego, R.G., \& Peralta, A.G. (2013). Engagement factors and Motivation in E-Learning and Blended-Learning Projects. In: Proceedings of the First International Conference on Technological Ecosystem for Enhancing Multiculturality - TEEM '13, Salamanca, Spain, pp. $453-460$

Prozesky, D. (2000). Teaching and learning. Community Eye Health, 13 (34), 30-31.

Prozesky, D.; Stevens S.; \& Hubley, J. (2006). Effective Teaching and Learning for Eye Health Workers. Adapted from a series in the Community Eye Health Journal.Londres: International Centre for Eye Health.

Reynolds, M. (1998). Reflection and Critical Reflection in Management Learning. Management Learning, 29 (2), 183-200.

Rocha, R.L. (2015). Jogos digitais como estratégia de aprendizagem: uma proposta de aplicação para o ensino da administração pública. (Dissertação de Mestrado). Escola Brasileira de Administração Pública e de Empresas, Fundação Getúlio Vargas, Rio de Janeiro.

Roesch, S.M.A. (2001). Pesquisa-ação no estudo das organizações. In: Caldas, M.; Fachin, R.; Fischer, T. (Orgs). Handbook de estudos organizacionais - v.2. São Paulo: Atlas.

Roodt, S.; \& Joubert, P. (2009). Evaluating serious games in higher education: A theorybased evaluation of IBMs innov8. In Proceedings of the European Conference on Gamesbased Learning - 3rd European Conference on Games Based Learning, ECGBL 2009; FH JOANNEUM University of Applied SciencesGraz; Austria, 332-338 
Salas, E.; Wildman, J.L.; \&Piccolo, R.F. (2009). Using simulation-based training to enhance management education. Academy of Management Learning \& Education, 8 (4), 559-573.

Salas, E.; Wilson, K.A.; Lazzara, E. H.; King, H.B.; Augenstein, J.S.; Robinson, D.W., et al. (2008). Simulation-based trainingfor patient safety: 10 principles that matter. Journal Patient

Safety, 8(4), 3-8.

Sampieri, R.H.; Collado, C.F.; \& Lucio, P.B. (2006). Metodologia de pesquisa. (3 ed.). Tradução: Fátima Conceição Murad, Melissa Kassner, Sheila Clara Dystyler Ladeira. São Paulo: McGraw-Hill

Sanders, J. (2015). By the Numbers: 10 Stats on the Growth of Gamification. Obtido de http://www.gamesandlearning.org/2015/04/27/by-the-numbers-10-stats-on-the-growth-ofgamification/

Sanderson, I. (2001). Performance management, evaluation and learning in "modern" local government.Public Administration, 79, 297-313.

Sekaran, U.; \& Bougie, R. (2009). Research Methods for Business: A Skill Building Approach (4 ed.), New York: Wiley

Shuell, T.J. (1986). Cognitive conceptions of learning. Review of Educational Research, $56,411-436$.

Schunk, D.H. (1991). Learning theories: An educational perspective. New York: Macmillan.

Shadish, W.R.; Cook, T.D.; \& Campbell, D.T. (2002). Experimental and quase-experimental designs for generalized causal inference. Belmont, CA: Wadsworth Cengage Learning.

Sitzmann, T.A. (2011). Meta-analytic examination of the instructional effectiveness ofcomputer-based simulation games. Personnel Psychology, 64 (2), 489-528.

Sreelakshmi, R.; McLain, M.L.; Jayakrishnan, R.; Rajeshwaran, A.; Rao, B.; \& Bijlani, K. (2015). Gamification to enhance Learning using Gagne's learning model. In 6th International Conference on Computing, Communications and Networking Technologies, ICCCNT 2015; Denton; United States

Stones, E. (1966). An introduction to educational psychology. London: Methuen.

Swanson, R.A.; \& Holton III, E.F. (2009). Foundations of Human Resource Development. 2 ed. San Francisco, CA: Berret-Koehler Publishers

Tabachnick, B.G., \& Fidell, L.S. (2013). Using Multivariate Statistics, $6^{\text {a }}$ ed. Boston: Pearson.

Tabachnick, B.G., \& Fidell, L.S. (2007). Experimental Design Using ANOVA. New York: Thomson Brooks/Cole.

Teixeira, H.J.; Salomão, S.M.; \& Teixeira, C J. (2010). Fundamentos de Administração: $a$ busca do essencial, Rio de Janeiro: Elsevier 
Thorpe, R. (1990). Alternative theory of management education. Journal of European Industrial Trainingl4 (2), pp. 3-15

Various games adapted for members of the medical profession. (1823). The Lancet, 1 (10), 343-345.

Vergara, S.C. (2012). Métodos de pesquisa em administração. (5 ed). São Paulo: Atlas.

Vieira, E.S.; \& Gomes, J.A.N.F. (2009). A comparison of Scopus and Web of Science for a typical university. Scientometrics, 81 (2), 587-600.

Villoria, M.; \& Iglesias, A. (2011). Leadership in public management: some theoretical and methodological considerations. Innovar, 21 (42), 175-189.

Vygotsky, L. S. (1978). Mind in society: The development of higher psychological processes. Cambridge, MA: Harvard University Press.

Walker, R.M.; \& Andrews, R. (2013). Local Government Management andPerformance: A Review of Evidence. Journal of Public Administration Research and Theory, 25, 101-133

Webb, N. L. (1997). Criteria for alignment of expectations and assessments in mathematics and science (Council of Chief State School Officers and National Institute for Science Education Research Monograph No. 6). Madison:University of Wisconsin-Madison, Wisconsin Center for Educational Research.

Webb, N. L. (2007). Issues related to judging the alignment of curriculum standards and assessments. Applied Measurement in Education, 20, 7-25.

Webster, J.; Trevino, L. K.; \& Ryan, L. (1993). The dimensionality and correlates of flow in human-computer interaction. Computers in Human Behavior, 9, 411-426.

Weinberger, L. (1998). Commonly held theories of human resource development.Human Resource Development International, 1(1), 75-93.

Werbach, K.; \& Hunter, D. (2012). For the win: How game thinking can revolutionize your business. Philadelphia: Wharton Digital Press.

Werbach, K. (2014). (Re)Defining Gamification: A process approach. In A. Spagnolli, L. Chittaro, \& L. Gamberini (Eds.) Persuasive Technology: 9th International Conference, PERSUASIVE 2014, Padua - Italy: Springer, 266-272.

Werbach, K. (2015). Gamification in Context. Obtido de https://class.coursera.org/gamification-004/lecture/27

White, B. (2014). Is "MOOC mania" over? In S.K.S. Cheung, J. Fong, J. Zhang, R. Kwan \& L.F. Kwok, Hybrid Learning: Theory and Practice. $7^{\text {th }}$ International Conference, ICHL 2014, Shanghai, China, August 8-10 Proceedings, 11-15. 
Wolfe, J. (1993). A history of business teaching games in English-speaking and post-socialist countries: The origination and diffusion of a management education and development technology. Simulation \& Gaming, 24, 446-463.

Wood, D.; Bruner, J.; \& Ross, G. (1976). The role of tutoring in problem solving. Journal of Child Psychology and Child Psychiatry, 17, 89-100.

Wu, W.H.; Hsiao, H.C.; Wu, P.L.; Lin, C.H.; \& Huang, S.H. (2012). Investigating the learning-theory foundations of game-based learning: a meta-analysis. Journal of Computer Assisted Learning, 28, 265-279.

Wouters, P.; Van Nimwegen, C.; Van Oostendorp, H.;\& Van der Spek,E.D. (2013). A metaanalysis of the cognitive and motivational effects of serious games.Journal of Educational Psychology ,105 (2), 249-265.

Wyse, A.E., \& Viger, S.G. (2011). How item writers understand Depth of Knowledge. Educational Assessment, 16, 186-206.

Ysa, T.; \& Salvador, S. (2015). Liderazgo y dirección pública: el ciclo de vida del cargo directivo. Revista del CLAD Reforma y Democracia, 62, 38-76

Zemke, R. (1990). Training is not education light. Training, 3 (38), 31-32.

Zichermann, G. (2013). Gamification: the hard thruths. The Huffington Post. Obtido de http://www.huffingtonpost.com/gabe-zichermann/gamification_b_2516376.html

Ziegler, B.E. (2009). Methods for Bibliometric Analysis of Research: Renewable Energy Case Study. [Working Paper CISL\# 2009-10]. Composite Information Systems Laboratory (CISL) - Sloan School of Management - Massachusetts Institute of Technology (MIT), Boston, MA.

Zyda, M. (2005). From visual simulation to virtual reality to games.Computer38(9), 25-32. 


\section{Apêndice A Desenvolvimento do Liderança em Jogo}

Este apêndice descreve, em linhas gerais, o funcionamento do Liderança em Jogo: Competências, Papéis e Responsabilidades.

\section{A1. Dinâmica do jogo}

O jogo precisava ser pensado em termos de viabilidade técnica e didática, visando passar conteúdos que contribuam para o desenvolvimento dos gestores públicos do estado de São Paulo. O jogo se passa em uma unidade imaginária dentro do serviço público, a Secretaria de Formação e Informação (SFI).

A unidade fictícia criada no jogo tem por função receber pedidos de aquisição de bens materiais ou de contratação de serviços e transformá-los em editais para publicação e posterior contratação. A decisão básica que o jogador deve tomar é a de escolher qual funcionário deve se ocupar de qual documento, ou seja, fazer a distribuição do trabalho (Figura A1). Esses documentos são equivalentes a pedidos de compra e são referidos no jogo simplesmente como processos ${ }^{42}$, que não devem ser confundidos com a ideia de processo como sendo entrada-processamento-saída. Assim, o processo básico do jogo é a entrada de pedidos (processos administrativo), o processamento pelos funcionários da área e a saída de editais de contratação de produtos ou serviços.

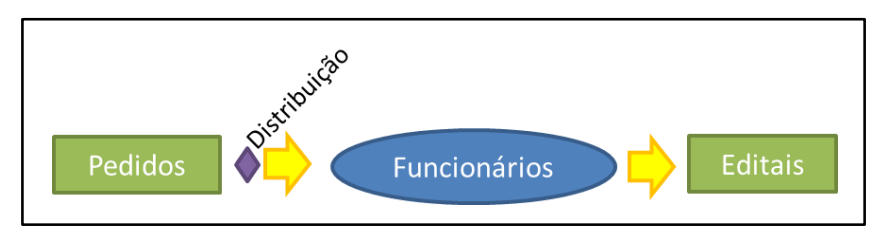

Figura A1- Visão básica do processo do jogo.

\footnotetext{
${ }^{42}$ O termo "processo" no jogo tem a mesma conotação do serviço público em geral, ou seja, refere-se aos processos administrativos, que são conjuntos de documentos relativos a algum assunto de interesse do Poder Público. Neste trabalho são referidos como "pedidos" apenas para não gerar confusão com o conceito de processo.
} 


\section{A2. Atributos dos pedidos}

Os pedidos que compõem os processos administrativos do jogo têm quatro atributos que geram níveis de dificuldade diferentes e desafios diferentes especialmente quando conectados aos funcionários da repartição: (1) especificidade do objeto, (2) qualidade do pedido recebido; (3) prazo para publicação; (4) se consta de uma contratação de serviço ou aquisição de bens materiais. O jogador pode perceber diretamente os dois últimos atributos (prazo e se é serviço ou bem material) e indiretamente os dois primeiros (especificidade e qualidade). A especificidade é notável pelo próprio assunto tratado no pedido (objetos banais como móveis e serviços básicos são menos específicos e termos técnicos tendem a ser muito específicos). $\mathrm{E}$ a qualidade é sistematicamente associada às áreas solicitantes, de forma que o jogador só pode perceber o impacto no resultado final, tendo concluído em prazo menor e/ou resultando em um edital de melhor qualidade.

Esses atributos geram variabilidade das entradas. O prazo diz respeito à urgência requerida para a entrega do produto final. E seu cumprimento tem impacto no desempenho geral do gestor do jogo (jogador). Já a qualidade diz respeito a como o processo chega à unidade. É o ponto de partida para gerar um resultado de maior ou menor qualidade. Os pedidos que chegam à unidade aparecem em uma caixa de entrada na mesa do gestor/jogador. Ao clicar ali, o jogador pode ver quantos são os processos e optar por distribui-los para os funcionários. Nesse momento ele já fica ciente de qual o objeto de contratação e de qual é o prazo para conclusão do trabalho (Figura A2). 


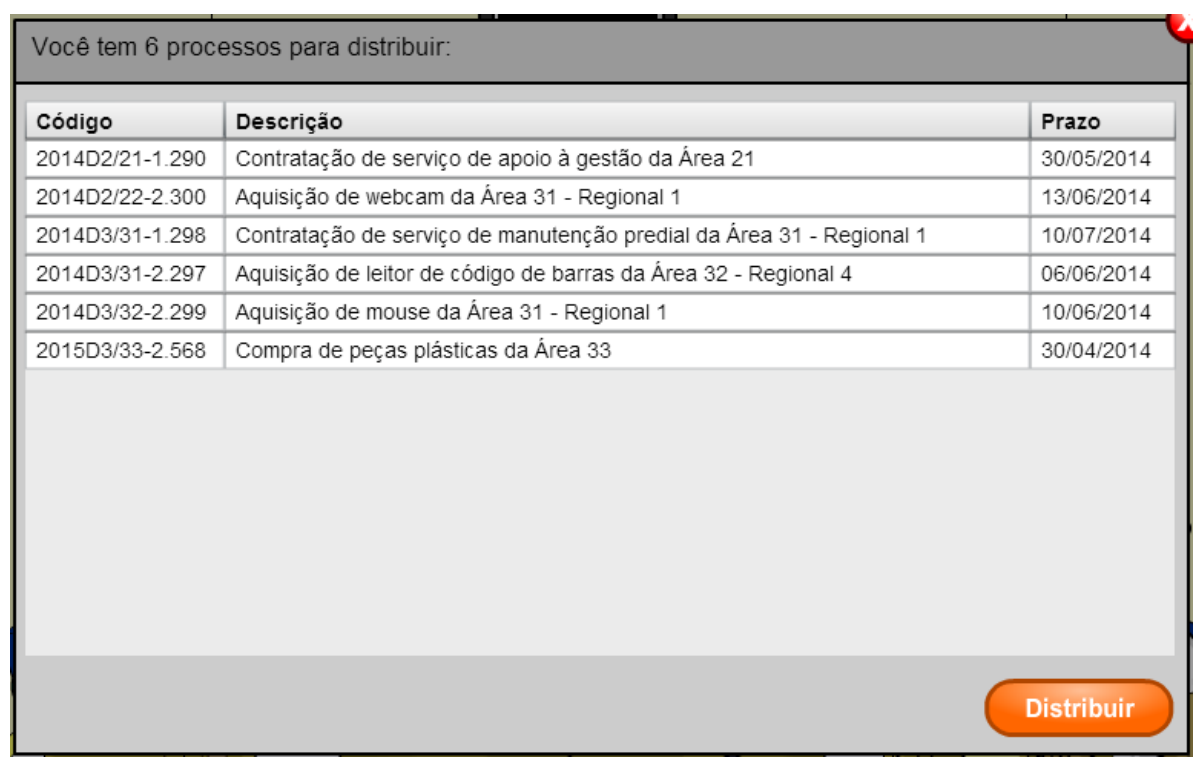

Figura A2- Visão da lista de pedidos na caixa de entrada do jogador.

Cada edital finalizado fica disponível numa caixa de saída e o gestor/jogador deve assiná-los para sua liberação. Se não estiver satisfeito com o resultado, o jogador pode pedir para que o trabalho seja refeito pelo funcionário que o executou ou por outro (Figura A3). Na mesa de trabalho do gestor/jogador há três objetos. Um computador que pode ser clicado para ver os emails que chegam, a caixa de entrada à direita e a caixa de saída à esquerda (Figura A4).

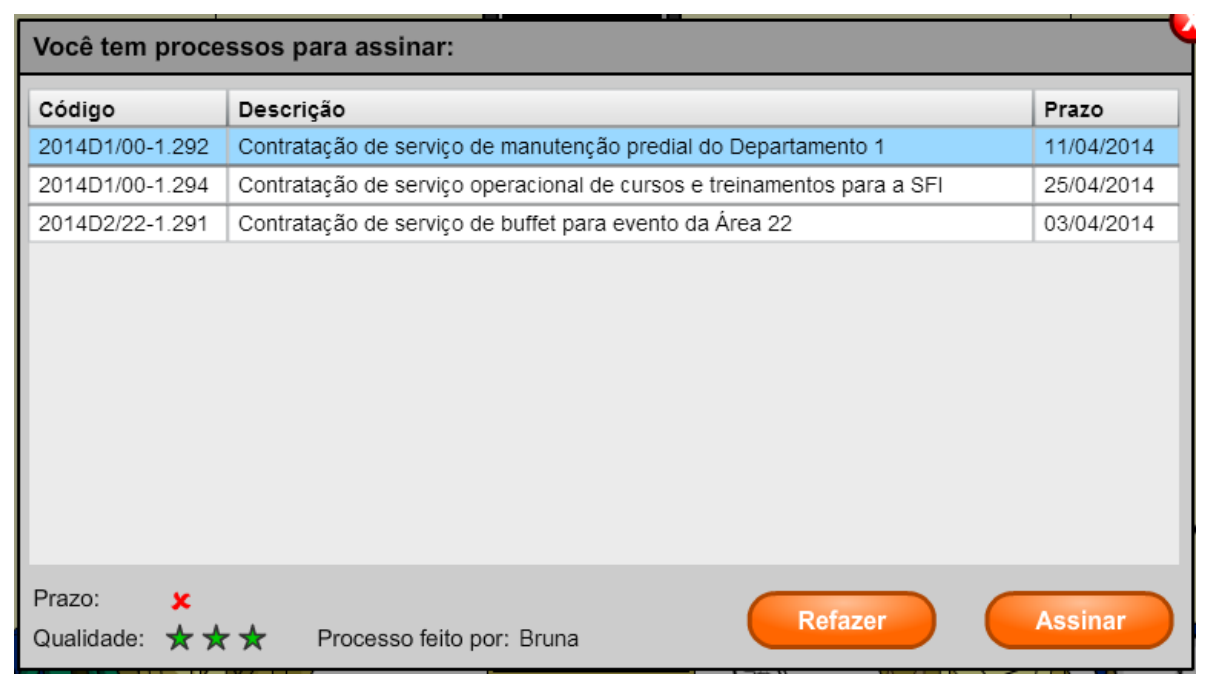

Figura A3 - Visão dos editais concluídos na caixa de saída do jogador. 


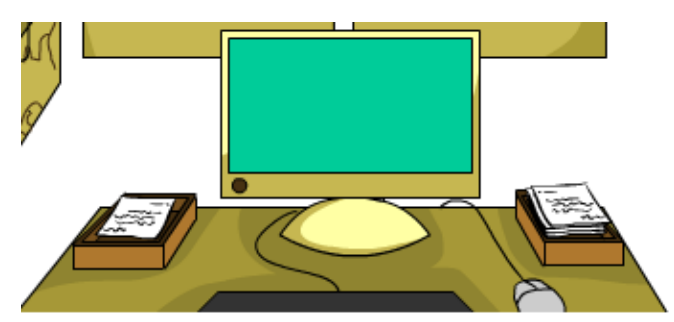

Figura A4 - A mesa de trabalho do gestor/jogador e as caixas de entrada (direita) e saída (esquerda).

Assim, a primeira função do jogador é conectar seus funcionários aos pedidos, definindo quem executa qual trabalho. $\mathrm{O}$ desenrolar destas conexões permitirá que sejam percebidos os conceitos de maneira indireta. Nesse aspecto destacam-se os papéis do gestor como planejador, na integração da equipe, bem como a conscientização para suas responsabilidades.

Somado a isso, o trabalho de transformação dos pedidos em editais passa por quatro fases: (1) leitura do pedido, (2) busca de informações, (3) redação do edital e (4) revisão do edital. A duração de cada fase é variável e depende das características do pedido (especificidade e qualidade) como também de qual funcionário é encarregado pelo trabalho. Cada funcionário tem características diferentes que influenciam na forma como ele realiza o trabalho.

\section{A3. Os funcionários: personagens do jogo}

Sob a gestão do jogador foram colocados cinco funcionários com perfis diferentes. Os funcionários são entidades do jogo que possuem seis atributos: (1) engajamento, (2) foco em resultados, (3) facilidade de comunicação, (4) capacidade analítica, (5) experiência e (6) vocação. Esses atributos combinados determinarão a produtividade do funcionário em cada tipo de processo que é destinado à sua unidade. $\mathrm{O}$ engajamento, por exemplo, permite a determinação de uma função falta. Ou seja, a probabilidade de o gestor poder contar ou não com aquele funcionário na consecução da tarefa em determinado dia.

O foco em resultados diz respeito ao empenho em chegar a um resultado satisfatório, o que se liga ao cumprimento dos prazos no jogo. A comunicação trata da capacidade de receber e transmitir informação, manifestada pelo edital produzido (e implicitamente pelo decorrer do trabalho para obtenção de informações para produção do edital), e se relaciona diretamente à qualidade final do edital. A capacidade analítica possibilita ao funcionário a análise de pedidos complicados, mas também pode ser um ladrão de tempo para quem tenha essa 
capacidade muito alta. Esses três atributos dos funcionários caracterizam o que se poderia chamar de competências. Os demais também influenciam no resultado do trabalho, mas de forma geral e não pela associação direta com os atributos dos pedidos como os três em questão.

Por fim, a experiência é um índice de quanto o funcionário conhece da estrutura e quanto mais alta pode tornar um pedido complexo em um trabalho mais ágil com relação a outros funcionários com pouca experiência, por exemplo. Já a vocação diz respeito ao tipo de assunto que o funcionário prefere tratar na confecção dos editais. Um pode ser mais técnico, enquanto o outro prefere serviços. Independentemente da vocação e experiência, todos os funcionários melhoram ao realizar trabalhos semelhantes ao longo do tempo (curva de aprendizagem). Outra possibilidade de o funcionário melhorar a realização do trabalho (reduzir o tempo ou melhorar a qualidade) é por meio da participação em cursos de capacitação que podem melhorar os atributos correspondentes às competências.

O gestor, inconsciente da existência destes atributos como tais, gerenciará a chegada de pedidos e vai distribui-los aos funcionários. Na dinâmica desenvolvida, o jogador deve supervisionar a entrada de pedidos e a saída de editais, observando os funcionários enquanto eles desenvolvem suas atividades e interferindo quando necessário. O jogador pode influir na priorização do trabalho que está sendo feito. Por exemplo, ao distribuir um novo pedido, o funcionário relata o que está fazendo. Com base nessa informação o jogador decide se outro funcionário deve se encarregar da tarefa, se o pedido deve entrar na fila do funcionário em questão ou se deve ser priorizado (Figura A5). 


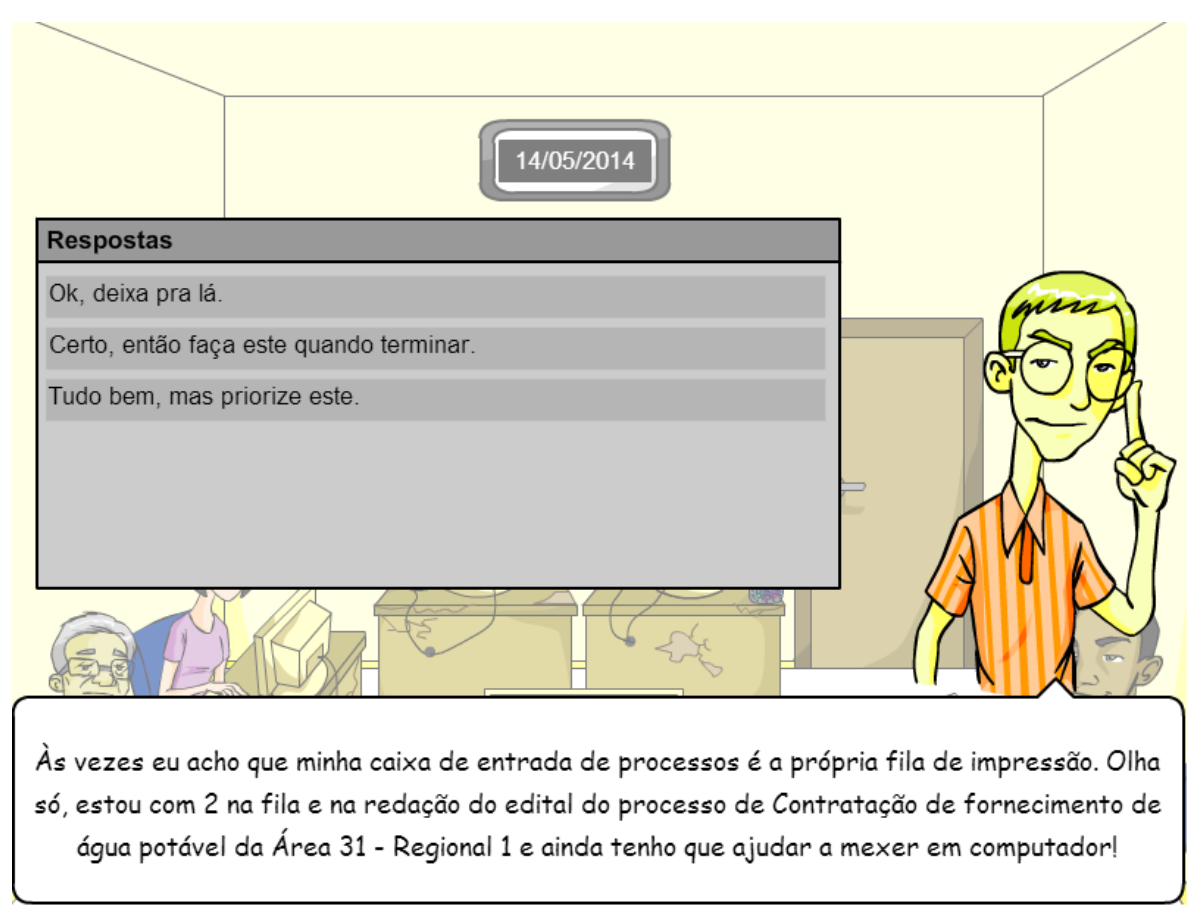

Figura A5 - Interação com funcionário e opções de priorização do trabalho

O resultado do trabalho dos funcionários é sempre um edital, que pode estar ou não dentro do prazo estipulado e pode ter uma qualidade final baixa (uma estrela), média (duas estrelas) ou alta (três estrelas). O jogo trabalha com um trade-off entre prazo e qualidade e o jogador, ao perceber isso, deve dar foco ao que considerar mais importante em cada momento. A Figura A6 apresenta o processo básico do jogo com a influência dos atributos dos pedidos que chegam à área e do perfil dos funcionários. $\mathrm{O}$ desempenho da área do jogador é o resultado dos desempenhos individuais.

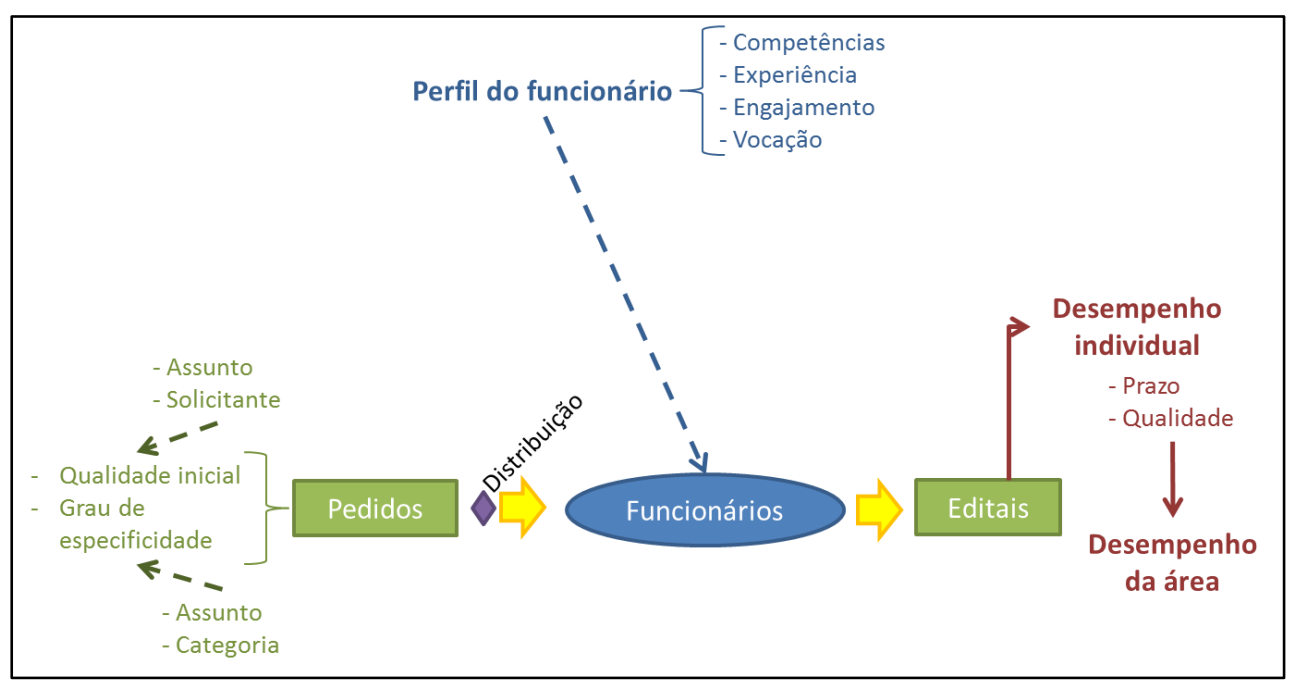

Figura A6 - O processo básico do jogo influenciado pelos atributos dos funcionários e dos pedidos 
O jogo contém uma sexta personagem, que é a diretora da unidade que o jogador comanda e, portanto, superior imediata dele. O papel dela é dar feedback às decisões tomadas no jogo, bem como dar as orientações sobre o que deve ser feito a cada momento dentro dos ciclos do jogo (Figura A7).

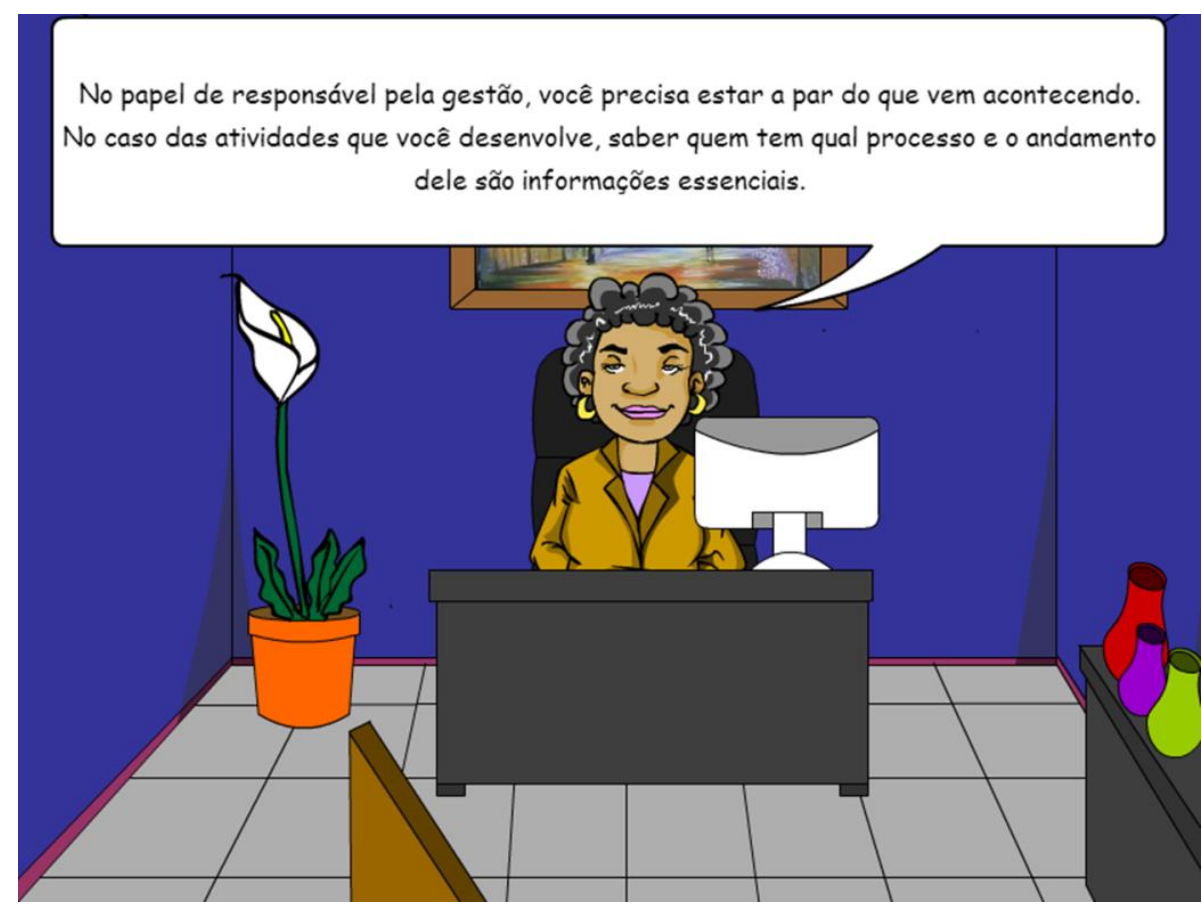

Figura A7 - Diretora da unidade do jogador dando orientações ao jogador

\section{A4. Linha do tempo}

O jogo é composto por um período virtual extenso, de forma que o jogador possa passar por duas fases importantes existentes na administração pública: o levantamento e entrega do orçamento para o próximo ano e a avaliação de funcionários. O primeiro momento acontece no meio do ano, enquanto a avaliação de funcionários acontece a partir de fevereiro. Para chegar a respostas para esses dois desafios, o jogador deve realizar suas tarefas de maneira consciente (observação reflexiva), não automática. O processo contínuo de transformação de pedidos em editais e as interações com os funcionários com o passar dos dias, aliada à percepção dos resultados encontrados e os experimentos possíveis ao conectar funcionários e pedidos (experimentação ativa e experiência 'concreta') devem permitir ao jogador que se prepare para os desafios e, mais importante, perceba os conceitos adaptados ao jogo (conceituação abstrata). 


\section{A5. Metas da unidade}

O jogador/gestor deve definir e monitorar metas em sua unidade com base em dois critérios: cumprimento de prazos e qualidade final do trabalho. Para cada funcionário, o jogador define uma meta com relação ao número de processos dentro do prazo e de percentual de processos finalizados com qualidade ótima.

Para tentar retratar a realidade dos novos gestores, no primeiro ciclo o jogador/gestor irá se familiarizar com o jogo, sendo que para o segundo ciclo entra a questão da definição de metas e avaliação do desempenho da equipe. Os valores de meta que o jogador pode escolher são definidos com base no quanto cada funcionário conseguiu fazer no ano anterior. Além disso, sua unidade terá uma meta global, definida pela personagem que é a chefe do gestor, encarregada pelas principais dicas e orientações ao jogador.

\section{A6. Avaliação de desempenho}

Um dos núcleos do jogo, tratado amplamente em cursos presenciais sobre o tema da gestão pública, é a avaliação de desempenho e sua relação com a definição de metas e o desempenho da equipe. O jogador herdará uma tradição de se fazer avaliação de desempenho atribuindo-se nota máxima a todos os funcionários, independente de seu desempenho, o que é, por si só, uma violação dos princípios por traz dessa metodologia. Assim, será encorajado a ser mais justo e levar em conta o que cada funcionário é capaz de fazer. Além disso, perceberá as diferenças individuais que levam a resultados diferentes e deve, então, definir metas para o segundo ciclo e acompanhar sua execução. Por fim, deve avaliar os funcionários e, ao término do jogo, receberá um relatório comparando o que cada funcionário fez, qual era sua meta e qual avaliação ele atribuiu a cada um, como instrumento final de reflexão.

Os fatores de avaliação são justamente aqueles que podem ser observados pelo desempenho dos funcionários: assiduidade, cumprimento de prazos e qualidade do trabalho realizado, além do desempenho geral (Figura A8). Com exceção dos itens avaliados, o sistema de avaliação

de desempenho adotado no jogo é um espelho daquele utilizado pelo Governo do Estado de São Paulo, esfera em que se foca o jogo, no que se refere aos conceitos de avaliação e ao formato do formulário. 


\begin{tabular}{|c|c|c|c|c|}
\hline Funcionário & $\begin{array}{c}\text { Engajamento / } \\
\text { Assiduidade }\end{array}$ & $\begin{array}{c}\text { Desempenho no } \\
\text { trabalho } \\
\text { Qualidade }\end{array}$ & $\begin{array}{c}\text { Desempenho no } \\
\text { trabalho } \\
\text { Prazos }\end{array}$ & $\begin{array}{c}\text { Desempenho no } \\
\text { trabalho } \\
\text { Geral }\end{array}$ \\
\hline Álvaro & 5 & 5 & 5 & 5 \\
\hline Bruna & 5 & 5 & 5 & 5 \\
\hline Carlos & 5 & 5 & 5 & 5 \\
\hline Dirce & 5 & 5 & 5 & 5 \\
\hline Eduardo & 5 & 5 & 5 & 5 \\
\hline
\end{tabular}

Figura A8 - Visão do formulário de avaliação de desempenho.

A avaliação de desempenho afeta o chamado "clima" da área. Se "sentirem" que a avaliação foi injusta (isto é, não corresponde ao real desempenho que os funcionários tiveram no período), o "clima" entre os funcionários pode ficar ruim e, em consequência disso, o andamento do trabalho pode ser afetado. Por outro lado, se a avaliação for condizente com o desempenho, o "clima" pode melhorar e o resultado sobre o trabalho ser positivo.

\section{A7. Fatores ambientais}

O desempenho geral da área e dos funcionários é também afetado pelas condições ambientais do jogo. A infraestrutura ambiente de trabalho do jogo possui quatro atributos: (1) condições dos equipamentos de informática, (2) condições do mobiliário, (3) ambiente físico e (4) disponibilidade de material de consumo.

O jogador pode influenciar na melhora das condições de trabalho pela atuação sobre os fatores ambientais. Existem "janelas" no jogo para que o jogador tome as decisões relativas a essas questões, que fazem parte dos desafios apresentados na próxima subseção. A Figura A9 apresenta o processo do jogo com a inclusão da influência dos fatores ambientais, bem como a representação do impacto sobre o desempenho da área para consequente definição de metas e avaliação de desempenho. 


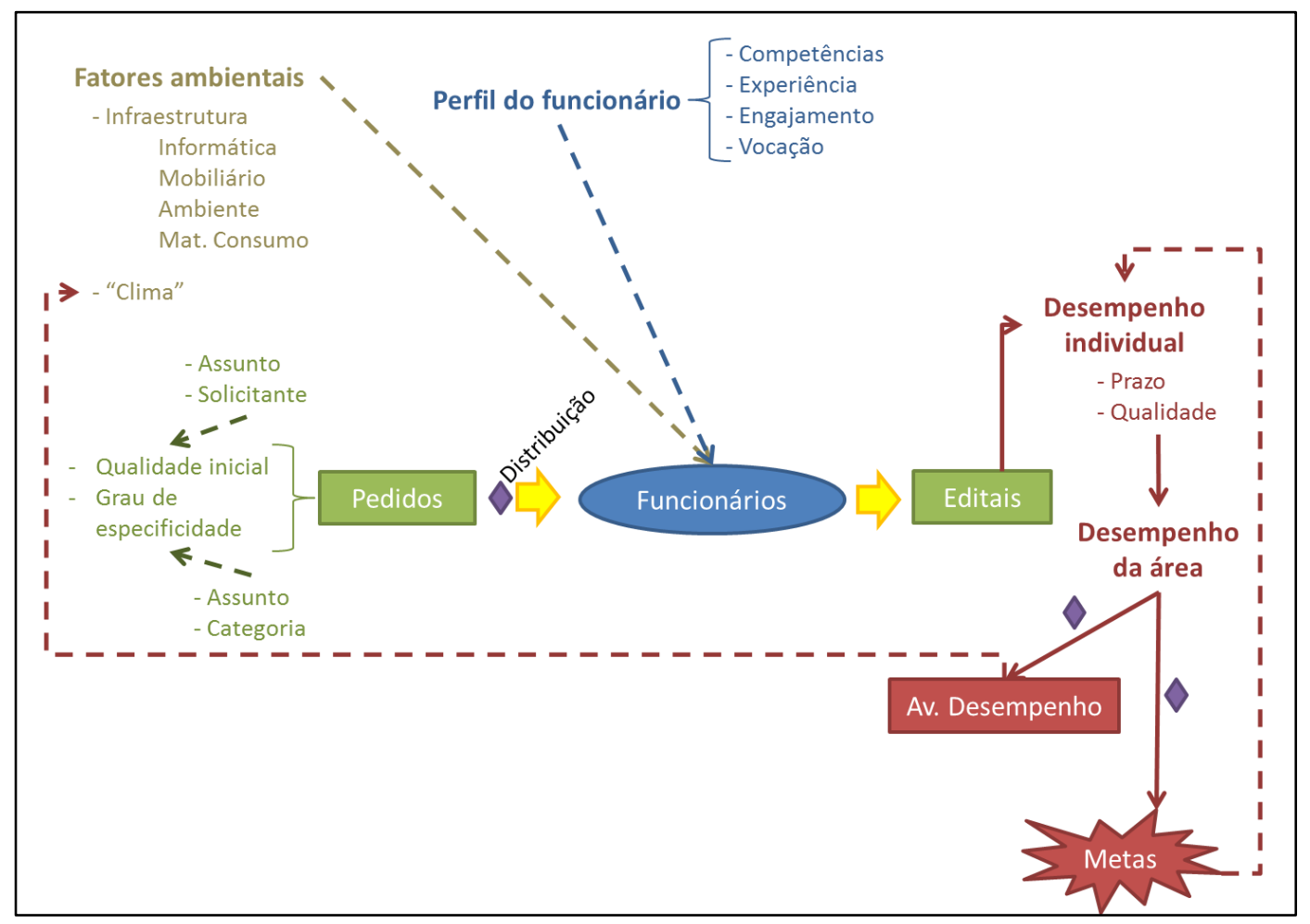

Figura A9 - Processo do jogo, fatores de influência no desempenho e os resultados da área

\section{A8. Desafios}

O jogo é composto, ao longo dos dois ciclos que o jogador poderá interagir na plataforma, por desafios que levam a diferentes desdobramentos em função de suas decisões. Os desafios também caracterizam as mini-histórias que compõem o jogo.

Troca do mobiliário: Nesse minicaso, o gestor deve aprender que houve um planejamento feito no ano anterior (pelo seu antecessor fictício) e que, uma vez parte do orçamento de sua unidade, ele deve executá-lo. Além disso, reclamações dos funcionários darão pistas de que isso deve ser feito (Figura A10). Contudo, a decisão de seguir ou não com um pedido de troca de mobiliário (que será, posteriormente, processado dentro de sua própria unidade) é do gestor. Se optar por efetuar a troca, verá mais disposição de seus funcionários. Caso não faça, será "repreendido" por sua diretora por não executar seu planejamento orçamentário, observará queda de produtividade dos funcionários e reclamações ao longo de todo o jogo. 


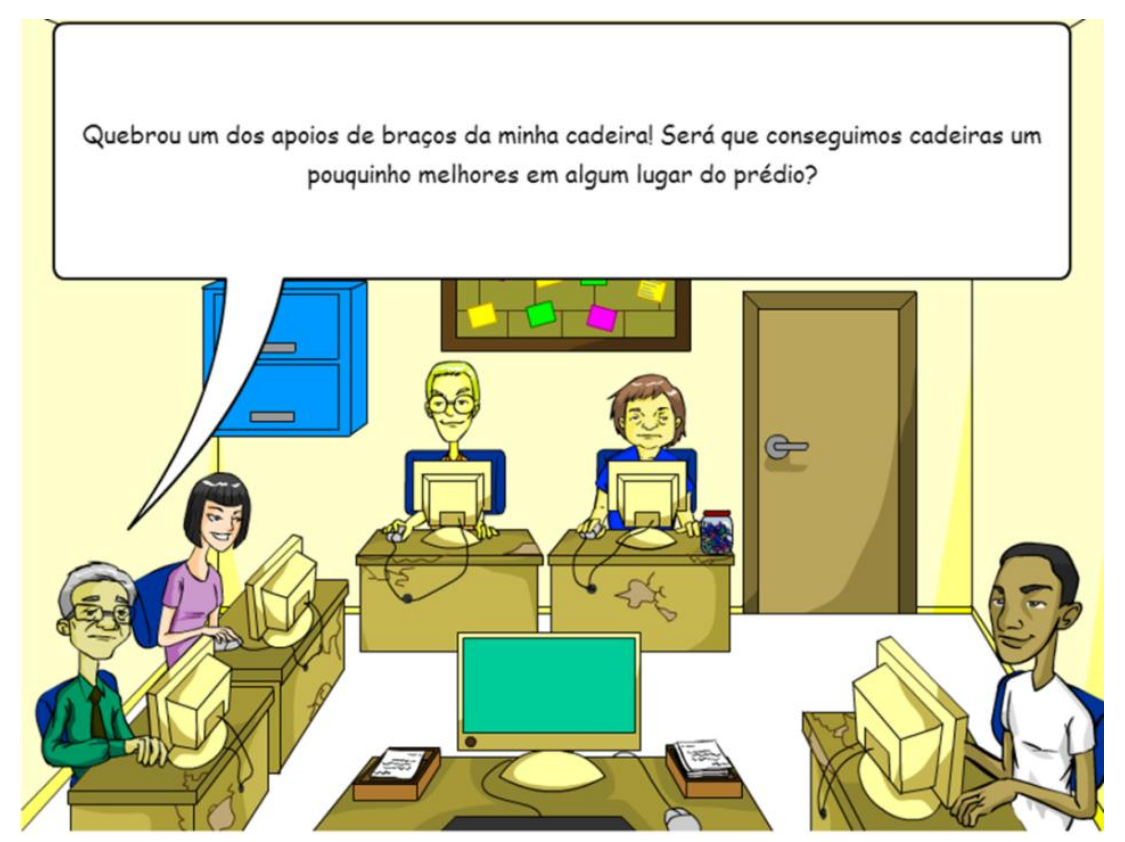

Figura A10 - Funcionário dá dica de que as condições do mobiliário não são as ideais

Troca de computadores frustrada: Na mesma linha do item anterior, no entanto, tratando de um item que não foi previsto em orçamento. A ideia é que o gestor aprenda que não pode executar (em princípio) algo que não foi planejado e que, se deseja efetivar uma melhoria em sua unidade, deve prevê-la no orçamento. Esse é um dos elementos envolvidos em sua decisão na confecção do orçamento, pois seja qual for sua decisão (seguir ou não com um processo para troca de computadores), ela não se efetivará dentro do primeiro ciclo (Figura A11). Só será possível fazer a mudança, caso o jogador considere esse aspecto em seu planejamento orçamentário para o ciclo seguinte.

Troca de computadores efetiva: Caso preveja a troca de computadores em seu orçamento, o jogador terá a oportunidade de executá-lo no segundo ciclo do jogo. O objetivo é que aprenda que, mesmo tendo previsto o item, a execução não é automática. Ele deve tomar a decisão de seguir ou não com esse processo. 


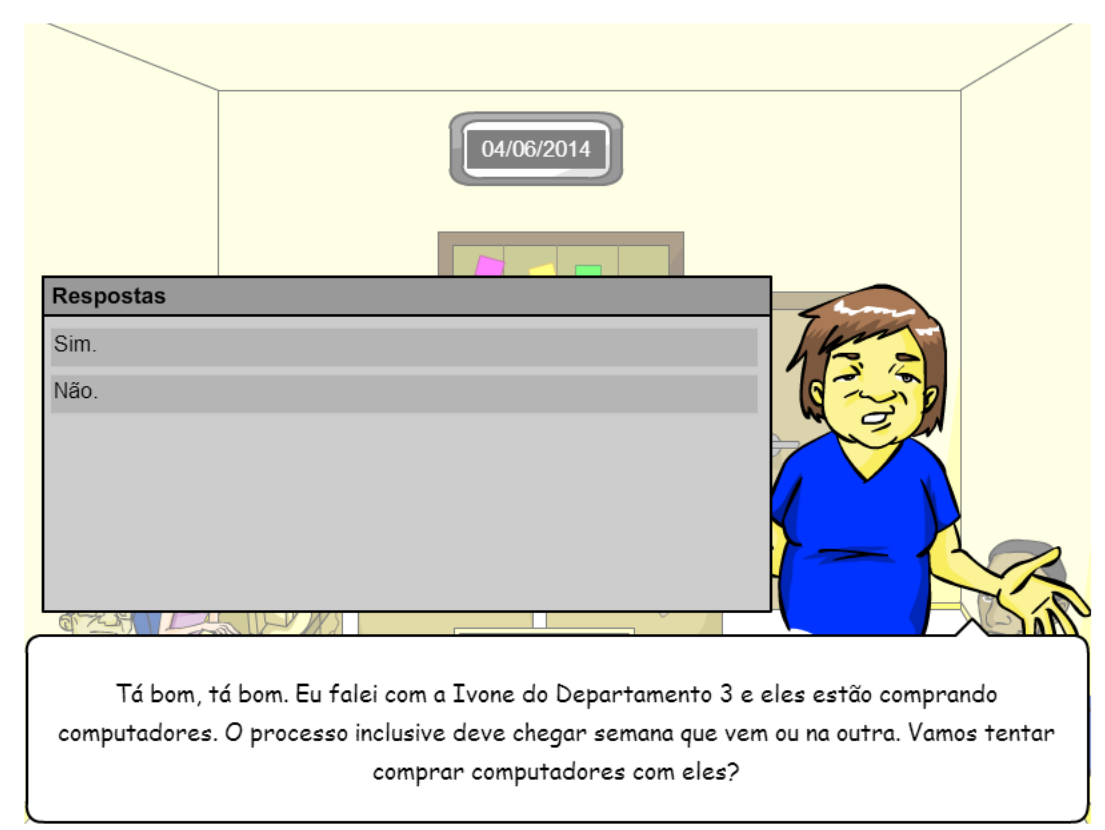

Figura A11 - Momento da decisão sobre a troca de computadores

Aquisição de software: Outro item que comporá o planejamento orçamentário do jogador é um software (TextOptimizer), sugerido pelos funcionários e capaz de melhorar a confecção de editais pela unidade. Optada por sua inclusão no planejamento orçamentário, o jogador deve executá-lo no ciclo seguinte, como no desafio anterior. A sua implantação traz benefícios efetivos à produtividade da unidade, contudo, o trade-off é o jogador ter que abrir mão de dois de seus funcionários por alguns dias para capacitação. Além disso, no mesmo período, ocorre um outro curso que, se planejado no orçamento do ano anterior, acarreta a ausência de um terceiro funcionário no mesmo período. O objetivo é que o jogador se depare com decisões focadas no curto e longo prazos e perceba que soluções ótimas no curto prazo podem prejudicar o longo prazo e, da mesma maneira, sacrifícios no curto prazo podem resultar em bom rendimento no futuro.

Contratação do serviço de limpeza da SFI: Num dado momento do jogo, a secretaria terá problemas com a empresa prestadora de serviço de limpeza e terá que fazer um processo rapidamente. O objetivo é que, nesse momento, o jogador já "conheça" seus funcionários e saiba quais deles estão mais aptos a lidar com esse tipo de urgência para definir sua atuação nesse processo e trabalhe as questões de priorização e urgência. É o uso do "motor" do jogo em sua plenitude. 
Curso de motivação para o trabalho: Nesse mini-desafio o tema do curso importa menos do que a decisão envolvida em si. É a noção de que investir na formação de funcionários é importante que permeia esse caso. Dessa forma, o jogador deve abrir mão do trabalho de um dos funcionários por dois dias para que ele, potencialmente, volte melhor nos outros dias. Contudo, o próprio impacto do curso no funcionário depende de seu engajamento (que pode ser percebido por observação ao longo do jogo). Além disso, a escolha de um funcionário em detrimento de outros pode afetar o desempenho de todos. É preciso fazer escolhas.

Curso de pacote Office avançado: Semelhante ao item anterior, o jogador tem a oportunidade de qualificar mais um funcionário (ou o mesmo). No caso desse curso, a possibilidade é para melhorar a capacidade analítica do escolhido. Contudo, o jogador, dependendo de sua escolha, verá sua decisão "revertida" pelos funcionários. O objetivo é que aprenda que as pessoas têm habilidades e aptidões diferentes e que não é todo mundo que pode ser desenvolvido em qualquer aspecto.

Curso Relacionamento e Comunicação: Ao contrário dos dois itens anteriores, esse curso ocorre no segundo ciclo e, portanto, precisa ter sido planejado. Se estiver presente no planejamento orçamentário vai gerar conflito com a capacitação para uso do software do (desafio aquisição de software). Dos cinco funcionários, pode ser que, num determinado momento do jogo, o gestor precise abrir mão de três deles ao mesmo tempo.

Curso de Produtividade e Foco em Resultados: Como no item anterior, esse curso depende de planejamento prévio. A ideia é que o gestor compreenda que é preciso fazer escolhas e que não pode fazer tudo com uma determinada dotação orçamentária. Ou ele escolhe capacitar sua equipe ou escolhe melhorar a infraestrutura. O papel desse curso é o de aumentar o leque de opções e deixar o trade-off mais evidente.

Controle de processos: Logo no início do jogo, o jogador/gestor deve perceber que sem controle fica impossível administrar. Assim, embora sugira o tempo todo que o jogador faça acompanhamentos em meios externos à plataforma do jogo (caderno ou planilhas, mais próximo de como seria na vida real), o jogo oferece um instrumento (sugerido pela chefe do jogador, em formato de planilha eletrônica) que permite que o jogador priorize e acompanhe os pedidos/editais nas mãos de seus funcionários. 
Reposição de material de consumo: Nesse minidesafio, o jogador deve perceber que determinadas atribuições devem ser delegadas e não centralizadas em sua figura. O trade-off nesse caso é a diminuição de produtividade do funcionário incumbido pela tarefa de reposição do estoque de material de consumo, mas com a melhora para todos. Dessa forma, as reclamações sobre o tema cessam e a produtividade deixa de ser afetada pela falta de um item banal. Se optar por não delegar, a produtividade dos funcionários não é afetada pela delegação, mas faltas constantes de material ao longo do jogo serão notadas pelo jogador.

Lâmpadas queimadas: $\mathrm{O}$ objetivo desse minidesafio é trabalhar com as diferentes formas de tomar decisão. Se optar por resolver algo rapidamente, mas sem nenhuma participação de seus funcionários, embora obtenha uma boa solução, não conseguirá "conquistá-los". Por outro lado, se investir tempo numa tomada de decisão mais participativa, embora demore mais para ter a solução, observará melhores resultados no compromisso da equipe. Esse desafio é influenciado pelas ideias da Escola de Relações Humanas de Administração.

\section{A9. Planejamento orçamentário}

O jogador deve realizar dois planejamentos orçamentários no jogo e executar um planejamento posto a priori por seu antecessor fictício e outro feito por ele mesmo. A ideia é que o jogador/gestor aprenda a relação entre planejamento e execução do orçamento e, mais do que isso, possa se ver no "dilema" de fazer escolhas entre melhorar as condições de trabalho versus capacitar sua equipe.

O orçamento no jogo é considerado de maneira bastante simplificada, apenas para fins didáticos (especialmente na percepção da necessidade de planejamento para a execução futura e atenção para a execução de itens que foram planejados, como mostra a Figura A12). O intuito é que dentre uma gama de cinco itens possíveis o jogador perceba que sua verba permite que sejam feitos no máximo três. A escolha dentre eles é livre. Mas as consequências são diversas em função das escolhas. 


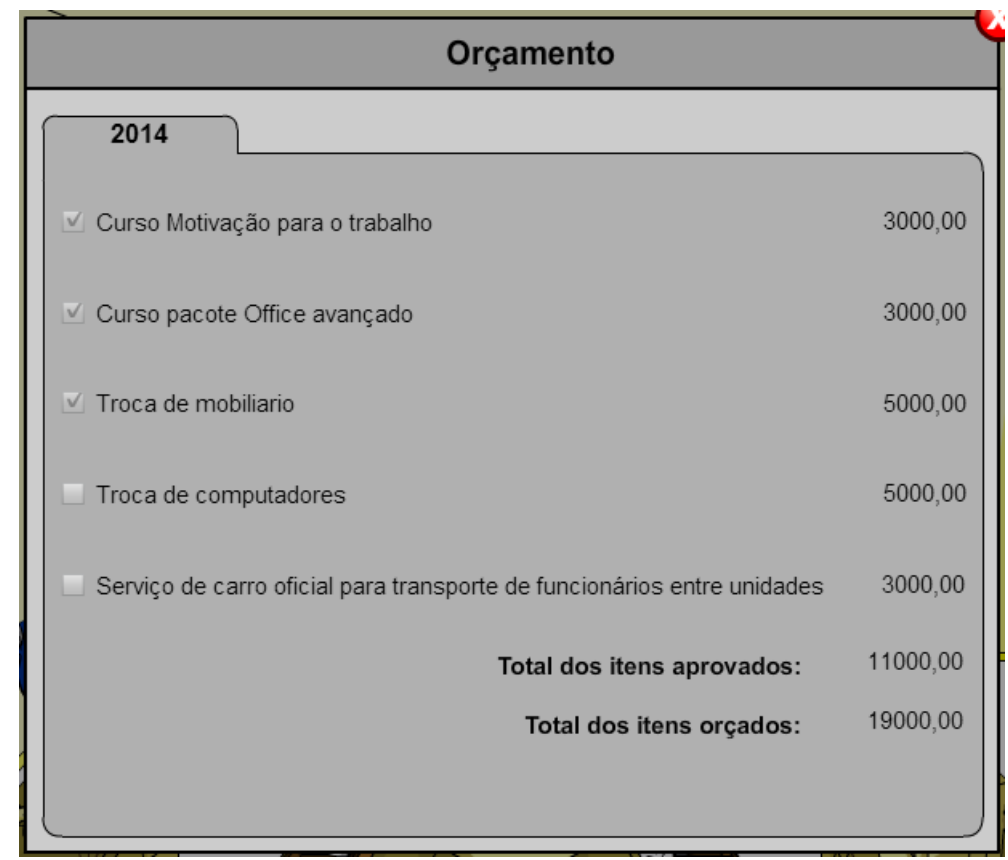

Figura A12 - Orçamento simplificado do jogo

\section{A10. Ilustração do sistema dinâmico do jogo}

Todos os pontos destacados na seção anterior compõem um todo mais complexo e interrelacionado no jogo que constitui um sistema dinâmico. A Figura A13 apresenta a visão esquemática dessas inter-relações de maneira completa. 


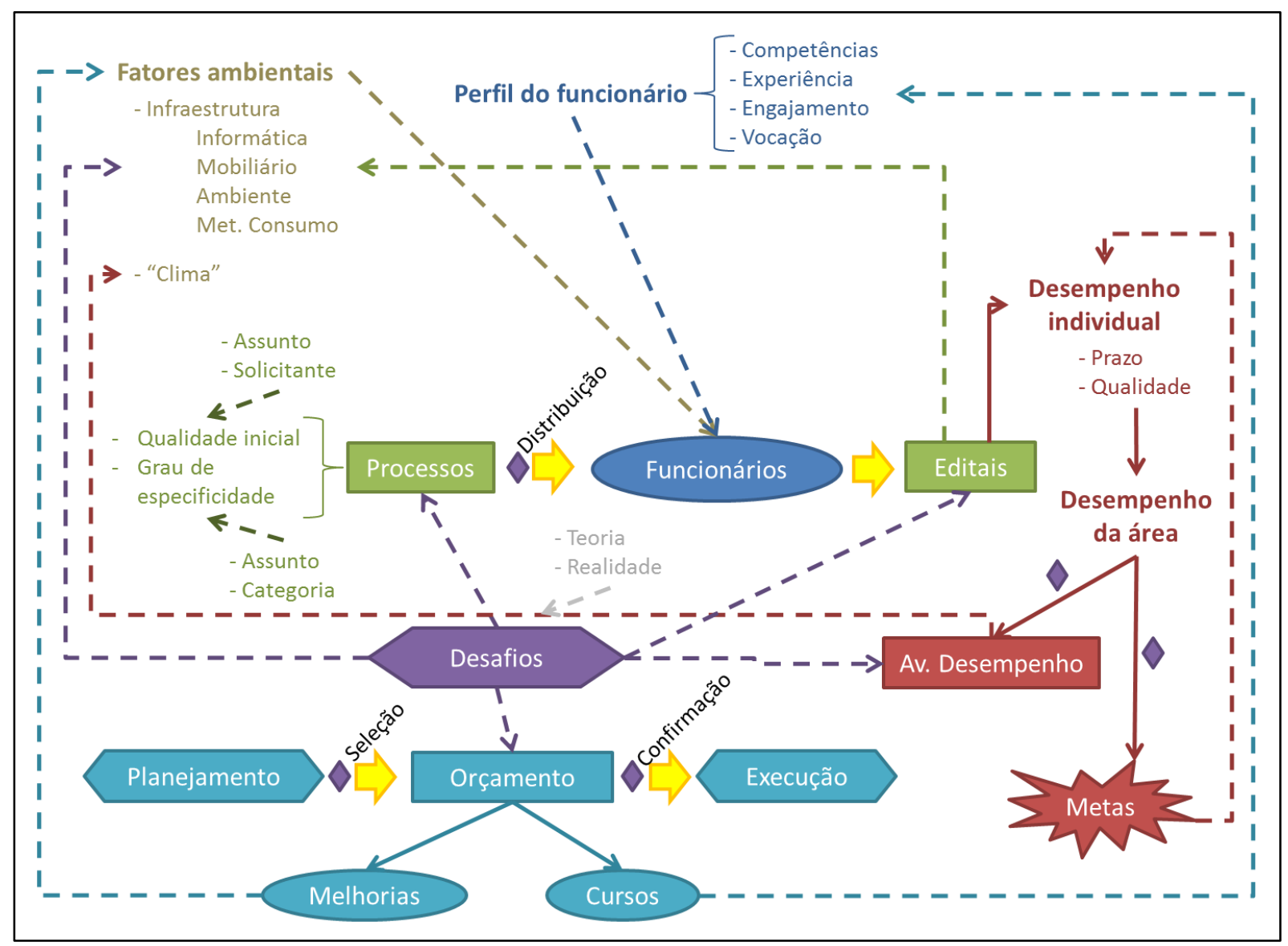

Figura A13 - O sistema dinâmico do jogo "Liderança em jogo: competências papéis e responsabilidades" 


\section{Apêndice B Termo de consentimento para participação no estudo}

\section{TERMO DE CONSENTIMENTO LIVRE E ESCLARECIDO}

$\mathrm{Eu}$, (Nome do servidor) identidade $\mathrm{n}^{\mathrm{o}}$ servidor da instituição e-mail venho declarar que tenho disponibilidade para participar das aulas presenciais e das atividades que serão solicitadas durante o desenvolvimento do curso " Gestão Pública - Teoria e Prática ", que será realizado nas seguintes datas:

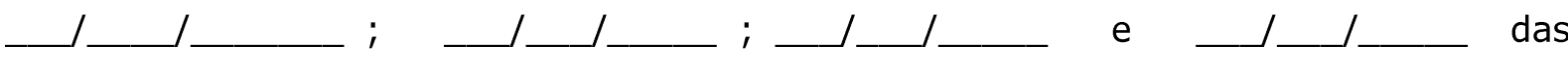

09:00h às 13:00horas.

Declaro também que concordo com os termos abaixo descritos:

Você está sendo convidado a participar de um projeto de pesquisa sobre características de gestores públicos.

O estudo é conduzido pelo pesquisador Fernando Nascimento da Silva, aluno em nível de doutorado do Programa de Pós-Graduação em Administração da Faculdade de Economia, Administração e Contabilidade da Universidade de São Paulo - PPGA/FEA-USP, sob orientação da Profa. Dra. Bernadete de Lourdes Marinho (FEA-USP).

Todos os dados coletados serão utilizados exclusivamente para finalidades acadêmicas. Nenhuma informação pessoal, sob nenhuma circunstância, será divulgada no processo de disseminação dos resultados.

A pesquisa foi desenhada prevendo sua participação em um curso sobre administração aplicada ao setor público, denominado Gestão Pública: Teoria e Prática e prevê, além da exposição de conteúdos teóricos a participação em atividades práticas, em sala de aula. Ao longo do curso, você poderá ser requerido a participar de avaliações e/ou preencher questionários. Embora possam demandar identificação individual, cabe ressaltar que os dados tanto das avaliações quanto dos questionários serão utilizados anonimamente e/ou em conjunto, com o único objetivo de avaliar o curso e para fins de rastreabilidade dos dados no âmbito da pesquisa.

Sua participação no projeto é completamente voluntária e você pode decidir por não participar de todas as etapas propostas, por qualquer razão, sem qualquer penalidade. Sua escolha em participar ou não dessa pesquisa não impactará seu trabalho ou qualquer status junto à Secretaria Estadual de Saúde do Estado de São Paulo.

Se você leu e compreendeu as informações acima e voluntariamente concorda em participar do projeto de pesquisa descrito, por favor, marque a opção abaixo. 
$\square$ Li e estou de acordo com o termo de consentimento de de 2016.

Nome e cargo na instituição 


\title{
Apêndice C Questionários IMMS
}

\section{C1. Questionário RIMMS Original}

Extraído de Keller (2010, pp.283-284) - Em destaque os itens que compõem o RIMMS, de acordo com Loorbach et al. (2015).

\author{
Instructions \\ Instructional Materials Motivation Survey \\ There are 36 statements in this questionnaire. Please think about each statement in relation to \\ the instructional materials you have just studied and indicate how true it is. Give the answer that \\ truly applies to you, and not what you would like to be true, or what you think others want to \\ hear. \\ Think about each statement by itself and indicate how true it is. Do not be influenced by your \\ answers to other statements. \\ Record your responses on the answer sheet that is provided and follow any additional instructions \\ that may be provided in regard to the answer sheet that is being used with this survey. Thank you. \\ Use the following values to indicate your response to each item. \\ $1($ or $\mathrm{A})=$ not true \\ 2 (or B) $=$ slightly true \\ $3($ or $\mathrm{C})=$ moderately true \\ $4($ or D) $=$ mostly true \\ $5($ or $\mathrm{E})=$ very true \\ $01 \mathrm{C} 01^{1}$ When I first looked at this lesson, I had the impression that it would be easy for me. \\ $02 \mathrm{A01}$ There was something interesting at the beginning of this lesson that got my attention. \\ $03 \mathrm{C02}$ This material was more difficult to understand than I would like for it to be.* \\ 04003 After reading the introductory information, I felt confident that I knew what I was \\ supposed to learn from this lesson. \\ 05S01 Completing the exercises in this lesson gave me a satisfying feeling of accomplishment. \\ 06R01 It is clear to me how the content of this material is related to things I already know. \\ $07 \mathrm{C04}$ Many of the pages had so much information that it was hard to pick out and remember \\ the important points. ${ }^{*}$ \\ $08 \mathrm{A02}$ These materials are eye catching. \\ 09R02 There were stories, pictures or examples that showed me how this material could be \\ important to some people. \\ $10 \mathrm{R} 03$ Completing this lesson successfully was important to me. \\ $11 \mathrm{~A} 03$ The quality of the writing helped to hold my attention. \\ $12 \mathrm{A0} 04$ This lesson is so abstract that it was hard to keep my attention on it.* \\ 13005 As I worked on this lesson, I was confident that I could learn the content. \\ $14 \mathrm{~S} 02$ I enjoyed this lesson so much that I would like to know more about this topic. \\ $15 \mathrm{~A} 05$ The pages of this lesson look dry and unappealing.* \\ 16R04 The content of this material is relevant to my interests. \\ 17 A06 The way the information is arranged on the pages helped keep my attention. \\ 18R05 There are explanations or examples of how people use the knowledge in this lesson. \\ 19006 The exercises in this lesson were too difficult.* \\ $20 \mathrm{A07}$ This lesson has things that stimulated my curiosity.
}


$21 \mathrm{~S} 03$ I really enjoyed studying this lesson.

$22 \mathrm{~A} 08$ The amount of repetition in this lesson caused me to get bored sometimes.*

23R06 The content and style of writing in this lesson convey the impression that its content is worth knowing.

24 A09 I learned some things that were surprising or unexpected.

25007 After working on this lesson for a while, I was confident that I would be able to pass a test on it.

26R07 This lesson was not relevant to my needs because I already knew most of it.*

$27 \mathrm{~S} 04$ The wording of feedback after the exercises, or of other comments in this lesson, helped me feel rewarded for my effort.

$28 \mathrm{~A} 10$ The variety of reading passages, exercises, illustrations, etc, helped keep my attention on the lesson.

29A11 The style of writing is boring.*

30R08 I could relate to the content of this lesson to things I have seen, done or thought about in my own life.

31A12 There are so many words on each page that it is irritating.*

$32 \mathrm{~S} 05$ It felt good to successfully complete this lesson.

33R09 The content of this lesson will be useful to me.

34008 I could not really understand quite a bit of the material in this lesson.*

35009 The good organization of the content helped me be confident that I would learn this material.

$36 \mathrm{S06}$ It was a pleasure to work on such a well-designed lesson.

*Asterisked items should be recoded prior to data analysis $(1=5,2=4,4=2$ and $5=1)$.

${ }^{1} 02 \mathrm{AO} 1$ is the second item of the IMMS scale and the first item of the A construct, 03002 is the third item of the IMMS scale and the second item of the $\mathrm{C}$ construct, etc. Codes were added for reference; in the original IMMS, items are numbered 1 through 36. 


\section{C2. IMMS - versão do Experimento 1}

\begin{tabular}{|c|c|c|c|c|c|c|c|c|c|c|c|c|c|c|c|}
\hline \multirow{2}{*}{$\begin{array}{l}\text { Classific. } \\
\text { ARCS }\end{array}$} & \multirow{2}{*}{ Item } & \multicolumn{7}{|c|}{ Turma 1 (cotrole) } & \multicolumn{7}{|c|}{ Turma 2 (tratamento) } \\
\hline & & 1 & 2 & 3 & 4 & 5 & 6 & 7 & 1 & 2 & 3 & 4 & 5 & 6 & 7 \\
\hline $\mathrm{R}$ & $\begin{array}{l}\text { É claro para mim como o conteúdo desse curso se relaciona a } \\
\text { coisas que já sei. }\end{array}$ & 0 & 0 & 2 & 2 & 3 & 9 & 8 & 0 & 0 & 1 & 1 & 7 & 4 & 2 \\
\hline A & A qualidade das aulas ajudou a prender a minha atenção. & 0 & 0 & 0 & 1 & 3 & 14 & 6 & 0 & 0 & 0 & 0 & 3 & 4 & 8 \\
\hline $\mathrm{C}$ & $\begin{array}{l}\text { Enquanto participava do curso, eu estava confiante de que } \\
\text { poderia aprender o conteúdo. }\end{array}$ & 0 & 0 & 0 & 0 & 2 & 12 & 10 & 0 & 0 & 0 & 1 & 1 & 6 & 7 \\
\hline A & $\begin{array}{l}\text { A forma como as informações foram organizadas ajudou a } \\
\text { manter minha atenção. }\end{array}$ & 0 & 0 & 0 & 1 & 3 & 14 & 6 & 0 & 0 & 0 & 0 & 4 & 7 & 4 \\
\hline $\mathrm{S}$ & Eu realmente gostei de participar desse curso. & 0 & 0 & 0 & 0 & 1 & 6 & 17 & 0 & 0 & 0 & 1 & 2 & 2 & 10 \\
\hline $\mathrm{R}$ & $\begin{array}{l}\text { Os tópicos e sua forma de apresentação nesse curso passam a } \\
\text { impressão de que o seu conteúdo vale a pena ser aprendido. }\end{array}$ & 0 & 0 & 0 & 0 & 5 & 5 & 14 & 0 & 0 & 0 & 1 & 1 & 5 & 8 \\
\hline $\mathrm{C}$ & $\begin{array}{l}\text { Depois de um tempo participando do curso, eu fiquei confiante } \\
\text { de que seria capaz de passar em uma prova sobre ele. }\end{array}$ & 1 & 0 & 0 & 0 & 6 & 14 & 3 & 0 & 1 & 0 & 1 & 6 & 3 & 4 \\
\hline A & $\begin{array}{l}\text { A variedade de atividades, exercícios, ilustrações etc. ajudou a } \\
\text { manter a minha atenção no curso. }\end{array}$ & 0 & 0 & 0 & 1 & 1 & 13 & 9 & 0 & 0 & 0 & 0 & 2 & 6 & 7 \\
\hline $\mathrm{R}$ & O conteúdo desse curso será útil para mim. & 0 & 0 & 0 & 0 & 2 & 6 & 16 & 0 & 0 & 0 & 0 & 2 & 5 & 8 \\
\hline $\mathrm{C}$ & $\begin{array}{l}\text { A boa organização do conteúdo me ajudou a ficar confiante de } \\
\text { que eu poderia aprender o conteúdo. }\end{array}$ & 0 & 0 & 0 & 0 & 4 & 10 & 10 & 0 & 0 & 0 & 1 & 2 & 7 & 5 \\
\hline $\mathrm{S}$ & Foi um prazer participar de um curso tão bem estruturado. & 0 & 0 & 0 & 0 & 1 & 6 & 17 & 0 & 0 & 0 & 0 & 3 & 1 & 11 \\
\hline
\end{tabular}




\section{C3. IMMS - versão do Experimento 2}

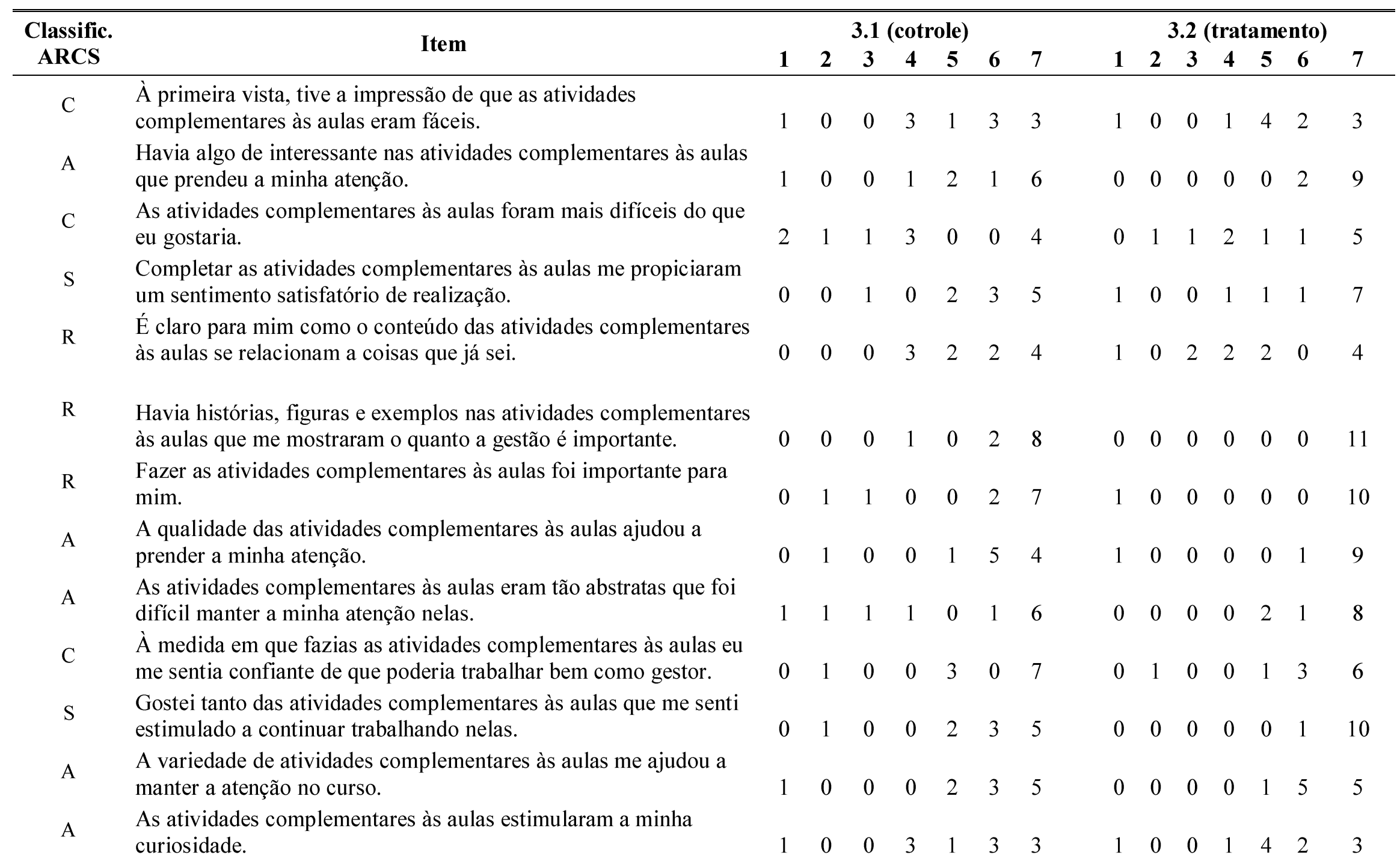




\begin{tabular}{|c|c|c|c|c|c|c|c|c|c|c|c|c|c|c|c|}
\hline \multirow{2}{*}{$\begin{array}{l}\text { Classific. } \\
\text { ARCS }\end{array}$} & \multirow{2}{*}{ Item } & \multicolumn{7}{|c|}{3.1 (cotrole) } & \multicolumn{7}{|c|}{3.2 (tratamento) } \\
\hline & & 1 & 2 & 3 & 4 & 5 & 6 & 7 & 1 & 2 & 3 & 4 & 5 & 6 & 7 \\
\hline $\mathrm{S}$ & Eu realmente gostei das atividades complementares às aulas. & 1 & 0 & 0 & 3 & 1 & 3 & 3 & 1 & 0 & 0 & 1 & 4 & 2 & 3 \\
\hline A & $\begin{array}{l}\text { Aprendi coisas surpreendentes e inesperadas com as atividades } \\
\text { complementares às aulas. }\end{array}$ & 1 & 0 & 0 & 3 & 1 & 3 & 3 & 1 & 0 & 0 & 1 & 4 & 2 & 3 \\
\hline $\mathrm{C}$ & $\begin{array}{l}\text { Após fazer um pouco das atividades complementares às aulas eu } \\
\text { me senti confiante de que poderia responder questões sobre elas. }\end{array}$ & 1 & 0 & 0 & 3 & 1 & 3 & 3 & 1 & 0 & 0 & 1 & 4 & 2 & 3 \\
\hline $\mathrm{R}$ & $\begin{array}{l}\text { As atividades complementares às aulas não foram relevantes para } \\
\text { mim, pois eu já sabia a maior parte do conteúdo. }\end{array}$ & 1 & 0 & 0 & 3 & 1 & 3 & 3 & 1 & 0 & 0 & 1 & 4 & 2 & 3 \\
\hline $\mathrm{S}$ & $\begin{array}{l}\text { Durante as atividades complementares eu me sentia recompensado } \\
\text { pelo meu esforço ao fazê-las. }\end{array}$ & 1 & 0 & 0 & 3 & 1 & 3 & 3 & 1 & 0 & 0 & 1 & 4 & 2 & 3 \\
\hline $\mathrm{R}$ & $\begin{array}{l}\text { Eu pude relacionar o conteúdo das atividades complementares às } \\
\text { aulas a coisas que eu já tinha visto, feito ou pensado a respeito } \\
\text { antes. }\end{array}$ & 1 & 0 & 0 & 3 & 1 & 3 & 3 & 1 & 0 & 0 & 1 & 4 & 2 & 3 \\
\hline $\mathrm{S}$ & Me senti bem ao completar as atividades complementares às aulas. & 1 & 0 & 0 & 3 & 1 & 3 & 3 & 1 & 0 & 0 & 1 & 4 & 2 & 3 \\
\hline $\mathrm{R}$ & $\begin{array}{l}\text { O conteúdo das atividades complementares às aulas será útil para } \\
\text { mim. }\end{array}$ & 1 & 0 & 0 & 3 & 1 & 3 & 3 & 1 & 0 & 0 & 1 & 4 & 2 & 3 \\
\hline $\mathrm{C}$ & $\begin{array}{l}\text { Eu não entendi boa parte das informações das atividades } \\
\text { complementares às aulas. }\end{array}$ & 1 & 0 & 0 & 3 & 1 & 3 & 3 & 1 & 0 & 0 & 1 & 4 & 2 & 3 \\
\hline $\mathrm{C}$ & $\begin{array}{l}\text { A boa organização do conteúdo das atividades complementares às } \\
\text { aulas me ajudaram a ter confiança de que eu poderia aprender a } \\
\text { ser um bom gestor. }\end{array}$ & 1 & 0 & 0 & 3 & 1 & 3 & 3 & 1 & 0 & 0 & 1 & 4 & 2 & 3 \\
\hline S & $\begin{array}{l}\text { Foi um prazer trabalhar com atividades complementares às aulas } \\
\text { tão bem estruturadas. }\end{array}$ & 1 & 0 & 0 & 3 & 1 & 3 & 3 & 1 & 0 & 0 & 1 & 4 & 2 & 3 \\
\hline
\end{tabular}




\section{Apêndice D Saídas do SPSS para o nível de reação}

\section{D1. Experimento 1 - modelo ARCS.}

\section{Hypothesis Test Summary}

\begin{tabular}{|c|c|c|c|c|}
\hline & Null Hypothesis & Test & Sig. & Decision \\
\hline 1 & $\begin{array}{l}\text { The distribution of } \mathrm{A} \text { is the same } \\
\text { across categories of Turma. }\end{array}$ & $\begin{array}{l}\text { Independent- } \\
\text { Samples } \\
\text { Mann- } \\
\text { Whitney U } \\
\text { Test }\end{array}$ &, $809^{1}$ & $\begin{array}{l}\text { Retain the } \\
\text { null } \\
\text { hypothesis. }\end{array}$ \\
\hline 2 & $\begin{array}{l}\text { The distribution of } \mathrm{R} \text { is the same } \\
\text { across categories of Turma. }\end{array}$ & $\begin{array}{l}\text { Independent- } \\
\text { Samples } \\
\text { Mann- } \\
\text { Whitney U } \\
\text { Test }\end{array}$ &, $338^{1}$ & $\begin{array}{l}\text { Retain the } \\
\text { null } \\
\text { hypothesis. }\end{array}$ \\
\hline 3 & $\begin{array}{l}\text { The distribution of } \mathrm{C} \text { is the same } \\
\text { across categories of Turma. }\end{array}$ & $\begin{array}{l}\text { Independent- } \\
\text { Samples } \\
\text { Mann- } \\
\text { Whitney U } \\
\text { Test }\end{array}$ &, $679^{1}$ & $\begin{array}{l}\text { Retain the } \\
\text { null } \\
\text { hypothesis. }\end{array}$ \\
\hline 4 & $\begin{array}{l}\text { The distribution of } \mathrm{S} \text { is the same } \\
\text { across categories of Turma. }\end{array}$ & $\begin{array}{l}\text { Independent- } \\
\text { Samples } \\
\text { Mann- } \\
\text { Whitney U } \\
\text { Test }\end{array}$ &, $484^{1}$ & $\begin{array}{l}\text { Retain the } \\
\text { null } \\
\text { hypothesis. }\end{array}$ \\
\hline
\end{tabular}

Asymptotic significances are displayed. The significance level is , 05 .

1 Exact significance is displayed for this test.

Variável Atenção:

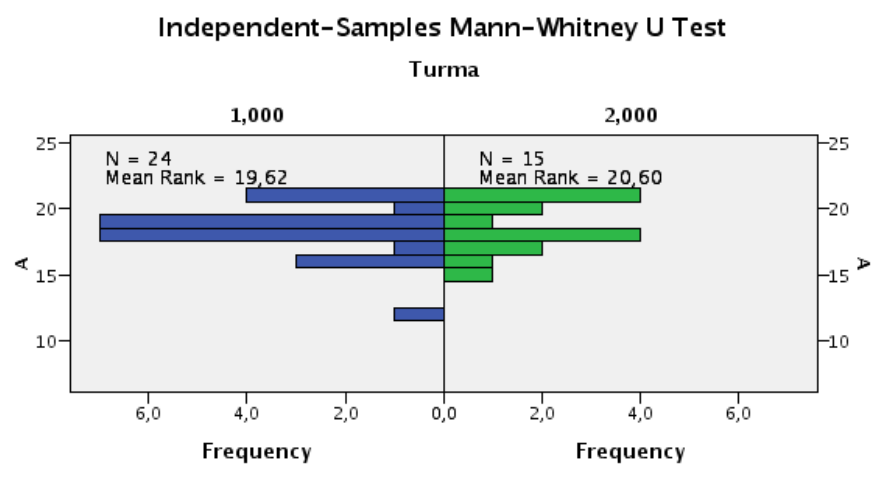

\begin{tabular}{|lr|}
\hline Total N & 39 \\
\hline Mann-Whitney U & 189,000 \\
\hline Wilcoxon W & 309,000 \\
\hline Test Statistic & 189,000 \\
\hline Standard Error & 33,922 \\
\hline Standardized Test Statistic &, 265 \\
\hline Asymptotic Sig. (2-sided test) &, 791 \\
\hline Exact Sig. (2-sided test) &, 809 \\
\hline
\end{tabular}


Variável Relevância:

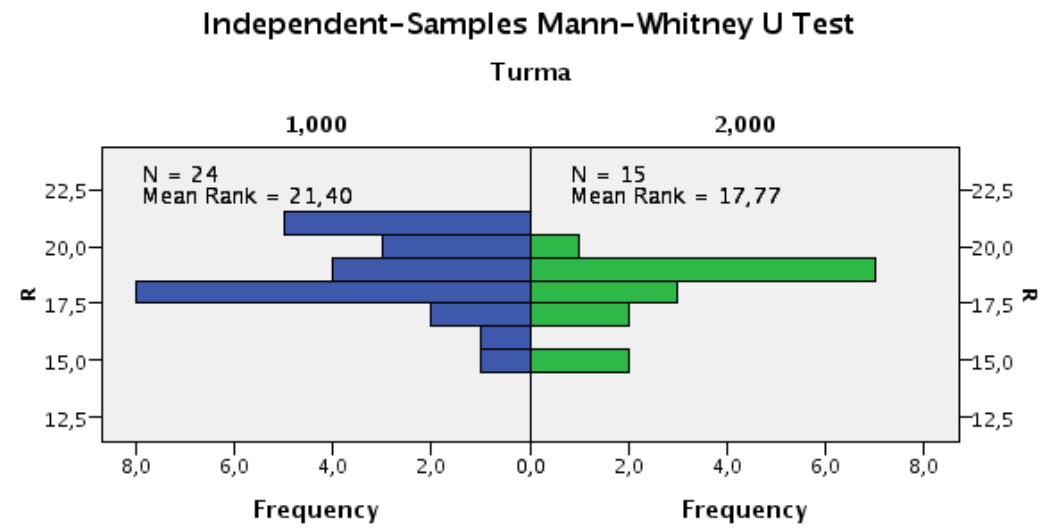

\begin{tabular}{|lr|}
\hline Total N & 39 \\
\hline Mann-Whitney U & 146,500 \\
\hline Wilcoxon W & 266,500 \\
\hline Test Statistic & 146,500 \\
\hline Standard Error & 33,782 \\
\hline Standardized Test Statistic &,- 992 \\
\hline Asymptotic Sig. (2-sided test) &, 321 \\
\hline Exact Sig. (2-sided test) &, 338 \\
\hline
\end{tabular}

Variável Confiança:

Independent-Samples Mann-Whitney U Test Turma

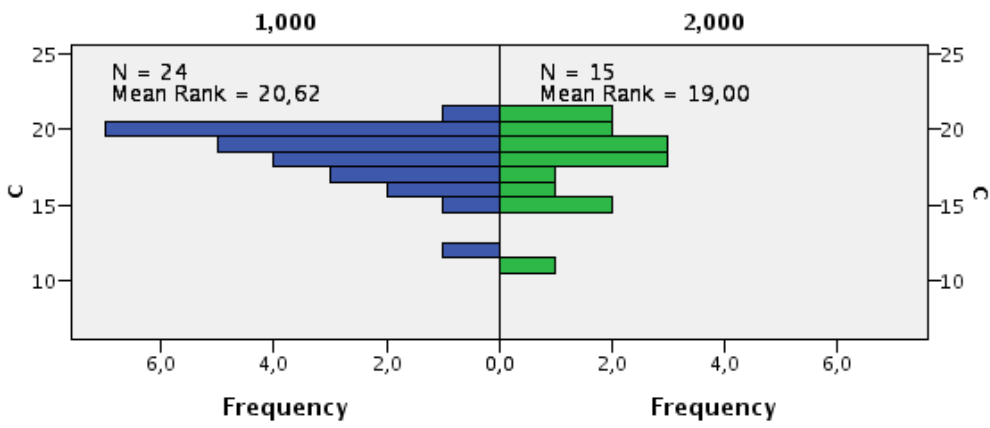

\begin{tabular}{|lr|}
\hline Total N & 39 \\
\hline Mann-Whitney U & 165,000 \\
\hline Wilcoxon W & 285,000 \\
\hline Test Statistic & 165,000 \\
\hline Standard Error & 34,143 \\
\hline Standardized Test Statistic &,- 439 \\
\hline Asymptotic Sig. (2-sided test) &, 660 \\
\hline Exact Sig. (2-sided test) &, 679 \\
\hline
\end{tabular}


Variável Satisfação:

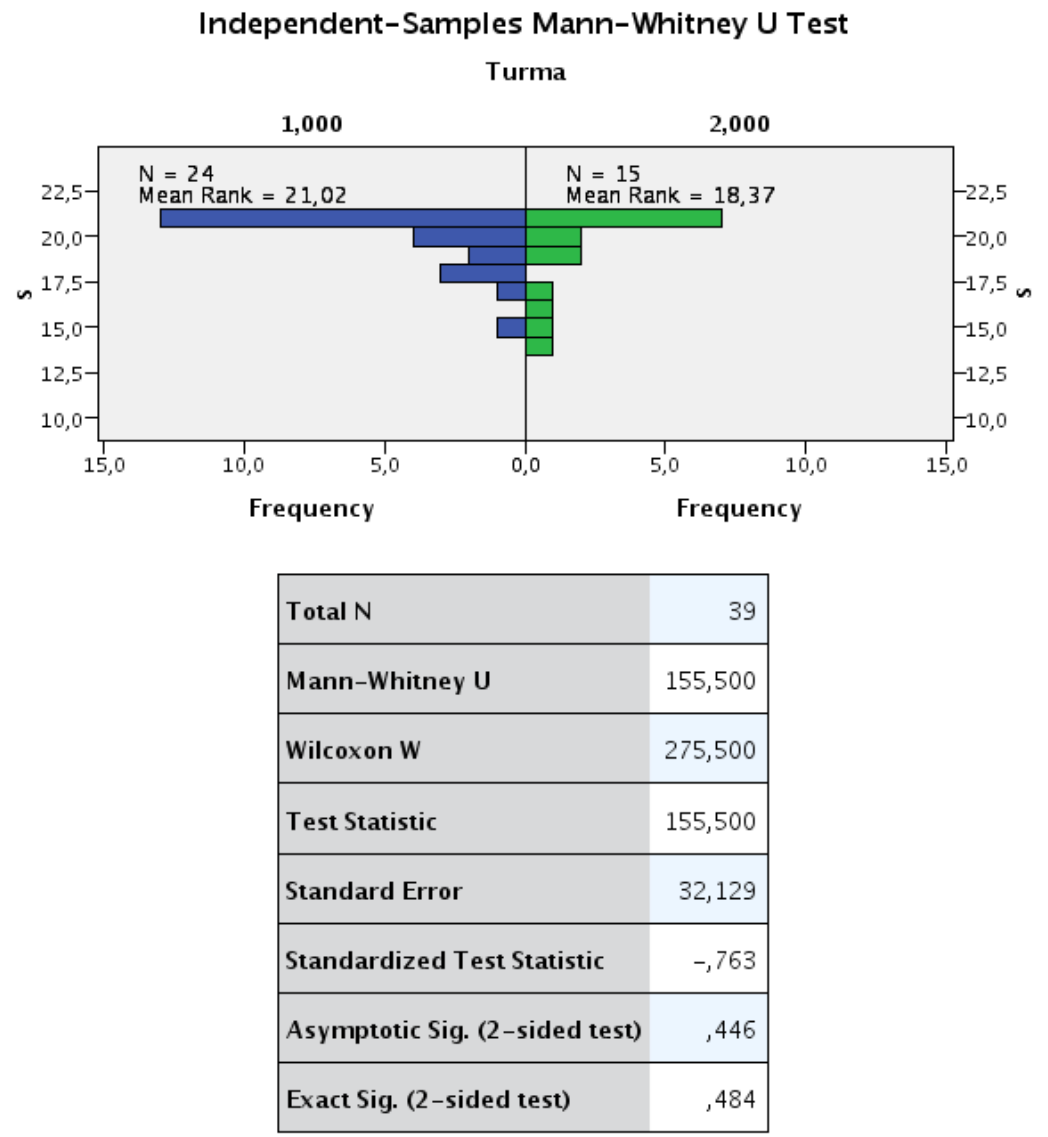


D2. Experimento 2 - modelo ARCS

Hypothesis Test Summary

\begin{tabular}{|c|c|c|c|c|}
\hline & Null Hypothesis & Test & Sig. & Decision \\
\hline 1 & $\begin{array}{l}\text { The distribution of A is the same } \\
\text { across categories of Jogo. }\end{array}$ & $\begin{array}{l}\text { Independent- } \\
\text { Samples } \\
\text { Mann- } \\
\text { Whitney U } \\
\text { Test }\end{array}$ &, $076^{1}$ & $\begin{array}{l}\text { Retain the } \\
\text { null } \\
\text { hypothesis. }\end{array}$ \\
\hline 2 & $\begin{array}{l}\text { The distribution of } \mathrm{R} \text { is the same } \\
\text { across categories of Jogo. }\end{array}$ & $\begin{array}{l}\text { Independent- } \\
\text { Samples } \\
\text { Mann- } \\
\text { Whitney U } \\
\text { Test }\end{array}$ &, $065^{1}$ & $\begin{array}{l}\text { Retain the } \\
\text { null } \\
\text { hypothesis. }\end{array}$ \\
\hline 3 & $\begin{array}{l}\text { The distribution of } \mathrm{C} \text { is the same } \\
\text { across categories of Jogo. }\end{array}$ & $\begin{array}{l}\text { Independent- } \\
\text { Samples } \\
\text { Mann- } \\
\text { Whitney U } \\
\text { Test }\end{array}$ &, $652^{1}$ & $\begin{array}{l}\text { Retain the } \\
\text { null } \\
\text { hypothesis. }\end{array}$ \\
\hline 4 & $\begin{array}{l}\text { The distribution of } \mathrm{S} \text { is the same } \\
\text { across categories of Jogo. }\end{array}$ & $\begin{array}{l}\text { Independent- } \\
\text { Samples } \\
\text { Mann- } \\
\text { Whitney U } \\
\text { Test }\end{array}$ &, $519^{1}$ & $\begin{array}{l}\text { Retain the } \\
\text { null } \\
\text { hypothesis. }\end{array}$ \\
\hline
\end{tabular}

Asymptotic significances are displayed. The significance level is , 05 .

1 Exact significance is displayed for this test.

Variável Atenção:

Independent-Samples Mann-Whitney U Test

Jogo

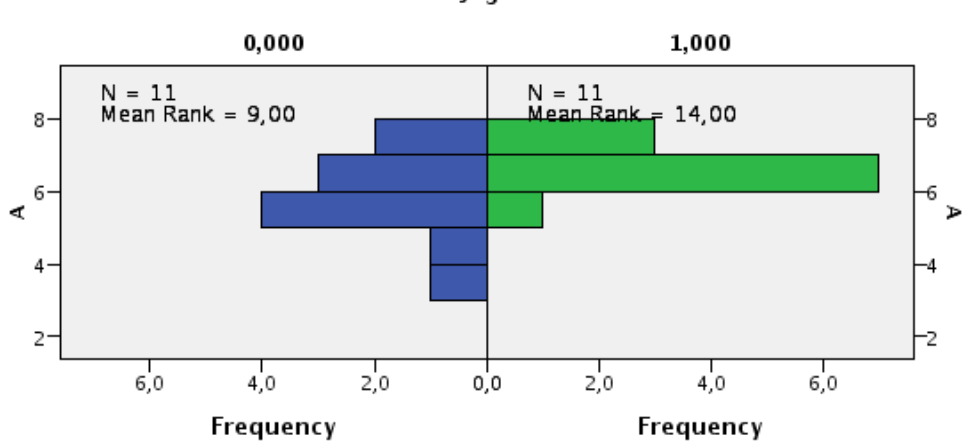

\begin{tabular}{|lr|}
\hline Total N & 22 \\
\hline Mann-Whitney U & 88,000 \\
\hline Wilcoxon W & 154,000 \\
\hline Test Statistic & 88,000 \\
\hline Standard Error & 15,108 \\
\hline Standardized Test Statistic & 1,820 \\
\hline Asymptotic Sig. (2-sided test) &, 069 \\
\hline Exact Sig. (2-sided test) &, 076 \\
\hline
\end{tabular}


Variável Relevância

Independent-Samples Mann-Whitney U Test

Jogo

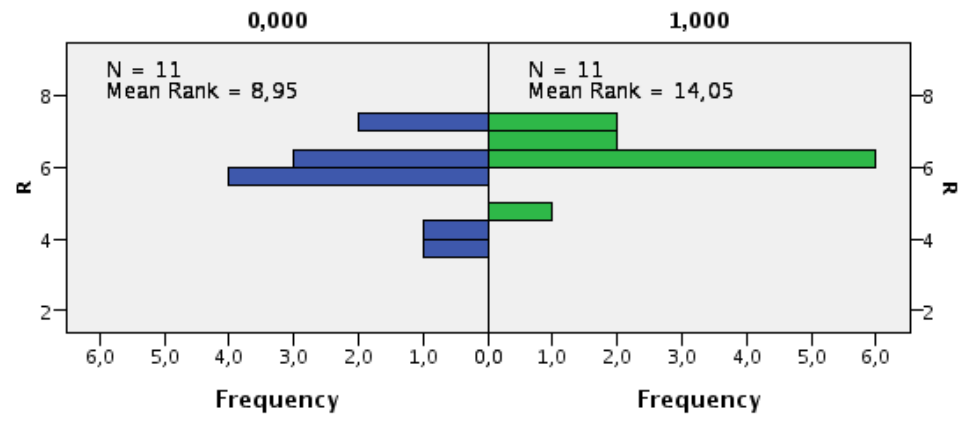

\begin{tabular}{|lr|}
\hline Total N & 22 \\
\hline Mann-Whitney U & 88,500 \\
\hline Wilcoxon W & 154,500 \\
\hline Test Statistic & 88,500 \\
\hline Standard Error & 15,082 \\
\hline Standardized Test Statistic & 1,857 \\
\hline Asymptotic Sig. (2-sided test) &, 063 \\
\hline Exact Sig. (2-sided test) &, 065 \\
\hline
\end{tabular}

Variável Confiança:

Independent-Samples Mann-Whitney U Test

Jogo

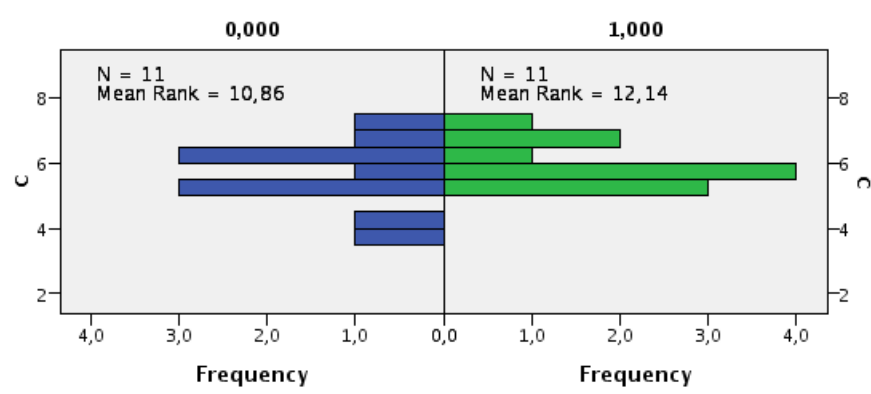

\begin{tabular}{|lr|}
\hline Total N & 22 \\
\hline Mann-Whitney U & 67,500 \\
\hline Wilcoxon W & 133,500 \\
\hline Test Statistic & 67,500 \\
\hline Standard Error & 15,181 \\
\hline Standardized Test Statistic &, 461 \\
\hline Asymptotic Sig. (2-sided test) &, 645 \\
\hline Exact Sig. (2-sided test) &, 652 \\
\hline
\end{tabular}


Variável Satisfação:

Independent-Samples Mann-Whitney U Test

Jogo

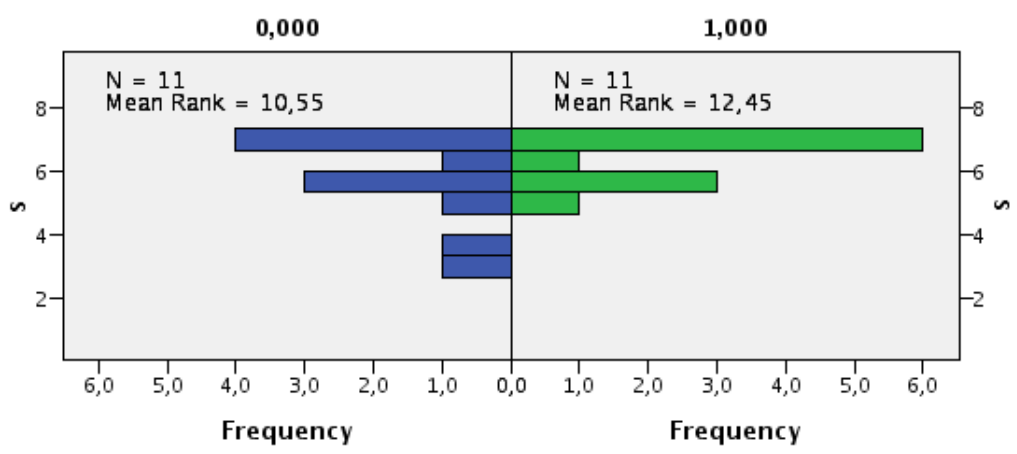

\begin{tabular}{|lr|}
\hline Total N & 22 \\
\hline Mann-Whitney U & 71,000 \\
\hline Wilcoxon W & 137,000 \\
\hline Test Statistic & 71,000 \\
\hline Standard Error & 15,043 \\
\hline Standardized Test Statistic &, 698 \\
\hline Asymptotic Sig. (2-sided test) &, 485 \\
\hline Exact Sig. (2-sided test) &, 519 \\
\hline
\end{tabular}




\section{Apêndice E Questões utilizadas nos experimentos}

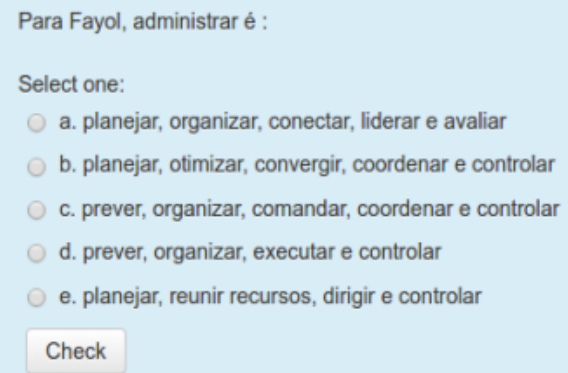

\begin{tabular}{|l|c|c|c|c|c|c|}
\hline & \multicolumn{3}{|c|}{ Experimento 1 } & \multicolumn{2}{c|}{ Experimento 2 } \\
\cline { 2 - 7 } & \multicolumn{2}{|c|}{ Pré-teste } & \multicolumn{2}{c|}{ Pós-teste } & \multicolumn{2}{c|}{ Pós-teste } \\
\hline $\begin{array}{l}\text { Acertos geral: } \\
\text { Respondentes: }\end{array}$ & \multicolumn{2}{|c|}{$\begin{array}{c}13,0 \% \\
23\end{array}$} & \multicolumn{2}{c|}{$\begin{array}{c}14,3 \% \\
21\end{array}$} & \multicolumn{2}{c|}{$\begin{array}{c}45,5 \% \\
22\end{array}$} \\
\hline & Turma 1 & $\begin{array}{c}\text { Turma 2 } \\
\text { (Jogo) }\end{array}$ & Turma 1 & $\begin{array}{c}\text { Turma 2 } \\
\text { (Jogo) }\end{array}$ & Turma 3.1 & $\begin{array}{c}\text { Turma 3.2 } \\
\text { (Jogo) }\end{array}$ \\
\cline { 2 - 7 } & $18,8 \%$ & $\begin{array}{c}0,0 \% \\
7\end{array}$ & $\begin{array}{c}13,3 \% \\
15\end{array}$ & $\begin{array}{c}16,7 \% \\
5\end{array}$ & $\begin{array}{c}45,5 \% \\
11\end{array}$ & $\begin{array}{c}45,5 \% \\
11\end{array}$ \\
\hline
\end{tabular}

A função da administração que determina os objetivos e qual a melhor maneira de atingi-los è denominada:

Select one:
a. Execuçăo
b. Organização
c. Liderança
d. Controle
e. Planejamento
Check

\begin{tabular}{|c|c|c|c|c|c|c|}
\hline & \multicolumn{4}{|c|}{ Experimento 1} & \multirow{2}{*}{\multicolumn{2}{|c|}{$\begin{array}{c}\text { Experimento } 2 \\
\text { Pós-teste }\end{array}$}} \\
\hline & \multicolumn{2}{|c|}{ Pré-teste } & \multicolumn{2}{|c|}{ Pós-teste } & & \\
\hline $\begin{array}{l}\text { Acertos geral: } \\
\text { Respondentes: }\end{array}$ & \multicolumn{2}{|c|}{$\begin{array}{c}81,3 \% \\
16\end{array}$} & \multicolumn{2}{|c|}{$\begin{array}{c}85,7 \% \\
21\end{array}$} & \multicolumn{2}{|c|}{$\begin{array}{c}77,3 \% \\
22\end{array}$} \\
\hline & Turma 1 & $\begin{array}{c}\text { Turma } 2 \\
\text { (Jogo) }\end{array}$ & Turma 1 & $\begin{array}{c}\text { Turma } 2 \\
\text { (Jogo) }\end{array}$ & Turma 3.1 & $\begin{array}{c}\text { Turma } 3.2 \\
\text { (Jogo) }\end{array}$ \\
\hline $\begin{array}{l}\text { Acertos: } \\
\text { Respondentes: }\end{array}$ & $\begin{array}{c}80,0 \% \\
10\end{array}$ & $\begin{array}{c}83,3 \% \\
6\end{array}$ & $\begin{array}{c}85,7 \% \\
14\end{array}$ & $\begin{array}{c}85,7 \% \\
7\end{array}$ & $\begin{array}{c}72,7 \% \\
11\end{array}$ & $\begin{array}{c}81,8 \% \\
11\end{array}$ \\
\hline
\end{tabular}

Verbo: Lembrar

Nível: DoK1
Verbo: Lembrar

Nível: DoK1 
A função da administração que envolve monitorar o desempenho, comparando os

resultados com os objetivos planejados e fornecendo feedback e, se necessário, correçăo é

denominada:

Select one:

a. Organização

b. Controle

c. Execução

d. Planejamento

e. Liderança

Check
Código da Questão: PEC1.03

Verbo: Lembrar

Nível: DoK1

\begin{tabular}{|c|c|c|c|c|c|c|}
\hline & \multicolumn{4}{|c|}{ Experimento 1} & \multirow{2}{*}{\multicolumn{2}{|c|}{$\begin{array}{c}\text { Experimento } 2 \\
\text { Pós-teste }\end{array}$}} \\
\hline & \multicolumn{2}{|c|}{ Pré-teste } & \multicolumn{2}{|c|}{ Pós-teste } & & \\
\hline $\begin{array}{l}\text { Acertos geral: } \\
\text { Respondentes: }\end{array}$ & \multicolumn{2}{|c|}{$\begin{array}{c}56,5 \% \\
23\end{array}$} & \multicolumn{2}{|c|}{$\begin{array}{c}70,0 \% \\
20\end{array}$} & \multicolumn{2}{|c|}{$\begin{array}{c}72,7 \% \\
22\end{array}$} \\
\hline & Turma 1 & $\begin{array}{c}\text { Turma } 2 \\
\text { (Jogo) }\end{array}$ & Turma 1 & $\begin{array}{c}\text { Turma } 2 \\
\text { (Jogo) }\end{array}$ & Turma 3.1 & $\begin{array}{c}\text { Turma } 3.2 \\
\text { (Jogo) }\end{array}$ \\
\hline $\begin{array}{l}\text { Acertos: } \\
\text { Respondentes: }\end{array}$ & $\begin{array}{c}53,5 \% \\
15\end{array}$ & $\begin{array}{c}62,5 \% \\
8\end{array}$ & $\begin{array}{c}63,3 \% \\
11\end{array}$ & $\begin{array}{c}77,8 \% \\
9\end{array}$ & $\begin{array}{c}63,6 \% \\
11\end{array}$ & $\begin{array}{c}81,8 \% \\
11\end{array}$ \\
\hline
\end{tabular}

A função da administração relacionada com ensinar pelos exemplos, dirigir e motivar os

funcionários a ter um desempenho efetivo para atingir os objetivos da organização é

denominada:

Código da Questão: PEC1.04

Select one:

Verbo: Lembrar

a. Execução

b. Planejamento

c. Organização

d. Controle

e. Liderança

Check

Nível: DoK1

\begin{tabular}{|l|c|c|c|c|c|c|}
\hline & \multicolumn{3}{|c|}{ Experimento 1 } & \multicolumn{2}{c|}{ Experimento 2 } \\
\cline { 2 - 7 } & \multicolumn{2}{|c|}{ Pré-teste } & \multicolumn{2}{c|}{ Pós-teste } & \multicolumn{2}{c|}{ Pós-teste } \\
\hline \multirow{2}{*}{$\begin{array}{l}\text { Acertos geral: } \\
\text { Respondentes: }\end{array}$} & \multicolumn{2}{|c|}{$\begin{array}{c}85,7 \% \\
14\end{array}$} & \multicolumn{2}{c|}{$\begin{array}{c}6,7 \% \\
15\end{array}$} & \multicolumn{2}{c|}{$\begin{array}{c}86,4 \% \\
22\end{array}$} \\
\hline & Turma 1 & $\begin{array}{c}\text { Turma 2 } \\
\text { (Jogo) }\end{array}$ & Turma 1 & $\begin{array}{c}\text { Turma 2 } \\
\text { (Jogo) }\end{array}$ & Turma 3.1 & $\begin{array}{c}\text { Turma 3.2 } \\
\text { (Jogo) }\end{array}$ \\
\cline { 2 - 7 } & $71,4 \%$ & $\begin{array}{c}100 \% \\
7\end{array}$ & $\begin{array}{c}66,7 \% \\
6\end{array}$ & $\begin{array}{c}66,7 \% \\
9\end{array}$ & $\begin{array}{c}72,7 \% \\
11\end{array}$ & $\begin{array}{c}100 \% \\
11\end{array}$ \\
\hline $\begin{array}{l}\text { Acertos: } \\
\text { Respondentes: }\end{array}$ & 7 & 7 & & & \\
\hline
\end{tabular}


A função da administração que providencia a equipe adequada e atribui as

responsabilidades e tarefas aos individuos e grupos, de forma a melhor atingir os objetivos

é denominada:

Select one:

a. Execução

b. Liderança

c. Organização

d. Controle

e. Planejamento

Check
Código da Questão: PEC1.05

Verbo: Lembrar

Nivel: DoK1

\begin{tabular}{|c|c|c|c|c|c|c|}
\hline & \multicolumn{4}{|c|}{ Experimento 1} & \multirow{2}{*}{\multicolumn{2}{|c|}{$\begin{array}{c}\text { Experimento } 2 \\
\underline{\text { Pós-teste }}\end{array}$}} \\
\hline & \multicolumn{2}{|c|}{ Pré-teste } & \multicolumn{2}{|c|}{ Pós-teste } & & \\
\hline $\begin{array}{l}\text { Acertos geral: } \\
\text { Respondentes: }\end{array}$ & \multicolumn{2}{|c|}{$\begin{array}{c}30,0 \% \\
20\end{array}$} & \multicolumn{2}{|c|}{$\begin{array}{c}50,0 \% \\
20\end{array}$} & \multicolumn{2}{|c|}{$\begin{array}{c}40,9 \% \\
22\end{array}$} \\
\hline & Turma 1 & $\begin{array}{c}\text { Turma } 2 \\
\text { (Jogo) }\end{array}$ & Turma 1 & $\begin{array}{c}\text { Turma } 2 \\
\text { (Jogo) }\end{array}$ & Turma 3.1 & $\begin{array}{c}\text { Turma } 3.2 \\
\text { (Jogo) }\end{array}$ \\
\hline $\begin{array}{l}\text { Acertos: } \\
\text { Respondentes: }\end{array}$ & $\begin{array}{c}41,7 \% \\
12\end{array}$ & $\begin{array}{c}12,5 \% \\
8\end{array}$ & $\begin{array}{c}53,8 \% \\
13\end{array}$ & $\begin{array}{c}42,9 \% \\
7\end{array}$ & $\begin{array}{c}27,3 \% \\
11\end{array}$ & $\begin{array}{c}54,5 \% \\
11\end{array}$ \\
\hline
\end{tabular}

Costuma-se dizer atualmente que as funções do administrador são:

Select one:

a. monitorar, organizar, controlar e avaliar funcionários

b. planejar, controlar, alocar recursos e definir objetivos

c. monitorar, controlar, avaliar e comandar funcionảrios.

d. planejar, organizar, controlar e liderar funcionários.

\section{Check}

Código da Questão: PEC1.06

Verbo: Lembrar

Nivel: DoK1

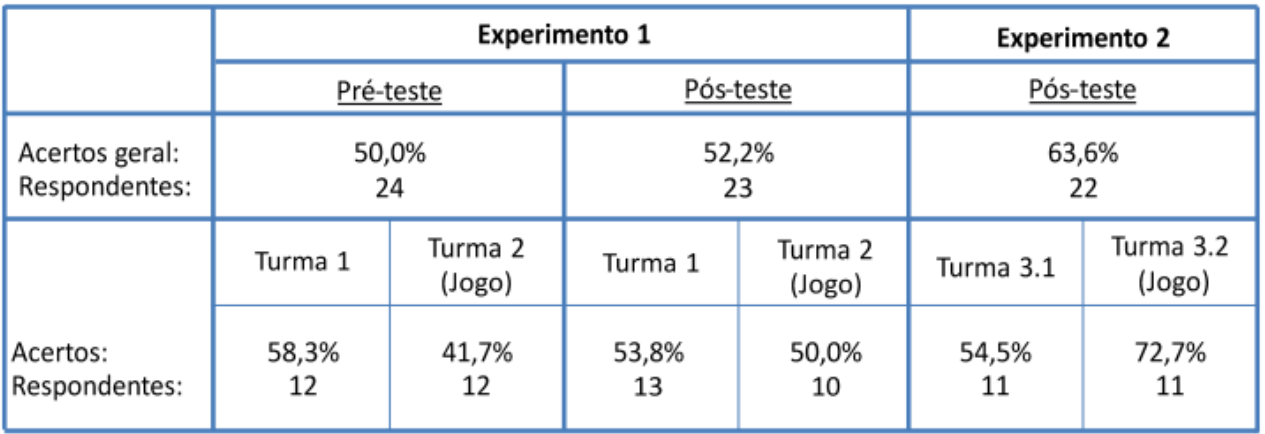




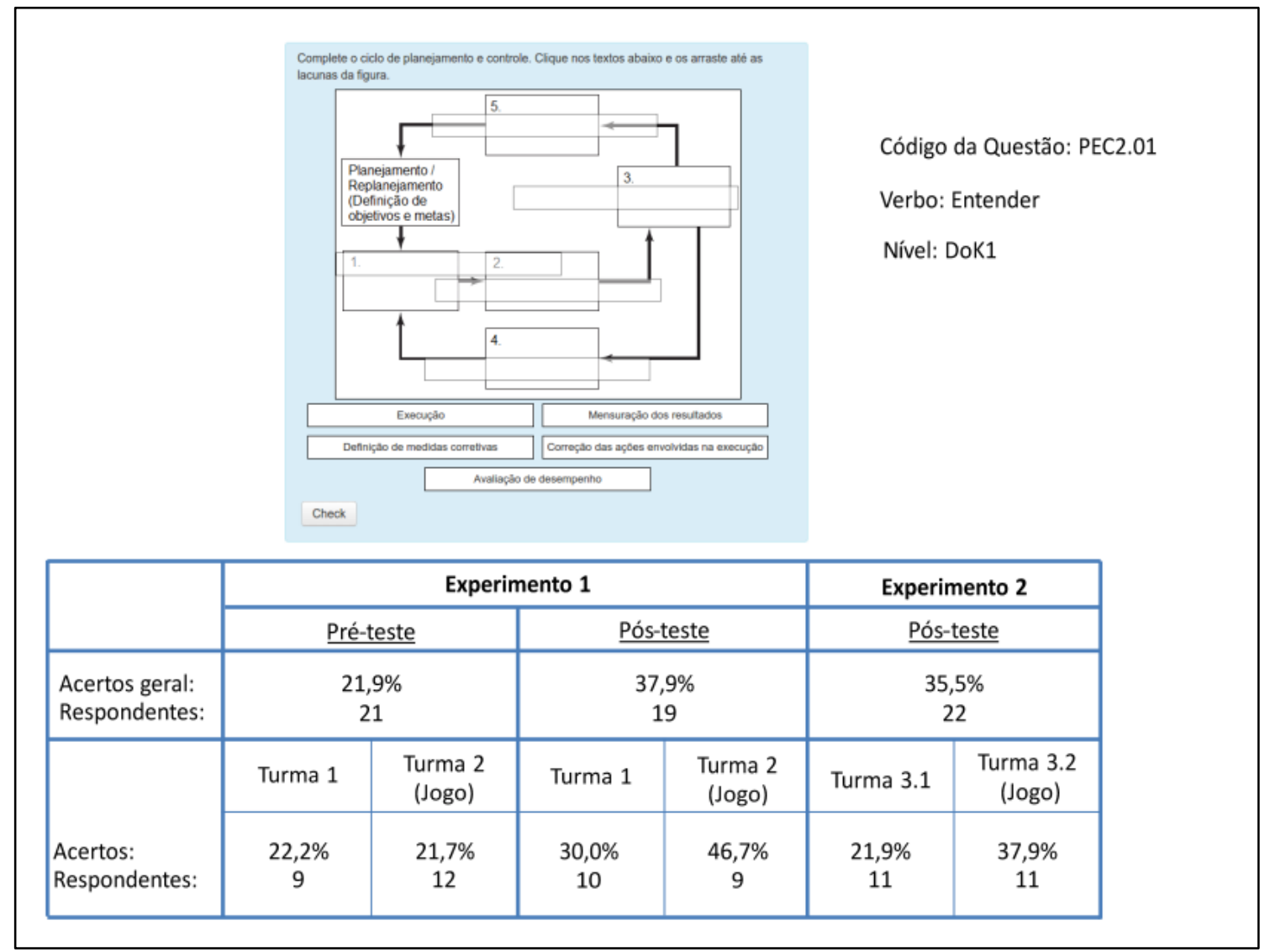

Identifique a sequência correta dos passos no ciclo de planejamento-execução-controle. Clique nos textos abaixo e os arraste até os números.

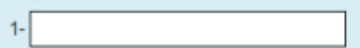

Código da Questão: PEC2.02

2-

3-

Verbo: Entender

$4-$

Nível: DoK1

5

Comparação do real com o planejado Mensuração do desempenho

\begin{tabular}{|c|c|}
\hline Desempenho real & Plano de açōes corretivas \\
\hline
\end{tabular}

Análise das causas das diferenças

Check

\begin{tabular}{|c|c|c|c|c|c|c|}
\hline & \multicolumn{4}{|c|}{ Experimento 1} & \multirow{2}{*}{\multicolumn{2}{|c|}{$\begin{array}{c}\text { Experimento } 2 \\
\underline{\text { Pós-teste }}\end{array}$}} \\
\hline & \multicolumn{2}{|c|}{ Pré-teste } & \multicolumn{2}{|c|}{ Pós-teste } & & \\
\hline $\begin{array}{l}\text { Acertos geral: } \\
\text { Respondentes: }\end{array}$ & \multicolumn{2}{|c|}{$\begin{array}{c}35,8 \% \\
19\end{array}$} & \multicolumn{2}{|c|}{$\begin{array}{c}31,4 \% \\
21\end{array}$} & \multicolumn{2}{|c|}{ - } \\
\hline & Turma 1 & $\begin{array}{c}\text { Turma } 2 \\
\text { (Jogo) }\end{array}$ & Turma 1 & $\begin{array}{c}\text { Turma } 2 \\
\text { (Jogo) }\end{array}$ & Turma 3.1 & $\begin{array}{c}\text { Turma } 3.2 \\
\text { (Jogo) }\end{array}$ \\
\hline $\begin{array}{l}\text { Acertos: } \\
\text { Respondentes: }\end{array}$ & $\begin{array}{c}41,3 \% \\
15\end{array}$ & $\begin{array}{c}15,0 \% \\
4\end{array}$ & $\begin{array}{c}34,3 \% \\
14\end{array}$ & $\begin{array}{c}25,7 \% \\
7\end{array}$ & - & - \\
\hline
\end{tabular}


Daniel gerencia um time que não atingiu os objetivos de produção nos últimos três meses. Após analisar o registro de desempenho de cada funcionário, ele ajustou os objetivos de vendas para levar em consideração medidas adicionais de controle de qualidade. Por que esse é um exemplo da função "controlar"?

Select one:

a. Porque é o único elemento que é importante para desenvolver a estratégia de longo prazo da empresa

b. Porque alguém provavelmente será demitido com o resultado dessa análise

c. Porque medidas adicionais de controle preparam o caminho para potenciais medidas corretivas

d. Porque Daniel agiu como um lider e assumiu a responsabilidade pelo projeto

Check

Código da Questão: PEC3.01

Verbo: Entender

Nivel: DoK1

\begin{tabular}{|c|c|c|c|c|c|c|}
\hline & \multicolumn{4}{|c|}{ Experimento 1} & \multirow{2}{*}{\multicolumn{2}{|c|}{$\begin{array}{c}\text { Experimento } 2 \\
\text { Pós-teste }\end{array}$}} \\
\hline & \multicolumn{2}{|c|}{ Pré-teste } & \multicolumn{2}{|c|}{ Pós-teste } & & \\
\hline $\begin{array}{l}\text { Acertos geral: } \\
\text { Respondentes: }\end{array}$ & \multicolumn{2}{|c|}{$\begin{array}{c}81,8 \% \\
22\end{array}$} & \multicolumn{2}{|c|}{$\begin{array}{c}75,0 \% \\
20\end{array}$} & \multicolumn{2}{|c|}{$\begin{array}{c}81,8 \% \\
22\end{array}$} \\
\hline & Turma 1 & $\begin{array}{l}\text { Turma } 2 \\
\text { (Jogo) }\end{array}$ & Turma 1 & $\begin{array}{c}\text { Turma } 2 \\
\text { (Jogo) }\end{array}$ & Turma 3.1 & $\begin{array}{c}\text { Turma } 3.2 \\
\text { (Jogo) }\end{array}$ \\
\hline $\begin{array}{l}\text { Acertos: } \\
\text { Respondentes: }\end{array}$ & $\begin{array}{c}81,8 \% \\
11\end{array}$ & $\begin{array}{c}81,8 \% \\
11\end{array}$ & $\begin{array}{c}80,0 \% \\
15\end{array}$ & $\begin{array}{c}60,0 \% \\
5\end{array}$ & $\begin{array}{c}81,8 \% \\
11\end{array}$ & $\begin{array}{c}81,8 \% \\
11\end{array}$ \\
\hline
\end{tabular}

Identifique qual alternativa é um exemplo da função "organizar":

Select one:

a. Tom é o diretor de uma grande empresa de tecnologia da informação e está tentando determinar como seus funcionários desempenharam no último trimestre.

b. Tom é o gerente em uma empresa de relações públicas e está tentando determinar quais pessoas ele deve contratar para trabalhar numa nova linha promocional.

c. Tom é um gerente de projetos em uma empresa de Tecnologia da Informação e está definindo como ele deve distribuir os recursos e alocar os papéis de cada funcionário

d.

Tom é um advogado em uma grande empresa de relaçöes públicas e está preparando todos os seus colegas sobre os testemunhos que eles precisarão dar.

Check

Verbo: Entender

Nível: DoK1

\begin{tabular}{|c|c|c|c|c|c|c|}
\hline & \multicolumn{4}{|c|}{ Experimento 1} & \multirow{2}{*}{\multicolumn{2}{|c|}{$\begin{array}{c}\text { Experimento } 2 \\
\text { Pós-teste }\end{array}$}} \\
\hline & \multicolumn{2}{|c|}{ Pré-teste } & \multicolumn{2}{|c|}{ Pós-teste } & & \\
\hline $\begin{array}{l}\text { Acertos geral: } \\
\text { Respondentes: }\end{array}$ & \multicolumn{2}{|c|}{$\begin{array}{c}72,7 \% \\
19\end{array}$} & \multicolumn{2}{|c|}{$\begin{array}{c}84,2 \% \\
19\end{array}$} & \multicolumn{2}{|c|}{$\begin{array}{c}81,8 \% \\
22\end{array}$} \\
\hline & Turma 1 & $\begin{array}{c}\text { Turma } 2 \\
\text { (Jogo) }\end{array}$ & Turma 1 & $\begin{array}{c}\text { Turma } 2 \\
\text { (Jogo) }\end{array}$ & Turma 3.1 & $\begin{array}{c}\text { Turma } 3.2 \\
\text { (Jogo) }\end{array}$ \\
\hline $\begin{array}{l}\text { Acertos: } \\
\text { Respondentes: }\end{array}$ & $\begin{array}{c}72,7 \% \\
11\end{array}$ & $\begin{array}{c}75 \% \\
8\end{array}$ & $\begin{array}{c}83,3 \% \\
12\end{array}$ & $\begin{array}{c}85,7 \% \\
7\end{array}$ & $\begin{array}{c}81,8 \% \\
11\end{array}$ & $\begin{array}{c}81,8 \% \\
11\end{array}$ \\
\hline
\end{tabular}


Diz-se que a única coisa que é permanente no mundo é a mudança. Uma mudança pode ocorrer no ambiente interno ou externo de uma organização, não importando o que os gestores façam. O planejamento não pode eliminar a mudança, mas os gestores usualmente usam os planos para

Código da Questão: PEC3.03

Select one: Verbo: Analisar

a. se proteger de mudanças repentinas que sejam feitas pela alta gestão

b. antecipar mudanças e desenvolver formas efetivas de responder a elas

c. estar preparados para quando as mudanças na alta gestão acontecerem

d. ter os materiais adequados disponiveis quando a demanda por eles chegar

e. decidir o que precise ser feito quando uma mudança no ambiente acontecer

Check

Nível: DoK2

\begin{tabular}{|c|c|c|c|c|c|c|}
\hline & \multicolumn{4}{|c|}{ Experimento 1} & \multirow{2}{*}{\multicolumn{2}{|c|}{$\begin{array}{c}\text { Experimento } 2 \\
\underline{\text { Pós-teste }}\end{array}$}} \\
\hline & \multicolumn{2}{|c|}{ Pré-teste } & \multicolumn{2}{|c|}{ Pós-teste } & & \\
\hline $\begin{array}{l}\text { Acertos geral: } \\
\text { Respondentes: }\end{array}$ & \multicolumn{2}{|c|}{$\begin{array}{c}29,4 \% \\
17\end{array}$} & \multicolumn{2}{|c|}{$\begin{array}{c}57,1 \% \\
21\end{array}$} & \multicolumn{2}{|c|}{$\begin{array}{c}31,8 \% \\
22\end{array}$} \\
\hline & Turma 1 & $\begin{array}{c}\text { Turma } 2 \\
\text { (Jogo) }\end{array}$ & Turma 1 & $\begin{array}{c}\text { Turma } 2 \\
\text { (Jogo) }\end{array}$ & Turma 3.1 & $\begin{array}{c}\text { Turma } 3.2 \\
\text { (Jogo) }\end{array}$ \\
\hline $\begin{array}{l}\text { Acertos: } \\
\text { Respondentes: }\end{array}$ & $\begin{array}{c}35,7 \% \\
14\end{array}$ & $\begin{array}{c}0,0 \% \\
3\end{array}$ & $\begin{array}{c}45,5 \% \\
11\end{array}$ & $\begin{array}{c}70,0 \% \\
10\end{array}$ & $\begin{array}{c}27,3 \% \\
11\end{array}$ & $\begin{array}{c}36,4 \% \\
11\end{array}$ \\
\hline
\end{tabular}

Um gestor público decide contratar um serviço para sua unidade e inicia um processo junto ao departamento de compras. Ele pesquisa as melhores alternativas e escreve um edital detalhado de tudo o que precisa. No entanto, na hora de aprovarem o processo licitatório do serviço, o gestor é informado de que não havia "dotação" em sua unidade para aquela contratação, que é cancelada. Em que função administrativa foi a maior falha do gestor?

\section{Select one:}

a. Na liderança, pois deveria ter persuadido seus superiores de que o serviço era importante

b. No planejamento, pois deveria ter incluido o serviço no orçamento daquele ano

c. No staffing, pois se tivesse uma equipe competente, teria sido avisado antes de iniciar o processo

d. Na organização, pois não verificou a dotação antes de demandar o serviço

e. No controle, pois deveria ter acompanhado de perto todos os passos do processo de contratação na secretaria

Check

Código da Questão: PEC3.04

Verbo: Analisar

Nível: DoK2

\begin{tabular}{|c|c|c|c|c|c|c|}
\hline & \multicolumn{4}{|c|}{ Experimento 1} & \multirow{2}{*}{\multicolumn{2}{|c|}{$\begin{array}{c}\text { Experimento } 2 \\
\underline{\text { Pós-teste }}\end{array}$}} \\
\hline & \multicolumn{2}{|c|}{ Pré-teste } & \multicolumn{2}{|c|}{ Pós-teste } & & \\
\hline $\begin{array}{l}\text { Acertos geral: } \\
\text { Respondentes: }\end{array}$ & \multicolumn{2}{|c|}{$\begin{array}{c}31,8 \% \\
22\end{array}$} & \multicolumn{2}{|c|}{$\begin{array}{c}60,0 \% \\
20\end{array}$} & \multicolumn{2}{|c|}{$\begin{array}{c}63,6 \% \\
22\end{array}$} \\
\hline & Turma 1 & $\begin{array}{c}\text { Turma } 2 \\
\text { (Jogo) }\end{array}$ & Turma 1 & $\begin{array}{c}\text { Turma } 2 \\
\text { (Jogo) }\end{array}$ & Turma 3.1 & $\begin{array}{c}\text { Turma } 3.2 \\
\text { (Jogo) }\end{array}$ \\
\hline $\begin{array}{l}\text { Acertos: } \\
\text { Respondentes: }\end{array}$ & $\begin{array}{c}33,3 \% \\
12\end{array}$ & $\begin{array}{c}30,0 \% \\
10\end{array}$ & $\begin{array}{c}60,0 \% \\
10\end{array}$ & $\begin{array}{c}60,0 \% \\
10\end{array}$ & $\begin{array}{c}63,6 \% \\
11\end{array}$ & $\begin{array}{c}63,6 \% \\
11\end{array}$ \\
\hline
\end{tabular}




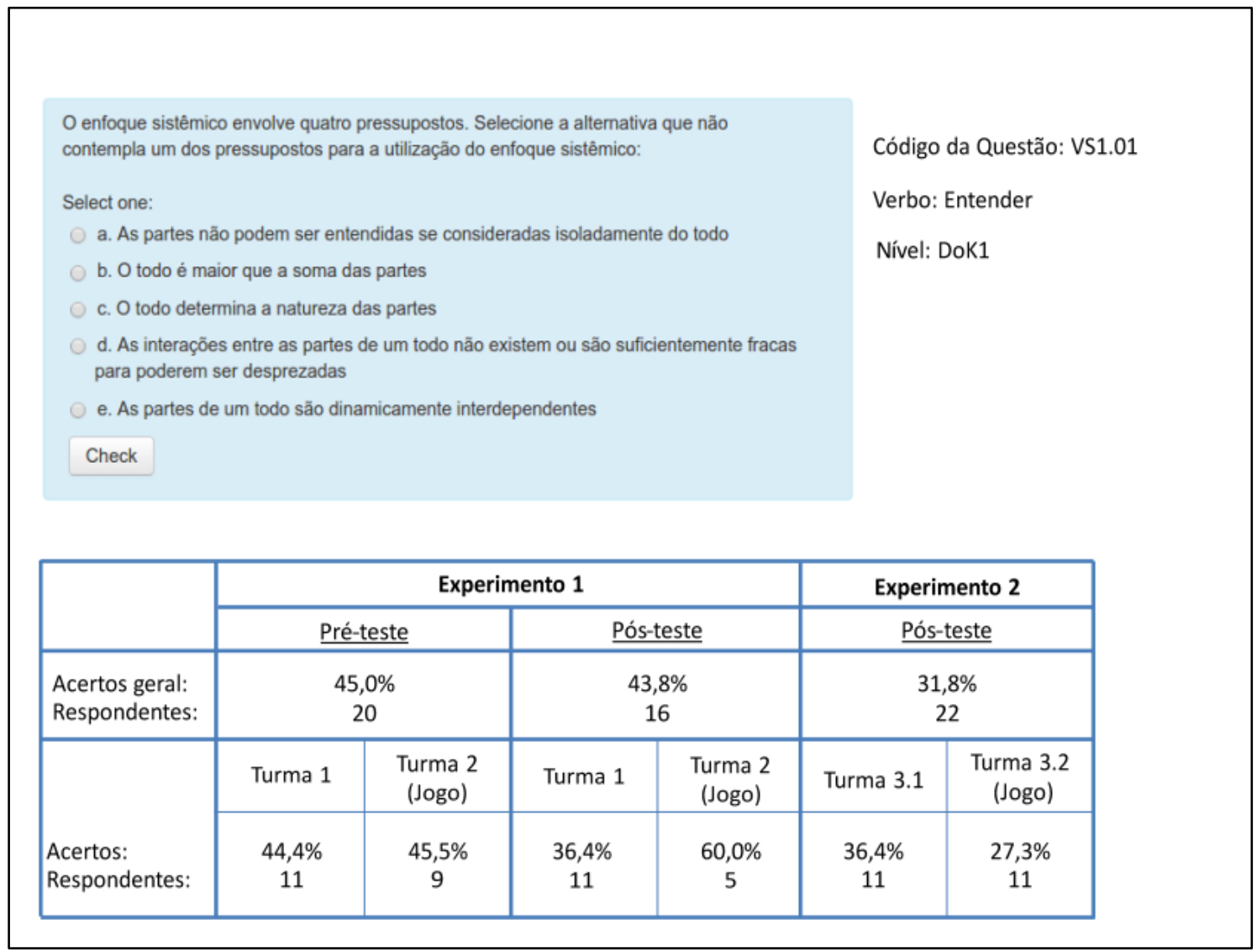

\begin{tabular}{|c|c|c|c|c|c|c|}
\hline \multicolumn{5}{|c|}{$\begin{array}{l}\text { A presença dos componentes Entrada, Processamento, Saida, Objetivo e Feedback } \\
\text { (retroalimentação) è caracteristica de: }\end{array}$} & \multicolumn{2}{|c|}{ Código da Questão: VS1.02 } \\
\hline a. Modelos burocráticos & \multicolumn{4}{|c|}{ Select one: } & \multicolumn{2}{|c|}{ Nível: DoK1 } \\
\hline \multicolumn{5}{|c|}{ b. Processo administrativo } & & \\
\hline \multicolumn{5}{|c|}{ c. Sistema Aberto } & & \\
\hline \multicolumn{5}{|l|}{ d. Estrutura } & & \\
\hline \multicolumn{5}{|c|}{ e. Inovação fechada } & & \\
\hline \multirow[t]{3}{*}{ Check } & & & & & & \\
\hline & \multicolumn{4}{|c|}{ Experimento 1} & \multicolumn{2}{|c|}{ Experimento 2} \\
\hline & \multicolumn{2}{|c|}{ Pré-teste } & \multicolumn{2}{|c|}{ Pós-teste } & \multicolumn{2}{|c|}{ Pós-teste } \\
\hline $\begin{array}{l}\text { Acertos geral: } \\
\text { Respondentes: }\end{array}$ & \multicolumn{2}{|c|}{$\begin{array}{c}41,2 \% \\
17\end{array}$} & \multicolumn{2}{|c|}{$\begin{array}{c}41,7 \% \\
24\end{array}$} & \multicolumn{2}{|c|}{-} \\
\hline & Turma 1 & $\begin{array}{c}\text { Turma } 2 \\
\text { (Jogo) }\end{array}$ & Turma 1 & $\begin{array}{c}\text { Turma } 2 \\
\text { (Jogo) }\end{array}$ & Turma 3.1 & $\begin{array}{l}\text { Turma } 3.2 \\
\text { (Jogo) }\end{array}$ \\
\hline Acertos: & $45,5 \%$ & $33,3 \%$ & $50,0 \%$ & $30,0 \%$ & - & - \\
\hline Respondentes: & 11 & 6 & 14 & 10 & - & - \\
\hline
\end{tabular}


Uma organização pode ser definida como um sistema aberto pois

I. Tem partes inter-relacionadas e interdependentes (departamentos e divisões) que

funcionam como um todo

II. Recebe inputs (entradas) e distribui outputs (saidas) ao ambiente externo

III. Impacta e è impactada pelo ambiente externo

IV. É estruturada e deterministica.

Estão corretas apenas as afirmações

Select one:

a. III e IV

b. II e III

c. Ie II

d. I, II e III

e. I, II e IV

Check

Código da Questão: VS1.03

Verbo: Entender

Nível: DoK1

\begin{tabular}{|c|c|c|c|c|c|c|}
\hline & \multicolumn{4}{|c|}{ Experimento 1} & \multirow{2}{*}{\multicolumn{2}{|c|}{$\begin{array}{c}\text { Experimento } 2 \\
\text { Pós-teste }\end{array}$}} \\
\hline & \multicolumn{2}{|c|}{ Pré-teste } & \multicolumn{2}{|c|}{ Pós-teste } & & \\
\hline $\begin{array}{l}\text { Acertos geral: } \\
\text { Respondentes: }\end{array}$ & \multicolumn{2}{|c|}{$\begin{array}{c}61,9 \% \\
21\end{array}$} & \multicolumn{2}{|c|}{$\begin{array}{c}68,8 \% \\
16\end{array}$} & \multicolumn{2}{|c|}{$\begin{array}{c}72,7 \% \\
22\end{array}$} \\
\hline & Turma 1 & $\begin{array}{c}\text { Turma } 2 \\
\text { (Jogo) }\end{array}$ & Turma 1 & $\begin{array}{c}\text { Turma } 2 \\
\text { (Jogo) }\end{array}$ & Turma 3.1 & $\begin{array}{c}\text { Turma } 3.2 \\
\text { (Jogo) }\end{array}$ \\
\hline $\begin{array}{l}\text { Acertos: } \\
\text { Respondentes: }\end{array}$ & $\begin{array}{c}78,6 \% \\
14\end{array}$ & $\begin{array}{c}28,6 \% \\
7\end{array}$ & $\begin{array}{c}66,7 \% \\
9\end{array}$ & $\begin{array}{c}71,4 \% \\
7\end{array}$ & $\begin{array}{c}63,6 \% \\
11\end{array}$ & $\begin{array}{c}81,8 \% \\
11\end{array}$ \\
\hline
\end{tabular}

Observe a seguinte lista de caracteristicas:

I. É perfeitamente deterministico e previsivel.

II. Não há troca entre o sistema e o ambiente externo

III. Representa uma visão realista.

IV. É flexivel e adaptável.

São caracteristicas de um sistema fechado apenas as opçōes:

Select one:

a. I elI

b. III e IV

c. II e III

d. I, II e III

e. I IV

Check

Código da Questão: VS1.04

Verbo: Entender

Nível: DoK1

\begin{tabular}{|c|c|c|c|c|c|c|}
\hline & \multicolumn{4}{|c|}{ Experimento 1} & \multirow{2}{*}{\multicolumn{2}{|c|}{$\begin{array}{c}\text { Experimento } 2 \\
\text { Pós-teste }\end{array}$}} \\
\hline & \multicolumn{2}{|c|}{ Pré-teste } & \multicolumn{2}{|c|}{ Pós-teste } & & \\
\hline $\begin{array}{l}\text { Acertos geral: } \\
\text { Respondentes: }\end{array}$ & \multicolumn{2}{|c|}{$\begin{array}{c}63,6 \% \\
22\end{array}$} & \multicolumn{2}{|c|}{$\begin{array}{c}50,0 \% \\
24\end{array}$} & \multicolumn{2}{|c|}{-} \\
\hline & Turma 1 & $\begin{array}{c}\text { Turma } 2 \\
\text { (Jogo) }\end{array}$ & Turma 1 & $\begin{array}{c}\text { Turma } 2 \\
\text { (Jogo) }\end{array}$ & Turma 3.1 & $\begin{array}{c}\text { Turma } 3.2 \\
\text { (Jogo) }\end{array}$ \\
\hline $\begin{array}{l}\text { Acertos: } \\
\text { Respondentes: }\end{array}$ & $\begin{array}{c}57,1 \% \\
14\end{array}$ & $\begin{array}{c}75,0 \% \\
8\end{array}$ & $\begin{array}{c}50,0 \% \\
14\end{array}$ & $\begin{array}{c}50,0 \% \\
10\end{array}$ & - & - \\
\hline
\end{tabular}



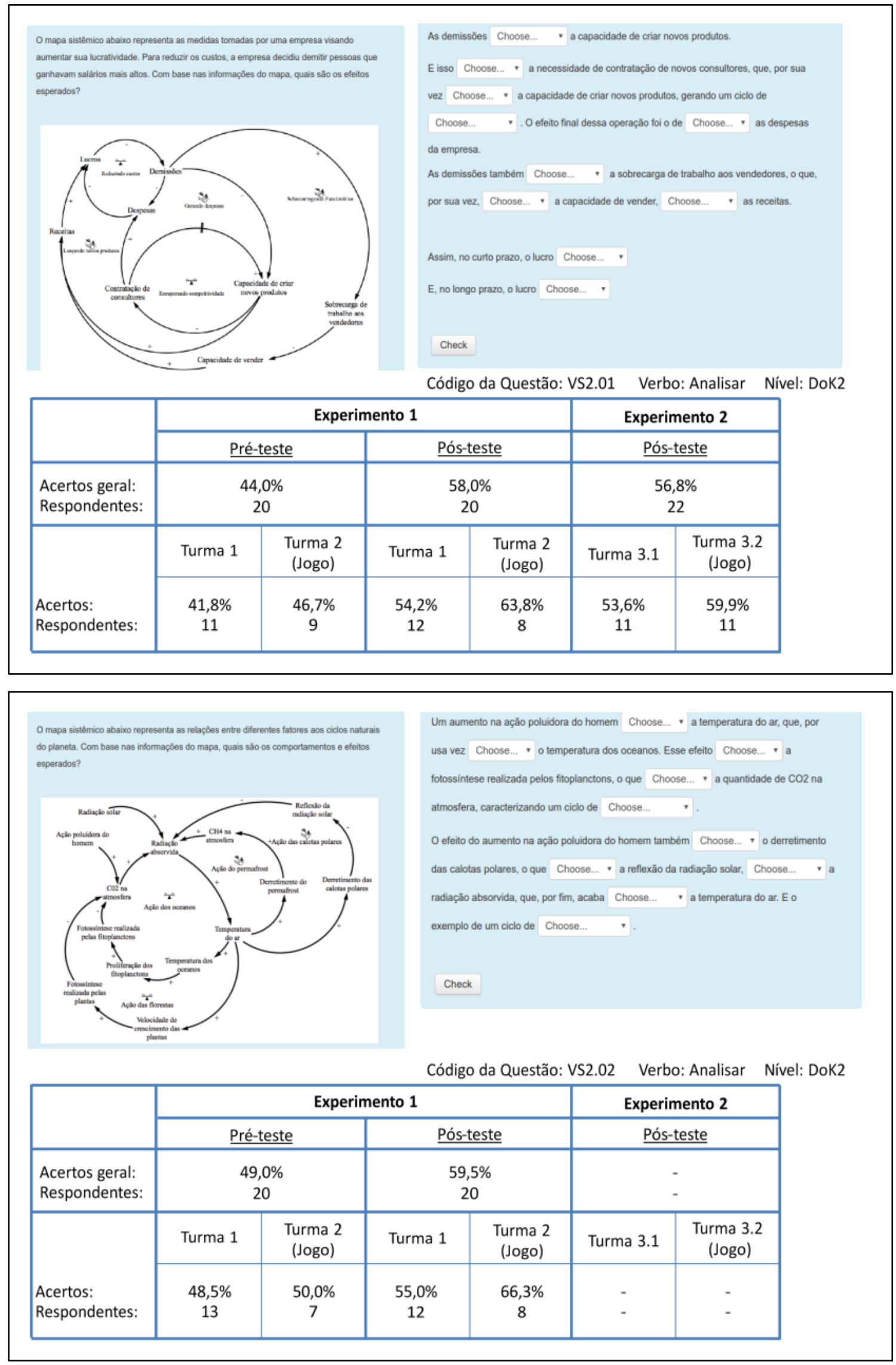
Indique a alternativa que não contém um exemplo de um papel decisorial, de acordo com a definição de Mintzberg

Código da Questão: PG1.01

Select one:

a. Empreendedor

b. Manipulador de distúrbios

c. Imagem do chefe

d. Negociador

e. alocador de recursos

Check

Verbo: Lembrar

Nível: DoK1

\begin{tabular}{|c|c|c|c|c|c|c|}
\hline & \multicolumn{4}{|c|}{ Experimento 1} & \multirow{2}{*}{\multicolumn{2}{|c|}{$\begin{array}{c}\text { Experimento } 2 \\
\text { Pós-teste }\end{array}$}} \\
\hline & \multicolumn{2}{|c|}{ Pré-teste } & \multicolumn{2}{|c|}{ Pós-teste } & & \\
\hline $\begin{array}{l}\text { Acertos geral: } \\
\text { Respondentes: }\end{array}$ & \multicolumn{2}{|c|}{$\begin{array}{c}43,8 \% \\
16\end{array}$} & \multicolumn{2}{|c|}{$\begin{array}{c}41,7 \% \\
24\end{array}$} & \multicolumn{2}{|c|}{ - } \\
\hline & Turma 1 & $\begin{array}{c}\text { Turma } 2 \\
\text { (Jogo) }\end{array}$ & Turma 1 & $\begin{array}{c}\text { Turma } 2 \\
\text { (Jogo) }\end{array}$ & Turma 3.1 & $\begin{array}{c}\text { Turma } 3.2 \\
\text { (Jogo) }\end{array}$ \\
\hline $\begin{array}{l}\text { Acertos: } \\
\text { Respondentes: }\end{array}$ & $\begin{array}{c}37,5 \% \\
8\end{array}$ & $\begin{array}{c}50,0 \% \\
8\end{array}$ & $\begin{array}{c}36,4 \% \\
11\end{array}$ & $\begin{array}{c}46,2 \% \\
13\end{array}$ & - & - \\
\hline
\end{tabular}

De acordo com Mintzberg, os papeis gerenciais podem ser divididos em papeis

interpessoais, informacionais $\mathrm{e}$

Código da Questão: PG1.02

Select one:

a. conceituais

b. técnicos

c. de contato

d. decisoriais

e. de liderança

Check

Verbo: Lembrar

Nível: DoK1

\begin{tabular}{|c|c|c|c|c|c|c|}
\hline & \multicolumn{4}{|c|}{ Experimento 1} & \multirow{2}{*}{\multicolumn{2}{|c|}{$\begin{array}{c}\text { Experimento } 2 \\
\text { Pós-teste }\end{array}$}} \\
\hline & \multicolumn{2}{|c|}{ Pré-teste } & \multicolumn{2}{|c|}{ Pós-teste } & & \\
\hline $\begin{array}{l}\text { Acertos geral: } \\
\text { Respondentes: }\end{array}$ & \multicolumn{2}{|c|}{$\begin{array}{c}23,8 \% \\
21\end{array}$} & \multicolumn{2}{|c|}{$\begin{array}{c}43,8 \% \\
16\end{array}$} & \multicolumn{2}{|c|}{ - } \\
\hline & Turma 1 & $\begin{array}{c}\text { Turma } 2 \\
\text { (Jogo) }\end{array}$ & Turma 1 & $\begin{array}{c}\text { Turma } 2 \\
\text { (Jogo) }\end{array}$ & Turma 3.1 & $\begin{array}{c}\text { Turma } 3.2 \\
\text { (Jogo) }\end{array}$ \\
\hline $\begin{array}{l}\text { Acertos: } \\
\text { Respondentes: }\end{array}$ & $\begin{array}{c}18,2 \% \\
11\end{array}$ & $\begin{array}{c}30,0 \% \\
10\end{array}$ & $\begin{array}{c}40,0 \% \\
10\end{array}$ & $\begin{array}{c}50,0 \% \\
6\end{array}$ & - & - \\
\hline
\end{tabular}


Mintzberg sugere que o trabalho de um gestor pode ser dividido em papeis que compõem

três grupos. Os grupos são:

Código da Questão: PG1.03

Select one:

a. Papéis interpessoais, informacionais e de decisão

b. Papéis interpessoais, informacionais e de gerenciamento

Verbo: Lembrar

Nivel: DoK1

c. Papéis de autoridade, tecnológicos e informacionais.

d. Papéis de relacionamento, de alocação de recursos e de decisão

e. Papéis informacionais, tecnológicos e de alocação de recursos

Check

\begin{tabular}{|c|c|c|c|c|c|c|}
\hline & \multicolumn{4}{|c|}{ Experimento 1} & \multirow{2}{*}{\multicolumn{2}{|c|}{$\begin{array}{c}\text { Experimento } 2 \\
\underline{\text { Pós-teste }}\end{array}$}} \\
\hline & \multicolumn{2}{|c|}{ Pré-teste } & \multicolumn{2}{|c|}{ Pós-teste } & & \\
\hline $\begin{array}{l}\text { Acertos geral: } \\
\text { Respondentes: }\end{array}$ & \multicolumn{2}{|c|}{$\begin{array}{c}23,8 \% \\
21\end{array}$} & \multicolumn{2}{|c|}{$\begin{array}{c}11,8 \% \\
17\end{array}$} & \multicolumn{2}{|c|}{$\begin{array}{c}50,0 \% \\
22\end{array}$} \\
\hline & Turma 1 & $\begin{array}{c}\text { Turma } 2 \\
\text { (Jogo) }\end{array}$ & Turma 1 & $\begin{array}{c}\text { Turma } 2 \\
\text { (Jogo) }\end{array}$ & Turma 3.1 & $\begin{array}{c}\text { Turma } 3.2 \\
\text { (Jogo) }\end{array}$ \\
\hline $\begin{array}{l}\text { Acertos: } \\
\text { Respondentes: }\end{array}$ & $\begin{array}{c}16,7 \% \\
12\end{array}$ & $\begin{array}{c}33,3 \% \\
9\end{array}$ & $\begin{array}{c}14,3 \% \\
14\end{array}$ & $\begin{array}{c}0,0 \% \\
3\end{array}$ & $\begin{array}{c}54,5 \% \\
11\end{array}$ & $\begin{array}{c}45,5 \% \\
11\end{array}$ \\
\hline
\end{tabular}

Os papéis informacionais, segundo a teoria de papéis gerenciais de Mintzberg são:

\section{Select one:}

a. Imagem do chefe, líder e contato

b. Comunicador, alocador de recursos e lider

c. Empreendedor, manipulador de distúrbios e negociador

d. Monitor, disseminador e porta-voz

e. Comunicador, contato e porta-voz

Check
Código da Questão: PG1.04

Verbo: Lembrar

Nivel: DoK1

\begin{tabular}{|c|c|c|c|c|c|c|}
\hline & \multicolumn{4}{|c|}{ Experimento 1} & \multirow{2}{*}{\multicolumn{2}{|c|}{$\begin{array}{c}\text { Experimento } 2 \\
\text { Pós-teste }\end{array}$}} \\
\hline & \multicolumn{2}{|c|}{ Pré-teste } & \multicolumn{2}{|c|}{ Pós-teste } & & \\
\hline $\begin{array}{l}\text { Acertos geral: } \\
\text { Respondentes: }\end{array}$ & \multicolumn{2}{|c|}{$\begin{array}{c}4,8 \% \\
21\end{array}$} & \multicolumn{2}{|c|}{$\begin{array}{c}14,3 \% \\
21\end{array}$} & \multicolumn{2}{|c|}{$\begin{array}{c}22,7 \% \\
22\end{array}$} \\
\hline & Turma 1 & $\begin{array}{c}\text { Turma } 2 \\
\text { (Jogo) }\end{array}$ & Turma 1 & $\begin{array}{c}\text { Turma } 2 \\
\text { (Jogo) }\end{array}$ & Turma 3.1 & $\begin{array}{c}\text { Turma } 3.2 \\
\text { (Jogo) }\end{array}$ \\
\hline $\begin{array}{l}\text { Acertos: } \\
\text { Respondentes: }\end{array}$ & $\begin{array}{c}6,3 \% \\
16\end{array}$ & $\begin{array}{c}0,0 \% \\
5\end{array}$ & $\begin{array}{c}25 \% \\
12\end{array}$ & $\begin{array}{c}0,0 \% \\
9\end{array}$ & $\begin{array}{c}18,2 \% \\
11\end{array}$ & $\begin{array}{c}27,3 \% \\
11\end{array}$ \\
\hline
\end{tabular}


Quais são os três papéis interpessoais, segundo Mintzberg:

Select one:

a. Monitor, coordenador e disseminador

b. Imagem do chefe, lider e contato

c. Porta-voz, lider e coordenador

d. Monitor, disseminador e porta-voz

e. Comunicador, organizador e porta-voz

Check
Código da Questão: PG1.05

Verbo: Lembrar

Nível: DoK1

\begin{tabular}{|c|c|c|c|c|c|c|}
\hline & \multicolumn{4}{|c|}{ Experimento 1} & \multirow{2}{*}{\multicolumn{2}{|c|}{$\begin{array}{c}\text { Experimento } 2 \\
\underline{\text { Pós-teste }}\end{array}$}} \\
\hline & \multicolumn{2}{|c|}{ Pré-teste } & \multicolumn{2}{|c|}{ Pós-teste } & & \\
\hline $\begin{array}{l}\text { Acertos geral: } \\
\text { Respondentes: }\end{array}$ & \multicolumn{2}{|c|}{$\begin{array}{c}10,0 \% \\
20\end{array}$} & \multicolumn{2}{|c|}{$\begin{array}{c}11,1 \% \\
18\end{array}$} & \multicolumn{2}{|c|}{$\begin{array}{c}31,8 \% \\
22\end{array}$} \\
\hline & Turma 1 & $\begin{array}{c}\text { Turma } 2 \\
\text { (Jogo) }\end{array}$ & Turma 1 & $\begin{array}{c}\text { Turma } 2 \\
\text { (Jogo) }\end{array}$ & Turma 3.1 & $\begin{array}{c}\text { Turma } 3.2 \\
\text { (Jogo) }\end{array}$ \\
\hline $\begin{array}{l}\text { Acertos: } \\
\text { Respondentes: }\end{array}$ & $\begin{array}{c}15,4 \% \\
13\end{array}$ & $\begin{array}{c}0,0 \% \\
7\end{array}$ & $\begin{array}{c}16,7 \% \\
12\end{array}$ & $\begin{array}{c}0,0 \% \\
6\end{array}$ & $\begin{array}{c}27,3 \% \\
11\end{array}$ & $\begin{array}{c}36,4 \% \\
11\end{array}$ \\
\hline
\end{tabular}

\section{São exemplos de papéis decisoriais, segundo Mintzberg:}

\section{Select one:}

a. Empreendedor, Porta-voz e Lider

b. Empreendedor, Manipulador de distúrbios e Negociador

c. Imagem do chefe, Lider e Contato

d. Alocador de Recursos, Negociador e Lider

e. Negociador, Disseminador e Monitor

Check
Código da Questão: PG1.06

Verbo: Lembrar

Nível: DoK1

\begin{tabular}{|c|c|c|c|c|c|c|}
\hline & \multicolumn{4}{|c|}{ Experimento 1} & \multirow{2}{*}{\multicolumn{2}{|c|}{$\begin{array}{c}\text { Experimento } 2 \\
\text { Pós-teste }\end{array}$}} \\
\hline & \multicolumn{2}{|c|}{ Pré-teste } & \multicolumn{2}{|c|}{ Pós-teste } & & \\
\hline $\begin{array}{l}\text { Acertos geral: } \\
\text { Respondentes: }\end{array}$ & \multicolumn{2}{|c|}{$\begin{array}{c}14,3 \% \\
21\end{array}$} & \multicolumn{2}{|c|}{$\begin{array}{c}12,5 \% \\
24\end{array}$} & \multicolumn{2}{|c|}{$\begin{array}{c}31,8 \% \\
22\end{array}$} \\
\hline & Turma 1 & $\begin{array}{c}\text { Turma } 2 \\
\text { (Jogo) }\end{array}$ & Turma 1 & $\begin{array}{c}\text { Turma } 2 \\
\text { (Jogo) }\end{array}$ & Turma 3.1 & $\begin{array}{c}\text { Turma } 3.2 \\
\text { (Jogo) }\end{array}$ \\
\hline $\begin{array}{l}\text { Acertos: } \\
\text { Respondentes: }\end{array}$ & $\begin{array}{c}16,7 \% \\
12\end{array}$ & $\begin{array}{c}11,1 \% \\
9\end{array}$ & $\begin{array}{c}15,4 \% \\
13\end{array}$ & $\begin{array}{c}9,1 \% \\
11\end{array}$ & $\begin{array}{c}27,3 \% \\
11\end{array}$ & $\begin{array}{c}36,4 \% \\
11\end{array}$ \\
\hline
\end{tabular}


Considere a seguinte situação hipotética que poderia ocorrer no dia a dia de um gestor e os papéis gerenciais segundo Mintzberg.

O gestor recebeu uma ligaçăo de seu colega, gestor de uma unidade, para cobrá-to do atraso no envio de um relatório. A análise que subsidia o relatório está sendo feita por um

funcionário da sua equipe e deveria ter sido concluida há duas semanas.

Código da Questão: PG3.01

Qual papel gerencial o gestor está exercendo, considerando-se a parte destacada em Verbo: Aplicar

negrito?

Nível: DoK2

Select one:

a. Porta-voz

b. Lider

c. Imagem do chefe

d. Contato

e. Disseminador

Check

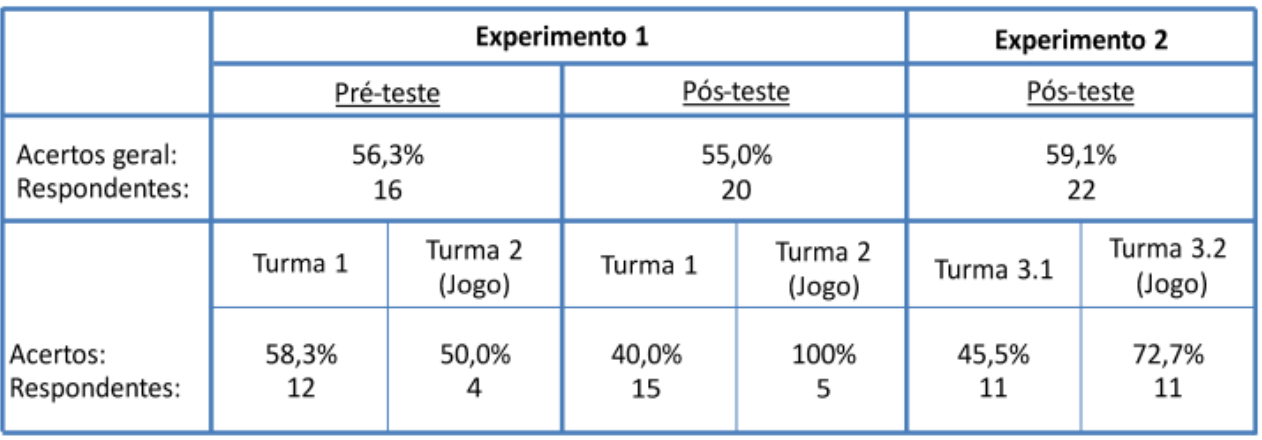

Considere a seguinte situação hipotética que poderia ocorrer no dia a dia de um gestor e os papéis gerenciais segundo Mintzberg.

O gestor, ao saber que um funcionário de sua equipe vai se aposentar, deu início a um processo seletivo para buscar internamente na própria secretaria de seu departamento uma pessoa para substitui-la.

Qual papel gerencial o gestor estả exercendo, considerando-se a parte destacada em negrito?

Verbo: Aplicar

Nível: DoK2

Select one:

a. Imagem do chefe

b. Alocador de Recursos

c. Disseminador

d. Negociador

e. Manipulador de distúrbios

Check

\begin{tabular}{|l|c|c|c|c|c|c|}
\hline & \multicolumn{3}{|c|}{ Experimento 1 } & \multicolumn{2}{c|}{ Experimento 2 } \\
\cline { 2 - 7 } & \multicolumn{2}{|c|}{ Pré-teste } & \multicolumn{2}{c|}{ Pós-teste } & \multicolumn{2}{c|}{ Pós-teste } \\
\hline \multirow{2}{*}{$\begin{array}{l}\text { Acertos geral: } \\
\text { Respondentes: }\end{array}$} & \multicolumn{2}{|c|}{$\begin{array}{c}63,2 \% \\
19\end{array}$} & \multicolumn{2}{c|}{$\begin{array}{c}81,8 \% \\
11\end{array}$} \\
\hline & Turma 1 & $\begin{array}{c}\text { Turma 2 } \\
\text { (Jogo) }\end{array}$ & Turma 1 & $\begin{array}{c}\text { Turma 2 } \\
\text { (Jogo) }\end{array}$ & Turma 3.1 & $\begin{array}{c}\text { Turma 3.2 } \\
\text { (Jogo) }\end{array}$ \\
\cline { 2 - 7 } & $62,2 \%$ & $\begin{array}{c}100 \% \\
6\end{array}$ & $\begin{array}{c}80,0 \% \\
5\end{array}$ & $\begin{array}{c}83,3 \% \\
6\end{array}$ & - & - \\
Acertos: \\
Respondentes:
\end{tabular}




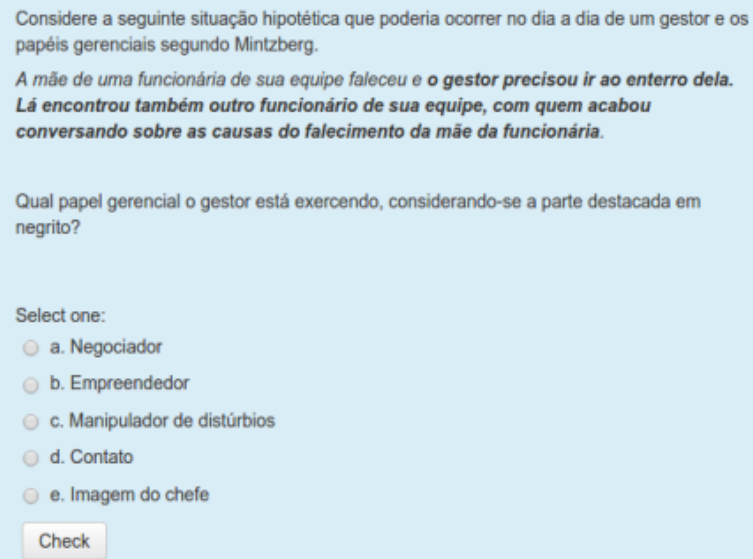

Nível: DoK2

\begin{tabular}{|l|c|c|c|c|c|c|}
\hline \multirow{2}{*}{} & \multicolumn{4}{|c|}{ Experimento 1 } & \multicolumn{2}{c|}{ Experimento 2 } \\
\cline { 2 - 7 } & \multicolumn{2}{|c|}{ Pré-teste } & \multicolumn{2}{c|}{ Pós-teste } & \multicolumn{2}{c|}{ Pós-teste } \\
\hline $\begin{array}{l}\text { Acertos geral: } \\
\text { Respondentes: }\end{array}$ & \multicolumn{2}{|c|}{$\begin{array}{c}33,3 \% \\
21\end{array}$} & \multicolumn{2}{c|}{$\begin{array}{c}39,1 \% \\
23\end{array}$} & \multicolumn{2}{c|}{-} \\
\hline & Turma 1 & $\begin{array}{c}\text { Turma 2 } \\
\text { (Jogo) }\end{array}$ & Turma 1 & $\begin{array}{c}\text { Turma 2 } \\
\text { (Jogo) }\end{array}$ & Turma 3.1 & $\begin{array}{c}\text { Turma 3.2 } \\
\text { (Jogo) }\end{array}$ \\
\cline { 2 - 7 } & $25,0 \%$ & $\begin{array}{c}44,4 \% \\
9\end{array}$ & $\begin{array}{c}26,7 \% \\
15\end{array}$ & $\begin{array}{c}62,5 \% \\
8\end{array}$ & - & - \\
Acertos: \\
Respondentes:
\end{tabular}

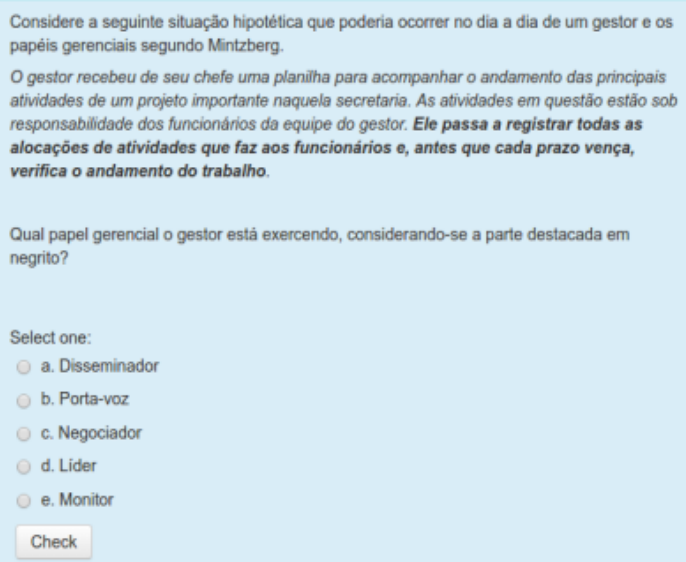

O gestor recebeu de seu chefe uma planïha para acompanhar o andamento das principais atvidades de um proieto importante naquele secretaria. As atividades em questio est responsabilidade dos funcionários da equipe do gestor. Ele passa a registrar todas as alocacōes de atividades que faz aos funcionários e, antes que cada prazo vença verifica o andamento do trabalho.

Qual papel gerencial o gestor está exercendo, considerando-se a parte destacada em negrito?

\begin{tabular}{|l|c|c|c|c|c|c|}
\hline \multirow{2}{*}{} & \multicolumn{4}{|c|}{ Experimento 1 } & \multicolumn{2}{c|}{ Experimento 2 } \\
\cline { 2 - 7 } & \multicolumn{2}{|c|}{ Pré-teste } & \multicolumn{2}{c|}{ Pós-teste } & \multicolumn{2}{c|}{ Pós-teste } \\
\hline \multirow{2}{*}{$\begin{array}{l}\text { Acertos geral: } \\
\text { Respondentes: }\end{array}$} & \multicolumn{2}{|c|}{$\begin{array}{c}81,8 \% \\
22\end{array}$} & \multicolumn{2}{c|}{$\begin{array}{c}93,3 \% \\
15\end{array}$} & \multicolumn{2}{c|}{-} \\
\hline & Turma 1 & $\begin{array}{c}\text { Turma 2 } \\
\text { (Jogo) }\end{array}$ & Turma 1 & $\begin{array}{c}\text { Turma 2 } \\
\text { (Jogo) }\end{array}$ & Turma 3.1 & $\begin{array}{c}\text { Turma 3.2 } \\
\text { (Jogo) }\end{array}$ \\
\cline { 2 - 7 } & $72,7 \%$ & $\begin{array}{c}90,9 \% \\
11\end{array}$ & $\begin{array}{c}87,5 \% \\
8\end{array}$ & $\begin{array}{c}100 \% \\
7\end{array}$ & - & - \\
Acertos: & 11 & & & & - & - \\
Respondentes: & & & & & & \\
\hline
\end{tabular}


Considere a seguinte situaçăo hipotética que poderia ocorrer no dia a dia de um gestor e os papeis gerenciais segundo Mintzberg.

Ao notar que os prazos de trés entregas importantes estâo findando, o gestor, em uma reuniäo com a diretora da unidade que depende dessas entregas, consegue

estabelecer novos prazos para a finalizaçảo dos trabalhos.

Código da Questão: PG3.05

Qual papel gerencial o gestor está exercendo, considerando-se a parte destacada em negrito?

Verbo: Aplicar

Nível: DoK2

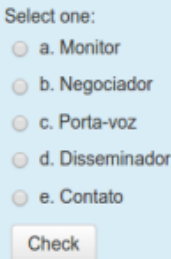

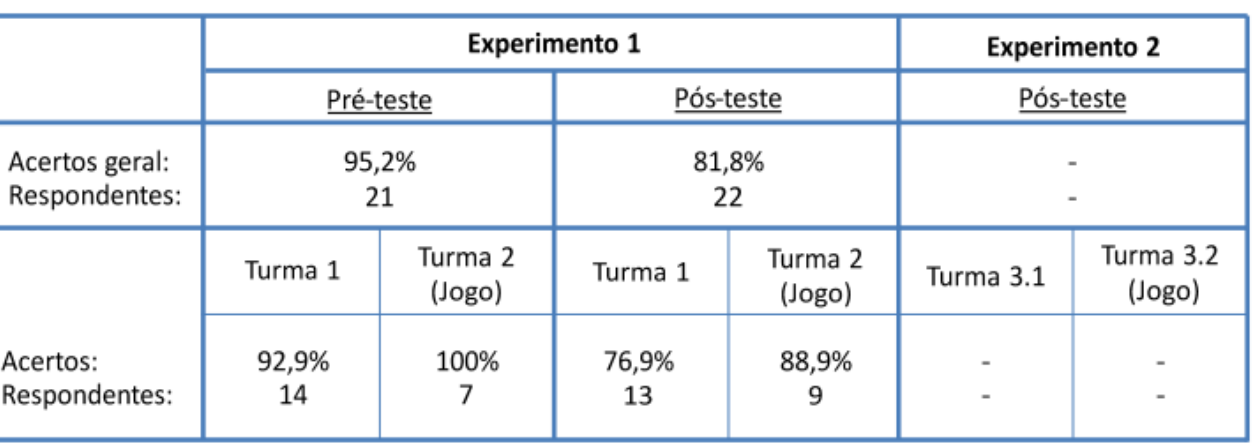

Considere a seguinte situaçăo hipotética que poderia ocorrer no dia a dia de um gestor e os papéis gerenciais segundo Mintzberg.

O gestor recebe uma informação do chefe de gabinete de sua secretaria de que a pante de feriado de Corpus Christi na próxima sexta-feira nâo sera "emendada", ou seja, os

funcionários ferāo que vir trabalhar normalmente. Ele repassa essa informaçāo por e-mail todos os funcionários.

Qual papel gerencial o gestor está exercendo, considerando-se a parte destacada em negrito?

Verbo: Aplicar

Nivel: DoK2

\section{Select one:}

a. Negociador

b. Lider

c. Contato

d. Disseminador

e. Porta-voz

Check

\begin{tabular}{|l|c|c|c|c|c|c|}
\hline & \multicolumn{3}{|c|}{ Experimento 1 } & \multicolumn{2}{c|}{ Experimento 2 } \\
\cline { 2 - 7 } & \multicolumn{2}{|c|}{ Pré-teste } & \multicolumn{2}{c|}{ Pós-teste } & \multicolumn{2}{c|}{ Pós-teste } \\
\hline \multirow{2}{*}{$\begin{array}{l}\text { Acertos geral: } \\
\text { Respondentes: }\end{array}$} & \multicolumn{2}{|c|}{$\begin{array}{c}30,0 \% \\
20\end{array}$} & \multicolumn{2}{c|}{$\begin{array}{c}29,4 \% \\
17\end{array}$} & \multicolumn{2}{c|}{$\begin{array}{c}59,1 \% \\
22\end{array}$} \\
\hline & Turma 1 & $\begin{array}{c}\text { Turma 2 } \\
\text { (Jogo) }\end{array}$ & Turma 1 & $\begin{array}{c}\text { Turma 2 } \\
\text { (Jogo) }\end{array}$ & Turma 3.1 & $\begin{array}{c}\text { Turma 3.2 } \\
\text { (Jogo) }\end{array}$ \\
\cline { 2 - 7 } & $\begin{array}{c}20,0 \% \\
\text { Acertos: } \\
\text { Respondentes: }\end{array}$ & $\begin{array}{c}20,0 \% \\
10\end{array}$ & $\begin{array}{c}30,0 \% \\
10\end{array}$ & $\begin{array}{c}28,6 \% \\
7\end{array}$ & $\begin{array}{c}54,5 \% \\
11\end{array}$ & $\begin{array}{c}63,6 \% \\
11\end{array}$ \\
\hline
\end{tabular}


Considere a seguinte situaçăo hipotética que poderia ocorrer no dia a dia de um gestor e os papeis gerenciais segundo Mintzberg.

Ao notar que uma das funcionárias trabalha melhor em atividades relacionadas a analises

com planiihas e que outro funcionário tem facilidade para produzir apresentaç̧⿸es e elaborar

relatónios, o gestor passa a concentrar trabalhos analiticos com a primeira funcionári

e destina, sempre que possivel, a elaboraçáo de relatórios e apresentaçóes para o

segundo.

Código da Questão: PG3.09

Qual papel gerencial o gestor está exercendo, considerando-se a parte destacada em

Verbo: Aplicar

Nível: DoK2

Select one:

a. Disseminador

b. Alocador de recursos

c. Imagem do chefe

d. Negociador

e. Lider

Check

\begin{tabular}{|l|c|c|c|c|c|c|}
\hline & \multicolumn{4}{|c|}{ Experimento 1 } & \multicolumn{2}{c|}{ Experimento 2 } \\
\cline { 2 - 7 } & \multicolumn{2}{|c|}{ Pré-teste } & \multicolumn{2}{c|}{ Pós-teste } & \multicolumn{2}{c|}{ Pós-teste } \\
\hline $\begin{array}{l}\text { Acertos geral: } \\
\text { Respondentes: }\end{array}$ & \multicolumn{2}{|c|}{$\begin{array}{c}52,6 \% \\
19\end{array}$} & \multicolumn{2}{c|}{$\begin{array}{c}50,0 \% \\
20\end{array}$} & \multicolumn{2}{c|}{$\begin{array}{c}50,0 \% \\
22\end{array}$} \\
\hline & Turma 1 & $\begin{array}{c}\text { Turma 2 } \\
\text { (Jogo) }\end{array}$ & Turma 1 & $\begin{array}{c}\text { Turma 2 } \\
\text { (Jogo) }\end{array}$ & Turma 3.1 & $\begin{array}{c}\text { Turma 3.2 } \\
\text { (Jogo) }\end{array}$ \\
\cline { 2 - 7 } & $36,4 \%$ & $\begin{array}{c}75,0 \% \\
8\end{array}$ & $\begin{array}{c}46,2 \% \\
13\end{array}$ & $\begin{array}{c}57,1 \% \\
7\end{array}$ & $\begin{array}{c}36,4 \% \\
11\end{array}$ & $\begin{array}{c}63,6 \% \\
11\end{array}$ \\
\hline
\end{tabular}

Considere a seguinte situaç̆on hipotética que poderia ocorrer no dia a dia de um gestor e os

papeis gerenciais segundo Mintzberg

Ao saber que a ponte de feriado de Carpus Christi na próxima sexta-feira nảo sera

"emendada", ou seja, os funcionàrios terăo que vir trabalhar normalmente, uma funcionária

de sua equipe fica nervosa e informa que ja tinha viagem marcada. No mesmo momento,

outro funcionário avisa que ela nảo tem viagem nenhuma e que só está procurando uma

desculpa para nẫo vir trabalhar. Os dois discutem até que o gestor decide conversar

com ambos para que os ânimos exaltados se acalmem.

Qual papel gerencial o gestor está exercendo, considerando-se a parte destacada em

negrito?

Código da Questão: PG3.07

Verbo: Aplicar

Nível: DoK2

Select one:

a. Manipulador de distúrbios

b. Negociador

c. Lider

d. Imagem do chefe

e. Empreendedor

Check

\begin{tabular}{|c|c|c|c|c|c|c|}
\hline & \multicolumn{4}{|c|}{ Experimento 1} & \multirow{2}{*}{\multicolumn{2}{|c|}{$\begin{array}{c}\text { Experimento } 2 \\
\underline{\text { Pós-teste }}\end{array}$}} \\
\hline & \multicolumn{2}{|c|}{ Pré-teste } & \multicolumn{2}{|c|}{ Pós-teste } & & \\
\hline $\begin{array}{l}\text { Acertos geral: } \\
\text { Respondentes: }\end{array}$ & \multicolumn{2}{|c|}{$\begin{array}{c}25,0 \% \\
28\end{array}$} & \multicolumn{2}{|c|}{$\begin{array}{c}36,4 \% \\
22\end{array}$} & \multicolumn{2}{|c|}{$\begin{array}{c}54,5 \% \\
22\end{array}$} \\
\hline & Turma 1 & $\begin{array}{c}\text { Turma } 2 \\
\text { (Jogo) }\end{array}$ & Turma 1 & $\begin{array}{c}\text { Turma } 2 \\
\text { (Jogo) }\end{array}$ & Turma 3.1 & $\begin{array}{c}\text { Turma } 3.2 \\
\text { (Jogo) }\end{array}$ \\
\hline $\begin{array}{l}\text { Acertos: } \\
\text { Respondentes: }\end{array}$ & $\begin{array}{c}16,7 \% \\
18\end{array}$ & $\begin{array}{c}40,0 \% \\
10\end{array}$ & $\begin{array}{c}30,8 \% \\
13\end{array}$ & $\begin{array}{c}44,4 \% \\
9\end{array}$ & $\begin{array}{c}63,6 \% \\
11\end{array}$ & $\begin{array}{c}45,5 \% \\
11\end{array}$ \\
\hline
\end{tabular}


Considere a seguinte situaçāo hipotética que poderia ocorrer no dia a dia de um gestor e 05 papèis gerenciais segundo Mintzberg

A área do gestor está encarregada de uma etapa importante de um projeto da Secretaria. $O$ gestor analisa as atividades e, em funçâo das capacidades e aptidōes de cada um dos funcionários de sua equipe, escolhe funcionário se ocupará de cada uma das

atividades.

Qual papel gerencial o gestor está exercendo, considerando-se a parte destacada em negrito?

Nível: DoK2

Select one:

a. Lider

b. Empreendedor

c. Disseminador

d. Negociador

e. Alocador de recursos

Check

\begin{tabular}{|c|c|c|c|c|c|c|}
\hline & \multicolumn{4}{|c|}{ Experimento 1} & \multirow{2}{*}{\multicolumn{2}{|c|}{$\begin{array}{c}\text { Experimento } 2 \\
\text { Pós-teste }\end{array}$}} \\
\hline & \multicolumn{2}{|c|}{ Pré-teste } & \multicolumn{2}{|c|}{ Pós-teste } & & \\
\hline $\begin{array}{l}\text { Acertos geral: } \\
\text { Respondentes: }\end{array}$ & \multicolumn{2}{|c|}{$\begin{array}{c}42,9 \% \\
21\end{array}$} & \multicolumn{2}{|c|}{$\begin{array}{c}43,5 \% \\
23\end{array}$} & \multicolumn{2}{|c|}{ - } \\
\hline & Turma 1 & $\begin{array}{c}\text { Turma } 2 \\
\text { (Jogo) }\end{array}$ & Turma 1 & $\begin{array}{c}\text { Turma } 2 \\
\text { (Jogo) }\end{array}$ & Turma 3.1 & $\begin{array}{c}\text { Turma } 3.2 \\
\text { (Jogo) }\end{array}$ \\
\hline $\begin{array}{l}\text { Acertos: } \\
\text { Respondentes: }\end{array}$ & $\begin{array}{c}54,5 \% \\
11\end{array}$ & $\begin{array}{c}30,0 \% \\
10\end{array}$ & $\begin{array}{c}40,0 \% \\
15\end{array}$ & $\begin{array}{c}50,0 \% \\
8\end{array}$ & $\begin{array}{l}- \\
-\end{array}$ & - \\
\hline
\end{tabular}

Considere a seguinte situaçāo hipotética que poderia ocorrer no dia a dia de um gestor e os papeis gerenciais segundo Mintzberg.

Ao notar que uma das funcionairias trabalha melhor em atividades relacionadas a analises

com planihhas e que outro funcionánio tem facilidade para produzir apresentaçes e elaborar

relatónios, o gestor passa a concentrar trabalhos analiticos com a primeira funcionária e destina, sempre que possivel, a elaboraçăo de relatórios e apresentaçóes para o

segundo.

Código da Questão: PG3.09

Qual papel gerencial o gestor está exercendo, considerando-se a parte destacada em

negrito?

Verbo: Aplicar

Nível: DoK2

Select one:

a. Disseminador

b. Alocador de recursos

c. Imagem do chefe

d. Negociador

e. Lider

Check

\begin{tabular}{|c|c|c|c|c|c|c|}
\hline & \multicolumn{4}{|c|}{ Experimento 1} & \multirow{2}{*}{\multicolumn{2}{|c|}{$\begin{array}{c}\text { Experimento } 2 \\
\text { Pós-teste }\end{array}$}} \\
\hline & \multicolumn{2}{|c|}{ Pré-teste } & \multicolumn{2}{|c|}{ Pós-teste } & & \\
\hline $\begin{array}{l}\text { Acertos geral: } \\
\text { Respondentes: }\end{array}$ & \multicolumn{2}{|c|}{$\begin{array}{c}52,6 \% \\
19\end{array}$} & \multicolumn{2}{|c|}{$\begin{array}{c}50,0 \% \\
20\end{array}$} & \multicolumn{2}{|c|}{$\begin{array}{c}50,0 \% \\
22\end{array}$} \\
\hline & Turma 1 & $\begin{array}{c}\text { Turma } 2 \\
\text { (Jogo) }\end{array}$ & Turma 1 & $\begin{array}{c}\text { Turma } 2 \\
\text { (Jogo) }\end{array}$ & Turma 3.1 & $\begin{array}{c}\text { Turma } 3.2 \\
\text { (Jogo) }\end{array}$ \\
\hline $\begin{array}{l}\text { Acertos: } \\
\text { Respondentes: }\end{array}$ & $\begin{array}{c}36,4 \% \\
11\end{array}$ & $\begin{array}{c}75,0 \% \\
8\end{array}$ & $\begin{array}{c}46,2 \% \\
13\end{array}$ & $\begin{array}{c}57,1 \% \\
7\end{array}$ & $\begin{array}{c}36,4 \% \\
11\end{array}$ & $\begin{array}{c}63,6 \% \\
11\end{array}$ \\
\hline
\end{tabular}




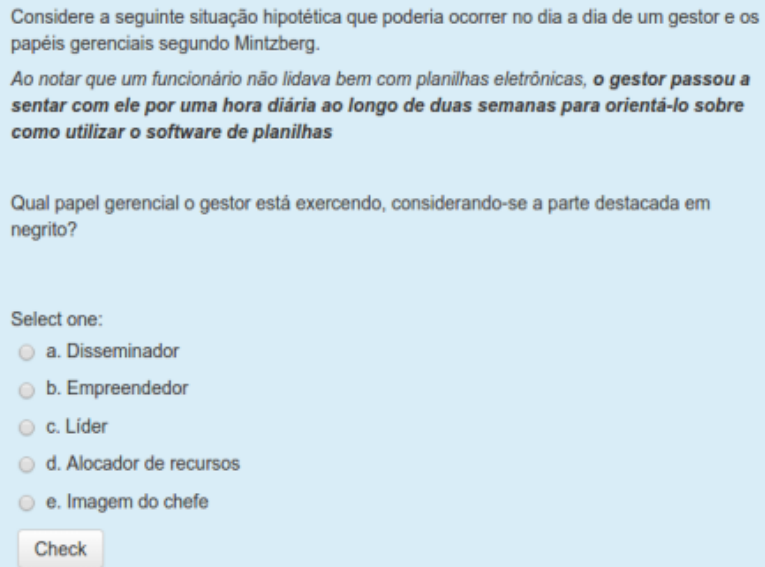

Select one:

a. Disseminador

b. Empreendedor

c. Lider

d. Alocador de recursos

e. Imagem do chefe

Check

Nível: DoK2

\begin{tabular}{|l|c|c|c|c|c|c|}
\hline & \multicolumn{3}{|c|}{ Experimento 1 } & \multicolumn{2}{c|}{ Experimento 2 } \\
\cline { 2 - 7 } & \multicolumn{2}{|c|}{ Pré-teste } & \multicolumn{2}{c|}{ Pós-teste } & \multicolumn{2}{c|}{ Pós-teste } \\
\hline $\begin{array}{l}\text { Acertos geral: } \\
\text { Respondentes: }\end{array}$ & \multicolumn{2}{|c|}{$\begin{array}{c}30,8 \% \\
13\end{array}$} & \multicolumn{2}{c|}{$\begin{array}{c}40,9 \% \\
22\end{array}$} & \multicolumn{2}{c|}{$\begin{array}{c}54,5 \% \\
22\end{array}$} \\
\hline & Turma 1 & $\begin{array}{c}\text { Turma 2 } \\
\text { (Jogo) }\end{array}$ & Turma 1 & $\begin{array}{c}\text { Turma 2 } \\
\text { (Jogo) }\end{array}$ & Turma 3.1 & $\begin{array}{c}\text { Turma 3.2 } \\
\text { (Jogo) }\end{array}$ \\
\cline { 2 - 7 } & $25,0 \%$ & $\begin{array}{c}40,0 \% \\
5\end{array}$ & $\begin{array}{c}40,0 \% \\
10\end{array}$ & $\begin{array}{c}41,7 \% \\
12\end{array}$ & $\begin{array}{c}54,5 \% \\
11\end{array}$ & $\begin{array}{c}54,5 \% \\
11\end{array}$ \\
\hline
\end{tabular}

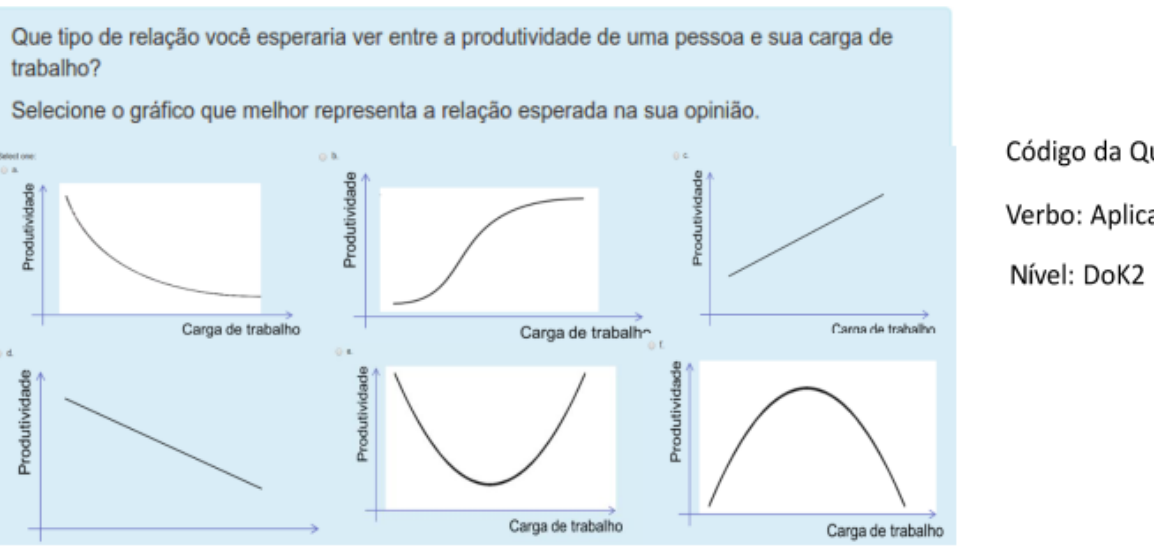

\begin{tabular}{|c|c|c|c|c|c|c|}
\hline & \multicolumn{4}{|c|}{ Experimento 1} & \multirow{2}{*}{\multicolumn{2}{|c|}{$\begin{array}{c}\text { Experimento } 2 \\
\text { Pós-teste }\end{array}$}} \\
\hline & \multicolumn{2}{|c|}{ Pré-teste } & \multicolumn{2}{|c|}{ Pós-teste } & & \\
\hline $\begin{array}{l}\text { Acertos geral: } \\
\text { Respondentes: }\end{array}$ & \multicolumn{2}{|c|}{$\begin{array}{l}- \\
-\end{array}$} & \multicolumn{2}{|c|}{$\begin{array}{c}10,0 \% \\
40\end{array}$} & \multicolumn{2}{|c|}{-} \\
\hline & Turma 1 & $\begin{array}{c}\text { Turma } 2 \\
\text { (Jogo) }\end{array}$ & Turma 1 & $\begin{array}{c}\text { Turma } 2 \\
\text { (Jogo) }\end{array}$ & Turma 3.1 & $\begin{array}{c}\text { Turma } 3.2 \\
\text { (Jogo) }\end{array}$ \\
\hline $\begin{array}{l}\text { Acertos: } \\
\text { Respondentes: }\end{array}$ & $\dot{-}$ & - & $\begin{array}{c}8,3 \% \\
24\end{array}$ & $\begin{array}{c}12,5 \% \\
16\end{array}$ & - & - \\
\hline
\end{tabular}




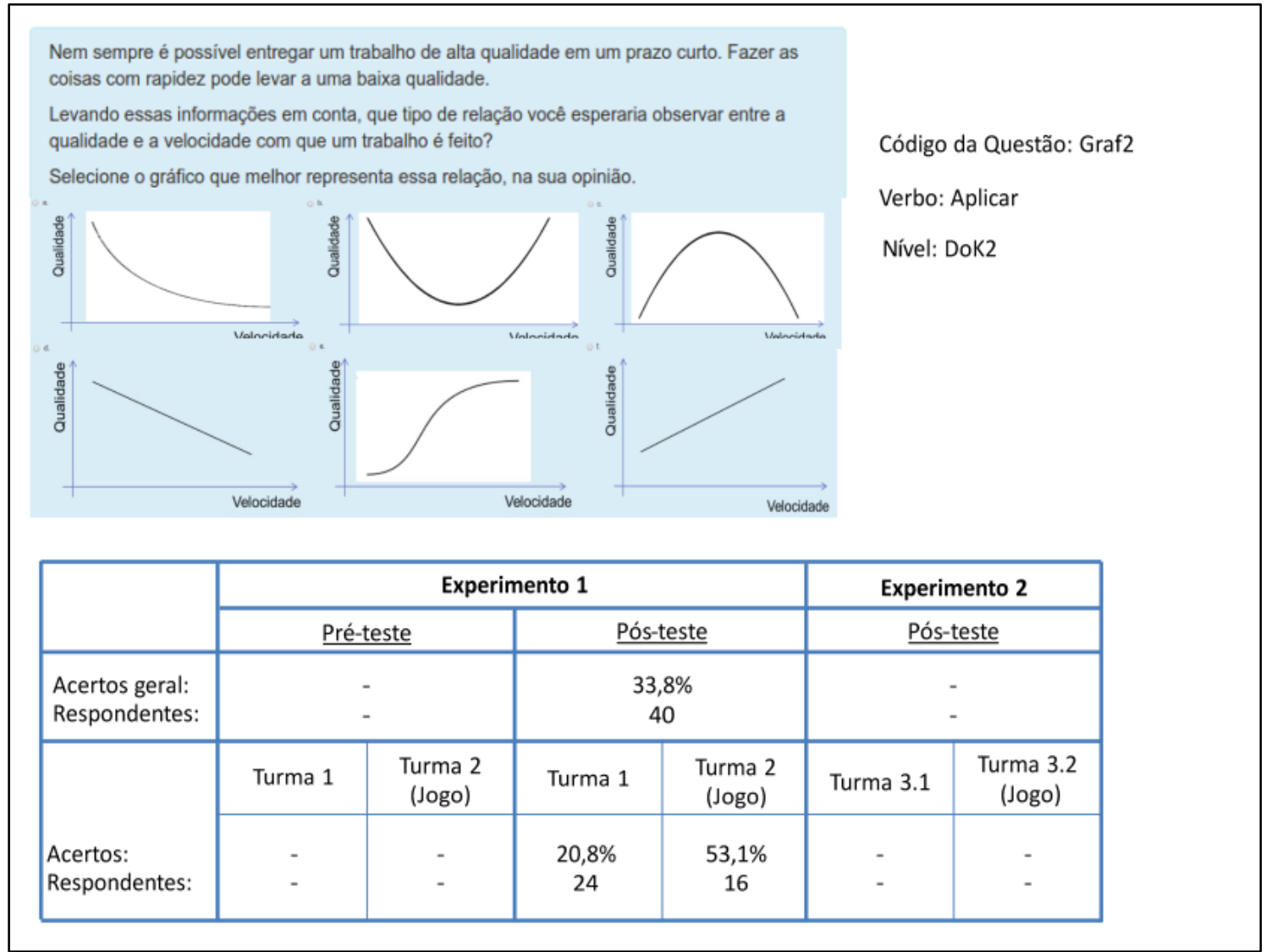

O que você espera que aconteça com o tempo para a realização de uma tarefa à medida que a pessoa tem a oportunidade de realizar tarefas similares?

Selecione o gráfico que, na sua opinião, melhor representa essa relação.
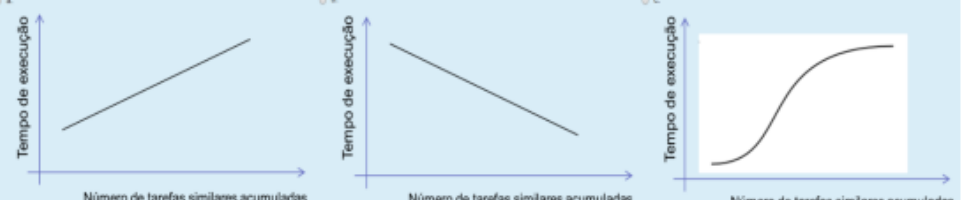

Código da Questão: Graf3

Verbo: Aplicar

Nível: DoK2

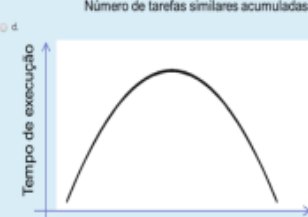

Número de tarefas similares acumuladsos

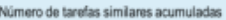

Nimero de tarefas similars acumulatios
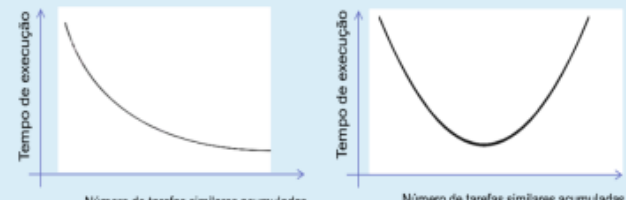

Nimero de tarefas simiares acomulads

Número de tarefas similares acumuladas

\begin{tabular}{|c|c|c|c|c|c|c|}
\hline & \multicolumn{4}{|c|}{ Experimento 1} & \multirow{2}{*}{\multicolumn{2}{|c|}{$\begin{array}{c}\text { Experimento } 2 \\
\text { Pós-teste } \\
\end{array}$}} \\
\hline & \multicolumn{2}{|c|}{ Pré-teste } & \multicolumn{2}{|c|}{ Pós-teste } & & \\
\hline $\begin{array}{l}\text { Acertos geral: } \\
\text { Respondentes: }\end{array}$ & \multicolumn{2}{|c|}{$\begin{array}{l}- \\
-\end{array}$} & \multicolumn{2}{|c|}{$\begin{array}{c}36,3 \% \\
40\end{array}$} & \multicolumn{2}{|c|}{$\begin{array}{l}- \\
-\end{array}$} \\
\hline & Turma 1 & $\begin{array}{c}\text { Turma } 2 \\
\text { (Jogo) }\end{array}$ & Turma 1 & $\begin{array}{c}\text { Turma } 2 \\
\text { (Jogo) }\end{array}$ & Turma 3.1 & $\begin{array}{c}\text { Turma } 3.2 \\
\text { (Jogo) }\end{array}$ \\
\hline $\begin{array}{l}\text { Acertos: } \\
\text { Respondentes: }\end{array}$ & - & - & $\begin{array}{c}25,0 \% \\
24\end{array}$ & $\begin{array}{c}53,1 \% \\
16\end{array}$ & - & - \\
\hline
\end{tabular}




\section{Apêndice F Saídas do SPSS para Experimento 1}

\section{F1. Teste das premissas da ANCOVA.}

- Homogeneidade de variâncias

Descriptives

\begin{tabular}{|c|c|c|c|c|c|}
\hline \multicolumn{4}{|c|}{ Turma } & \multirow{2}{*}{$\frac{\text { Statistic }}{4,3821}$} & \multirow{2}{*}{$\begin{array}{r}\text { Std. Error } \\
, 25888\end{array}$} \\
\hline \multirow[t]{26}{*}{ Nota2 } & \multirow[t]{13}{*}{1,0} & Mean & & & \\
\hline & & \multirow{2}{*}{$\begin{array}{l}95 \% \text { Confidence Interval } \\
\text { for Mean }\end{array}$} & Lower Bound & 3,8465 & \\
\hline & & & Upper Bound & 4,9176 & \\
\hline & & 5\% Trimmed Mean & & 4,3586 & \\
\hline & & Median & & 4,3400 & \\
\hline & & Variance & & 1,608 & \\
\hline & & Std. Deviation & & 1,26826 & \\
\hline & & Minimum & & 2,36 & \\
\hline & & Maximum & & 6,84 & \\
\hline & & Range & & 4,48 & \\
\hline & & Interquartile Range & & 2,25 & \\
\hline & & Skewness & & .236 & .472 \\
\hline & & Kurtosis & &,- 860 & 918 \\
\hline & \multirow[t]{13}{*}{2,0} & Mean & & 5,2056 &, 27656 \\
\hline & & \multirow{2}{*}{$\begin{array}{l}95 \% \text { Confidence Interval } \\
\text { for Mean }\end{array}$} & Lower Bound & 4,6161 & \\
\hline & & & Upper Bound & 5,7951 & \\
\hline & & $5 \%$ Trimmed Mean & & 5,1368 & \\
\hline & & Median & & 4,7700 & \\
\hline & & Variance & & 1,224 & \\
\hline & & Std. Deviation & & 1,10625 & \\
\hline & & Minimum & & 3,93 & \\
\hline & & Maximum & & 7,72 & \\
\hline & & Range & & 3,79 & \\
\hline & & Interquartile Range & & 1,45 & \\
\hline & & Skewness & & 1,164 &, 564 \\
\hline & & Kurtosis & &, 723 & 1,091 \\
\hline
\end{tabular}

- Normalidade da distribuição

Tests of Normality

\begin{tabular}{|ll|r|r|r|r|r|r|}
\hline & \multicolumn{3}{|c|}{ Kolmogorov-Smirnov $^{\mathrm{a}}$} & \multicolumn{3}{c|}{ Shapiro-Wilk } \\
\cline { 3 - 8 } & Turma & Statistic & \multicolumn{1}{c|}{ df } & \multicolumn{1}{c|}{ Sig. } & \multicolumn{1}{c|}{ Statistic } & \multicolumn{1}{c|}{ df } & \multicolumn{1}{c|}{ Sig. } \\
\hline Nota2 & 1,0 &, 125 & 24 &, 200 &, 968 & 24 &, 615 \\
& 2,0 &, 209 & 16 &, 060 &, 879 & 16 &, 038 \\
\hline
\end{tabular}

*. This is a lower bound of the true significance.

a. Lilliefors Significance Correction
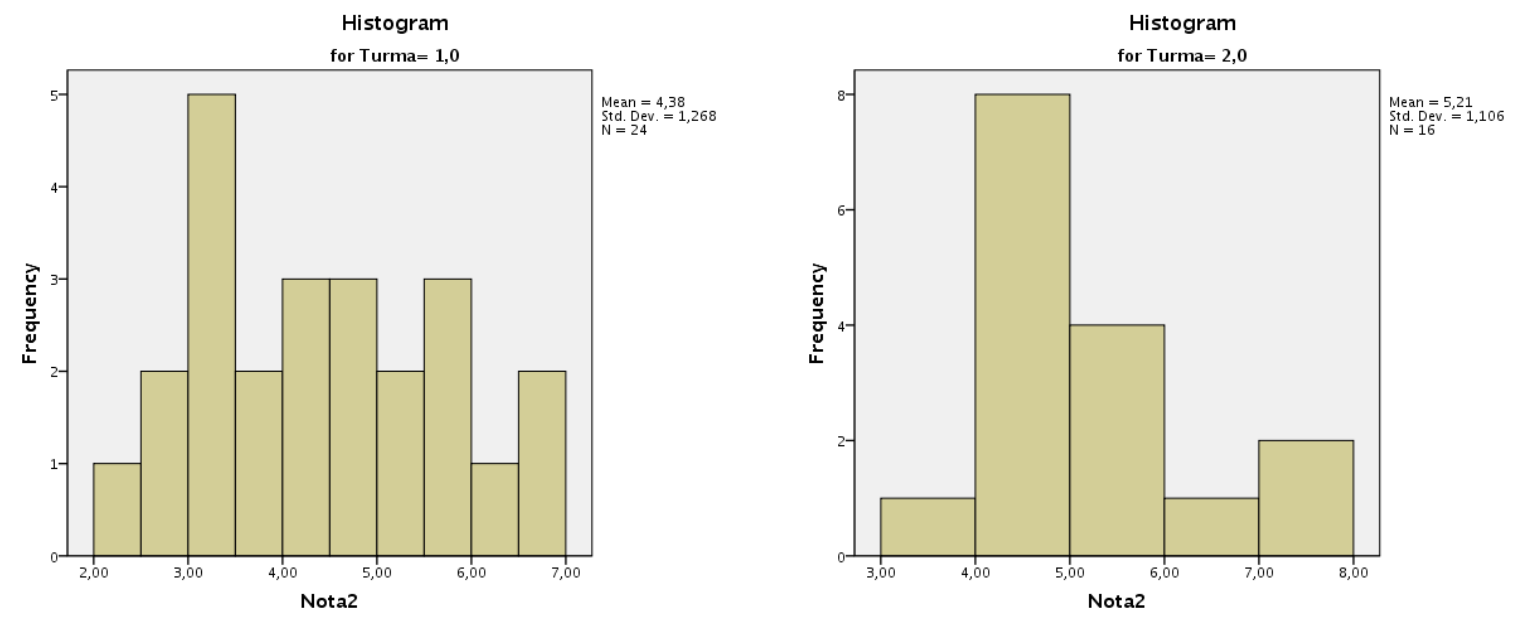

- Ausência de outliers 
Extreme Values

\begin{tabular}{|c|c|c|c|c|c|}
\hline \multicolumn{4}{|c|}{ Turma } & $\begin{array}{c}\text { Case } \\
\text { Number }\end{array}$ & Value \\
\hline \multirow[t]{20}{*}{ Nota2 } & \multirow[t]{10}{*}{1,0} & \multirow[t]{5}{*}{ Highest } & 1 & 38 & 6,84 \\
\hline & & & 2 & 14 & 6,54 \\
\hline & & & 3 & 1 & 6,04 \\
\hline & & & 4 & 42 & 5,68 \\
\hline & & & 5 & 55 & 5,67 \\
\hline & & \multirow[t]{5}{*}{ Lowest } & 1 & 6 & 2,36 \\
\hline & & & 2 & 12 & 2,58 \\
\hline & & & 3 & 17 & 2,74 \\
\hline & & & 4 & 32 & 3,09 \\
\hline & & & 5 & 18 & 3,21 \\
\hline & \multirow[t]{10}{*}{2,0} & \multirow[t]{5}{*}{ Highest } & 1 & 47 & 7,72 \\
\hline & & & 2 & 59 & 7,31 \\
\hline & & & 3 & 44 & 6,09 \\
\hline & & & 4 & 31 & 5,92 \\
\hline & & & 5 & 30 & 5,78 \\
\hline & & \multirow[t]{5}{*}{ Lowest } & 1 & 24 & 3,93 \\
\hline & & & 2 & 13 & 4,03 \\
\hline & & & 3 & 39 & 4,38 \\
\hline & & & 4 & 10 & 4,43 \\
\hline & & & 5 & 52 & 4,44 \\
\hline
\end{tabular}

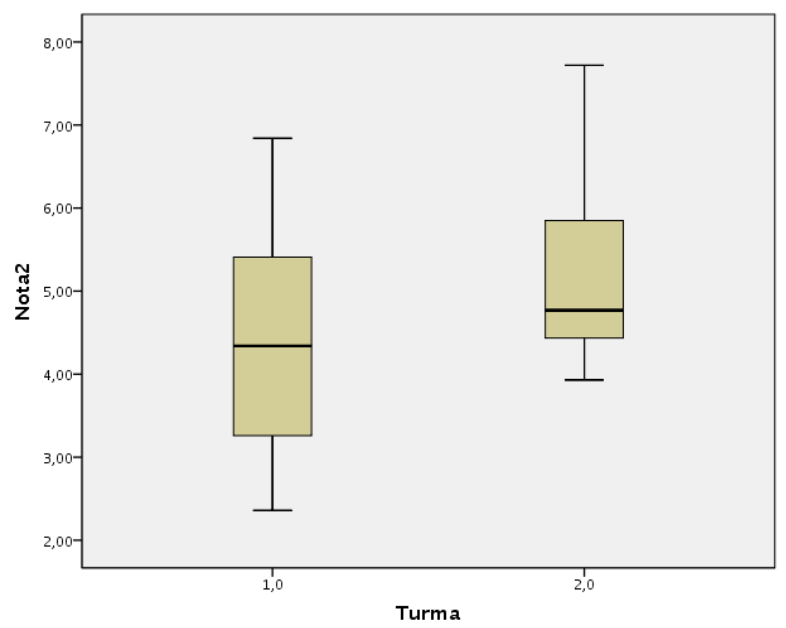

- Linearidade da relação entre variável dependente e covariável

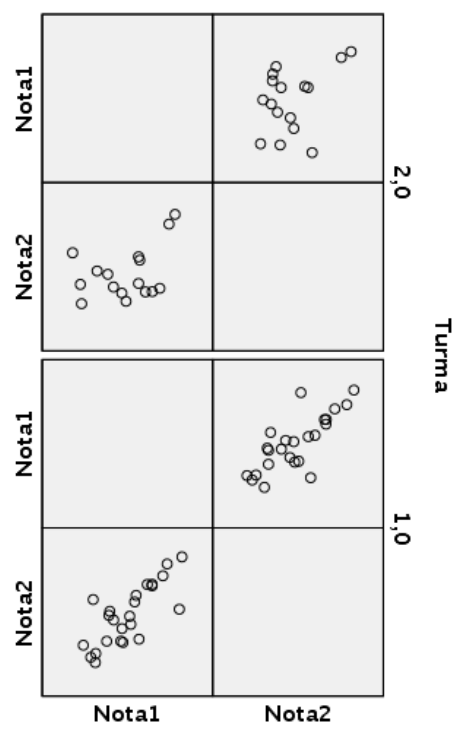




\begin{tabular}{|c|c|c|c|c|c|c|}
\hline \multicolumn{7}{|c|}{ Coefficients ${ }^{\mathbf{a}} \mathbf{b}$} \\
\hline \multirow{2}{*}{\multicolumn{2}{|c|}{ Model }} & \multicolumn{2}{|c|}{ Unstandardized Coefficients } & \multirow{2}{*}{\begin{tabular}{|c|}
$\begin{array}{c}\text { Standardized } \\
\text { Coefficients }\end{array}$ \\
Beta \\
\end{tabular}} & \multirow[b]{2}{*}{$\mathrm{t}$} & \multirow[b]{2}{*}{ Sig. } \\
\hline & & B & Std. Error & & & \\
\hline 1 & (Constant) & .624 & 681 & & ,916 &, 370 \\
\hline & Nota1 & 830 & 146 &, 772 & 5,697 &, 000 \\
\hline
\end{tabular}

a. Dependent Variable: Nota 2
b. Selecting only cases for which Turma $=1,0$

Coefficients $^{\text {ab }}$

\begin{tabular}{|c|c|c|c|c|c|c|}
\hline \multirow{2}{*}{\multicolumn{2}{|c|}{ Model }} & \multicolumn{2}{|c|}{ Unstandardized Coefficients } & \multirow{2}{*}{\begin{tabular}{|c|}
$\begin{array}{c}\text { Standardized } \\
\text { Coefficients }\end{array}$ \\
Beta \\
\end{tabular}} & \multirow[b]{2}{*}{$t$} & \multirow[b]{2}{*}{ Sig. } \\
\hline & & $B$ & Std. Error & & & \\
\hline & (Constant) & 3,397 & 1,166 & & 2,913 & .011 \\
\hline & Nota1 & 406 & 255 & 392 & 1,592 &, 134 \\
\hline
\end{tabular}

a. Dependent Variable: Nota2

b. Selecting only cases for which Turma $=2,0$

\section{- Homogeneidade dos coeficientes lineares}

\section{Tests of Between-Subjects Effects}

\begin{tabular}{|c|c|c|c|c|c|c|c|c|}
\hline Source & $\begin{array}{c}\text { Type III Sum } \\
\text { of Squares }\end{array}$ & df & Mean Square & $\mathrm{F}$ & Sig. & $\begin{array}{c}\text { Partial Eta } \\
\text { Squared }\end{array}$ & $\begin{array}{l}\text { Noncent. } \\
\text { Parameter }\end{array}$ & $\begin{array}{l}\text { Observed } \\
\text { Power }^{b}\end{array}$ \\
\hline Corrected Model & $27,341^{\mathrm{a}}$ & 2 & 13,670 & 14,652 & .000 &, 442 & 29,303 & 998 \\
\hline Intercept & 5,956 & 1 & 5,956 & 6,383 & .016 & , 147 & 6,383 & .692 \\
\hline Turma * Nota1 & 27,341 & 2 & 13,670 & 14,652 &, 000 & ,442 & 29,303 & ,998 \\
\hline Error & 34,522 & 37 & ,933 & & & & & \\
\hline Total & 949,792 & 40 & & & & & & \\
\hline Corrected Total & 61,863 & 39 & & & & & & \\
\hline
\end{tabular}

a. R Squared $=, 442$ (Adjusted R Squared $=, 412$ )

b. Computed using alpha $=, 05$ 


\section{F2. ANCOVA para o pós-teste, com o pré-teste como covariável}

Between-Subjects

Factors

\begin{tabular}{|rr|r|}
\hline & & \multicolumn{1}{|c|}{$N$} \\
\hline Turma & 1,0 & 24 \\
& 2,0 & 16 \\
\hline
\end{tabular}

\section{Descriptive Statistics}

Dependent Variable: Nota2

\begin{tabular}{|l|l|r|r|}
\hline Turma & Mean & $\begin{array}{c}\text { Std. } \\
\text { Deviation }\end{array}$ & \multicolumn{1}{|c|}{$\mathrm{N}$} \\
\hline 1,0 & 4,3821 & 1,26826 & 24 \\
2,0 & 5,2056 & 1,10625 & 16 \\
Total & 4,7115 & 1,25946 & 40 \\
\hline
\end{tabular}

\section{Levene's Test of Equality of Error} Variances $^{\mathbf{a}}$

Dependent Variable: Nota2

\begin{tabular}{|c|r|r|r|}
\hline$F$ & df 1 & df2 & Sig. \\
\hline 1,453 & 1 & 38 &, 236 \\
\hline
\end{tabular}

Tests the null hypothesis that the error

variance of the dependent variable is

equal across groups.

a. Design: Intercept + Nota1 + Turma

Tests of Between-Subjects Effects

Dependent Variable: Nota2

\begin{tabular}{|l|r|r|r|r|r|r|r|r|}
\hline Source & $\begin{array}{c}\text { Type III Sum } \\
\text { of Squares }\end{array}$ & df & Mean Square & \multicolumn{1}{c|}{ F } & \multicolumn{1}{c|}{ Sig. } & $\begin{array}{c}\text { Partial Eta } \\
\text { Squared }\end{array}$ & $\begin{array}{c}\text { Noncent. } \\
\text { Parameter }\end{array}$ & $\begin{array}{c}\text { Observed } \\
\text { Power }\end{array}$ \\
\hline Corrected Model & $29,370^{\mathrm{a}}$ & 2 & 14,685 & 16,722 &, 000 &, 475 & 33,444 &, 999 \\
Intercept & 6,832 & 1 & 6,832 & 7,779 &, 008 &, 174 & 7,779 \\
Nota1 & 22,859 & 1 & 22,859 & 26,030 &, 000 &, 413 & 26,030 &, 775 \\
Turma & 7,307 & 1 & 7,307 & 8,321 &, 007 &, 184 & 8,321 \\
Error & 32,493 & 37 &, 878 & & & &, 802 \\
Total & 949,792 & 40 & & & & & \\
Corrected Total & 61,863 & 39 & & & & & \\
\end{tabular}

a. R Squared $=, 475$ (Adjusted R Squared $=, 446$ )

b. Computed using alpha $=, 05$

\section{Estimated Marginal Means}

Turma
Dependent Variable: Nota2
\begin{tabular}{|l|l|r|r|r|}
\hline & & \multicolumn{2}{|c|}{$95 \%$ Confidence Interval } \\
\cline { 4 - 5 } Turma & Mean & Std. Error & Lower Bound & Upper Bound \\
\hline 1,0 & $4,362^{\text {a }}$ &, 191 & 3,975 & 4,750 \\
2,0 & $5,235^{\text {a }}$ &, 234 & 4,760 & 5,710 \\
\hline
\end{tabular}
a. Covariates appearing in the model are evaluated at the
following values: Nota1 $=4,4990$.




\section{F3. ANCOVA para os níveis de profundidade (verbos) da taxonomia de Bloom} modificada e para o DoK de Webb.

Verbo "lembrar"

Between-Subjects
Factors
\begin{tabular}{|ll|r|}
\hline & & \multicolumn{1}{c|}{$\mathrm{N}$} \\
\hline Turma & 1,0 & 24 \\
& 2,0 & 16 \\
\hline
\end{tabular}

Descriptive Statistics

Dependent Variable:
\begin{tabular}{|l|c|r|r|}
\hline Turma & Mean & $\begin{array}{c}\text { Std. } \\
\text { Deviation }\end{array}$ & \multicolumn{1}{c|}{ N } \\
\hline 1,0 &, 4100 &, 19170 & 24 \\
2,0 &, 3930 &, 19387 & 16 \\
Total &, 4032 &, 19026 & 40 \\
\hline
\end{tabular}

\section{Levene's Test of Equality of Error}

$$
\text { Variances }^{\mathbf{a}}
$$

Dependent Variable: Remembering_depois

\begin{tabular}{|c|c|c|c|}
\hline $\mathrm{F}$ & $\mathrm{df} 1$ & $\mathrm{df} 2$ & Sig. \\
\hline , 378 & 1 & 38 & 543 \\
\hline
\end{tabular}

variance of the dependent variable is

equal across groups.

a. Design: Intercept + Remembering_antes

+ Turma

Tests of Between-Subjects Effects

\begin{tabular}{|c|c|c|c|c|c|c|c|c|}
\hline Source & $\begin{array}{c}\text { Type III Sum } \\
\text { of Squares }\end{array}$ & df & Mean Square & $\mathrm{F}$ & Sig. & $\begin{array}{c}\text { Partial Eta } \\
\text { Squared }\end{array}$ & $\begin{array}{l}\text { Noncent. } \\
\text { Parameter }\end{array}$ & $\begin{array}{l}\text { Observed } \\
\text { Power }\end{array}$ \\
\hline Corrected Model & $177^{\mathrm{a}}$ & 2 & .088 & 2,650 & .084 & .125 & 5,300 & 494 \\
\hline Intercept & ,499 & 1 & 499 & 14,961 &, 000 & ,288 & 14,961 & 965 \\
\hline Remembering_antes &, 174 & 1 &, 174 & 5,218 &, 028 &, 124 & 5,218 &, 604 \\
\hline Turma &, 005 & 1 &, 005 & 149 & ,702 & .004 & 149 &, 066 \\
\hline Error & 1,235 & 37 &, 033 & & & & & \\
\hline Total & 7,914 & 40 & & & & & & \\
\hline Corrected Total & 1,412 & 39 & & & & & & \\
\hline
\end{tabular}

a. $R$ Squared $=, 125$ (Adjusted $R$ Squared $=, 078$ )

b. Computed using alpha $=, 05$ 


\section{Verbo "entender"}

\section{Between-Subjects} Factors

\begin{tabular}{|c|c|c|}
\hline & & $\bar{N}$ \\
\hline \multirow{2}{*}{ Turma } & 1,0 & 24 \\
\hline & 2,0 & 16 \\
\hline
\end{tabular}

Descriptive Statistics

Dependent Variable: Understanding_depois

\begin{tabular}{|l|c|c|r|}
\hline Turma & Mean & $\begin{array}{c}\text { Std. } \\
\text { Deviation }\end{array}$ & \multicolumn{1}{c|}{ N } \\
\hline 1,0 &, 4200 &, 23962 & 24 \\
2,0 &, 4488 &, 23557 & 16 \\
Total &, 4315 &, 23539 & 40 \\
\hline
\end{tabular}

Levene's Test of Equality of Error Variances $^{\mathrm{a}}$

Dependent Variable: Understanding_depois

\begin{tabular}{|c|c|c|c|}
\hline $\mathrm{F}$ & df 1 & df2 & Sig. \\
\hline, 013 & 1 & 38 & 909 \\
\hline
\end{tabular}

Tests the null hypothesis that the erro

variance of the dependent variable is

equal across groups.

Design: Intercept +
Understanding_antes + Turma

Tests of Between-Subjects Effects

Dependent Variable: Understanding_depois

\begin{tabular}{|c|c|c|c|c|c|c|c|c|}
\hline Source & $\begin{array}{l}\text { Type III Sum } \\
\text { of Squares }\end{array}$ & df & Mean Square & $\mathrm{F}$ & Sig. & $\begin{array}{l}\text { Partial Eta } \\
\text { Squared }\end{array}$ & $\begin{array}{l}\text { Noncent. } \\
\text { Parameter }\end{array}$ & $\begin{array}{l}\text { Observed } \\
\text { Power }\end{array}$ \\
\hline Corrected Model & $301^{\mathrm{a}}$ & 2 &, 151 & 2,997 & .062 & .139 & 5,994 &, 547 \\
\hline Intercept &, 771 & 1 &, 771 & 15,347 &, 000 & 293 & 15,347 & 968 \\
\hline Understanding_antes & ,293 & 1 & 293 & 5,836 & .021 &, 136 & 5,836 &, 653 \\
\hline Turma &, 053 & 1 &, 053 & 1,057 &, 311 &, 028 & 1,057 &, 170 \\
\hline Error & 1,860 & 37 & .050 & & & & & \\
\hline Total & 9,610 & 40 & & & & & & \\
\hline Corrected Total & 2,161 & 39 & & & & & & \\
\hline
\end{tabular}

a. $\mathrm{R}$ Squared $=, 139$ (Adjusted R Squared $=, 093$ )

b. Computed using alpha $=, 05$ 
Verbo "aplicar"

Between-Subjects

Factors

\begin{tabular}{|rr|r|}
\hline & & \multicolumn{1}{|c|}{$\mathrm{N}$} \\
\hline Turma & 1,0 & 24 \\
& 2,0 & 16 \\
\hline
\end{tabular}

Descriptive Statistics

Dependent Variable: Applying_depois

\begin{tabular}{|l|c|c|r|}
\hline Turma & Mean & $\begin{array}{c}\text { Std. } \\
\text { Deviation }\end{array}$ & \multicolumn{1}{c|}{ N } \\
\hline 1,0 &, 4583 &, 26811 & 24 \\
2,0 &, 6344 &, 21964 & 16 \\
Total &, 5287 &, 26187 & 40 \\
\hline
\end{tabular}

Levene's Test of Equality of Error Variances

Dependent Variable: Applying_depois

\begin{tabular}{|c|c|c|c|}
\hline $\mathrm{F}$ & df 1 & df 2 & Sig. \\
\hline 1,886 & 1 & 38 &, 178 \\
\hline
\end{tabular}

Tests the null hypothesis that the error

variance of the dependent variable

equal across groups.

a. Design: Intercept + Applying_antes +

Turma

Tests of Between-Subjects Effects

Dependent Variable: Applying_depois

\begin{tabular}{|l|r|r|r|r|r|r|r|r|}
\hline Source & $\begin{array}{c}\text { Type III Sum } \\
\text { of Squares }\end{array}$ & df & Mean Square & \multicolumn{1}{c|}{ F } & \multicolumn{1}{c|}{ Sig. } & $\begin{array}{c}\text { Partial Eta } \\
\text { Squared }\end{array}$ & $\begin{array}{c}\text { Noncent. } \\
\text { Parameter }\end{array}$ & $\begin{array}{c}\text { Observed } \\
\text { Power }\end{array}$ \\
\hline Corrected Model &, $582^{\text {a }}$ & 2 &, 291 & 5,148 &, 011 &, 218 & 10,295 &, 793 \\
Intercept &, 611 & 1 &, 611 & 10,797 &, 002 &, 226 & 10,797 \\
Applying_antes &, 285 & 1 &, 285 & 5,034 &, 031 &, 120 & 5,034 &, 892 \\
Turma &, 157 & 1 &, 157 & 2,777 &, 104 &, 070 & 2,777 \\
Error & 2,092 & 37 &, 057 & & & &, 368 \\
Total & 13,858 & 40 & & & & & \\
Corrected Total & 2,674 & 39 & & & & & \\
\hline
\end{tabular}

a. R Squared $=, 218$ (Adjusted R Squared $=, 175$ )

b. Computed using alpha $=, 05$ 
Verbo "analisar"

\begin{tabular}{|c|c|c|}
\hline \multicolumn{3}{|c|}{$\begin{array}{c}\text { Between-Subjects } \\
\text { Factors }\end{array}$} \\
\hline & & $\bar{N}$ \\
\hline \multirow[t]{2}{*}{ Turma } & 1,0 & 24 \\
\hline & 2,0 & 16 \\
\hline
\end{tabular}

Descriptive Statistics

Dependent Variable: Analysing_depois

\begin{tabular}{|l|c|c|r|}
\hline Turma & Mean & $\begin{array}{c}\text { Std. } \\
\text { Deviation }\end{array}$ & \multicolumn{1}{c|}{$\mathrm{N}$} \\
\hline 1,0 &, 5411 &, 18090 & 24 \\
2,0 &, 6478 &, 15111 & 16 \\
Total &, 5838 &, 17573 & 40 \\
\hline
\end{tabular}

Levene's Test of Equality of Error Variances $^{\mathbf{a}}$

Dependent Variable: Analysing_depois

\begin{tabular}{|c|c|c|c|}
\hline $\mathrm{F}$ & df 1 & df2 & Sig. \\
\hline 193 & 1 & 38 &, 663 \\
\hline
\end{tabular}

Tests the null hypothesis that the error
variance of the dependent variable is

equal across groups.

a. Design: Intercept + Analysing_antes +

Turma

Tests of Between-Subjects Effects

Dependent Variable: Analysing_depois

\begin{tabular}{|l|r|r|r|r|r|r|r|r|}
\hline Source & $\begin{array}{c}\text { Type III Sum } \\
\text { of Squares }\end{array}$ & df & Mean Square & \multicolumn{1}{c|}{ F } & \multicolumn{1}{l|}{ Sig. } & $\begin{array}{c}\text { Partial Eta } \\
\text { Squared }\end{array}$ & $\begin{array}{c}\text { Noncent. } \\
\text { Parameter }\end{array}$ & $\begin{array}{c}\text { Observed } \\
\text { Power }\end{array}$ \\
\hline Corrected Model &, $138^{\mathrm{a}}$ & 2 &, 069 & 2,399 &, 105 &, 115 & 4,799 &, 454 \\
Intercept & 2,329 & 1 & 2,329 & 80,813 &, 000 &, 686 & 80,813 \\
Analysing_antes &, 029 & 1 &, 029 & 1,008 &, 322 &, 027 & 1,008 \\
Turma & 1,066 & 37 &, 029 & & &, 090 & 3,676 \\
Error & 14,835 & 40 & & & & &, 465 \\
Total & 1,204 & 39 & & & & & \\
Corrected Total & 106 & & & & \\
\hline
\end{tabular}

a. R Squared $=, 115$ (Adjusted R Squared $=, 067$ )

b. Computed using alpha $=, 05$ 


\section{DoK1}

Between-Subjects

Factors

\begin{tabular}{|rr|r|}
\hline & & \multicolumn{1}{|c|}{$\mathrm{N}$} \\
\hline Turma & 1,0 & 24 \\
& 2,0 & 16 \\
\hline
\end{tabular}

Descriptive Statistics

Dependent Variable: DOK1_Depois

\begin{tabular}{|l|c|r|r|}
\hline Turma & Mean & $\begin{array}{c}\text { Std. } \\
\text { Deviation }\end{array}$ & \multicolumn{1}{c|}{ N } \\
\hline 1,0 &, 4151 &, 18702 & 24 \\
2,0 &, 4227 &, 13508 & 16 \\
Total &, 4182 &, 16631 & 40 \\
\hline
\end{tabular}

Levene's Test of Equality of Error Variances

Dependent Variable: DOK1_Depois

\begin{tabular}{|c|c|c|c|}
\hline $\mathrm{F}$ & df 1 & df 2 & Sig. \\
\hline 1,094 & 1 & 38 &, 302 \\
\hline
\end{tabular}
Tests the null hypothesis that the error
variance of the dependent variable is
equal across groups.
a. Design: Intercept + DOK1_Antes +
Turma

Tests of Between-Subjects Effects

Dependent Variable: DOK1_Depois

\begin{tabular}{|l|r|r|r|r|r|r|r|r|}
\hline Source & $\begin{array}{c}\text { Type III Sum } \\
\text { of Squares }\end{array}$ & df & Mean Square & \multicolumn{1}{c|}{ F } & \multicolumn{1}{c|}{ Sig. } & $\begin{array}{c}\text { Partial Eta } \\
\text { Squared }\end{array}$ & $\begin{array}{c}\text { Noncent. } \\
\text { Parameter }\end{array}$ & $\begin{array}{c}\text { Observed } \\
\text { Power }\end{array}$ \\
\hline Corrected Model &, $205^{\mathrm{a}}$ & 2 &, 102 & 4,335 &, 020 &, 190 & 8,669 &, 717 \\
Intercept &, 279 & 1 &, 279 & 11,809 &, 001 &, 242 & 11,809 \\
DoK1_Antes &, 204 & 1 &, 204 & 8,645 &, 006 &, 189 & 8,645 &, 917 \\
Turma &, 010 & 1 &, 010 &, 429 &, 517 &, 011 &, 429 &, 098 \\
Error &, 874 & 37 &, 024 & & & & \\
Total & 8,073 & 40 & & & & & \\
Corrected Total & 1,079 & 39 & & & & & \\
\hline
\end{tabular}

a. R Squared $=, 190$ (Adjusted R Squared $=, 146$ )

b. Computed using alpha $=, 05$ 
DoK2

Between-Subjects

Factors

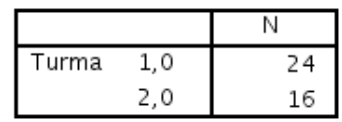

Descriptive Statistics

Dependent Variable: DOK2_Depois
\begin{tabular}{|l|c|c|r|}
\hline Turma & Mean & $\begin{array}{c}\text { Std. } \\
\text { Deviation }\end{array}$ & N \\
\hline 1,0 &, 5162 &, 17129 & 24 \\
2,0 &, 6440 &, 13323 & 16 \\
Total &, 5673 &, 16777 & 40 \\
\hline
\end{tabular}

Levene's Test of Equality of Error Variances $^{\mathbf{a}}$

Dependent Variable: DOK2_Depois

\begin{tabular}{|c|c|c|c|}
\hline F & df 1 & df2 & Sig. \\
\hline .093 & 1 & 38 &, 762 \\
\hline
\end{tabular}

Tests the null hypothesis that the error

variance of the dependent variable is

equal across groups.

a. Design: Intercept + DOK2_Antes +

Turma

Tests of Between-Subjects Effects

Dependent Variable: DOK2_Depois

\begin{tabular}{|c|c|c|c|c|c|c|c|c|}
\hline Source & $\begin{array}{c}\text { Type III Sum } \\
\text { of Squares }\end{array}$ & df & Mean Square & $\mathrm{F}$ & Sig. & $\begin{array}{c}\text { Partial Eta } \\
\text { Squared }\end{array}$ & $\begin{array}{l}\text { Noncent. } \\
\text { Parameter }\end{array}$ & $\begin{array}{l}\text { Observed } \\
\text { Power }\end{array}$ \\
\hline Corrected Model & $.244^{\mathrm{a}}$ & 2 &, 122 & 5,281 & .010 & 222 & 10,562 & 804 \\
\hline Intercept & 981 & 1 & 981 & 42,502 &, 000 &, 535 & 42,502 & 1,000 \\
\hline DOK2_Antes &, 087 & 1 &, 087 & 3,773 &, 060 & .093 & 3,773 & 473 \\
\hline Turma &, 126 & 1 &, 126 & 5,464 & .025 &, 129 & 5,464 & 624 \\
\hline Error & 854 & 37 &, 023 & & & & & \\
\hline Total & 13,971 & 40 & & & & & & \\
\hline Corrected Total & 1,098 & 39 & & & & & & \\
\hline
\end{tabular}

a. $\mathrm{R}$ Squared $=, 222$ (Adjusted R Squared $=, 180$ )

b. Computed using alpha $=, 05$ 


\section{F4. ANCOVA para os diferentes assuntos considerados}

Assunto: Ciclo Planejamento-Execução-Controle

\begin{tabular}{|c|c|c|c|}
\hline \multicolumn{4}{|c|}{$\begin{array}{c}\text { Between-Subjects } \\
\text { Factors }\end{array}$} \\
\hline & & $\bar{N}$ & \\
\hline \multirow[t]{2}{*}{ Turma } & 1,0 & 24 & \\
\hline & 2,0 & 16 & \\
\hline \multicolumn{4}{|c|}{ Descriptive Statistics } \\
\hline \multicolumn{2}{|c|}{ Dependent Variable: } & PEC_Total_de & \\
\hline Turma & Mean & $\begin{array}{c}\text { Std. } \\
\text { Deviation }\end{array}$ & $\mathrm{N}$ \\
\hline 1,0 & 45,6000 & 19,01667 & 24 \\
\hline 2,0 & 51,5813 & 13,78860 & 16 \\
\hline Total & 47,9925 & 17,18147 & 40 \\
\hline
\end{tabular}

Levene's Test of Equality of Error Variances $^{\mathbf{a}}$

Dependent Variable: PEC_Total_depois

\begin{tabular}{|}
\begin{tabular}{|c|c|c|c|}
\hline $\mathrm{F}$ & df 1 & df2 & Sig. \\
\hline 1,501 & 1 & 38 &, 228 \\
\hline
\end{tabular} \\
Tests the null hypothesis that the error
\end{tabular}

Tests the null hypothesis that the error

equal across groups.

a. Design: Intercept + PEC_Total_antes +

Tests of Between-Subjects Effects

Dependent Variable: PEC_Total_depois

\begin{tabular}{|l|r|r|r|r|r|r|r|r|}
\hline Source & $\begin{array}{c}\text { Type III Sum } \\
\text { of Squares }\end{array}$ & df & Mean Square & \multicolumn{1}{c|}{ F } & \multicolumn{1}{c|}{ Sig. } & \multicolumn{1}{c|}{$\begin{array}{c}\text { Partial Eta } \\
\text { Squared }\end{array}$} & \multicolumn{1}{c|}{$\begin{array}{c}\text { Noncent. } \\
\text { Parameter }\end{array}$} & $\begin{array}{c}\text { Observed } \\
\text { Power }\end{array}$ \\
\hline Corrected Model & $2278,391^{\mathrm{a}}$ & 2 & 1139,196 & 4,564 &, 017 &, 198 & 9,129 &, 740 \\
Intercept & 3478,617 & 1 & 3478,617 & 13,938 &, 001 &, 274 & 13,938 \\
PEC_Total_antes & 1934,948 & 1 & 1934,948 & 7,753 &, 008 &, 173 & 7,753 \\
Turma & 659,225 & 1 & 659,225 & 2,641 &, 113 &, 067 & 2,641 \\
Error & 9234,517 & 37 & 249,582 & & & &, 774 \\
Total & 103644,110 & 40 & & & & & \\
Corrected Total & 11512,908 & 39 & & & & & \\
\hline
\end{tabular}

a. R Squared $=, 198$ (Adjusted R Squared $=, 155$ )

b. Computed using alpha $=, 05$ 
Assunto: Visão Sistêmica

Between-Subjects
Factors
\begin{tabular}{|rr|r|}
\hline & & \multicolumn{1}{|c|}{ N } \\
\hline Turma & 1,0 & 24 \\
& 2,0 & 16 \\
\hline
\end{tabular}

Descriptive Statistics

Dependent Variable: VS_Total_depois

Dependent Variable: VS_Total_depois
\begin{tabular}{|l|c|c|r|}
\hline Turma & Mean & $\begin{array}{c}\text { Std. } \\
\text { Deviation }\end{array}$ & N \\
\hline 1,0 & 53,8167 & 18,06172 & 24 \\
2,0 & 62,5000 & 17,48653 & 16 \\
Total & 57,2900 & 18,12614 & 40 \\
\hline
\end{tabular}

Levene's Test of Equality of Error Variances $^{\mathbf{a}}$

Dependent Variable: VS_Total_depois

\begin{tabular}{|c|c|c|c|}
\hline $\mathrm{F}$ & df 1 & df 2 & Sig. \\
\hline, 013 & 1 & 38 &, 909 \\
\hline
\end{tabular}

Tests the null hypothesis that the error

equal across groups.

a. Design: Intercept + VS_Total_antes +

Turma

Tests of Between-Subjects Effects

Dependent Variable: VS_Total_depois

\begin{tabular}{|l|r|r|r|r|r|r|r|r|}
\hline Source & \multicolumn{1}{|c|}{$\begin{array}{c}\text { Type III Sum } \\
\text { of Squares }\end{array}$} & df & Mean Square & \multicolumn{1}{c|}{ F } & \multicolumn{1}{c|}{ Sig. } & $\begin{array}{c}\text { Partial Eta } \\
\text { Squared }\end{array}$ & $\begin{array}{c}\text { Noncent. } \\
\text { Parameter }\end{array}$ & $\begin{array}{c}\text { Observed } \\
\text { Power }\end{array}$ \\
\hline Corrected Model & $739,223^{\mathrm{a}}$ & 2 & 369,611 & 1,133 &, 333 &, 058 & 2,265 &, 234 \\
Intercept & 19901,307 & 1 & 19901,307 & 60,984 &, 000 &, 622 & 60,984 \\
VS_Total_antes & 15,380 & 1 & 15,380 &, 047 &, 829 &, 001 &, 047 &, 000 \\
Turma & 722,084 & 1 & 722,084 & 2,213 &, 145 &, 056 & 2,213 \\
Error & 12074,493 & 37 & 326,338 & & & &, 305 \\
Total & 144099,480 & 40 & & & & & \\
Corrected Total & 12813,716 & 39 & & & & & \\
\hline
\end{tabular}

a. R Squared $=, 058$ (Adjusted R Squared $=, 007$ )

b. Computed using alpha $=, 05$ 
Assunto: Papéis Gerenciais

Between-Subjects
Factors
\begin{tabular}{|rr|r|}
\hline & & \multicolumn{1}{|c|}{ N } \\
\hline Turma & 1,0 & 24 \\
& 2,0 & 16 \\
\hline
\end{tabular}

Descriptive Statistics

Dependent Variable: PG_Total_depois

\begin{tabular}{|l|c|c|r|}
\hline Turma & Mean & $\begin{array}{c}\text { Std. } \\
\text { Deviation }\end{array}$ & N \\
\hline 1,0 & 36,9792 & 22,56608 & 24 \\
2,0 & 46,0937 & 18,66299 & 16 \\
Total & 40,6250 & 21,32434 & 40 \\
\hline
\end{tabular}

Levene's Test of Equality of Error Variances $^{\mathbf{a}}$

Dependent Variable: PG_Total_depois

\begin{tabular}{|c|c|c|c|}
\hline $\mathrm{F}$ & df 1 & df2 & Sig. \\
\hline 1,596 & 1 & 38 &, 214 \\
\hline
\end{tabular}

Tests the null hypothesis that the error

variance of the depens.
equal across groups.

a. Design: Intercept + PG_Total_antes +

Tests of Between-Subjects Effects

Dependent Variable: PG_Total_depois

\begin{tabular}{|l|r|r|r|r|r|r|r|r|}
\hline Source & $\begin{array}{c}\text { Type III Sum } \\
\text { of Squares }\end{array}$ & df & Mean Square & F & Sig. & $\begin{array}{c}\text { Partial Eta } \\
\text { Squared }\end{array}$ & $\begin{array}{c}\text { Noncent. } \\
\text { Parameter }\end{array}$ & $\begin{array}{c}\text { Observed } \\
\text { Power }\end{array}$ \\
\hline Corrected Model & $3734,930^{\mathrm{a}}$ & 2 & 1867,465 & 4,936 &, 013 &, 211 & 9,871 &, 775 \\
Intercept & 1451,603 & 1 & 1451,603 & 3,837 &, 058 &, 094 & 3,837 &, 479 \\
PG_Total_antes & 2937,404 & 1 & 2937,404 & 7,763 &, 008 &, 173 & $, 7,763$ &, 374 \\
Turma & 119,934 & 1 & 119,934 &, 317 &, 577 &, 008 &, 085 \\
Error & 13999,445 & 37 & 378,363 & & & & \\
Total & 83750,000 & 40 & & & & & \\
Corrected Total & 17734,375 & 39 & & & & & \\
\hline
\end{tabular}

a. R Squared $=, 211$ (Adjusted R Squared $=, 168$ )

b. Computed using alpha $=, 05$ 
Apêndice G Saídas do SPSS para Experimento 2

\section{G1. Teste das premissas da ANOVA}

- ausência de outliers

\begin{tabular}{|c|c|c|c|c|c|}
\hline \multicolumn{6}{|c|}{ Extreme Values } \\
\hline \multicolumn{4}{|c|}{ Jogo } & $\begin{array}{c}\text { Case } \\
\text { Number }\end{array}$ & Value \\
\hline \multirow[t]{20}{*}{ Grade/10.00 } & \multirow[t]{10}{*}{0} & \multirow[t]{5}{*}{ Highest } & 1 & 11 & 6,39 \\
\hline & & & 2 & 16 & 5,83 \\
\hline & & & 3 & 20 & 5,83 \\
\hline & & & 4 & 13 & 5,56 \\
\hline & & & 5 & 17 & 5,56 \\
\hline & & \multirow[t]{5}{*}{ Lowest } & 1 & 18 & 2,50 \\
\hline & & & 2 & 19 & 3,89 \\
\hline & & & 3 & 15 & 4,17 \\
\hline & & & 4 & 14 & 4,44 \\
\hline & & & 5 & 21 & 4,72 \\
\hline & \multirow[t]{10}{*}{1,0} & \multirow[t]{5}{*}{ Highest } & 1 & 4 & 6,94 \\
\hline & & & 2 & 6 & 6,94 \\
\hline & & & 3 & 22 & 6,67 \\
\hline & & & 4 & 2 & 5,83 \\
\hline & & & 5 & 3 & $5,56^{\mathrm{a}}$ \\
\hline & & \multirow[t]{5}{*}{ Lowest } & 1 & 10 & 4,44 \\
\hline & & & 2 & 9 & 5,00 \\
\hline & & & 3 & 8 & 5,00 \\
\hline & & & 4 & 1 & 5,00 \\
\hline & & & 5 & 7 & $5,56^{\mathrm{b}}$ \\
\hline
\end{tabular}

a. Only a partial list of cases with the value 5,56 are shown in the table of upper extremes.

b. Only a partial list of cases with the value 5,56 are shown in the table of lower extremes.

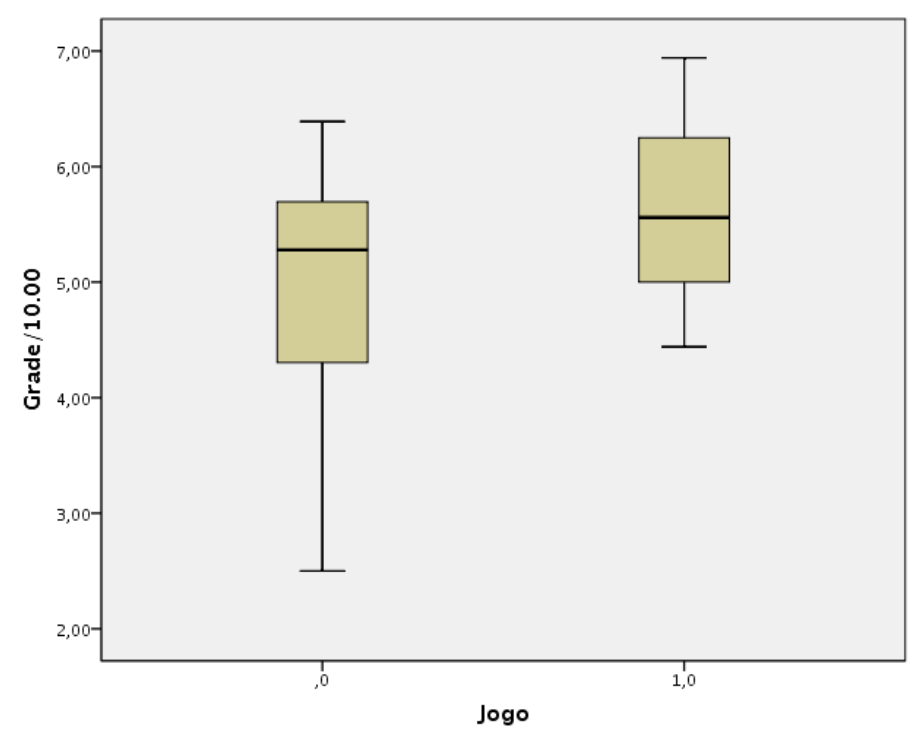

- homogeneidade da variância nos grupos 


\section{Levene's Test of Equality of Error}

Variances ${ }^{a}$

Dependent Variable: Grade/10.00

\begin{tabular}{|c|c|c|c|}
\hline $\mathrm{F}$ & df 1 & df 2 & Sig. \\
\hline 936 & 1 & 20 &, 345 \\
\hline
\end{tabular}

Tests the null hypothesis that the error

variance of the dependent variable is

equal across groups.

a. Design: Intercept + Jogo

- distribuição normal da variável dependente nos grupos

\begin{tabular}{|c|c|c|c|c|c|}
\hline \\
\hline & Jogo & & & Statistic & Std. Error \\
\hline \multirow[t]{26}{*}{ Grade $/ 10.00$} & \multirow[t]{13}{*}{.0} & Mean & & 4,9245 & .33731 \\
\hline & & \multirow{2}{*}{$\begin{array}{l}95 \% \text { Confidence Interval } \\
\text { for Mean }\end{array}$} & Lower Bound & 4,1730 & \\
\hline & & & Upper Bound & 5,6761 & \\
\hline & & \multicolumn{2}{|l|}{ 5\% Trimmed Mean } & 4,9778 & \\
\hline & & \multicolumn{2}{|l|}{ Median } & 5,2800 & \\
\hline & & \multicolumn{2}{|l|}{ Variance } & 1,252 & \\
\hline & & \multicolumn{2}{|l|}{ Std. Deviation } & 1,11874 & \\
\hline & & \multicolumn{2}{|l|}{ Minimum } & 2,50 & \\
\hline & & \multicolumn{2}{|l|}{ Maximum } & 6,39 & \\
\hline & & \multicolumn{2}{|l|}{ Range } & 3,89 & \\
\hline & & \multicolumn{2}{|l|}{ Interquartile Range } & 1,66 & \\
\hline & & \multicolumn{2}{|l|}{ Skewness } &,- 936 & 661 \\
\hline & & \multicolumn{2}{|l|}{ Kurtosis } &, 793 & 1,279 \\
\hline & \multirow[t]{13}{*}{1,0} & \multicolumn{2}{|l|}{ Mean } & 5,6818 &, 25488 \\
\hline & & \multirow{2}{*}{$\begin{array}{l}95 \% \text { Confidence Interval } \\
\text { for Mean }\end{array}$} & Lower Bound & 5,1139 & \\
\hline & & & Upper Bound & 6,2497 & \\
\hline & & \multicolumn{2}{|l|}{$5 \%$ Trimmed Mean } & 5,6809 & \\
\hline & & \multirow{2}{*}{\multicolumn{2}{|c|}{ Median }} & 5,5600 & \\
\hline & & Variance & &, 715 & \\
\hline & & \multicolumn{2}{|l|}{ Std. Deviation } & 84533 & \\
\hline & & \multicolumn{2}{|l|}{ Minimum } & 4,44 & \\
\hline & & \multicolumn{2}{|l|}{ Maximum } & 6,94 & \\
\hline & & \multicolumn{2}{|l|}{ Range } & 2,50 & \\
\hline & & \multicolumn{2}{|l|}{ Interquartile Range } & 1,67 & \\
\hline & & \multicolumn{2}{|l|}{ Skewness } & .421 & 661 \\
\hline & & \multicolumn{2}{|l|}{ Kurtosis } & -938 & 1,279 \\
\hline
\end{tabular}

Tests of Normality

\begin{tabular}{|cc|r|r|r|r|r|r|}
\hline \multirow{2}{*}{} & \multicolumn{3}{|c|}{ Kolmogorov-Smirnov $^{\mathrm{a}}$} & \multicolumn{3}{|c|}{ Shapiro-Wilk } \\
\cline { 3 - 8 } & Statistic & \multicolumn{1}{c|}{ df } & \multicolumn{1}{c|}{ Sig. } & Statistic & \multicolumn{1}{c|}{ df } & \multicolumn{1}{c|}{ Sig. } \\
\hline Grade/10.00 &, 0 &, 170 & 11 &, $200^{*}$ &, 932 & 11 &, 434 \\
& 1,0 &, 194 & 11 &, $200^{*}$ &, 903 & 11 &, 198 \\
\hline
\end{tabular}

*. This is a lower bound of the true significance.

a. Lilliefors Significance Correction

- independência dos erros
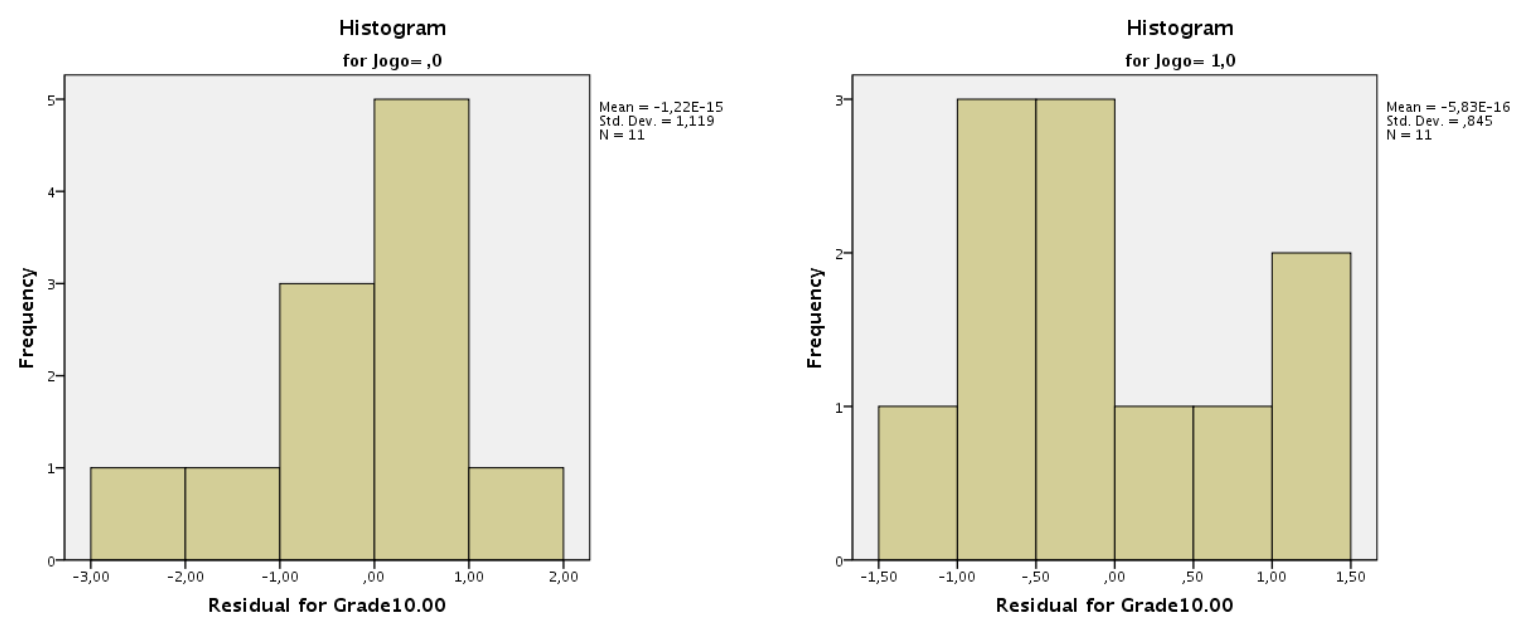


\begin{tabular}{|c|c|c|c|c|c|c|c|}
\hline \multicolumn{8}{|c|}{ Tests of Normality } \\
\hline & \multirow[b]{2}{*}{ Jogo } & \multicolumn{3}{|c|}{ Kolmogorov-Smirnov } & \multicolumn{3}{|c|}{ Shapiro-Wilk } \\
\hline & & Statistic & df & Sig. & Statistic & df & Sig. \\
\hline Residual for Grade 10. & .0 & .170 & 11 & $200^{\prime \prime}$ & .932 & 11 & .434 \\
\hline & 1,0 & 194 & 11 &, $200^{*}$ & ,903 & 11 & 198 \\
\hline
\end{tabular}

*. This is a lower bound of the true significance.

a. Lilliefors Significance Correction

\section{G2. ANOVA}

Between-Subjects
Factors
\begin{tabular}{|ll|r|}
\hline & & \multicolumn{1}{|c}{ N } \\
\hline Jogo &, 0 & 11 \\
& 1,0 & 11 \\
\hline
\end{tabular}

Descriptive Statistics

Dependent Variable: Grade/10.00

\begin{tabular}{|l|c|r|r|}
\hline Jogo & Mean & \multicolumn{1}{|c|}{$\begin{array}{c}\text { Std. } \\
\text { Deviation }\end{array}$} & \multicolumn{1}{|c|}{$\mathrm{N}$} \\
\hline, 0 & 4,9245 & 1,11874 & 11 \\
1,0 & 5,6818 &, 84533 & 11 \\
Total & 5,3032 & 1,04233 & 22 \\
\hline
\end{tabular}

Tests of Between-Subjects Effects

Dependent Variable: Grade/10.00

\begin{tabular}{|c|c|c|c|c|c|c|c|c|}
\hline Source & $\begin{array}{c}\text { Type III Sum } \\
\text { of Squares }\end{array}$ & df & Mean Square & $\mathrm{F}$ & Sig. & $\begin{array}{c}\text { Partial Eta } \\
\text { Squared }\end{array}$ & $\begin{array}{l}\text { Noncent. } \\
\text { Parameter }\end{array}$ & $\begin{array}{l}\text { Observed } \\
\text { Power }\end{array}$ \\
\hline Corrected Model & $3,154^{\mathrm{a}}$ & 1 & 3,154 & 3,208 & .088 &, 138 & 3,208 & 400 \\
\hline Intercept & 618,722 & 1 & 618,722 & 629,370 &, 000 & 969 & 629,370 & 1,000 \\
\hline Jogo & 3,154 & 1 & 3,154 & 3,208 &, 088 &, 138 & 3,208 &, 400 \\
\hline Error & 19,662 & 20 & 983 & & & & & \\
\hline Total & 641,538 & 22 & & & & & & \\
\hline Corrected Total & 22,816 & 21 & & & & & & \\
\hline
\end{tabular}

a. R Squared $=, 138$ (Adjusted R Squared $=, 095$ )

b. Computed using alpha $=, 05$

\section{G3. ANOVA para o pós-teste do experimento 1 - comparativo}


Between-Subjects

Factors

\begin{tabular}{|rr|r|}
\hline & & \multicolumn{1}{|c|}{ N } \\
\hline Turma & 1,0 & 34 \\
& 2,0 & 28 \\
\hline
\end{tabular}

Descriptive Statistics

Dependent Variable: Nota2

\begin{tabular}{|l|c|c|c|}
\hline Turma & Mean & $\begin{array}{c}\text { Std. } \\
\text { Deviation }\end{array}$ & N \\
\hline 1,0 & 4,0544 & 2,16514 & 34 \\
2,0 & 3,3814 & 2,52573 & 28 \\
Total & 3,7505 & 2,33959 & 62 \\
\hline
\end{tabular}

Levene's Test of Equality of Error

Variances $^{a}$

Dependent Variable: Nota2

\begin{tabular}{|c|c|c|c|}
\hline $\mathrm{F}$ & $\mathrm{df} 1$ & $\mathrm{df} 2$ & Sig. \\
\hline 2,506 & 1 & 60 & 119 \\
\hline
\end{tabular}
Tests the null hypothesis that the error
variance of the dependent variable is
equal across groups.
a. Design: Intercept + Turma

Tests of Between-Subjects Effects

Dependent Variable: Nota2

\begin{tabular}{|c|c|c|c|c|c|c|c|c|}
\hline Source & $\begin{array}{l}\text { Type III Sum } \\
\text { of Squares }\end{array}$ & df & Mean Square & $\mathrm{F}$ & Sig. & $\begin{array}{l}\text { Partial Eta } \\
\text { Squared }\end{array}$ & $\begin{array}{l}\text { Noncent. } \\
\text { Parameter }\end{array}$ & $\begin{array}{l}\text { Observed } \\
\text { Power }\end{array}$ \\
\hline Corrected Model & $6,954^{\mathrm{a}}$ & 1 & 6,954 & 1,276 & 263 & .021 & 1,276 & 199 \\
\hline Intercept & 848,995 & 1 & 848,995 & 155,808 &, 000 &, 722 & 155,808 & 1,000 \\
\hline Turma & 6,954 & 1 & 6,954 & 1,276 & 263 & 021 & 1,276 & 199 \\
\hline Error & 326,940 & 60 & 5,449 & & & & & \\
\hline Total & 1205,994 & 62 & & & & & & \\
\hline Corrected Total & 333,894 & 61 & & & & & & \\
\hline
\end{tabular}

a. $R$ Squared $=, 021$ (Adjusted R Squared $=, 005$ )

b. Computed using alpha $=, 05$ 
G4. ANOVA para os níveis de profundidade (verbos) da taxonomia de Bloom modificada e para o DoK de Webb

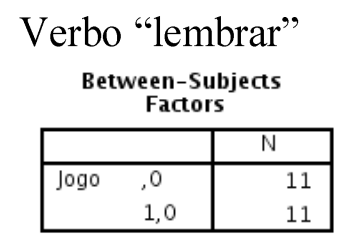

Descriptive Statistics

Dependent Variable: Remembering
\begin{tabular}{|l|c|c|c|}
\hline Jogo & Mean & $\begin{array}{c}\text { Std. } \\
\text { Deviation }\end{array}$ & \multicolumn{1}{c|}{ N } \\
\hline, 0 &, 464 &, 1433 & 11 \\
1,0 &, 582 &, 1601 & 11 \\
Total &, 523 &, 1602 & 22 \\
\hline
\end{tabular}

Levene's Test of Equality of Error Variances $^{\mathbf{a}}$

Dependent Variable: Remembering

Dependent Variable: Remembering
\begin{tabular}{|c|c|c|c|}
\hline $\mathrm{F}$ & df 1 & df 2 & Sig. \\
\hline, 088 & 1 & 20 &, 770 \\
\hline
\end{tabular}
Tests the null hypothesis that the error
variance of the dependent variable is
equal across groups.
a. Design: Intercept + Jogo

Tests of Between-Subjects Effects

\begin{tabular}{|c|c|c|c|c|c|c|c|c|}
\hline Source & $\begin{array}{c}\text { Type III Sum } \\
\text { of Squares }\end{array}$ & df & Mean Square & $\mathrm{F}$ & Sig. & $\begin{array}{c}\text { Partial Eta } \\
\text { Squared }\end{array}$ & $\begin{array}{l}\text { Noncent. } \\
\text { Parameter }\end{array}$ & $\begin{array}{c}\text { Observed } \\
\text { Power }\end{array}$ \\
\hline Corrected Model &, $077^{\mathrm{a}}$ & 1 & .077 & 3,327 & .083 &, 143 & 3,327 &, 412 \\
\hline Intercept & 6,011 & 1 & 6,011 & 260,335 &, 000 & ,929 & 260,335 & 1,000 \\
\hline Jogo & .077 & 1 & .077 & 3,327 &, 083 &, 143 & 3,327 &, 412 \\
\hline Error &, 462 & 20 & .023 & & & & & \\
\hline Total & 6,550 & 22 & & & & & & \\
\hline Corrected Total &, 539 & 21 & & & & & & \\
\hline
\end{tabular}

a. R Squared $=, 143$ (Adjusted R Squared $=, 100$ )

b. Computed using alpha $=, 05$ 
Verbo "entender"

\section{Between-Subjects}

Factors

\begin{tabular}{|ll|r|}
\hline & \multicolumn{1}{|c|}{$N$} \\
\hline Jogo &, 0 & 11 \\
& 1,0 & 11 \\
\hline
\end{tabular}

\section{Descriptive Statistics}

Dependent Variable: understanding

\begin{tabular}{|l|r|r|r|}
\hline Jogo & Mean & \multicolumn{1}{|c|}{$\begin{array}{c}\text { Std. } \\
\text { Deviation }\end{array}$} & \multicolumn{1}{|c|}{ N } \\
\hline, 0 &, 476 &, 1859 & 11 \\
1,0 &, 517 &, 1334 & 11 \\
Total &, 496 &, 1593 & 22 \\
\hline
\end{tabular}

Levene's Test of Equality of Error Variances $^{\mathbf{a}}$

Dependent Variable: understanding

\begin{tabular}{|c|c|c|c|}
\hline $\mathrm{F}$ & df 1 & df2 & Sig. \\
\hline, 462 & 1 & 20 & 504 \\
\hline
\end{tabular}

Tests the null hypothesis that the error

variance of the dependent variable is

equal across groups.

a. Design: Intercept + Jogo

Tests of Between-Subjects Effects

Dependent Variable: understanding

\begin{tabular}{|l|r|r|r|r|r|r|r|r|}
\hline Source & $\begin{array}{c}\text { Type III Sum } \\
\text { of Squares }\end{array}$ & df & Mean Square & F & \multicolumn{1}{c|}{ Sig. } & $\begin{array}{c}\text { Partial Eta } \\
\text { Squared }\end{array}$ & $\begin{array}{c}\text { Noncent. } \\
\text { Parameter }\end{array}$ & $\begin{array}{c}\text { Observed } \\
\text { Power }\end{array}$ \\
\hline Corrected Model &, $009^{\text {a }}$ & 1 &, 009 &, 353 &, 559 &, 017 &, 353 &, 087 \\
Intercept & 5,413 & 1 & 5,413 & 206,792 &, 000 &, 912 & 206,792 \\
Jogo &, 009 & 1 &, 009 &, 353 &, 559 &, 017 &, 353 \\
Error & 5,524 & 20 &, 026 & & & &, 000 \\
Total &, 536 & 22 & & & & & \\
Corrected Total & 21 & & & & \\
\hline
\end{tabular}

a. R Squared $=, 017$ (Adjusted R Squared $=-, 032$ )

b. Computed using alpha $=, 05$ 


\section{Verbo "aplicar"}

Between-Subjects
Factors
\begin{tabular}{|ll|r|}
\hline & & \multicolumn{1}{|c|}{$\mathrm{N}$} \\
\hline Jogo & 0 & 11 \\
& 1,0 & 11 \\
\hline
\end{tabular}

Descriptive Statistics

Dependent Variable: Applying
\begin{tabular}{|l|c|r|r|}
\hline Jogo & Mean & $\begin{array}{c}\text { Std. } \\
\text { Deviation }\end{array}$ & \multicolumn{1}{c|}{ N } \\
\hline, 0 &, 509 &, 2256 & 11 \\
1,0 &, 600 &, 2683 & 11 \\
Total &, 555 &, 2464 & 22 \\
\hline
\end{tabular}

Levene's Test of Equality of Error Variances $^{\mathrm{a}}$

Dependent Variable: Applying

\begin{tabular}{|c|c|c|c|}
\hline $\mathrm{F}$ & $\mathrm{df} 1$ & $\mathrm{df} 2$ & $\mathrm{Sig}$. \\
\hline, 552 & 1 & 20 &, 466 \\
\hline
\end{tabular}

Tests the null hypothesis that the error

equal across groups.

a. Design: Intercept + Jogo

Tests of Between-Subjects Effects

Dependent Variable: Applying

\begin{tabular}{|l|r|r|r|r|r|r|r|r|}
\hline Source & $\begin{array}{c}\text { Type III Sum } \\
\text { of Squares }\end{array}$ & df & Mean Square & \multicolumn{1}{c|}{ F } & \multicolumn{1}{c|}{ Sig. } & $\begin{array}{c}\text { Partial Eta } \\
\text { Squared }\end{array}$ & $\begin{array}{c}\text { Noncent. } \\
\text { Parameter }\end{array}$ & $\begin{array}{c}\text { Observed } \\
\text { Power }\end{array}$ \\
\hline Corrected Model &, $045^{\mathbf{a}}$ & 1 &, 045 &, 740 &, 400 &, 036 &, 740 &, 130 \\
Intercept & 6,765 & 1 & 6,765 & 110,089 &, 000 &, 846 & 110,089 &, 000 \\
Jogo &, 045 & 1 &, 045 &, 740 &, 400 &, 036 &, 130 \\
Error & 1,229 & 20 &, 061 & & & & \\
Total & 8,040 & 22 & & & & & \\
Corrected Total & 1,275 & 21 & & & & & \\
\hline
\end{tabular}

a. R Squared $=, 036$ (Adjusted R Squared $=-, 013$ )

b. Computed using alpha $=, 05$ 
Verbo "analisar"

Between-Subjects

Factors

\begin{tabular}{|ll|r|}
\hline & \multicolumn{1}{|c|}{$\mathrm{N}$} \\
\hline Jogo &, 0 & 11 \\
& 1,0 & 11 \\
\hline
\end{tabular}

Descriptive Statistics

Dependent Variable: Analysing
\begin{tabular}{|l|c|r|r|}
\hline Jogo & Mean & $\begin{array}{c}\text { Std. } \\
\text { Deviation }\end{array}$ & \multicolumn{1}{c|}{ N } \\
\hline, 0 &, 522 &, 1345 & 11 \\
1,0 &, 583 &, 1622 & 11 \\
Total &, 553 &, 1486 & 22 \\
\hline
\end{tabular}

Levene's Test of Equality of Error

$$
\text { Variances }
$$

Dependent Variable: Analysing

Dependent Variable: Analysing
\begin{tabular}{|c|c|c|c|}
\hline F & df 1 & df 2 & Sig. \\
\hline 131 & 1 & 20 &, 721 \\
\hline
\end{tabular}
Tests the null hypothesis that the error

Tests the null hypothesis that the error

variance of the depender

a. Design: Intercept + Jogo

Tests of Between-Subjects Effects

\begin{tabular}{|c|c|c|c|c|c|c|c|c|}
\hline Source & $\begin{array}{c}\text { Type III Sum } \\
\text { of Squares }\end{array}$ & $\mathrm{df}$ & Mean Square & $\mathrm{F}$ & Sig. & $\begin{array}{c}\text { Partial Eta } \\
\text { Squared }\end{array}$ & $\begin{array}{l}\text { Noncent. } \\
\text { Parameter }\end{array}$ & $\begin{array}{l}\text { Observed } \\
\text { Power }\end{array}$ \\
\hline Corrected Model &, $020^{\mathrm{a}}$ & 1 & .020 & 900 &, 354 & .043 &, 900 &, 148 \\
\hline Intercept & 6,716 & 1 & 6,716 & 302,529 &, 000 & ,938 & 302,529 & 1,000 \\
\hline Jogo &, 020 & 1 &, 020 &, 900 &, 354 &, 043 &, 900 & 148 \\
\hline Error &, 444 & 20 &, 022 & & & & & \\
\hline Total & 7,180 & 22 & & & & & & \\
\hline Corrected Total &, 464 & 21 & & & & & & \\
\hline
\end{tabular}

a. R Squared $=, 043$ (Adjusted R Squared $=-, 005$ )

b. Computed using alpha $=, 05$ 


\section{DoK 1}

\section{Between-Subjects}

Factors

\begin{tabular}{|ll|r|}
\hline & \multicolumn{1}{|c|}{$N$} \\
\hline Jogo &, 0 & 11 \\
& 1,0 & 11 \\
\hline
\end{tabular}

\section{Descriptive Statistics}

Dependent Variable: DOK1

\begin{tabular}{|l|c|r|r|}
\hline Jogo & Mean & $\begin{array}{c}\text { Std. } \\
\text { Deviation }\end{array}$ & N \\
\hline, 0 &, 4693 &, 10878 & 11 \\
1,0 &, 5508 &, 11877 & 11 \\
Total &, 5100 &, 11872 & 22 \\
\hline
\end{tabular}

\section{Levene's Test of Equality of Error} Variances $^{\mathbf{a}}$

Dependent Variable: DOK1

\begin{tabular}{|c|c|c|c|}
\hline $\mathrm{F}$ & df1 & df2 & Sig. \\
\hline, 001 & 1 & 20 &, 973 \\
\hline
\end{tabular}

Tests the null hypothesis that the error

variance of the dependent variable is

equal across groups.

a. Design: Intercept + Jogo

Tests of Between-Subjects Effects

Dependent Variable: DOK1

\begin{tabular}{|l|r|r|r|r|r|r|r|r|}
\hline Source & $\begin{array}{c}\text { Type III Sum } \\
\text { of Squares }\end{array}$ & df & Mean Square & \multicolumn{1}{c|}{ F } & \multicolumn{1}{c|}{ Sig. } & $\begin{array}{c}\text { Partial Eta } \\
\text { Squared }\end{array}$ & $\begin{array}{c}\text { Noncent. } \\
\text { Parameter }\end{array}$ & $\begin{array}{c}\text { Observed } \\
\text { Power }\end{array}$ \\
\hline Corrected Model &, $037^{\text {a }}$ & 1 &, 037 & 2,820 &, 109 &, 124 & 2,820 &, 359 \\
Intercept & 5,723 & 1 & 5,723 & 441,283 &, 000 &, 957 & 441,283 & 1,000 \\
Jogo &, 037 & 1 &, 037 & 2,820 &, 109 &, 124 & 2,820 &, 359 \\
Error &, 259 & 20 &, 013 & & & & \\
Total & 6,019 & 22 & & & & & \\
Corrected Total &, 296 & 21 & & & & & \\
\hline
\end{tabular}

a. $R$ Squared $=, 124$ (Adjusted $R$ Squared $=, 080$ )

b. Computed using alpha $=, 05$ 
Dok 2

Between-Subjects

Factors

\begin{tabular}{|ll|l|}
\hline & & $N$ \\
\hline Jogo &, 0 & 11 \\
& 1,0 & 11 \\
\hline
\end{tabular}

Descriptive Statistics

Dependent Variable: DOK2

\begin{tabular}{|l|c|r|r|}
\hline Jogo & Mean & $\begin{array}{c}\text { Std. } \\
\text { Deviation }\end{array}$ & \multicolumn{1}{|c|}{$\mathrm{N}$} \\
\hline, 0 &, 5185 &, 14100 & 11 \\
1,0 &, 5875 &, 12918 & 11 \\
Total &, 5530 &, 13661 & 22 \\
\hline
\end{tabular}

Levene's Test of Equality of Error

Variances $^{a}$

Dependent Variable: DOK2

Dependent Variable: DOK 2
\begin{tabular}{|c|c|c|c|}
\hline $\mathrm{F}$ & $\mathrm{df} 1$ & $\mathrm{df} 2$ & Sig. \\
\hline, 140 & 1 & 20 &, 712 \\
\hline
\end{tabular}

Tests the null hypothesis that the error

variance of the dependent variable is

equal across groups.

a. Design: Intercept + Jogo

Tests of Between-Subjects Effects

Dependent Variable: DOK2

\begin{tabular}{|l|r|r|r|r|r|r|r|r|}
\hline Source & $\begin{array}{c}\text { Type III Sum } \\
\text { of Squares }\end{array}$ & df & Mean Square & \multicolumn{1}{c|}{ F } & \multicolumn{1}{c|}{ Sig. } & $\begin{array}{c}\text { Partial Eta } \\
\text { Squared }\end{array}$ & \multicolumn{1}{c|}{$\begin{array}{c}\text { Noncent. } \\
\text { Parameter }\end{array}$} & $\begin{array}{c}\text { Observed } \\
\text { Power }\end{array}$ \\
\hline Corrected Model &, $026^{\mathrm{a}}$ & 1 &, 026 & 1,436 &, 245 &, 067 & 1,436 &, 207 \\
Intercept & 6,728 & 1 & 6,728 & 367,970 &, 000 &, 948 & 367,970 \\
Jogo &, 026 & 1 &, 026 & 1,436 &, 245 &, 067 & 1,436 \\
Error &, 366 & 20 &, 018 & & & &, 2000 \\
Total & 7,120 & 22 & & & & & \\
Corrected Total &, 392 & 21 & & & & & \\
\hline
\end{tabular}

a. $\mathrm{R}$ Squared $=, 067$ (Adjusted R Squared $=, 020$ )

b. Computed using alpha $=, 05$ 
G5. ANOVA para os diferentes assuntos considerados

Assunto: Ciclo Planejamento-Execução-Controle

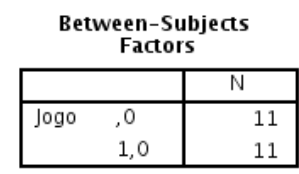

Descriptive Statistics

Dependent Variable: PEC
\begin{tabular}{|l|c|c|r|}
\hline Jogo & Mean & $\begin{array}{c}\text { Std. } \\
\text { Deviation }\end{array}$ & N \\
\hline, 0 &, 503579952 &, 127527617 & 11 \\
1,0 &, 594922977 &, 091517976 & 11 \\
Total &, 549251465 &, 117974542 & 22 \\
\hline
\end{tabular}
Levene's Test of Equality of Error
Variances

Dependent Variable: PEC

Dependent Variable: PEC
\begin{tabular}{|c|c|c|c|}
\hline $\mathrm{F}$ & df 1 & df 2 & Sig. \\
\hline 2,174 & 1 & 20 & 156 \\
\hline
\end{tabular}
Tests the null hypothesis that the error
variance of the dependent variable is
equal across groups.
a. Design: Intercept + Jogo

Tests of Between-Subjects Effects

Dependent Variable: PEC

\begin{tabular}{|l|r|r|r|r|r|r|r|r|}
\hline Source & $\begin{array}{c}\text { Type III Sum } \\
\text { of Squares }\end{array}$ & df & Mean Square & \multicolumn{1}{c|}{ F } & \multicolumn{1}{c|}{ Sig. } & \multicolumn{1}{c|}{$\begin{array}{c}\text { Partial Eta } \\
\text { Squared }\end{array}$} & \multicolumn{1}{c|}{$\begin{array}{c}\text { Noncent. } \\
\text { Parameter }\end{array}$} & $\begin{array}{c}\text { Observed } \\
\text { Power }\end{array}$ \\
\hline Corrected Model &, $046^{\mathbf{a}}$ & 1 &, 046 & 3,725 &, 068 &, 157 & 3,725 &, 451 \\
Intercept & 6,637 & 1 & 6,637 & 538,735 &, 000 &, 964 & 538,735 \\
Jogo &, 046 & 1 &, 046 & 3,725 &, 068 &, 157 & 3,725 \\
Error &, 246 & 20 &, 012 & & & & \\
Total & 6,929 & 22 & & & & & \\
Corrected Total &, 292 & 21 & & & & & \\
\hline
\end{tabular}

a. R Squared $=, 157$ (Adjusted R Squared $=, 115$ )

b. Computed using alpha $=, 05$ 
Assunto: Visão Sistêmica

Between-Subjects

Factors

\begin{tabular}{|ll|r|}
\hline & \multicolumn{1}{|c|}{$N$} \\
\hline Jogo &, 0 & 11 \\
& 1,0 & 11 \\
\hline
\end{tabular}

Descriptive Statistics

Dependent Variable: vs

\begin{tabular}{|l|c|c|c|}
\hline Jogo & Mean & $\begin{array}{c}\text { Std. } \\
\text { Deviation }\end{array}$ & N \\
\hline, 0 &, 529940120 &, 154161092 & 11 \\
1,0 &, 590092542 &, 146274903 & 11 \\
Total &, 560016331 &, 149844463 & 22 \\
\hline
\end{tabular}

Levene's Test of Equality of Error Variances

Dependent Variable: VS

\begin{tabular}{|c|c|c|c|}
\hline $\mathrm{F}$ & df 1 & df 2 & Sig. \\
\hline, 051 & 1 & 20 &, 823 \\
\hline
\end{tabular}

Tests the null hypothesis that the error

variance of the dependent variable is

equal across groups.

a. Design: Intercept + Jogo

Tests of Between-Subjects Effects

Dependent Variable: VS

\begin{tabular}{|c|c|c|c|c|c|c|c|c|}
\hline Source & $\begin{array}{l}\text { Type III Sum } \\
\text { of Squares }\end{array}$ & df & Mean Square & $\mathrm{F}$ & Sig. & $\begin{array}{c}\text { Partial Eta } \\
\text { Squared }\end{array}$ & $\begin{array}{l}\text { Noncent. } \\
\text { Parameter }\end{array}$ & $\begin{array}{l}\text { Observed } \\
\text { Power }\end{array}$ \\
\hline Corrected Model & $.020^{a}$ & 1 & .020 & 881 & 359 & 042 & 881 & 145 \\
\hline Intercept & 6,900 & 1 & 6,900 & 305,549 &, 000 & 939 & 305,549 & 1,000 \\
\hline Jogo &, 020 & 1 & .020 & .881 & ,359 &, 042 & 881 & 145 \\
\hline Error & 452 & 20 &, 023 & & & & & \\
\hline Total & 7,371 & 22 & & & & & & \\
\hline Corrected Total & 472 & 21 & & & & & & \\
\hline
\end{tabular}

a. R Squared $=, 042$ (Adjusted R Squared $=-, 006$ )

b. Computed using alpha $=, 05$ 
Assunto: Papéis Gerenciais

Between-Subjects

Factors

\begin{tabular}{|ll|l|}
\hline & \multicolumn{1}{|c|}{$N$} \\
\hline Jogo &, 0 & 11 \\
& 1,0 & 11 \\
\hline
\end{tabular}

Descriptive Statistics

Dependent Variable: PG

\begin{tabular}{|l|c|c|c|}
\hline Jogo & Mean & $\begin{array}{c}\text { Std. } \\
\text { Deviation }\end{array}$ & N \\
\hline, 0 &, 363636363 &, 157847474 & 11 \\
1,0 &, 444444444 &, 216595430 & 11 \\
Total &, 404040404 &, 189511748 & 22 \\
\hline
\end{tabular}

\section{Levene's Test of Equality of Error} Variances

Dependent Variable: PG
\begin{tabular}{|c|c|c|c|}
\hline $\mathrm{F}$ & df 1 & df 2 & Sig. \\
\hline 716 & 1 & 20 &, 408 \\
\hline
\end{tabular}

Tests the null hypothesis that the error

variance of the dependent variable is

equal across groups.

a. Design: Intercept + Jogo

Tests of Between-Subjects Effects

Dependent Variable: PG

\begin{tabular}{|c|c|c|c|c|c|c|c|c|}
\hline Source & $\begin{array}{c}\text { Type III Sum } \\
\text { of Squares }\end{array}$ & df & Mean Square & $\mathrm{F}$ & Sig. & $\begin{array}{c}\text { Partial Eta } \\
\text { Squared }\end{array}$ & $\begin{array}{l}\text { Noncent. } \\
\text { Parameter }\end{array}$ & $\begin{array}{l}\text { Observed } \\
\text { Power }\end{array}$ \\
\hline Corrected Model & $.036^{\mathrm{a}}$ & 1 & .036 & 1,000 & .329 & .048 & 1,000 & .159 \\
\hline Intercept & 3,591 & 1 & 3,591 & 100,000 &, 000 & 833 & 100,000 & 1,000 \\
\hline Jogo & .036 & 1 &, 036 & 1,000 & .329 & .048 & 1,000 & 159 \\
\hline Error & ,718 & 20 & .036 & & & & & \\
\hline Total & 4,346 & 22 & & & & & & \\
\hline Corrected Total &, 754 & 21 & & & & & & \\
\hline
\end{tabular}

a. R Squared $=, 048$ (Adjusted R Squared $=, 000$ )

b. Computed using alpha $=, 05$ 


\section{Apêndice H Análise de Conteúdo dos textos}

\section{H1. Textos analisados e categorização}

Os itálicos marcam visões "hard" de gestão, enquanto os sublinhados destacam as visões mais "soft".

\begin{tabular}{|c|c|c|c|c|}
\hline Usuário & Turma & Texto & Hard & Soft \\
\hline aluno28 & $\mathrm{T} 1$ & $\begin{array}{l}\text { O gestor é o responsável pelo andamento de um } \\
\text { serviço, no que se refere ao plano de ação e controle } \\
\text { dos resultados ao longo de sua execução. }\end{array}$ & 1 & 0 \\
\hline aluno43 & $\mathrm{T} 1$ & $\begin{array}{l}\text { DEVE-SE PLANEJAR, DISTRIBUIR TAREFAS } \\
\text { CONSIDERANDO OS PONTOS FRACOS E FORTES } \\
\text { DE CADA MEMBRO DA EQUIPE, TER UMA } \\
\text { COMUNICACCÃO CLARA E OBJETIVA, } \\
\text { PROMOVER O DESENVOLVIMENTO DE SUA } \\
\text { EQUIPE, MONITORAR TAREFAS E PRAZOS E AO } \\
\text { FINAL DAR FEEDBACK A CADA UM, } \\
\text { BUSCANDO MELHORIA CONTÍNUA DE TODOS. }\end{array}$ & 3 & 4 \\
\hline aluno76 & $\mathrm{T} 1$ & $\begin{array}{l}\text { O Papel e a responsabilidade do gestor é de suma } \\
\text { importancia para a organização, de forma que o mesmo } \\
\text { deve possuir uma visão sistemica sobre as metas e } \\
\text { objetivos da entidade, para que assim se alcance o } \\
\text { proposto. }\end{array}$ & 1 & 0 \\
\hline aluno11 & $\mathrm{T} 1$ & $\begin{array}{l}\text { O PAPEL DE UM GESTOR É DE GERENCIAR } \\
\text { COM UMA VISÃO AMPLA NÃO SÓ SEUS } \\
\text { AFAZERES E RESPONSABILIDADES MAIS TAMBÉM } \\
\text { ESTAR GERINDO COM SEUS FUNCIONARIOS EM } \\
\text { TODOS ASPECTOS PERTINENTES AO SEU SETOR, } \\
\text { E TAMBEM EM CONJUNTO COM A INSTITUIÃO } \\
\text { EM SI , PARA QUE JUNTOS POSSAM CHEGAR A } \\
\text { UM OBJETIVO COMUM... }\end{array}$ & 2 & 0 \\
\hline aluno27 & $\mathrm{T} 1$ & $\begin{array}{l}\text { A responsabilidade de um gestor é planejar } \\
\text { e controlar as atividades pertinentes à sua equipe. } \\
\text { Executar suas atividades de orientador, disseminador, } \\
\text { oferecendo respaldo e incentivando sua equipe em } \\
\text { busca da excelência nas suas atividades. }\end{array}$ & 2 & 1 \\
\hline aluno54 & $\mathrm{T} 1$ & $\begin{array}{l}\text { Conhecer a cultura e o clima organizacional, identificar } \\
\text { os pontos fortes fracos e critico compreender o papel } \\
\text { do setor dendro da organização e como se relacionam. } \\
\text { Assumir a responsabilidade do que lhe e de verdade. }\end{array}$ & 2 & 1 \\
\hline aluno71 & $\mathrm{T} 1$ & $\begin{array}{l}\text { O gestor deve apresentar visão buscando objetivos de } \\
\text { alcançar o planejado pela entdade. }\end{array}$ & 9 & 1 \\
\hline & & $\begin{array}{l}\text { Também pode edeve influenciar no panejamento da } \\
\text { entidade com vistas a atualizar ou mesmo embasar o } \\
\text { caminho a seguir para o alcance da meta. }\end{array}$ & & \\
\hline & & $\begin{array}{l}\text { Deve ser capaz de incentivar sua equipe e manter o } \\
\text { gurpo coeso, fazendo com que todos sintam que o } \\
\text { objetivo maior (da entidade) também é o objetivo de } \\
\text { cada um do grupo. }\end{array}$ & & \\
\hline & & $\begin{array}{l}\text { Deve possuir habilidade para planejar a melhor } \\
\text { alocação dos recursos (materiais e humanos) tendo } \\
\text { como foco uma meta clara, precisa e possivel. }\end{array}$ & & \\
\hline
\end{tabular}


Usuário Turma Texto

Hard Soft

Deve compreender seu papel no sucesso da instituição bem como reconhecer que sua responsabilidade pelos erros e pelos fracassos, independnete da ação ou omissão de um ou mais interantes do seu grupo.

aluno07 T1 O gestor deve planejar, organizar, controlar e mensurar resultados da equipe afim de corrigi-los no decorrer do processo. Também é seu papel conhecer seus funcionarios, competencias e aptidoes de cada um com o proposito de alocar cada um em atividades com o objetivo de atingr a produtividade e prazos planejados.

aluno26 T1 O GESTOR TEM COMO SUA META, ORGANIZAR

SEUS FUNCIONÁRIOS A CADA QUAL EM SUA

FUNÇÃO E REMOVÉ-LO A CADA PONTO

POSITIVO, DEIXANDO SEU AMBIENTE DE

TRABALHO AGRADÁ VEL, SE TIVER ALGUM PROBLEMA TER DISSERNIMENTO E REVER OS PONTOS NECESSÁRIOS PARA UM BOM DESENVOLVIMENTO NO SETOR.

aluno47 T1

aluno45 T1

aluno31 T1

aluno49

$\mathrm{T} 1$

Planejamento, controle e organização.

Planejar, organizar, destribuir tarefas fazer feedback e liderar.

Dentro das atribuições de gestor cabe desenvolver atividades como planejar e avaliar o desenvolvimento da equipe ao logo da execução da equipe.

Estar atento as demandas internas e externas e intervir sobre situação que podem comprometer seus resultados.

Saber planejar as ações.

Saber organizar as ações

Monitorar as ações que estão sendo realizadas

Ter o controle e decidir no momento certo

$\underline{\text { Saber se comunicar com a equipe }}$

Ser habilidoso, negociador e ter bom comportamento

aluno26

A RESPONSABILIDADE DE UM GESTOR ,TEM

COMO ORGANIZAR SEUS FUNCIONÁRIOS CADA

UM COM SUAS FUNÇÕES E SE NECESSÁRIOS

TREINÁ-LOS DE ACORDO COM SUAS

ATRIBUIÇÕES, SENDO ASSIM , PLANEJAR

ATIVIDADES QUE CADA UM TEM COMO O

MELHOR A FAZER. CONTRIBUIR COM UM

AMBIENTE AGRÁDAVEL.

aluno82 T1

O papel de um gestor é controlar, liderar, avaliar, ter um bom relacionamneto interpessoal, ser organizado, compreender cada individuo em suas dificuldades.

aluno55 T1 Conhecimento dos recursos disponiveis

Planejamento

Acompanhamento

Controle

Mensuração dos resultado / tarefas

Desenvolvimento de pessoas

aluno08 T1

Planejamento, organização, decisão, imagem.

O gestor precisa manter a percepção da visão sistêmica,
1 
Usuário Turma Texto

aluno32 T1

aluno56

T1

aluno10

aluno01

aluno21

* PLANEJAR analisar a sua prática e a de seus subordinados. $\mathrm{O}$

papel de liderança e de mediador de responsabilidades e tarefas estão intimamente ligadas as suas competências.

O gestor tem como planificar todos os recursos

necessários, de forma que tenha uma visão sistêmica de todos os processos de sua gestão, de forma que possibilite atingir os propositos que foram planejados. No entanto a liderança é um ponto crucial nas metas e relações com seus subordinados, para isto o controle e a execução do trabalhos são ferramentas para a execução de um trabalho de qualidade.

* organizar

* controlar

* MOTIVAR

* LIDERAR

* MONITORAR

* alocar recursos

* INOVAR

Planejamento das tarefas a serem realizadas, delegação e controle das tarefas, disseminador de conhecimento, motivador, gestor de conflitos. DENTRO DE SUAS RESPONSABILIDADE UM GESTOR DEVE SEMPRE SE ANTECIPAR DAS SITUAÇÕES QUE PODEM SE TORNAR CRISES E PLANEJAR ADEQUADAMENTE AS METAS E OBJETIVOS DA MELHOR MANEIRA QUE SE ENQUADRE EM SUA UNIDDE. COM CONSIDERAÇÃO DA MONITORAÇÃO E CORREÇÃO.

Gestor é a pessoa que deverá conduzir uma equipe, de forma eficaz, para a obtenção de resultados programados, ao longo de um período.

O gestor deve ser um bom líder, ter conhecimento tecnico sobre os assuntos que irá gerir e excelencia em relação interpessoal.

organizar, planejar, controlar custos, conhecer sua área de gestão, conhecer seus subordinados, saber priorizar.

Um bom gestor deverá conduzir uma equipe, de forma periodo de tempo.

Liderança, conhecimento técnico e excelecia em relacionamento interpessoal são, na minha opinião, as principais características de um bom gestor.

Os principais papeis de um gestor são planejar, organizar, alocar recursos, liderar, controlar. As principais responsabilidades, por sua vez, são decidir, manejar conflitos e propor soluções.

o gestor deve planejar, organizar, liderar e aos detalhes, qualidades e dificuldades de cada funcionário, atenvendo mudanças e lidando com elas da melhor forma possível. 
Usuário Turma Texto

aluno68 T2 Planejar, Organizar, executar (juntamente com a

Hard Soft

equipe), ver os resultados obtidos e repassar um

2

3

respaldo a equipe e as superiores, sempre pensando em melhorar no processo administrativo.

Ser um gestor se define em: Visionário, Apoiador,

Batalhador e Estrategista. devemos saber equilibrar esses quatro arquetimos para conseguirmos uma liderança de sucesso.

aluno48 $\quad$ T2 $\quad$ O gestor deve estar apto a identificar as capacidades de seus subordinados, ter conhecimento dos recursos orçamentários alocados para a sua unidade o que the permitiria organizar as atividades a serem desenvolvidas no exercício. Monitorar o desenvolvimento dos servidores, atribuindo as tarefas de acordo com o perfil de cada um.

aluno69 T2 fazer com que as coisas funcionem harmoniozamente com respostas rápidas eficazes e eficientes.

aluno03 T2 $\quad$ o gestor deve saber como está o andamento das atividades de seu setor, verificar as competencias de cada um de seus subordinados, se organizar para atender a todos os prazos, conhecer as demais estruturas que interferem no andamento de seu setor, tentar distribuir as tarefas de acordo com as aptidões, delegar as funções que puder para se dedicar mais.

aluno25 T2 o papel do gestor e:planejar para que as cosas acontecam dentro do planejado, executar conforme o planejado

aluno19 T2 -

aluno52 T2 O gestor tem como papel planejar, monitorar e avaliar os processos de sua area para ter retorno positivo. A responsabilidade dele é de controlar e monitorar as ações de forma que o processo seja mais claro e fácil.

aluno67 T2 Os principais papéis do gestor são planejar e controlar as atividades do setor, devendo ser responsabilizado pelas falhas de sua gestão, posto que ele deve saber administrar as dificuldades de sua equipe, prestando auxílio aos subordinados nesses casos.

aluno30 T2 Fazer o planejamento considerando, quando possível, a opião de sua equipe, fazer o controle do trabalho, manter a equipe informada de todas as ações que acontecem dentro da Secretaria (ações que influenciará direta ou indiretamente o trabalho da equipe), estimular a equipe (elogiar quando o trabalho for bem feito). Um gestor deve conduzir sua equipe com controle de suas atividades, sabendo ser líder, orientando quando necessário, ajudar a equipe a solucionar os problemas encontrados no dia-a-dia, trazendo sempre inovações, dar aos seus subordinados a oportunidade de opinar e dirigindo de forma não opressora, sabendo dosar as opiniões e discuti-las com os mesmos com clareza.

O gestor precisa saber ouvir os subordinados, e também fazer uma crítica construtiva quando necessário, avaliar o desempenho do mesmo dando feedback, sempre que possível para que não seja necessário diminuir suas pontuações. 
Usuário Turma Texto

Hard

Soft

O gestor precisa saber quais os recursos necessários para melhorar o ambiente de trabalho.

Enfim, precisa ser líder, saber monitorar, dividir os trabalhos adequadamente, mensurar as atitudes tomadas

H2. Comparação de médias - Teste-U de Mann-Whitney

\begin{tabular}{|ll|r|r|r|}
\multicolumn{6}{c|}{ Ranks } \\
\hline & Turma & N & Mean Rank & $\begin{array}{c}\text { Sum of } \\
\text { Ranks }\end{array}$ \\
\hline hard & 1,0 & 21 & 21,57 & 453,00 \\
& 2,0 & 14 & 12,64 & 177,00 \\
& Total & 35 & & \\
\hline soft & 1,0 & 21 & 14,83 & 311,50 \\
& 2,0 & 14 & 22,75 & 318,50 \\
& Total & 35 & & \\
\hline
\end{tabular}

Test Statistics ${ }^{\mathbf{a}}$

\begin{tabular}{|l|r|r|}
\hline & \multicolumn{1}{|c|}{ hard } & \multicolumn{1}{|c|}{ soft } \\
\hline Mann-Whitney U & 72,000 & 80,500 \\
Wilcoxon W & 177,000 & 311,500 \\
Z & $-2,628$ & $-2,321$ \\
Asymp. Sig. (2-tailed) &, 009 &, 020 \\
Exact Sig. [2*(1-tailed &, $011^{\mathrm{b}}$ &, $024^{\mathrm{b}}$ \\
\hline Sig.)]
\end{tabular}

a. Grouping Variable: Turma

b. Not corrected for ties. 


\section{Apêndice I Roteiro das entrevistas e questões da consulta online}

\section{I1. Questões para guiar as entrevistas:}

1) Como você compararia o curso que você fez com outros cursos de treinamento em gestão?

2) Durante o curso (no fim do curso) você teve a oportunidade de jogar o jogo "Liderança em Jogo: Competência, papéis e responsabilidades".

a. O que o jogo trouxe de novo?

b. Você conseguiria listar 3 coisas que você aprendeu com o jogo que não teria aprendido somente com as aulas?

3) Depois que você voltou a trabalhar, alguma situação do seu dia-a-dia lhe lembrou das situações do jogo?

a. Se sim, quais? O que você fez?

b. Se não, por quê?

4) De que forma você acha que o jogo poderia ser mais bem utilizado nas aulas? (Antes da exposição? Ao final? Fora do tempo de aula?)

5) Que tipo de condições (preparo/conhecimento de informática/vivência na gestão pública) você acha que são necessárias para que a pessoa possa aprender gestão com esse tipo de jogo?

6) O que você passou a fazer de diferente por que jogou que eu não teria feito se não tivesse jogado?

7) Você quer fazer mais algum comentário sobre o jogo?

\section{I2. Questões da consulta online:}

1) Em que ter feito o curso contribuiu para o seu trabalho? (mudanças de comportamento, aplicações de conhecimento). Algo mudou?

2) O que você aprendeu com o jogo "Liderança em Jogo: Competência, papéis e responsabilidades" e o que isso influenciou na sua prática do dia-a-dia? 


\section{Apêndice J Questionário sobre resultado projetado}

\section{J1. Versão online no questionário}

\begin{tabular}{|c|c|c|c|c|c|c|c|}
\hline \multicolumn{8}{|c|}{$\begin{array}{l}\text { Pensando exclusivamente no que você aprendeu ao longo desse curso, qual o impacto que você espera observar dos } \\
\text { conceitos aprendidos e discutidos com relação aos seguintes itens sobre o seu trabalho como gestor(a): }\end{array}$} \\
\hline \multicolumn{8}{|l|}{ Considere a seguinte escala: } \\
\hline \multicolumn{8}{|l|}{1 = não vai contribuir em nada } \\
\hline \multicolumn{8}{|l|}{$7=$ vai contribuir substancialmente } \\
\hline & 1 & 2 & 3 & 4 & 5 & 6 & 7 \\
\hline Qualidade das entregas da unidade & 0 & 0 & 0 & 0 & $\bigcirc$ & 0 & 0 \\
\hline $\begin{array}{l}\text { Identificação das demandas de treinamento da } \\
\text { equipe }\end{array}$ & $\bigcirc$ & $\bigcirc$ & 0 & 0 & $\bigcirc$ & 0 & 0 \\
\hline Planejamento orçamentário da minha unidade & $\bigcirc$ & 0 & $\bigcirc$ & 0 & 0 & 0 & 0 \\
\hline $\begin{array}{l}\text { Eficiência nos processos realizados pela minha } \\
\text { unidade }\end{array}$ & $\bigcirc$ & 0 & 0 & 0 & 0 & 0 & $\mathrm{O}$ \\
\hline Relacionamento com os subordinados & $\bigcirc$ & 0 & 0 & 0 & 0 & 0 & 0 \\
\hline Execução orçamentária da minha unidade & $\bigcirc$ & 0 & 0 & 0 & 0 & 0 & 0 \\
\hline $\begin{array}{l}\text { Melhoria geral do serviço prestado pela minha } \\
\text { unidade }\end{array}$ & 0 & 0 & 0 & 0 & 0 & 0 & 0 \\
\hline Planejamento das atividades dos meus subordinados & 0 & 0 & 0 & 0 & 0 & 0 & 0 \\
\hline $\begin{array}{l}\text { Levar em consideração o perfil de competências dos } \\
\text { funcionários na hora de distribuir as tarefas }\end{array}$ & 0 & $\bigcirc$ & 0 & 0 & 0 & 0 & 0 \\
\hline Cumprimento dos prazos & $\bigcirc$ & 0 & 0 & 0 & 0 & 0 & 0 \\
\hline Relacionamento com os superiores & 0 & 0 & 0 & 0 & 0 & 0 & 0 \\
\hline
\end{tabular}

\section{J2. Saída do teste U de Mann-Whitney}

\begin{tabular}{|c|c|c|c|c|c|c|c|c|c|c|c|}
\hline \multicolumn{12}{|c|}{ Test Statistics ${ }^{\mathbf{a}}$} \\
\hline & ResultProj1 & ResultProj2 & ResultProj3 & ResultProj4 & ResultProj5 & ResultProj6 & ResultProj7 & ResultProj8 & ResultProj9 & ResultProj10 & ResultProj11 \\
\hline Mann-Whitney U & 25,000 & 36,500 & 35,000 & 28,500 & 28,500 & 20,500 & 39,500 & 33,000 & 21,500 & 41,500 & 31,500 \\
\hline Wilcoxon W & 80,000 & 91,500 & 90,000 & 83,500 & 83,500 & 75,500 & 94,500 & 88,000 & 76,500 & 96,500 & 86,500 \\
\hline$z$ & $-2,526$ & $-1,498$ & $-1,444$ & $-1,910$ & $-2,039$ & $-2,625$ & $-1,221$ & $-1,726$ & $-2,635$ & $-1,013$ & $-1,759$ \\
\hline Asymp. Sig. (2-tailed) & .012 & 134 & 149 & .056 & .041 & .009 & 222 & .084 & .008 & ,311 & .079 \\
\hline $\begin{array}{l}\text { Exact Sig. [2*(1-tailed } \\
\text { Sig. })]\end{array}$ & $.036^{\mathrm{b}}$ & $.197^{\mathrm{b}}$ & $.173^{\mathrm{b}}$ & $.061^{\mathrm{b}}$ & $.061^{\mathrm{b}}$ & $.013^{\mathrm{b}}$ &, $282^{\mathrm{b}}$ & $.132^{\mathrm{b}}$ & $.016^{\mathrm{b}}$ & $.349^{\mathrm{b}}$ & $.099^{b}$ \\
\hline
\end{tabular}

a. Grouping Variable: Jogo

b. Not corrected for ties. 


\section{Anexo 1 Questionário de avaliação de reação - CT\&D/Cefor - SES-SP}

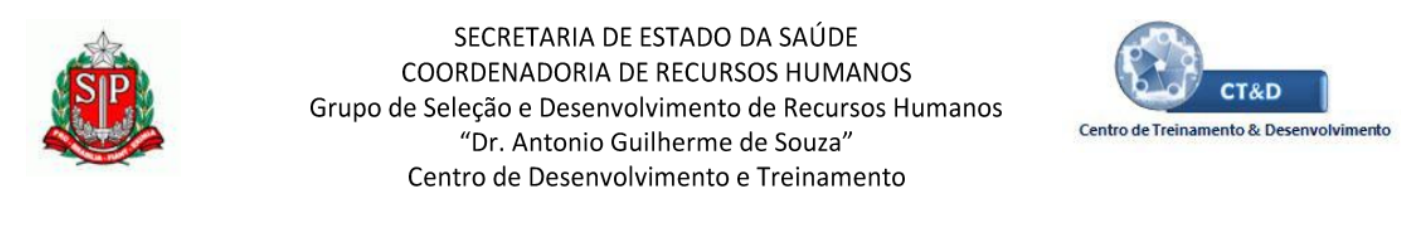

AVALIAÇÃO: “GESTÃo PÚBLICA - Teoria e Prática "

DATA: $X X / X X / 2016$

PROFESSOR : Fernando Nascimento

É muito importante para o CEFOR conhecer sua opinião sobre o curso que acabou de realizar para que possamos aperfeiçoar nossas atividades.

Por favor, leia atentamente os fatores de avaliação abaixo e assinale com um " $\mathrm{X}$ " o campo que mais se aproxima de sua percepção.

Agradecemos sua participação!

\begin{tabular}{|c|c|c|c|c|}
\hline \multirow[t]{2}{*}{ Desempenho do Instrutor } & \multicolumn{4}{|c|}{ Nível de Satisfação } \\
\hline & Excelente & Bom & Regular & Deficiente \\
\hline \multicolumn{5}{|l|}{ 1. Demonstrou domínio dos conteúdos apresentados } \\
\hline \multicolumn{5}{|l|}{$\begin{array}{l}\text { 2. Utilizou linguagem adequada à melhor compreensão dos } \\
\text { conteúdos }\end{array}$} \\
\hline \multicolumn{5}{|l|}{ 3. Expôs as idéias com clareza } \\
\hline \multicolumn{5}{|l|}{ 4. Relacionou os conceitos à realidade do serviço } \\
\hline \multicolumn{5}{|l|}{ 5. Estimulou a participação dos treinandos } \\
\hline \multicolumn{5}{|l|}{ 6. Esclareceu as dúvidas e questionamentos dos treinandos } \\
\hline \multicolumn{5}{|l|}{$\begin{array}{l}\text { 7. Recebeu de forma positiva as críticas e sugestões } \\
\text { apresentadas pelos treinandos }\end{array}$} \\
\hline \multicolumn{5}{|l|}{ 8.Administrou o tempo de forma produtiva } \\
\hline \multicolumn{5}{|l|}{ 9.Cumpriu o programa proposto para ogrupo } \\
\hline \multicolumn{5}{|l|}{ Comente: } \\
\hline Processo de Aprendizagem & Excelente & Bom & Regular & Deficiente \\
\hline \multicolumn{5}{|l|}{ 10. Nível de integração entre os participantes e o instrutor } \\
\hline \multicolumn{5}{|l|}{ 11. Nível de relevância dos temas abordados } \\
\hline \multicolumn{5}{|l|}{$\begin{array}{l}\text { 12. Em que nível você classifica como adequadas as } \\
\text { atividades e os recursos didáticos utilizados }\end{array}$} \\
\hline \multicolumn{5}{|l|}{$\begin{array}{l}\text { 13. Em que nível você classifica o conteúdo apresentado e } \\
\text { como ele contribuirá para aperfeiçoar o seu desempenho } \\
\text { profissional }\end{array}$} \\
\hline \multicolumn{5}{|l|}{$\begin{array}{l}\text { 14. Aplicabilidade do conteúdo do curso à sua realidade de } \\
\text { trabalho }\end{array}$} \\
\hline \multicolumn{5}{|l|}{ 15. Como você avalia sua participação durante o treinamento } \\
\hline Comente: & & & & \\
\hline
\end{tabular}

Vide Verso 


\begin{tabular}{|c|c|c|c|c|c|}
\hline INFRA-ESTRUTURA E APOIO & Excelente & Bom & Regular & \multicolumn{2}{|c|}{ Deficiente } \\
\hline \multicolumn{6}{|l|}{$\begin{array}{l}\text { 16. Qualidade das instalações (espaço, refrigeração, } \\
\text { iluminação) }\end{array}$} \\
\hline \multicolumn{6}{|l|}{ 17. Qualidade e adequação dos equipamentos } \\
\hline INFRA-ESTRUTURA E APOIO & Excelente & Bom & Regular & Deficiente & $\begin{array}{l}\text { Não } \\
\text { houve }\end{array}$ \\
\hline \multicolumn{6}{|c|}{ 18. Qualidade do material didático (textos, apostilas, slides) } \\
\hline 19.Organização do curso: & Excelente & Bom & Regular & \multicolumn{2}{|c|}{ Deficiente } \\
\hline \multicolumn{6}{|l|}{ 19.1. Divulgação } \\
\hline \multicolumn{6}{|l|}{ 19.2. Inscrição } \\
\hline \multicolumn{6}{|l|}{ 19.3. Atendimento CEFOR } \\
\hline \multicolumn{6}{|l|}{ Comente: } \\
\hline \multicolumn{6}{|l|}{ COMO FICOU SABENDO DO CURSO? } \\
\hline \multicolumn{6}{|l|}{ Email CEFOR ( ) } \\
\hline \multicolumn{6}{|l|}{ Terceiros ( colegas, etc) ( ) } \\
\hline \multicolumn{6}{|l|}{ Site da CRH ( ) } \\
\hline \multicolumn{6}{|c|}{ Divulgação na Instituição (RH - Área de treinamento/ desenvolvimento, Chefia, Educação Continuada, etc) ( ) } \\
\hline
\end{tabular}

NA SUA OPINIÃO, QUAIS TEMAS/ASSUNTOS O CEFOR PODERIA INCLUIR, EM SUA PROGRAMAÇ̃̃O, QUE AJUDARIAM EM SUA PRÁTICA PROFISSIONAL?

\begin{tabular}{|l|}
\hline VOCÊ VOLTARIA AO CEFOR PARA OUTROS CURSOS? \\
\hline $\operatorname{Sim}($ ) \\
\hline Não ( ) \\
\hline Porque? \\
\hline \\
\hline
\end{tabular}

